- 15

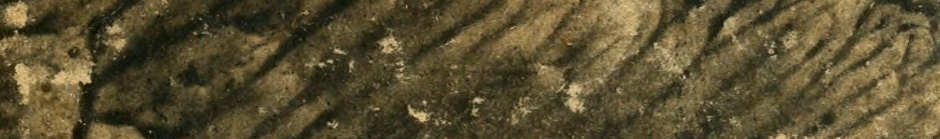

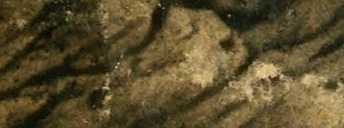

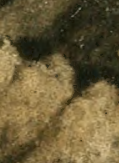

\title{
(2) 120
}

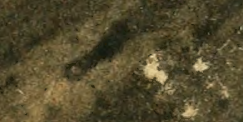

Why

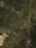

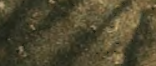
as: 
4

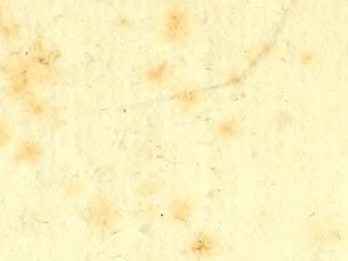

the

wit 


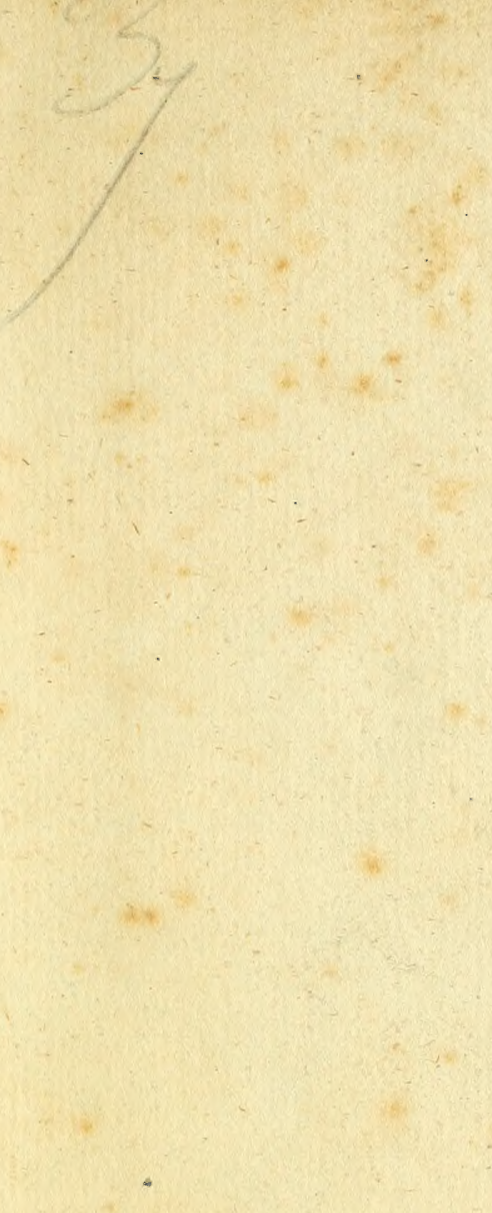

ㄴ.

$\sqrt{3}-\frac{1}{8}$

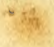

iv 

Geschichte und Beurtheilung

\section{aller Systeme}

in der

\section{$\begin{array}{llllllllll}2 & 0 & 0 & 1 & 0 & \mathrm{~g} & \mathrm{i} & \mathrm{C}\end{array}$ nach ihror}

En twiklungs fol ge von Aristoteles

bis

auf die gegenwärtige Zeit,

vo n-

Johannes Spix,

der Weltweisheit und Arzneikunde Doktor, der mathematisch - physikalischen Klasse der Königl. Baier. Academie der, Wissenschaften in München Adjunkt und Conservator der zoologisch-zootomischen Sammiungen。

$\mathrm{N}$ ür n e r $g$, in dex Schrag'schen Buchhandlunga

1811 .

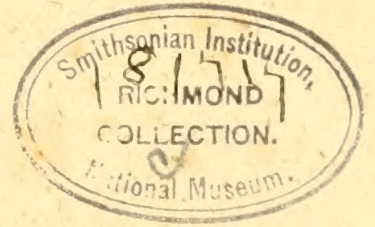


Experientia in rebus medicis debet animari ratiocinits, sins quibus non est nisi res mortua ac velut rudis indigestaque moles; rationes experientia destitutae nihil juvant, ut pote quae ingeniorum opera sua abutentium, mera sunt somria, mera phontasmata ac meteora.

Caroli Linnaei, oratio de pere: grinationis necessitate, habita $U_{P-}$ saliae anno 1741 ad medicinae professoris munus suscipiendum. 


\section{Seiner Excellenz}

dem

Hochgebornen Grafen

$$
\mathrm{H} \text { e } \mathrm{r} \text { r } \mathrm{n}
$$

Maximilian Jose $p h$

\section{Grafen von Montgelas,}

Sr. Königl. Majestät von Bayern Ersten und dirigirenden Staats - und Conferen - Minister der auswartigen Angelegenheiten, des Innern und der Finanzen; Grofskanzler des Civil-Verdienst - Ordens der bayer. Krone, Ritters des St. Huberti-Ordens, Grofskreuz der Ehrenlegion, Grofskreuz des Königl. Sächsischen Ordens der grünen Krone, Grofse kreuz des Malteserordens etc. etc. 



\section{Hochgeborner Graf!}

Hochgebietender, dirigirender Minister!

Gnädiger Herr!

Frankreich preist noch seinen Colbert als Stifter der Akademien der Wissenschaften und Ihünste, und als neuen Schöpfer des Pflanzengarten zu Paris. Wem anders verdankt Baiern dasselbe, als Eurer Excellenz, welche zu einer Zeit, wo Liebe zu den Wissenschaften und zu dem Volke auf dern Throne sizt, die Alademien der Wissenschaften und der Künste gegründet hat, und nun auch durch Errichtung eines Pflanzengarten und durch Begünstigung dor naturgeschichtlichen Frabinette dem gegenwärtig in England, Frankreich, Italien und Teutschland herrschenden Genius der $\mathbf{N a}$. turwissenschaften auf vaterländischem Boden finen Tempel erbauet. - Auch ich verdanke meine bisherige Ausbildang für Naturgeschichte einzig der Huld Eurer Excellenz, welche mich zu diesein Zwecke auf eine Reise nach Frankreich und Italien befördert, und nun als Adjunct und als Conservaton der zoologischzootomischen Sammlungen bei der königlichen, 
Akademie der Wissenschaften gleichsam an die Quelle des ferneren Studiums versezt hat.

Belieben daher Eure Excellenz diese erste, wenn auch geringe Frucht als einstweiliges Opfer meiner Dankbarkeit und Vaterlandsliebe aufzunehmen, bis ich im Stande seyn werde, durch kräftigere Theilnahme an der Wissenschaft mich ganz des hohen Zutrauens. Eurer Excellenz würdig zu machen. Der ich mit dem Gefühl der dankvollsten Ergebenheit und der iiefsten Verehrung verharre

München,

den 1. May 1811.

\section{Eurer Excellenz}

unterthänig gehorsamer Johannes Spix, Dr. 


\section{Vorred e.}

Die Lücke finhlend, welche für das Studium der Zoologie aus dem bisherigen Mangel einer Ge schichte derselben entsteht, beschlofs ich, mich an die Lösung dieser Aufgabe zu wagen, und wählte zu meinem Gesichtspunkte das Wesentliche und gleichsam den Mittelpunlit derselben, die Darstellung aller Systeme, welche von Aristoteles an bis jezt ans Licht getreten sind. Aber

„Tausende, gleichwie Blätter und knospende Blumen im Frühling,

Dicht, gleichwie der Fliegen unzählbar wimmelnde Schaaren. “

standen sie mir ror Augen, als ich die bisher in dicsem Fache erschienenen Schriften mit einem Whle zu überschanen anfing, so, difs dem rüstig. licymmden beinahe der Muth zur Ausinitrung enticl. Jedoch bald wurde ich gewalır, dafs anch in der Geschichte der Zoologie, wie in Reiche der Thicre selbst, nicht Zufall und Williühr, sondern gesetzmärsige Nothwendiglieit herrsche, und dafs, wie in der Zeit überhaupt, so in der Entwiklungs。 
folge der bisherigen Systeme, kein Noment aus scinem Gefiige vereülit werden hönnte. Zugloich bemerhte ich, dafs die Lrockimng der einzclnen Systeme genau mit den gleichzeitigen Weltverän derungen zusammenhinge, und dafs daher dic Geschichte der Zoologie so viel mögich, wie sic in dem Boden der allgemeinen Wellugescinchte wurzle, rorgetragen werden müfste. Mit Yergnigen ergriff ich diesen Faden, welchen mir in diesem Labyrinthe die Matur der Sache selbst dabot, and folgte so ren Aristoteles bis anf Limé und Curier dem Wachsthume eines Baumes, wel hey im Alterthume wuzelnd $3 n$ cinem Stan'me sich vereinigte, und dann in viele giune, aber zu ciner einzigen Blithe strehende, Zweige ansschlug. Noch stellte sich mir aher eine andere Schwierigkeii entgegen, die, gefahrolicr als die erble, sinch in meinem Unternelmen wanliend machen liomn ke: sch fand nänlich, dafs in dieser Knwihlungsfolge der Waclifolger immer die Lüichen sentes Vorgüngers anflehie and rerbesserte 0.7\%: wh dem eben geltenden Systeme wegsciwnd. we rog

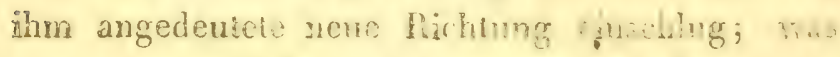
war demnach naturlicher, als der Gesch intu des Systeme eine Kritik porallel lanen du lassen? Nachsirht lalibs enem jungen Mame, welcher der Beobachtung dex Natur ans lanteren sime and blos zur Defrieuigung seines 'Trimites, dis Nas 
tur liennen zu lernen, ergeben, seine wissunschefIiche Aufgabe anch liritisch anselien zu missen glaubte, und ïber die Thaten von solchen triän nern, wie Linné, Cuvier, Blumeubach, Latham, Lacepede, Fabricius, Lamarch, Ellis u. s. W.., Ur. theile zu fillen, sich erhïhnet, nicht, wie sio ilm scine Verehrung der Verdienste diesen floroon, sondern die Geschich!c scilost in die Hände liefert? Niemals wünde ich mich za ciner so schwioigon Aufgabe, wozn sich gar heine Vorabei darle: rerslanden haben, hätte ich nich zuren fectegurheit gehabt, mich in der Natur sellst unzuschaten,

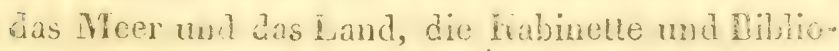
theken ron Fruntreich und Italien, welche Lander zu bereisen, mir gluchicher Weise verstutet war, mit eigenen Augen zu mener Ausbildung za bountzen, den Ungang von vorzüglichen Natuforschern zu geniefsen, und so die Zoologic glcichsam ans der Quelle zu studieren. Insbesondere aber habe ich die Anfulmug dicses Therles r.er

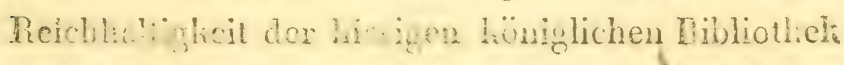

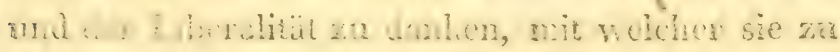

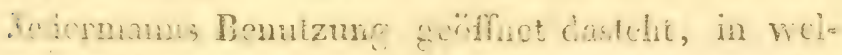
the Hhaselt ich ronzinglich die Gefalligheit des

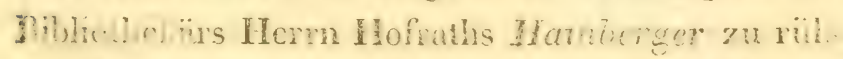
nern habe; Aucl: dem Hem Baron r. Moll binge ich wegen seiner edlen liberalitat, mit welchere:

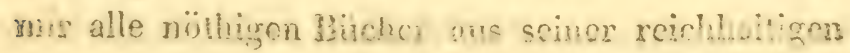


Priratibliothek verabfolgen liefs, den schuldigen Dank dar. Vor allen aber ist es cin schelling, welcher, wie Göthe die Poesie neu erschuf, die Philosophie den sophistischen Wizeleien und Schwärmereien unseres Jalnhunderts entrifs, und der Natur wieder antieimg $₫$, und weicher mir gleich in Anfange meiner medizinischen Laufbahn den unvergefslichen Rath ertheilte: „nich nicht sowohl an die Worte und gedruliten Schriften, als im Geiste eines Swammerdam an das offene Buch der Natur sclbst zu halten, und so in Allem die Erfahrung zu meiner Geführtin zu machen,"

cin Curier, welcher der Zoologie, ja selbst der gezanmten Naturgeschichte unserer Zeit durch die Eearbeitung der verglcichenden Anatomie eine ganz noue Richtung gab, und wolcher nich während meiner Anwescnheit in $T$ aris nicht blos an seinen anatomisclien Alleitn und zwar zur Serie seines vortrefiniclisu Gehinlfen in der Anatomie, Fousceur, Theil nehmen, sondern nir auch das zoologio sche und das zootomische habinett, und seine Privatsammlung fossiler Knochen zum Studium, ja sogar zur beliebigen Abzeichnung. öfnen liels,

For allen sind es diese Mämner, welchen ich hier 
offentlich dic Gefühle meiner innigsten Verchrung und meines Dankes anzudeuten, und zugleich um Nachsicht für dieses mein exstes Werh zu bittcis wage, Männer, welche, statt Jïnglingen ron Trich und Fleirs Hindernisse in die Bahn zu werfen, ihnen viclmehr grofsmüthig alle Wege zur Áusbildung zu öffnen suchen.

Noch glaube ich cinem Verdacht ropheugen zu müssen, als schiene auch ich, da im Verlaufe diesor Schrift heines der aufgezählten Systeme ohne unrerbesserliche Lücken aufgefunden wird, ein Freund des beliebten Spruches zu seyn:

"dafs die Menschen eigcratich nichts wissen können, und nur gleichsam wie cin Sisyphus inmer wieder herabrollende Steine fruchtlos aufwärtswälzen; dafs daher nur jener der II eise sey, welcher die Windungen der Wissenschaften, als cines Grillenspiels einmal kennend, genü̈hlich und höhnisch den Anstrengungen des Forschers zuschaut."

Jedoch ferne sey ron mir cine solche, der Menschlicit unwürdige RTeinung, indem mir immer solche obscurante Genäichlichlritsapostel wie IMenschen, welche ihren Kopf unicr den Armen tagen, vorliommon. Die Forschungen nach der Finsicht in die Natur, sind so alt als die Natur solbst: Dem niederen Thiere isi es nur vergönnt, sich und die 
änsere Welt Jiwch Finpfindung und gleichsam milielst Fïhiörnern wahzunchmen; höheser Thieron ist dir eigene und die äusscre Natur schon in cincr gröseren Pajpherio mittelst Gefuhlen mul Torstillungen aufueschlossen; ror dem Merschen als dem wahren Ebenbid Gottes, steht die imnere mud ässere Natur in ihrer vollsten Ausurhnung und zwar ror seinem crinthe in Glauben, vor srinem geistigen Auge in / 'isch anfigeschlos. sen da; ja wissenschaftiche Fogschng naci Natur, feschichte und secle war lant den Doru. Inenten der ithturgeschente immer allen it atio-

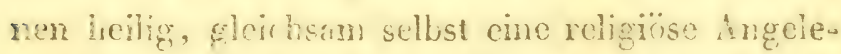
grubeit, und chen dicser göllhirhe Trieb is! es, weldicr Universtaten crichtete. Acadenien, niche des Nichtwisocns sonden der Misscnschaften, an prlanzte, mat zum Prisidin in denselben die wissenschaflichsten Verscher der Nahu, wie rinst den unsterblichen Newton, und Nïmner, erẹtut in dem Sudium risd in den Fachforschmeren des

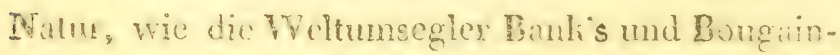

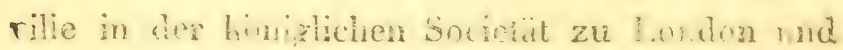
in Inscitute za Paris crlob; ja clecin dicese Swh the lönte zum Beweise angefibert wertmi, at fir nicht mul an eincm rollständ on snd wahmen Nalursyo

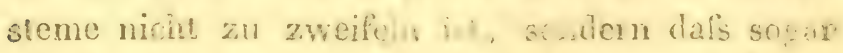

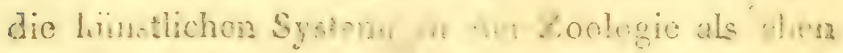

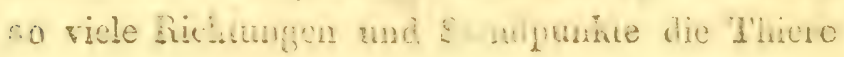


nach allen Seiten bisher liennen lehrten, und allmählig durch wechselseitige Verbesscrung und Einverleibung zu dem einzigen wahren Systeme der Natur (systema nuilurae) sich umbilden.

Gleich entfernt ron mir sey auch jene den Beobachtung eben so geführliche Parthei unserer zeit, welche durch leeres Crïboln, Analysiren knd sophistisches Spielen nit hohlen Begriffen, die Ratur unter Geselze zu bingen trachtet, seibst von Lrfahung verlassen immer, wie z. B. Frofeso sor Link, die Erfahmug im Munde fülıt, und dieses fruchlose Thm und Treiben für Empirie ausschreien mögte.

Der Plilosoph wic der Naturforscher sollen Ganz gesondert den Weg ibrer Forschungen gehen; dieser soll rein und gewissenhaft beobachten and cxperimentiren, dann die, aus der Menge ahnlicher Fakten - aus der Analogie - sich ergebenden Schlïsse ziehen; jener aber soll die Beobachtungen des Natuforschers über das Physische und Psychische in Saft und Blut rerwandeln, nund inciem ex die zu Grunde liegenden Gesetze als solche, gleichsam als das Ideal der Natur, Funst and Wissenschaft, aus der concreten Wclt herans. liebt, das Allgemeine (a priori) in dem Besonde. gen (a posteriori) nachweisend behrüftigen, und so die Philosophie selbst als eine blos beschauliche Reobachtung der Natur darthun. 
Hemit übergebe ich nun diese Schrift dem Publiknu, und bitte in derselben nicht auch die Darstelhng ron solchen Schriften und Ansiciten zu suchen, welche leinen wesentlichen Einflufs anf die Zoologie als Wissenschaft gehabt, oder auch das volle Bürgerreclit noch nicht erhalten lıaben. Aus cinem ähnlichen Grumde habe ich auch unterlassen, dic Citaten aus den zerstreuten, einzelnen Abhandlungen des Aristoteles über die Thicre zu nehmen, sondẹm mich auf seine Geschichte der Thiere beschränlt, indem ich Leztcre als das Ganze, das jene sich einverleibt enthält, gleichsam als die Ilias und Odyssee der Zoologie ansehe. Ich schliel'se mit Cicero's Worten, die ich zu don meinigen mache:

"aggredior non tam perficiendi spe, quam experiundi voluptate; "

mag der einsichtsvolle Leser mit der nämlichen Wahrheisliebe, wie das vorliegende Werk geschrieben ist, dasselbe beurtheilen, und die gerechie Zeit über das Gelungene oder Fehlerhafte. richten, und das Lüclicuhafte ergänzen. 


\section{I $\mathrm{n}$ h a $\mathrm{I}$ t.}

\$.

1. Tdeo der Natur.

3. 5. Begriff der Zoologie; ilır Verhältnifs su den tibrigexs Wissenschaften.

4. Bedeutung der Ausdrücke: „Reich, Klasse, Orinung, Faw milie, Gattung, Art, Methode, System in der Zoologie."

5. Mögliche Ansichten von der Natur - Kïnstliche Systeme, natïrliches System.

6. 7. Vorzug des natürlichen Systemes vor den künstlichen,

8. Nothwendigkeit des früheren Ursprungs der künstlichen Systeme vor dcm natürlichen; Zustand der naturgeschichtlichen Bildung bei den frühesten Völkern; philosophische Ansichten von der Natur im Alterthume; erster gründlicher Entwurf zur 'Loologie als Wissenschaft von Aristoteles; Aristoteles bleibt als Philosoph bis auf Kant, als Zoolog bis auf Linné der Grund und Boden aller weiteren Ausars beitung in diesen Fächern.

ER S TE, A B THEILUNG.

Fon den kiinstlichen $S y s t e m e n$ in der Zoologie im Allgemeinen.

ERSTES KAPITEL。

Periodedes Keimens der Zoologie.

g.

8. Arístoteles. Kurze Biographio desselben; gedrängto Uebera sicht seiner Geschichte der Thiere.

Aristoteles als Zoolog, Zootom und Psycholog; ssine vurberschendo Ansicht und Klassification der Thiers. 
\$.

g. Beurtheilung der Lezteren.

10. Zustand der Zoologie und Anatomie nach seitem Ioü a... bei seinen Schülern - während der Weltherrschaft der Römer - auf dem römischen Gebiethe selbst.

11. I'linius Secundus als Naturhistoriker. Kurze Bingraphie desselben, geträngte Lebersicht des Inhaltes seiner Schriften, hesond.rs jener über die Thiere; seine vorherschendInsicht und Klassification der Thiere,

12. 13. Beurtheilung der Lezteren; Vergleichung des Arisioteles und Plinius als Naturforscher.

I4: Linlluis der Somiften des Solinus, Aelian, Oppian, Dio Cassius, Seneca, Atlenäus, Apulejus u. s. w. auf die Zoos logir. Gewinn für Zoologie und Anatomie mit der Erscheis nung des Galenus.

\section{ZWEITES KAPITEI.}

\section{Periode des Grünens der Zoologie.}

15. (Gothisches Zeitulter). Einfluis desseiben auf das naturge schichtliche Studium.

Darstellung und Jicurthilurig der Ferdicrstz des Isiloz von Sevilla um die Zoologie.

86. (Arabisehes Zuilalier! Gegenwärticer Zustand tier Wissenschattew, urd sein Eintluis aut das naturgeschichtliche Studium.

Wiederanfuben der Zoologie mit Theobaldus, Albertuz Magnus, No onbers, Cuba ; Darstellums und Reurtheilung ihrer Ansichten und Verdienste in der 'Zoologie.

\$\%. Merkwärdige Folıen des blühenden Seehaudels, der nower Entulecking von Weltheilen, der lieformation, der Erfinciung der Buchdruckerei, der Lnternehmung ron Expeditionen zur näleren Kenntwifs der Erde, und der Prollukte der einzolnen Weltheile.

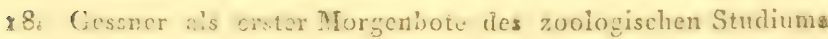
auf teuischen Buden. Biugraphie desselben; Darstullung 
5.

und Beurtheilung seines Sysiemes und seiner Verulienste in der Zoologie. Belebung des naturgeschichtlichen Studiura. durch Belon und Rondelet auf französischem Boden.

21. Wotton auf erglischem Boden. Sein Verdienst in Hinsich: der Erveckung des Aristotelischen Systemes der Znolusie überhaupt; Biographie desselben; Darstellung und Reurtheilung seines Systemes und seiner Verdienste in der Zoologie.

20. Aldovandus auf italicnischem Boder. Piographie desselo ben; Darstellung unri Beurtheilung seines Systemes und seiner Verdienste in der Zoologie, desgleichen seiner treuen Anhänger, des Jonșton und Charleton.

21. Schilderung der Toutsinitte in der Anatomic seit Galenus bis jezt, durch Mundinus, Vesalius, Sylvius, Piccolomini, Asellius, Bartholin, Pequet, Eustachius, Willis, Harveys Swamerdam, Tyson, Sthenon, Malpighins, Perrault u. . w.

Günstiger Einflufs auf Zoologie durch die Herausgabo von Latalogen, von Deschreibungen vonkuseen, von öffentliclion und Privatkabinetten, und dirch die Erriclotung akademischer Cosellyschaften auf englischem, franäusischem und teutschem Boden.

22. Ray. Biographie desselben; Darstelling uno Beurtheilung seines Systemes und seiner Verdienste in der'Zoologie.

23. Klein. Biograplice dessclben; Darsteliung und Beurtheia lung seines Systemes und seiner Verdienste in der Zoologie.

24. Linné. $M I$. ihm wird Tag über die gesnimmte Naturgeschichte; umstänriliche Biographie dissellen; Enthusiasm und Liebe seiner Schüler für ihn, und tïr die gesammto Naturgeschichte; Parallele zwischen ihm und Aristoteles.

25. Darstellung des Crundrisses seines gesammten Naturgebäudes.

26. Durstellung sciner Miftliode und Klassification im Reiche der Thiere.

2\%. Niletamorphosen der Lezteren durch die successiven Ausgabers seines Natursystemes hindurch. 
5.

28. Trurtheilung coines Systemes und seiner Fordienste in de Zoologie.

29. Natureselnich!licher Lifer auf ientschem, ilalioniscut:n und englischem Loden.

Die Naturgeschichte verleget ihren Sitz-von Upsal und zwar das Studium der Geolegie nach Teutschland, jenes dia Zoologie nach Paris.

5o. Düfon. Biographic desselbon; Darstellung und Beirthei Iung seiner Verdienste um Zoologie.

31. Trisson. Dirsteliung und Deurtheilung scines Systemes rits Zoologie.

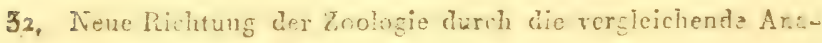
tomie; geschichtliche Darstellung der successiven Ausbildung der. Iezteren seit Democritus bis auf gegenwärtige Zeit; ihr Zerfillen in veterinäre und menschliche Anatomie und Physiologic; die Verdienste von dew vorzüglichsten Männern in diesen Fächern.

23. Cuvier. Biographie und Schilderung der Verdienste dos Daubenton und Vicq d'Azyr als der nächsten Vorgänger desselben in der vergleichenden Anitomie.

Cuvier als Reformator der vergleichenden Anatumie und eben hiedurcln dur Zoologie; Liographis dessolben; larstellung seiner anssordentlichen Virdicmste als die ptolie aller spöteren Perivaserang des Limucischen Natursystemes durch Lamári, Iacemade, Dosk, Jüineril, Geotroi, Lí treille, Desmarest, Denys, MIontfort, Roissy u. s.w.

54. 55. Würdigung der Forthile und Füge der N'achtheile, welche aus der bishefon Entwiilutig dieser neuen Ricltung der Zoologie entstehen.

Kurzer Ribhlick auf den Stantpunht der Zoologie withrend dea heinten Periodus ihrer Lntwiklung bis auf unsero Keit. 
Z WEITE. ABTHETLUNG.

Eon dien fiusilichen Systemen insbe. sondere.

\section{ERSTES CAPITEL。}

$\S$.

$$
\text { Säugthiere - MIastodologia. }
$$

36. Aristoteles. Seine Verdienste um diesen Thril der Thiexw geschichte; Darstellung der verschiedenen Methoden, wolo che or zur Abthcilnng angiebt.

Plinius Verdienste in diesem Fache.

37. Ray, Albert, Cessner, IFotton, Aldrovand, Jonston hehen eine der Aristotelischen Abtheilungen heraus; Ray wirft sirh als Klasciker in der Ausfillimm derselben auf; Darstellung der Verdienste der Einzelnea.

39. Beurtheilung dieser bisherigen Richtung.

5iv. Timne füht eine nene Richtung ein; Darstellung und Eeurtheilung dieser seiner neuen Methode, nehst der. Angabe Blirer Nieimorphosen durch die einzelnen Ausgaben stines. Nivtursystemes.

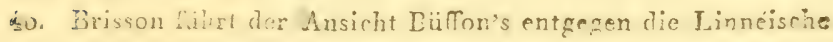
Richtung aoch consequenter durch; Darstillung und Leurtheilung.

4: Klein thut ein Gleiches mit jener des I.ay; Darstollung und BeurtheiIung.

42. Pennant vereinigt die Ansichten seiner Vorgänger zu cio nom eklelulischen Systeme; Darsteth ng und Bewzheilunös

45. Zimmermann giebt eine neue Richtung an; Darstellung und Beurtheilurg; grelegenieitiche stus mug der Assicho ten dos Verfasers uher dic Echiphrung urd Ausbildumi les Erde, über die Sintstehun iher Wultheile; Fachw zweier, allgcmeiner lerioden, nämlith ùcs Alesthums üb Neuerthums durch alle inre Geschöpte. 
9.

44. 45. 46. Verhesserung des Linnéischen Systemes durch Scopoli, Erxlehen, Blumentarh, S'orr. Darstellung und Eeurtheilung der Verdienste jedes Einzelnen.

47. Bonnet, Hermann, Boddaert, Batsch, Treriranus, Schubert, streben das künstliche System Linne's in ein natürliches, was aber im Grunde doch wieder, ein künstliches ist, umzuwandeln. Darstellung und Beurtheilung.

48. Vieq d'Azyr, hesonders aler Cuvier, bringen wichifge Verändrungen an dem Systeme der Süusthiere Linne's hervor. Darstellung und Beturtheilung.

49. Dümeril, Geoffoi, Desmarest :ehen auf dem. Whege Cusvier's fort. Darstell. und Beurtheil.

Uebersicht über die Bearbeitung der Säugthiere, der lebenden sowohl als der fossilen.

\section{ZWEITES KAPITER.}

$$
\text { Vögel. - ornithologia. }
$$

5o. Aristotcles. Seine Verdienste un die Bearbeitung dieser Thiere; Aufz̈̈hlung der verschiedenen Hithoden, welche er zur Abtheilung angiebt.

Verdienste des Plinius, Oppian.

51. Verdienste des Isidor, Albert, Turner, Langolin, Belon, Gessner, Wotton, Aldrovand, Jonston, Charleton. Willughby und Ray filhren die von jenen angegetuene Richtung aus. Darstell, und Beurtheil.

52. Linné eröffnet cinen neuen Weg. Darstell. und Beurth.

53. Klein exöfnet ehenfal's eincn neuen. Darstell, u. Benrih,

54. Nöhring errichtet cin neues System. Darstell. u. Beurllis.

55. Brisson als Eklektiker. Darstell. und Beurtheil.

56. Silberschlag deutet eine neue Methode an, Darstell, uril Beurtheil.

57. Eatham wirft sich als Oherhaupt der bisherigen Bearbeitung auf. Darstell. und Beurtheil. 
6.

58. Teske, Blumenbach, Batsch, Mermann, Treviranus, Becho stein, Meyer und Wolf arbeiten an der Verbesserung des Linneischea Systemes. Darslall. und Beurtheil. jedes Einzelnen.

59. Cuvicr, Dimeril u. s. w, als Verbesserer des Iathamischen Systemes.

Uebersicht der bisherigen Bearbeitung der Orwithulogio sowohl in Betralf des Zoolosischen, Anatomischen und Fossilen.

\section{DRITTES KAPITEL。}

Amphibien. - Herpetologia.

6o. Aristoteles, Plinius, Nicander. Ihre Verdienste in diesera Fache.

51. Isidor, Albertus, Gessner, Wotton, Ray, Ielron dieso Thiere näher kennen.

62. Linne bringt sie in ein System und weist ihnen ihren Platia in der Therreihe an. Darstell. und Beurtheil.

6j. Klein hält sich an die Kupfer des Seba, Catesby u. s. w: una bringt sie unter eigene ALtheilungen. Darstell. und Beúrtheil.

64. 65. 66. Laurenti, Scopoli, Cronov, Blumenoach, Lacepede rerbessern das Linneische System. Darstell. und Beurtheil. der Verdienste jedes Einzelnen.

67. Prongniart als Obcrhaupt in der bisherigen Bearbeitung der Amphibien.

Darstellung dessen, was bis jezt in der Anatomie dieser Tlicre ciurch Swammerdam, Perrault, Charras, Tyson, Düverney, hiisel, Caltlesi, Gottwaldt u. s. w. in der Zoologie neuerdings durch Schneider, Russeil, Schaw u. s. w. geschehen ist.

Darstell. und Deurtheil. des Systemes von Brongniart.

68. Latreille, Daudin, Dümeril verbessern das Leztere.

6g. Uebersicht der hisherigen Bearbeitung der Herpetologie in Betreff des Zoolosischen, Anatomisclen und Fossilen. 
VIERTES KAPITIL.

g.

$$
\text { Fische. - Ichthgologi } i \text {. }
$$

70. Aristoteles, Plinius, Oppian. Ihre Vordienste in dicsem I'ache.

71. Decius, Isidor, Albertus, Jovius liefern cinige Beiträge : Beion, Rondelet, Salviani geben eine noue Richtung an; Wotton, Gessner, Aldrovand, Jonston folgen den nämlichen Ansichten.

72. Beurtheilung der zwei bisher herschenden Ansichten.

73.9 Ray führt eine neue MTethode ein; Dalejus und Artedi vervollkommen dieselbe.

74. Linzé sucht sie au vollenden. Darstell. und Beurtlacil.

75. Klein, Schäffer, Gronov, Brünnich, Gonan verändern verschiedcnes an dem Systeme ihres Vorgängers.

76. Scopoli heht aus dem nämlichen Systeme einen Nebengesichtspunkt als Hauptgesichtspunkt heraus, Darstell. nnd Beurtheil.

77. Uebersicht dessen, was bis jezt in der Anatomie der Fische gethan ist. Larépéde als Eklektiker aller seiner Voräinger und als Haupiclassiker in diesem Fache. Vergltichung sciner Verdienste mit denen des Bloch; Darstell. und Beurthl. seines Systemes.

75. a. Lutreille, Dumeril, Lamarc': verbessorn dess Eystem r.es Lacepules. Lebersicht der bisheriznn Eearicitung de ichthyologie in Betreff des Zoologischen und Fossilen, Darstellung des Inhaltes des IVerkes: "it tiolitologia veronese."

\section{FiiNFTES KAPITEL.}

Mo 11 uske-n. - Conchyliologia. -

79. b. Aristuteles, Plinius, Oppian; Mre Fradienste um die so Fach.

-g. Isidor, Albertus, Votton, Dulon, Rondelet, Salriani, Cessner, Aldrovand, Jonston, Charleton, Columna, Najor, Sibbald, Bonnani, Tournefort, Pumpf, Langius, Valentin, Jebenstreit, Breynius, Lister, Arsenville, Gualtieri, Lesser. Darstell. der Wrethole und der Vorcienste jedes Einzelnen. 
§.

8o. Linné füht die bisherige Ansicht, auf die, Scliale dieser Thiere erbaut, 211 einem vollständigen Systeme aus.

8. Klein, Adanson, Martini und Cheminitz, Geoffroy, Schröter, Regenfu[s, Geven, Gronov, Borm, Spalowsky, Scopoli, Leskr, Blumenbach, Brigniere verbesican verschiccientlich das Schualensystem des Linné.

82. Beurtheilnng der beiden bisherigen Systeme, welche anf den Aufenthalt odei auf die Scliai is dieser Thiere gegrindet sind.

83. Poli wählt einen neuen Gesichtspunkt, mäılich statt de Schaale, den Bewohner derselben. Darstell. und Beurthl.

8i. Cuvier geht auf dem Wege seines Vorgängers fort, und errichtet ein anderes System wach einem ähulichen Gesiçhtspunkte; seine Verdienste um die Anatomic dieser Thier im Vurglciche der bisherigen anatomischen Kenntnisse derselben.

25. ¿. I) incril, Lamarck, Bosc, Latreille, Jiontfurt, Draparnaud bringen Verbesserungen an dem Systeme Cuvier's an. Uarstell. und Beurtheil. der Verdienste jedes Einzelnen. I

Oken giebt cinen neuer Gesichtspunkt zu einem Systeme dieser-Thiere an. Beurtheil.

15. 3. Beurtheilung des Systemes von Cuvier, und der aut die Bewohrer der shuten hisher gtbaten Systene üherlaupto

Uebersicht der bisherigen allgemeinen sowohl als monoErophischen Burbutung der Conchyliologie in Betreff des Zoologischen, Anatomischen und Fossilen.

\section{SECHSTES KAPITEL}

Insekten. - Entomologia." "

66. Aristoteles Verdienste um diese Klasse; seine verschiedene Ansichten zur Klassification derselben.

Plinius und Nicander's Verdienste.

37. Isidor, Albertns, Wotton, Moulfet, Aldrovand, Jonston, versuchen ruschicdene Cesichtspunkte zur Klassification dieser Thiore. 
5 .

88. Ucbrrsicht dessen, was bis jezt in Hinsinhte cier Lintstenurg und der Anatomie der Insekten ausgemittelt ist.

Stuammerdam als Stifter eines neuen Systemes und als Begründer der, Anatomie der Insekten.

8g. Beutheilung des bisher herrschendin, auf die Nictamorphose gebauten Systemes.

90. Vallisnieri deutet eine neue Ansiclnt zur Klassification an. Darstell. und Beurtheil.

91. Verdienste de Reaumür, Lyonnet, Rösel um die Entomologie.

22. Linné benuzt dio Andeutung seiner Vorgänger, und errichtet darauf ein neues System.

g3. Tebst andern Schriftstellern verbessert vomziglich Geofiroy das System seines Vorgängers.

4. Drury, Degeer, Sepp, Ernst, Esper, Borkhausen, Cramer, Ifïbner, Wilkes, Harris, Silnfiermiller, Lans, Orhsenhcimer, Abbot, Schrank, Laicharting, Preissler, Schmiedlcin, Jablonsky, Herbst, Stoll, Martyns, Voet, Paykull, Meigen, Müller u. s, w. tragen zur Entwiklung der einzelnen Ordnungen dés Linné bei; Scopoli, Blumenbach, Ersleben, Leske, Patsch, Brünici machen einige Abönderungen ara Linnèischen Systeme.

Darstellung der Verdienste jedes Einzelnen.

Beurtheilung des Linnẻischen Systemes.

95. Fcbricilis stellt ein neues bystem der Insekten auf. Fingras phie desselben; Nietamorplosen seiner Ansirht, nach seinen einzelnen Schriften; Darstell. seines Systemes.

96. Beurlicilung des Fahricischen Systemes; Parallele desse?ben mit dem Linnéisthen.

97. Coquebert, Bömer, Rossius, P'uner, Siurm, Walkenaer, Hentschins, Klug, Kirby, lligher entwickeln und verbesserxs das Fabricische System.

Olivier, Clairville, Lamarck, Latrcille, Dümeril hilden aus dem Linneischen und Fabricischen Systene neue eklekw tische; Darstell. der Verdienste jedes Einzelnen.

Jirine deutet eine neue Ansicht $3 n$ cincm neuen Systeme, oiler doch zur Ergänzuug les Linnéischei an. 
S.

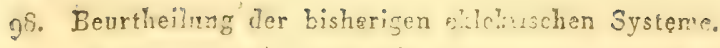

Uebersicht der hihherigen Bearbeitung der Entomologio in Betreff dus Zuologischea, Anaromischen und Fossilen,

\section{SIEBENTES KAPITEL.}

Würmex. - IIelninthologia.

99. Aristoteles. Scine Abheilung der Würmer und seine Verdienste un ihre Bearbeitung.

100. In wie wcit dic Wirmer einem Isidor, Albertns, Wotton, Belon, Rondelet, Mouffet, Aldrorand, Jonston, Klein, jene der Eingeweide, cinem Reti, Lowenhok, Andry, Vallisnieri, Clericus bekannt waren.

Linné bringt endlich die Würmer üherhahpt in ein Sy stem. Darstell. des Lezteren:

צor. Müller erweitert und berichtiget das Linneische System; Brünnich, Scopoli, Blumenbaci, Leske, Batsch, Erxleben

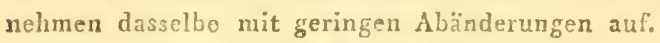

Pallas, Goze, Bloch, Müller, Schrank legen den Grund zu dem Systeme der Eingeweilien iirmer; Zeder und liudolphi bereichern und vervollkommen dasselbe; Darsteld. und Beurtheil. der Verdienste jedes Einzelnen.

102. Uebersicht dessen, was bisher in der Anatomie der Würmer geleistet ward.

Cuvier macht eine ganz neue Anordnung, nämlich auf dis Vollkommenheit der inneren Thrile des Körpers dieser Thiere gegriindet; Lamarci, und nach ihm Losc, Dünseril, Latreille benutzen die Andeutumgen Cuviers, und verbessern die Anordnung desselben.

103. Uehersicht der bisherigen liearbeitung der Felmintlioiogis in Betreff des Zoologischen, Anatomischen, Fossilen.

\section{ACHTES KAPITEL.}

Zoophten. - Zoophytologia.

201. Aristoteles Ansicht und Terdienste in diesem Fachu; Plinius Meinung von diesen Thieren. 
5.

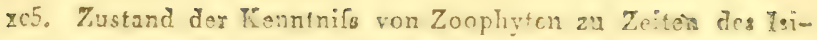
dor, Allumbus, Wotton, Belon, Perúclet, Gessucr, Imperati, Aldrovand $u$. s. w.

Peyssonel macht das Studinm der eisentlichen Zonphyten als Thiere rege; Trembley jenes der Polypen; Donati, besonders aber Ellis liefert cine Mionograpitie der eigentlichere Zoophyten.

Limé weiset nun den Zoorhyten ihren Platz im Naturreiche an.

זீô. Fernere Entwiklung dieser Klass * von Thieren durch Linkius, Klein, Dicquemaer, Backer, Schäffer, Rösel, Baster, Slaber, Ledermüller bis anf Pallas, welcher eine neue mo* zographische Umarbeitung dieser Thiere veranslaltete,

Löwenhök, Needham, Wrisberg, erwecken das Studium einer neuen Ordnung von Zoophyten, nämlich der Intusorien, und Müller wirft sich als Nonograuh derselten auf. Scopoli, Blumenbach, Batsch, Leske, Erxleben, werbessern das Liunéische System. durch diese nenen Zusäıze. Darstellung der Ansicht und der Verdienste jedes Einzelnen.

10\%. Rogues de Maumout, Bruguzere, beswaters ahes Cuviez und nach ihm Lamarck, Bosc, Dïmeril suchen das Linncische System dadurch zu verbessern, dafs sie, so weit dass. Innere dieser Thiere bisher hehanut ist, durels betuhsirhugung desselben aine Rangordiung herstellen, I)astell, und Beurtheil. ihrer Verdienste.

¿oc. Uebersicht und Beurtheilung der bisherigen Bearbailung der Zoophytologie in Betrefl des Zoologischen, Antumischen und Fossilen, und dann in Bezug auf lie Liststex hung dieser Thiere. 


\section{ก. 1.}

Die Natur bildet ein in sich beschlosscnes, rols lendetes Ganze. Was immer in die Simne fällt, ist daher nichts als ein Glied dieses colossalen, ewig sich selbst erhaltenden Gebäudes. Sie em pfüngt nicht das Lebcn, wic ein organischer hör. per dic Anregung dazu, von aussen; nein, sie trägt in sich selbst den Grund ihrer Existenz und Befruchtung, und ertheilet dicse in höhcrem oder geringerem Grade allen Wesen, welche auf Wirklichkeit Anspruch machen. Zwar scheint diese zauberische Schöpfungskraft manchen ihrer Ge* schöpfe zur Nachahmung verliehen zu scyn; aber wo ist wohl von der regelmäfsigen Zelle der Biene an, bis zu den lief ausgedachten Tempeln griechischer Meister, den Statuen eines Praxiteles und den Gemälden eines Raphael das regsame sich selbst erhaltende Leben, welches den Kërper der Bienen, so wie dieser grofsen menschlichen Fiunstler beseelet hat? Todt und erstarrt stehen sie da, und gefallon nur noch durch den täuschenden Schein jener unvergünglichen Natürlichkeit. In den urspüunglichen hunstwerlien der 
Nutm in regentheite ist alles reicnt und spre-

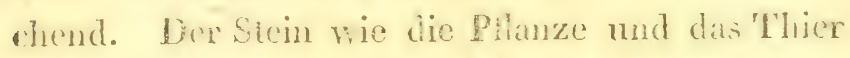
sind ron dem Triebe ihrer selbstrhallung hereclet; nit diesem leimmden samenlione dahice blinhet die verwellite Butcpllanze in nochmali-

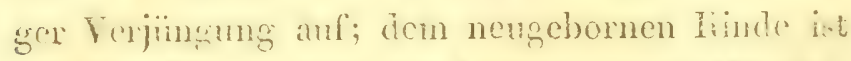
mit dem fü̈per auch die Secle seiner schaffenten Zenger vingebilad, beide gestalten sich mit jedem Momente von Nenrm, und leben endlich remittelst 'Lenw!ng immer so wiedergeboren, durch ewige Zciten fort. Freilich ist das Wasser ron der Luft, diese ron dem Lichte abhängig, das Mincral, dic Pllanze und das Thier erhalien sich nur durch ihren wechselscitigen Einflufs, und dann duch jenen cines höheren Gestines. Wohl ist alles hinzche disser hërper - und Geisterwolt bedingt und der Veranderung unterworfen; allein wer wagie die gesammte Nathis, in deren (iliedern Golt, wie die secte in organiscien hörper, wohnet, abhings zu nenicn? Ther wagle dis Ganze anzulisten, das Ginze, welches, wie Parmenikles sich atsdrita "), zwar in abweciselndem Dalancircis erschenend, doch ïber alle Zeit

a) Platon. oper, edit. bipont T. 10. Parmenid. p. Íf. Tó

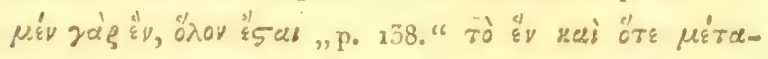

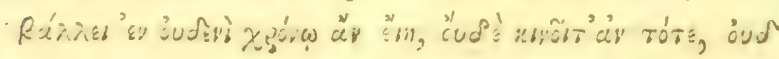
ür sain 
crhahen, immer in Ruhe und Gleichgewichte rerbleibet? Nur von dem Ganzen gilt also, was Timäus aussayt $a)$, dafs es immer Dasselbe, freivon aller Füulnils und Zerstörung, seclig und ewig vollkommen rerbleibe, alles Einzelne aber ist, wie die weissagende Diotima über die Grotheit des Amors den Solirates untervichtet ${ }^{b}$ ), ron Liebe durchdrungen, und daher in inmerwährend entstehendem und rergehendem Wechsel begुriffen, jenes unvergängliche Vorbiid in sich auszudriilien.

\section{§. 2.}

In der Natur ist das geistige Leben nicht ron der Materic getrennt, sondern eines mit ihr, und spricht sich in ihren einzelnen Gliedern aus. Dic grölste Herrlichlicit ist aber zuroderst an den Welthörpern (universum) ausgeprägt. Erst auf diesem Grund und Doden entfalten sich jene drei * Epochen, ron welcher jode Periode eines joner uncrnessticlen Reiche (regnum) des elementari-

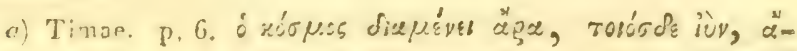

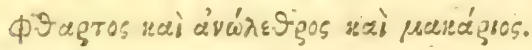

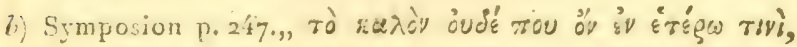

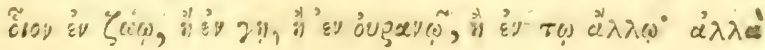

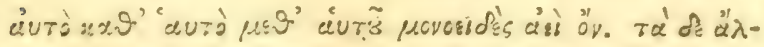

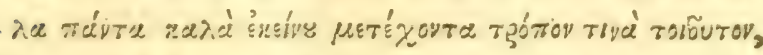

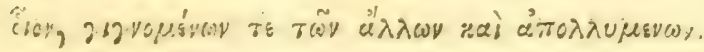


schen und mineralischen, des regetaliven, des animalischen - in sich begreift. Wird dieses archi* telitonische liunstwerk als solches auch in der Rede wiedergrgeben, so heist ein solches wissenschafliches liedegebäude Physiologie - Natnrwissenschaft - Philosophie-M'eltweisheit, und erhält nach den einzelnen Absäzen und Gliedern dieses Naturkörpers den Namen: System der Welt- und Himmels-hïrper (Astronomie) Systom der Elemente und Mineraiien (Physiti und Mineralogie) System der Pflanzen (Phytologie Botunili) System der Thiere (Zoologie). Die Physiologic, welche sich an die Stelle der schaffenden Natur versezet, und nur die Idee und den Archetypus derselben im Auge behält, zeiget sich auf einem niederen Standpunkte, wo sie blos die Gebilde als äussere Erscheinungen nach der successiren Entwiklung in der Zeit durch die Rede darstellet, in einem historischen Gowande, Ind tritt als Weltgeschichte auf. Diese - das Bindeglied zwischen $W$ issenschaft und Fumst - ist somit der Ocean, worin die Weltweisheit sich wie in einem Spiegel reflektirt, und endlich in den Monumenten der funst, und der Religion auch dem simnlichen Auge aufgeht. Weit entfernt, dafs die Geschichte die Wisscnschaft widerlege, soll crstere dis leztere vielmehr bestilligen und rersimlichen, und was der Zoolog in der Wis. 
senschaft andeutet, soll sich in der crzählenden Durchführung durch alle Thiere - in der Thiergeschichte - erproben.

\section{3.}

Erscheint dic Natur auf der nicdrigston Stuffe ihrer Bildung - in den Elementen und Mineralieil - mchr lcblos, erscheint illr Geist, obwohl täuschend, wie fremd und nur zuffillig der Materie adhärirend als magnetische, elchtrische und chemische Kraft, so tritt er in den Theilen der Pflanze und noch mehr in denen des Thieres wie ganz verwandt und ihnen cinverleibt als Function auf. Mit Rechte nennen wir diese Theile der Materie, welche in den beiden lezteren num reif sind, jonen ganz in sich aufzunehmen, Organe, and die Natur selbst in Bildung der Elcmente und Nineralien anorganisch, hier aber in Bildung der Pflanzen und Thiere belebt und organisch. So wie die Materie von Elementen an durch Pflanzen mud Thicre sich allmählig veredelt; eben so entwilielt sich nach und nach die Secle, und stellt sich cndlich in den reredelsten Förpern der Thicre, wie die Pflanze in der Blüthe, als gleich voredclter, und rolliommener Geist in ihrer Sclbstbeschaumng hin. Die Zoologie theilt sich daher gleichwie die Physik in Atomistik und Dynamik, eben so, in wie ferne sic mehr den hörper oder 


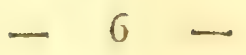

den Geist der therischen Organisation herilisichliget, in die Lohre ron den einzchnen Oranen und Finhlionen des thierischen liöpers (mit RechlePlysiolngie genamut, weil sich die Natur ansser den Thelthiorpern in Organismen am vernehmlichston ansepricht), und in die Lehre vou den Facultiten der Seele (Paychologi' $)$. Doch hat die allgencine. Zoologie nicht blos cinzche Thiere nach ihrem änsseren und imneren Gliedrer bane, nach inren hërperlichen und goistigen Iigenschaften zu beschreiben - Zoographic, Nonogruphe; - sondern sie hat alle Thiere zisammen wie cinen Stat aufunfissen, und ihre Verhälnisse naclu Ordnung und Rang darzuatellen. Auf solete Art wint sie, stalt eine trohese und willabihlide Aufzahlumg der Büger dieses thierischen States zu lichm, sich oben durch Aner-

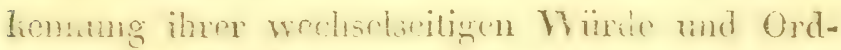

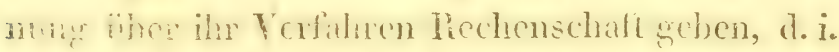
sies systhisilisch und gröndlich aufzili!en. ZooIongir is al:so im eigentlichen Sime eine wissenschafiliche Thicreschichte, welche ans der vergicithenden Phisiologio und Psychologic durch alle Thiere hindurch hervorgehet.

$$
\text { ). } 4 \text {. }
$$

Das Thicreich sondert sich ron den übrigen Tiaturencien als ein weiter rollendeter lireis ab, 
dessen Raum durch allmihlig engere líreise, un 1 diese wieder durch verschieden-winlilichte Figuren ansmefiillet sind. In dem Grade, als sich dicse fireise nach und nach rerengern, in eben dem Grade tritt die animalische Natur immer mehr ins Enge und Dunlile zurüh. Diese hresartigen $\Lambda$ bsäze eines Reiches heissen ron dem äussersten angefangen: Flasse (chasis), Ordnung (ordo), Fumilie (funitia), Gutime (genus), Lrt (species), Abart (varietas). Jedoch ist in jeder Mbart die Organisation ebon so ganz und rollstindig als in dem Reiche; nur, gilchwie im Winlel nud Zirlicl ein nud der nänliche Raum beschä̈nlt, die Acusserung und Darstallumg desselben (Form) aber rerschieden ist, cben so ist dic organisehe Form dort medter, hier aber edler und volliommener. In der Abat wuzeit daher gleichsm dus Reich nnd blibot in der Ritasse. Dieser lohauptung

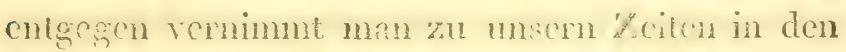
Schriften der ersten Gelebten bei atlen Nationen allgencin die Sprache, dafs diere archithonische Verhellumg der Geschëpe niehl in der valur gegrïndei, sondern das Prudult ciner hlufen Vill-

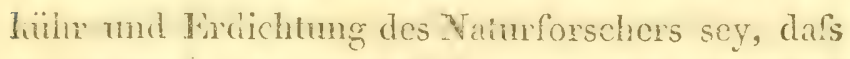
es weder Reiche noch Flassen, weder Fanilien noch Gallungen in der Natur, aber wohl und alIein in den löpfen der Gelehrten gäbe. Viches Icil für dic Naturgeschichte, wo man zulezl sidt 
Ordnung cinen blofsen Zufall, statt einer unabän derlichen Gesezmälsigheit in der Natur nur seine imaginäre Willlülır anerkenne!! eine Annahme, welche sich mehr in der Biographie unserer Zeit als in der Geschichte ïberhaupt bewährte. Gleichwie der thierische hörper durch Organe, der menschliche Staat oder die militärische Gescll, schaft durch Dignitäten gegliedert ist; cben so sind es in der Nalur dic Thicre unter einander, and wie dic Töne in der Musik sich zu einem Conzerte gruppiren; so ist in der Natur dieses harmonische Gefiige durch concrete Gestalten aus. gesprochen. Dic Zoologie hat somit das nämliche Gebälh wie die Natur selbst zu beobachten, and jedes Individum in seinem Gefiige abzuhan, deln. Zu diesem Ende hat sie sich an cine bestimmte Art und Weise, nach welcher sie ihren architelitonischen Plan ausführet, festzuhalten. Diese Art und Weise heifst in der Zoologie Me. thode (methodus) und die mit jener zusammene stimmende Ausfiihrung System (systema),

\section{S. 5 ,}

Bctrachtet man cinen Gegenstand blofs ron einzehnen Seiten - von Nord oder Süd, Ost oder West - so gehen hicraus sben so vicle Meinumgen, als es Ansichten waren, hervor, und nur der, welcher ihn nach allen Richtungen beschauet, ist 
eigentlich im Stande, zur Beurtheilung scines Wesens und Characters zu gelangen. Man könnte jene Ansichten nach einzeinen Richtungen die liüstlichen (method. artificiales), so wie die lezte, welche bei der Peripherie das Zentrum nicht vergifst, die natürliche (method. naturaiis) heissen. In der Zoologic giebt es also, so viel liünstliche Ansichten möglich sind, eben so viele künstliche Systeme (systernata artificialia). Wenn man bei den Thieren blofs das Blut berülisichriget, so liann man sie in solcho mit rothem Blute (sanguifica) und mitweifsem (exsanguia) - nach dem Fnochengerüste in solche mit Rükenwirbeln (vertebraía) und ohne Shelet (non vertebrata) nach der Haubedeliung in solche mit Haaren, Fe。 dern, Schuppen, oder in nakte - nach dem Respirationsorgane in solche mit Lungen, Branchien, Tracheen - nach den Nerven in solche mit blow sem sympathischen Nerven, mit Rükenmarlie, mit Gehirne - abtheilen; hurz wählet man auch nur cinen einzigen Punkt, und sey es die Kante eines Knochen, oder ein einziger Zahn, so kann man auf demselben ein künstliches Thiergebände errichten. Hier von den künstlichen Systemen gilt der Spruch: So viel Köpfe, so viel Sinne.

$$
\text { 5. } 6 \text {. }
$$

Bei den hünstlichen Systemen wird willliühr Iich ein beliebiger Theil zur Vergleichung durch 
alle Individuen hindurch licrausgehoben, und alle werden nach diesem Standpunkte geordun. Freilich hanin cin solcher hïnstlicher Gesichtwmint ant cine wnd dic nämliche Erschemurg gestizt, went ex in seiner sncessiven Fntwihlung durch allo Thiere consequent hindurchgefihel wird, natirtich hessen; aber anch hier werden sich, obgleich anch nur zur Tärchung, WViderspriche und sprüne rutgegensteilen und erweitsen: dafs man die Natu nur dam im Einzelnon zu crhonnen sich rühmen. liöme, wenn man sie schon nach ihrem ganzen Umfinge betachtet mod erhamt hat. Allein ein System, welches sich, was immer für einen Theil z. B. die Zähne zur Festsezung der Lnterseliede der Thiere ausgewählet hat, und olne fiulisicht anf die successive Lntwilhung und den Grat der Vollionmenheit oder Unrolliommenheit des Ganzen oder des Theils nach Guldinlien und Villkiilu die Gruppen der 'Thiere formiret und reihet, dieses isi das eigentlich litustliche System, welches sogur dos natiolichen Anstriches entiohere, und ans blofser subjeliter Wilkwin abstammet.

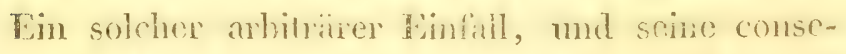

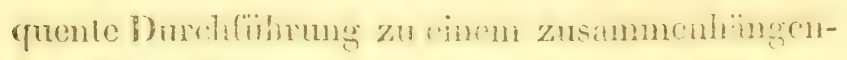
den bilde (Systeme) glevehe cinem erdichnen

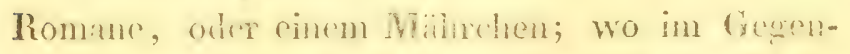

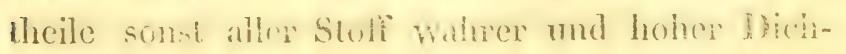
tung aus dem Mecre der Geschichte geschinjol, 
unci im Geiste dieser ausgefïhrt seyn soll. Die sogenanule natüliche Methode soll dalier nicht blofs an einer cinziren Erscheimung der Thiere hafen, sondern alle Theile und Kigenschaften derselben beobachten, ihre Rangoranung und Edelheit nach ihren Bane und ihrer Bestimmung abmessen, und in der nämlichen Ordnung, wie die Organe dieses einzigen Thieres, eben so alie Thiere unterenander als zerstrente Glieder eines cinzigen colossalen organischen liüpers ariluliren. Eine solche durchgefiilirte Mcthode, welche jedem Organe und jedem Thiere seinen Plaz, den es im Verhithisse zu andern hat, in der Nahur nachweiset, verdienct allein den Namen des naturlichen Systems (systema naturale).

\section{\$. 7 .}

Das matirliche System hat also den Vorzug vor allen liüstlichen, indem leztere das Einzelne den Ganzen vorzichn̆, das erstere im Gegentheile alle liunstliche Richungen gebrancht, um das Wahre und Wesentliche in seiner Zersplitterung zu sehen und zu zeigen. Das natüliche einverleibet sich alle die einzelnen Richtungen, und betrachtet sie als Glieder zum ganzen hörper, während das liüstliche nach herrorspringender Afchion alles Uebrige beurtheilet und richtet. Jeloch behauptet jenes den Vorrang ror dem 
lezteren blos durch scinc innere Würde, nicht so nach der Entwillung in der Zeitfolge.

$$
\text { 5. } 8, a \text {. }
$$

Die artikulirte Sprache des Menschen geht zwar dem Schalle und den emzelnen Tünen der Thicre der innern Volliommenheit nach ror; aber doch thun diese, wie auch das neugebohrne hind ihre Empfindungen und Gefuhle zu allererst durch pantomimische Bewegung, Micnen, und abgebrochene Töne kund, und, nur indem lezteres zur Besonnenheit des mümlicheren Alters heranreifet, dann erst legt es sein Inneres durch die articulirte Wortsprache dar. Der inneren Finngordnung geradezu entgegen treten ebenfalls in der Bildung der Nationen zu allererst Religion, dimn Kunst und endlich Geschichte und Wissenschaft, und bei dieser zu allererst die künstlichen, und nur zulezt die natülichen Systeme herror. Der Mensch ummïndig und unwissend auf den Naturschauplaz gesezt, schauct sich zu allernächst in seiner bezaubernden Ungelung um, und angetrieben durch instinlitarlige Gefinhle sucht er seine dürfigen Kenntnisse der Natur auf die Befriedigung seiner nolhwendigsten Bedïrfuisse cinzuschränken. Erst nachden er dio Natur nach seinen ölionomischen Zwelien liennt, dann schwelget er mit ihrem überflüfsigen Reichthume, und 
suclit erfincierisch seine Bedürnisse in den Schein der Bedünfnifslosigheit einzuhüllen. Jezt erst tritt Aer Z.citpunht ein, wo das forschende Ange des Menschen nic'lt mehr das Interessirte und Dürlige ron der Natur auffasset, sondern wo ihm selbst der Blik für das VTahre und Schöne derselben geöffiet ist. So wic alle Zweige des Wissens, so hatte auch die Zoologie ihre Epoche des Keimens. Die Pliönicier, Chaldäer, Juden, Syrer, Perser, und Griechen, waren im Anfange herumziehende Morden, und lcrnten mit abwechselnden Iändern, besonders aber durch Erfindung der Schifflunst immermehr dic Natur kennen. ZWar sorgten sie, nur die Bedïfnisse des Kürpers zu stillen, allein in kindlicher Unschuld immer mehr einsehend, wie manchfaltig und unabhängig von ihnen die Gestirne, Elemente, Pflanzen und Thiere - die Natur - existirte, jezt ergriff sic ein heiliger Schauder, und alles ausser ihmen, je nachdem. es ihnen vortheilhafter, wunderbarer oder füchterlicher erschien, war ihnen göttlich, von einem höheren oder niederen Gotte bewohnt; so betheten sie die Sonne und den Mond, die frühesten Aegypier selbst den Ibis, Apis, das Frokodil und andere Thiere an. Ja belehret, wie verwandt unter sich alle Wesen in der Natur seyen, zählten sic sich selbst als Glied zu derselben, nalımen cin. stimnig die Verwandlung aller liörper und Secles 


\section{- 1í}

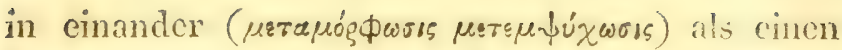
Artilicl in ihre Religionsgeheimnisse anf, and Auguren und Haruspicen waren aufgestcht, hic Breicnisso der Nation ans denen der iveitui Mrtur -

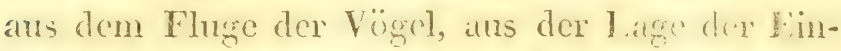
grweide der Schlachthicre, aus der Iichung der Vinde - voranszudenten. Alle die manchfaltigen Dinge der Natur erhelten als eben so vide Götlergestalien ihre cigcnen Benemnngen, und anch in der Wortsmache dieser Tölier bihlete sich so nach mo mach dis Vergëttemeng der Nather zu cinem hamonischen Ganzen aus, was den Vamen Mythologie fuhluret. Biese erreichte in der spiteren Epoche der Aegypticr und nachier besonders in der früheren der Griechen ilhe vollfonmene Blählo. Hier traten die Gröter in der nämlichen Würde und Stammfolge, wic dio Dinge in der Matur selbst, anf, und Wiirdiges wurde nur zu dem Verwancit n gesellet; in diesen Sinut ist der Aller dem Jupiter, der Ilund dem Plulo, das Pfrat dem Neptim, die Schlange dem Apollo, die Gule der Minerva, der Pfum der Juno, die Taube dex Venus, der Schmetterling der Psyche I. s. W. buighent. Jeduch dieses goldene Zeitaltex der lidigion und Natubeschammg dancre nicht lange; der linulliche Simn, und die heilige Betüuburg firr die Natur rerlor sich durch immer nähere Licmutnifs der Masse derselbun, und hicmit 
die mythische Beschaung der ihr innwohnenden Gülter. Das Suchen nach dem Einen Prinzipe umd dem Merescher der Natur - die Losmogenic und Philosophie - wurde reger, und Peligion als Vergötterung der Natur tritt allmählig his Dunlile zuriti. Mlloyses sicht nach geschicdenem Chaos cer Schöpfung den Herscher der Natur (Jchora) ball im bremenden Dombusche, bald in der Gewitterwollie. - Zoroaster vergleich seine zwei Grunddämonen Ormuzd und Ahrinan, jenen mit dem Lichte, diesen mit der Finsternifs. Thales, der Gründer der jonischen Schule, giebt sciner Treltsecle das Vrasser, sein Schüler Anaxiincnes die Luft zum Elemente. - Anaxagoras, der Lehrer von Perikles und Euripides, da er den Verstand als alleinige Ursache der Natui offentlich beliemt, wird in Athen der Irreligiosität angelilagt. - Pythagoras der Stifter der italienischen Schule, vertrauet nur auserlesenen Mämern ganz. geheim die Annahme seines Monotheis'm in der Natur, welche er gleich Zahlen und Figuren geo slieciert ansah, und logt seine Neignug für 'das geistige Gebich durch I'estsezung sittlicher Nor. men für die menschliche secle an den Tag. - Sokrates, der Yater der altischen Weisen, spricht endlich die Macht des Geistes über die Natur frei, sowohl durch scin Betragen, als durch seine Philosophie, welche jene Aufschrift des delphi- 


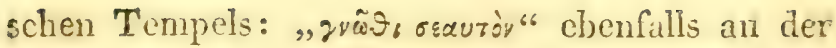
Stine trug, aus, wird als Lüsterer der Gütter angelilagt, und füllt so als $\mathrm{Opfer}$ einer lï̈nftigen Re. ligion. Von nun an war die Natur so zicmlich entgeistet, der Geist selbst ist zur wetteifernden Entwiklung in entschicdenen Gegensaz mit ihr gelangt, und jezt, so wie ron der jonischen und italischen Schule her Parmenides, Empedocles, Democritus dic Entstehung und Eimrichtung der Welt zu enthüllen trachtelen, so streben jezt ron der atlischen Schule her Plato, Aristipp, Lpiliur nnd Zeno das Innere der Seele zu entfalten; ein System reihct sich auf psychologischem Gebiethe an das andere, und der Menge sezt sich endlich die nagende Sophistik entgegen. In dieser Ungebung trat der Schüler Platos, Aristoteles ron Stagira in Macedonien, als Stifter der peripatelischen Schule auf; nit ihm war der tiefe und ruhige Blik Platos, welcher nichts als das Eine, Schöne und Harmonische in der Scele und in allen Dingen sah, beinahe bis auf unsere Zeiten verdränget, und Bcobachtung und Scharfsim, welche alles nur zersplittert auffassen, sind an scine Stelle geireten. Aristoteles, jenen Gegensaz noch bleibender fixirend, enträzelt, wenn gleich im dialek。 tischen Spicle, die Eimichtung und den Reichthum der Seele und Natur mit einem Detail, wie es ror ilum noch nie geschulh, und welches bis 
auf den Verfasser des Systems der Natur, und jem nen der Fritil der reinen Vernunft, der Grund und Boden aller weiteren Ausarbeituug rerblieb.

ERSTE ABTHEIL UNG.

Won dcn künstichen systemen in der Zoologie im allgemeinen.

ERSTES CAPITEL。

Erste Periode der Zoologie.

Aristoteles.

গ. 8.6 .

Aristoteles, cin angeblicher Abliömmling Aeskulaps, lebte 554 Jahre vor Christus, zur nämlichen $Z$ eit, wo ein Perililes, Demosthenes und Plato im Rufe zu Athen standen. So wie Mippolirates alles sammelte, was bis anf seine Zeit in der Medizin beobachtet, und in Tempeln zum cwigen Gedächt- nisse aufbewahret wurde, eben so that es auch dieser in Hinsicht der henntnis der Thiere; Aristoteles hatte aber einen noch riel weiteren Spielraum. Philipp, Fiönig von Mazedonien, berief ihn als Lehrer seines Sohnes Alexander an den Hof, und dieser grofse Held, welcher der gesammten Weltgeschichte eine neue Richtung gab, mufste 
sich durch seinen grofimithigen Dank auch an der Naturgeschichte verewigen. Die Neigung seines Lehers kennend, wicls er ihm zur rollständifreren Bubeilumg der Geschichte der Thiere 800 Talente an, uid stelte ihm melirere Lnsend Minner zu Gebothe, welche die croberten Lïnder durchreisen, Thiere beobachten, und inn alle Merkwürdiglieiten zuähbringen sollten. Hicrdurch beham Aristoteles die Gelegenheit, das ginnze Reich der Thiere so ziontich zu Herschanen, and uns VVerhe zu hinterlassen, welche ihn als Vater der Zoolugie für immer rerewigen. Lcider! sind ans von seinen Schriften über die Thicre, deren Plinius 50, Antigonus 70, Diogenes Laertius 31 erwähnen, nicht mehr als 9 zurulgeblieben, mit der Ueberschilt: "Geschiche der Thiere -

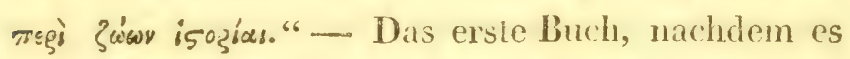
einige Erlänterungen über den Begriff von similären und dissmilären Theisen, über die Aehnlichkeit und Verschiedenheit der Thiere im allgemeinen, nach Lebensart, Sitten und Organen ertheilet hat, lenkt sogleich anf die umständlichere Betrachtung des thierischen liörpers ein, und stellet hiezu als Muster und Vorbild aller Vergleichung, den henschen hin, dessen hörperban hierauf nach den äussern und imnern Theilon in anaLomischer Beschreibumy anscinandergelegt wird, and zwa mil so meisterhaflem Detail, dafs er 
such den Kleinsten Rülsichten, z. B. ob ein Theil rechts oder links, vor - oder rükwärts, oben oder unten liegt, Bedeutungen giebt.

Im zweiten wird die grofse Scheidung der Thiere, in solche mit und ohne Blut, worauf sein ganzes Werk gebauet ist, vorgenommen. Er beginnt hierauf blos die erste Abtheilung zur Betrachtung herauszuheben, sczet die Anzahl und Ordnung ilner Hauptglieder, und zwar als lebendiggebährender oder eierlegender Quadrupeden, als Vögel, Fische, Schlangen, mit Berührung ihrer ähnlichen und verschiedenen Theile fest, und beschäftiget sich besonders mit der ferneren Vertheilung der Quadrupeden.

Im dritten führt er fort, die nämlichen Thiere mit Blut, nach anderen Theilen, nach den Geschlechtswerkzeugen, nach Kinochen, Blutgefürsen, Nerven, Haaren, Nägeln, F'ett zu untersuchen.-

Mit dem vierten eröffnet er die zweite Grundabtheilung der Thiere, nämlich der blutlosen, die er, je nachdem sie die harten Theile nach innen oder nach aussen haben, absondert, und nach den Verdamungsorganen und einigen andern innern und äusseren Merkmalen beschreibt; die lezte Hälfte dieses Buches enthält sodann die Vergleichung aller Thiere mit und ohne Blut, nach Sin. nen, Stimme, Schlaf und Geschlecht. 
Das finfte sezl diese lergleichnng, und zwar in Dinsicht der Art und Zeit der Begatung, des reifen Alters, und der Daner fïr Zeugnmg und Trächliglicit fort, und erwähnet nebstbei der NICtamorphosen dex Inseliten, von denen er einen. grofsen Theil aus LIulz, Schlamm u. s. W. entstehen läfst.

Das sechste fuihrt den Inhalt des rorhergelienden Buches in noch weiterem Detail, ïber Vügel, Fische und Süngthiere durch,

Das siebente nimmt den Faden wie ganz rou vomen anf, und begleited den neugebonen MLenschen, von scincr Enlstehung bis zu seiner Mamnbarleci, wobei er alle möglichen Zufalle für Mutter und find berïhret.

Mit dem achten verlïst er gröfstentheils die Betrachtung der Thiere nach den Eigcuschaften inres Rörpers, und nimmt besonders jene ihrer Sede zum fogensiande. Zurörderst erwähnet er allex dieser rcrschiedenen Eigenschaften, spriche hicrauf ron der innigsten Verwandschaft der unbelebten Natur mit der belebten - der Ptlanzen mit den Zwophiyten - nud sezi umständlich die äusseren Einflïsse des Iilina, der Wärme und Tailte, wobei er die Wanderung und den Winterschlaf crörtert, dio verschicdene Nahrumg und dic manchfilligen hianliheiten, durch alde Ordnungen der Thiere cinzclu auscinaudes. 
Das nemte ist beinalıc das stärkste, mnd blos der Betrachtung der Seelenäusserungen sämmulicher Thiere gewidmet. Hicr zeigt er, in wiefera sich diese denen des Menschen nähern, wie sich der Mamn gegen das VTeib, Familien gegen Familien, Lilassen gegen hilassen betragen, und nach den verschiedensten Verhältnissen, Grofsmulh, Schlanheit oder Filughcit äulsern。

$$
\text { 5. } 9 .
$$

Aus dieser Darstellung erhellet, dafs AristoteJes über das ganze Reich der Thiere, vom Menschen bis zum Zoophyten, scinen forschenden Blik ausgedelnet hat. Nicht eingenommen für das Jlofse Acusscre oder Inncre der Thiere, handelt er beides in gleichem、Maase und gleicher Veitlïufigkeit ab, und thut ron Beobachtungen Erwihtnumg, welche nur in einer Zeit, wie die unsrige, wo die Vergröfserungsgläser entdelat und veredelt wurden, zu crwarten gewesen wïren. Mit Rechte kamn man ihn daher, wenn gleich Democritus ron Abdera zuerst anfing, dic verschicdensten Thiere zu zerghiedern und zu rergleichen, den Urheber cines Werlies, so wie über Zoologie, anch z̈ber vergleichende Anatomie nennen. Ja des Aristoteles Umsicht ging noch weiter: nicht blos den Körper, sondern selbst die Secle der Thive nahm er zum begensiande seiner Vergicichuner. 
nnd gerade, wie er sie nach den anatomischen Theilen zusammengestellet und unterschieden hatte, so that er es hicr in Hinsicht ihrer Sitten und Charahtere. Das ganze Thier war somit die Aufgabe seiner Bearbcitung, und scine Durchlithrung beweist, dafs er, Zoologie mur durch Vereinigung der Physiologic und Psychologie zu begründen, sich bestrebte - eine Aufgabe des alten zoologischen Weisen, über die sich unser Zeitalter lileinmüthig hinwegsezt. Ohne nur das geringste ron den Seeleneigenschaflen cines Thicres in ihren Schriften anzumerlien, belieben die Zoologen unserer Zeiten gröfstentheils, selbst die anatomischen Theile, als geringfïgig wegzulassen, und begnügen sich, die Oberflïche des Thieres, scine Hautbedckung, Zäline, Schnabel, lilauen, Füfse zu kemnen. - Doch Aristoteles, ferne seinen Reichthum zu einem Ganzen zu gestalten, war zufrieden, ein Chaos von Beobachtungen und Ansichten, gleichsam als Materialien zu hïnftigen Gebäuden niedergeleget zu haben. Scine Geschichte der Thiere gleichet daher einem reichen Viktualienmarkte, auf welchem man nach Villkühr wählen kann. Haben Pythagoras nud Plato alles nur in Einem gesehen, so sicht er im Gegentheile alles nur zerstrent, and wie in seiner Metaphysik und Ethik alles nur durch Dialelitil, so sonderte und vereinzelte or hier alles mit seinem 
anatomischen Messer und beolbachtenden Blike. Zwar liebt or sehr seine Vergleichumgen in gomeinschaftiche Regeln zusammenzufassen, ohne doch selbst diese wieder zu verketlen. So abgerissen stehen damn an linde weitläufiger Untersuchmogen dergleichen allgemeine, theils wahre, theils falsche Resultate: „Jedes lebendiggebährende Qnadruped hat Hane - alle, die Haare haben, siud lcbendiggebahrend - jedes Hörnertragende wiederkäuet _- alle Wiederkäuer haben oben heine Schneidezähne - alle Thiere mit Blut haben eine hnöcherne oder grätigte Rülicusäule ${ }^{a}$ )“. Allein eines seiner Resultate scheint herrschender zu seyn, und wiederhohlet sich in seinen sämmtlichen Büchern so oft, dafs man zu der Meinmeg verleitet wird, es scye stillschweigend und nachlälsig allen jenen zu Grunde gelegt. Wie zu rermuthen, so wird ancll hier des Aristoteles künstlicher Blik an etwas hünstichem haften; die Anwesenheit oder der Mangel des Blutes ist dieser herrschende Gesichtspunt, nach welchem or alle Thicre in zwei Hauptgruppen - in solche mit

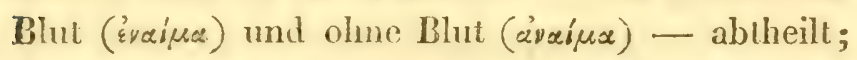
die erstere unterscheidel er nach den Extremitäten

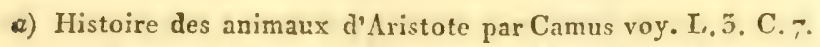

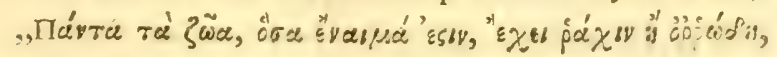

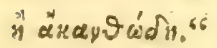


und der Frucht, in Quadrupeden, velche lebmitige

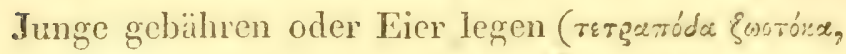
wistóna), in solche mit zwei Fülsen und Flïgch -

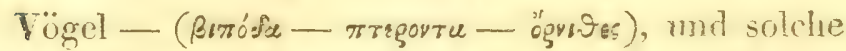
ohne Fülse, aber mit Flossen - Fische - (irsidos,

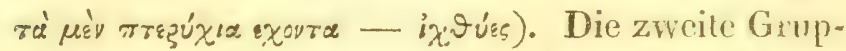
pesondert er, je nachdem sie die weichen Theile nach aussen, dic festen aber nach inncu zuritkgedrängt haben, oder umgeliehrt, in vier Ordnungen

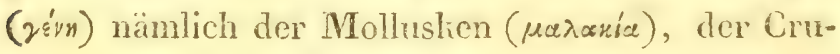

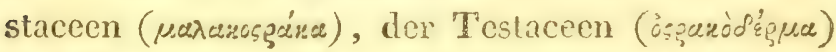

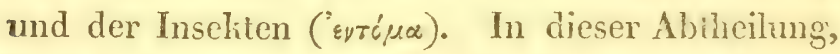
Zahl und Aufeinanderfolge, durchgeht num Aristoteles immer alle Ordnungen ron Thieren, sowohl in allen seinen Büchern, als auch, wo er cin einziges Organ durch alle 'Thiere hindurch vergleicht, - cin Grundrifs, dessen Ansfuhrung alle scine Nachfolger bis auf unsere Zeiten beschïfligte. -

$$
\text { S. } 10 \text {. }
$$

Dic Natur bleibet sich auch in dem Keinsien und Einzehen getren, jedoch auf Nebenwegen ist eher Verirung nöglich, als anf der breiten Strasse, daher sie für den manfmerlisamen Forscher manchmal im kinzehen wechschnd und wandelbar erscheinet, während sie im Ganzen immer sich consequent und gleich verbleibet. Dicfs nümliche gill von der Ansicht, die Thicre nach dem 


\section{$-25-$}

Blute zn ordnen. Allerdings lïnnte man diesen liünstlichen Gesichtspunkt so genau durclifuhhren, dafs er ein ganz natiirlicices Aussehen belïme. So wie jedes Individum eine andere hörperconstitution; eben so hat es mit derselben auch alle einzelne Theile als: linochen, Nerren, Muskieln, Säfte u. s. w. verschicden. Die Säfte, worans sich der ganze Förper inmer neu gestaltet, sind also bei rerschiedenen Thieren ebenfalls matichfatlig and terschieden, gerade wie sie anf dem Gebiethe der Pflanzen, bei Tuphorbien weifs, bei Chelitcnien $\mathrm{gellb}$ sind. Antiallender jedoch zeigt sich diese Variclät an gröfseren Gruppen, als bei einzelnen Individuen. Tiein Wunder ist es daher, dafs der Abstand des Blutes, bei Thicren mit und ohne Finochen, so merklich isı, da schon die Süugthicre und Vögel mehr rothes, die Amphibien und Fische mehr schwarzes Blut, die MLollushen melir bläulichgranen und endlich die iibrigen unvollliommenen Thiere, mehr durchsichtigen, und somit weniger sichtbaren Chylus haben. Nicht blos Klassen und Familien, sonderu selbst Gattungen und Abarten, liesen sich nach diesem Charahter, sogar in ihrem rerschiedenen Nitter unterscheiden und reihen. So hann man bei dem Fimbryo anfangs am Blute gar lieine Farbe unterscheilen, erst nach und nach wird es gelblich, dam schwärz: lich, und nun mit dem heranwachsonden Alteg 
röthlich a); gleiches wiederhohlet sich alläglich mit den Speisen, die erst zu grauem Safte, dann zu Veneublut, und endlich zu arteriellen melatmorpiosint werden; Ja Aristoteles bemerht selbst den Unterschied des röhlheren Blutes beim Manne, des schwärzeren beim Weibe ${ }^{b}$ ), und vielleicht, dafs das Blut in Winter and bei Nacht schwä̀zer und langsamer, im Frïhling und bei 'Tage lieller ist, so wie es auch wirklich munterer pulsiret. Welchen Einflufs endlich hat nicht der Aufenthalt in der $L$ uft oder im Vasser, auf die Farbe dieses Saftes? Das Blul des Wassertanchers scheint mir scliwärzer als las eines liaben zu seyn, eben so ist nach Caldesi ${ }^{c}$ ) das Bhut eines Frosches, im Vergleiche mil dem der Lidechse und besonders der Schildliöte, vicl schwärzer. Findet man aber diesen Saft bei Inscliten noch grau, so scheint auf der niedrigsten Stufe der Thiere, nämlich bei Medusen das Mcerwasser, welches vom Munde, oder bein Mangel desselben, blos von den Gefäloüfnumgen am Raude des Körpers aufgenommen, wahrscheinlich wenig Veränderungen erleidet, und son gleich zur sfilatinösen, wasserhellen Masse des Körpers gerimt, ausser Theren selbst die Stelle der Nahrung und des Blules zuglcich zu vertre.
a) Ialleri opera minor. T. II, p, 357 .
b) Aristote I. c. L. 5. C. 19.
c) Caldesi osservat, anatom, intorno alle tartarughe p. Go, 
ten. Allein nchme man statt der Farbe ein ande. res Merlimal des Blutes, und die nämlichen Unterschiede werden sich ebenfalls einstcllen. Von Amphibien und Fischen ist es behamnt, dafs sie lialtes - die Temperatur der Atmosphäre nicht überschreitendes - träges Blut habcn, im Gegentheile, die Säughtiere und Vögel warmes ind schnelleres. Allerdings wäre man so im Stande, alle Thiere nach den Abstufungen des rothen oder grauen Saftes zu rubriziren, ja jedem Einzelnen seinen unabänderlichen Plaz anzuweisen; aber wer wagte wohl alle diese Nïanzen durch einzelne Individuen hindurch anzugeben? und gesezt auch es geschähe, dann müfste man die Ammeliden (Blutigel, Regenwurm, Serpulen u. s. w.), bei welcben die Gefäfse einen rothen, blutartigen Saft führen, ganz aus ihrer Sphäre, in die der Finochenthicre rersezcn, und die Vögel, deren Blut das rötheste und am schnellsten pulsirende ist, würden wohl mit den Sängthieren um den Vorrang liämpfen. Doch dem Aristoteles war es nicht darum zu thun, seiner kïnstlichen Ansicht diesen natürlichen Anstrich zu geben, sondern er blieb ganz im künstlichen gefangen, er begnügte sich schon, den Unterschied von Blut-habend und Blut-los im allgemeinen in die Thiere gebracht zu haben, und theilte sie ferner nach ganz andern Gesichtspunliten ab. 
Diefs ist die fruhere Grundiage z.n finf ro. schichte der Thiere, wolche in ihrem morlowen Reichthume ron Beobachumgen gestallos, wie das Wasser, erst in folgenden Zeiten zu anegcbil. deteren Gestalten anschiefst.

$$
\text { S. } 11 .
$$

Mit Aristoleles war fir die wissenselinflindir Naturgeschichte eine Norgenöthe anfgegangen. Kurz nach ihm, erweiterte sich zwar der Horizonl, allein diese Erweiterung crstrehte sich vichehr anf das, was man durch jenen schon besals. Die Merrscher Mazedoniens fuhren fort, dic Naturforscher in Schnz zu nelmen. Theophrast trat als Lehrer in dic Fufstapfen des grofsen Peripateli. liers, ohme eben den Geist seines Meisters zu ersezen; Fr wählte sich dic Eihili zu scinem Hauptfache, während des Aristoteles Licbe fü Anatomic, in zwei Mimmern crwachte, welche mit Rechte den Namen Zootomen verdienen; Erasistratus, sein Enkel und Schiiler, entlelict in Pierde die Venen and Arterien, welche er fim Infgefilse hält, or berichtiget seinen Lehres, dafs die Nerren nicht vom Lierzen, sondern rom Gehime liommein, und alndet zu allerst den Nuzen der Valvulu im Herzen. Herophilus von Calcedon, beschäfliget sich rorzüglich mit dem Gelirne, er wird Entdelier der Ventrilieln, dex Bluldeiter und des calanus 
seriptorius in demsclben u. s. w. Spüter noch, aber gleichzeitig mit Attalus, Tï̈ng von Pergamus, liefert Nicander ron Coluphon in scinen poetischen Werhen, genannt Therialion und Alexipharmakon, Beschreibungen ron dem Aeussern der giftigen Schlangen, Scorpionen, Spinnen, Fliegen und andern Thicren. Von nun an gewann alles ein reues Ansehen: der Scepter ron Mazedonien geht aufliom über, und mit ihm der Nachhall der liunst und Wissenschaft der gestïrzten Frcistaaten Griechenlands. Statt Religion und Tiefsinn, erwachet der leichisinnige Luxus, und gleich Hummeln nähret man sich ron dem Honig der Griechen. Jedoch, gewam auch jezt gleich nicht die Geschichte der Thiere an innerem Geiste, so erhicit sie doch durch den Hang der nenen Eroberer für simnliche Schwelgerei, alle Gelegenheit, sich an Masse zu bereichern. Weder die vergütternde Andacht der Alten, noch der philosophische Tiefsinn der neneren Griechen; sondern blos deL Trieb, mit wollüstiger Phantasic in der Natur zu schwelgen, bemächtigte sich dieser Nation, welche mit dem Nuthe auch den Hang zur Ländlichleit ron der Voulfin gesüugt hatte, und alle Erfindun gen und Eimrichtungen des gemeinen Volkes, wie die öfentlichen Schauspiele der Consuln und Kaiser, dienten nur dazu, sich in diesen Taumel zu erhalten. Was daher die Nahurgeschichte zu don 
Zeiten der Fömer gewaun, hat sie nicht dem besomenen Ernste, sondern der leichtsimnigen Schwelgerei dieses Volkes zu danken.

Fulvius Hirpinus a) erfind zuerst die einge-

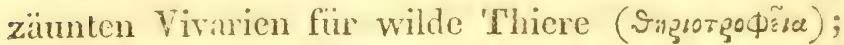
er war der erste, welcher solche lür Nage- und dann fur Schaal-Thicre anlegte, und leztere nach den Prorinzen in solche von Illyrien, Afrika, Solitanien abthcilte. M. Latenius Strabo, unterhielt sich zuerst mit Ariarien b). Sergias Orata richtole sich Behälnisse fü Austern in Bajä cin c). Zu glcicher Zeit dachte Lucinius Murctena die Piscinen aus, und $C$. Hirrius liefert zu einem Triumphgastmale des Diktator's Cäsar, 6000 Aalc ${ }^{d}$ ) - eine Schwelgerci, weicher späterhin die des Kaisers Vitellius, welchem sein Bruder zu cinem Gastnale 2000 Fische und 7000 Vögel auftragen Iicfs, noch immer nicht gleich kam. - Optatus Elipertius, Präfekt einer Flotte, läfst in Zeiten des Filaudius aus fremden Meeren Fische hommen, und zerstrcuet sie zwischen Ostia und Campagina ${ }^{c}$ ), Curius Dentalus $f$ ) brachte nach geendigtem Kriege mit Pyrrhus, und nach ihm Metel-

a) C. Plin. secund, natural, histor, L. IX. C. 82 .
b) ejusd. L. X. C. 72 .
c) ejusd. L. IX. C. 79 .
d) ejusd. I. IX, C. So.
e) ejust. L. IX. C, 29.
f) ejusd. I. VIII. C. 6. 
lus, eine ungeheure Menge ron Elephinten nach Italien. $M$. Scaurus ${ }^{a}$ ) läfst fün lebendige linocodile in Euripus zur Schau vorfihhen, wihlorend. ebenfalls der Hippopotanus lebendig zar Schau auscrestellt ward. Cn. Anfidius, als er das Tribunat fiihrte, hob das Verboth, Panther nach Italien zu bringen, auf, und liers solche zu den circensischen Spielen herbeihohien; M. Scaurus sendete hierauf 150 nach Rom, Pompejus Magnus 410 , Augustus $420^{b}$ ). Das Rhinozeros, ron welchem nachler blos einige noch Furopa wieder gesehen hat, verherrlichte die Spicle des Pompejus, den Triumph des Augustus ïber die Clcopatra, und wurde zu Domitians, Antonin des Frommen, Gordians, Eliogabals und Heraclius Zeiten gezeigt ${ }^{c}$ ). Die Giraffe erscheinct in Jihr fos nach Erbauung der Stadt Rom in den circensischen Spielen des Diktators Cäsar d). In den Spielen des Pompejus sah man zum ersten Male den Luchs und den äthiopischen Hundsaffen. Augustus zeigte, zur Einweihung des Marcellus Theaters, den ersten zahmen Tiger, welcher unter Domitian, Antonin, Gorian lieme Seltenheit meln war, und Antonius lehrte sogar die Löwen am
a) C. Plin. L. VIII. C. 2 G.
b) ejusd. L. VIII. C. 17 .
c) 'ejusd. L. VIII. C. 20 - Dio Cass. L. 15. - Martial.
d) ejusd. L. VIII. C. I8 - Dio Cass. L, 45 J 
iTagen zichen. Titus Vespusianus erbouet endlich, was schon ror ihm Fero versuchie, das CoTisuenm, und liefs zur Iinweilung deselben 5000 wilde Thiere schlachten a). WWard aur römischem Eoden fir dic Gütter das Pantheon errichtet, so stand jezt das Cofisïun als Gebiüde der Natur da, und leztere ward hier rermittelst der Wett= liümple der Thiere unter einander, oder mit Menschen, den rönischen Volhe gleichsan zur Schau vorgefinht. - Anch die lündliclie und cinheinische Natur, mulsic dem Vergnïgen der Römer risuen. Nan legte allonthalben Oelionomien und Landhänser an. Cuto, Furro, Columeila, Palladius, suchen selbe durch ihre Beobachtungen in Schrifton zu renbessern; Ptroilius besinget mit Begreisicrung den Anban dex Planzen, die Zucht der Bienen und der vibrigen Hausthiere; mur das Tuslintum rerunlafst in Cicoro die ammuthigen und lchrechen Schrifien. Vegetius macht sich die Zucht und die Franhlieiten der Hansthiere zum Gregentande eines Werlies, welches den Namen Veterinuliunst führct. Bioscorictes endlich, stellt in ciner schriêt beinalie Goo Pflanzen zusammen, and erwïhnt hier den arzncilichen Gebranch sowohl diescr, als sellost auch vieler Thiere. - Von

a) Eutrop. T. F. in fone - I. Aurel. Cassiodor, in chroni:o apud Ligouium p. 608. 
den ineisten dieser Anstalten finden wir auch noch jezt die Reste auf italischem Boden. Wir sehen noch die colossalen Ruinen des Colisäum in Rom, in Pozzuoli und Frejvs, die Piscinen eines Hadrian, nächst Tiuoli, jene piscina mirabilis nächst Neapel, cine andere in jenem Pallaste zu Pompeii, wir sehen noch die Tuslulen eines Cicro, die Landhäuser eines Lentulus, eines Lucullus. -

So rerflossen denn seit Aristoteles zweihundert Jahre, ohne dafs sich ein grofser Zuwachs zu seinen Entdekungen über die Thiere hätte anschliefsen liönen. Zwar ist die Liebe für Naturgeschichte allgemeiner geworden, und das römische Volk lernte so manche Thiere, und ihre Silten auf fremdem und einheinischem Boden sowoli durch scine Eroberungen, als auch durch die öffentlichcn Schauspiele und Triumphe liennen; aber der gröste Theil dieser Beobachtungen wäre mit dem schwelgerischen Volke selbst erstorben, hätte nicht die Nation, so wie an Livius ihren politischen, an Plinius inren Natur-Historitier ge. funden:

$$
\text { 5. } 12 .
$$

Cajus Plinius Secund a

Plinius Secundus ron Verona, oder wie einige behaupten, von Norocoma, ward unter der Regierung des haisers Tiberius geboren. Angetrichen durch scine Liebe für die Naturgeschichte, bestieg 


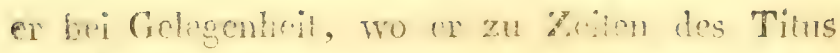

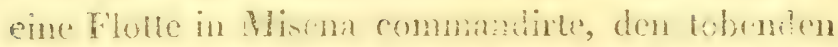

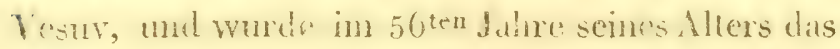
Opfer scines natmgeschidthichen Vifirs. Die himfigen Damprivolien dieses Fencrinerdes, erstili-

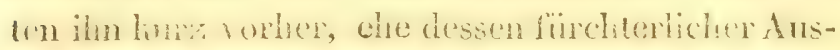
brach sulbst die stadte Herhulanum und Pompej iiberschintere und untergrub. Viele von den Schiften dieses rimischen Itistmihers, sind durch die Zaiten verloren gegangen; doch scin Latiptschaz, ans 57 bitchern bestehend, ist uns unter dem Ti-

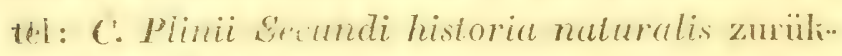

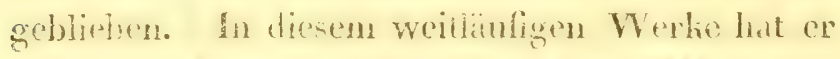
die ganze Yatur lon den Gestimen, Weltuheilen

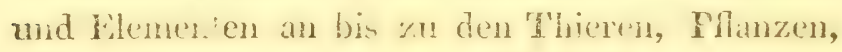

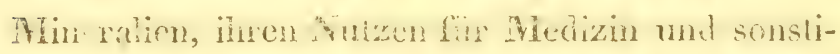
ge hiumste zu umfassen sich bestrebet, mul zu

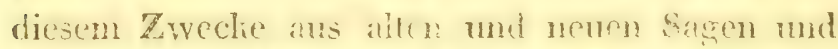
Schriften olme Lnterschicr, das Fabelhatle mit dem Trakien zusammengeralh. Fathdem er in den ersien sechs Büchem rine bhschreibung von der Well, den Gratimen, klemisen und eine geographische and pisyshalische Uebersicht der Frde, Berge, Mepre, Fliisse und Vïlher von Luropa, Asien und Afriha geliefert hal, so beginnt er mit dem siebenten Buche die Ceschichte der Thiere,

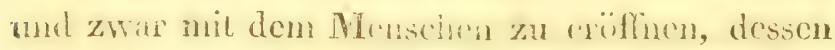
hierpericie und geistige Ligenscharten er in histo- 
sirhon Notizen dirstellet; im achten Buche handelt er von Laindhieren (terrestria), hebet hier mit dem Elephanten, als welcher durch seine vernïnftige Lebensart und Religion zunächst mit dem Menschen verwandt wäre, an, hommt hicrauf zu dem cbenfalls massiven Brachen, dem Tiger, hameele, Rhinozeros, Wolfe, Icheumon, lirocodile, Ilippopotam, Fischotter, zu den wilden, dam halb und ganz zahmen Thieren u. s. w.; im neunt'n sprichl er in gleich rerwirnter Mischung ron nllon jenen Thieren, welche im Wasser leben, (aynatilia) und schreitet ron Balänen, Tritonen zu den Schildiröten, Fischen, Mollusken, Lirebsèn und Polypen, wobei er erinnert, darfs man sie nach der Hautbedeliung, je nachdem sie nakt oder mii Schildem, Schaulen, Schuppen, lirusten bedch, oder sonst rauh seyen, abtheilen liönne; das zehute handelt von jenen Thieren, deren Element melı die Luft ist, wie die Vögel (volatilia); das eilfte endlich von den Insehten (insecta), als welche theils Landthieren, theils Vögeh gleichen, and schliefset zulezt mit der:Auseinandersetzung der Verschiedenheit aller Thiere zusummen wach ihren cinzelnen Förpertheilen.

$$
\text { 5. } 15 .
$$

IIat Aristoteles sein Werk mehr aus der offenen Natur, so lat Plinius das seinige mehr aus 
den Schrifstellern und Sagen der ältern und nen* eren Zeit zusammengetragen. Man könnte dakrer jenen einen Compilator der Natur, diesen den der Schriftsteller und Sagen nennen. Auch in ihm darf man somit nicht das System und die Wissenschaft, sondern blos Notizen als Materialien hiezu suchen. Zwar sind seine meisten Beobachtungen aus Aristoteles wiederhohlet, jedoch umsonst suchte man dessen Grundansicht, die Thiere nach der Gegenwart oder dem Mangel des Blutes abzutheilen, in den Büchern über die Thiere des Plinius. Was Aristoteles in seinem ersten Buche über den Einflufs des verschiedenen Aufenthaltes der Thiere im Wasser oder in der Luft oder auf Erdek, blos wie zufällig anmerket, dieses hat Plinius zu seinem Hauptgesichtspunlite herausgchoben, und darnach die allgemeineren Gruppen formiret. Jczt ist daher nicht mehr die Sprache von solchen, dic rothes Blut haben, oder denen es fehlet, sondern das Element, der Aufenthalt im Wasser, in der Luft, oder auf dem festen Lande, diefs weiset ihnen ihre Stelle und Ordnung an, eine Ansicht, welche bis auf Gefsner die herrschendste blicb, und von da mit der aristotelischen vermischt, bis auf Raius sich forterbte.

$$
\text { S. } 1 \% \text {. }
$$

Es ist wahr, nicht ohne Bedeutung ist das Element, worin das Thier lebet. Ein Räderthierchen 
aus dem Flüssigęn auf das Trokne gebracht, rerwellit sogleich; ein Säugthier oder Vogel erhebet sich nach wenigen Minuten aus dem Wasser empor, um Antheil an der freien Luft zu nehmen; sin Condur gefällt sich nach Humbolds Berichte, in einer Höhe von beinahe 3000 Toisen in der Luft, während der Mensch in gleicher Höhe sich übel befindet. Gleichwie das Nervensystem das Licht, das Respirationsorgan die Luft, der Kreis. lauf des Blutes das Flüssige, das Verdauungssystem das Feste liebct; eben so sind bestimmte Thiere an bestimmte Medien und Grade derselben gebunden. Ueberhaupt, je tiefer wir in die Thierreihe vom Menschen an hinabsteigen, desto mehr nimmt die Menge derjenigen, die im Wasser leben, zu, jene aber, die auf dem Lande und in der Luft sich aufhalten, ab. Bei Säugthieren ist die Anzahl derjenigen, die das feste und trokne Land bewohnen, viel stürlier, als der, so gleich Amphibien das Wasser zuweilon besuchen, oder gleich Fischen dasselbe gar nicht verlassen liömen. Bei Vügeln neiget sich die Anzahl jener des Lan* des schon beinahe mit jenen des Wassers zum Gleichgewichte. Bei Amphibien wird das Wasser schon das vorherrschende Element, mit den Fischen aber beginnt die eigentliche Herrschart des Neptun, und von hier an, wenn man die Insekten fusnimmt, welche nach durchlaufencn Metamer 
phosen auf dem Gebiethe der blutlosen Thicre die Vügel zu repräsentiren scheinen, sind alle Thiere, weiche der Rücliensäule und des rolhen Bluies pntbeluren, zu dem Iilenente des Wassers verdanmet. Auch die Lanischurche suchet num bethaute Platze anf, der Erdwurn bohret sich nur in fenchte Frde, und die Astcrien, die Sueigel, so wie das ganze Iteer der Polypen, Infusorien und Zooplyten, verlassen bis zal ihrm Tode nie das Element des Vassers. Wahrhaft, der anfmorkisime Forscher der Matur verlachet nicht jene Hypothese, welcher Leibniz erwahnet a), dafs sich alle Thiere ars dem VVasser in Amphibien und cublich in die des troknen Landes umwandeln. Will man auch nicht mit Thales das Vasser als die Geburtsstitte, ans der sich alles Tebende bildn, annehmen, so bleibt doch soriel gowifs, ditis athe Theile eines Pfluzen- oder Thierhörpors sich ans seinem weilsen oder roihen blute gestalien, und daís eben so jedes Thier, aus dem flïsigen Saamen entstehond, die früheste Periode spines Jebens in cinem feuchten und flüssigen Medium zu-

(i) Eifuirlem Haud ignoro, esse quosdam, qui eo usque licentia conjectandi procedant, ut tegente omnia oceano animalia, quae nunc terram habitant, aliquando aquatica fuisse arbitrentur, panlatimque destituente clemento amphibia, postremo primas sedes derlidiciss. - virl. opera omnia Leibnizii, protogae. S. 205. Genev. 1768 . 
bringe, ja dafs sich so an einem einzolnen Individum die nünliche Metamorphose wiederhohle, wclche dic animalische Vatur im Colossalen, von. galatiöisen Polypen im VTasser an, bis herauf zu den hinochenthieren auf dem Lande und in der Luft, ausfuhret. In steichen Sime wie harrey denSatz: ., omne vic ann ex ovo" so liönute man much diesen aufstellen, dafs alles Granische ans eiurn Vasser- sich in cin Luthis nuwandle: "omne vivum ex humido." — A Aus allen diesen eriellet, dafs, so wie es unter den Elenenten von der Yrode durch das Wasser bis zur luft mut zu dem Lichte, cine Rangordnung gicbt, die nümlikhe sich anch unter ihren Bcwohnern wiederhohle. Erhlïre man dieses auch, wie man wolle, behanple man, dafs die Wasscrthicre nur deswegen in diesen Llemente leben, um sick mit ihrem unvollkmmenen Rervensysteme gegen das lräfligere Licht zu verbergen, dafs dic Micerpolypen nur deswegen die donkien Felsenhiufte aufsuchen, die Schwämme uni Sertularien hur deswegen von der untern Vand des Peliens gegen die Tiefe des Mecres zu, oder selbst schon in dicser zu wachsen lieben, dafs eben deswegen diese niedrigen Geschöpfe sich nicht bcim hellen Mittage, sondern blos gegen Morgen und Abend, gegen Frühling und Herbst aus ihren dunklen Schlupfwinkieln. herauswazcn, crklüe mun diese Verschiedenlicil 
des Körperbaues als Folge des Aufenthaltes in dite sem Elemente, oder diesen als Wirkung ron jener, oder richtiger, beides gleich einer prästabilirten Harmonie; hurz ein Thier in der Luft ist ron dem im Wasser eben so verschicden, als es diese Elemente selbst untereinander sind. Allein demahngeachtet ist es nicht möglich, blos die verschiedenen Elemente zur Gruppirung von Thieren zu gebrauchen. Welche Verwirrung entstünde nicht, wenn der Fischotter, die Phoke und die Cetaceen von den übrigen Säugthieren, die Schildliröte und Schnecke des Landes, von der des Wassers getremnet, und ganz ron einasder gerisson würden? Aber alles dieses müfste nach dicser Methode ge: schehen, denn in jeder Klasse und beinahe in jeder Familie, widerhohlet sich jene Verschiedenheit der Elemente: So leben die Cetaceen immer iup Wasser, die Pachydermon und Schwcine halten sich gerne gleich Amphibien mehr zunüchst dem: selben in Morästen auf, dic ubrigen Süugthiere hingegen lieben gröfstentheils mehr das trolne Land, und nur unter den Nagethịeren wechseln zwischen Land und Wasser der Bibẹ und einige Ratten, bei den Fleischfressern der Fischotter und die Phola, obgleich im Durchschnitte für diese Klasse von Thieren die Luft, und besonders für den Menschen das Tageslicht das eigentliche Ele. ment ist. Für den Vogel ist zwä einstimmig die 


\section{$-41-$}

freie Luft das Medium, in welchem alleine er sich am besten gefallt, aber auch bei ihnen suchen die Gänse mehr ihren Aufenthalt im Wasser, die Stor: che längst dem Strande desselben, und nur die Hühner, besonders aber die Sing - und Raubrögel, suchen trolnen Boden und die Gipfel der Bäume oder Felsen. Noch mehr als einzelne Familien in den vorhergehenden Kliassen, streben die sogenannten Amphibien dem Wasser zu, und halten sich deswegen nur in der feuchten unterirdischen Luft der Höhlen, oder am morastigen Ufer des Wassers auf; und doch leben die Eidechsen am Tiebsten in Iiühlen Löchcrnn, dic Chameleone auf Büumen, die Schlangen und Frösche sind am meisten ans Wasser gewöhnet, und die fischartigen Sirenen, Proteen, verlassen' sie wohl je das Element des Flüssigen? So ist der allgemeine Wohnsiz der Fische das Wasser; allein auch bei ihnen zciget sich noch jener dreifache Charaliter der Elemente: Dịe Aale halten sich mehr in Löchern der Felsen auf, und verlassen selbst öfters das Wasser, um auf bethauten Wiesen ihrer Nahrung nachzugehen, die Fische des süfsen Wassers leben auf dem seichteren Boden der Flüsse, oder auch der tieferen Seen, sie gehen öfters an die Oberfläche des Wassers, und schnappen und springen freudig nach der Luft, während die. Rajen, Haifische und die meisten Kunọpelfischẹ, dị 
gröfste Ticfe des Meeres bewohnen, und nur hier, in der hohn See, dem Fischer zur Eente wadn. Eben so sind die nakten und cinschaaligten Schuechen mehr an" fenchim lioden, oder zwischen ten Felsen des Strandes de's salzigten und sïfsen V Vassers, wo in Gegentheile die zweischalimen don Boden oder die Fetsen in der Tirfe des vireves oder der Flüse und Seen aufsuhen, nad nur hier sich die ungeheuren Bänte von Austern ind Efsmuschehn dem Neze dorbicten. Auch unter den Inseliten leben die hartochabigien Firebse nirm am Strande des Massors, die hifer in fencheren Loden, die weichlïglichten husehten aber licintn, wem sie ihre luppe in feuchen Boden verlaseca laben, und als rerlitirter Vogel erscheinen, die Iruchene Juft, die Batter und Blumen der Platz:n. Lin ähnlicher Unterschied liefse sich selbot noch bei Vürmen und Zoophyten nachweizen. - Niemals diönen somit die Llenente allem viber die Anordnung dor thliere cutscheites, wrom matu nicht anders alle Bande der Patur zerreissen will; und chen dieses Fohles liat sich Phins schullig gemacht, indem er genitis dieser Mothode, einige Schildirüten und Eidechsen bei den Theren des Landes, andore bei denen dos Wassers anfrihlol, and änliche Tremnngen anch in den öbrigen Familieu sich erlaubet. Zwar trägl jedes Buch beinahe seine Methode an der Slinu, cenolnge- 


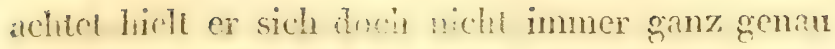
an dieselbe. So sind noch vick Landhiere in der Rubrit der Tasscrthire angehandelt und umgelichrt, cin Vorfahen, wclches ihn remmblich anch dazu nölligte, anf die Thiere des Landes, nicht die Vügel, sondmen jone des Wiasers folgen zu hassen. Doch dem Plinius als Polyhistoren war es noch weniger un System, als drin Aristoteles zu linn, obglcich dic Nachifolgex die Polylistorie dessetben, lange Zeit anch als Musiex des Systemes nachahmten, und scine fibellaten Thicre als wirkliche forlführten.

\section{ก. 15.}

Den Fufsiapfen des römischen Naturhistoriliers folgic zi allernächst Solinus, der uns cin lilcines Werk, Polyhistoria belitclt, hinterliefs. Micr gehet re von der Frbaumg der Stadt Rom aus, beschreibet hierauf Italien, Corsilia, Sardinien, Germanien, Gallien, Afrika, und erwähnet so nebenbei der behanntesten Thiere dieser Lünder. Er blicb den Schriften scines Vorgängers so getreu, dafs die sninige als ein hurzer Auszug ans jenen angeschen werden liann. - Plinius hatte unterlassen, die Sitten der Thiere so veitläufig zu berühren, als es Aristoteles that; allein diefs geschah gerade jezt zu Zeiten des Marc Aurel ron dem Griechen Aclian, wolcher dic rerschiedensten 
Anelidoten von Thieren, aus Sagen und SchriftstelIern, in siebenzehn Büchern zusammentrug, ein Werk, welches als weifere Bestätigung und Ausführung des lezten Thierbuches des Aristotcles, and als Supplement des Plinius in Hinsicht dieses Gegenstandes angeschen werden hann. So wie Aelian die Betrachtung der Sitten der Thiere ergänztc, so that das nämliche Oppian in zweiten Jahrhunderte nach Christus dadurch, dafs er die verschiedenen Arten und Wcisen, die Thiere zu jagen, und dabei die lezteren selbst beschreibet, and in griechischen Versen besinget. Wan darf nur nach seinem Dialog mit der Diana das Thema des Dichters lesen, so ersicht man schon, welchem Nuster er in seinem idyllischen Werlie gefolget ist; kühnen Fluges beginnt er;

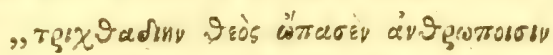

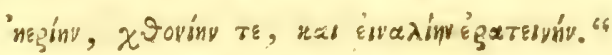

Getreu, so der Ordnung des Plinius im Ganzen, wie im Einzehnen, besinget er die Jagd der Landthiere in vier, der des Wassers in fün, und der der Vögel in drei Büchern. - Gleichzeitige Verdienste um die Geschichte der Thiere, erwarben sich auch Dio Cassius, Marcellus, Seneca, Athenacus, Macrobius, Apulejus und andere, wel. che zerstreute Beobachtungen über cinzche Thiere in ihren Schriften auf bewahret haben. Aber nun stelle! sich dem plining ans der alexandrịischen 
Schule, 131 Jahre nach Christus, ein Nam entgegen, welcher die zootomischen Beobachtungen rorhergehender und gegenwärtiger Zeiten, eben so wie jener die zoologischen zusammchlas, mit seinen eigenen bereicherte, und die Anatomie zu einer abgesonderten Wissenschaft erhob. War im Aristoteles Zoologie und Zootomie veremiget, so traten sie ron nun an gesondert, we ron zween rerschiedenen Mämmern bearbeitel, auf. Galenus aus Pergamus sammelt die zer. streuten Entdeckungen der ersten Stifter ter Anitomic - eines Democritus, Erasistratus und Heroo philus, benutzet die Arbeiten der gleichzeiligen Anatomen - eines Marinus, Lylins, Pelops und Aclian, trägt die aristotelische Philosophie auf die Medizin über, und errichtet auf Hippocrates Grund und Boden, durch Herrorhebung der vier Elcmente und eben so vieler Flüssigkeiten und Temperamente, ein Gebäude der Medizin, so wie durch umständliche und genaue Auseinandersetzung der Theile des thierischen Körpers, ein Gebäude der Anatomie, erstere bis auf Boerhare, leztere bis auf Vesal das herr. schendste und rolliommenste verblieb. Zwar hatte sich die heilige Ehrfurcht dem Leichnam des Menschen noch bis jezt fortgecrbet, und seine Zergliederung rerbothen; jedoch in Alexandrien fingen die Aerzte schon an, ihren Zöglingen die 
Fnorhen des menschlichen höppers ronzuzeigm.

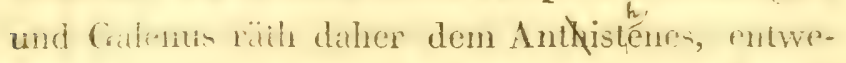
der datim z:n gehen, oder wie er selbst dic Cimovrien antzusuchen, oder die menschlichen Shelete : on Waiser daher geschwemmet, oder

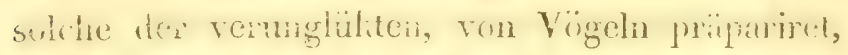
zu seiner Belphrung za benuzen, oder cintich Afien, wel he denn Vienschen am nächsten hänon,

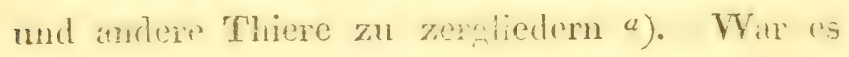
auf solche Theise dem Galenus nicht rergënncl, alle Theile des monschlichen hiörpers zu zertegen, and gesteht er selbst ${ }^{b}$ ), dafs er sich mit der Aniltomic der Inselien und der vibrigen lileinen Thiere nicht beschifltigete, so that er dieses nath seinem weiteren Gestündnisse un so mehr an Affen, MIn-

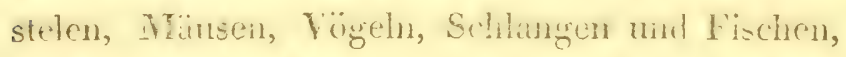
und nach allen Deschreibungen war es der menschenätnliche Orang-Outang, der iln immerfort beschäfigglc. Nur solche unermüdeie Arbriten kommten ihn in den Strmb setzen, die Artuicn als Bintgefulse gegen lixisistratus zu rechtertigen, die Selnen ron den Nerren gegen Aristoteles zu muterscheiden, und für die lezieren sämmtlich das Gehim und das Rüchenmali, nicht aber wie Aristuteles das Herz, als die erste Que!le, zu bestim-
a) Galeni opera omnia Venet, 1556. T. 1. S. 63, f.
b) cjusd. liber, anat. Gitus. S. $8 \mathrm{~g}$. g. 
men, die Glieder des hörpers eben so gesondert und zu einem Systeme gruppiret, abzuhandeln, als sie es im thierischen Körper seibst sind, und ron Knochen, Muskeln, Nerren, Arterien, Venen, Lungnn, Verdaunngswerkzengen u. s. w. sowohl die Luennungen, als anch die umständlichen Beschreibungen, in immer cigenen Kapiteln festzusetzen. Spricht dieser grofse Anatom an verschiedenen Stel. len seiner Werlie gleichwohl dem Aristoteles und Plinius gemüs, ron Thieren mit unả ohne Plut, auf dem Lande, in dem Wasser, und in der Luft, so sielit man doch in scinen meisten Eüchern, dafs sich in diesem Physiologen ein ganz anderer Geist zur Flassificirnng der Thicre regie, man sicht, wie sehr er diese seine Vrorte durch die That in seinen Schriften bestittiget hat c):

„Sind gerade nicht viele Affen zu zergliedern rorhanden, dann liebster Antisthenes! wähle ande. re Thiere, und sogleich will ich dir zeigen, in wie weit sie sich ron cinander unterscheiden."

\section{Z WEITES CAPITEL.}

Zweite Periode der Zoologie.

$$
\text { S. }: 6 \text {. }
$$

Wach Galen geriethen alle Zweige der Wisscn. schaften in Stocliung. Das poly theistische Zeitalter verwellite, und das neue monotheistisclie begann zy

a) Galeni Oppá T. is, S, 6r, b, 
Jicimen. Der Teltgeist licfs für diesen Augenis licks alles Uebrige im dunheren Andenken, und strebte nur jenen christichen Tiein zu phegen, aus dem ein ganz nenes Alter, nänlich das des Geistes emporcteigen sollte. Das römische Reich als das her schende war crliohren, fuir jencu Saamen den Boo den darzugreben. Allein dic Götterwelt nufste, wenn jencs aufblihen sollte, erst ganz zertrümment werden. Fach den creten Stöisen, welche der zömische Col', durch die Angrifie der hraftrollen Lewohner der germanisclien Wälder erhalten hatte, mufston sich neue Völlichlorden aus $A$ sien, und von den Cränzen Europa`s her, gegen den Mittelpunkt der Welt bewegen; Gothen, Vandalen, Lon. Gobarien and metırere andere Sẗ̈mme auf dem Schatiplatz erscheinen, um das seinem Zerfall längst nahe gebrachte römische Reich völig aufzulösen, was in 5ten Jahrhundert wihlich geschah. Doch cben diese nomadischen Völker waren bestimmt, das anf sie geimpfte Reis des christlichen Glaubens zн seiner höchsten Blüthe in Europa zu bringen. Zu dieser schwankenden Zeit, welche sich mit dem Sieg des Christenthums und dem Ursprung zener, aus der römischen durch Vermischung und Verderbnifs entstandener Sprachen endigte, und die man ron dem mächtigsten eben jener Völker Rie Gothische nemnen lï̈nte, flüchteten sich die Wissenschaften, fiünste und ihre Pfleger nach 
dem Orient, als dem einstweiligen Asyle, und der neue Völkerstamm war gezwungen, mit der Religion auch die Wissenschaften und Lïnste ron neuem zu schaffen und anzubauen. Daher alles im tiefesten Stillschweigen, bis in das sicbente Jahrhundert, wo zuerst wieder unter dem Thiser Mauritius der spanische Bischoff Isidor ron Sevilla aufstund, und bei der Geschichte der christlichen Dogmen und Päste, auch der Naturgoschichte gedachte. Im Sime von Plinius strebet er die gesammte Natur zu umfassen, und nur, nachdem cr von Sternen, Nincralien, und in cillten Buche ganz allein ron dem Menschen, seinex Würde und sciner Fortpflanzmig gesprochen hat, liefert er im zwölften, betitelt über die Ordnung der Naturen (de ordine nuturarum), cine Aufzählung ron allen ihm dumals beliannten Thieren; das erste Kapitel hebt ron den zalmen (de pecoribus et jumentis) - dem Pferde, Schweine, Schaafe - an, das zweite hande]t von den Bestien: Tiger, Elephanten, Füchsen, Affen, Kameleon u. s. w.; das dritle von den lifeineren Thieren (de minutis) - den Mäusen, Maulwürfen, Grillen, Ameisen; - das vierte von den Schlangen - Drachen, vipera, seps, scytale, amphisbaena, hydra natrix, boa, lacertus, salamandra, stellio; - das fünfte von den Würmern, - Spimnen, Scorpionen, Schnecken, Wanzen, Ti- 
nen; - das sechste ron den Fischen: - balacua, delphin., fihoc., crocodil., hippopotann., echencis, uranoscopus, squáus, anguilla, poTypus, lorperto, sepia lolligo, concha, cancer, cchinus, rana penicella, - das siebente ron den grörouen Vögehn, das achte von den klemeren (de minulis volatilibus) den Biencn, lüfern, Fliegen, Papilionen, Meuschrechen. Hicraus ersieht man wohl, wie Isidor seinen Büchern über die Thice die Abtheilung ron Plinius zu Grumbe gelegt laal. Obwohl aber seine ganze Bescheibung nt? in der Ableiung der Benennmog bestelet, so orhellet toch, dals er bemihet war, die Thicre unter nubere Ablheilungen zu brizgen, als es jener gethun het, wenn or sic gleich anch bjos ron dem tënscicnden Silnine hernalim.

$$
\text { গ. } 17 .
$$

Xit dem sielsenten Jihhunderte fing der christicle fejm an, ant satuz lirmden buten zu

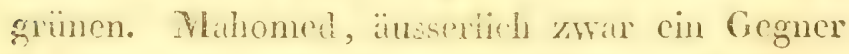
desselben, lehrt in Sinne ron Christus die Menschen Gotes - mal Nüchstenliebe. Allenthullen

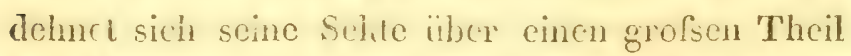
ron Aegyplen und Asien aus, und der Líalif Omar gab cullich Aem Ileidenthme durch Verbrenmung der Bibliothel, welche die ptoloneischen fiönige in Alcxandrien angelegt hallen, den lezten 
Stofs. Gleich hierauf rerbreiteten sich die Araber, ar:geflan met durch den Enthusiasm fuir ihre Relio gion, in Luropa, besonders in Spanien, und trugen so zur noch weitercn Begründung des zarten Orien。 talism, wclchen Christus und jene Horden des Aufo ganges schon nach Europa verpflanzet hatten, bei。 Die Araber sind es, welche das zarte Gemüth des Menschen aufregten, und den Saamen zu einer Weltanschaumg legten, welcher erst in folgenden Jallrhunderten in Europa aufging. Bei ihnen hatte sich die griechische Litteratur noch ror dem Untergang erhalten, und durch sie mufste dieselbe, nach. Een die Christuslchre fest genug gewurzelt war, wieder nach Europa - den Sitz der neuen Religion - übergetragen werden, um jezt die Ausbildung: dor Wissenschaften und Iiünste ron da an wcite. zu befördern, wo sie mit dem Ursprunge der christlichen Mythe stillgestanden hatte. Ja die Araber erweliten unter sich selbst das Andenlien an die Grie。 chen, sie stellten sich Aristoteles, Plinius, Dioskorides und Galen als Muster ihrer allgemeinen Nachahmung auf, und nun waren Pflanzenkinde, Astralogie, Alchimie und IIedizin jene Fächer, welche nebst den Arabern alle Gelehrten Europens beschäftigten; Mesue, Razeus, Aricenna, Arerrhoes gaben jezt den Ton in der Medizin an, und Hamdalla Abuber macht sich durch sein Werk : „das Vergnügen Indiens“ Mahomed Zaman durch das: „der Garten der Well" und so noch Andere, um diẹ Na. 
turgeschichte rerdient. Alle firäfte der Niatur, se wie die Liebe fur die griechische Litteratur, wuren nun durch die Araber rege gemach re, und der christliche Glaube hatte jezt unier dem wissenschaftichen ichutze Larl des Grofsen alle Mittel sich auf eige.'m Bocen auszubilden, obgleich durch das Reich a.r Sarazenen, das Karl zwar auf Spanicn ein. schünkte, aber doch nicht ganz aus Luropa vero d. iingen konnte, und ien in den folgenden Jahre lunderten herrschenden religiösen Titrieb, das lie lige Land den Feinden des Glaubens zu cntreissen, das $A$ bendand noch immer in Berührung mit der Morgenland blieb, und nebst and̉ern Schatzen der

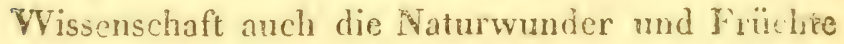
j'ner fremden Länder, unmerkilich anh Europa wanderten.

Dieses arabische Zeitalter war, wie jenes mythologische der aiten Acgyptier und Griechen, gleichsam das der Geburt. Man strebte in demselbon, die Natur nicht in Kabinetten, oder durch trockene Nomenclatur im Gedächtnisse aufzubewahren, ncin, man suchte die Sympathie und Licbe, welche Christus als Moralprinzip in Men. schen nachwies, chenfalls in der gesammten $\mathrm{Na}$ tur auf, und trachtcte relig:ösen Sinn in Werken der Kunst atszuprägen. Nicht der blorse Leib, sonảern besonders der Geist der Natur war rege gemacht, und in diesem ganzen Zeitalter spricht man von nichts als von dem geheinen simne der 


\section{$-53-$}

Zahlen, Figuren, von der Verwandlung, der Sympathie, Antipathie und den geheimen Kräften der Sterne, Thiere, Pflanzen und Elemente zu einander. Diefs ist der cinstimmige Genius dieser Zeit, der Genius, welcher nicht blos die neue Religion begründete, mit ihrer Entwililung eine eigene Form der Baukunst - die Gothische, - später mit dem vierzehnten Jahıhunderte auf florentinischem Boden, die Mahlerei und Dichthunst wieder crwechte, und hiczu cincn Cimabue und Dante ge3)ahr, sondern auch später cinen Paracelsus, Helmont und Böhme begeisterte. - Mit Christus wurde der Geist von der Natur getrennt, und diese dient nur als Vergleich oder als Spiegel, um das Wesen des ersteren, wie ihn das neue Exangelium rerkïndet, in ihr noch deuilicher zu beschauen. Daher alle Schriftsteller und Zoologen dieser Zeit das alte und neue Testament auch auf wissenschaftlichen Boden als ihr Gesetzbuch ansahen, die Laster und Tugenden des Menschen, so wie die Herrlichlieiten Gottes an Thieren und an andern Geschëpfen zu crliären sich bemühen, und ihre ganze wissenschaftiche Naturgeschichte auf die mosaische Schöpfungsurkunde einschrünlien. Von dieser Art ist das lileine und unwesentliche Werkichen : "Theobaldi episcopi physiologia" welches an zwölf Thieren, als entsprechend der Anzahl der Apostel, nümlich in dem Löwen, Ad- 
ler, der Sullinge, Ampise, dem Fuchlse, Hirsche, der Spine, dem WVallfische, der Sirene, dem Iilephanten, des Tuteltaube mel dem Panther, welche in dieser Ordnmes in latemischen brisen beschrichen werden, manche stelle der bibel anzzulegen trative. Doch anch durch solches theolo. gisches Forkchen trat endlich die Naturgeschichte allmählig zur Dümmexumg herror. I. ider! war aber alles Narisuchen und Farhspüren blos auf die häufig copirten Handschriften der Griechen nud Pömer, und anf die Übericferten Nachrichten wanderuder Toller cingeschränlt, woher denn die Schribternler dicser Zeiten aus Mtungel an eigener Erfahrung das Wahre mit dem Fibchafien Znsammentrusen, wud Zeichnungen ron Thicren blos den Sagen uud Beschrebungen dex Alten gea tren, in gevisenhafter Einfalt entwarfen; So sprea chen sie von Drachen, Sirenen, Karpyen, Gryphen, Pegasis, Zcntaur, Meermünchen, Mecrbischüfen u. s. w. als ron wirlilichen Geschïpfen, welche fabehafte Bilder und Amahmen sich erst

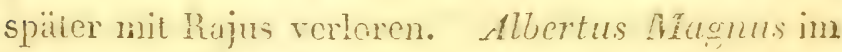
dreizehnten Sahrhunderte ist der erste, wilcher wieder die sämmlichen Whicre als Ganzes aulfarste, und hioriber ein Thirbuch in latemischer Sprache lieforte, welches, obwohl sirolzent ron jenen Lngehoucrn, und nur reich an mowesentlichen und cinfaltigen Deschreibungen, doch den 


\section{$-5 j$}

Geist welte, die Natur als ctwas Ganzes aufru. nelmen und zu ordnen, und eben licrdurch das erste Muster für die nachfolgenden Naturforscher aller Nationen aufstellte. 'Wwar erwälnt or nicht ausdrithich der Alcthode, welche er bei Ablheilung der Thicre befolget hat; allein aus seinen Leberschriften ersicht man, dafs er nur den Plinius in Auge behieli, mu mit ilim alles zu den Fischen rechnet, was sicle inmer im Trasser oder nächst bci demselben auflhili, nur hat $\mathrm{cr}$ sich in etwas ron jenem dadureh enifernet, dafs er dis Vügel vor den Aquatilion gesezt hat, und die Individuen jedes Buches nach dem Alphabete, das er inmer rou dem eraten Buchstaben der lateinischen Benennung jedes 'Thicres hernimml, aufeinander folgen läfst. Das erste Buch ist allein dem Menschen, und der Aufzilhlumg seiner Eigenschafton gewidmet; das zwoite enthait die Süughthiere, die crecradezu Thiere nennt, als den asinus, castor, tutra, mulus n. s.w.; das dritte die lögel, worunter auch die Fledermäuse begriffen siml; das ricrte dic Fische, wohin cr alle Trasserthere zablilet, als batacna, cancer, coctulea, celphis, crocodilus, hippopnoianus, phoca, testudo u. s. w.; das fiunfe betitelt sich die Schlansen, alles liriechende Gewirm und dergleichen Ungeziefer, als: Barilisk, Drache, Eildelse, Salumander u. s. w., dich nïnliche cuthit auch 
die blutlosen Thiere, wie die Inseliten, apis, hufo, Timax, vermis, vespa u. s. w. - Nach diesena Werke erschien ein anderes unter der Benenuming: „das Buch der Natur"; Conrad Megenberg liat es aus dem Latein übessetzot, und morliet an, dafs der ursprüngliche Verfasser fünfzelm Jahre daran gearbeitet, und es aus hirchenrätern, aus Aristoteles, Plinius, Isidor, Aricemna zusammengetragen habe. Ordnung und thihalt ist gicich wic bei seinem Vorgünger, nur hat er nicht blos die Thiere, sondern auch gleich anfangs die Sterne und Elemente, und am Ende des Verkes, die Mineralien abgehandelt. Beide lebten nachmals in dem Werke: "hortus sanitatis" auf; der Verfasser ging in etwas ron dem ersteren ab, indem er sich noch mehr an die Eintheilung des Plinius anschlofs, und die gesammte Natur in rier Büchern: "ron den kriechenden, fliegenden, schwimmenden Thicen und von den Mincralien "durchlauft, Mier hat ex in jedem Buche gleichfalls nach dem Alphabete greordnet, und z. B. alles, was nur hricchet, als: Süugthier, Schlange, Wurm in ein und das nämliche Buch zusammengebracht, und so zu den Vögeln ebenfalls die fliegenden Insekten gestellet; statt Beschreibungen ist vielmehr der äztliche Gebrauch angefuiht, und, was überhaupt den beiden erstcren noch von fabelhaften Thicren abgehct, ist hier sicher ersezt, indem das 
ganze Werk ron solchen wimmelt, und selbst die Hausthiere in den illuminirten Holzschnitten monströse Figur erhielten.

Hiemit endiget sich seit Plinius ein Theil der Periode für die Geschichte der Zoologie, welche sich jenen blos zum Muster genommen hatte, da im Gegentheile die folgende sich wieder an Aristotcles anschliefst. Sicht man auch gleichwohl, dafs mit der nenen Zeitrechnung - der Christlichen wic alles, anch dic Zoologic gleichsam von neuem lieinte, und sich in Armuth langsam wie aus cinem Rülfalle emporhebet; so kann man doch nicht rerkennen, dafs man in dieser Zeit mehr nach innerer Ordnung strebte, als es in der des Aristoteles und Plinius geschah. Freilich komnte es, da der Genius dieser Zciten blos auf die Ausbildung der neuen Religion conzentrirt, und die Natux für den Naturforscher blos aus Sagen und Handschriften gehannt war, nur bei diesem Streben verbleiben, und erst liünftigen Zeiten ist es vorbchalten, diesen strebenden fieim zur vollkom. menen Pflanze zu entfalten.

\section{18.}

Mit dem füfzohnten Jahrhunderte that sich das Welmeer auf, und mit ihm der VVeg zu unbekamnten Weiten. Heinrich, der Schiffer, der Bruder des Fönigs Erlwarti des ersten, entdecliet 
Porto santo, Diaz das Vorgebürg der gutci Hoffnumg, Gama landet zuerst in Calcut, criffinet die Strasse nach Ostindien, Columb, in der Schule Heinich des Schiffers in Portugal gebildet, entdechet Amerika, _Magelhaen misegelt cndilich die gesanme Frde, und die Philippinen, China, Jipon, die Molluliken, und das Polyneien treten durch ilm auf for Landliarte auf. Von nun an wryden DTissienäre in alle Wreltheste geschichet, ind Nationen weteifern un den hiulm Portugalls, so wie um dir. Forthile neis cntuther Lander. Dio Hollander entrifsen at huze Zeit den Porugiesen den ostinuischen Irandel, Mralie, als der erste miter den Fngtüntom, zim Stolze suines Vaterlandes, cbenfills eine Weltunscglung unternahm, Cooli solche dreimal wiederholitend, dio Entdechungen seiner Vorginger beliräftigte und erweiterte, Nenholland culdehic, und Engtand seitdem durch Weltumsegler und Commerz viber das Meer gedinethot. So nur, wo sich mit der hiemtnifs des Meeres und mit der Intdecliung der Welttheile der Morizont der Natur crwciterte, crwciterte sich anch der des Gristes: den Wissenschuften werden öfentliche Asyle erriclitet, die Buch. diucherei vird erfinden, mithorer und Calvin verkiunden öfentlich dio Freiheit des Nenschen im Gegensatze der Natur, dio Moral der Gesimmmg gegen den blinden Glauben àcr Ficligion. Jezt 
erat trat der Forschungsgeist auf, und man strehet nicht sowohl den lebendigen Geist, als viehmehr den Purichthum der Finur liennen zu lernen, um gleichsam die Nacht und den Vorzug des Geistes des Nenschen über die todte Natur als in cinem gröfseren Spiclraum zu betheures. Angeflammt durch den Gewinn, welcher bisher fiir das Wohl cinzcher Staaten und der gesammin Menschneit ans der Schifhmst herworging, beeiferten sich jezt alle Nationen, Txpeditionen, selbst blos zur

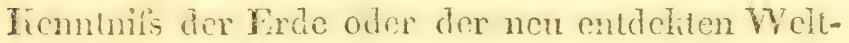
theile anizisenden. Than licnnt die gelchrten Reisen cins Ilerpandez, Gonsalvi, Sloane, Anson, cines Pitmier, Contanine, Dampier, Lapeyronse, Bongainille, Peron, u. s. w., und nun stehen die fme treluheile ron Portngiesn, Spaniem, Nollindern, Engländern, Russen und Franzosen ausgeforscht ming geplinicrt ror uns. Tir licnnen Ancrikia beinalę so szit, als msern europäischen Boden, Asiens Prodnlite lassen auf semen weicien Reichthum schicfsen, und die wenigen Soltenheiten, welche wir ron Afrika und sonderlich ron Neulolland besitzen, erweclien die Aufmorhambrit einsichtsroller Nonarchen, diesen boiden Weluheilen ferner nachzuspoiren; ja wir fiblen uns beinahe schon in Stunde, die nenente

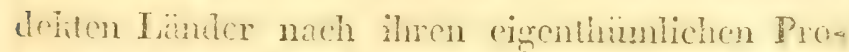

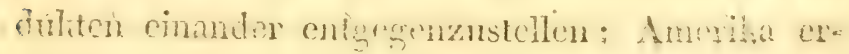


scheinet uns als das ausschliefsende Vaterland der Sarigues, des Tapirs, Taton, Faulthiers, Amciscnbäres, des Pekari, Lama, der Vicogna, des Kaiman थ. s. w.; Afrika nähret allein bis jezt den Hippopotamus, dic Giraffe, den Ichnemnon und das Frocodil; so wie nur Asien und Afrilia dem Rhinozeros und Elephanten zum Aufenthalte dienen; Neuholland endlich sezt durch die wunderbaren und nirgends mehr vorkommenden Gestalten der Kängeruch, des Ornithorhynchus, und der Echidna alle Naturforscher in Erstaunen. So wie in der Natur, so hänfet man auch die Intdeckungen auf dem Gebicthe des Geistes, und gerade verdrängct hier ein liünstliches System der Metaphysik das andere, während auf naturgeschichtlichem Boden seit $\Lambda$ lbert dem Grofsen bei Teutschen, Engländern, Franzosen und Italienern, die Zoologie mit gemeinschaftlichen Fräften bearbeiret wird.

$$
\begin{gathered}
\text { 5. } 19 . \\
\text { Gessner, } 1516-1556 .
\end{gathered}
$$

Fionrad Gessuer, in Zïrch geboren, nahm nach scincn Reisen nach Strasburg und Paris, endJich in Montpellier die Dohtorswïrde, und starb in seiner Vaterstadt als Professor der Ethili und Physili. Statt, wie bisher, die Natur aus blofsen Sagen und Handschriften zu studicren, wandte er sich an jene selbst, und war zwar nicht der crste, 
welcher die sümmtlichen Thiere überschaute, und einzeln beschrieb, was schon vor ihm geschah, aber der erste, welcher seine Beschreibungen und Zeichnumgen der Thiere mehr aus der Anschauung, und somit lienntlicher und richtiger verfertigte, zu welchem $Z$ weck er troz seiner Armuth einen eigenen Zeichner und Holzstecher hielt. Ansgerüstet durch viele Sprachen, worin er schon. in scinen früheren Jahren, als öfentlicher Lehrer der Grammatili in seiner Vaterstadt Unterricht ertheikte, trug er mm zur umstündlicheren Charakterisirung jedes cinzelneu Thieres in aclut Absäzen alles zissammen, was er in Rüksicht des Namens, Vaterlands, der Sitten, der innern und äussern Theile des Körpers, des medizinischen und öhonomischen Nutzens je las, oder beobachtete. Dieser litterarische und grammatikalische Aufwand. machte, dafs seine Schriften über dic Thiere zu fünf dicken Foliobänden heranwuchsen, von welchen ein jeder in lateinischer Sprache abgefafst ist, und die Thiere nach dem Alphabete ordnet. Im ersten handelt er ron den lebendiggebährenden Quadrupeden, im zweiten von denjenigen Vierfïfsern, welche Eier legen; im dritten von den Vögeln und den darin begriffenen Fledermäusen; im vierten von den Fischen und sämmtlichen Wasserthieren als: astacus, balaena, cancer, castor, concha, phoca, salamandra, salmo, spongia, te- 
siudo, vermes; zu dru Wiumern reshet or noch die Nureiden, Meerigel, Mcersientue und das Mecrperetchen, und als einen Anhang zu diescm Bunde friget or am Tince alle jene fubelintien Acerwunder, und difenigen Quadripedca (hij)popoiam. inus ayualic. hydra), welche gü̈stentheils im Wasser leben, bey; der fünfte ist firr die Drachen und Schtangen bestimmt. Leider! entrifs inn der Tod, whitend ex sich die Inseliten zu bearbeiten sorgenommon hatte, cin Lntemelmen, welches bald darait Wotton und endlich Moufiche ausfihten, mal so ciese Geschichte der There duch ihre Arbeit erginzten. Anch in Gessner Inbet noch der Geist der rorbergelumen Zeitcn fort. Wie Abertus, hat anch ar dir fobelhaften Thise unter die whllichen verset, und wie jener das Alphabet zom Schema der weiteren biassifution seiner flblicilungen, mo das grammatikalische Forschen nach der Wtymolowis der.amen, zun Mtauplawecke seiner Beschroinungen genommen, nur hat crlatut oligen die Ansicht des Aristoteles meir herausgohoben, and die des Plinius blos zur hlodification der crstercn gebrauchet, ein Verfahren, welches auf französischem Boden der durch seine heisen und Beobachlungen so verulicnte Belon, so wic anch Rondelet, fast zu gleicher Zeit mit diesen, bei Bearbeimng cinzelner $\mathscr{Z}$ weige der Thiorgeschichte befolget haben. 


\section{$-63$}

Alloin hierin ist Gessner mit lieinem gnten Beispirte vorgegangen, duis u den Michochen aus dem Peiche der Thiere anssich, mul reanuthlich ans Flirturcht nirgends Aessethen in seinen Werhen gedentiet, wolchen lithnu stine vathfolger getreulich fort erhielten, whe durch die setiarfinnige Zusammenstellung und vergheichende Benennums des Slielets des Tugels mit dem des Menschen, was Belon so meisterlaft schon in jener zeil, und selbst in heipfern versuchte, darauf antimerlisam gemacht zu werden. Mit der $\mathbf{F r}$ scheinumg dieses teutschen Naturforschers, hat also die Zoologic nicht sowohl am Systeme, als vielmehr durch die Beobachtungen und getreueren Limper an zurerlïsiger Genaugheit gewomen. Besonters aber ist es der zu scincr $Z$ eit her. schende fieschmack an literarischen und grammaiilialischen Untersuchungen, weichen auch er als das Wesentlichste auf naturgeschichtichen Boden versezte, cin grammatilialischer Pomp, wodurch die Geschichte der Thiere wie wasscrsüchtig anzuschwellen anfing, und welchen diescr mermüdete Forscher cbenfalls als den vorzüglichsten Gesichtspunlit zur Beurtheilung seiner Verdienste um dieses Fach, in der Vorrede zu den Fischen, mit den treuherzigen Worten angiebta):

a) alphabeticum auten ordinem secutus sum, quoniam omnis tractatio nostra fere grammatica magis yluam philosu- 


\section{- 64 -}

"Wir haben die alphabeische Ordnung befolgt, weil unser ganzes Bemühen mehr das eines Grammatiliers als Philosophen ist."

5. 20 .

Wotton-1555.

Wiaen die beiden Tentschen, Albert und Gessner, die Wichererwecher des zookngischen Studiums fïr Europa, so wurden es bald hieraut Wotton fïr England, Belon und Fondelet für Franlireich, und Aldrovand für Italien. Die Zoologic war bisher durch dic herrschende Ansicht des Plinius cin bunter Haufen geblieben. Fuluad Wotton, Dolitor der Medizin aus Oxford, erscheint, hebt scharfsimnig das System, welches stillschweigend den Thierbüchern des Aristoteles zu Grunde liegt, heraus, und bringt auf solche Art Licht und Ordnung in dic verworrene Masse. Thm gebühret daher die Ehre, die oberflüchliche Ansicht des Plinius vernichtet, und das aristotelische System wieder nach seinem ganzen Unfange in die Zoologie eingefulhet zu haben, eine Ehre, welche diesem präcisen Denker bei seinen charakteristischen Beschreibungen der einzelnen Thiere fur die damalige Zeit selbt ror dem grossen Rajus, der sich ihn zum Muster genommen

phica est. Gessner de pisc. et aquatilium natura L. IV. praefatio S. 2. Tiguri 1558. 
znt haiben scheint, den Vorzug ertheilct. Ganz in Geiste des Aristoteles, sezt er die Unterschiede der Thiere nach allon einzelnen Theilen des Fiörpers, in den crsten drei Büchern scines Werlies, botitelt: "de differentiis animaïum " aus einander, stellet im rierten den Menschen als Fürsten aller Thiere hin, und begimnt in fümfen mit den Blut-habenden, und zwax nit den lebendiggebährenien Guadupeden (multifida, bisulat, solipe$d(s)$, lürst anf diese die eierlegenden Fidechsen nnd Schlangen; im siebenten die Vügel (fidipedes, aquaticae); im achten die Fische und Cetaceen; im neunten folgen die blutlusen und zwar die Inselten, und dann im zehnten die noch übrigen (mollia, crustata, testate, zoophyta). Doch suchte er nicht so blindlings den Aristoteles, wie seine Vorfuhrer den Plinius nachzuahmen, sondern berichtigte in manchem scin Vorbild; So ist er der erste, welcher die Fledermänse von den Vögeh zu den lebendiggchöhihenden Quadrupeden versezt, der zweifelhaften Familie der Schlangen ihren Platz zunächst den Eidechsen giebt, das Mrectipfsidelien bei den Tïschen aufzählt, und den bluwsen Thieren noch die fïnfte Illasse - die Zoophyten - hinzufingt, welche noch später Marsiglius und zum Theile selbst noch Linné zu den Pflanzen rechnoten. Scin pliidusophischer Geist dehnte sich sellost noch über 
Familien, Gallumen und Allon ans. Toit chi-

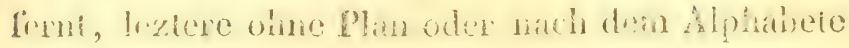

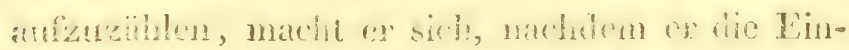

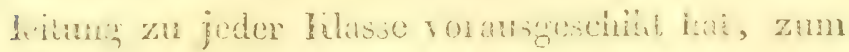
Cesctze, inmer nur an das follhommene das nindex Volhonmene anzuschlicsen, nud juke hapi-

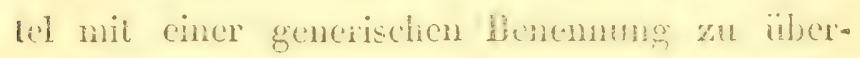
schreiben, velche von dem an-gezeichuden Individum levgenommen ist. In diosua Sime

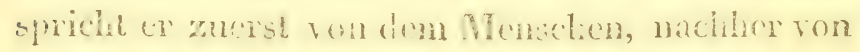
den Lephanten, Mron, Inuden, hyänen, Löwrn, 'Tisern, Dïron, anthich ron den zwei- dian ein-

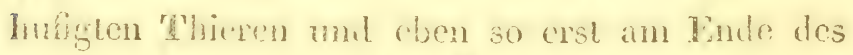
sanzen Bandes von den Eoophyien. So präris

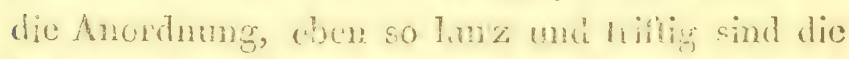

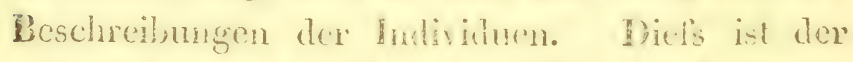

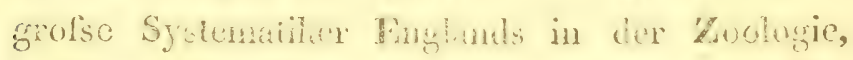
wetcher, obwohl weng ghant, wir ein lieller Sicrin aus der dimhen Voratit herrorlcuchet.

\section{\$. 21.}

A ld x ovand. $1522-1605$. Jonston, 1603Charleton.

Mit àm englischen Foulogrn betrith and ila-

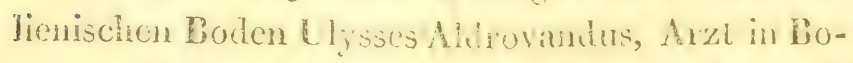
nonien, gleiche Tarubaln. Bie Jirbe fä Salurgeschichte ging bei luzhern so weit, dafs a sein grofes Yormögen fï sin Noturaliculibinet und 


\section{$-67-$}

fiir reli: Puisen terwondele, und endlich arm unt blind im spitale zu Bolognat gestorben seyn soll. Zeichent sich Wolton mek durch philosophische Küze und Präcision ans, so hat Aldrorand an Belesmleit liemen seines Gicichen. Was je in cinem thene der Alten B̈ber Pencmume, Vaber-

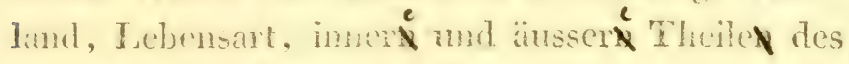

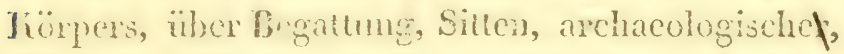
ölononischef oder medirinisched Anwendung eines Thieres benertied ist, hat srine monönte Geduld und I itteratur, zur näheren Beschreibung des Thiores, in vielfach sesonderten $A$ bschnitten zusammengetragen; so dafs lilos die Familie der einand dimn der zwei-hufigten jade zu einem dichen Folioband angeschwollen ist. Wr ham daher wahrhaft als ein gelehries Repentorium der Zoologic betrachtet werden. Doch war dieser grofse Litterator nicht blos ein Sammler wie Gessner, mo obwohl man glanlien sollte, dat's die Masse seiner Polyhistoric ilim die Ordnung ausser Augen gerücht hätie, so limbet man doch die Thice in der genauesten Vertheilung, und beinahe mil Anfange, nicht nur jedes Buches, sondern sclbst jedes liapilch, wiederhohlet sich sein Strebon, jedes Individmm nach sriner Dignitit und Vollkommenheit an das andere anzmeihen; nur hat er sich im Begrîfe der Vollhommmheit geirret, indem er leztere üfters mit der Nëzlichlicit rerwedhschte, 


\section{$-63$}

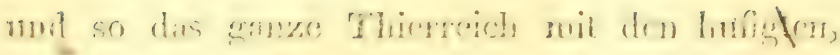

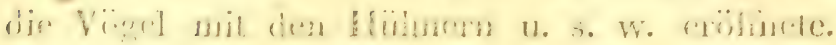

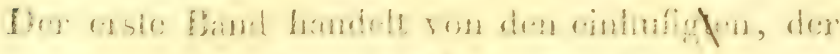

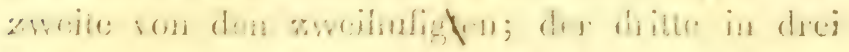

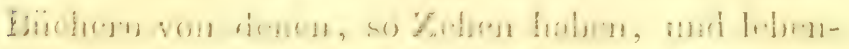

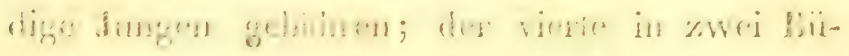

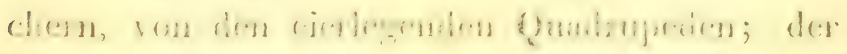

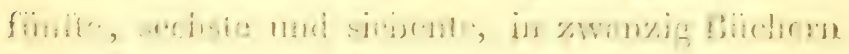
von den vögeln; der achls in fünf von den Fischen und Cetaceen, der neminte von den Schlangen; der zchnte ron den Inseliten, wozi or auch die Schnechen, Würmer, Mcerpicrdchen, den Synguathis, BReerstem, die Serpulen u. s. w.

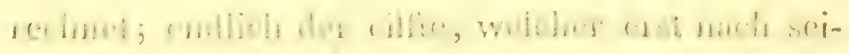

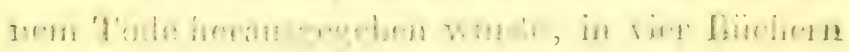
von den zibrigen bluilosen Shlieren. Man er-

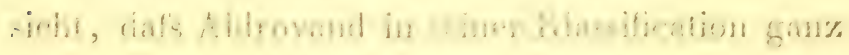

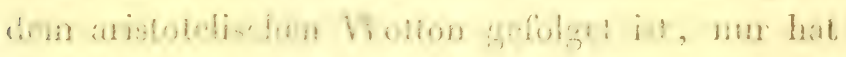

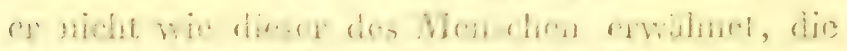

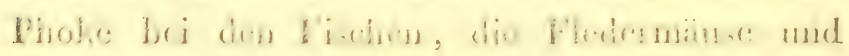

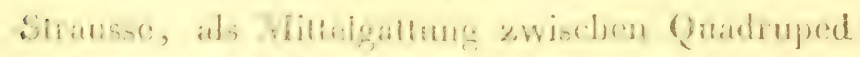

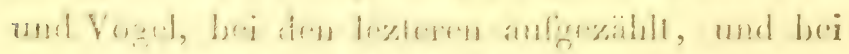

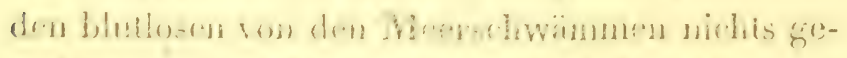

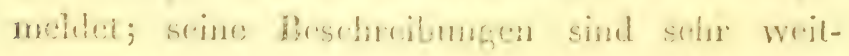

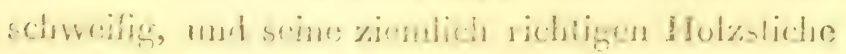

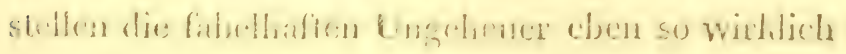
als die übrigen Thice das. 


\section{$-69$}

Dem Ahrovand folgh Eohaunes Jonston, Arzt zu Strablen in Grols-Poblon, getnz getren nath,

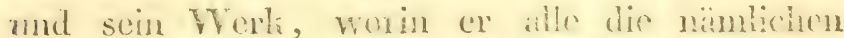

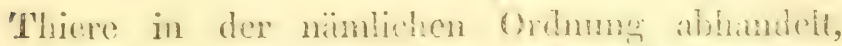

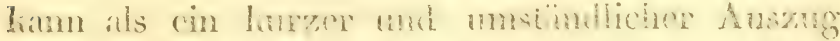

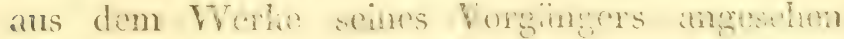

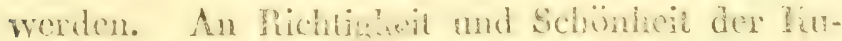

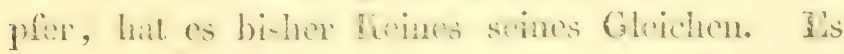

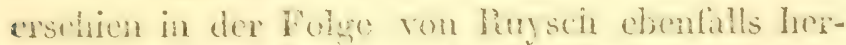

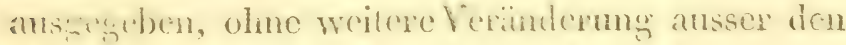

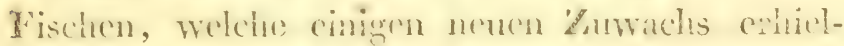
ton, und muter don Titel: "theatrum anime-

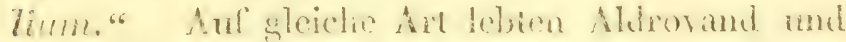
Annton in dem Worhe: ,Ommasticon zoicon?"

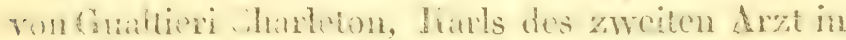

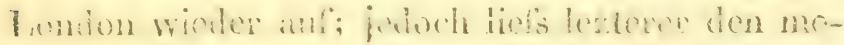

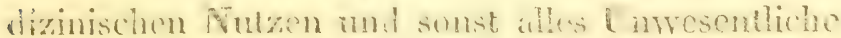

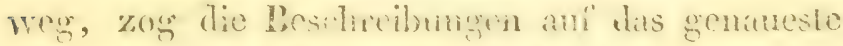

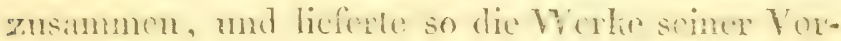
gringer wie in dem cinfachsten Gitundrise, desseu Hamplzwedi und Verdienst in die elmologische Ableiung der Nanen dee Thiere gesezt ist.

\section{(1. 22.}

Ifat der Siame der Zoologie mil Aristoleles,

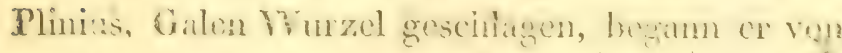

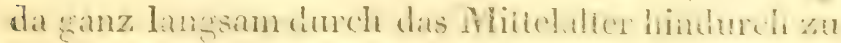
heimen, so scheint sich dor fotere Staimm duscit 


\section{$-70 \quad-$}

Gessner. Wolton, Aldrorand zu bitden, mm sich in der Folge in unendich viele $\mathscr{L} w$ cige zu verästeln. Das heramaheme sicbenzehne Juhnhmdert ist die glibliche Lipocie, wo nath alien lichtumgen in den Forschern der Trieb rege warde, die Natur bis anf das likeinste zu curchinithen.

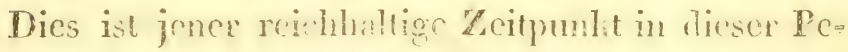

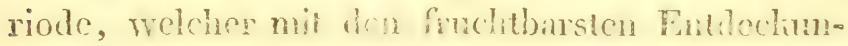

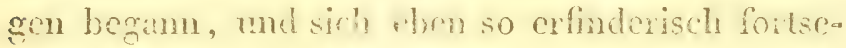

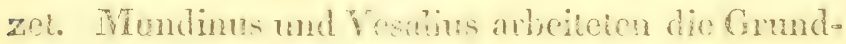

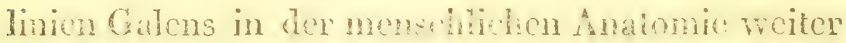

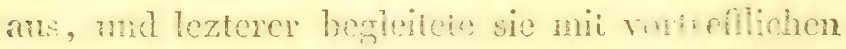

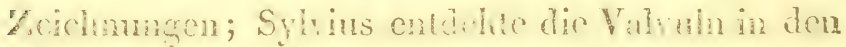

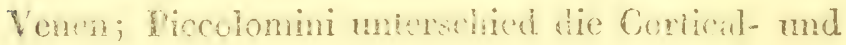
Metulhar-sabstanz im Gelina; ron mun an blciben die Naturforscher nixht blos bei der Inirro suchumg des menschlichen lö̈pers und seiner grö̈ beren Organe stehen, sondern setzon dites bis auf die heninden und einfacisten forl, und verghleichen die der 'thicre mit jenen des Menschen. Durch Zergliederung der Süngthice golciet, enteclet Aselihis dis Minchgefifse, Barholin die Lymphgefifse, Poqunt und Eustachins den Brmilimal; Willis reruleichet den schindel, das Gehirn und die Secleneigenschafien des Menschen init jenen anderer Thiere, und leyel seine vortreflichen Fintdechungen an Nerrensysteme in Ricinnmoen dar; ju dieser grofse Anatom nud Physiolog zcich. 
ncte schon damal in dem Trdwurm sin Organ ab, welches erst in unswer Zeit Mangili für das der verren darthat; Horrey endeclet, gycichwie

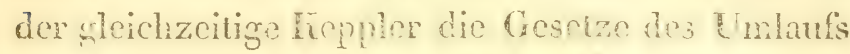

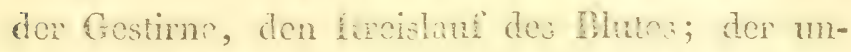
stebliche Swammerdem wax auscrholiren dor

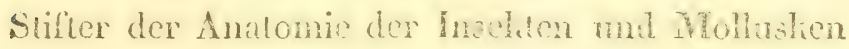
zu seyn, er enthint die bisher rerboryen gevesenen Wunder der Natur, und das Iferz, dic Tracheen, das Nerven- Geschliedis- nud PerdaungsSystem an jenen lilvinen Geschüplen nachweisend, bestätiget or den Satz: "Lotum et in minimis" Blasius unermüdeter Ileil's liefert in Zechinungen and Beschrobungen die Anatomie von cinzelnen Theilen ron thieren ans allen hassen; Malpi-

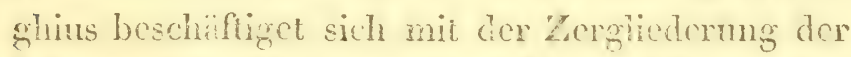
Planzen, des Gehines, der Zmonge, Lunge des Menschen, und ist sckon dunch die muständliche Anatomie des Sciricischnctenhongs als Muster dem Swammerdam roreggangen; Tj son, dic Anaiomie äber noch inchir Thicke and noch nehr Theile dersolben andermen, als stimon, zoiget die Aemlichlicil und Fersenicdentucil des Nahrungsimales der meivien Thieve in Finjern, und waget sich endich seibst an die Zargliederung der Afen, des Pecari und der Iilapperschlange; Redi störst die Entstehm cines Thieres ars leblosen. oder faulenden Dingen un!, und Löwenkök be。 


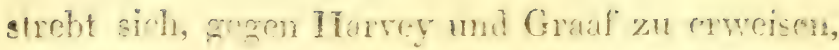

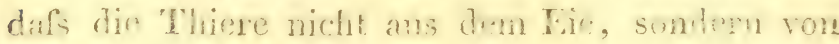

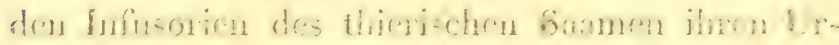

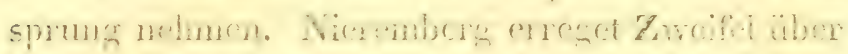

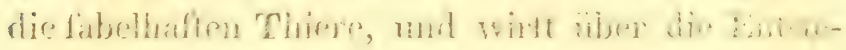

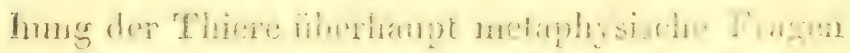

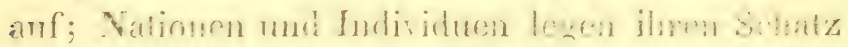
von Naturalion in örontlichen hatahgon dar. Dhe

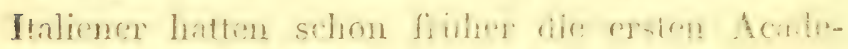

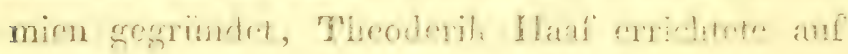

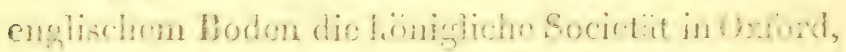

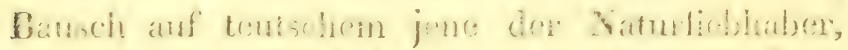

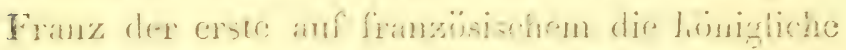

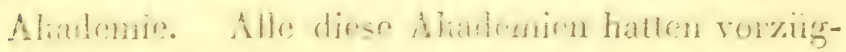

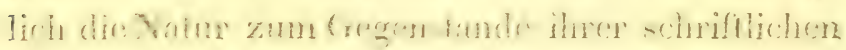

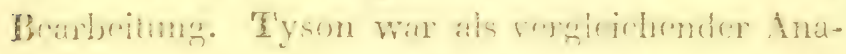

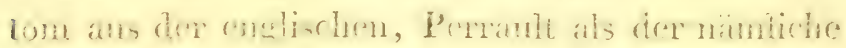

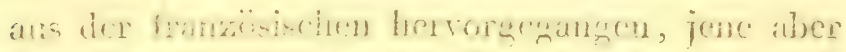

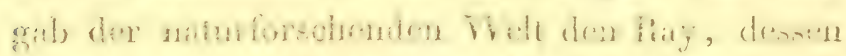

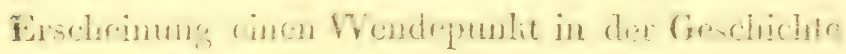
der Zoologie bildet.

\section{กิ. 2.3.}

R a y. $1628-1705$.

Dic Monge ron zoolugischan Endededuerem

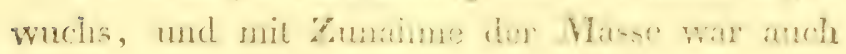

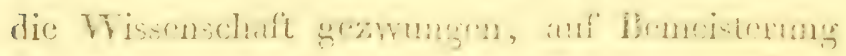

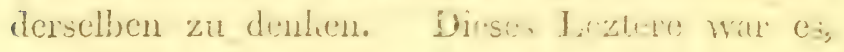


was Ray, zu Blank Nolhleg in der Grafschaft Essex geboren, ant seiner naturseschichtlichen Laufbithn vor allem in Arge late. Fr hatte sich auf scinen heisen, welche er nit Willughly durch ilir sietertande, durch Tentschland, italien und Frantreich mache, in der Nelt migesohen, and mulig fafse en jezt den Fintschufs, die $\mathscr{Z}_{\text {uologie }}$

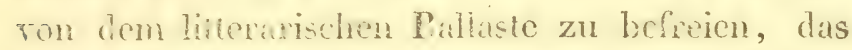
Nescutiche daron zisimmenzuzichen, nud dem

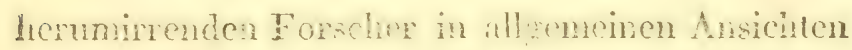

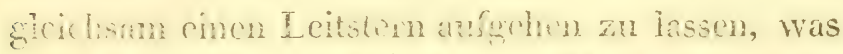
ex anch vindeh in dem himen Werhe, betitelt: „synopisis qutichuplutum, uvium el piscium"

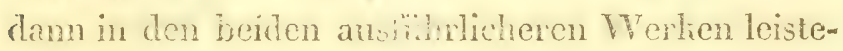
tcle, woron er das blex Vugel mel Fische nit Wilhuthy gemeinsam, jenes über Inschen aber alloin heranszab. Das aristolulische Sy sram hatte sich mil der Liweiterung der fiemunisse in der Natur, und mit seiner bisherigen Anwendung dar anf immer deulicher anszesprochen. Kirem so scharibnigen Geist als Rayus, homten die hervorspringenten Lücken nicht unbenerht bleiben. Er bertirte daher dicselben gleich beim Eingange des crsten thextes zx den Quadrupeden, berichtigte den Regriff ron Blut dahin, dass es rom Chy lus sich blos durch dic rolue Firbe mierscheide, er merket an, dafs der Frdwum sich zwar durch rothes Blut anszeiche, aber doch unter die wiros 
bliiigen 'Thiere gehöre, dafs die Figenschaft, Fier zul les,'n, bei Schlangen und Fischen Ausnahmen leide, iborhanpt, lebendige Junge gebaimen und

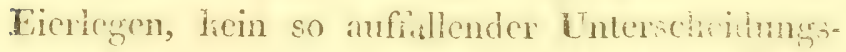
Cliarahter sey, indem alle Thiere das Juige in der Iälle des lies bei sich trägen, und es chtweder in derselben als noch zum Anshrechmen moif zur TVelt bingen, oder es soghteich dine sulbes als lebendiges gebäiren; er behaniet froi, dafs die Denemung Quatruped falsch sey, indem die Schlanorn ganz fufstos, der imanili aber ohne Ilinterfifse ary, obgleich beide nach der

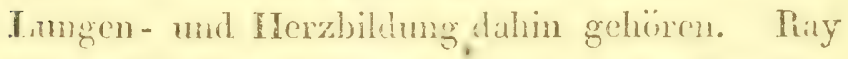
finhlle alle diese Lüchen, allein, da tas Zocitilior ihm heinen Boden zu cinem nenen systeme darboth, so wolle or sich nicht als ficformitere schel-

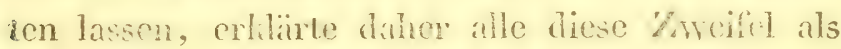

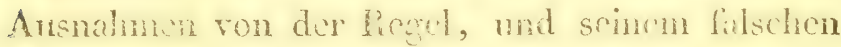

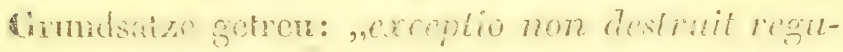

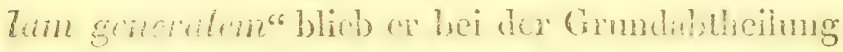

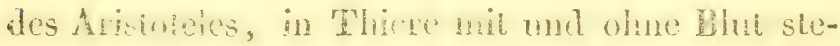
hen. Awh in der nidchsten Linterabtheilung der ersteren Grupe, lublighte of dem griechischen Zoologen; er mberscheidet beharte Quadrupeden, Iifst auf diese die mbehaten Pidechsen und Schlangen fulgen, und sccllet hisaní dic Yrigel and Fische als cigne Abschiete hin; nur suchet er sie nit neuen Chavaleren noch meln zu bele- 
stigen, and nimmt ? ese zuvoderst ron den hrmgen wand Branchicn, dann von dem Ireszen nit cince oder zwoen Lamizern, von der Kignenschait des Lebentiggebïhrens oder Eierlegens, nut endlich ron dom Aufuhlate am Yrasser oder anf der fier Eade her. Alle dise Tnterschiede, den der verschichener Mlevilihms ausenommen, hatte s. bon zerstrent Aristoles angegeben, doch Rajus

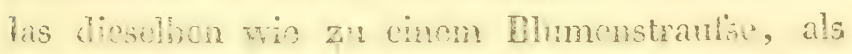

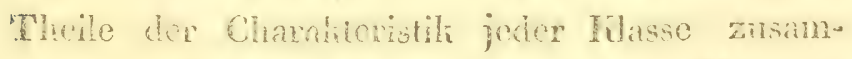

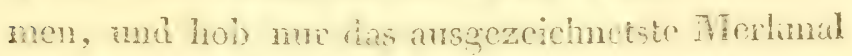
anch an nachemblichsen vor den iblorigen herats.

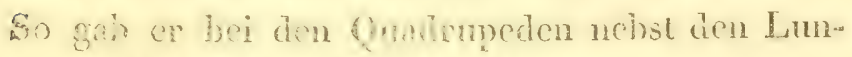
gen mo den doppelun the \%hanmen, besondors die Anwenheit der Itatere, bei den Videchsen und Schkingen die Lunge unt dus finlinmmerigh Ifrz,

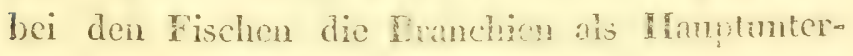

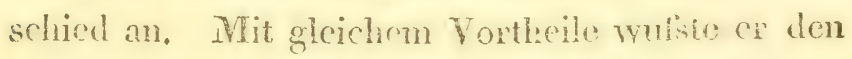
Aristoteles auch im Tnnern jeder Thasse ber seinen behatatun (ungrulata, meguiculata) wo cr die Nägel mol fiaton und nach diesen die Zaime berühichlige, bei den Thieron mit Blute, Lamsen and einfahon Merzen (rana, tesiudo, Tacerta, scrjenzes), bei den Vögeln (terrestres, uquaticae), bei den Fischen (mit Lungen: celucea mit Branchien: pisces curtilagrinei - ossei) zu benulzen. Pei den butesen Thieren wich er zwar nicht ron der Anzahl der Abtheilunesu dos 


\section{$-76-$}

Aristoteles ab, aber doch suchte er sie unter zwoen allgcneine Gesichtspunlite zusammen zи zielsen, and nont sie grörsere (majora: molita, sutwtacet,

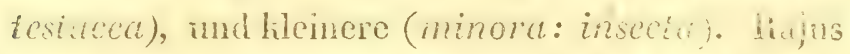

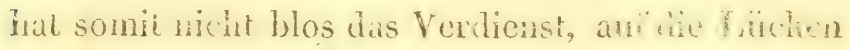

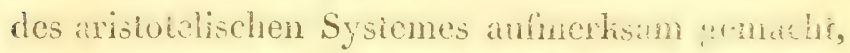

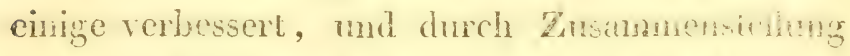
mohrerer Charalitere, besonders jenes des lferzins, welchen er zu allererst ans der Schule dex Mnat

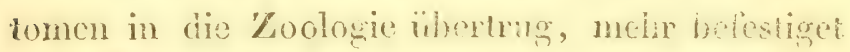
zu haben, sondem cin vorzilghiches Verdinst hat

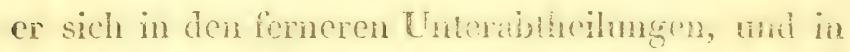

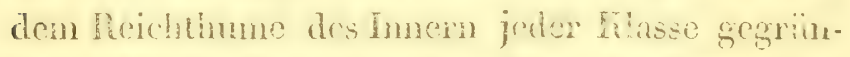
det. In ist der erste, woloter dic fabelhaften Thicre aus semen Schifen weghlilst, wezu n' frcilich aus Vebereing anch den urats guto und den didus ineptus recher, ma alles, was $\mathbb{H e r}$ mandez fir Thudrchungen in Mexilio, Piso in beiden Indien, Maregraf in linasilion, Ifuns flowe in

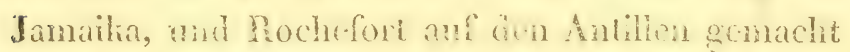

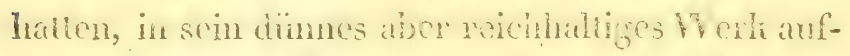
nimmt. So geachah es denn, dafs der Manali, Tapir, dzs Decari, Iama, sowic bei Wögeh und Fischen sehr vicle neue 'White, zum ereton Male

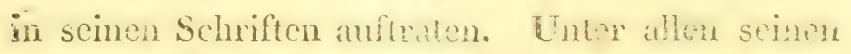
Vorgingern hat Rajus hemen seines Geinkn ats den Wotton; wie dieser, so hat andh jester sich zat

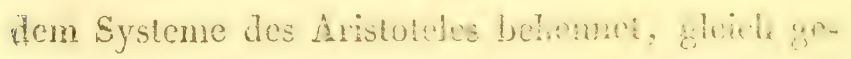




\section{$-77 \quad-$}

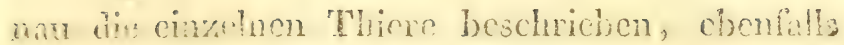
dis shanen mit den Didochsen, die Thedemaus, Phwin, des: Biber, Fischotter mil den behaaren, den synumathus sud hippocumpus mit den Fischen verbunden; ja en that noch mons: Tieince vir han hatte noch bemerkt, dafs die Cetacesn nicht zu den Fischen sondern zu den behaarten Qnathurdon gehöron, und lieiner latte noch so vichice Pruhte zur Gliederung des Imem rersncht. Mnein darin blicb er weit hinter Wotton zurik: in lanter liünsliche Netzo verwichelt, beliümmert er sich gar niclit um die Schätzung der Vollhommenheit cines Thieres oder ciner Familie, ja cr lïfst sogar den Menschen ans semer Naturgeschichte weg, beginnt diese mit den so urvollhommenen Thefhieren, linupfet den Behnarten sogleich die Eidechsen und Schilingen an, und giebt nirgends zu erkennen, ob nach den Behaarten die Fische vor den Vügeln, oder umgetiehrt stchen sollen. So ein grofser Systematilier er auch war, so ist in keinem Schriftsteller die Aengstlichleit sichtbarer und auffallender als in ihm. Er fühlet die Jüichen des aristotelischen Systemes, aber, in* den er sich ausser Stand sah, sie von Grund ans zu bessern, windet und hiüummet er sich, entschuldiget sich mit der Vermeidung aller Neuerung, sucht sich und andere durch den falschen Satz: dafs Atsmahmen von der Regel diese nicht aulhe- 


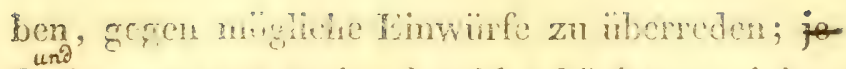
waget or wurh, obrwhil schinchern, cinges

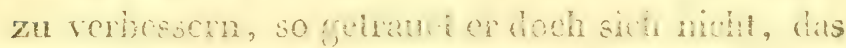

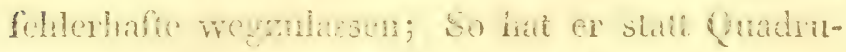
ped die benemmeg binat cmploblen, abor noch immer ist sein lluh mil dem Tike "dutrupe-

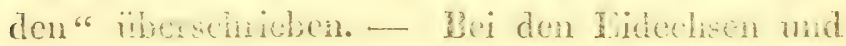
Schlangen hat er die alle bufschift, cielestide

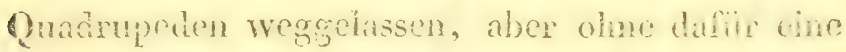

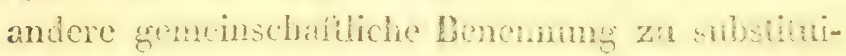
ren. Wr furr atso fort, in mersthen Geistule zu wolmen, und alle dicoe sche fusbestrumen simd nichts ais ein Flihwert, um den nahen Finsurz desselben noch in Ltwas aufzulaiten. So wenigg wie der Ansdrik "Onadruped" ist anch der des Bohartscyns allen dicsm Theren gemon not auszcichnend: Pllanzen, Inschitu, Spimen sind behart, bei Stransen sind dic Vedern hamatig, dor hals und die Aurenbranmen dersoben wirklich behant, bei den Pachidemen, beim Talan, Mtani ist dur Ifatrwates gatr nicht affallent, ja vichush das Gegentheil, und hälte Ray semem Vorhaben genüls die Cuaceen in jene hlasse versezt, an wehhom thik: hes ganz nahicn Dehhins häte er wohl srinen Ghamber - die Hatre aufgeinden? Seicher noch als diese Verbesse-

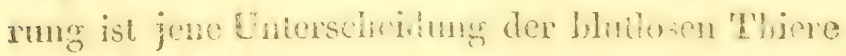

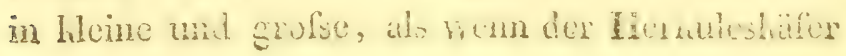




\section{$-\quad 9$}

inel noch so viele lnselten nicht grïfser waren, als manche, ja tausende ron den weichen oder heschmalten! - Nichts wïre fï liajus Icichen gevesen, a tus allon diesen schlingen sich zu zichen, th womi or den Charalitex der rerschiehonen Jlerzbiling durch alle Thicre kindurch vorfolgt hätle. Stati jenem baufulligen Gebände stinde cin nenes mricinel da, und flassen und Gatmegen befän* den sich unverülibar an ihren angenessenen Plïzen. Statt den Tirieren mit und olne Bhnt, wäro nur von solchen mit oder ohne Ferren, mit cincm Herzen ron zwo hammern (Mammalen, Vügel), ron ciner cinzigen liammor, abes auch mit zwei Ilerzohren (Eidechsen, Schlangen), ron ciner einzigen fiammer mit cinem cinzigen Herzohre (Frosch, Fisch, Mollusk, Crustacec), cndlich ron Thieren ohne Herzen, welche weder liamnern noch Herzohren haben (Inseliten, Würmer, Zoophyten) die Rede. Es ist nicht zufillig, dafs bei dem Menschen das Herz ganz zur Linken, bei den übrigen Süugthicren und Vïgeln gegen die Mitte, und endich, jenchr man zu den unrolliommeneren Thieren herabsteigt, immer mehe rechts sich lichret und rïcliet; dafs es bei dem Menschen mehr im unteren Theile der Brust liegt, bei den Süugthieren und Vügehn mehr gegen den Liopf zu heraufrücliet, bei Amphibien endlich den Platz selbsi schon wechselt, bei Lidechsen näm- 


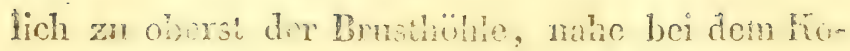
pie, bei manchen schlangen ganz dief grom den

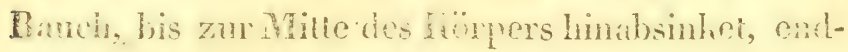

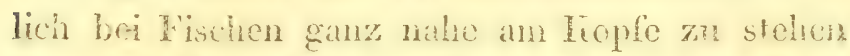

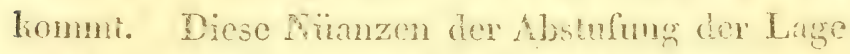
des herzens, nach rechls oder Thiks, nach oben

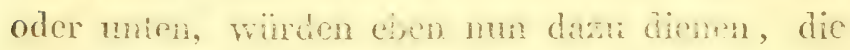

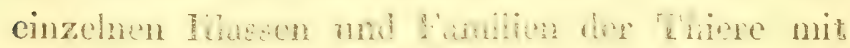

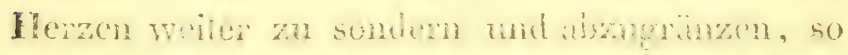

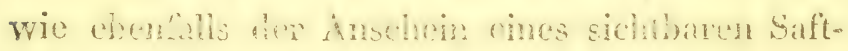

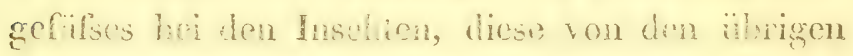

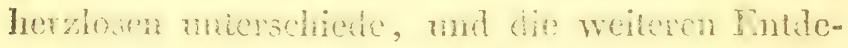

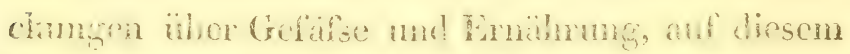

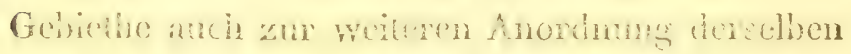
grobrantin winden. Anf solche Wreise wire die

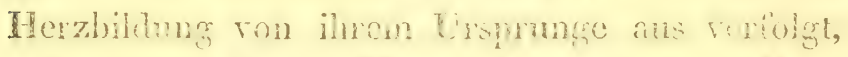
wo nänhich weder Henz, Arhie, nowle Vone whinohmbir, aber ein biefser bressinal, oder

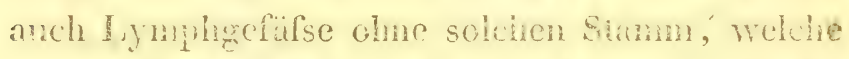
wie die hohlen Tentacils der Ahtinion, wie dic Wassergefife der Merusen, zugleich die fmilion ron Nahungs- mallespirations-Organen rereinigen, zu venmthen ist. man sähe ein, wie mit den Insekten sich schen gleidsam ene hinpigle Rüclicnvene, mit den Mobusticn, Fischen mu Amplibien cin cintannumbigles Lungen - oder Venen-

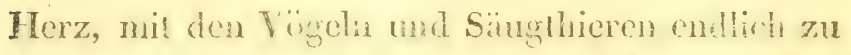

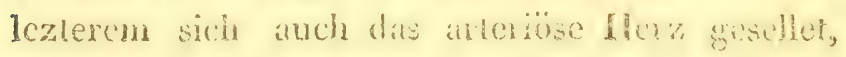


mad hier endich rolliommen und ausgebildet als z.weihammerigles ind zweiolrigtes, schwarz und roth Bht führendes Ierz auftritt, cine successive Tntwililung, deren Stufen sich rielleicht auch im Einzehen an menschlichen Embryo nachweisen liefsen; wenigstens unterscheidet man allgemein jene Periode der menschlichen Frucht, wo die Lumgen, noch leberarig, nicht zur Circulation des Entes dienen, von jener, wo sich dieser Umstand liebt, und endlich durch die Verwachsung der Eustachischen Valvul die ummittelbare Communication der Ilerzliammern aufgehoben und bcide, so wie ebenfulls das Blut, genau in die schwarzblutfiihrende Lungen - orer Venen-Tammer, und in dio rothblutführende Arterienkinmer abgesondert werden. Gerade diesementsprechend, wïrde es vollstündige IIcrzthiere, Thiere mit blos arteriösem, mit blos renösem Herzen, mit blofsen Lymphgefarsen ohne IIerz geben. Jedoch hat auch Rajus nicht den Ruhm, cin neucs System, wozn er doch so nachdritilich dic Terinlassung gab, crbanet zu haben, su blribt diesem grofsen Natuforscher Englands doch jener: das bisher herrschende System des Aristoteles erschütert, neuc Charalitere und. Ansichten rege gemacht zu haben, und eben hicrdurch dex Vorlänfer des nun bald erscheinenden Nordlichtes in der Naturgeschichte zu seyn. 
K 1 e in. $1674-1.75 \mathrm{~g}$.

falob Theodor hilcin fillet die hurze Zeit zwischen dessen Lrscheinung und scinem Vonlinfer atus. Doch hat cr diasselle nicht verspä̈tet, sondem trug glcich bei seinem Aufgange zu seiner nähren Entwilang bei. Aus Tönigsterg gebarilig, widmete or hier seine früheren studien der Jurispudenz, machte hicranf Reisen durch Tentiothind, Hoiland, Fongland, Niedortande unt Tyrol, und wurde endlich nach seiner Rüichlehr zum Sehretär der Stadt Banzig ernemet. Jezt war es, wo cr sich seinem angebornen Hange für Natureschichte ïberiefs, whd eben zu diesen $Z$ Zweclie den Grund zu seintm nachmals so reichhaltigen Naturalienhabinctle lember Vor allen war es aber dem doch die Geschichte der Thiere, welche ihn anzog, und ilm auch in der Zulimift als Scinifisteller verewigie. Dus crste Weili, womit er seine Laufliahn begam, war die Beschreibung der Meeröhren; bald lieraní erschien jenes über die Riferigel, welches ich sowohl durch scine neue Beobachtungen, besonders ibiber die verschiedene Lage der Mund - und Attr-Oelimme, als anch durch die vorirefitichen und zalliwichen Tiupfer noch jezt auszeichnet. Num wandte er sich an die Beabeitung dex Fische, zu dern Fintheilung, so wie später bei jener der Muscheln, 
(1. elikhlisch die Systeme seiner Vorgünger compilinte, wid manche newere Entdechungen, wie die der inneren Gehörwerkzenge der lische, mit Nachdrick zur Sprache brachte. Von jezi an war das System dor Nulur von Limé erschienen, welches, so vicier Yormt?eile seiner Vorgünger sich entschlagent, cinen wanz neuen Wegy zu erönen schirn. Julein war noch zu sehr an dicse Vorurthrile, besonders an das System des Rajus gewöhnet, auch hatte er schon die An-oder Abwesenheit des Fïse, die Anzahl und Verschiedenheit der Zehen und Flanen, welche jencr bei seinen Quadrupeden, Vügeh und selbst Fischen zur Anordnung gebrancht hat, als Grumdlage seiner Ansicht wnd als Abrifs in dem Werlie über die Meerigel niedergeleget, ex whärte sich daher in einer Schrift, genamnt: "Summa dubiorum" offentich gegen den Plan des Limn'ischen Systenes, und führte jwot nach und nach in dem Prodromus über die Vögel, ̈̈ber die Anordnung der Muadmpeden, in einen Versuche über Ostrakologie, in einem andern über Erpetolucie, cndlid in scinen zweien

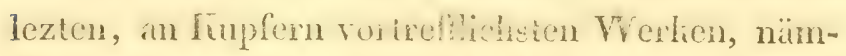
lich: in den stemmaten ter Vögel, und in der Sammlung der Vögreler, scin eigenes System in lateinischer Sprache durch. Vor ihm hatte man schon die Thiere, welche nach den drei Plementen abgesondert waren, wie Clarleton seine Lamdthic- 
xe, Monffette und Aldrovand die Inschien, nach der Zahl der Fïfse abgetheilt. Doch Kicin lief, wie Rajus, die Ansicht des Plinins ausser Spiel, whd schicd das ganze Thierreich in zwei $N_{\text {j- }}$ schnitle: in Thiere nit Füsen (pedata), rnd ohne Fülse (apocta). Von jenen läsi er auf die behaarten Oundrupeden (ungulata - digitata) dis haarlosen (quadrupedu depilata: testudinata,

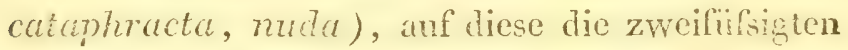
Vogel, bipeda (aues): digitata (pedibus ditri-tetia - penta - hexa - dectylis), wind palmipeda, dann die violfufsigten Inseliten (multipoda: loricata! (cancri), insecta (pedestria, 2:olatilia) folgen. Die zweite Reihe, nünilich der Fufslosen, begimnt or mit den Reptilien (reptilia: nuda (lumbrici, Tinaces), membranaced (ungues), testacea (conchae, tubuli, echini), mit den Flofsinioren (pinnata s. pisces: cetacei, branchiales), mit den sternarigen (radiata: stellae, sepiac, polypi), und endei endlich mit den anomalen Thieren ( anomula: holothwia, penna, urtica marina). Es ist nicht zu lüugnen, dafs Fiein das, was bisher nur an einzelnen filassen rersucht wurde, selbst durch das gauze Thierreich durchführte, und so consequent /seinem Gesichtspunlite rexblieb, dafs er jedes einzehe liapitel ron jedem $\mathrm{Abschnille,} \mathrm{blos} \mathrm{allein} \mathrm{nach} \mathrm{der} \mathrm{succesir}$ sleigenden Anzahl des Zehen, und Jee den Fufolo- 


\section{$-85$}

scn nach ähnlichen Theilen ordnete. Wic aber an einer forligen Statue die Fehler oder Vorzüge auch am deutlichsten in dic Augen springen, eben so ist es auch hier in dem consegitent durchgefühten Systeme Kíleins, weiches sich seit der Einfiihrung der Benennumen: "Qnadruped, Biped“6 ans Aristoteles, anf solche Art nach und nitch in den Schriftstellern bis anf ihin entwickelte. Jedermamn sieht ein, dal's die Inseliten nicht anf die Quadrupeden folgen, die Sillangen nit den WVürmern nicht verbunden werden liönnen; ja hälic er in seiner Methode noch sirenger erscheinen wollen, so müfsten die Fulslosen Thicre zuerst, dam die zwcifufsigten Vügel nach den Fischen, hicranf die Quadrupeden, und an Ende die vielfiifsigen Insekten stehen, eine Ordnung, wolche, mit der der Natur verglichen, sogleich als Unordumg auffallen muss. In henem hïnstlichen Systeme, wenn es anch den natiulichen Anstrich belommi, zeigen sich die Lüdicn und Sprünge (sallus) deutlicher, als in dem Tileinis"ten, anf die Zahl der Füfse erbanten. Veicher ausserordentliche Wechsel in Minsicht der Anzahl der 'Lehen, findet blos bei den Süugthieren statt! Uater den Affen haben die Aielen allein an rorderen Händen nur vier Finger, dio viverra tetradactyla Linn. isi dic cinzige in der Familie der Marder, welche nur vier Zehen an den Hinterfifsen hat, die fiatzen 
mal die mriten Ifunde haben an deneolben ebenfalls num vien Zehen, obgleich mir anch schon Thude mit finf ror Angern gelionmen sind; bei don Tagen ist zwischen dex Anzalu der Zehen der vorderen uni hineren Fifse, beinale immer

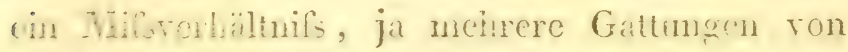
Amermbianen heben rom vier oder zwei, die

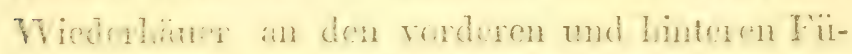

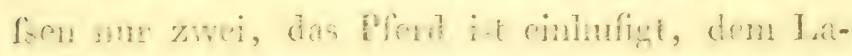

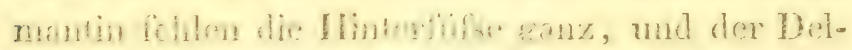

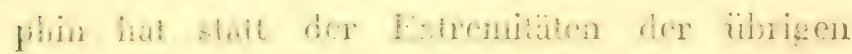
Sinfiline, wahre Hlosscu, so dafs ich die Anzahl

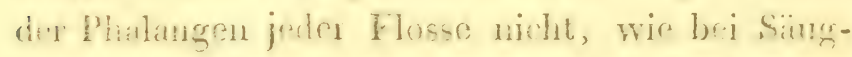
thieren ans ducien, somben wir bei Fischen aus

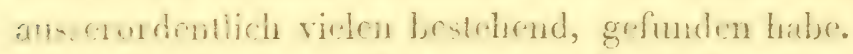

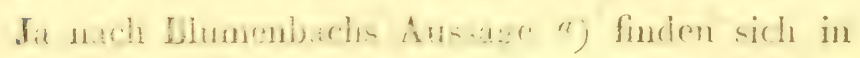

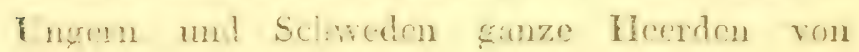

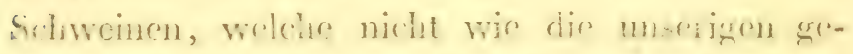

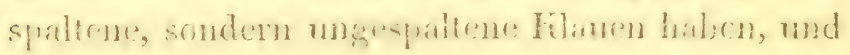
Molina beacheibe eine in Chili sich befindende

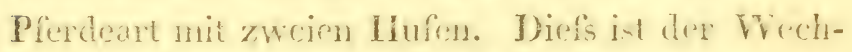
scl der Zall der Füfse, Zohen odrex Flauen bei

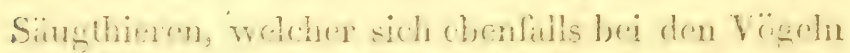

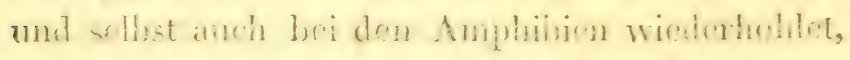

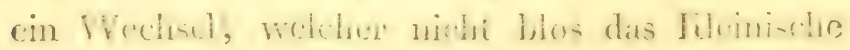
Syatem wiblekgel, sumbern alle dngrhten von

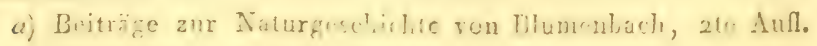
Görtingen. 1806. S. 57 . 
Propression in der Natur umzustossen scheinet; demn wer wagte bei diesen Widersprüichen mut Protestationen der Natur an eine lielte, an eine furtlaufende Linic oder lieihe der (ieschöpfe, oder selbst nur an eincn solchen natiirlichen Anstrich der liünstlichen Systeme zu denken? Wor dic unliungaren Kilifte und Sprïnge in der Natur nicht zu reimen weis, immer wird dem aus Mangel an umsichlicher lienumits anf organischem oder unorganischem Cebieihe, die Nulur als Choos, als Wunder, als Gespenst und Monstrosität erscheinen, und Villiühr wird sich mit Vergnïgen an diesen regellosen Haufen marhen, und zu cinem wahren Fontraste nit der Natur ordnen, was cben auch filein in scinem Systome, wie in dor Folge noch näher gezeigt werden wird, gethan lat. Jedoch bleibet ihm das unsterbliche Verdienst, seine neue Methode consequent duxchgeführt, durch hartnäclige tertheidigung derselben gegen das Linnéische System zur Berichiigung, Boreicherming und Begrindung des lezteren beigetragen, und so wider seinen Willen den Aufgang jenes neuen Lichies befördert zu haben.

\section{ก. 25 .}

I inné. $1707-1778$.

Die beeden Teutschen, Albert und Gessner, waren die Morgenbothen in der Naturgeschichte, 
und verlïindeten die über den Iforizont langsam sich erhebende Sonne, mit dem Ialiener Aldrorand rerbreitete sie anf alle Sciten ihre enlenchtenden Strahlen, mit den Ergländern Woton mi Pay stand sie schon in ihrer vollen Morgen huth da; aber num ist anch ine tanchender Glanz revschwmden, and ganz holl whd heiter steht sie am Minmel, and rüchet gegen Phitag horat. Limé trat 1741 in semem Vaterancie als Profensor der Zoolugie ant, und nit ihm want Tag über die gesammic Notur. Zu Stenbrolitht, einer Provinz ron Smolund in Schwction geboren, wurde Limnéen in fribler Jugend ron seinem Vater, einen Pastor, die Thebe zur Dutanile cingeflüfst. Scine erstm Jehrer auf dem Gjmmasium in Wexion, schioplten zawar nicht die beste Ioffinug ron seinen Talenten, ja sie rieluen ihm seibst von deni Pflanzenstudiun ab; doch scine Neigung zu demselben warde anf der Lmener Ahademie in Schonen, die er 1727 besuche, durch die Nihe des berihmten Stobäus noch reger. Im folgenden Jalne begrab ea sich anf das Lycüum nach Lparl, mol genofs allda dic Hulerstiizmng und Aufmunterung des Professors Cedsius. lhier war es, wo cr sein erstes Augenmerk ant die Geschlechtstheile der Pflanzen warf; sein schrifiicher Aufsalz hieräber gefich dem hëniglichen Schatzmeisier Pubbek, er belam seine liinder zum Unterrichte, mol bald 
darauf wurde or ron der dortigen lïniglichen Gesellschaft zu ciner Reise nach Lappland anserwihhlet, aus welcher seine erste litterarische Frucht: „Lapplands Flora" herrorging. Er machte hierauf noch cine Reise in die Provinzen von Schweden, und so scin Vaterland kennend, schiclict or sich $1755 \mathrm{zu}$ einer noch gröfseren, nänlich ins redic Aviland an. Tenlschland war der crste Boden, den er besuche, er eilte hieranf nach Mollaud - den dimaligen Silzo der Medizin - und nahm gicich in ersten Jahe sciner Wanderms zu Ilarder in dic Doliterswïnde. Jezt war es, wo Linné die erste Ausgube ron seinem Systeme der salur in Leyden vexansialtete, eine Ausgabe, welche, jezt noch dïm und hlein wic ein Samenkorn, in der Folge zu cincm buschigien Baume voll Früchte cmporwuchs. Boerhaie bemcrlict das keimende Talent, und Linné, emprohlen ron ihm an den Holländer Fliefort, der einen rortrefilichen botanischen Garten zwischen Rartecomp und. Leyden besilf, erhät die Oberaufsicht ïber dicsen Garten. Mier lebte er nun ganz in der Pfanzenwelt, und benutzle anch diese Gelegenheit, sovohl Lngland zu besuchen, als auch botanische Grundlinien, Gattungen der Pflanzen, und eino Beschreilung dieses Gartens herauszugclen. Freilich hälte or hier die angenehmste Lage gethabt; jedoch dic Liche zu seinem Vaterlande ust zas coin 


\section{$-90$}

ner Gelicbten, welche er dort zurïckgehasen hatte, und anch späterhin heirathete, waren cin slärlier'T Magnet, und zogen ihn auf den cinheimischen Boden zurüch, allwo er ïber Franlireich mu über die Schweiz, in Jahre 5738 ankiam. Iange war er hier gezwungen, seinen Cuterhat durch medizinische Praxis zu suchen, bis er endlich Vorlesungen an dem mincralugischon libllegium eröfnete, und ron dem Reichsolande beanftragt wurde, Ocland, Gothland, Westgollitand und Schonen in naturgeschichticher Ilinsicht zil bereisen, welche Reise er üfentlich im 1)ruclic beschrieb. Limm war er ron diesem Geschitife znriichgehommen, so trat er als Professor der Medizin in die Fufstapfen seines alten Lehrers $P_{0}$ bergs, mit der gïnstigsten Elanbnifs, in $/ . n h u n f$ mil der Professur der Botanili tanschen za diufen, was er aus Licbe fur das Pflanzenstudium auch wirklich that. Von mun an, nachdem cr eine: grofsen Theil ron Furopa durchreist hate, den Zustand der naturgeschichilichen Bildung an hitbinetten und Grelehrten im Imm- und Auslande kannte, trat er auf, die Flora und Fanna ron Schweden, die Philosophie der Botanik zu schreiben, sein System der Natur durch verschiedene Auflagen hindurch zu rerrollkommnen, und Beiträge zu cinem Werlie, anter dem Titel: „, amoenitates academicae" welches wahrhaft! Upsal als 
den damaligen Sitz nuk Flor aller naturgeschichtlichen Facher vertibude zu lieforn, wnd gründete cine Schule, aus der die ersten Forscher der Naunr hervorgingen. Nicht durch dic Macht seines Ichromes oder höberen Alters, sondern durch die Marlyt sciner fiemntusse und scines Vortrayes, entlammie er in der Jugend dic Liebe unt den Muhh zu geofsen Untomehmungen fiir die situmgeschichte. Hassclyast reiset nach Aegypen unt Palästina, Kalm nact Pessyburien und hamada, Ternatrom nach Asinn, Toren nach thahbar und Snral, Osbeti nach China und Jara, Nartin nach Spizitrupen, Solander nach Lappland, Forshal nueh Ambirn, Thunberg ans Vorgeburg der gliton Thentung, Sparman in dic Insehn des fredilchen Meeres, und wer henuct nicht die Wortir cines Pabrizus, Schrebers, Mublers, Bahmhi, die Arbeiten cines Murray u. s. w.? in inhte der

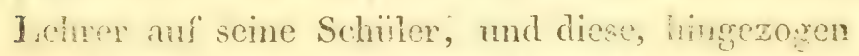
von Liche und Achung fir ihen Heder, theilten demiciben allo ihre Endechmgen mo schätzo. mit, und anf solche Ant lemte Limé nicht blos aus halbinctlen und Bescheibungen, sondern durch erine schüler als Augenzengen, das Inn- und Ausland hemen, und wude endlich das, wozu cr sich anfwarf, nümlicl Reformaior der gesammten Naturgeschichte. - Die Matcrialien zu diescri architchtonischen Tiunstwerke, waren schon scil 
dem Beginne der Naturgeschichte bis aul ihn rorhanden: zichende Völker, hühne Welumnsegler, reisende Gelehrte, alles war bestimm, gleich suchenden Bienen, zur Vermehrung jener beizutragen. Wie die Niasse, so wuchs auch nach und nach die innere Ordnung. Aristoteles hatle schon, obwohl ganz leise, den ersten Grundrifs in das Chaos der Naturgeschichte gevorfen, Wotion und nach ihm Aldrovand und Ray, strebien jenem Plane gemäls das Gebäude aufzufüren, Lezterer reinigte die Masse ron den fabelhaften und falscìen Zusätzen, und jezt fehlte nichts als cin liluger Kïnstler, welcher Masse und Plan umfafste, erstere durch lezteren giliederte, und so dis be. gomene Gebäude des Aristoteles sciner Vollendung näher brachte. Diefs war nm der Ritter Limué; er war auserwählet, die reife Frucht der Zeit zu brechen, und den Plan der Geschichte zu vollenden, welcher seit ein und zwanzig Jahrhum* derten sich successiv entwicliclte.

\section{ง. 26 .}

Wie der heidnische Dichter, welcher sich zusörderst an die Muse wendeb, so eröfnet Limé die Vorrede zu seinem VVerhe, betilelt: „Systema naturac" mit der Betrachtung Gottes als cinzigen Beherrschers der Vilemente und der Gestirne, and nun wendet sich der hünstiche Architeht an 


\section{$-9^{3}$}

- las Gebäude der Natur selbst, und erbanct es seinen Vorgängern gemärs ans drei Ltagen. Die untere bildiet das Minera! - die mittlere das Pflanzendie oberste das Thierreich. Gerade die wesentlichsten Punlite hob er heraus, um diese $\mathrm{Ab}$ schnitte zu begründen; die Vermchrung der ersteren geschicht durch $\Lambda$ ggrcgation, die zweite wächset und pflanzet sich durch cigene dazu bestimmte Organe fort, die dritte wächst, beweget sich fiei und empfindet. Auch in dem Innorn dieses Kumstgebändes zeiget sich Limné als rortreflicher Künstler. Getreu seinem Gesichtspunlite, rerthcilet er die Steine blos nach der Art der an einandergesetzien Theile in einfache (petrae), componirte (minerae) und aggregirte (fossilia); ihr ferneres Verhälnifs zu Wasser und Fener rollendet ihre weitere Vertheilung, Aber das Grbieth, auf welchem Limné sein unsterbliches Verdienst als Naturforscher begründete, ist das der Pflanzen. I Hier ist es, wo der consequente Kïnstler in seiner völligen Macht erscheint. Er machte nicht, wie Cäsalpin den Keim und die Wurzel, wie Tournefort die Blume zu seincm Betrachtungspunkte, nein, er drang tiefer in das innere Geheimnifs der Rhanzenwelt ein; er hatte bemerkt, dafs die Begattung das Streben und Ziel des Lebens der Pflanze ist, und wählte daher dic Organe dieser stillen Sponsalien, um die Verwandschaft jencr 


\section{- 94.}

unter emander dazuthm. Absondernd jenc Phanzen, wo die Nalur die Fonplanzung dem mensch-

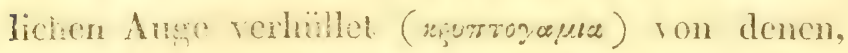
bei welchen das Hochacitiest sich vor dem Auge

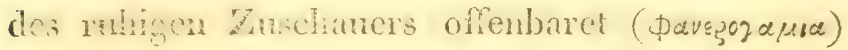

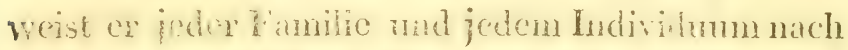

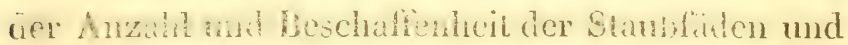
zum Theile nach jenen der Pisthlen, in drei und

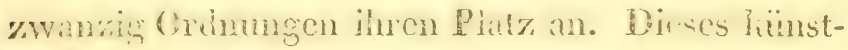
lichedewebe sidget zwar, wie alde abrigen, mit der

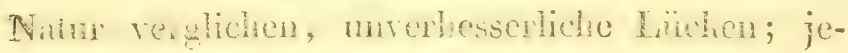
doch, crliche die Consegnenz descelben inte noch

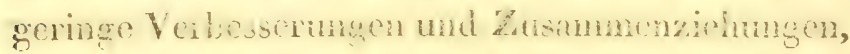

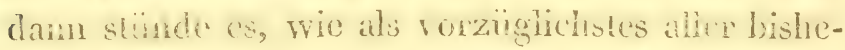

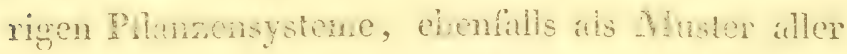
lïnshicien ï, erham, da. Anf anhalischen Ge-

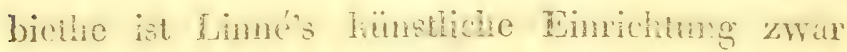
nicht so wohentet, wite an regetabitisthem, doch wind man jenes an Lrfindeng und Reichthun dicsem nicht so ungleich finden.

\section{5. $2-$.}

Arisubles hat in seiner Geschiche ron den Thicen allo ine Verschiedenheiten und Achulichlieien angeregt, aber lic ine so wesentlich herausgehoben, als jene der Anwesenheit oder des Man-

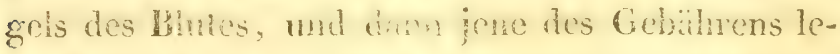
bendiger Iniggin and des Livitegens. Mie der 


\section{- 9i -}

heincude Same sich ursprünglich in das Wirzelwien und Fiderchen, eben so schliefset sich diesex Gesichtspunl t des Aristoteles in zwei Hanptabiheilimgen von Thicren auf: die Quadrupeden, Vögel, Fische stehen in dieser Anzahl und Aufemanderlolge aul' der einen Scite, die Molluslien, lirustat ceen, Testaceen und Inseliten auf der andern, nämlich der blutlosen Thiere. Freilich waren so die Fauptgruppen angegeben, allein die damals behannten Individuen ebenfalls in einer bestimmten Ordnung abzuhandeh, diefs lag, wie ïberlaupt das Systemalische, gar nicht in seinem Plane. Die Ninge von Enttecliungen und Beobachtungen ahim zu, und Albert und Gessuer strebten der Velerschwemmung durch alphabetische Ordnung zu Hülfe zu Liommen, Votton und Mldrorand verdrängten diese, und führten dafür die leisen Andeutungen des Aristoteles ans, Rajus machte aufmerksam, wie viche Lücken sich bisher in der Machinerie des zoologischen Systemes zeigten, Limné die Arbeiten aller dieser Naturforscher überschauend, sah das Fehlerhafte und die damit rerbundene Ebbe und Fluth, welche in der Ordnumg des Innern herrschte, ein, er salı ein, dafs die Gegenwart rerschiedener Zungen und verschiedener Benemungen des nämlichen Gegenstandes, in der Zoologie die nämliche Verwirrung, wie bei dem Thurmbane zu Babel herrorbringe, 
und dachte nun darauf, die immor mohr anschwellende Nassc in Ruhe und Crdnung zu bringen. Er gab einer der Benennungen seiner Vorgänger die gehörige allgeneine Dentung, und Autorität, und blich dieser durch alle seine Schriften getreu, er entwarf ein bestimntes Schema ron hlasse, Ordnung, Familie, Gatlung, Art, sezte jeder dieser Abtheilungen den unterscheidenden Charahter als den ordnenden Gecichispunkt roran, zählte endlich alle zu der Gaiung gehörgen Aren auf, fïgie den lezteren den ansgezeicheten Charakter bei, ging sodam die Synonymien der verschiedenen classischen Schriftsteller durch, und schlofs endlich die Shandhug jeder Art mit einer hurzen historischen Notize über Lebensirt, Vaterland, Anfentialtsort u. s. W. Durch die Pestsezung und Einfuhrung eines so hilar anspedachten Schema's, war num das Feld der Zoologic zur dentichen Veberschanung ausgenessen, und bis auf das cinzehnsic gुclinget, so wie durch dion Reichthum der Synonymien der Verwirume, welche gleichsan aus den rerschiedenen Sprachen entstanden war, gehörig gesteuert ist; unl num ging Linné an die Ausbessorming der Lüichen des aristoielischen Systemes selbst; er ziehet die vier Flassen, woraus die blutosen Thicre bei jenem bis jezt bestanden, in zwei, nämlich in die de: Insekten und Würmer zusummen; dis Schlangen, 
whir bei Aristoteles eigrulieh olme Platz ber-

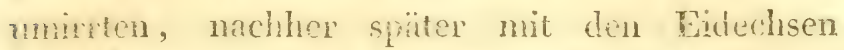
zwar rerbunden, aber immer noch als Quadrupeden zwischen den Situghieren und Tögeln standen, malum Limó aus dieser Verbinding, und wies ihnen ihen Platz zwischen den bageln and Fischen menten Namen: ,Ampibien" an; scinen borgängern chegegen gab ex, wie Wollon, den inseliten den Vorrang ror den Wirmern, und lezicre mïssen nach ihm cben so an der untern Gränze des Thiomeichs stehen, wie die boharien Guatrupeden, dic or mit drm nonen Namen: "Manmalien - Singthere" tante, den Eingang und den Zug der ritiere crörneton; wn endlich der Inge des Rajus gegen die aristolelische

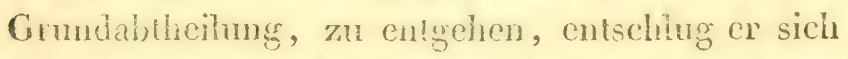
dieses limuslichen $Z_{\text {wanses, }}$ und stalle die aristotelischen Abschible solcher Gestalt rerbessert, gleichsan als mïchlige, fin sich stwhonde Säulen, an Luhl und Anfemanderfolge durch alle seme Sciniften unrez̈udent, ror scinen ganzen Thiergebainde also hin: Süngtiere (mammatia), Tïgul (ares), Amphibien (aniphibia), lische (pisces), Inseliten (insecta), Wïmer (vermes).

\section{28 。}

Jimn: war, glvich cirem Insclie, sieletei VerWandhugen unterwonten, und mit diesen criselt 
suin Systrm der Pratur gleich viele Auflagen. Alion dis zehne Albgube stelle jene anfiallende

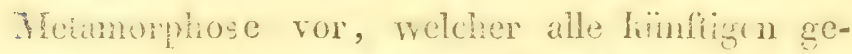
Henor und wenger wandibar reritielen, bis zu dir do cirtinten, als der lezten, die nach tem Tode Limís ron einen Wanne, mehr reich an LiteraLur als an Nuturgesibihte, veranstaltet wurde. Alivin anch in der ersten findet sich schon sein genzer flian deullich angesprochen; - der Schmetterling ist schon in seiner fribhesten Larre lemulich, med entwichelt sich nur nach met nach ans seiner Hölle. In Ganzen und in Einzelnen blib) immer sein Grichopmhi der nämliche: So sind es ron seinem friblesten Werhe inmer die Zahne bei den Singtheren, der Schublel und die Iilanen bei den Vögch, die Extremiaten bei den Amphibien, die Flossen bei den Fischen, die Flïgel bei den fnsehten, mu! die rerschiedene äussere Hatubededing bei den Wirmern, wornach $\mathrm{el}^{\circ}$ dieschen in Abtheilungen bringel. Allein die fatsche Anwewdung, die modentiche fenumis mancher Inhidhen, die nicht schenen Widersprüche

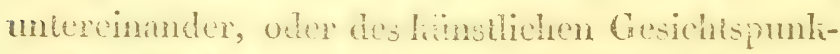
les mit der Nalur, lnathen ihn gat of in Vewirrung, nud verursachion die hänigen Ferändrumgen und Versplzmen. Nit den Arbeiten gleich-

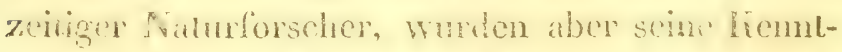
nisse hliber, und and solde Art wude en endich 


\section{$-99$}

dahin gebracht, dic Lithophyten, wolke or in fruberen Ausgaben bei den Planzen anfizhle, in Simne von Wotton nud Inssien in der sechsten unter die Thiere anfzunchmen; eben so folnte er dem Beispicle Brissons, und rersezte erst in der zwïlficn die Cetaceen ron den Fiscleen zu den Süugthieren, in der nünlichen und schon in der zehnten, tremte er die hinorpelfische ron den grätigten, und transplantirte sic als schwimmende Amphibien in diese dritte Ordnung. Jedoch im Imnern der Tilassen, in den Versetzungen der Gattungen, in der Verviteligmng der Arten zu Lezteren, lice ist eigentlich seme Verwandhung zu suchen, wïnend die Iinssen selbst an Zalı, Anfrinanderfolge und Benemming, immer mrerändert blieben, mit der einzigen Ansnahme, dafs er sich fribher des Wortes: "Onadruped" und in der Folge dafuir jenes ron fiammalien bediente. Aber bei allen diesen Metamorphosen und mit jeder neuen Mnlage, ging sein llauptbestroben duhn, die charahteristische Begräzung, der filassen sowohl als der Gattungen wat Alien, durch Vermehrung der mulerscheidenden Arenhale, fester und sichtbarei zu machen. Haite er in früheren Ausgaben nur wenige und unbedentende Eigenschaften zur Beschreibung einer likasse oder einer Art angefüht, so hat er später mit Erweiterung seiner Litteratur auch die Umsicht in der Charaliterisirung 


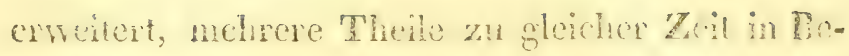

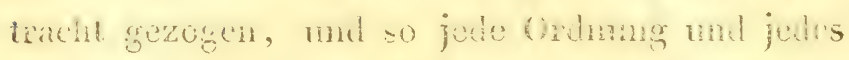

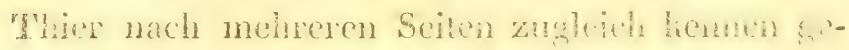

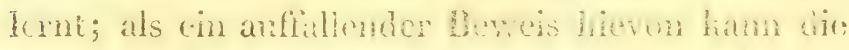

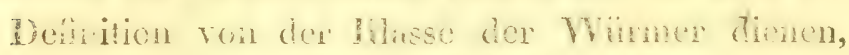

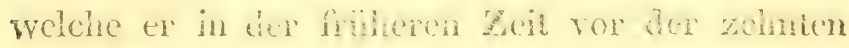
Ansgibe und dain in den folgenten gab:

,f'ermes: musculi corporis nuivo piricto solido a!l $i x i x$.

:Times: cor unilutulare inumitum, sumie frigida.

Spiracula: obscura, maxillae mullifariae

penes : varii hermaphroditis anclrogy= nis.

Sensus: tentacula, ocuti (p)erisque) cerebrum nullum, noncures nec nares.

legmenta: calcarea aut nulla nisi spincue

fulcra: nulli pedes aut pinnae.

(1. 29.

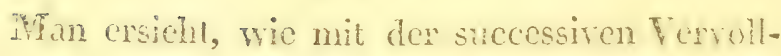
fommmung dex "Ihiergesdiche almidhig das

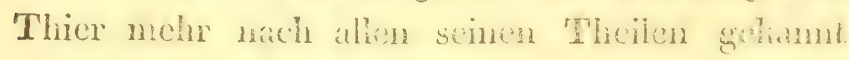

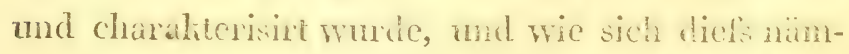

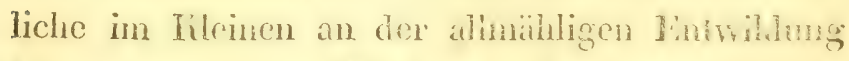

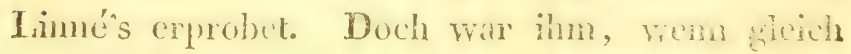

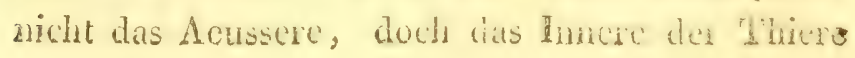


mein vie! zu mbelatmen, nu sic nach allen Scilen

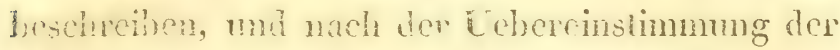
Nohneit yon Chamberen crinme zu hömen. Anch scheint nicht dich der Zavel seines Systemes

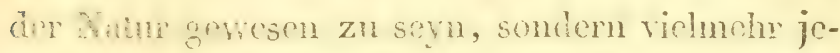
nos, suine indis idmolle Absicht mol seinm hy pothetischen Plan, whbchumert, ob cr auch jener do Natum bei Bildume dar Gathugen, Familicis,

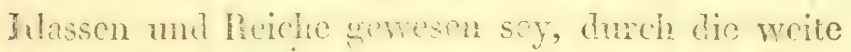

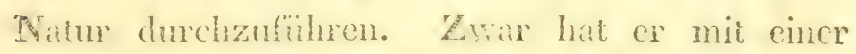
solelien hibnstichen Harter die Natux bri seinen

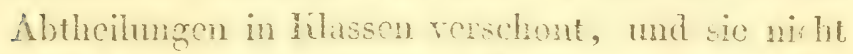

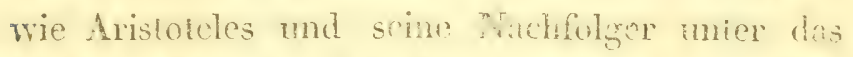

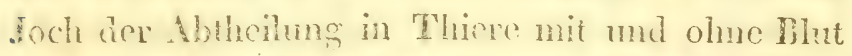
zu zringen gुesuht, sondem seme sechs lilassen

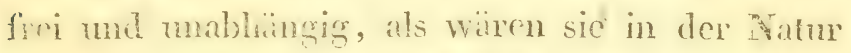

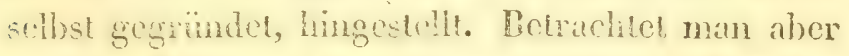
anderer Seits, mit wekinn conseitigen Chavhteren cr disoben nutersinget hat, nud wie affel-

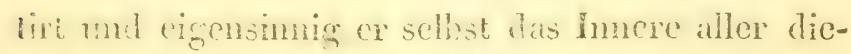
ser Flassen navil cinzolne Bentinalen und einzel-

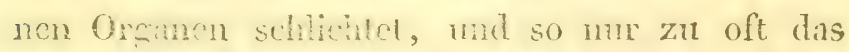
Ferwande zu tremen, das lieloiegour zu versnigen sich gezwmuren sicht, damm ergicbt sich deutich: auch er habe mit dem hünslichen Auge des fristoteles die Thiere durchmustert, mallo Futdechungen und Beobacixumgen nu als weitere Zugabe gebrancliet, un scine vorgefariste Ansiclat 
damit zu lefestigen und anszuschmiiclicn. Dafs Jimé die Ordmungen der Thiere nicht so nach cinem rinzigen Gesichlspmite, wie er es hei Mineralion und Planzen gethan hat, retheder, son-

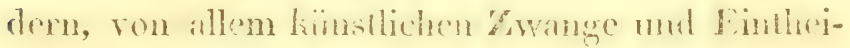

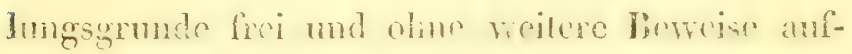
stellet, dicse Abweichnirg, sowohl in stinem fanzen Systrme iberianut, ats selbst in den einzelnen Fannilien, mufs dither entweder cincm ghihlichen Tinfate, oder, was wahrscheinlicher ist, der

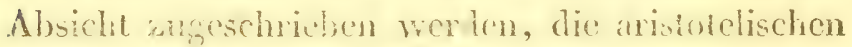

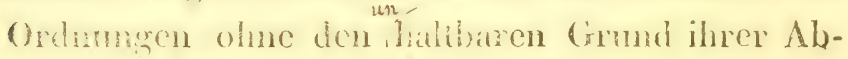
theilung hinzuseizen, um wengetens sich nicht

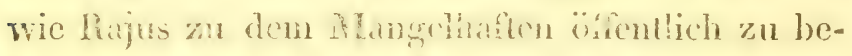

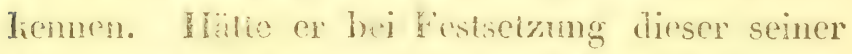
Ordn muen je bedalht: dars die Nalm das ginze Thier nicht als Dohunent einer einzigen beschaffenheit z. L̀. des Bluies, der Zailune, der Anwesenheit der Flossen, sondern mogelieht alle cinzelnen Theile für und weren dem ganzen 'ilherdats es dieser Ilensch, Ifund n. s. w. sey, erschalie, hatte ci dirses beribluchtiged, sicher wire es damn nicht in seiner Trmmologie vernachlässigl; allein so hat ex die Benenumgen yon einer cinzehen, gleichwohl wrellen Vigenschaft hergenommen, und Ordnmeren und Familien mit den Limslwörtern: Mammairn, Amphihien, Inechlen, Raubrïgel, Grallen, Lartlingler, Netzlligler u. s. 
w., iberschricben, obgleich $\mathrm{cr}$ auch hier sich nicht consequent blich, sondern cbenfalls Benenmungen ron den lierschendsen Individuen, wie z. B. Yägel, Mïhner, Ginse u. s. w. gewählt hat. Freilich scheint er das Struben, die Thiere nach der Stule der Vollionmenheit, nämlich den Menschen zuerst, den Finn zulezt in Thicmeiche zu ordnen, bei seincn Iilasecn im Ganzen sowoll,

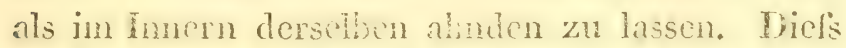
ist es richledicht, warim er lie erste lamili: der Sänghiore Primates namle, warum er dio linorpeifische in den Rang der Amphibien, die Cetacren zu Sängtheren emporiob. Jedoch zn dicsem Zweclic liate er zuror die Viunde niul Raszordume der cinzehen Organe cines arinatischen Individume wissen, mut erst nadber in eirn diesem Sinne alle There zneammenilum nössen; aber so werden, Treqz, Lumge, Iintalle, Ge-

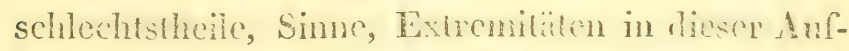
cinanderfolge und dalier so bunt durchenamber aufgezialt mad beschrivben, difs man wohl cil:sicht, Limé war nidits wenime ats knatom, noch weniger aber Plysiolog. Iir hat ber Errichtung des Systemes der Nalur alles dieses, und so die Natur selbst nicht im Auge gehabt. Fir fand bei einer Menge sonst ahmlicher Thiere Mtammen und diese $\Lambda$ rt von Ziilmen, bei andern Fliggel und diese Art ron Sclmabel mul filucn, bei andern Flos- 
sen und diese Anzahl and Sthing derwibnu, nud so waten dem alle Thiser, bey denen disers

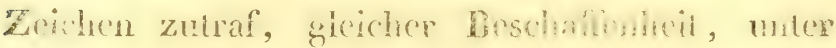

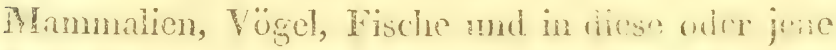

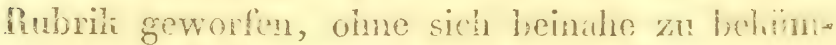
men, wio sich die Individnen der cinzehen Mau-

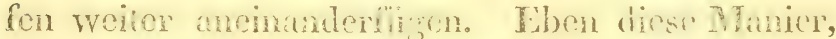

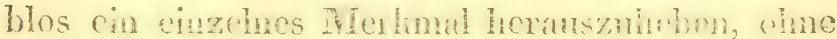

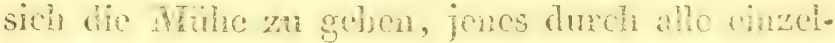

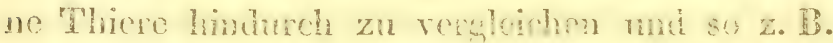

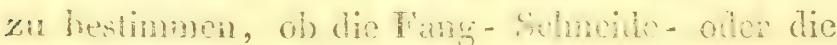

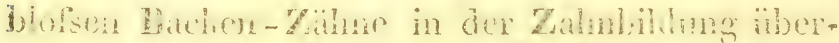
hanpt den Vorrang and mie Hunen diese Thives

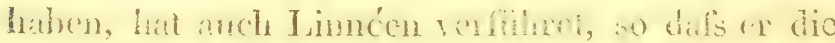

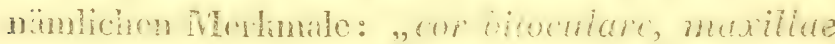
incumbentes, sensus lingher, nares, lactus 1?. S.

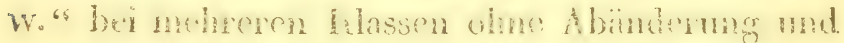

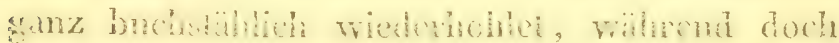

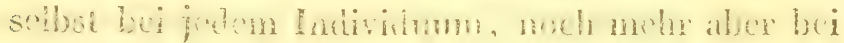

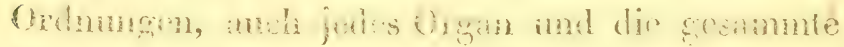

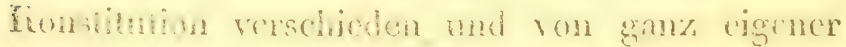

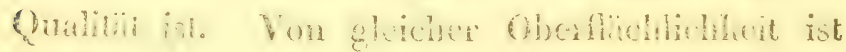

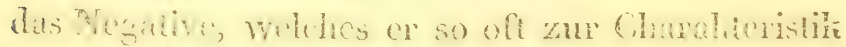

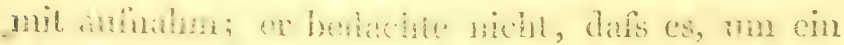

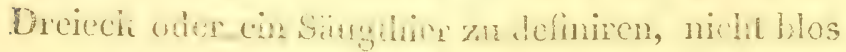

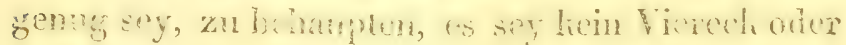

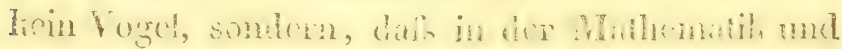

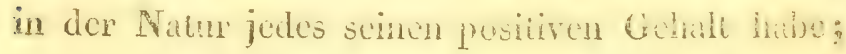


daher ist mit jenen Charahteren: "pedes nutli, pimae mulac, penis mullus, plerisyuc - exeppto - varia variis" das Positive von Shakten odex Creschlechtsileilen noch gai nicht bechmot.

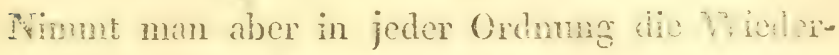

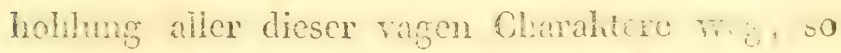

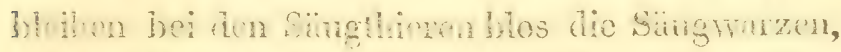
bue den Vogehn die Fenem and Flügel, bei den Amphibu der nbwedselnde Auenhal zwischen Matsen und Land, bei Jisticn die Fiosen, bei

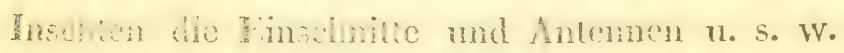

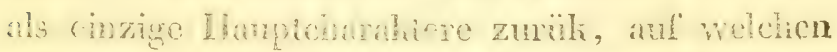

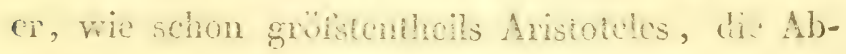
theilug der Ordmmen gündels, Chablitere, dic, wie jede enzehne kighenschath, nimis die

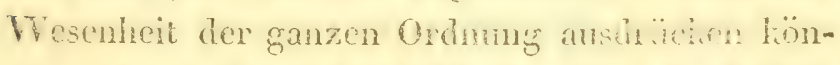

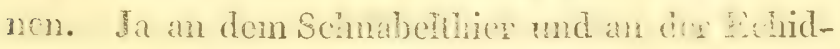
nu, welke mit Reche bei den Sän then auf-

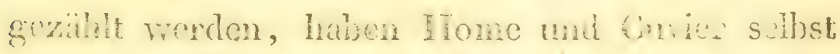
an den im viengeiste anbewahten Wxenthen frine spun von Süuwarzen entechen fönen;

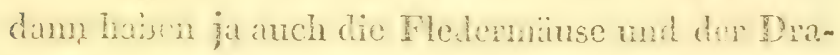
lo Nliggr; - die Schnippen an den Whi, he der

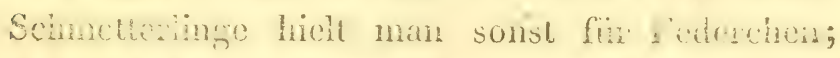

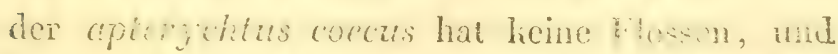

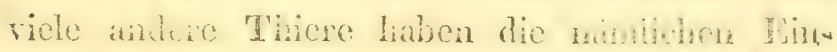

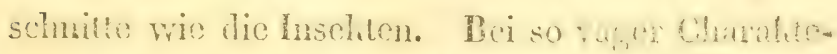
ristih ist es daher lucin Whader, wen min sivh 
beklagh, dafs man bei cinem rorkommenden Thiere öfters selbst nicht seme Ordnung, noch viel weniger seine Familie and Gatlung tach diem Systeme der Natur des Linnés besimmin han, ein Vorwur, der, als das Gegentheil wn stucm botanischen Systeme, hier nin so slätiter muldill. Mehr noch als diese ragen Buclureibungen, springen dem Leser die Enringlieiten, wethe hr Verfasser ans schuldloser Unwisenheit scher Zeit in jene mit anfiahm, und welche der Herauseder der dreizchuten Anflage anch getren mit roritils$\mathrm{xet}$, in dic Augen: nicht anf alle Amphibien passet der Charakter: „cor miloculare, uniumbilum" Acmn Schildiröten und Lidechsen haben das Ihorzohr dopplt, Frösche, Salamander und Sirenen aber cinfach. Den Inscliten liommt nicht zu: „'or zmiloculare, mitauritum" da nur die Crustacen cin Herz mit einem Ohre haben, den übrigen aber, wem man auch das pulisirende Rüchengefirs als eine Vene oder Arterie anerlicnnel, beides fehlet. Boi den Wümern hat Linnéen mit dem Charakter: "cor aniloculare incuritum" die Phantasic verfihiret, denn wer lat je noch an cinem Mecrsicrne, Secigel, an den Intestinalwürmern und andern eine Spur von cinem Herzen oler seilbst fireislauf entdeclict? Selbst bei dem Erdwurm, der Serpule, wo man jenes gar wohl vermulhen liam, ist es noch nicht dargehiam, und 
bei Schneclien it das Merz gar wohl heohret. Die Eigenschaft: „puhienes respirantes reciproce" giit nicht blos von Sanghthier"n und vögehn, sondim anch ron Amphibien, bei dencn er abes jene fitschlich weylifst, und die sonst richtige beobachtung: "arbitrarie" hinzusezt; doch was gïlle num wohl ron Sirenen, welche ne? den Inugen anch noch wie Fische, Bran hiv linbon? Die Norhmale bei den Fischen: ,Lrawhie exlas coinflimentae" unlerscheidet leztere nicht rom den firebsen und Schnechen, denen giches eigen, aber ron ihm nicht azgenerhe ist, dalide ist aber dic Bezoichnumg bei Inseliten: „spiracula: port lutrules" nichl anf hirustacen anwendbar, weld he nit Branchion athen. Bei Virmern ist der Ausdrack: „spiracula obscura" ganz falsch, dem die schntchen allimen mit Brathien, eben so die Nereiden, Aphroditen, bei welchen sie bald mehr odrr weniger hizufig nach anson oder inun gerichet sind; bei den Ringeweidwürmern sieht nian lingst den beiden Sciten des fiörpers dentiche Poren, bei Mecrigeln, Astuien, Alimien, sind es dir schlanchardigen lande, welche sie imner in Thasser heransstrechen, mit lezterem füllen, und sich dimit anch anhängen. - „MLaxilZate incuinbentes tectae dentious plerisque intrusis" ist nicht allen Sängthieren eigen; so haben der Omihorhynchus und dic Lichidna, liprentoso 


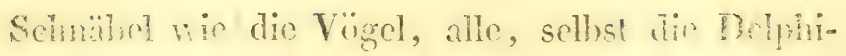

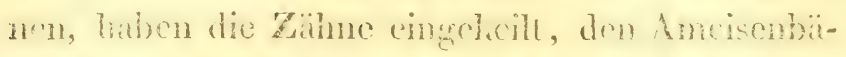

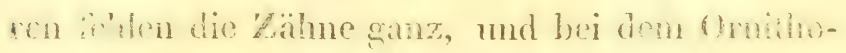

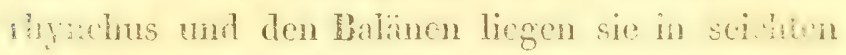

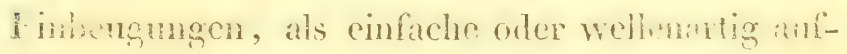

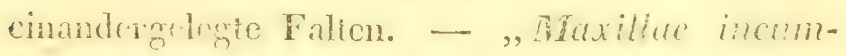
bentes" bei Anphibien, lommt niche meler recht

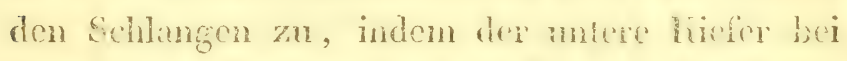

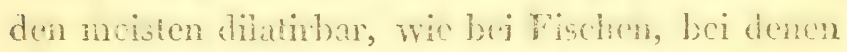
es auch sogut der obere ist. - Der Ausdruch fire

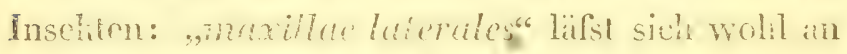

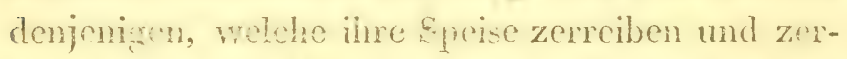
nagen (brogents), nicht aber an soldien, welche

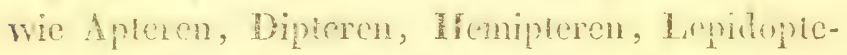
ren diesullye aufsugen (supeurs), nachweisen. -

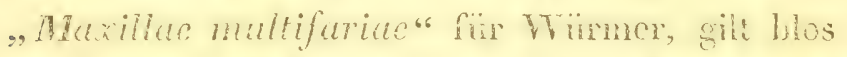
ron emigen Schnedienaren, den Supien und

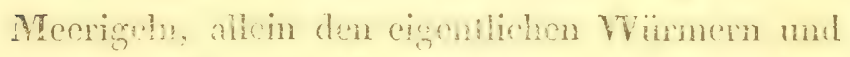

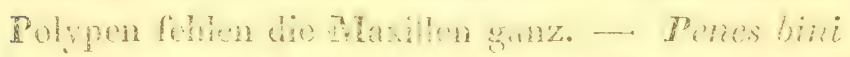

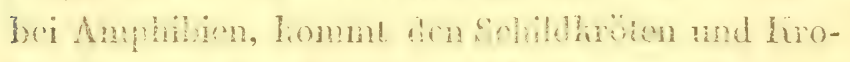

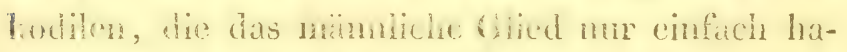

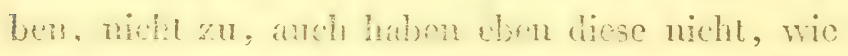

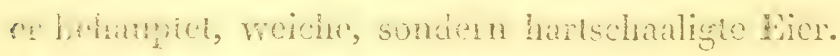

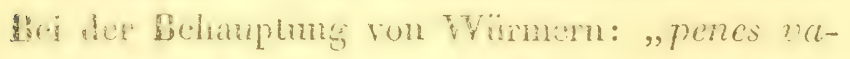

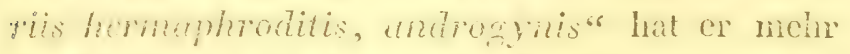

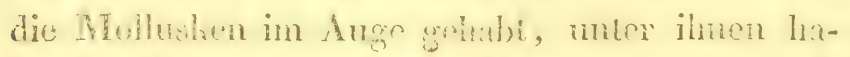

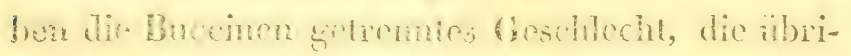

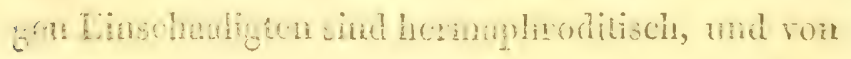


flen zwei- mnd mehrohatigten soll jodes Individum sich selhst begatten; bei den cignmlichen

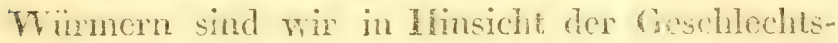

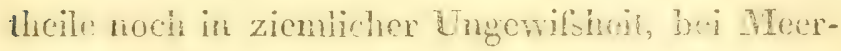
slemon, Mhinen und 'Hoophytu, habe ich zivar

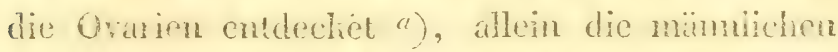
Geschlechstheile sind anch in 2 weifel, obnleich

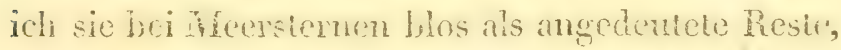

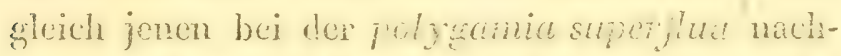

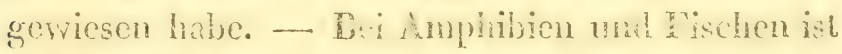

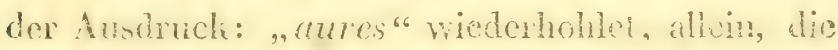
Schildiroien, Fidechson, die Blindscheiche mad. den Uphisan ansyonommen, sind diest beishlangen und Fischen nicht änssenlich, sondern blos innerlich sichbar. - Y macht, wo er ron der Nase der Fische sprichl, cin Fragezeichen, was er cher bei dem Geschmaclie hïle n!acheis sollen, dem alle haben äusserlich sichtbare Nasembohlen, und bei Pewomyzonen glambe ich sic in den Sprizlöchern enidechet zu haben; auch haben ja nicht alle Fische die Augen so unbedingt, der apterychtus coecus und der gastrobrunchus liömnen als Beispicl dienen; jedoch fand ich sic bei den leztern

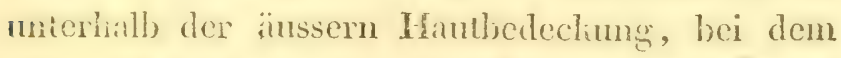
erstern hat sic einer meiner Beliammlen bestimmi geschen, und abgezeichnet. - Bei den Insel.

a) annales du musće- T. 15. mémoire sur l'asterie rongé,

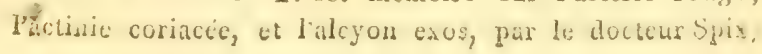


ten heist es: ,lingua, oculi, anteman in capile absyue cerebro, non aures, non numes allein bei den firebsen hat Scarpa die Gehörabule cntdechet, umel mit vieler Miahschrinlichlit remmthe man sic anch bei don bibrigen laselibn; der

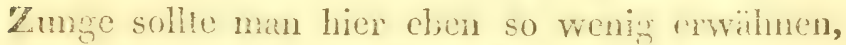
als num es in linsichl der fase, wohn vidoicht die Palpen bestinnut sind, linat. Vas dits iverensysim ter Inselitu angine, so besitzen sie wohl solches, mal man liënntesulbit das oberste Ganglion desselben eben so gnt Gelimn nemen, als Linné sich lier des Frures: , lioplobedient. Bei den Wimmprn hat Guelin hesser gethan, der friberen thavateristik: ,fentacula, oculi, cerebrumn unlum, non aures nec rates"s linzuzusctzen: ,plerisyne outi" demn die cigentidion Vümer, belypen, Notuben und die meistrn

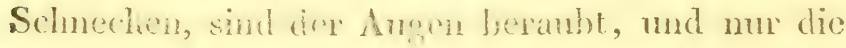

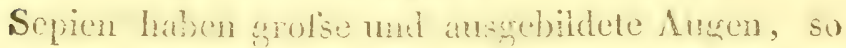

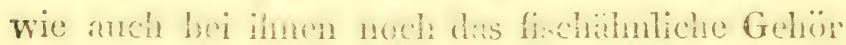
anzutreften in; Foner laben die somechen, An-

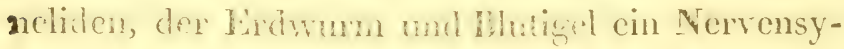

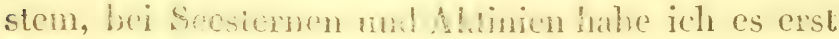

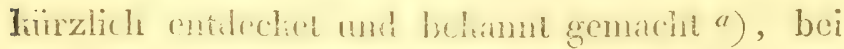

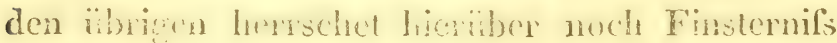

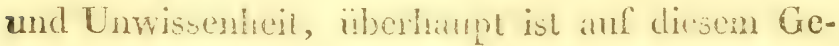

a) s, inémoire sur l'asterie 1. c. 
bicthe der Ausdruck: „Gehirn“ eben so wenig pasecend, als bei Insekten. "Tegumenta: pili“ bei Satughieren konmt den ganz naliten Delphinen gar nicht zti. - Bei Amphibien heist es: „tegumenia: cutanea nuda"; allein bei Schildhröten, Eideclisen und Schlangen ist diefs nicht der Fall, und selbst bei den sonst nakten Fröschen machen einige eine Ausnalme. - "Squamae imbricatae" ist nicht Charahter aller Fische, die Petromyzonen, Mrurenophis mal Murünen haben cinen nakten, schlüpfrigen lï̈rer, die meisten linorpelfische haben die Obenfliche des Tïrpers rauh, höhericht oder stachlicht mud nur die Gräienfische haben meistens jene dachfümigen Schuppen. Alle Inschiten sind zwar cataphracta, aber nicht alle cute ossea sustentante, wic es z. B. auf Schmetterlinge nicht anwendbar ist. - Bei den Würmern gilt es zwar: calcarea aut mulla nisi spinat, nur sollte noch nisi pili hinzugesezt werden, den die Aphrodien, Arcuiliolen, zeichnen sich eben hierdurch aus. - ,Fulcra: pedes quatuor, exceptis mere ayzulicis, quibus pedes posteriores plane afficiunt, cauda plerisque" fiur Süughiere, ist ziemlich unbestimmt, bei der Pholia sind die Hinterfülse zurïcligelchnt, der trichecus manatus hat gar heine hinteren Füfse, die Cetaceen haben statt der Fülsc, Brust- BauchSchwanz- und Rüichen - Flossen, ja selbst die Pha- 


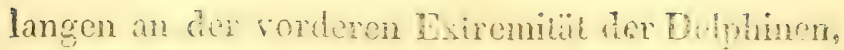

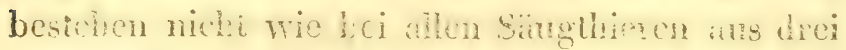

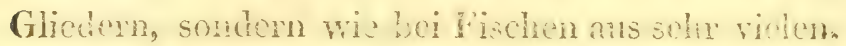
Eine Gloche Chodmung hersch, wie es in zweilun Theile gezeigt werden wird, anch im ho nem der Ondmanen - cin Foh'r, weher blos

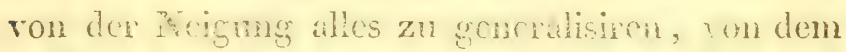

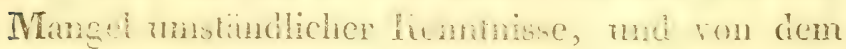

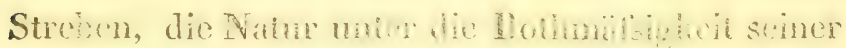

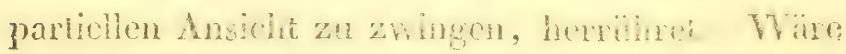

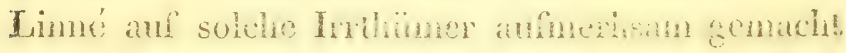
worden, oder häte er sebis die reichtaligen Ent-

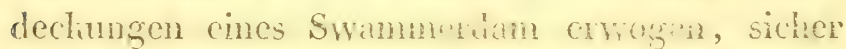
würde er nicht so heterogute Geschible in che and die namliche Rubrih, wic die des It bmore bei inm ist, gebncht haben. Jener halle schon das Iterz in der Sepii, der Cartenselnecle, das

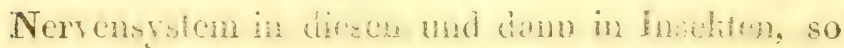

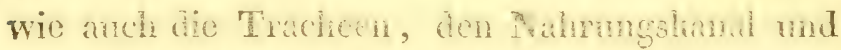
die Gesdlechisheile entinchet, und in suines Bi-

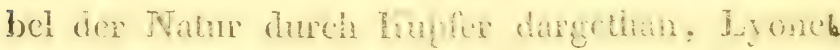
hat das Mushelsyctem der fanpe enthilled, Willis

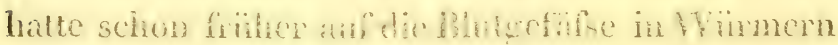
aufmerlsam gemacht, Margili in monn Raten

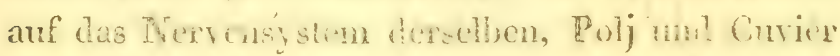

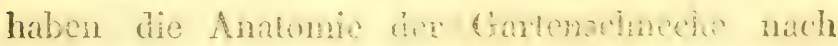
Swammertam veitu vefolet, nud din innere

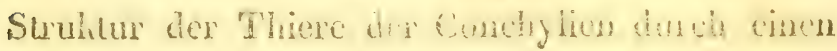


selr grofen Theil dieses Gebiethes ausser Zweifel gesezt, und num schen wir cin, dafs die Tracheen der Schnectien, Nereiden, Molothurien so wie anch der Lirustaccen, hiemenartig, wie bei Fischen, seyen, dafs diese erst als solche bei Inschten, nämlich als sclbstündige Scitenlöicher und Íanäle erscheinen, bei Aclinicn uber in dem Organ des Tastens, und bei Medusen vermuthlich in den Wasserhanäten, welchc zugleich das Geschüft der Lymph - und Nahnumgagefafse haben, sich rereinigt haben, dais das ferrensystem sich noch tiefer, nänlich bis an A sterien nnd Ahinien erstredic. Wir sehen cin, ders Limé Geschöpfe zusammengebracht hat, welche remönge dieser nun belannten Strulilur gar nicht zusammengèüren. Aber eben diese Winhechmen machten es den Nichfolgem müglich, licr durch Scheidung dieser Ordnmg sich das nutste Verdienst un die Verbesserung seines Systemes zu erwerben. - Aus allem erheliet, dals cas Liméische System nicht von Fchlern frei, noch weniger ron der Art ist, dafs man die Gruppirung der Thiere in demselben natürlich nennen liönnte; die rorzüglichste Quelle aber aller dieser Irrthümer lag darin, dafs Linné als Zoolog nicht ein chen so vollständiger Zootom war, und somit nicht das ganze Thier, sondem immer blos einzelne Theile von demselben kannte. Niätte er das Innere wie das Aeussere, die Seele 


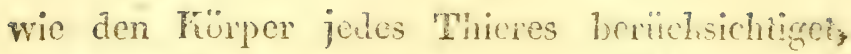

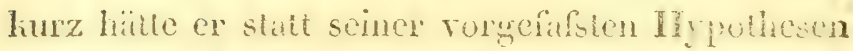
immer num die Xain zum thuster genommen; so hätle es nicht follen hönnen, Tafs cin so muensendes Genic stati cines hanstichen Anifalis nicht die Ordinary und das System der Falur selbsi dax. gestellt lailte. Zwan hiat on ment als alle scine Vongäger ron dem hibinstichen ans dem aristotelischon Celunde mud selbst die Linstiche Gruntlage desse?ben buscitignt, so, dafs duren ilin dis

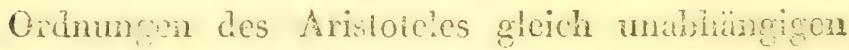

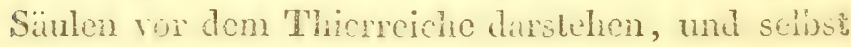
ron dicom den Cruncifs cntwonfen ist; jedoch

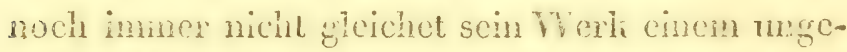
trubten liristalle, oder dem gediegenen, ion Sclnlaclien gercinigten Golie. Ein zweiloi Inmé muls arifstehen, das noch alrige Manierirle - den frenden Zusalz — abslreifen, ma in der Werlslitte der Natne in Limblicher Fimfalt lernend und in ihren Geis!c denlicud, wird or den greleimen Glicderban dicser Iïustlerin, welche untrombar und cines mit ilrem Rimstrverie lebet, ron Sternen an duxch Flemente, Mincralien, Planzen und Thiere hindurch bis zu dem Menschen, in wissenschaflicher Rede wiedergeben, und so cin System crbauen, wozn Aristoleles schon die Grundlinien entworfen, scine Nachfolger die Ausfintmg desselben begonnen, und zu desen rülizen Vullen. 
dmog Limé durch Winfihinng eines Schema, ciner Terminologie, Synoninie, cinem liüntigen Zeitalter den Weg gebahnet, und selbst schon den Titel: "Systema naturat" hergelichen hat.

$$
\text { (1). } 50 .
$$

Lime nufste, wie alles in der Natur, liämpent gegen feindsulige Filemente aus eigener Firaft emportachen. Ber grofse Mineralog Walleriv's crlibite sich geggen ilm, Siegeslek bestritt das System dex Pflanzen, Binfon und Itein das der Thiere. Allein alle hämple dienten nur dazu, den Trumph der Wubheit noch ofentlicher zu machen. Mit seinem Tode lebte erst sein Geist wie von neuem auf, und reibreitele sich ron den likenen Upall ans über alle Provinzen und Nationen Europens. Teutschland, England und Frankreich taten $n$ medteifend auf, den angeregten Geist fir Naturgeschichte auf eigenem Boden weiter atuszubilden. Fast zu gheicher Zeit mit ihm belustigten sich bei den Teutschen ITerianin, Rïscl, Frisch und Schäfer mit Inscliten, beide lezlere anch mit Vögeln, und bereicherten die Littcratur nit vortreflichen Lupfern und Bobbachtumgen; lićammur, Lyonet, Trembley und Gcofroi rerewigen sich ebcn liscrin auf franzüsischem Boden, während Ellis, Lister, Ldward, Catesby und Shav unler den Engliudern dio Naturgeschichte 


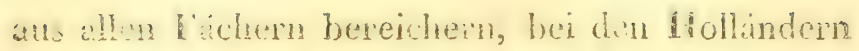
ses cin waires hepertorim der rowlogio licfert, und bei den Kicderiandern stuli, Seep und Framer un die Bearbeinng der Insthen nut Vögel dieses fandes unter sich wetteiern. Ton $11 m$ an beginn nun shon, sich dem Lincischen Systeme anzuschlicsen. Aluthi und Chemmiz werfen sich zu hasuischen lowbeitem der Conchylien

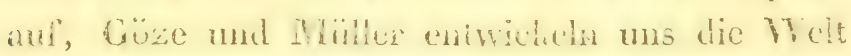

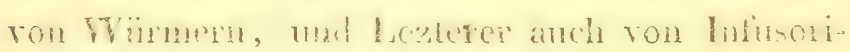

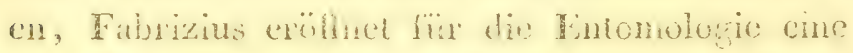

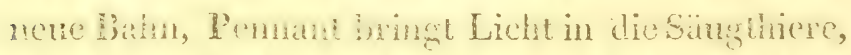

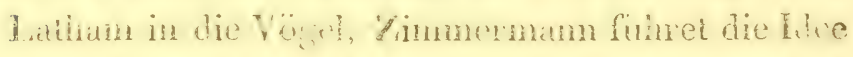
cince himatischen Loographie an Ë̈usineren ants, Erxleben und Plmenhach streben dis fysiton Linnces zu resoessem, Poli enthulled aie siruhtror der Bivaluen, Carollini jene rer belypen. Mit

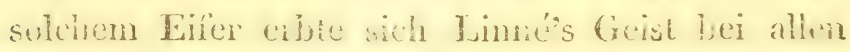

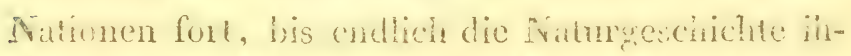

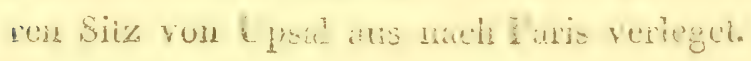

\section{31 .}

Buffor. $8707-1783$.

Geonges Lonis Lecterc ron Buffon zu Montsar Goburan, begann sebine ersten Studicin in Bijoan, begleitete hieranf seinen Fremed hoxd hingston anf ciner liedse nach bingland mat flalien, und whude 1759 and der Stolle deo Durai, Uber- 


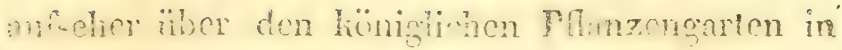

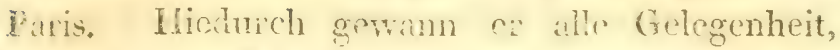
sich ganz Are Naturgesshichte zu wollen, und erregte nach Verlaul roil zelm Jaliren duxch den exten Band sciner Wulmgestlictar, in welchem er

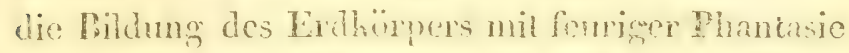
mel mit libunen fypotisesen ofnich einem Elitze

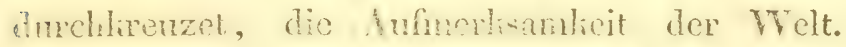
Dald herat legte ei in zirien whd hitten scine atomistische Ansicht s: ichle des Menschon dar, srint in der Folge in

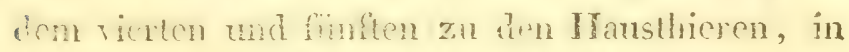

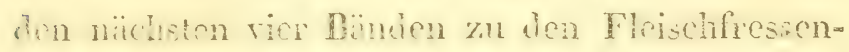
dim fort, shlicte ren hier his zu drm vierzehnfon mit nabrischen Pins?, aber in bunten Goni-

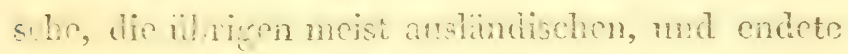

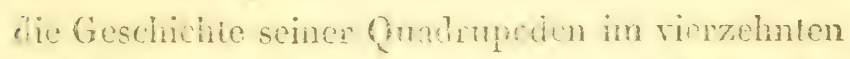

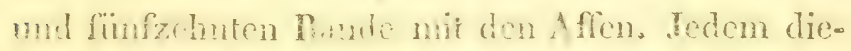

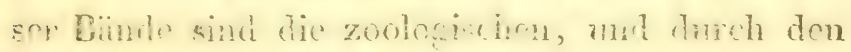

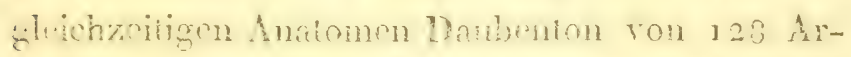

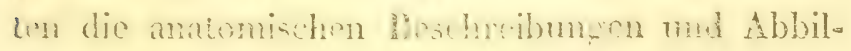

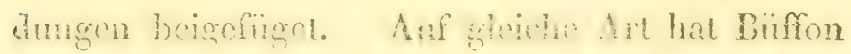

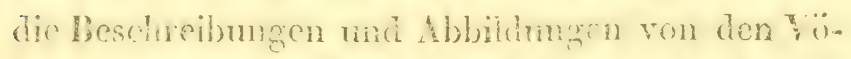
genth, wolder en in Papagey, Nacht- Tag- mod

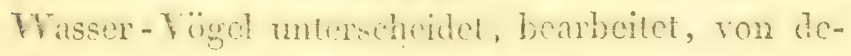

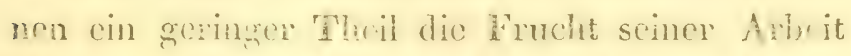

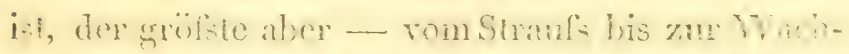

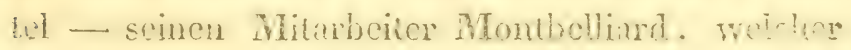


den piltoresticn Pinsel seines Mcistors bis zur 'Tüuschung zu führen wufse, zmon Uheber liat. Im Sime der Geschichte dre Vede, der Ouadrupeden und der V̈̈gel, gedache burron anti: die noch Zibrigen Fäher zu brabeicu, allein ter Tod unterbrach sein Vorkiben, und Lacmede als $\mathrm{L}_{\mathrm{i}} \mathrm{be}$ scince rorhandenen waien ïber Anphibien und Fische ron ihm eruannt, lieferte als Fortsctzung diese berilun Iilassen mil gheicher Beredsmlicit, nur nit dem Unterschieds, dafs or anch das Systematiche mit in seine Boabeitung arínahm. Von hicr ans war die rednerische Laulbalu, welcle Duron mit Verdränguns aller Mehode in die Natmgeschidete einzufuhen sich bemine, anch beinabe schon rollewici. Fow crmangeten seine

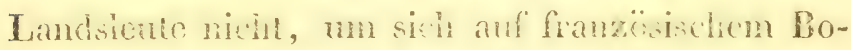

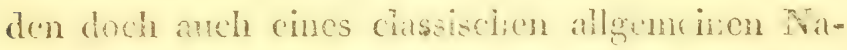
twhisonthers ribmen mu hiomen, die noch ührigen filassen und lieiche anszuabeicon, mel unter dem Pamen des Bifitis, und als Fortsetzung seiner Naturgeschichte in rerschichenen Ansgaben und Formaten, bei Deterville nud Diffarn gröstentheils unter der liedalition des Sonini erscheinen zu lason. Micr venachidsigten zwar diese Patroten - Lacepede, Lativille, Daudin, Soñini, Cose, Tigny, troissy nichi, ihe Arbeiten ganz im rednerischen and geschichlichen Geiste abzufassen, doch wichen sic daduch ron ihrem Aulos 
ab, dafs sic als Frenule rom Systrm sich auch an dasselbe, und was now mohr isi, an jenes Ferluatsle les I imné anschlofen, cine Iferausnahme, weren weicher die Mlanender eigntichen Echriften Diblons rat jonen seiner Fortsetzer immenth in

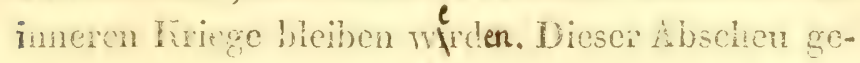
gnn alle Theorie in der $Z$ Zoologic, wmate in Biflon nich blos durch den Pulan des Limmischen Systcmes, sondern sellsot durh scine wamen Gefible fin die Natur rege semacht; anfrevelit durch diese, und viclleich nichl che alle Eirwilung des gleichzeitiogen bonnet, fibhls or in der Natur von den Welthöpern bis zu dem Heinsten Stübchen, nicht cine cinseitige und willäblirliche Anerdnung, scndern cine allgnmeine Ilarmenie und Verwandschaft aller Dinge durch bjofe Rïanzen geschicden; allein rmmäthlig, dieses Concert dor Natur auch in cine besonmene Pede anfzulifsen, blich ihm bios das heife Gefuhl in der Scele zurücli. Stait zu reihen und zu ordnen, überliels or sich also seinem entfammicn Cemïthe, und sircble, wenigsiens durch gefilhtrolle Beschrcibung das zu ersetzen, was er curch Vissenschaft zu geben nichi im Stande war. Lezeistert ïber die Iteimath des hanecls, über die sonderbare monstrüse Form und riber das brsommen scheinende Betragon des Elephanten, Hiber dic Gestalt and Fabe eincs Fanichi, und foo bei Be- 
trachtung des Auslindischen oder Iimlindischen, des Zuhmen oder Wilden an thicren, rmachlïs-

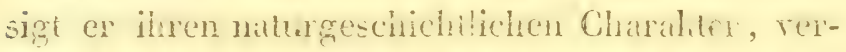
gifot die Nethole and das Syston, und ist schon zafuieden, sciuc cinzehen Abhandhugen inti den Notizen der licisebeschrebier anszaschälidien,

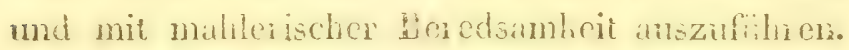
So wurde Bufion mehr cin pittoresher Lonsedner der vains, als cin conseguenter Systemuliher derselben, und lionite ex anch aud liesen weiten Gebiethe sich nicht funz aller binthitung cutinatten, so nachie er von dicicr doch in Gebranch, um scine mâterischen lichen übre die cinzehnen Thiere nichi in so ganz losen Zusammenhange, oder bnat cincheinander erscheinen, oder sie gar

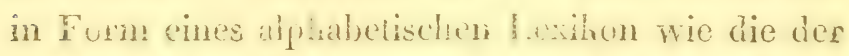

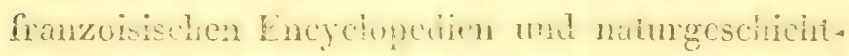
lichen Dihlionäre sind, orhien zi mü̈sen. Findet anf solche Art der linere Titurfursche" in den

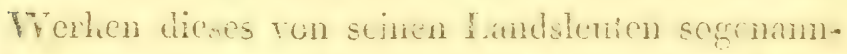

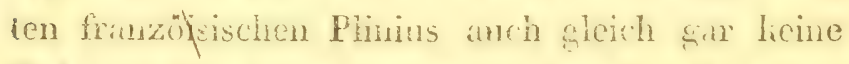
frahmug fir scincu systemilizchen Geist, so ist doch nicht zu liugnen, dafs man in dem Fluge seiver phantusiereicien Beredsamheit, die rortrefflichsten firesin und Hypothesen angedentet findet, so wie auch der sich Zerstreumg suchende Leser hier in der schönlen Zntsammenstellumg der seltensten Beobachtungen, Lilieidering und Vergnïgen, 


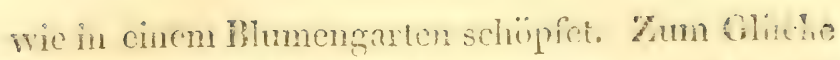
fir die wissensciantliche Beubeitung der Namysschichie, dauerto diese hodnerperiode auf franzofsisciem Boden nar larto Zeit, und furchitlofs blich bei Franzosen mid andron Nationcu dpr Ansspluch in der Einleitumg zu seinem erstein Bande: "en effet se proposer ald faire mat melhole purfatie, cest se proposer un trieunt immosn sible".

\section{ก. 52 .}

Brisson.

Fast zu gicicher Zeit, wo die Nalureschichte durch Büron Gefah licf, zur Modelehtüre herabgrewïrdigt zu werden, trügt Brisson, Conserrato

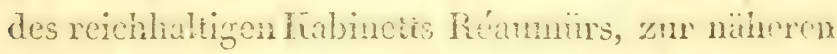
Begründung und Verbreitung des Linnéischen Sysicmes bei. Ferne ron dem rednerisclen Pruihe, strebte er, die Ordnungen limés noch sirenger and conerquenter als dieser selbst zir durchmeslern, prïciser zu rubrimen, whd elien so genan zu beschreiben. Freilich mag er den Plan gelrabt haben, mil solcher Crïndlichlocit das gunze Thier reich wu bearbeiton, allen or hinterlicfs nichts als cin Vork äbor Sänghisere. in welchem die . Ve-

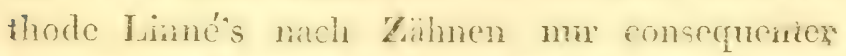

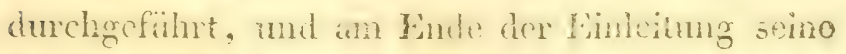
Einheilung dur Thicre in Flasscnàngehangt ist, und cin anderes übor Vöge!, deres Anerabat; 
auf die Terschiedenlicit ron Schmabel und Zolsen çrbant ist. Ninmt man nachfolgende Verinderungen aus, so ist Brissons Arbeil blos als Vubesscrung des Linnéischen siemes anznschen. Arisioteles hat schon geänssert, dafs die Celiceen nicht recht miter Fische parsten, Woiton und Raijus haben sie als gesonderte Rubrili bei denselben aufyezihlet, Lezterer sagl sogar ans, dat's er sie mer dic behar!en Quadmpeden rechnen frïrde, wenn or nicht allen Schein ron Neuerung vermeiden wollte, Brisson waget endlich den Schrilt, nud sezt sie als cine cigrne liblse zwischen Sängthieren und Vögehn, Linné bennzte endlich diesen Winh, wnt rereingte sie mit den Mammalien selbst. Achniches that bivson mit den linorpelfischen mit mit den lirusiacen; ersteren weist er als gesmolerer Wasse ihen Maiz zwischen Reptilien und ciondlichm Tischen an, lezteren, welcho sclbst schon bei Aristoteles ron Inschten getrent dastehcn, zwishen dic:en mod den Fischen, dic Inschicn selbst und die Virmer bleiben urenündert we bei Inimé an ihrem Platze. Walle lieser nur sechs Ondungen, so sind sie bei brisson in noun anfgelofst, tragen aber glciche Benemmus, susser, dafs er statt Mammalien den Fanen GuaAruped, statt Amphibien den ron Reptilien gebrauchte. Zur Legrintimg seine' Ortimugen sind nicht rage Claraldere gewälet, sontern mit 
Weghasung alles Uelontissigen, auch nur die

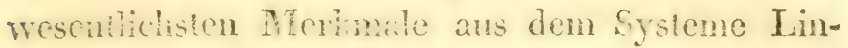
ne"s bentizei: die thare mal die rier Fitse bei den Cnatrupeden, die beficderten Tlügel mad die

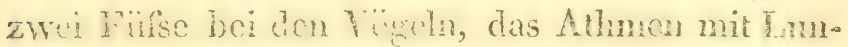
gen, der beschumple der nahe, befufste otor

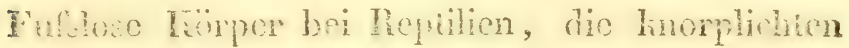

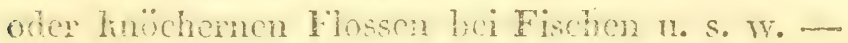

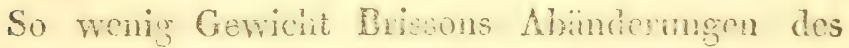

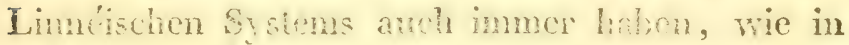
don zweiten whe saber enthen wh, so wird

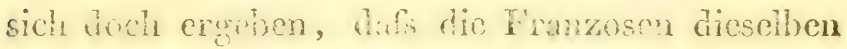
annatimen, circh rer lnivende Anatonie bestärk-

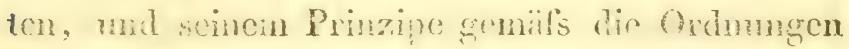

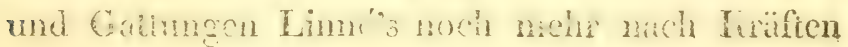
zu verrielfaltigen strebten.

\section{ศ. 35.}

Von nun an brginu cine ganz nome Richtung in der Geschichte der Zoolorie. Selun beim $A$ a begime dersellen wande der blick ron lem Aeusa scrir ar das Innere ter Where gewendet; doch

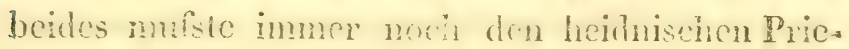
slem blos zum Gegenchure der Rewmademing und geheimnilswolen Deamigy dienen; ned num beginnt durch Aesholips fewpinte, athüblig das, was in Anfage zur Religion und zu blofen be-

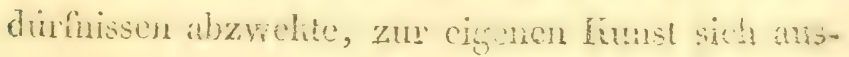


zubithen; ju im Demokritus ron $A b d e: a$, dem Jehrer des Ilippoliratos, erwachet sellot der wissenschuftiche lifer, und nicht zufrielen, das Thier blos nach Ansen zu lionnen, miersuchet of auçh das funcre desselhen, und bleibt, wenn gleich durch leine Schriften, doch durch sein eif-

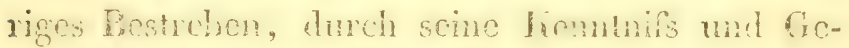

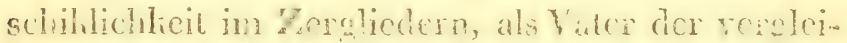

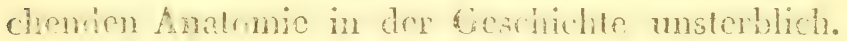

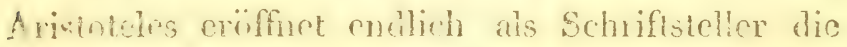
Geschide der Tlime, nnd ohne and je des l'n-

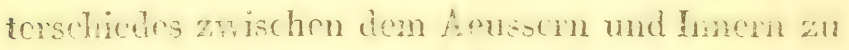

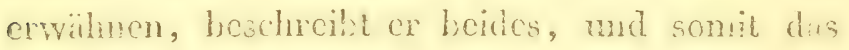
gonze Thier. Aber ron num an ience sioh dr

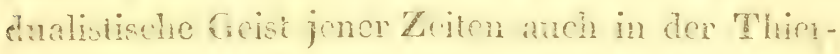
geschichte an: Plinus nimmt gröstrndeils nu

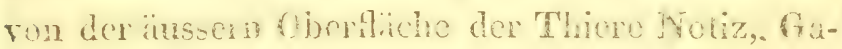

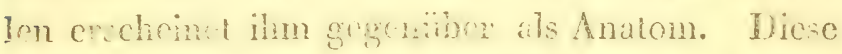
fondselige splumg bihde sich immer mehi, bis

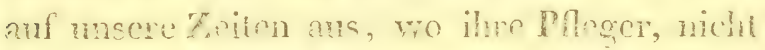

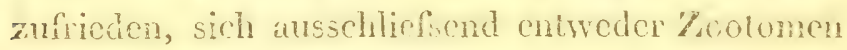
odcr blos Zorongen zn nemen, selbst als Physiologen sich den Anatomen, und diese, zur Fhrenelwnong, sich als menschliche Anatomn die Beschäli-

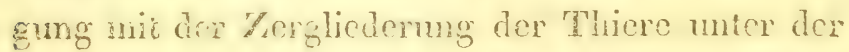
Denowneg des Vegelius: "Voterinälnust" (ars

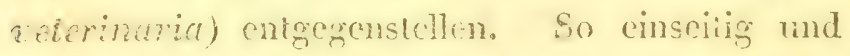
citcl anch dieser litterärische fimpl selbst woch in 


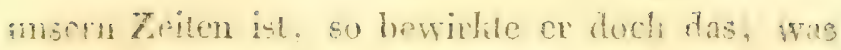

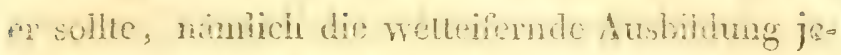
des gesonderten Fachese bo rendeslen wir dic

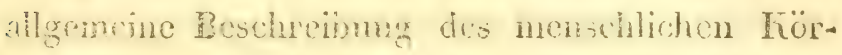
pets finm Tceal, Bantholin, Sabaline, Herster, bin-low wnd don Anatomen Teubchlands-Sün-

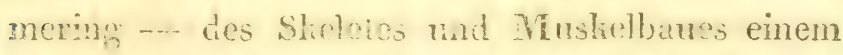
Albin - dor temen cincui Monro, Scarra, Vralter, Camper, Mrisherg, Mchel, Fischer, Zimndes Gehimbanes einem Willis, Düremai, Vieusens, Vird d'Azyr, Sünmening und den vertienstvollon Gehinamatomen Gail - dor Simesorgane cinem Däromai, Catsorius und vor allen denselben inulonen Tentudnlands, weloher scine vor treflirben himfer immer mit glcich senaten Descripliunen begleitel, - der Lymplugefife cinen Bartholin, Cruilishant, MLascagni, welcher Leztero in liuzer Zeit die gesanmte Anatomie des ITen-. schen wnd aller Theile in Verbindung in Lebensgrölse herausgeben wird, und wozu ich schon die ferligen hupfer in Florenz geschen habe. Im gilcichen Schritte, wic der menschliche Iörper meln geliani und beschieben wurde, entwickelte sich anch allnählig die veterinäre Zootomie: Severimus, Plasius crönincten die Bahn, Swammerdam wird der Anatum der Insekten und IVIolluslien, Tyson grent aus der cnglischen Ahadenie als Zootom licrvor, Perraul, Chamas zu gleidrer 


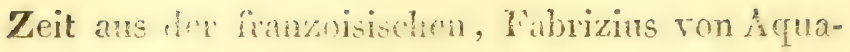
pendente untersuchet dic stachgeburt rerschiedener 'Thiere, und beobachet wie Malnighins die successive Lnitwiling des Vogels aus dom Tié, Villis let seine findedungen im Gehime und Püchensate verdicherien There dar, Valentini mache ein Ampiahedun zoctomilimu behomnt, Lyonet cribuhet den Ban der Weidemaupe, Collin nul Nono beaberten die Antomie der Wische, Leztcres anch der ubrign There, Goltwald die der Schidabüten, Mcirs beveichert das anatomische Gebiet nit Abzeichmsen ricker Shelete aus allen Thichlassen, Martonlus und Camper be-

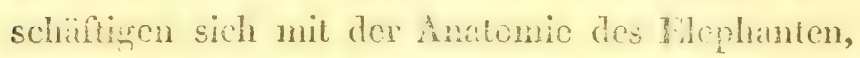
und Lezteer auch des Rhinozeros, Niths, Réatl-

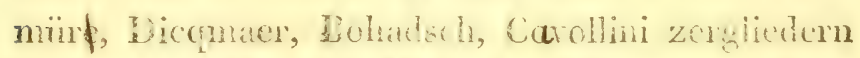
Zoopiyten, Poli dic Neilushen, Scapra zeichnet der reschenden Anumie duch scin Werk

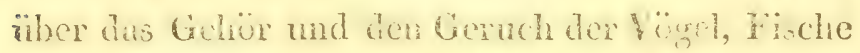

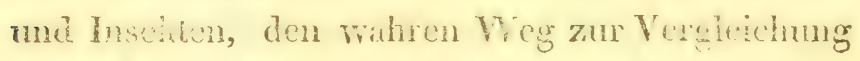
ror, Alhers, Josephi, Wicheman, Jisther wettcifern, Cireses Fach durch newe Lntersuchungen zu erweiturn, Bhinenbach sammelt endlich die ailgemeinen Dradechungen in cincm Landinche der vergleichenden Anatonic zusammen. Doch strebten die meisten ron innen, wicht blos mechanisch die Theile desmenschlichen oder sonst thicrischen Törpers zu beschreibon und abzcichon zu lassen, 
sondern cbenfalls inre Finktion, das Johen umd Incinandergreifen derselben zu beobachen, und so entwichelte sich dam anch allmühlig die Physiologir. Seit Ilippolatates and Galenns, crhob sie sich mit der Schnle des Parazelsus, II tmont, Stahl, md besonders cines Börhave immer höher, Haller stellet endlich mit allen Theilen des Förpers, des Menschen sowohl als der Thicre, Versuche an, um ilir Leben zu erforschen, er entdecliet, ähnlich der Elelitrizitat der anorganischen Kürper, die Irritabilitit anf organischen Gebiethe, bestimmet den Grad der Sensibilitït aller Organe, nnd bahnte durch scine erfinterischen Versuche und Beobachtungen einem Reil, Bichat und Gall den Weg, an der Vervellliommnung der Physiologie mit mehr Lusicht und Gedeihen zu arbeiten.

$$
\begin{gathered}
\text { S. } 34 . \\
\text { C u vi e r. }
\end{gathered}
$$

Durch solche thäligge Theilnahme crhob endlich die Zootomie ihr Maupt, und getrante sich als cine selbstündige Wissenschaft der $Z$ oologic gegeniibcrzusiellen. Danbenton, 1716 in Montbar gea boren, rerbündet sich nit Büfon, und fafst den liuhnen Entschluf, den zoologischen Abbildungen in den Werlien des Lezteren die zootomischen gleich laufen zu lassen. Fiaum hatte er eine grofse Anzahl zu den Säugthieren geliefert, so hinderto 
Buffuns neidischer med späher Blick die vefere Ausfilmung des Planes; doch Daubenton suchte semer verigmg fir vergleichente Anatomie dadurch eincin Spicham, and selbst linflufs auf dic naturgeschichtiche Pildung Frantireichs zu verschaffen, dafis $\mathrm{er}$, so wie man der $Z$ uoolugie bislicr dine Gallerie erridiel halte, num anch mit Thiie des bemonstraiors der Anatonio im fiflanzengarien - Rherind - fir die Zootomie den

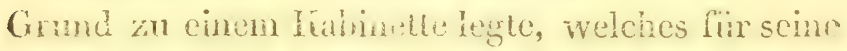
Zeit zwar noch dinfier, nichts, als was in den Werten Duffons absebildet ist cntirelt, jezt aber durch seme Neuheit sow oh ats seinen vernehren

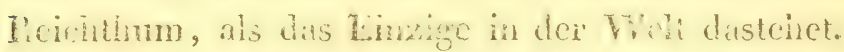

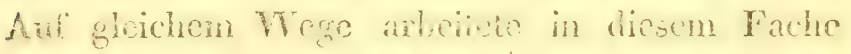

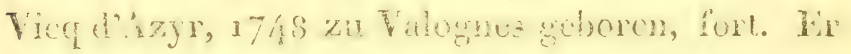
batte den ersten thereicht in der vergleichmen Anatomie ron Dambenton, in der menschiohen

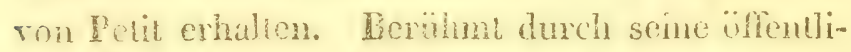
chen l.wisen, wurle or von den Ieztern zu seinen Nachfolger, als Professor der menschlichen Anatonie in Planzengarion bostimmt, allcin Büffon crhatrte sich dagegren, nud dor noch lebende rerdienstrulle Portal trat in diese Stelle cin; doch Düron starb, und Vicr dXzyr wurde an seiner Stelle als Mitglied in der Nhademie zu Paris anfgenommen, entilich selbst zum Seliretïr der medizinischen Schule alldort ermemet. Dieser gründ- 
liche Arzt und Zootom, beschrünkte sich nicht blos auf die Zergliederung des menschlichen hörpers oder blos ciniger anderer Thiere und auf ihre mechanische Abzcirhnumg und Beschrcibung, sondern er umfafste mit physiologischem Bliche das ganze Thierreich, und fihlie scine Veroleichung Gurch alle einzelno Thiere hindurch, un so die Abstuffung und Nitmzen eines Organes liennen zu lomen. Von dieser Art ist seine erste Arbeit über die Fische, und seine zweite die MIuslieln der Vügel, durch deren Vergleichung and Benennumg nach denen des Minschen or sich ein ganz originelles Verdienst un die vergleichendo Anatonie crwarb. Von num an wurde bei ihm das Verggleichen herrschender, jezt zeigte er selbst die Parallele zwischen den obern und untern Extremiläleir des Menschen und zum Theile der z̈hrugen Süughiere, verglich den Fehlhopf und dis Stimme der Saugthiore and der Vögel mit einander, nimmt licranf das Gehirn des Menschen zum Gegenstande seiner Untersuchnig, und liefert nach der damals herrschenden Miunier, dasselbe stühweis und ohne Zusammenhang zu zergliedern, nicht minteressanie Zeichnungen und Bcschreibungen daron, endlich-fafst or den liiimen Entschlufs, alle filassen und selbst Arten ron Thieren, nach ihren anatomischen Theilen zu beschreiben, und ebenfalls darnach zu rubriziren, 
vozu er in der Encylhopedie mit dem Bande, "inatomisches System der Quadnueden" überschrieben, den Anfang macht. In Eingange zu demselben, theilet er die Natur in dic der todten und organischen fiörper ab, giebt eine Lebersicht über das Picich der Pflanzen, über ihre anatomischen Theile, einen neuen Versuch zu einem Systeme derselben, ähnlich jenem des Jüssien, und nu entwirft er die Anzahl und den Rang der r'unktionen des thier ischen Förpers, als: der Ossitikation, Irritabiliail, Cirfulation, Sensibilität, Respiration, Digestion, Seliction, Generation, versuchet nach diesem anatomischen Bilde das Innere der Liméischen Lilassen zu ordnen, und beginnet die detaillirte Auscinandersetzung mit.den Affen und Nagern, von denen er über hundert anatomisch beschreibet, ein Unternehmon, dessen Ausfuilrung diesem grofsen Physiologen die Lüclien sowohl seines Entwurfes der thierischen Funktionen, wie auch mancher neuer Unterabtheilung und Zusammenstellung der Thiere gezeigt haben wïide. Leider! unterbrach ihn aber der Tod in der weiteren Ausfïhrung, dieses Planes, der nichts anders zum Zwecke hatte, als ein Werk der vergleichenden Anatomie aller Thiere zu liefern. Nach seinem Tode erhob sich eigentlich der Mann, welcher sich zum Stifter der Zootomic, wie Linné zu jenem der Zoologie aufwarf. Georg Cuvier, 
baclite Ordnung in das Chaos der rhapsodischen Bearbeitung der Zootomie. Kaum hatte er cinen Blicli über die rorhandenen Materialien geworfen, so fühlte er wohl, wie nothwendig es sey, alle bisherigen Arbeiten in der Natur selbst zu wiederhollen. Aber eben durch einen solchen genauen Umgang mit der organischen Natur, wurden dem scharfsimnigen Forscher die Lüclien dieses Faches um so sichtbarer; er bestrebte sich daher, diese auszufillen, und günstige Umstände gaben ihm hiezu die Gelegenheit. Mit der Rerolution ward bei der franzoisischen Nation der Sim für Natur. geschichte reger, der Pflanzengarten des gefallenen lï̈nigs ward wie ron neuem organisirt; Büffon und Daubenton trugen noch jezt zu seinem alten Ruhme im Inn - und Auslande bei, bis endlich Curier von Mümpelgard, in der berühmten Tiarls Akademie in Stuttgardt gebildet, und dort Zeit - und Studiengenosse des geistreichen Kielmeycr, zum Nachfolgex seines Lehrers Mertruds als Professor der vergleichenden Anatomie und als Oberaufseher des von Daubenton angelegten zootomischen Kabinettes ernannt wurde. Nun war seiner Liebe für die rergleichende Anatomie aller Spielraum geöffnet, um dieses Fach zu der gewünschten Vollkommenheit zu bringen, Zuvörderst dachte er darauf, das kleine Kabinett, zu welchem Daubentons rastloser Eifer den Grund 
getngt hate, thin ciner allgencinn, alle Zweige dor Z̆ouhgie vuldssenden anming zu machen.

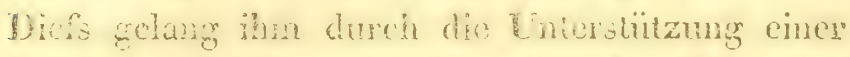

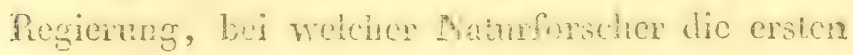
Stellen chatamen, mul durch dis patriotische Theinahre sciner Biblüger, welche auf ihron Drobermgen, Expeditionen, und Reisen überhaupt, ans allen Gogentim beiträge zum naionalen Eigenthrune herbogrhben. So mit Thioren des I andes und ds: Necres versehen, hatte or alle Gelegenheit, die imere wie die intssere Strnhitur rom Menschen durch alle lilassen, bis zu den Zoophy ten 7.u verfugen, und aus seinem Planr, ging so das zootumische habinet in Pfanzengaten zu Paris hervor, in wolchem man stat der biicher, worin die Entdeckngen der rergleichenden Anatomic enthatten sind, diese selist an natuiden rixcmplaren aufgestellt sieht. So wie in zoulogischen habinete die Gestallen des Pherreichs, selbst entfernter Veilheile, zur Ueberschanng conzentriut, sich darbichon, so biohet in den zootomischen der gehommifsulle Glicherban der Thiere entaltet und enischleich 3. Ja dex Mlan des heroischen Verfuswers gehi norh weice: d!as Thochengerïst ist es, worin sich die Struitur des ganzen Thicres abspiegeli, mul eine zathirciche Sammlmig ron Sheleten offenbart dem stillen Forscher den architektonischen Plan der Natur, nach 
welchem sie alle Slichere, gleicisam ats Gilieder ci nes cinzigen colossaten thieres erbanh, und zwar mit enex solden inneren Fvoluwendigheii, thes, wic in der Atathenatia cine belianne Grörse die unbehannte, so hiea die blose Gegenwan! cines cinzigen Iü̈öhchens die gesämme Axtitination cines

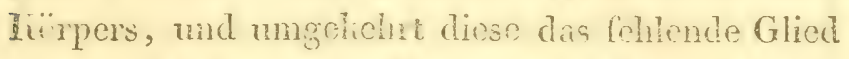

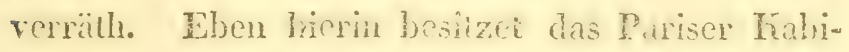
nett seinen gröfsten und unvergënlicheren Schatz. Diese reichhaltige und anscrlesene sammlmo won Binochengebäuden aus alten Thichlinssen, setrot nun ihren scharfomigen fienner in ten Stant, aus dem lileinsten hiöcheichen, welches sich in den kidschichen rergraben vormuld, auf dic Itasse, oler Ordnumg der auf unserem Planetor roch existirendicn oder ausgestorbenen Gatumg za sehliersen; daher dic hïhne und prophetischo Sprache dicses grofen geologischen 2 wologen ${ }^{a}$ ): ,et unc seute dent m'a pour ainsi dive, tout annonce." Schon wächst durch likse scine liel,Jingsneigung und seinen Tieils dis Anlage zu eincer Sammlnug fosiler finochen heran, welche nichtnur die Lüchen des zoologischen Sysicmes ausfinter, sontern auch einst cin Fingerzeig wercien wirt, auf die Entwililungsperioden und das Alter cinzcher Gegencion oder unseres gesamminu Plante-

a) memoire sur íaninal fussle de mastricht, anna cs To L. 


\section{$-134$.}

ten, ja selbst der ganzen Weltenordnung zu schliefsen. Durch Errichtung eines Kabinettes der Anatomie von so umfassendem Plane und Reichthume, mufste der Urheber das Innere der gesammten Thierwolt durchlaufen, und nun als Vertrauter der Natur war er im Stande, die bisherigen $\mathrm{A} r$ beiten der Zootomen mit den seinigen zu vergleichen, das Vorhandene mit neuen Beobachtungen zu ergänzen, und das, was er im Buche der Natur und in Schriftstellern gelesen hatte, zu cinem gleich natürlichen Ganzen zu gruppiren. Jezt erschien ein vollstindiges Handbuch der vergleichenden Anatomie in fünf Bänden, worin der Verfasser ein organisches System um das andere von dem. unrollhommensten Thiere - dem Zoephyten bis zu dem rolliommensten - dem Mensclien durchführet, und durch solche stuffenweise Zusammenstellung und successiv fortschreitende Beschreibung dor anatomischen Theile der Thiere, den Weg, welchen ein ähnliches Werk der vergleichenden Physiologie kïnftig zu gehen hat, andeutet. Nun sind wir im Besitze ron dem, wornach die Geschichte schon seit Demokritus und Aristoteles gestrebet, und wozu sie durch einzelne Männer einzelne Bruchsiticlie geliefert hat, und nun haben wir einen, wenn gleich noch dümnen, doch ganzen Leitfaden, un uns durch die Finsternifs und das Labyrinth verborgener Organe thicri- 


\section{$-135$}

scher hörper durchzuhelfen. Das Genie eines liunftigen Zeitalters möge sich die gebrochene Bahn erweitern, und in cinem eben so consequenten und reichhaltigen Systeme, gleichsam im Bilde der Rede, die Anatomie und Physiologie wiedergeben, wie sie in dem lebenden Gliederbaue der Thiere ausgesprochen ist.

\section{35.}

Hat man seit der ersten Periode der Thiergeschichte mehr die äussere Gestalt in Betrachtune gezogen, so fingt man jezt an, das Innere des Thieres mehr kennen zu lernen, und die Zootomic scheint nun über die Zoologie zu herrschen. Die franzofsische Nation hat hiczu den vorzüglichsten Anstofs gegebon, und allmählig werden schon cigene Kabinette und Lehrstühle für die rergleichende Anatomie auf franzöfsischem, italienischem und zum Theil teutschem Boden öfentlich crrichtet. Nicht unwichtig liam daher dic Betrachtung seyn, welche Abänderungen die Zoologie bis jezt durch die vergleichende Anatomic, und - in wicfern dieses noch immer der Grund und Boden ist, auf dem man nur einzelne Acnderungen rornahm -das Limnéische System durch jenes erlitten hat. Allein von allen diesen Verbesscrungen ist Cuviers Handbuch der vergleichenden Anatomie bisher die riste Quelle, und dieser verdienstrolle Forsher hat 
Edbige entwolor in scinem Handhuche er Zocilou gic mul der vergle ichenelon Anatomie, oules in seineil zerstrenter Menowen selbst an'gegeben, dex eincichtsvolle Daturforsher, welche, wie ein Lamark, Lacepede, Dimeril, Brogniart, Lubeille, Bosk, Geoffroi n. s wo an dieser neven Periode der Zoologie den eifrigsten Antheil nahmen, lrahen diesalben bios anf Autoritit scines Zerolicderum. gen genacht. Wine de ersten Veründenumen weiche dor franzofische Scharfimm an der Gesammtheit der Lime'ischen Ordmungen romahn, ast dicse, dafs er dicseblen nicht unter das alto Joch der Thire mit oder ohne bint, sondern under ein nenes aber älnliches, nümlich nunter das

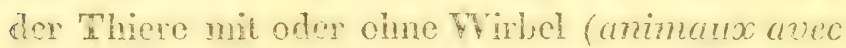
oit sans vertibres) zwang. Aristotcles hate schon dicsen Enterschied angegelien, Sioll in semem Prodromo aber Sanghiere, ned nachlor Curier in

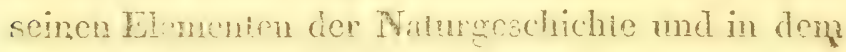
Tandbuche der vergle sentich heransuchoben, bis endich Lamark als der ersto inn sclbst zum Titel scines Werles: , animatux suns vertibres" gebrauche, Allerdings lierse sich dicser Gesichtspunt rergleichent durch die Thiere hindurchfuhen, Gleichwie man an cntsichouden Embryo noch licine Spur ron Inochen bemerliet, sondern cret mach una nach dieselben Inorplicht, dann schyvamige und enulicla 
consistenter, und reif erscheinen, wie ferner anch Bichat in seiner plyysiologischen Anatomic dieso Siuffen, und an insgewathsenen hörpern selbst

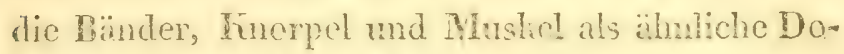
Inmenic dieser Abstufing uachwies, cben so liefse sich an der fonzen Thiorrile, als an cinen colossalen Thiere, das nümlicho nachzeigen: dis Wirbellosen stellon blose Manthicre dar, be: we?chen der hinoche nit der llaut rewwachsen, sicis Gleichsam mohr hart oder weichbänderigt zaiget 8.ci Schaahhicren sondert sich jence schon als Tialykirnste von der fleischichten Hant ab - bei Aplysien, Dolabollen, wird diese Iialphliruste wie der crsic huochenpunkt zum Sliclete, in Form cin ner Schippe ron der Haut ïberzogen - bei Sco pien erscheinet nebst dieser nur mehr vergrǘserten Rüclienschuppe (os sepiac) schon im Topfe cia rigener Finorpel, welcher ganz cinem Püsliswire bel ähnlich, das sogenannte Gohirn und dio ans. strahlenden Nerven in sicli rerwahrt - bei Lario preten tritt zum crsten Male cino Rüchicnsünto anf, welche abor noch immor lederartig nud dio Form der Virbel nur durch Furchen angedonif? rorstellet - mit den Rajen, Squalen und drox äibrigen Knorpelfschen, glcichet der hinorpel schen einem schwammigten, locheren Iinochen --. in den Grätonfrechen wird or schon ror Harto beis

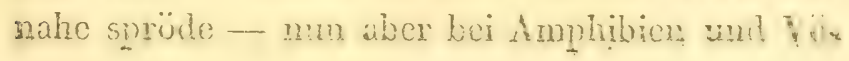


geln, obwohl noch etwas schwammigt, zeiget or sich im Innern als lecre Wöhle, nach aussen als festere Substanz - bis endlich in Säugthicren, wid besonders in dem Menschen, dic Hant alles hnochenartige ablegt, und der früher bond - und lederartige Hautlinochennum vollends von ihr ge. trennt, als ausgewachsener, fester, mit seinem inneren Lumen ins Glcichgewicht getretener, als langer, flacher und schön gewölbter linochendas Innerste der weichen Theile einnimmt, und als liunstrolles Gebände der Architektur, jenen zur Grundlage und zum gemeinsamen Träger dicnet. Vie nach den Niianzen der Blutbereitung, so lömte man auch hier nach der Stuffe der hinochenbildung alle cinzelnen Thiere zu einem planmäsigen Ganzen fügen. Aber nic wird dieses durch so schneidende Abtheilungen in Thiere mit und olne Blut, mit Pïckenwirbeln und ohne Rückensänle bewirkt werden; miilsten doch sonst dic Sepien, derer Liopfhochen unlügbar cinen linorplichten Rïclienwirbel rorstellet, ron den übrigen verwandten Molluslien getrennt, und zu den Fischen gesezt, oder die Lampreten, bei denen die Wirbel an der lederartigen Rückensänle nur durch Furchen angedeutet sind, ron den Fischen zu den Mollusken geworfen werden. Ja will auch jemand alle die Grade der Abstuffungen in der linochenbildung anomilln, niomals ist or hiezu im 
Stande, nimmt er nicht die Betrachtung der übrigen Organe, und somit das ganze Thier zi seinem Leitfaden. Uebrigens gleichet eine so abgerissene und nicht weiter detaillirte Eintheilung einem Blitze, von welchem das gemeine $\Lambda$ ug wohl die grelleste Erscheinung, nicht aber die Art seines Entstehens una Vergehens cinsicht. MIchr Veränderung als die Ordnungen des Linnéischen Systemes im Ganzen, hat das Innere der einzclnen erlitten, und vor allen jene der Wiirmer, zu welchen Linné, blos auf das Acussere, mehr oder weniger Nalite sehend, alle nach dem Innern auch noch so heterogene Thiere zusammengeworfen hat. Diese Ordnung begreift bei ihm alle schaalenlosen Würner als: die Intestinalen, dann Schnechen, Holothurien, Mecrigel, Meersterne unter dem Namen der Mollusken, die mit Schaalen bedekten unter dem der Testaceen, und endlich die Zoophyten in sich. Gerade in unsern Zeiten fing man an, dic Natur in ihren verborgensten Winkeln aufzusuchen, und, so wie dic Fryptogamie bei den Pflanzen, so sind es gerade bei den Thieren die Würmer und Zoophyten, welche jezt sehr viele Naturforscher beschäftigen. Schon Brüguiére, obwohl noch immer nur das Acussere berülisichtigend, war zwar nicht mit dem Platze, aber mit den Limnéischen Abthcilungen der Würmer unzufrieden, und gruppirte sie daher nach seiner eigenen dnsicht als Infusorien, Intesti- 


\section{$-140$}

nen, Mollusken, Echinodermen, Testacéen und Zoophyten. Zwar schienen diese Gruppen so zientich natürlich, allcin ihre Anfeinanderforgo war noch immer in $\mathbb{Z}$ weifel cingehnill, bis end. lich der Blick ron ausscu, anch auf die immere Strnktur dieser Thicre gerichtet wurdo. Hier sind es aber vorzüglich die franzófischen Naturforscher, welche anf diesem bisher so dumblen Boden die rergleichende Anatomie erprobten, mil Licht und Ordumng in die Aufeinanderfolge dieser Thice brachien. Freilich sind sie nicht die ersicn, welche den innern hörperbau einiger diescr Thiere cnthüllen, denn S; wammerdam hatte schon die imere Eimichtung der Gartenscheche mả mehrerer Inseliton, Willis die des Lrdwums, Lyonet die der WVcidenranpe, Miiller dic der Holothurion dargestellet, Poli sczie Swammerdams Fntdeclungen auch boi den zwei- und rielschaaligten Molluslien fort, Mangili cnidelite das Nerveneystcm in Erdwume, Cwricr stchet endlich auf, zergliedert alle diese Thiere nochmals, berichtiget Swammordam in den Geschlechtstheilen der Sclneclie, behauptet cinstimmig nit diesem holländischen Anatomen das als Nerrensystcm, was Poli irrig bei den zweischaaligten Mollustien als Lymphastem annimmt, and delnet ferner seine Zerglicderungen über Familien, Gatumgen und

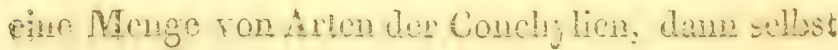


Wher Medusen, INecrigd und Zoophylen ars. Allein, nicht zufreden, die imere Linrichtumg dieser Thiere blos durch sich selbst zu liennen, strebet or die Beobachtungen seiner Vofuhrer mit den scinigen zu rereinigen, alle diese Thiere nach. der Nehrheit ähnlicher Organe zu gruppiren, und eben hiernach in ihre naturliche Rangordnung za bringen, cin Verfahren, wodurch eben die franzöłsischen Naturforscher in unsern Zciten als die ersten mit ihrem Beispicle rorgingen. Die Natur mehr als das Anselien Limés respelitirend, zersplittert nun Curier jene Ordnung der Wümer, sczt die Schnecken, als Thiere welche mit Brano chicn wie Fische athmen, whd durch Iterz, Nerven und beiderlei Geschlechtsorgane sich auszcichnen, vor den Inseliten, läfst auf jene die Irustaceen folgen, weil sie eben noch giche Charalitere haben, aber durch ihren gepanzerien und durch Einschnitte getheilten Kürper den Insehien gleichon, dann folgen die Insehten selbst, bei welchen zwar Nerven, Geschlechtstheile, aber statt Branchier Tracheen, statt cines Herzens bles ein pulsirendes Rïckengefirfs statt fnden, und nun endet er mit dem Hecre von Thieren, deren Einrichtung noch ģanz im Dunlichn liegt, nümlich, mit den Würmern, die er noch zur: lilasse ron Insehten rechnet; dann mit den Asterien, Echiniten, Polypen unter dem gemeinschaftichen Namen ron Zoophyten. 
Lamark, Düncril und die übrigen franzö\%schen Naturforscher, stimmen zwar ganz mit der Festsetzung dieser Charahtere, auch mit dem Plane ciner Rangordnung überein, aber demohngeachtet weichen sie in vielen von cinander ab. Dafs die beschaalien und schaalenlosen Mollusken gleich nach den Fischen den ersten Rang behaupten, hierin herrschet bei allen eine einstimmige Meinung; nicht eben so ist es mil den Frustaceen: Cuvier rechnet sie zu Insekten, und stellet sie an die Spitze derselben, Lamark, Dümeril und Latreille handeln sie als cine gesonderte Klasse unter dem Namen: "Irrustaceen" zwischen den Mollusken und Insehten al. Die Wïrmes, nud zwar die der Fingemveide sownhl ats die Amphitriten, Serpulen und den Erdwum, hat Cuvier, weil sie ganz die Gestalt und ahnliche Beschaffenheit der Raupen ha\}sen, wit den Inseliten zu einer gemeinsamen hlasse verbunden, Dümeril unterscheidet aber die lezteren Arten von Wümern, als welche mit Branchien athmen, von den erstern, bei denen diefs nicht der Fall ist, und sezt jene als eigene hlasse nach den Insekten, und verbindet diese mit den Zoophylen; Lamark lärst beide in seinem Verlie über wirbellose Thiere in einer Klasse beisammen und stellet sie zwischen Inseliten und seinen Radïirs, neuerdings aber in seiner philosophischen Zoologie tremt er die mit Branchien 


\section{$-143-$}

ailmenden Würmer, und sezt sie unter dem Nitmen: "Anneliden" was auch schon Latreille in dem Werlie: "tablean methodique d'histoire nafurclle" und später in seiner Entomologie that, zwischen den Mollusken und Krustaceen. Norh unierscheiden sie sich sehr in Hinsicht der noch ührigen Thiere dieser Ordnung, doch haben sie alle die Eintheilungen Briiguièts ancrkannt, und nur verschicdene Thassen oder Familien daraus forniret: Lamark stellet die Meersierne, Meerigel, Holothurien und Medusen unter dem Namen: "Radiaires "als eigene Tlasse nach den Intestinalwïrmern und zwischen seiner lezten, div er Polypen ïberschreibet, während Cuvier und Dümeril diese beiden lezten Flassen in eine zus:mmenziehen, und sic Zoophyten betiteln. So einstimmig also auch die Franzosen die Limnéischen Ordnungen vermittelst der vergleichenden Anatomie zu verbessern und zu befestigen streben, so erhellet doch aus dem Angeführten, dafs sie in ihren Verbesscrungcu der Anzahl und Aufeinanderfolge derselben noch im Kriege unter einander sind. Man wundere sich daher nicht, wenn man in den Elementen der Naturgeschichte von Cuvier acht Kilassen in eben so vielen Büchern als: Menschen, Mammiferen, Vögel, Reptilien, Fische, Mollusken, Insekten und Würmer, Zoophyten, - wenn man in dem Werke über die wirbellosen Thiere ron 
Lamarli cilf: Mammalien, Vügot, Thendien, Fí sche, Mollushen, Krusiacen, Arachinacn, Insoliten, Wirmer, Radiaires, Polypen, und in sener phlicophischen Zuologie nodh mit drei wenen Khasen: Cimhipeden, Ameliden, Infusorien rermelnt - cunlich in der andylischen Zoologie von Dumeril - nem : Domuiferen, Wügel, Reptilien, Fische, Molleshen, Limstacéen, Inschten, Würmer, Z.ooplyyten - nän wundere sich nicht, wem. man cine so ungleiche Anzahl me Aufeinanderfolge ron Ulassen bei den franzo\%sischen Naturforschem antrith; iln Inng, des Linnéische System durch die vergl ichende Anatomie zu completiren, die rüuchen desselben zi rerbessern, und eine Jangordnmo in die Vlassen der Thiere zu brinGen, bleibt nichts desto weniger lobenswiridig mod. gegriundet. Noch hinffger als hor, sind dic $A b-$ ünlenngen, welche sie im Inncru der Ordinungen herrorbrachton. Da Liné gröftetnlicils das Acnssce enes Thieres in seine Charahteristili anfnahin, und öfers mehrerc Gaitzmgen als blose $\Lambda$. ten anfstelle, so sind sic nur zu geneigt, recht viele Aren zu Gallungen zu crhoben, sic füger so viel mëglich der Chamalteristili des Aenssern anch die des Imom boi, md machen nach unstitien, und nach den verschiedensten Gesichispunliten in cincrund der nïmlichen hỉasse, entweder nach der auffallenden Beschafenheit eines Organs (carnas-- 
siers, pedimanes, plantigrades, rongeurs, identés, tardigrades u. s. w.), oder mach der Aehwlichleit einer ganzen Familie mit cinen Individuum (talpiers, chauvesouris, myrnecophages u. s. w. neue Familien und Aufschriften. Jedoch alle diese Veränderungen und Neuerungen sind nur ron der Art, dafs sie nicht als Widerlegung des allgemeinen Systemes des Linné, sondern als ein. zclne Verbesserungen anzusehen sind.

$$
\text { S. } 36 . \text { a. }
$$

Unverkennbar ist der Gewinn, welchen dio Zoologie in neueren Zeiten durch die vergleichonde Anatomie zu erhaiten, anfängt. Lernte man ehmals nur die äussere Oberfläche des Thieres liennen, so wird man von jezt das Innere desselben immer mehr enthüllen, und es, wie Rajus und Linné, noch mehr aber die Anhänger Cnviers, immmer häufiger in die Charakteristili mit aufnehmen. Allein forne, dafs in unscm Zeiten Zoologie und Zootomie zu einem freundschaftlichen Vereine sich wechselseitig einverleiben, stellen sich diese vielmelr cinander feindsclig gegenüber, und beinahe ist man schon im Stande, den Triumph der Zootomie über die $Z$ coologie firr ein liüftiges Zeitalter zu prophezeien. Noch ron Upsal aus wurde vorzüglich der alten Gewohnheit, die Thiere nach ihren üussern Beschaffenheiteu zu beurtheilen, ge- 
huldigt; aber nom beginnet in den Naturforschern zu Paris eine ganz entgegengesezte Pichlung. Zwar fordert man hier die Ciestalt des 7 hieres, scine zähne, Nägct, Haubedechung zu hemen, aber die imere Stmlitur desselben ist es, wornach alle über die Wesenheit des Theres, über scinen Rang und seine Ordnumg zu cutscheiden sich berifern. Es ist nicht zu laungnen, dal's diese von den Pranzosen schbs so sehr angeregte Seite, an Thirren bisher ziemlich remachlürsiget ward, und liaum mexhlich sich nach und nach zur Dämmerung emporhob. Aber num sind ihre Vertheidiger schon so gereizt, dafs sie sich beinnhe liämpfend der andern Parthei gegenüber stellen; nur noch ein Jahrhundert, und wir werden die Thicre eben so gut nach ihrem Imern, als jezt nach ihrem Aeussern liennen, ein Erfolg, velchen allein der Geist der Geschichte duch diese dualistische Richtung zu bezwechen gedenhet. Doch wie viel fehlt uns noch zur Realisirung dieses weit aussehenden Planes, nämlich alle 'Thicre nach ihren finochen, Musheln, Nerren, Gehirucs- Simnes- RespirationsGeschlechts - Verdaunngs - Cirlublations - Organen zn liennen, und sie so rergleichend zu mustern! Welche ungeheure Arbeiten, wie viele Alter von Naturforschern erfordert diese wichtige Aufgabe! Aber ist diese Zeit gelommen, damn erst werden wir einsehen, dafs auch die fienntnifs des fmnern 
nicht den gewünschten Aufschlufs verleihet, wenn uns noch jene der Seelen-Eigenschaften der Thiere fehlet. Nur dann werden wir uns wahrlaft rülmen hönnen, Einsicht von einem Thicre und der gesammten Thierwelt zu haben, wenn wir das Aeussere wie das Innere, den hörper wie die Secle der Thiere, und zwar in ihrer organischen Gliederung liennen, und nur jene Rede, welche dieses natürliche liunstwerk gleich natürlich and künstlich nacherzählet, wird unter dem Namen eines Systemes der Natur fortleben. Wie weit stchen wir aber auf unseren Nebenwegen noch von dem allgeneinen Ziele ab! Nicht die Idee des Acussern, noch riel weniger die des Innern ist uns aufgegangen. Immer ein cinzelnes Faktum aus dem Zusammenhange der Natur herausreissend, erbliclicn wir nichts als Zufall in ihr, und ist einmal die Nothwendigheit verdränget, damn mufs Willhïhr diese ersetzen, und die in Unordnung um das isolirte Faktum liegende Masse ordnen. Konn. ten wir z. B. nur dic Gestalten der Thiere, und es wïnde uns nicht mehr zufillig scheinen, dals der Mensch, wie die Blüthe der meisten Pflanzen, eine anfrechte, die Affen eine diagonale, die Amplibien und Fische eine horizontale Stellung haben, und wir würden, gleichwie in der Mathematik die Zahlen und Figuren unabänderlich nur so und nicht anders in einander greifen, ebenfalis in der 
Thierwelt finden, dafs dic Gestalt cincs Thieres die des folsenden bedinget, nm zusammen, gleich Punkten, cine bestimmte Figu zu constituiren. Allein unbeliümmert un eine so grenane in der $\mathrm{Na}$ tur als mabänderlich rorgeschriebene Ordnung, heben wir uns bald dieses bald jenes Faktum beliebig aus der Natur heraus, und machen uns den Spielranm und das Vergnïgen, die gemachte Verwirrung nach Williür zu cinem scheinbaren Gan$z^{m}$ zu oxdnen, und so entstehen und behämpfen. sich demn Legionen ron liünstlichen insichten und. Systemen auf ein äusseres oder inneres Merlimal exbauet. Ja wir gehen so weit, uns blos an das Imere zu halten, und das Aeussere zu vernachlässigen, obgleich dieses ein Spiegel ron jenem ist: demn wie anders liemen wir alle Dinge als blos xach ihrer äussern Erscheinung, nach ihrer Phy siognomie? Je tiefer wir ron dem Menschen zu den Pflanzen und Wincralien hinabsteigen, desto einfacher wird das Imere, und wird endlich beinahe ein blofses Aeusserliches. Nicht durch das Shalpell ist uns die Natur der Infusorien, die beinahe selbst dem bewaffneten Auge entgchen, fast eben so wenig jene der Pflanzen, sondern grölstentheils durch die Betrachtung ihrer äussern Gestalt bis jezt bekannt. Das Aeussere eines Thieres wird uns nur dann auch das Innere aufschliefsen, wenn wir, wie in der Musik, nicht blolsen isolir= 
ten Schall, sondern den Geist jedes Tones und die Melodie aller zusammen auffassen.

Gerade dieser Ansicht ciner unabänderlichen Nothwendigkeit in der Natur - dal's das Acusscre der Spiegel des Imnern, und dafs, so wic Körper und Scele zusammen das Thier, ebenfalls Physiologic und Psychologie die Zuologie constituren, denken, - noch melr als Limné seine CommentatoIen, - die Franzosen ganz enigerengesezt. Zwar immer nur das Einzelnste nud Grelleste an Thicren auffassend, tragen sie doch hein Bedenlien, die Aarnach gebildeten Gruppen (Planigraden, Anneliden, Radiärs, Reptilien u. s. w.) natïlich zu nenmen; ja sie führen dieses Vort immer in Munde, wollen zulezt gar das Manierirte für Natur verkaufen, und auf solche Art sich den Anschein goben, ein rom Linnéischen verschiedenes System zu crrichten. Wie bei linné, so stehen auch in iluren Charal.teristiken die Charaktere ohne physiologiscine Aufeinanderfolge und somit bunt durchcinander, die ncuen anatomischen sind hineingeschoben, die Charahicre sciust nicint von allen $\mathrm{Or}$ gancu eines Thieres, sondern von einigen der hervorstechendsten hergenommen, und der Seelens eigenschaften wird von ilhen weniger gedacht als von Limné, gleichsam, als wem dic Secle gar nicht zur Wesenheit des Thieres gehörte. Um so molr âser strebon sio die Limedischen Ordiungen, Faw 
milien, Gattungen und Arten, auch nach der unbedeutendston Veranlassung, zu zersplitern, und zwar mit solchem Eifer, dafs zulczt zu befüchten steht, die Arten mögten endlich ganz verdrünget, und alles nur gleich Gattung mol Llasse, ja der gemeine Kriegsmann selbst Anfuhrer werden. $Z$ Wwar erscheinen durch solche Absonderungen dic einzelnen Charalitere offenbarer, die Tinicre gokannter; allcin in cben drm Grade weicht zurleich der Creist des Ganzen, so, dafs zulezt alles wie olme Bund dastchet. IHit eben dem Rechte, als man die Trustacéen von Inseliten, die Anneliden ron Viurmern absondert, lünnte man auch die Cetacéen von Säughthieren, die Stransse ron Vögeln, die Schlangon ron Reptilien, die Kunorpelfische ron Fischen, die Spinnen von Inseriten, die VTeichflügler von Irartfüglern, die Echinodernen von Zoophyten u. s. w. als separirte Klassen aufstellen; aber dann würde man ein simples hapitel in der Weltgeschichte zu einer Epoche, einen Trabanten zu ciucm Fixstern erheben, was doch immer dem Ganzen zuwider ist. Auch eine neue Sprache hat man auf franzölsischem Boden versuchet. Leider! bestehet aber die Neuhcit blos in der Uebersetzung ins Griechische, mit ciner frauzôtsischen Endigung, oder ist auch dic Benenmung wirklich neu, so ist sie, wic z. B. radiaires, cephatotes (grofskïpfigte Fische), reptiles u. s. w. nur ron einer cinzi- 


\section{$-151$}

gen Eigcnschaft, von der sich ja doch immer Ausnahmen vorfinden, hergenommen, da doch die Benemung einer lilasse uicht ciac einzige Eigenschaft, sondern das Wesen aller Charalitere der darin enthaltenen Thiere, jem, einer Gatung nicht eine einzige Beschaffenheit, sondern den Charaktcr aller Arten ausdrücken soll.

Hiemit endiget sich die erste und zweite Pe. riode der Geschichte der Zoologie, in welchen ihre bïnstliche und einscilige Betrachtung, gleich einem Stamme, von Aristoteles bis auf Plinius und Galcnus, von Isidor bis anf Limné und Cuvier, in vicle grüne Zweige ausschlug. Mehr als sonst, sucht man jezt schon slatt des fïnstlichen das Natïrliche in der Natur auf, und nur liünfige $Z$ citalter mögen dic lezte Periode - des Blühens herbeifuhren, und statt der bisherigen Hypothesen und der Annahme eines Zufalles das Eine und nothwendige System in der Natur (Systema natur(se) gleich einem Heraklitus, welcher sein Werk über die Natur der Dinge im Tempel der Diana zu Epliesus aufbewahren liefs, auf dem Altare der unveründerlichen Ewigheit niederlegen. 


\section{Z WEITE ABTHEILUNG。}

Yon den künstlichen systemen insbesondere.

EISTES CAPITEL.

Säugthicre - Mammalia - Mastodologia:

ง. 36.6 .

Aristo $=$ ristoteles, nachdem er im ersten Buche die teles.

Thiere nach ihrem Aeusseren und Inneren manchfaltig unterschicden, ihre Hauptabtheilungen ange. geben, und dann den Micnschen, wclchen er eir IViuster aller Thiere, das vollkommenste Bild des Universum, und unter allen allein durch dic Gabe des Wiliens ausgezeichnet nennt ${ }^{a}$ ), anatomisch beschrieben hat, eröffnet das zwveite mit den besonderen Unterscheidungen, wødurch sich dic Thiere der orsicn Abtheilung, nämlich jene mit Blut, von einander absondern. Dic einzelnen Gruppen so

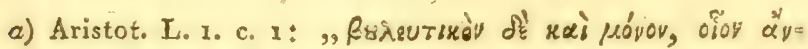

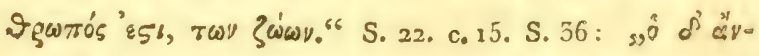

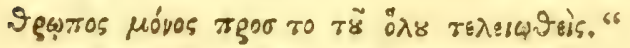


festsctzend, begint er, wo er ein Organ durch alle hindurch vergleichet, inmer zuerst ron der nïmlichen, und läfst auf diese die übrigen in im. mer gleicher Ordnung folgcn. Diese erste Gruppe crscheint unter der Benennung lebendiggebähren-

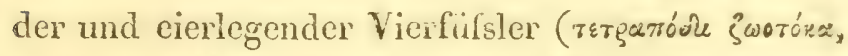
w̨тórx). Von den lebendiggebährenden merket er an, dafs man sic nach folgenden Gesichlspunliten ron einander zu unterscheicien vernöge: So könie man sie

- nach Beschafenheit des vorderen Endes der Extremitäten in solche mit Händen (

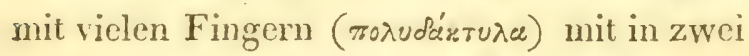

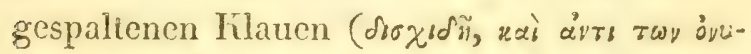

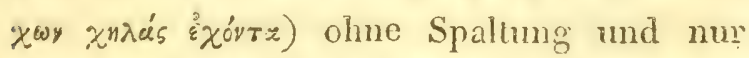

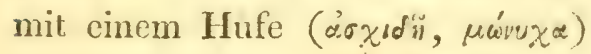

- nach den Hörncrn ( mit diesen oder ohne diese,

- nach der Lage und Zahl der Säugwarzer

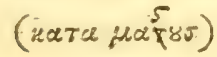

- nach den Geschlechtswerkzeugen, so ferı sic nach Innen oder Aussen, frei oder an. gewachsen liegen?

- nach der Beschaffenheit der Zühne, in solche, welche an dem oberen hiefer mach rornen gar lieine, welche herausragende ( $x$ surósog. 
тá) weiche in Form einer Säge, oder endlich ganz platte Zähne haben,

- nach der weiteren oder engeren Oeffuung des Mundes von einander absondern.

So umstïndlich Aristoteles anch alle diese Gesichtspunlite durchfuhhrt, so ist er doch weit entfernt, irgend cincm den Vorzug vor dem andern zu gebeil, obwohl er im Uebergange auf jene nach den I ifsen und den Zähnen eincu bedentenderen Rachdmek zu legen scheint. Was die Eigenschaften der Thiere ron dieser Klasse angeht, so

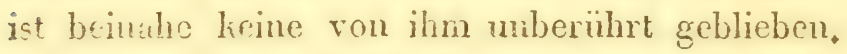
An rerschiedenen Stellen spricht er ron der Lebensart, Nahrung, Aufenthaltsort, Zeit der Begattung, Daner der Schwangerschaft, Zahl der Jutzgen u. s. w. ja im achten Buche crwähnt er sogar der Untcrschiede nach den Seeleneigenschaften, und liefert in leztein das vollständige Detail derselben. Ueber einige Familien findet man nicht immer einen gleich deutlichen Aufschlilufs: So gedenlit er der Fledermäuse ais Hautflügler bei Gelegenheit ron fliegenden Thicren, ohne sich zu erHïüren, ob sie wegen dieser Eigenschaft zu den Vögcln gehören a); die Cetacéen, die er durch die Anwessnheit von Sängwarzen, Lungen, Knochen und durch die Eigenschaft lebendige Junge

e) Arist, ho L, I, S, 8, 18 
sul gebihren, vor den Fischen anszeichnet, nemt er cine zu rubriziren zweilelhafte Familie a), die Schwcine höme man zu den Ein-oder Zweihufigten zählen ${ }^{b}$ ), die Affen halien die Mitte zwischen dem Menschen und dou übrigen Qnadrupeden ${ }^{c}$ ).

Plinius war es noch riel weniger als Aristoteles um Anordnung der Thicre zu thun; or unterschied sie daher nur nach dem ersten Bliclie, und zählte, nachdem er dem Menschen das ganze siebente Buch gewidmet hat, in den folgenden alle Quadrupeden des Arisloteles olme weitere Ordnung und ohne umständlichere und gewisscnhafte Beschreibung unter der Benennung: "Landthicre“ (terrestres) auf.

\section{ก. 37.}

Albert und Gessner crwekten die Naturgeschichte aus dem Schlummer, in wclchem sic so vicle Jahrhunderte hindurch lag, und fuhrten in das Innere der aristotelischen Ablheilungen die alphabetische Ordnung eir. Ersterer handelt in crsten Buche ron dem Menschen, im zwciten von den Icbendiggebihrenden Vierfissern, die er geradezu Thiere überschreibel; Lezterer gedenl.t
a) Arist. h. L. 8. C. 2 ,
b) ejusd, L. 2. S. Co.
c) ejusd, L. 2. S. 73 . 
schon nicht mehr des Meuschen, sondern beginut sogleich mit diesen.

Totton, dem Gange des Aristoteles getren, ficht nicht blos scine Benenumgei, sondern den Plan selbst, der allen seinen Büchern über die Thicre, wenn gleich stillschweigend, zu Grunde zu licgen scheint, herans, und ist der erste, welcher der Abtheilung der Guadrupeden nach der Anzahl der Einschnitte an Mänden und Fïfsten das Uebergewicht ertheilet. Nach ihm zerfallen sie in drei Ordumgen. Die erste bilden die Thiere Init mehreren Einschnitien (nultifida), die zweite mit zwei Gliedern (bisulca) die dritte mit einem einzigeu (solidungzula). Diesem tiefsimnigen Forscher ist es aber nicht gleichguiltig, dic eine Ordnung beliebig vor die übrigen zu setzen, sondern cr fängt mit dem Menschen, den er vou allen uibrigen obsondert, an, und handelt daun die Familien jeder Ordnung in der Aufcinanderfolge ab, wie sie sich nach ihrer Wirde und Vollkommenheit jenem nühern. Auf solche Art beschliefst er die Reihe der lebendiggebährenden Quadrupeden mit den Einhufigten, sezt jene mit Fingern zunächst đlem Menschen, und unter diesen zuerst, wic Phinius, den Elephanten, läfst daun die Affen, Hunde, Hyänen, Bären, Igel, Mäufse, jene, so im Wosser leben, ais: Fischotter, Biber, Phoka und

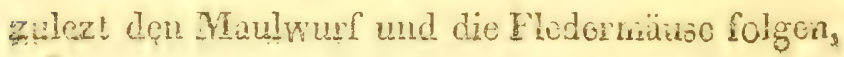


rwischen beiden Ordnungen liegt die der zweihtz figten in der Mitte, wo er denn zuerst die behornten, dann die hornlosen, wie das hameel und zulezt das Schwein aufzählt.

Aldrorand unterscheidet an den lebendiggebährenden Quadrupedea ebenfalls, wie Wotton, jene drei Ordnungen, nur bringet er noch weiiere hünstliche Vertheilungen in dieselben; so sondert er die zwchufigten, je nachdem sie im Wrasser leben, wie der Hippopotamus, oder auf dem Lánde, und hier, so ferne sie wiederhäncn oder nicht, gelwernt, oder Hönerlofs sind, ab; zat den Hüner tragenden Wiederhinucrn rechnct er filschlich auch das BToschustiner, weiches gar kcine Höner hat, und das Rhinozeros, dessen Hörner kein Finochen- sondern cin Hautgebild sind; zu den unbehornten das Liameel und die Giraffe; welche er sonst ganz richtig mit Hürnern abgebildet hat.

Jonston äderte nicht das Geringste an der $\Lambda$ b. theilung und Aufeinanderfolge dieser Thiere bei Aldrorand, nur liefs er den weitschweifigen Prunk von fremalartigen Erklärungen weg, und fügte seinen zoologischen Beschreibungen grörstentheils vortreffliche hupfer hinzu; bei den Schweinen. thut er, als der erste, des Tajassu, der Copybara und des Tapirs nach Maregraf Erwähnung. 
Ray.

Bishor hitle man die Nägel und Flauen gar nicht von den Einschnitten selbst unterschicden. Ray machte, als der erste, auf diesen Unicrschicd anfmerlisam, und nahm diese hornartige Bedeckung der äussersten Spitze der Plalangen, je uachdem sie das äusserste cilied derselben ganz unfafst (ungula) oder blos die obere Malfte bedecliet (unguis) zum Prinzipe seiner Abtheilung, and sonderte diese hlasse in zwei Hauptgruppen, nämlich in die mit Klaucn (ungulata), und in die mit Nügeln (unguiculata); die Anzahl der Phalangen hingegen, welche seine Vorgänger im Auge latten, gebrauchte er zur ferneren Vertheilung; die Thice mit hlauen zerfallen in folgende drei Familien: die cin - zwei - und damn dic vierhufigten (pede ungulato anomalo) zu welchen lezteren er den llippopolam, das Phinozeros, die Copybara, und das Bisamthicr rechnel, und welche alle bei Aldrovand unter den Bisullien stehen. Die zweilufgicn sundert er, seinen Vorgängern gemäfs, nach der Anwesenheit oder dem Mangel dor Hörner und des Wiederläucns ab, jedoch mit der Ergänzurg, dafs er die Höner, soferne sie hohl oder dicht, abfälig, bleibend, oder ästig sind, charakterisirct. Die Thiere mit Zehen werden nach der Anzahl dieser unterschieden, an ihrer Spitze stehet, als erste Familie, der Elephant, weil bei ihm die Klauen dadurch den Nïgeln gleichen sol- 
len, dafs er nicht mit diesen auftritt, dic Zehen aber doch noch nicht ganz getrenut, sondern bis weit nach rornen rerwachsen sind, wodurch er den Uebergang vou den Thieren mit Thanen zu denen mit Nägeln und getheilten Zchen mache. Die zweite Familie bilden jene mit zwei Zehen (genus Camelinum), die dritte die mil vielen Zehen; dicse haben entweder plattr: mui breite Nägel

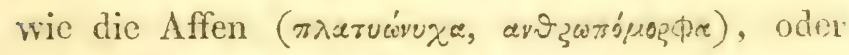
schmalc, und zwar mit Vorderzähnen oben und unten, wozu die gröfsern feischfressenden Thioxe mit zugerumdetem Kopfe und kurzer Scimauizo (genus felinum: felis, ursus) - nit verlingerten Kopfe und Gesichte (genus caninum: izepus, cunis, civetia, coati, viverra, putorius, vuipecuta, opossum, taxus, lulra, phoca, rosmartes, manati) - die Kleineren mit verlängerter Schnautze (g. mustelinum s. vermineum: musteici, viverra indica, genetta indica, ichneumon) - Pflanzenfressende mit zwei vorwiris gebeugten Schneidezähmen oben und unten (gen. leporinzum: lepus, histrix, castor, sciurus, mus, cavia); mit anomalen Schneidezühnen, wozu die mit Zühnen und mit verlängerter Schnautze (echinus, tatou, talpa, mus araneus), die ohne Zähne (tamandua), mit verhiüzter Schnauze und zwar fliegend (vespertiliones), oder einhergehend (ignavus) gehören. So wie Ray die bisherige Anordnung des Imnern 


\section{$-160$}

der lobendiggebuhrenden Quadrupeden präciser und consequenter durchführte, eben so rerbesserte or die Benennung und die Charakterisirung dieser Tlasse überhaupt. Da er die Cetacéen ron den Fischen in die Quadrupeden übertragen wolle, den Lamantin mit blosen zwei vorderen Füfsen wirlilich dahin rersezte, so pafste denn der bisherige Ausdruck Quadruped nicht mehr, er ergäinzte inn daher mit dem neuen Zusatze: „Behaart (pilos(i) “:

\section{ง. 38.}

ITit Thay macht die Geschichte der Säugthicre cinen Abschnitt. Scit Aristoleles wurde die Anzallt der Zehen, so wie auch der Nïigel und Kilanen als Mcthode gewähit; allein noch inmer nicht war dicse Ansicht auf das Liurzcste zusammengefafet. Diefs that num Ray, und nur an ihm ist man im Stande, anch zugleich die Verdienste seiner Vorgänger zu würdigen. Treilich ist die Denennung Quadruped ungenügend, aber eben so wenig charaliterisirt diese lilasse der Beisatz: „Belaaxt"; derin, wie im vorhergehenden Theile gczeigt ist, so liommt diese Eigenschaft Vügeln, Insoliten, ja auch Pfanzen zu, und gerade die Cetacéen und der Manati zeichnen sich, durch den Miangel oder die Seltenheit ron Haaren aus. Durchgreifender ist der Unterschied zwischen $\mathrm{Na}$ gel und hlaue, obgleich auch die Ceticéen und 
Jer Manati weder Kilaten noch rigel überhaupt, nm die Fledermäuse ebenfalls leine an den vier Fingern der vorderen Lratremität haben. Er füllte in der Ausführung die Schwierigheiten selhst, und find sich daher sciner Amahme gemäl's gezwumgen, die Nager "Copybara, Agouti, Paca"weil, obwohl sie vier vordere und drei'lintere Zehen, aber doch Tilanen statt Nägel haben, zu den Hufthieren zu rechnen; zu welchem Ende er das Rhinozeros und den Hippopotam init jenen in cine rigenc Familie "quadrisulea" genann, zusammenwarf, und diese noch falschlich mit dem MIoschusthier, das doch zw eihulggt ist, rermehrte. Aus gleichem Grunde muifsten hier an hi die Tatu, Fanllhiere, Ameisenbären, Känguruh, Damam, Schnabelthier, welche alle statt Migeh wahre Tilauen haben, autyezählt worden. Telche Tè. wirrung aber brächte so das strenge Urtheil für Nagel oder Fiaue unter den Thicren herrur! Div Elephant verdiente weyen den obigen Chaxahex en nicht, an die Spitze der Thiere mit vicien Zehen und mit Nägch gestelle zu werden, denn bei den Wiederläucrn sind jene mehr eingeschnitten ais hier, und damn steht "' auch (wenn gleich in seichten) Hufen. Auch bei dem fiamecle lassen sich die Hufe keine Nägrl nemen, und rirum soll dieser Wiederhäner zu den Thieren mit Niggelı, die so rerwaudte Gisaffe aber zu den zweihulig. 
ten geliencu? Die fernere Cutersheidmy nach breiten oder schmalen Nageln hat heinen Bestand, so haben die Sarigues, die Lemuren, der fliegende Hund, obgheich zu Afon geclirigr, duch schmale Nägel, andere aber wiez. b. die lienteltiiere und der Cleiromis halen den Nagel an Daumen des Hinterfufses breit. Bei den folgenden vielen $\mathrm{Ab}$ theilmgen zeigt or sich zwar als scharfichtiger: Benisachee, aber die Sache sellbst vird dadurch? wic in Sobehn cingehiiltt, anch laufen manche $\mathrm{Cn}$. richtigheiten darzwischen; so hat der Haase oben nicht zwei sumlern vier, blos lintereinander gellagerte Scincidezainne, der Lagomys hat oben und miten vier; was wïnde er endlich mit dem cocscoes, hingaruh, Phatangern u. s. w. angefangen haben, welche oben die Schneidezälne, wie die Fleischfresser, unten alser, wie die Nager haben? was mit dem Daman, bei welchem der umgehehrte Fail statt findet? Am unbestimmtesten ist der Unterschied in Gröffere und lileinere, in Fleisch- und Pflanzenfressende, in solche mit vorlaulender, oder abgehinzzter Gesichtsfläche: So dürfte der Bär weder als Fleischfresser noch wegen abgekïrztem Gesichte zu den Faizen gezühll werden, das Bologneser Hindehen ist hleiner als ein Marder, der Mopshund müfste weyen seiner stumpfen Schnau. the unter die liatzen gesezt werden; der Lamantin whe alle Eckzähne, und das Vallrofs, sind rex- 


\section{$-163-$}

mimthlich, aus damaligem Mangel an Kenntnifs hierViber, unter die Hunde gerathen, so wie dic Gruppen von der Spitzmanfs, dem Gürtel-Faulthiere und Fledermäusen blos aus Nothdurft gebildet zu seyn scheinen, weil er sie sonst nirgends unterzubringen wufste.

Ray hat alles seiner particllen Ansicht aufgeopfert, und kïmmerte sich nicht im mindesten darun, ob die Thiere in der Natn auf solche Art gruppiret sind. Ohne nur ein Gefühl für dic Sucression nach dex Vollkommenheit zu äussern, lüfst ex den Menschen ans dem Thicreiche weg, erüfnet dieses mit den Hufthieren, handelt die Afion in der Mitie, dic Nager, Fledermüuse und Faulthiere zulezt ab. In gleich buntem Gemische folgen sich die Individuen jeder Familie, und man sieht, dals er sich schon begniiget, diese Art ron Nägchn, filaucn, Zähnen und Schnautze an ihnen nachgewiesen zu haben; obwohl cr, wie VWotton, die Ucberschritien nich von einzchnen Theilen, sondern von dem herschendsten Individuun hergenommen hat. Jedoch liätte Ray die Menge der Thicre, die wir jezt besitzen, zu seiner Disposition gehabt, hälte or damn seine Ausicht dex Thicre nach Klauen und. Nägehn und nach der Zahl der Finger und Zehen myermischt und conseguent durch alle hindurch crprobet, wahrhaft, or wäre anch auf diesem liünstlichen Wege der Ordnung 
Ter Fotm matr goteten. Wie in Grofsen, so

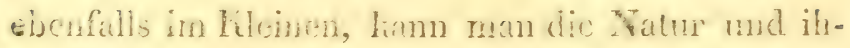
wan bildenden Geist crlennen. Auch in icm mubedentmudeten Theile - an dem Xited oder lhife -

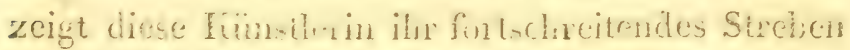

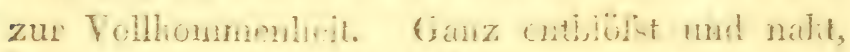

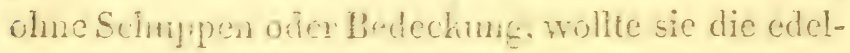
sten Gesclupre hinerellen, wnd nur noch eine ge-

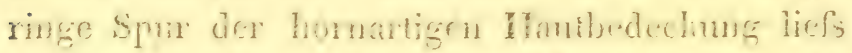
sie an den platen kigeln des Menachen zamirli; "ticfer in das L nwillommene hralsinhend, wöldt sie schon meh den Nagel, und suchet das ganzo rordere Glied in Iforn einzulaiblon: Bei den nagenden Tängasuls, Taton, Aneisonbüron, Fani-

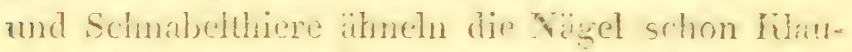
cn, bei der Copybart, und dem Daman, sind sic schon breite winhiche Thlanen, mit den PachiserInon. Schweinen mod dem Hornviehe nehmen dies. inner an Ticfe zu, bis sic cndilich an Pferde das ganze vordere Fuffolied unfascen, und dieses mun röllig senkrecht anf Horn aufritt; mit den Cetacén verlicen sich nicht blos die Júlauen, sondenn die Getromitaten selbst sind mangelhaft und misge-o bildet zeworden; bei Toggehn und Amphibien swe len sich die Nagel immer als Flanen dar, und bei den meisten. Fischen ïberzichen sie nicht nur die Fndspitze der Extremitaten, sondern als Schup= pen odr. Stacheln, die ganze Oberfläche des Fï̀- 
pers. - Eben so rexhailt es sich mit den Zohen. Auch diese, so wie alle antere rheile sind ein Fingerzeig der bildenden Natur. Fon dem Menschen, welcher an der Iland und dem Fufse immer fiuf Finger hat, steigt sie durch rier-und dreizchigte, durch Bisulken endlich zu dem cinhufgten Pferde herab, und an der Gränze dieser lilasse - in den Celacéen - scheint sie die Wirde der Nxtremiliten bei den rorhergotention, hier durch dio Mangelhafigkeit derselben, wo sic sie den Flossen der Fische ähnlich bauet, und bei den Delphinen statt den drei Plialangen, eine Menge, der Länge nach ancinander gereihter finöcholchen, gerade wie bei Fischen, gebildet hat, fuhlbar zi machen. Laum hat sie die Bildung des Trenschen verhassen, so ist schon unter den Affen, bei Atelen, der Daume der Hand, zwar nicht am Slielete, aber äusserlich verschwouden. Bei Katzen und Itunden fehlu er blos am Hintcrfufse, aber auch vom vorderen ist er schon nach linten gerillit; mind welches Spiel of enbart sich im Verhältnifs der Zahl und Stellung der Zaelen zrvischen den vorteren und hinteren Fürsen bei Nagen? Nicht. ohne Bedentung rermehret sich dieser Wechel boi Pachidernen, wo die Zehen auch schon anfan šen, mehr unter siche zu rerwachsen, und nur crsi mit den zwei - und einzehigten hat dio Natur

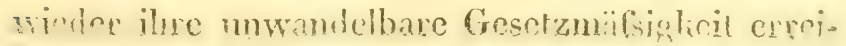


chet. Sclbst dic Anwesenheit oder der Mangel cines einzigen Fingers deutet so den Rang dieses, wic auch den des ganzen Thicres, ja die Epochen der ganzen Thierreihe an. Von dem. Menschen abwärts weicht unter allen Fingern der Daumeu zuerst nach hinten, und verschwindet endlich ganz; nach ihn wird der simmetrisch entgegengesczte - der lileine Finger - umregelmäfsig, und endlich unsichtbar; jezt erst liommt die Reilie an den Zeige-nachher an den Ringfinger, und num ist liciner mehr als der unsimmetrische Mittelfinger, auf welchem das Pferd sich stiuzl, zurïche gcblicben. In eben dieser Aufeinanderiolge verrücken ihren Platz, und verschwinden mit den Fingern die entsprechenden Linöchelchen der Mittelhand und des Mittelfufses. Obgleich aber einzelne Finger auch äusscrlich verschwunden, und in ihrer sclbständigen Gestalt und Lage nicht meln am Slielete zu finden sind, so sind doch von ihmen verkïmmerte Reste zurüligeblieben, und sey en es auch blofse Kinochisplitter oder hanten, wodurch sie sich am nächsten Knochen andeuten. (Die weitere Auscinandersetzung diescr Beobachtung werde ich in einer eigenen Abhandlung mit hiuperern dem Publikum liüftig darlegen) - Wie die Flaucn und Nägel, wic dic Anzahl der Zehen, eben so offenbart der Winliel in der Haltung der Leztern - die Stellung des Thieres - die Amï- 
herung oder Entfermung der Natur ron ihreni Idealle. Menschen, Affen und Büren, sind Plantigraden, mit den Hinden, fiazen und Mustelen macht dic Stellung der Füfse cinen, obwohl noch ziemiich spitzigen Winhel, mil don Nagern, selbst auch mit den Pachydermen, ncigt sich dieser Winliel mehr zum senkrechtrn, und die zxyei- und cinlunfigten treten endlich bles auf der äussersten Spitze des lezten Gliedes der Fülso auf. - Wollte man auf die Beschränltheit oder Vnbeschränktheit der Bervegung der Extremititen schen, so würde, sich ein Glciches ergeben. Der. Mensch hat dio Bewegung seiner Ilinde und Füfse - nach oben. und unten, ror - und rüliwärts, rechts und links oder diagonal - am meisten in der Willkïhr; bei den Affen, Bären, Ilunden, Kátzen und Nagern herrscht nebst der Strecking und Beugung auch noch Pronation und Supination, obgleich in lezteren schon ziemlich beschränkt; bei den Pachydermon, noch mehr bei den zwei- und cinhufigten ist diese beinahe ginzlich verschwunden, und blos Beugumg und Strecking zurüligeblieben.

Auf solche Art hätte auch diese liünstliche Ansicht der lebendiggebährenden Quadrupoden nach hlauen, Nageln und Zehen, wclche ans Aristoteles genommen, sich mach und nach bis auf Ray cntwiclelte, anf dic Sum drs Ganges dor Notur fuih- 
xen lionnen, was freilich bis jezt noch nicht geo schehen ist.

\section{\$. 39.}

Limé. Greich nach Pay schlugg Linné cinen andern Wegr cin, um Ordnung in die behaarten Quadrupe. den zu bringen. Aristoteles hatte schon, so wie die hornartige Bedccliung der Finger, ebenfalls die Zähne mit besonderem Nachdruck zur Gliederung dieser Kilasse empfohlen, Ray hat sic zu Unterabtheilungen gebraucht, Limné endlich machet sie zu seinem Hauptgesichtspunkte, zur Grundabtheilung wähict er dic Anzahl und Gestalt der Schneidezähre, zur weitercn Unierschcidung die Hundszähne, damn anch die Säugwarzen, und endlich die Zahl der Finger und ihre hornartige Bedechumg. Zwar hat or von der ersten Auş̧abe seines Systemes bis zur zchnten, viele Metamoiphosen durchgemacht; aber allen lag die nämliche Hauptansicht imme? ฉ:nverändert zu Grunde, und nur dic Nebenrïksichten waren diesen Verwandlungen unterworfen. So hat er in den frïheren Ausgaben einen höheren Werth auf die Zahl und Lage der Süugwarzen, als auf die Fürse gesezt, in den mitueren ist es umgeliehrt, und jener geschah selten mehr Erwähnu!g. So getren auch Linné seincm Prinzipe blieb, so veränderte er doch häufg die Gruppen der Thiere, welche er darnach hestimmte. In der Ausgabe ron Halle und Magdeling fanden sich fün Ordnun. 
gen nänlich: das Faullhicr, der Ameiscnfresser; Affe und Mensch bildcten die Anthropomorphen die Beutelthicre, Fledermäuse, Igel, das Tatu (unter dem Namen gepanzerter Igel) standen bei den Fleischfressenden ( ferce), der Elephant, das Rhinozeros (elephas naso cornigero), der Hipro. potam, das Pferd, Schwein, und die Spizmaufs (?) bei den Jumenten. In der Ausgabe 1748 liest man schon sechs Ordnungen: das Faulthier blieb bei der ersten, der Ameisenfiresser und das Schuppenthies als eigene Gattung wurden zu ciner neuen Ordnung "agria" erhoben, die Spitzmaus umd das Beutelthier zu den Nagern geworfen. Die zehnte Ausgabe 1760 hat unter allen om meisten Verwandlungen erlitten: Dis Ordnung ,ferac" wurde in noch cine andere ,besliae" aufgetiofst, der Name "agria" in den ,bruta", der ,jumenta" in den "bellucie" umgeändert, und die Cetacéen als die achte Orduung den MTamineren linzugefügt; hicr wurden auch die Fledermäuse zu den Lemuren, Affen und den Menschen gesel. let, und aie Crdnung sulbst, ,primates" benennt der Elcphant, trichecus, bradypus, myrmecophugu, munis machen dis zweite - sus, dasyp., sorex, diuteiph. unter dem Titel: "besíiae" liommen als die vicrte nach jener der ,ferae" - das Rhinozeros stehet in jenen der "glires" zunächst dem Lichlünchen - alus Pferd und der Hippopo. 
tam bleiben nach der Ordnumg "pecorce jener der „,belluats" ïbrig. Vit der zwölften Ausggabe iritt die Ebbe cin: dic Ordnmig "bestiae" wird jener der "ferae" jener der "Jruta" wird das Gürtelthier einverleibt, das Phinozeros und das Schwein werden zu der ,belluat" geworfen, die vesp.noctilio lionme zu den Nagcrn. Die dreizehnte Ausgabe läfst die nämliche Anzahl von siebcn Ordinugen, so wie auf gleiche Art das Imere derselben unverändert, nur trägt sie die noctilio zu den Fledermäusen, das Rhinozeros zu den Brutcn über, rud erhebt einige Arten von Mänsen z. B. cavia, dipus, myoxus, arctomys zu Gathugen, sezt. diesen das nenentdekte "Danan" hinzu, erweitert die Familie ,didelphis" mit den neuenideliten Gattungen, und stellet den Tapir, welcher in der zehuten Ausgabe als hippopotam. ierrestris gestanden, in der zwöiften abre weggelassen war, ncbst jenem als eigene Gathng auf. Bei allen diesen Veränderungen blicb die Ordinung ,pecora" doch immer unverändert, der Mensch und Affe standen immer beisammen, der Bir, Hund, Fischotter, dis liatze und Ploka reriesen nie jene der serce", der Haase, Biher, das Eichhorn, Stachelschwein und die Maus hamen nic aus jencr der Nager. so wio das Pferd nic aus der dre , jumenta s. belluae." Gerade aber jone Thicre, wolche arch nach iner Bidung die inndobiasten 
imd. räliselhaftesten in der Natur sind, z. B. di: ganze Ordnung „brula“ die Fledermäuse, das Schwcin, dis Sorex und Didclph. waren cinem beständigen Wechsel ausegesczt. Dic drrizelunte Ausgabe als die lezte, ist also auch dis Frucht, zu deren Zeitigung alle übrigen beirusgen, and die eben deswegen zum $\Lambda$ nhaltspunkte dienen soll.

Limné hat ron der zehnien Ausgabe an, diese Filasse, statt der bisherigen Benennumg Qnadruped mit der ,Mammalicn“ überschrieben. Allerdings sind die Mammen der Thiere von ausserordenticher Wichtiglicit. Zwar scheinen, wem wir von dem Menschen zu den Würmern und Polypen himabsteigen, andere organische Systeme rerschwinden zu wollen, das Lymphsystom aber als vorherrschendes zurükzubleiben, allein demohngeachtet betrügt man sich, wenn man dicfs Vorher:schen auch als eine gröfsere Vollkommenhcit dicses Systemes ansicht; denn erst nit den höheren Thieren und besonders mit dem Mienschen haben alle thicrischen Systeme und Organe ohne Unterschied die hürhste Stufie der Vollkommenhucit erreichet, und sich in ein harmonisches Gleichgewicht gegeneinander gestellet: Das Drüscnsystem ist also bei den Iebendiggebährenden Quadrupeden eben so vollhomnen und wichtig, wie das der Nerven, MIustietn, der Plugefirfe u. s. w; ja cben

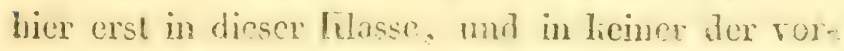


Trergehenden trill es in den bedeutenden Organon - den Mammen - wolche das Aufgesngene und Frzeuggte säugen, nach Aussen, und biethet dadurch die Gelegenheit dar, sowohl die ganze Tilasse darnach $\mathrm{zu}$ benenneis, als auch weiter z.u ordnen. Jedoch Linné beznügte sich schon, das Säugen als den gemeinschaftichen Farakter herausgehoben zu haben, und sching zur ferneren Unterscheidang andere Wege cin. Leider! schcint aber, so ausgezeichnet anch diese Figenscháft bei den meisten Thiercn dieser filasse ist, sie doch nischt auf alle zu passen, indem nach Home's mol Curicr's Uniersuchung an der Echidna und den Schnabelhiere sich nicht die geriagste Spur ron Nammen fundet, auch die den Vögeh so atmliche Beschaffenhcit der Geschlechtsorgane es zu bestit. tigen schenet; weswegon also die Ucherschrif Mammalion verdächlig und zweifolhaft wird. Wie die Mammen, so sind arch die Zühne romzinglive Thicile, un diese Thiere von cinander zu nuterschoiden. Die Zähne, wodmch so wie durch immliche Gchilde z. B. durch dic Nïgel, Schuppon, Hömer des Rhinozeros, homartigen Falcu in Munde der Vogel, Schilakröten and Balinen, dis: Stachel der haicn, des Meersternes, Necrigrle, nnd die leder-oder steinartigen hirusten der Zooplyyten, das Hautsystem seine Verwandschaft wnd Berührung mit dem der linochen an den Tag 
legt, und dieses hierin gleichsam atf seinem Gebiethe wiederhohlet, bichlen so viele Miunchfaltiglieit dar, dafs man nach ihrer Anwesenheit und Beschaffeuheit oder ihrem Mangel nicht blos die Süughinere, sondern das ganze Thierreich zu reihen in Stande wäre. Welche bedeutende Sielis die Zülne behaupten, ersicht man auch darans, dafs sic, wie sich die Extremitüten, Żehen ode: hornartige Bedecking umgestaltet, ebenfails mit diesen ähnliche Veränderungen einhalten. Mit den hiiipfenden Nagen, besonders mit den Beutelthicren und dem Daman, wetch auffallende VerschieAchiseit ist mit dem Wechsel und der abgënderten Lace der Zehen auch an den Zülmen sichtbar? Ber Blephanl, Tapir, das Schwein, Fanlhhier, Gürtwhire n. s. w. welch sonderbare Bildung der Fulse, aber zu gleicher Zcit anch der Zchen zeigen diese? mit den Pferden, den zweinufiglen Wiederkünern und fischartigen Cetacéen ist auch ane ganz eigcne Zahubildung eingetreten. So ftrne man nun in gleicher Abstuffung wie an den Zehen und Klanen die Zahmbildung durch alle Singihiere verfoigl, so wird sich auch an ihr der Typus der Rangordnuig derselben ergeben. Dreifach ist meer den Sïugthieren die Stuffe der Bildung der Zehen: zum Zeifleischen, Nagen und Kauen hat die Natur sic gestaltel, und so man ans der Beschaffenheit dex Zühne die Nahrung und 
dic I.cbensart deutet; so trift man nur eben so vicle Ordnungen von Säugthieren, als es Puhepunlite in ihrer Zahnbildung giebt, an, nämlich Schlave und Reissende, bei welchen die Echiz̈hne, Snchtsame Nayer, bei welchen die Schneidezähne, Aumne Viederküuer, bei welchen die Stolizähne vuhereschen; die ersten sind Sarkophagen, die iibrigen, vorziiglich die lezteren, Phytophagen. Auch der Mensch duchlauft nach und nach die nümlichen Perioden. Zahnlos und blos vom Flüssigen lcbend, tritt das neugeborne hind in die Welt cin, nun erscheinen die unteren damn oberen Schmeilezähne, und der neue Sprösling übt das Ceschät eines Nagthieres aus, später liemen die Ychähne heror, und jenes nimmt schon die Eigenschaft eines fleischfressenden Thieres an, endlich treton langsam auch die Stohzähne heraus, and mit ihnen zugleich das Geschäft des lianens, his zulezt in ihm jene drei Arten ron Zähnen sich in symmerie und wechselseitiges Gleichgewicht gesellt haben, und sich so in Menschen das, was in cinzclue Reihen von Säugthieren cinzeln vertheilet ist, zugleich und mit cinem Male wiederhohlet. Auf solche Weise wären auch die Zähne ein Spiegel, worin sich die Ruhepunlite der Natur in Bildung dor Säugthiere Fund gäben. Allein Limé nahm weder von der Bedeutung noch ron der Rangordnung der rerschiedenen Arten ron 
Zälnen Notiz. Blos ron den Schneidezälnen seine Charahtere entlehnend, vernachläfsiget er die ährigen, und begnüget sich, wenn Süugthiere in das Fachwerk ron bestimmten Aufschriften passen. Man wundere sich daher nicht, wenn er die erste Ordnung durch die Anwesenheit ron vier Schneidezähnen, die zweite durch die $\Lambda$ bwesenheit aller Schncidezäme, die dritte durch sechs vordere zund durch isolinte Hundszilhe, die Nager durch zwei aneinandergedrulite Schneidezähne ohne Hundszähne, die fïnfte durch sechs oder acht untere olme obere, die sechste durch abgestumpfte sheinedezilne charahterisiret. Wer ist aber wohl im Stande, daran: „dentes primores obtuse trun"ali" zu erliennen, dafs er das Pferd, Schwein, den Hippopolan mi Tapir meine? Wer hann das Rindvich, ron cinigen Flcdernäusen z. B. lepturus ferrum equinum unterscheiden, da auch diese untere, aber keine obere Schneidezähne besitzen? ver liamn es reimen, dafs er die erste Ordnung durch vier Schneidezähne oben und unten ausz.cichnet, während er Fledermäuse anfzählet, die vier, zwei oder gar lieine haben, und eben deswegen früher die noctilio zu den Nagern warf? Wer hamn die ,fercec" an sechs, zwei oder zehn Schneidezähnen und isolirten Eclizähmen erkemnen, da ein gleiches auch bei den Beutelthieren, Hirschen, Kameelen, Schweinen und manchmal bei Pfcrden 
nicht selen angoboffen wind? Duch lasse man tuns etwas näher, in die Charahteristili einzelnes Ordnungen eingehen.

Primates. Limne hat hier die Schneideziline als parallel angegeben; allein diefs gilt blos ron den Menschen und den zunächst verwandicn Orangen, in den übrigen iffen, besonders in dem Meulcr, weichen die zwei üussern schon mchr zur Scite, und ziblem lanfen sie ja urer allen Thicren am meisten in rem Mardergesclilechte parallel! - Dafs die Zahll von vier vorderen Zühiẹn nach obcu nicht auf alle Fledermätse passe, haben wir schon gezeigt, abor sclbst unter den Malis finnet sie nicht statt: so haben die Galago zwei wach oben und sechs nach unten, und dir 'Tarsier. Baben umgeliehrt vies nach oben und zwwi nach unten. Die zwei Mammen auf der Brust lommen nicht allein dieser Familic, sondern auch dem Elephanten, Faulthice, Aneiscubär, Tatu zu. Dic vorderen Füfse der Fledermäuse sind vergen ihres' Mangelhaftigkeit eben so wenig I Iinde zn nennen, als die der Phola. Das Mlertmal, becite Nägcl, fiur diese Ordnung, hat Grolii durch den Beisatz: „plerisques beschränlit, inden sie schon bei allen Affen ansser dèn Orangen schnal und hrallenartig sind. Die Unterscheiding der Affen nach dar Ge. genwart und Länge des Schwanzes, bringt öfters die heterogensten z. B. den Hundsaflen mit dem 
Orangen zusammen. Mit Recht hat Gmelin der. Troglodit, auf welchen doch seine Aufschrift: "nosce te ipsum" nicht pafst, von dem Menschen zu den Affen versezt.

Brutae. Hier ,wiederhohlet er, wenn man das Merkmal, dafs die Schneidezähne mangeln, ausnimmt, die nämliche Charakteristik, wie in der Ordnung „belluae“. Jenes Merkmal selbst pafst nicht auf alle hierin begriffene Individuen : so sind. die Hauzähne des Elephanten Schneidezähne, da sie im Zwischenkieferlinochen eingekieilt sind; ferner hat das einhornigte Rhinozeros zwar nach oben keine, nach unten aber vier Schneidezähne, das zweihornigte nach oben zwei und nach unten vier. Bei der Familie der Ameisenbären hat Gmelin die Linnéische Aufschrift „dentes nulli“ beibehalten, aber doch jenen rom Cap der guten Hoffnung, welcher oben fïnf Stock - und zwei unächte Hundszähne hat, hier aufgezühlt, wohingegen Geoffroi diesen unter dem Namen "Oryliterop “ nebst dem Tatu zu einer neuen Familie mit Rechte erhoben hat.

Ferae. Unter diese ist alles zusammengeworfen, was ihm sonst nirgends wohl taugte. Der Charakter von zwei, sechs oder acht Schneidezähnon, unterscheidet sie weder von der ersten und zweiten, noch von der fünften und sechsten Ordnung. Zwar hat er den Beisatz, ,längere Hunds- 
zahne" hinzugefügt, allein selbst die Pariane haben diese, und bei dem Igel und der Spitzmaus sind sie so mäfsig klein, dafs man sie für mächte Stochzähne ansehen hönnte, ferner fehlen sie mehreven hieher gerechneten Dentelhieren. Häte ex die Stockzähne der Bären und Coati untersucht, so hätte er gefunden, dafs der Charahter fur diese Ordnung , molares cuspidato conici, non truncati“" wohl auf alle liatzen, Hunde whd Viversen, nicht aber auf jene anwendbar ist, inden sic bei ihnen abgestumpft, wie bei Affen und Menschen sind. Die Ueberschrift: ,ferac ${ }^{66}$ lionmt wohl dem Tiger, Lüren und Hund» zu, aber dic Bentelthiere, der Maulwurf, Bär, Igel, die Spitzmaus u. s. w. sind weler ansgezeichnet reissende noch fleischfressende Thicre, ja die Phalangen und liängaruh sind nach iliren Zähnen und ilmer Lebensart wahre Nager.

Glires. Zwar haben alle hier anfgezählten Individuen keine Hundszähne, aber das Nerkmal „zwei Schneidezähne“ bestätiget sich nicht am Haasen, nud dem Lagonys; Gmelin beschreibt selbst vier untere Shmeidezähne an dem Daman, nud doch hat er hier desseiben erwälnet.

Pecora. Von diesen licifst es, dals sie oben lieine Schneidezähme haben, allein das Fameel hat zwei; ferner haben die meisten mehrere Eclizähne, bei dem Moschusthier sind diese celhst herror- 
springend; wie unterschieden sich diese also woll nach den Zähnen von allen übrigen Ordnungen, besonders, da die mehreren wiederkauenden Magen auch im Faulthiere, Pecari, Kängaruh, Cela" céen, und an den ersten dreien auch Fliucn sicls finden?

Welche Verschiedenheit an Zühnen findet sich endlich in den Individuen der Ordnung ,bellucte" ? und. doch, obwohl nach Zühnen und Flanen ganz verschieden, sind das Pferd, Schwein und der Hippopolam, an welchem ich nicht einmal obere Schneidezähne finde, hier zusammengebracht. -

Man sieht hicrans, dafs Linné ohne Pü̈lisicht einer Stuffenfolge, einer Vollkommenheit oder Unrollkommenheit in den Süugthieren, alles nur nach der Zahl und Beschaffenheit der Schneidezälne, soferne mchrere Individuen dahin zu passen scheinen, gruppiret hat. Es ist daher liein WVunder, wemn ein solcher Glitikfall Gruppen herrorbringt, worin sich die Individuen gar nicht gleich sehen. Bei dieser despotischen Williühr ist es ebcnfalls zu cntschuldigen, wenn auf die Ord̉nung der nack Zühnen und dem übrigen, vollkommensten Thiere, sogleich eine andere, wie die des Rhinozcros, Wallrosses. Ameisenbäres, Gürtclihiers, wvelche den Zähnen und auch dem ïbrigen nach, beinahe die unrolliommensten sind, folget. Eben so sind die Gattungen und Asten blos nach der herrorsprim- 
gendsten Eigenschaft, z. B. des Homes auf der Nase beim Rhinozeros, der häutigen Flügel bei deı Fledermäusen, der Stachel| bei dem Stachelschweine u. s. w. gebildet, die Ordnungen und Familien sind nicht nach dem herrschenden Charakter der Zähne, sondem bald nach ihrem Range, bald nach ihrer Lebensart beneunt, und die Bescheibung der Familien und Indiriduen widerspricht öfters der Ueberschrift der Ordnungen. Linne's innere Einrichtung der Süngthiere gleichet daher einem Acker, aul ivelchem mit der Frucht eben soviel Unhraut gesäet ist, und beides bunt durcheinander steht.

\section{40 ,}

Während Limné sich öfentlich bestrebte; die Natur nach einseitigen Ansichten zu ordnen, erwachet im Büfon der entgegengesezte Simn, dieselbe nämlich nach allen Richtungen als Ganzes zu umfassen. Allein die damalige Zeit both hiezu noch nicht den erforderlichen lieichthum an Thatsachen dar; ex überlicfs sich also seiner entflamnten Phantasie, und statt die Säugthiere systematisch zu behandeln, wählte er zu ilhrer Darstellung den mahlerischen Pinsel. In Büfons Verke der lebendiggebährenden Quadrupeden ist also nicht Anordnung, sondern Beschreibung zu suchen. Dals er jene in solche, welche zunächst unı den Menschen herum sind (quadrupeds donnestiques) und 
in ansländische (étrangers) abtheilt, diese auf jene lolgen lälst, - und seine reichhaltige und vortrefflich beschriebene Familie - die Affen - nach der Gegenwart oder dem Mangel des Schwanzes unterscheidel, alles dieses bewcifst mir, dafs auch er trotz seines Hasses aller lïnstlichen Systeme sich nicht ganz derselben enthalten konnte. Jedoch sein $\Lambda$ bscheu gegen das Künstliche, und sein warmer Eifer für das Natüliche, hemmten den Fort. gang der liünstlichen Systeme nicht. Kaum war zu gleicher Zcit das System der Natur von Linné in einigen Ausgaben erschicnen, so bestrebten sich sogleich Filem und Brisson, das System der Mammalien zu bearbeiten, und beide wurden glïkliche Commentatoren, jener des Ray, dieser des Ritter Limé. Brisson sah wohl ein, dafs Eimné dadurch, dafs er nur den Mangel oder die Anwesenheit und die Anzahl der Vorderzähne zur Abtheilung wählte, sich auf einen zu cngen Raum beschränkte, und deswegen Thiere in cinc und dic nämliche Ordnung brachte, welche nichts weniger als verwandt waren, Er falste daher liuhn den Entschlufs, nicht sowohl ron dem Prinzipe, als viểmehr von der Beschränltheil seines Vorgängers abzugehen. Indem er num dic Reihe der Säugthiere, in Hinsicht der Zahnhildung durchlief, bemerlte er, dafs ein Theil derselben der Zähne cntbchrte, ein anderer blos Siock-oder nebsi dem 
Eck-oder auch Schneidezähne besäfse, er machte daher diese Beobachtung zur Grundlage, wornach er diese Thiere ordnete. Allein nicht zufrieden, Linné's Ansicht durch die Betrachtung aller Arten von Zähnen erweitert zu haben, dachte er darauf, eine consequente Aufeinanderfolge seiner Ordnun gen herzustellen. Er suchte hierin dem Gange der Natur za folgen, und begann so zuerst mit jenen Thicren, welchen alle Zähne mangeln, schreitet hierauf zu denen, bei welchen sich blos Backenzähne finden, dann zu andern, bei denen sich nebst den Stock- auch die Echiähne cinstellen, and endet mit solchen, welche in der obern oder untern Maxille, oder in beiden zugleịch, StockEck - und Schneidezähne habcn. Zur weiteren Sonderung gebraucht er lierauf die Filauen oder Nägel, die Haare, Stachel, Schuppen oder Gürtel, die Zahl und Beschaffenheit der Zehen, der Hörner u. s. w., so, dafs hieraus achtzehn Orduungen hervorgehen; die Ameisenfresser und Schuppenthiere bilden als zahnlose die erste, die Faul- und Gürtelhiere mit blofsen Stockzähnen die zweite, der Elephant und das Wallrofs mit Stock- und Eclizähnen die dritte, das Kameel mit Schneidezähnen und zwar nur sieben am unteren Fiefer, die vierte, die Giraffe, der Ochs, Hirsch, das Schaaf, Moschusthier mit acht die fünfte, das Pferd mit Schneidezähnen an beiden Kicfern und 
mit cinem cinzigen Tufe die sechste, das Scimin mit zwei Hufen die siebente, das Phinozeros mit drei Hufen die achle, die Cavia und der Tapir mit vier Hufen nach rornen und drei nach linten, die neunte und zchnte, der Hippopotam mit vier Zchen nach vornen und linten die eilfte. Unter den Thieren nit Nägeln, machen mit zwei oberen und unteren Schneidezähnen, ohne alls Ficlizhlue, das Stachelschwein, der Biber, Haase, das Eichïmchen, die Ratte, die Haselmaus, der Igel die zwöllite, die Affen mit vier obern und untern Sclmeidezähnen die dreizehnte, die Mali, Fledermäuse mit vier oberen und sechs unteren Schneidezïlnen die vierzehnte, die Pholia mit sechs oberen and vier unteren die fünfzehnte, die Hyäne, der Hund, Marder, Bär, die hatze, der Fischolter mit sechs oberen und eben so vielen unteren die sechszehnte, der Maulwurf mit sechs oberen und acht untcren Schneidezähnen die siebenzehnte, das Philander mit zehn oberen und acht unteren Schneidezähnen die achtzchnte und lezte Ordnung aus. Was Liné an seinem Systeme vcrnachläfsigte, fiihrte auf solche Ait Brisson consequent durch. Jedoch auch er morlite bei aller sciner Präcision die Lücken seiner Ansicht. So sah er wohl ein, dafs die Nager, gemilfs ihrer Zühne, zwischen die cin- und zweihufigten Thiere gehörten, allein den Unterschied zwischen den Thicren mit Iufen mud 
Nägcin fühlend, rerliefs or also von der sechsten bis eilften Ordnung dic Berüksichtigung der Zähne, und machte diese Abtheilungen nach der Anzahl der Hufe an jedem Fufse, was ihn auch verleitete die Cavia, obwohl mit Nagezähnen, ron den Nagern zi den Behuften zu versetzen. Aber auch abgesehen von dicsen Irrwegen, welcher Widerspruch mit der Natur offenbart sich bei aller seiner Consequenz in der Bildung und Aufeinanderfolge seiner Ordnungen? Brisson liefs den Menschen ganz aus dem Reiche der Thiere weg, cröffnct es mit den zahnlosen Ameisenfressern, handelt dic Affen nach den Nagern und Hufthicren in der Mitte ab, und schliefst es mit den nagenden Berttelthieren! - Beinahe sollte man glauben, es liefse sich keine gröfsere Verwirrung als diese, selbst mit Absicht erdenken. Auch von Irrthümern ist seine Charakteristik nicht frei. Der Vam. pyr, weil er eine gleiche Anzahl von Schneidezähnen, wie die Affen, hat, wird von den Fledermäısen getrennt, und zwischen Affen und Makis in die Mitte gesezt; alle Fledermäuse sollen vier obere und sechs untere, alle Bcutelthiere zehn obere und sechs untere Schncidezähne haben! die Hauzähne der Elcphanten werden als Eckzähno angesehen, dem Lamantin werden auch Eckzähne beigelegt, die Haasen sollen nur zwei Schneidezähne haben; die Ordnungen haben lieine generi- 
sche Ueberschriften; für die ganze hlasse hat er die des Ray, nämlich bchaarte Quadrupeden beibehalten u. s. w. Brisson hat durch seine präcisen Beschreibungen manches am Linnëischen Systeme berichtiget, ist durch Versetzung der Cetacéen, als cigener Flasse, gleich nach den behaarten Quadri: peden, jenem als Muster vorhergegangen, und hat übcrhaupt durch consequentere Durchfuhrung ter Methode Limnés, ihre Lüclien um so offenbarer gemacht.

\section{S. 41 .}

fiurz vor Brisson trat Klein auf, und trug durch Bestreitung des Linnéischen Systemes zur Vervollhommnung dessclben bci. Seine Absicht. ging aber nicht allein dahin, die Irrthümer desselben aufzudecken, sondern die Ansicht der Zühne selbst zu bestreiten, bis er endlich sein eigenes System der behaarten Quadrupeden öfentlich bekannte ${ }^{\alpha}$ ). Er grïdete dieses auf die hornartige Bedechung der Extremitäten und auf die Zahl der Finger, gerade wie Ray, als dessen Commentator und Verbosserer er angesehen werden mufs. WaBrisson für Limné, diefs ist Kilein für Ray. Wir dieser, so überschrieb auch er diese Klasse als be haarte, lebendiggebährende Quadrupeden und theilte sie in zwei Ordnungen, nämlich in die mit

a) Jacob. Theodor. Ǩlein q'adrupedum dispositio. Lips, 175 : 
Klanca, und in die mit Nägeln ab. In der crsteren wich er beinahe gar nicht von seinem Vorgänger ab, und verbesserte nur einige Irrhümer dessclben; dafs z. B. das Rhinozeros nicht vicr, sondern dre: Klanen an jedem Fulse, dafs der Elephant nicht Nägel, sondern wahre filauen habe, und zu den Hulthieren gehöre. Durch diese $\mathrm{Ab}$ änderung erhielt er denn nebst den Familien ,,monochelon, dichelon, tetrachelon, (hippopotrm!.), noch diese zwei, trichelon und pentachelon". In der zweiten Abtheilung, nämlich der Thiere nit Nägch, ging er von Ray ganz ab; dieser hatle scine Ansicht ausser Acht gelassen, und tiese Thiere nach ganz andern Rüksichten geordnet; Iilcin aber hielt seine einmal gewäblte Anicht fester im Auge, und brachte sie nach dre Zahl der Zehen unter vier Familien, als: - didaciy7on: camelus, bradypus didactylus - triciaclylon: bralyp. tridactyl., Tamandus, - tetradactylon: ta!u, caviu - pentadactylon (constanter in anticis: lepus, sorex (sciurus, glis, mus, talpa, vespertitio), mustel: erinaceus, histrix, canis, Irupus, vulpes, coati, felis, ursus gulo, simiae. (anomalopes, pedibus anserinis: lutra, castor, rosmarns, phoca, manati) - Das nämliche System Kleins, nahm auch Hallen in seincr Naturgeschichte, welche sich durch cine angenehme Beschreibung der äusseren und inneren Theile, 
dann des ölionomischen jedes Thicres auszeichnet, anf a), obgleich er sonst die Systeme mit Gerüsten vergleichet, wclche man nach aufgerichtetem. Gebäude cinreisset. - Die Kritik, welche Klein an Linné ausübte, läfst sich auch an ihm wiederhohlen. Zwar ist auch er in etwas von seinem Prinzipe abgewichen, indem er bei der ersten Abtheilung die Filanen, bei der zweiten die Zehen berïlssichtiget, jedoch ist er im Ganzen immer auf dem nänlichen VVcge fortgegangen, und was Ray angefangen und unrollendet liefs, hat er auf das genaueste durchgefuilırt. $\Lambda$ ber nun springen auch die Lüchen jenes Systemes, da es seiner Anlage nach consequent vollendet ist, um so deutlicher in die Augen. Es giebt Faulthiere und Amcisenfresser, wo bei rerschicdenen Arten die Zahl der Zehen ron zwei, drei und vier - Tatu, wo sie zwischen vier und fünf wechseln; Alle diese Arten, gleichsam lïnder und Geschwister der nümlichen Familie, mufsten getrent, und, um consequent zu scyu, unter die verschiedensten Familien geworfen werden! Da die Hinterfüse besonders dem Wechsol unterworfen sind, ja der Lamantin gar lieine lat, so ist es der Villliuhr erlaubt, sich blofs an dic Vorderfïse zu halten, und doch haben unter den Affen die Atelen äusserlich nur vier Zehen

a) Johann Samuel Hallen Naturgeschichte der Thiere in systematischer Ordnung. Bd. x.2. Berl. 1757. 8 . 
nach rornen, die Hyäne hat beständig nur vier, an cinem Hunde habe ich einmal Gelegenheit gehabt, gleiches zu beobachten. - Auch diese, wie auch die vierzehigte Viverre, müfsten von ihren Verwandien losgerissen werden, und sich nach èer Gewalt fügen. Warum er das Kameel, welches doch Hufe hat, unter die Thicre mit Zehen rechnet, sieht man nicht ein, ausser er mürste sich durch die ticferen Einschnitte und jenen den Plantigraden ähnlichen Gang derselben dazu haben berechtigen lassen; aber dann verdiente auch das Fauthier, dessen Zehen bcinahe bis zu den Nägeln rerwachsen sind, mit mehr Rechte unter die Hufthiere gesezt $\approx u$ werden. Uchrigens gedenlit auch er bei den Thieren nirht melu des Menschen, fängt ron den Hufthicren an, zähict die $\Lambda$ ffen in der Mitte auf, ja macht beinahe damit den Uebergang zu scinen Schwimmfiufslern, und liummert sich überhaupt nicht um die Aufeinanderfolge der Individuen in jorler Familie. Hiemit wären nun die Wege, welche Ray und Linné zuerst eröfneten, Flein und Brisson aber noch ausbesserten, vollendet, und es steht jezt zu crwarten, ob die Zoologie sich entweder eine neue Bahn bricht, oder auf den Ruinen verweilt.

S5. 42.

Ray lebte nochmals unter seinen Landsleuten, rant. obwohl etwas verändert, auf. Pennant, berühmt 
durch seine arktische, dann auch durch seine britanische Zoologic und durch die Gattungen der Vögel, sah aus der mangelhaften Bearbeitung der Süugthiere seit Aristoteles bis jezl, wohl ein (und äussert es auch in der Vorrede zu seiner Geschichte der Quadrupeden) dafs das System nich: allein die Unterschiede, sondern auch die Verwandschaft der Thiere untereinander darthure sollte. Freilich erreicht man diesen Zweck nicht so leicht, weun man nur einen einzigen Theil des Lörpers berüksichtiget. Pennant fafste daher die ganze änssere Gestalt des Thieres (habitus) ins Auge, und suchte sie darnach so zu gruppiren, wie sie ihm verwandt zu seyn schienen. Doch sind es rorzüglich die Extremitäten - ihre Klanen, Nägel, freie oder mit einer Flug - oder Schwimmhaut verbundene Finger - welche ihn in seiner Abtheilungen leiten, wie aus den vier Ordnungen zu ersehen ist, womit sich sein Werk: "Synopsis s. history of quadrupeds" weillüufig beschäftiget, und die also aufeinander folgen:

- Vierfüsige Thiere mit Hufen (hoffed quadrupeds)

- mit Fingern (digitated)

- mit. Flofsfüfsen (pinnated. phoca trichecus, manati)

- mit Flughäuten (wingedbat)

Die erste sondert er in solche mit ungespaltenen (wholehoffed) und mit gespaltenen hlauen (Clo- 
ventioffed) Ochs, Schauf, Ziege, Giraffe. Antilo. pe, Hirsch, Moschnsthier, Kameel, Schwoin, Nashorn, Flufopferd, Tapir, Elephanty; die zweite ols die reichhaltigste und schwierigote, theilt er mehr dem Liuné gemais, in menschenahnliche (antheropomorphous: Affen und Malij), in Tanbthiere (rapacious: Hund, Hyane, Hotze, Bür, Dachs, Beutelthier, IViesel, Otter), in Narre (Caria, Hoose, Biber, Stachclthier. Murnelthicr, Eirhlorn, Vinterschlafer, Spinger, VIus. Spitzmaus, Maulwour, Iged, in snlche Thiere mit colder ohne Sehneidezalne (Fanl- murl Gurtelthier), nidro olne alle Zabne (Schuppenthier. Ameisenfreser).

Was bielue Foy und Ficin, Linnd and Brisson in dieser Nosso einzeln goleistet habon, alles

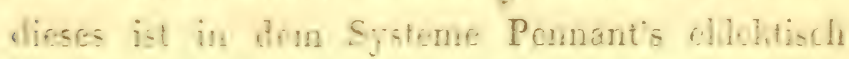
vereinigh, und glciclisan auf wenige und lcicht

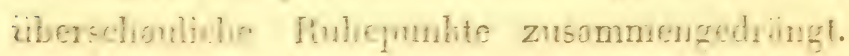
Bei Bildure und der Aufeinanderfolge der Orhnurgen, nolum en sich die beiden ersten, in jener der Grattungen und in den Unterabtheilungen, die beiden lezteren Verfssser zum Mister. Allow in feinom Systeme seiner Vorgänger fallen dirwes Thacre in so wenige und cinfoche Gruppen zosenmmen, als in den scinign: denn, was iat lricher, als auszumitteh, ob ein Thier Hufo, ob es Finger, Schwimmfules oder fine Flughant lobot So einfach und becquem aloer diese Gruppen sind, so 
will doch ricles nicht so natülich darmier passen, und der Verfasser selbst hat sich deswesen riele Ansnalimen erlaubt; so hätte er den fliegenden Mali nicht bei den menschenähinlichen Affen, das fliegende Beutelthier nicht bei den Raubthieren, das fliegende Eichhorn nicht bei den Nagern aufzählen sollen, sondern alle diese in scine Ordnung der Thiere mit Flughäuten setzen müssen: und gehörte nicht auch der Fischotter, Bieber. Ondatra, Hydromys und alle Thiere mit Schwimmfüfscn cben so gut, wie die Pholia, welche doch selbst dem Skelete und andern Theilen nach den Mardern so rerwandt ist, in dic Ordnung des Schwinimluifsler? Vienigstens wird er die Bencu. nung "Rossonfuifsler (pinnated)" nicht so genan. nach dem, als was es erscheint, sondern, was es ist, nchmen wollen, indem alle hier aufgezählten Individuen nicht Flossen, wie die Delphinen und Fische, sondern Finger, Füfse und Nägel, wie die übrigen Sängthiere, haben. Ferner finden sich bei der Cavia Copybara, dem Daman und Kïnguruh wirkliche Klauen, anch bei Ameisenfressern, Faulund Gürtelthieren sind dic Nägel riclmehr Klauen, die Zehen selbst so rerwachsen, dafs sie üusserlich betrachtet, nicht einmal mehr als Finger zu miterscheiden und zu nennen sind, und doch sind alle diese nicht bei den Thicren mit Infen, sondern mit Fingern zu finden! Ucberhaupt wäre Pen- 
nant ricl consequenter verfahren, wenn er die Hauptabtheilungen des Ray unverändert beibehalten, und blos dessen zweite Hauptabtheilung, nämlich die der Thiere mit Zehen, in solche unterschieden hätte, die frei und unverwachsen, oder mit einer Schwimm- oder Flughaut verbundene Zchen haben. Aber so ist trotz seiner eigenen Verbesserungen or rielen Irrhümern seines $L$ andsmanns getren geblicben. Wie dieser, so hat auch er die Ueberschift "Qnadruped" beibchalten, und sogar die Cetacéen, weil sie haar- und fulslofs seyen, von dieser hilasse ausgeschlossen; des Menschen wird gar nicht gedacht, und die Ordnungen und Individuen folgen, ohne gerade verwandt zu s'yn, aufeinander. Zwar sagt er, die Fleder. mäuse, als der Schlurs dieser Kilasse, sollen den Uebergang zu den Vögeln, das zweihufigte $\mathbf{P}$ ferd (Gnemel) jenen von den einhufigten zu den Bisullien machen; aber wer sieht wohl die geringste Verwandschaft eines Hufthieres, sey es auch der Elephant, mit cinem Alfen? wer die eines Otters mit einem Naglhiere, wer die des Ameisenfressers nit dem Wallrofs, des Manati mit der Fledermaus ein, und doch sind diefs die Gränznachbarn der Ordnungen untereinander. Eben so stehet, blos nach dem äussem Aussehen rerwand, eine Gatung zunächst der andern z. B. auf dio Maki folgt der Hund, auf die Bären die Beutelthiere, auf das 


\section{$-193-$}

Siungaruh die VViesel u. s. w. Bei solchen künstliden Cl:araliteren und allgemeinen Ueberschriften, horinte es niclit fehlen, dals manches im Inmern seiner Aufschrift widerspricht: so wird bei den einhufigten der Gnomel aufgezählt; die Affen mid Matii heissen nenschenühnlich und pflanzenfresserid, mad bald daranf werden viele Hund- und Kutzenartiģ, Insekten - Eier - Vögel - ïberhaupt * leischfiessend genenut; cine andere Fanilie wird als rünberisch und fleischfressend, mit Eck- und mit sechs oder mehreren Schneidezihnen überschrieben, während gleich darauf bei den Beutelthieren, Bären u. s. w. von vielen das Gegentheil behumptet wird; auch heifst es ron den Nagern, dals sie keine Eckzähne mi nur zwei Schneidezälue haben, und gleich darauf wird hier auch die Spitzmaus, der Maulwuxf und Igel aufgezählt, welche doch alle die Zahubildung der Fleischfresscr haben. - Das eklehtische System ron Pennant hat sich also bei der Verschnelzung der Ansichten seiner Vorgänger, anch die nicht zu hebenden Widersprüche, so wie ihre Irrthüner einverleibt, und obwohl einfach und rerständich, dem Innhalte nach sethst reich an vichei guien liupfern, und angonehm durch die geschichtichen Beschreibungen, ist ge nichts weniger als natülich. 
Der Anfenthalt und das Filima, Worin die Sängmann. thicre leben, warn bisher so zicmich rernachlissiget und ungewifs. Zimmermann, Professor der Matherintik mo I hysil in Branschweig, natm sich die Mühe, diese Lüclie anszulinllen, und entwarf cin systen, minl eine geographische harte, wo diese Thiere nach den Grade inrer Verbreitung auf der Erde georinct sind "). ZMu crsten Abtheimng gchören die überall rerbreiteten: Menscli, Hund, Ochs, Schaaf und Ziege, Pferd und Eiel, Schwein, hatze, Fuchs, Bär, Haase, Fianinchen; Hirsch und Reh, Eichhorn, Ratte und Maus, Wiesel und Hermelin, Scehund, Scebär, Seelïw, Manati. - Zur zweiten solche, die grolse Striche in beiden Velten bewolnen: Remnthier, Elen, Marder, Biles, Smmp- mnd Flufsotter, Viclfial's, Luchs, Zobel, ficgendes $\mathbf{H}$ ichionn, Murmelthicr, Dachs, Wasserulle, Feldnata, Meerschweinchen, gresireiftes Lichhönchen, Wallrofs. -

a) Eber. A. Cuil. Zimmermanu Specimen Zoologiae gengraphicae quidrup cdum clim tabulu zoograghica. Lugduni Batavorum 1777 .

- Gcographishe cieschichte des Kicnschen und der allcemein verbreiteten vierfüfsigen Thiere nebst einer zoologischen Weltcharte fon Zimbiermann, Bd. 1. 2. 3. Lcipz. $177^{8}$.

- desselben Taschenbucie der heistan, ister - gter Jahrg." aweiten Abtheil. für das Jahr 1810. Laipz. 
Zur dritten solche, die aul rerschiedene Theile der alten und neuen Welt eingeschränlit sind: Lemming, Dromedar, Igel, Spitzmaus, Büffel. - Zur vierten solche in heiser Zone: Vampyr, Mangoust, Zibethkatz, Löwe, Elephant, Nashorn, Orang Outang. - Zur fünften solche in der heisen Zone Amerikas: Cuguar, Jagnar, Glama, Vicogna. Zur sechsten endlich solche, die in dem beschränktesten Raume der aiten oder neuen VVelt leben: Afen, Antilopen, Dasypoden, Ameisenfresser, Schuppenthiere, Fledermüuse, Cavien.

Zwar lïst sich : Zimmermanns Ansicht ron dem lilimatichen Aufenthalte der Thiere niemals zu einem Systeme derselben ausbilden, iudem gerade dadurch wie im Büfon, der sie nach der Nähe oder Entfernung rom Umgange des Meuschen ordnet, die rerwandesten Familien und Arten gefrenut, die heterogensten aber terbunden werden, ja die Cetacéen alle Meere durchistreichon, viele Thiere, wie z. B. der Lenming, gegen Süden zu wimdern, die Biber selbst, wie schon ehmals die Elen und Pennthier nach Cäsars Beschreibung, sich allnänlig aus Tentschland, und dem Süden rerloren laben, und gegcn Norden anhäufen. Dieses scheint anch nicht so ganz seine Absicht gewesen zu seyn, deswegen er die lezte Abtheilung der Thiere in seiner lateinischen Ausgabe nach dem Systeme Linnés, in der teutschen nuch jenen des 
Pennant wihet. Aber leine Ansicht bisher giebt

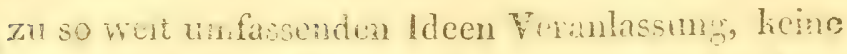
ist von so hïhnten Resultaten boglentet, als dic Zim-

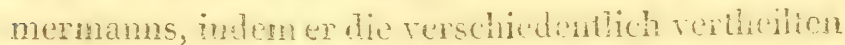
Thiere al Glied zum to

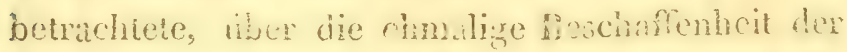
Erde zu nutheilen, dic Zoologie zur liosmologie leitede. Sind alle Thicre von cinem cinzigen Landstriche audegeganigen? sind sie vielleicht ron einem rinzigen Stammsater erzengt, und durch Auswanderung und allmählige Ansarung in anderen Lündern zu dieser Menge ron Gattungen und Arten lieran: cwachofn? und wie mufoten damals die Weltheile beschaten gewesen seyn, um diese Wandezung möglich zu machen? Jlefs sind dic bedenhlichen Fragen, die Zimmernanin be i der Betrachtung seiner zoosraphischen harte aufwirft, and als Resultate sunes Werlues an Ende desselben beantwortet. Las crste giebt er nur ron dem Menschen zu, wo die weissen Stammeltern, an dem Buckel ron Asien lebend, von licraus in die Welt auswanderten, and nuch den rerschiedenen Filinaten zu schwarzen Negeru, zu zimmethraunen Amerikanern, zu strohgeiben Asialen u. s. w. ansartcten; die übrigen Gatungen ron Thieren waren schon ursprimglich in der Weli zerstrent, nnd nur Arten degeneritun sach verschicdenen

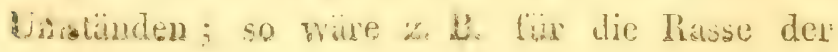


JTunde der Wolf, fir die Schaafe mol Ziege der Steinbock, für das zahmo Pferd und don Fscl das wilde Pferd, für dip Entwrine der Lber der ursprïngliche Stanmwatex. Da ferne bihs ler Norden ron Asicn, Europa und Ancinh viele der sümlichen Thiere, das studliche Asien viele nit Ausiralien, das siddiche luropa cinige mit dem nördichen Afrika enminum haben; so hilt er os

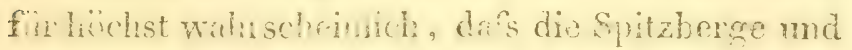
Cumbren nit An rihn, Nota Zembla mit Asien, Fimntschatha mit den Norden ron Amerilia, Siciien mit Calabrien, Fugland mit Gallien, Europa nit Arika, Jappon, Dorneo, Sumatra, Java und dic Plilippinen mit Asicn ehmals zusaninengehangen haben; allein Issland, Neuholland, Neuguinea, in welchen die bcnachbartsten Fïstenbewolnex ron cinander verschiedcn sind, odcr wie Otaheito rst durch Kolonien mit den Hausthieren bevölkert wurde, scheinen ihm frei aus dem Inecre, ot. durch vullianische Gewalt oder durch Zuruikwci. - himg des Wassers, heransgesticgen zu seyn. Welch hohe nud weilumfassende Weltansichten swachen nicht bei der Befrachtung der Verbres Imgg dicr Thiere und der darnus gexogenen Vermu. thwng der chmaligen Gestall merer Wrie! Vare es nus jezt schon vergünnet in den plan der Schï-

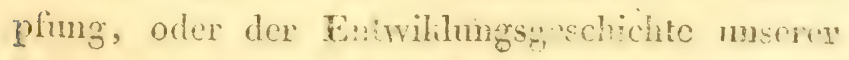

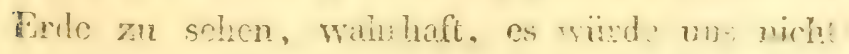


gleichgiltig vorkommen, ob dieses Thior in der heissen 'Zone, in der gemärsigten oder halten woh. ne. Wie die Erde nach ihrer abwechselnden Stellung zur Somne ihren Reichthum in der Aufeinanderfolge ron Tag und Nacht und von Jahreszeiten offenbahrt, cben so wuchern dic dadurch rerschiedenen Iflimaten an Manchfaltigheit und Verschicdenheit in ihren Produliten - den Mincralien, Planzen und Thicren, welche alle drei in ihrem Vorkommen einem Baume gुleichen, der im Norden wurzolt, aber durch die mittlere und heisse Zone geen den Sirden sich immer mehr verzweigt, und in allmählig mehrere Blithen sich aufschliclst. - - Die urspringlicisen Gehüuge liegen, so wie das ganzo Continent überhaupt, mohr gegen Nordost, die anfgeschwemmien gegen Sïdwest a); die Metalle wählın nịcht das primüre Urgebürge, sondern jenes der zweiten Formation der Urzeit, nümlich das der Gänge und hier mehr die gemäfsigte und heisse Zone, das Eisen, obgleich am häuifgsten verbrcitet, nach allen Daten mehr die halte, das Gold die heisse, das Blei und Quelisilber mehr den Westen, der rerbremnliche Schwefol und Phosphor mehr den Siiden zur Geburtsstätte. Die Nadelhiblzer, dis hriechende Moos, und die geruchlosen Grüfser, wachsen am licbsten auf nürdli-

a) Thel iiber den Bau der Ercle in dem Alpengebürge, 2ter Bd, S. 405, S. 413 . Zürich 1808. 
chom Boden, die breitblitteriston Bänme wat dio wohlriechenden fiäuter haben sich die wärmeren Gegenden anserliohren. Eben so sind anch dic Thiere nach ihren klimatischen Vohnplätzen verschieden: Der Mensch und die durch ihn bezälım. ten Hausthiere sind beinahe in der ganzen Welt rerbreitet, das Renn - und Elenthier lieben die hälteste Zone, das Afron - ma Tazengesclilecht dio hciseste, der Ameisenfresscr, das Fanl - und Gür. telthies, der Cuguar, Inguar, lebon nur in dem mittiglichen Amerika, das hüngaruh, SchnabelIlier, die Echidna und der Phaskolom blos in Neuholland. - Hat aber unser Planct immer diese Gestalt, seine Oherfliche immer dieses Ausseben, wio noch hant zî Tage gehabt, und ist seine Axc und Ehliptik seit seinem Ursprunge immer die nünliche geblieben? Diefs ist die schwere Frage, mit deren Aufösung sich noch .Jahrhunderte beschäftigen werden. - Auch die Frde hat, wie alles auf und in the Befindliche, rerschiedene Stuffen des Alters, und mit diesen ändert sich gerade, wie sich mit einem neu cingetritenen Alter allo Organe - hürper und. Scele - des organischen Individunms netamorphosiren, dic Constitution aller Individuen. Gleichwic man daher an den Gebürgen einen primitiven und secondären Ursprung, in der Weltgeschichte einen Zeitgeist des Alterthums and Nenerthums mistrscheider, eben so hiomte 
man auch an den Weltheilen der Frde die rer. sprüglichen und alten ron den jüngeren und neneren, an dew Thicren dic wsprünglichen und alten von den morlerien unterscheiden. Dafs Asicn, Furopa und Acgypten unter die alten Melubile gelören, dafir sprichi in mit der Geschichto gleich altes Andrulien, da!s aber jene drei zusan:men die alte, Anerilia und Australien tie nich nur der Futdechurgy sonden anch lem ir. sprunge sach nenc Welt aumachen, diefs mëge der Physiles und Grolog von Scite hmerilias aus der druch Sren und Flüsse zorissenon und hüble lichten Goutalt, aus der in dio Länge gezogenen Figur, ans der Beobachtung der storticres livile in dicsem Viltheile, aus den sonst nicht in $\mathrm{U}_{\mathbf{x}}$-son. dem in den Flötzgelïirgen rotiommenden und hicr so häufgen Vullianen, aus der Nalie ron Thamtschatha, möge er es hier ans der Neuhcit der Gebürge, dort ars ihrer äleren Formation u. s. w. erweisen, möge diefs der Inotanilier durch dic Achnlichkeit und Verschiedenheit der Pflanzen ansmitteln, der Zoolog fundet bis jezl sehr viele Beweise fin diese Vermuthung. Zwar ist Austrá. lien mit dem benachbarten Asien durch vicle der nämlichen Gallumgrn ron Thieren z. B. dem Filephinten, Rhinozeros, Tiges, Büfel, cingen Aren

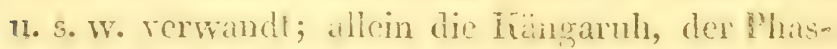
holom, das Schnabolihier und die Echidna ims 


\section{$-201$}

Ihim ganz cigen, und nirgents hat sich bis jezt ein itmliches Thicr auf asiatichem boden gefunden. Auffuliender noch ist dieses mit Amerika; umsonst winds man hier, ehe es bei scincr Rntdeckung mit meheren dieser Thiere berïllert wurte, den Gicphant und das Iihnozeros, das hamerl med die Girufre, das Schwcin, don Panther, das Pford und das Schan sesueht haben; Aber wie verindert,

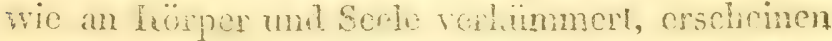
Iner joue Thicre, wedche sie ersetzen sollen! Der rapir, die bicoma vud das Glama, das Pehari'

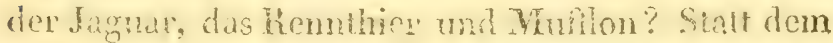
menschomidnlichen Orans Ontang und T'roglodyt acigt sich hier der Belzohn mit scinem langen Rollschwanze, statt dem Pongo der Jlenlaffe, statt den Gunonen und Parianen, die Saki, Sagnoins and Sapojous, statt dem Oryliternp in Acrypien der Ameisenfresser, statt drm Sirun!sse die unansehnliche, dreizchigte fihca u. $s_{a}$ w. - Erscheinen nicht so jene Thiere der uben Velt waluhati als alte Vorbilder, woron in Amorilia ham roch dis Copien sind? Jedoch ist es nirht zu liugnen, dat. anch diese Thicre von Amerila cin altliches Aus. schen labon, allein es and Abilien gleichsam ron der zweilen Fonmation, dic There der nenesten Rildung crhall tnorifia ral seit seiner Fratechung. Sey es nim jozt, duls wich mah der Wommg des 
rotreffichen Geologen Sieffen's ") das XIecr zwischen Afrilia und Schwedcn aus der aufgeschwemmten Ebene ron Enopa und dem Innem ron Afrilia zmöligezogen, durch Anschwellums um Australicn aber direses ron Asien, das mödliche Amerika ron Tamtachalia losgerissen habe, mid vielleicht das nürdliche Amerilia ron dem südlichen bei Panama, das Aegypten ron Asien bei Snez noch tremnen migte - dem sey, wie ihm wolle, rie triftixsten Gründe und Urthrile der meisten Gelehrten stimmen fur die Vermuthung, dafs dicir, Europa und Acgypten sich ricl früher, Ameritía mod Australien riel später gebildet und gestaltet laben. Viclleicht, dafs selbst die Mastudontes, die fossilen Arten ren Elephanten, Rhinozeros, Tai) ire, Ilippopotamus, Megatherim, Mrgalonix, Anaplotherimu, Paliotherim und alle so wunderhare Gestalten zu den Thieren der frühesten Epow che unserer Erde geiörten, viclieicht gar ilı Erbthum ron ciner fremden fir sie ehmais mütterlichen Felt waren, und jezt nur, wie die Antilien des griechischen Alterthums, theils als fossile Ruinen, theils in wenigen noch lebenden Bildern z. B. dem Elephanten, Rhinozcros, Hippopotan, der Dronte, dem Strausse u. s, w. den Menschen als

a) Geognostisch-geologisclie Auftätze als Vorbereitung zu einer inneren Naturgeschichte der Erde von $M$. Steffene S. 29. Hamb. 1810 , 
den IIcren der nouen Schöpfung an eine colossale Vorwelt eximnern sollen. - Allein wic geschah es, dafs sich zu den äteren Formationen noch jüngere hinzufügten? Un überhaupt über dic Bildungsgeschichle der Frde zu reden, sollte man immer die Analogic und dic Parallele ännlicher Schöpfumpen wie z. B. die Tntstehung anorganischer Indivituca durch den chemischen Prozel's, der organischen durch Zeugungr ror Augen haben. In beiden zeigen sich in den, aus dem Gleichgewichte weichen * den Gliedern, zuerst dic clchitrischen Phänomene des Lichtes und der Wärme, mil der Erscheinung des Vassers ist der hampf schon geleget, und ruhis gestaltet ich das sich Ausschcidende, oder in Bezug auf die anderen Ausgervorfene, aus dem IVasser heraus, als dem Versöhner alles lírieges, zur neuen Indiridualiät. Mit der Existenz des Tristalles oder des Embryo, sind also zu glcicher Zeit auch alle wesentlichen liëperlichen und dynamischen Beschaffenheiten vorhanden, und alle streben nur. sich aus ihrem Falle zu cinem harmonischen, ind: viduellen Ganzen zu entwickeln, und allnühlig fir cin höheres Element, als das VFasser ist, heranzu wachsen. Sey es nun, dafs die Teluliöper nicht. als losgerissene Weltheile sind, und dafs iher Bil. dung eine ähnliche Metamorphose, wie jene vor Trabanten, Planeten, Liometen und Somnen vorgeschrieben ist, soy es, daf die leate grofke hots. 
sirophe unserer Srde, die Umbildung ron cincm Trabanten in einen Planeten war, sicher hat sir, wo sie sich als Planct in Somensystem hinstelle, mit cinem gleichen eleliriachen Prozezse beonnen, wude hievarf in eine den lireg und die Sïnde des Abfalles tilgeade Fhul eingetancht, und hat sich so mit allmähliger Abnahme des Vassers, wie der liristall und dev Limbryo, zum Luft - ma Lichtrcich emporgelicben. Ist dieses abex dies wahrschemlichere Geschiche der Bildnug der Erde, damn düzt die Pehamphom dex nouen hanzisischen Gelehrten, dafs sir je weder ihre Axe noch Etiliptik ändere, als grvirilos zusammen, und sic hat schon und reäudert moch in jotem Whmenic thre Axe sowohl als ihre Riliptik, gerade wic es die Natur bei dem nexgebornen Finde, und bei den kiriechenden Thieren mit dom Eintrite in dass menschliche Ales thut, was freilich in unendlich weiten zeildistanzen geschicht. Gleichwic aber snit dem Beginne des Iimbyo Fnochen, Muskeln. Nerven u. s. w. fievich ancin den Milissigen Elcmente accommodint, vorhanden sind, ebenso viarm es auch nach analogischer Vermuthung bei jener grofsen IVictamorphose der Erde dic Cichnimse. Pflanzen wind Thierc; lieine der hlassen, Ori. nungen und IIauplsattungon oder Formitimen fehle, bis endlich von der alten Wrelt, mut ramar

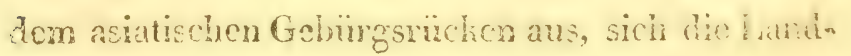


Lhirexe in den aus dem Wasser hervorgestiegencu? und unter sich rerbundẹn gewesenen Weltheilen verbreitcten, die urältesten Foruen von Thieren. cndlich ausstarben, und dic nach Verschicdenheit des Itlima und der Geschlentsrembchingy ausgearteten Familien und Gullungen zurükliesen, die Limmlhiere selbst aber ahmählig an gröfserer Mense: genen die ehnats vonterschenden Seethiere heranwuchsen. - Zwar stimmt die Geschichto wid die älteste Sage mit dicser Annahme der Bildungsgeschichte userer Lrde ganz überein, je. doch wer wagrt es bei unserer liurzsichtigheit sie für mehr als cine Muthmassung auszugeben? Erst, die späte 2 ukunft, wo die Geologie die Gebürgsformationen ron allen Weitheiten, die Zoologie und Botanil alle fossilen Bruchstïche der Lauplyopen organischer Bildung hemen wird, und wo alle Wissenschaften melir zu cinem organischen Ganzen sich anschliefsen werden, diese möge uns dann erlauben, die Erde wie cinen organischen. hörper gegliedert zu exlienen, eben diese Zulimft möge damn über mere gelegentheitlich hier geilusserte Idee ron der Pillung der Frde richten, und Zimmermanns Versuch una Ansichten über den ehemaligen Zusammenhang der Weltheile chen so wïrdigen und bestätigen, wie das gegenWirtige Zeitalter seine Verdienste un Bewerhistelligung einer zoographischen fiarte dex Süughier 
anerkemt, und allenthalben in andern Fichern nachahmt.

$$
\text { 5. } 4.4 \text {. }
$$

Von jezt fing nuan immer mehr, besonders auf teutschem Boden an, das Liméische System der Sätgthicre auszubessern, oder selbst anders zu gestitten. Scopoli ${ }^{a}$ ) stı ebte noch mehr als seine Vorgänger, die Linnéischen Ordnungen auf engere Gesichtspunlite zurukzubringen. Er unterschied sie in solche mit vier Fürsen (quadrupeda) und damn in Cetacéen, jene in die des Landes und des Wassers, sonderte sie ferner mit Ray nach den Nigeln und Flaten, endlich mit Limé nach der Niammen und Zilhnen ab, und entwarf so folgende Ordnung:

Gens A. Quadrupeda Divisio I. Terrestria

1. ord. unguiculata

- mammis 2 (homo, simia, lemul, vesperitil. $\operatorname{brady}$.)

- mammis 4 et pluribus:

a. dentib. primorib: nullis (myrmecophag. manis)

f. anticis senis (excepti didelphi) (didelph. urs.viver. mustel.talp.)

भ. anticis binis (sorex, sciur. mus, erinaceus, hystrix, cavia, lepus)

a) Jcamu. sint. Siopoli introductio ad historiam naturalem, Pragae $777 \%$ 


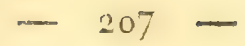

2. oxd. ungulata

a. ruminantia: moschus, bos, ovis, capra, antilope, cervus, giraffa, camelus.

B. non ruminantia: equus, tupir. sus, rhinocer. elephas.

Divis. II. Aquatilia:

hippopotam. hydrochoerus, castor, 7utra, rosmarus, phoca, trichecus, manatus:

Gens. B. Cetacea (balaena physetor, monodon delphin.)

So einfach diese Einrichtming ist, so beweist doch auch sie nur, dafs die Nitur durch solche kïnstliche Facher, wie cin Gefangener in Fesseln gelegt: werde. Der Lamontin hat heine hinteren Fülse, und pafst also nicht mer die Denennung Quadru. ped, mehrere Arten vos Landhieren z. B. ron Mänsen, leben ebenfalls wie der Biber, Fischotter, am Wasser; ferner eben diese lezten theilen ihren Aufenthalt zwischen Wasser mi Land, und können somit nicht ausschliefsend Wasserthiere genennt werden, was elier den Celacéen gebrihrte. Freilich lassen sich auch jene wenigen Lücken an dicsom Systeme verbessern, wenn man wie Scopoli, gau lieine Verwandschaft der Natur vor Augen hat, sondern seiner lï̈nstlichen Ansicht gemüls Nager, Fleischfresser, Thiere mit Zehen oder Nïgeln, zer* slücleln, und den einen Theil wegen des Aufenthalts am Wasser als Wasserthicre absondern will. 
Ganz anders duchte Eralebcu. Misragnigi uis. die bisher mifiungenen lerguche, die There in eine lininsliche Ordnung zu hringen "), shlug e: cinen venen Weg cin, anf welchem sic blos nach

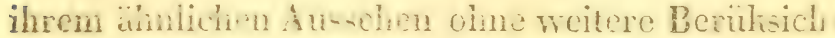
tigung cinzeher Theile zusmmengezilli worden.

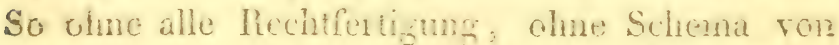
Ordmmen und Abthilmengen, zihlt er hie Galtmgen uach cinander ant, beghini mil dem Mcnschen, und fulirt den Taden, ohse abzusctzen, durch allo Gattungen bis zam Nonodon fort (hemo, simia. papio, cercopithecus, cebus, callitrix, lcmur, didelphis, bredyp. nomrneophag. manis, dasyp. taipa, sorex, pterop. crafletil. ursus, crinacedes,

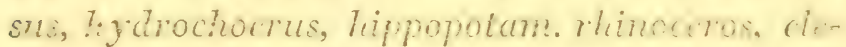
phas, cquus, cumbl. hus, or is, capres, antilop. cervus, mashus. Tepine, instrix, curia, wis sputax, mus jucul. sciur. custor, lalla. mustel. liverr. filis, cumis, phoca, tricheus, bahana; phyales, delphinus monodon\% bumblich war anch er von tem falschen Ginudisatze des Büron: ,les ordres et les classis neriennt, que

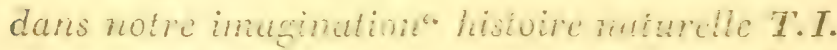
p. 58.) retleitet, und lief's daher alles systcmati-

a) p. IXIX, , ordines cideris frimaise dibliculur determinandi, si vere naturales quaeris, neque pecibus neque dethtibus distinguesdi" Crxlebon Systeme a gri animalis: Classis Io mammalia. Ligs, $1777^{\circ}$ 
sche Gewand weg. Hätte Erxleben das System unmitielbar in die Sache selbst grelegt, so, dafs der Charahter jeder Galtung in jenen dor nächsten wie ein Glicd einer hette in das andere eingriffe, and wechselseitig sich bedingten, dimn hätte es freilich der zeremonichen Ucberschriften und $\mathrm{Ab}$ theilungen nicht bedurt; allein diels that er nicht, sondern liefs sich durch das äussere Aussehen eines Thicres (habitus), wie er selbst in der Vorrete gesteht, leiten, un es zunüchst an dieses oder fin anderes anzureihen, und weder die Linnéschen Charaktere, welche er den Gattungen beisezet, noch sein Reichthm an zoologischen und anatomischen Bemerhungen bei den einzehen sehr präcisen Beschreibungen, hat auf diese Anordnung einen Einflufs gehabt. Even dieser trügerische Schein nach dem äussern Ausschen, wo gerade das Urtheil durch die grelleste Erscheinung bestimmt wird, hat auch ihis rerifihrel, dic beutelthiere, vermulhlich wegen ihrem freislehenden. Danmen am Hinteriulise, shleich nach den Affen, und auf sic die eben so rütlasclhaficn und unbehïlflichen Faul-Gürtel-Thicre und Amcisenfressur zu setzen, den Igul zum Bindeglied zwischen Biren und Schweinen, den Biber und Fischotter zivischen den Nagern unl den Fleischfressern, und die Pholia zwischen den Ifunden unel Cetacécr zu machen. Auf gleiche Weise ist stine Charali- 
terislif, dieser filasse: ,mammalia: maxillae in cumbenles, teciac, dentibus intrusis plorisyue, mammac lactiferac" blos von den grellesten Ligonschaften dieser There hergenommen, und pafst diher z. B. nicht auf das Schmabelthier und die Ichidna, whlche, wie dic Wugel, fü heine Liplen, Inammen und eingelicilte Zahne haben. Erabens System, obulcich durch routreffiche

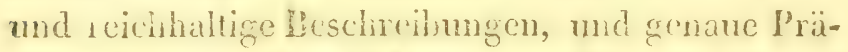
cision ausfyczeichet, ham zum Bewcise dienen, zu welcher Anarchie eine mifsrerstandene Idee rom Fatülichen, und dabei der Hafs gegen alle Regel, die Veranlassung geben liann.

\section{45.}

Ghiiliciner in der Verbesscrung des I,innéischen Systenes, war cier vergleichende Anatom Teulschlands, Blumenbach. Auch er äusscrt scinen Unwillen über die lï̈nsticlien Systeme, und sirebet ein natüliches zu crrichlcn. $\mathscr{Z} u$ dieser Absicht schü̈nhte or sich nicht, wie Ray und Limé, auf einzelne Eigenschaften ein, sondern suchte wie Penant, elichisch scine Vorgänger sich cinzur crleilen. Vie Ray und Pennant nahm er seine Hauptabilicibigen ron der Beschatenheit der Ixtrenititien, rind folgte in den Lnterabtheilungen dem Linné. Zur Inezcichnnng des Menschen gebratcht er den Atisciruch "Liman" 
dessen sich schon Aristoteles im fünften Buche, sechstem fiapitel sciner Thiergeschichte bedient, zu jener der Affen den von Büffon nämlich „Quadrumanen"; seine Ordnung der Thiere mit Fingern (digitata) ist rom Ray, ihre Unterscheidung in Nager, Wilde und Bruten vom Limé, die der Thiere mit hauen som Ray und Lilein, die der Cheiropteren und Amphibien von Pennant, die der Celacéen rom Linné hergenommen. Doch dieser scharfsimnige Natuforscher ist nicht zufrieden die cinzclnen Crdnungen aus genannten Schriftstellern zusammengetragen zu haben, sondern suchet sein Vertienst rorzinglich in der Aufeinanderfolge derselben geliend zu machen. Nicht wic Ray und Pennaut, beginnt er von den Infthieren, sondern im Geiste Linnés und des viel früheren Wotton mit den Bimanen, Quadrumanen, Clicropteren, Jilst hieranf die Thicre mit Fingern (glires, ferae, brula (Faulhier, Ameiscnfresser, Schnppen- zul Gürtelthier) folgen; die cin- und zweihnfigten machen die fünfte und sechste, die vielhufigten: Schwein, Tapir, Elephant, Nashorn, Nilpferd die siebente, die Schwimmfüfsler (amphibia) der Biber als Nager, ler Seehund, Fischotter als Wilde, das Schmabelhier, Walloofs, Manati als Bruten die achte, die Celacícn die neunte und lezte Ordnumg aus. - Was die Bildung der einzehen Ordmungru angeht, so lichen lice alle diejenigen be- 
merkungen zurili, welche bei den Verfassem, jo. nen dicediben angeheren, vorgebrach wurken.

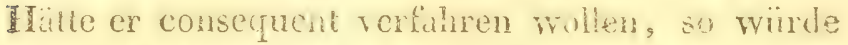

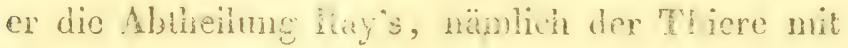
Fingern, wich? zu cinen besonderen ordnming ge-

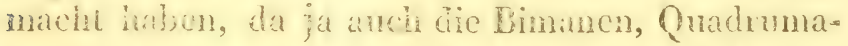
nen, Chciropteren tarin begrinen sind. Ferner haben some brvien, Wemn nan bios anf das $\Lambda$ ens. sere sicht, heme linger, da diese wie bei thubieren beinale his am lilane rerwalisen sind, auch lïlle ex dicue, nubl den Cavion und Pentellieren, vegen der lnostalt Nägel, (wire en sich consequent geblieben) bei den Thieren mit Irufen anf-

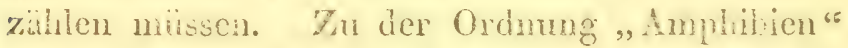
deren viclodige Denenumer zu melireren Nifirerslündussen Anlafs givbl, wäre rommblich anch

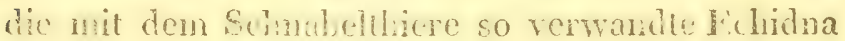

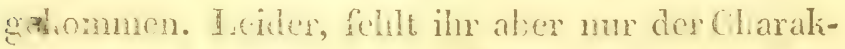
fer - dic Schninmand. - Dic Anécinanderfolge sciner Ordnungen and in diesen cher hudividuen, ist nichts wenime als nathrich. Fiat er absichtich mit dem Mlenschu bci den Sünghioren den Anfang gemacht, damu lätte er auch in dem nämichen Grade als die nach ron dirsem Anfürer culfernen, diese an jenen anschidson sollen. Aljer dieser Verfasser cines Worles riber rergleichende Anatomie, liefs sich hicrin nich in gुtringuten durch leztere leiten, 


\section{$-213$}

sondern allein durch die zufüllige Aelunlichleit nach dem Totathulitus Jlenden; wehn'n die Verfasser natülicher Systernef füschlich fir die eigentlicie Natur des Thieres Laten. Freilich haben dio Fiedexü̈use cinigo Aelnhichlicit mit den Nagem, er selust scheint vermittelst des fliegenden Sivbhous diese Vorbinumg herstellon zu wollen; alloin wic vicle so cinzolne Achulichlepion lassen sich an sonst woch so verschiedtmen Thicren auffinden? Dic Lori, wie sehr gleichen sie nach ih-

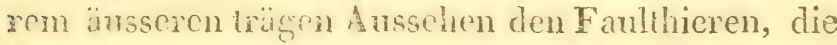
Paniane den Ilunder, die Springmaus, nach der Costali der Hinicrtifo den Tögein, die Fledero mäuse den Vücehn, die Delphine den Fischen? und doch hält sioh deswegen Nicmand berechtiget, eine solche Verbinduig zu veranshiten, welcho eine scheinbare Aelmlichleit im Einzelnen, abex cinen auffallenden Riontrast ins Ganze hinein bringt. Wisen dico Aehnlichleit nach dem äusscrn Mabitue, vicher genau betrachet, doch nur ron der auffillendsten Eigensclaft hergenomnien wird, hat den Verfasser verfihluet, den Nagern immer den Vorzug ror den Fleischéressem zu geben, don Biber und dic Phoka, woldie nach den innern Theilen in nichts ron jenen abweichen, weit hinter dext Tufthieren unter dic Amphibien zu rersetzen, ein Vergehen, welches or als rergtcichender Anaiom nicmals rechefertigen liann; ja er liefo sich cinige 
Male so woit duch das änscre Aussehen verfihren, dafs er den Igol, dis Spizmaus, den ITanltvurf und die Beutelhicre, bei welchen leztern sowohl die Zailue als auch die Nahrung jenen der Nager ähnlich wird, zu den reissenden Thiercn, das Schwein, obwohl zwcihnfig, zu den r iehnufigen rechnet. Hoch that or auch dieses mehr in Einzehen als Ganzen; denn wic gleichet wohl des Löwe den Fanhlier, das Panzerthier dem Pferde, ras Niblerd dem Riber, der Fischoter dem Scimabelniere? mol doch sind liese die Vedbindungsglieder der Gruppen in seinem Systeme. Der nümliche fontrast zeight sich audh in der Aufemanderfolge der tndividuen in jecier Ordnung; so müssen sich die Afren nach dem Mangel oder der AnwesenInit des Schivanzes, die Cheiropteren blos nach dev Ferechedenheit der vorderen Zühne an cinan-

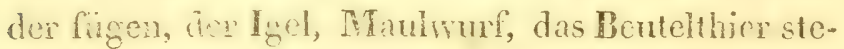
les an der Spize der Ruisonden, der Där, Inmd, Lüwe zulezt; unit den Thieren, welche die Finger der $Z$ ahl und Deschaffenhei nach am vollhommensten hat)en, ist seine Reihe eröfnel, und schreitet in diesem Plane allnählig bis zu Ameisenfreserm u. s. w. vor, wo jene mangelhaft werden; ron num aber wird dieser Plan auf ein Mal gë̈niert; statt mit den Virhufigen fortzufahren und bei den Einhufigen zu cuden, bryime er gerade enigegengesezt die Hufthicre mit dem Pferde, und schliefst 
sie mit dem Flęhanten, Nashorn und Nilpferde; eben so hat er zwar in cimigen Ordumgen den dreifuchen Unterschied in Nager, Vilde und Beuten wiedcrhohlet, ohne inn doch, als durch alle ührigen wiedcrliehrend, durchzufuhrein. U'eberhaupt lierrscht durch das Ganze nicht eine und die nämliche lebendige Auvicht, welche sowolil die Ordmungen, als auch die cinzehen Gatmugen unverriblibar an ihren Platz gestellt hät:e, was doch sicher ron diesem so kemninilsreichen Naturforscher zu erwarten gewesen wäre, hätte es ihm gefallen, auch in der $Z$ oologic von seincm Studium der vergleichenden Anaiomie und Physiologie Gebrauch zu machen, was, leider, nicht geschehen ist. Daher seine Verdienste un die Zoologie mehr in der Bearbeilung des Einzchnen z. D. in den Beiträgen zur Natugeschichte, ibber die verschiedenen AIenschen-Rassen, und in sonst zerstreutcn Aufsützon, als in der Beförderung des Ganzen zu suchen sind.

$$
\text { §. } 46 \text {. }
$$

Die nämliche Anzahl und Anfeinanderfolge der Ordnungen Bhmenbachs, behicll Gotulicb Storr, Professor der Naturgeschichte in Tübingen in seinem lrodrome zu Mammalien a) bei, und brachte

a) Gottl. Conr. Chr. Storr et Wolffer prodromus methodi mammalium, Tubingae 1780 . 
sic nur unter wenige mid allgnncine Geoichtoprukte zusamraen, welche noch genamer als bei Pennant, blos von der Beschaffenheit der Zahen oder Tinger hergenommen sind. Leske hatte. schon cin Jahr vorher, in scinen Anfangsgründen zur Naturgocinhe, die Sängthere, wolche er in den nanbichen sieben Ordnangen wie Limé and. cinander folgen läfst und charakterisiret, in sotche mil wahen Füfsen, worunter dic sechs eriten Ordumingen begriffen sind, mad in solche mit floses scuabnlichen Iüsen (Celacéen) abgetheilt; Stor folchir hirin scinem Beispive, nur mit den Ausnalne, dafs er juat noch mit einer dritten, nämlich der flosscnihulichen Fïlster Pemmants, oder der sogenanaten Pahnaten Plumenbachs rermehrle. Alle jone nit vollsändigen Glichmassen, sic mögen

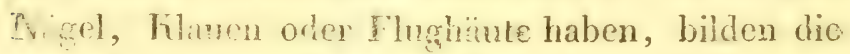
ci to Plalans mud heissen, pedata"6 - jens mit habbung fliedmassen biden die zweite, nnd. h. isicn: spimiplipela (phoca, trichecus, manatus)". - Jene mit Fimen, pinnata" die drilte, and enthallen die Cetacéen. Nur die crste PhaIans crleitet eine fernere Vertheilung in zwei Cohorten: zur ersten geü̈ren die Thicre mit Nigeln funguiculata: primates, rosores, mutici) und solche mit filanen (ungulate: jumbenta, pecora, belluae). Die häufigsten Absonderumgen liommen, wie folgt, bei der ersten Cohorte ror: in der 
ersten Ordnung dieser stehen dic ,primates und fercle des Linné", sie werden micrschicden, je nachdem ihre Extremitition handformig - manuati: Scct. 2. simia, prosimia, procebus, tarsius, lemur; Sect. 3. aidelph. phatanger - ode: niche handömig gebildel sind: cmunzati; Sect. 3. molutarsis prostratis incedentes: sorex, talp. crinaceris, miles, gulo, meliivora, ursus nasua. Sect. 2. digilorum epine incedentes: procyon, canis, hyacna. Seet. 3. unzuib. retractilib. feTis, vilerr. muster. lutre. Zu der zweitcn Ord. nung, në̈nlich zu den Nagern, rechnet or: hysirix, casior, lepus; zu der dritten (mutici) bradyp. calcipleract. photidor. myrmecophag; Zur ersten bei den Hnithierni blos allein das Pferd, zur zweisen die pecora des Linné; mu dritten die belluae: sus, hydrochoerus, rhinoceros, clephas, hippopotam. -

Bcimahe scheint es, als wenn Storr den Zweck des Sysienes in die Verielfäligung ron Fächern selze, dem wirkich hann man in dem seinen, durch die viclen Abtheilungen wie durch einen Nebel gehindert, die Saehe selbst haum zu Gesichte behommen. Zwar hat er den bisher bestandenen Unterseliced der Thicre nit Fingern, Zchen oder Flughiaut anfgeinoben and consequenter zu ihrer

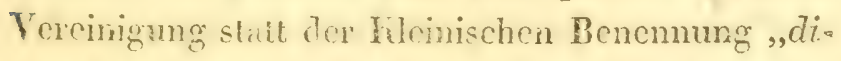
giluta" dic mene ,pectule" eingefiuhrt; alloin 
diese Bezeichnung wird, wenn dic Ueberschrift "Mlammalien" fulsch oder doch wenirsolens äussersl zweifelhaft i i, diesc Whicre nicht ron Replilien unterschaten, und macht ferner jue nene Phalanx, nämlich der flossenaihnlichen Füfler ülierflüssio, inden dic Fülse dieser Individuen (der PhoJa, des Lannatin, Trichecus) nicht wie die Flossen bei den Delphinen und Fischen, sondern wie bei Thieren mit Fingern gestaltet, und nux zmm Unterschiede mit einer Schwimmhaut in welchem Falle aber noch cine Menge ron sängthieren mit Schwimmfifsen aus ihren Ordmugen hätten gerissen, und hicher versezt verten mïssen. Eher, als die den Musielen so ähnlich gebaute Pholia, welche sich ja doch ausser dem Wasser, wie der Biber, Fichotter, wenn gleich nur kriechond foribewegen ham, hälten noch die Fledern̈unse rerdient, cine eigene Phalanx zu constituiren, da rior Glirảmassen ihres vorderen Fufses weder homartige Ecriccling, noch das gehörige Naafs und die ämiche Gestalt und Tïrze wie bei den übrigen Sängllieren haben, md deswegen in diesem Punkte nach den Cetacéen die unvolltommensten sind. Von gleicher Unzrilänglichkeit ist anch die Abtheilung der Primaten in solche mit oder nhe Ifïnde, demu schon bei den Pavianen, uoch nelir bei den liemuren, wetche grö́stentheils auf allen Vieren gehen, lcistan die 
Hïnde melır den Diens! der Füfse; aber am aller. wenigsten lassen sich dip Bentelthiere, von denen nur einige den Daumen des Hinterfufses auswïrts stehen haben, händeatig nennen, und deswegen soglcich nach den Afen seizen; denn in diescm Falle mülste anch der Cheiromis, bei dem das Näinliche stall findet, von den Manern hicher verpilanzet werden; eher noch, als diese, liönnten die plantigraden Bären auf diese Benemmg Anspruch machen. Tläte or dieser seiner Enterabtheilung conscment biriben wollon, damn müfsten auch die Nager wnd Zalmiosen hit der Rubrik derjenigen, wo die Füse nicht händeformig sestaltet sind, odcr rieluch die Faul-Gürtel-Schupnenthicrc und Ameisenfiesser, so wie viele der Buthelliere, weiche statt Nïgch hlauen haben, bei den Hufthicren aufgezihlt worden seyn, was or ja wirklich anch init dem Niger ,Hydrochoerus" that, und seiner bei den Belluen erwähnt. Man ersieht hicrans wohl, dafs Store ron cincr Vericgenheit in die andere gericth, aber cben dadurch zu vielen nenen Rïitsichten der Veranlassung giebt. So ist zwar snine Familic Plantigraden neu und scharfimnig, abex, wio weiter unten gezeigt werden wird, doch nicht geeignet, eine anpasscnde Familie zu bilden; seine Parallele, wclche er bei den Pinnipeden zieht, wo er die Pholia scinen Primaten, das Mallrofs den Bellucu, den 
Lamantin dem Fau?llier entsprechen läfst, und gleiche Anspielung auch bei dem Delphin, Diodon und Balän wicderhollet, ist sehr simmeich, leider aber nur cinem Blitze gleich, der sein Licht nicht auch über die übrigen Ordnungen aussendet. Im Ganzen lebet über die Grundabtheihung, Bil= dung und Bancumung der cinzelnen Ordnungen, besonders aber ibber die Aufeinanderfolge, dicer sowohl als ther Gattungen, in dem Systeme storr's das zuriche, was schon ibber seine Vorgunger, denen er himin gefolget ist, anseresagt ramde, ob. wohl er dadurch, dafs er dic reinsenden Thiere zu den Primaicn rechnete, nizd sie nach jenen zenen Gesichspmulten abtheilte nud benennte, so wie auch in der grofsen Scheidnng aller Thicre in sol. che mit oder ohne Finochen, ein MLuster dor frumzöfsischen Tachahmung wurde.

$$
\text { 5. } 47 \text {. }
$$

Von mun an nahm die Verarhung gegen die fiüstlichen Systeme inmer mohr zu, die Liebe für die naturlichen aber wuchs mil jedem Jahre mehr heran. Bomet hatte schon früher, dumch Annahme einer linienartigen Stuffenfolge in der Natur, die Aufmerhamlieit vieler Naturforscher auf sich gezonen. Donati und Olivi sezten dicser Hypothese cine andere, in der Veregleichnng der Verwandschaft aller Naturgegenstünde mit rinem 
Nivetze entgegen, wud moch sind beite dor Zank. apfel der Eegenwintigen Naturforsche!, welche stait der hïnstlichen Bancerüsto den Cinç der Natur selbst zu entdechen sich besireben. Mermann, Professor zu Strafsburg, ist der ersle, welcher die Ansicht der lezteren auf zoologischem Gebiche zu. rechtfertigen sucht a). Auch er giebt zu, dals dic Natur Cubergänge macle, jedoch lanfen diese nicht in cincr stäligen Linie fort, sondern verbreiten und berihen sich nach allon Seiten, wie die Naschen in cinem Netze, oder wie die Zweige an einem Baume. Auf solche Veise machen unter den Süngthieren die Fledermäuse zu den Vögeln, die Pholia und Celaccén zu den Fischen, das Schuppenthicr zu den Videchen, uner den Vögeln die Kolibri zu den Inschiten, der Königsfischer zu den Chameleonen, unter den Fischen die fliegenden zu den Vögeln, die Aale zu den Würmern u. s. w. die Ueberg̈̈inge. In diesem Sinne, welcher nicht im geringsten die Belienntiils zu irgend cinem liinstlichen Systeme ausschlicfst, wiederhollet er denu bei den Sünghieren das System Pemants, fügt de: Orinung :, pinnated " desselben, ancir die Colacén bei, ändert die Benennung jener in die „compedu“ um, füngt statt von Thieren mit Ifufen, von jenen mit Zehen an, behält

4) Joannes Irermann Tabula aflinitatum animalium, Argentorati 1783.4. 
die Limnétochen Bencimungen im Innern bei, erhebet die Spitzmans, den Maulwurf und Igel zu ciner eigenen Familie, und lälst seine vier Ordnungen, unter manchilligen Beziehungen und Vergleichngen der Thdis iducn also anfeinander folgen:

ord. I. digitata.

F: I. quadrumana: homo, simia, lemur, didelph.

- 2. bestiae: talpa, sorex, evinaceus.

- 5. ferae: canis, felis, viverr. mustel. lutra, ursus.

- 4. glires: hystrix, castor, cavia, hyrav, mus, sciurus, lepus.

- 5. bruta: bradip. myrmecoplug. mani, dasyp.

Ord. II. ungulata.

1.6. belluat: aleph. Fippopotam. tapir. rhinoceros, equus, sus.

- 7. pecora: camelus, cervus, bos, ovis, capra, antilop. moschus.

Ord. III. volatilia.

F.8. vespertiliones.

Ord. IV. compeda.

I. g. phocen, trichee. monodon, delphin. physet. balaen.

Mit gicich wamen Eifer suchet gleich darauf auch Boddaert") die Verwandschatt der Gegen-

a) 1'. Toddaert. Elenchus animalinm. Vol. I. sistens quadrupedia ad ductum naturate disposita. livtletciam. 1-85. 8. 
stä1ide der Natur darzuthun. Zivar gestehet er in der Vorrede ein, dafs alles nur netzartig verflochien sey, allein in seinem Streben, die Stuffenreihe ron dem fadenartigen Amianth und 'Zeolith zu den Liorallen und Pflanzen, welche ebenfalls aus Fibern bestchen, von den Tremellen zu den Mollustion, ron den hartschaaligten Inseliten zu den fliegenden Fischen, von den Aalen zu den Schlangen, bis zu den Vögeh, Sünghieren und Menschen, wo uns noch nach seiner Aussage die Mittelglieder fehlen, hinaufzufühen, erliennet man mehr den Anhïnger Bonnets als Donati's. Doch machte er von allon diesem bei den Sängthieren lieinen Gchrauch, sondern folgte, olne sich die geringste Abänderung zu erlauben, hicr ganz dem obigen Systeme Scopoli's, und bereicherte den Inhalt mit vielen neuen Arten und genauen Beschreibunger.

Die nämliche Sprache, obgrleich mit weniger Hitze, führet ebenfalls Batsch: „, Die Natur, sagt er ${ }^{a}$ ), füngt an mïchtiger zu werden, als das Vorurtheil " - allein die Verwandschaft ist nicht einer geraden Linie sondern einem Netze ähnlich.“6 Uebrigens blieb dieser Verfasser, welcher noch lange ror den Franzosen, alle Thiere nach der Abtheilung in solche mit Krnochen oder mit Schaalen

a) Aug. Joh. Ge, Karl Batsch Versuch einer Anleitung zur Kenntnifs und Geschichto der Thiere und hineralien. 1ster: Thl. S. 92, Jena 1788.8. 
Whatuleite, jei den Süughtheren den Ordnungen Limés getren; nur dal's er auch die Pimnipeden Storr's, dam dem Beispieis Hermanns gemäs, dis Spilzmans, den Maulwarf und Igel, unter der Denennum "rosores" velches leztere auch Linh in geinen Beiragen rachabute, als eigene Ordnungen anfstelle, und bie Aufeinanderfolge diesex neun Ordnumgen folgender Munsen von jener der Limucischen abanderte: pecoru, dellake, bruta, primaies, rosores, ghires, pinuijedes, cetucea.

Trevirmus trat einige $\mathbb{Z}$ eit später anf, und glauble das Leben der Natur in der Annahme einer Urhaft, welche durch Bezähmung der repulsiven häle der lebensfuhigen Watcrie, sich als Lebensfrraft, und ihre Vollhommenheit in der Zanahme

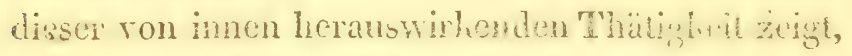
şchinden zu haben. Diesur atomistisch nuchanischen husicht genaffs, muterstheidet er dem die leInwlige Natur nach den aul versclictoneis Suffen inrer Lildurg vorwaltender Grundstofen in zwei Ablichungen, nämlìd der Thiere und Zoophyten, no der Stikstof heresche - má der Pliytozooen and Planzen, wo der fiohlcnstor obryalte, jedoch so, dal's sie von den Dicuiyledonen zu den Hosocolyledonen der Planzen, und rou diesen durch die Flechten, Tangei, Confersen und Schwänmen zu den Zoophyien, und von den übrigen Thieren bis zu dem Menschen enporsteige. 
Jefider, scheint dieser so kenntnif reiche Mann die Natur mehr in reichhaltigen Bibliotheken, als sn der Quclle selbst studicret zu haben; denn obglcich er eine Mlenge ron Thatsachen fü seine zwei lezten Bände zusammen gelesen, und recht simmreich zusammengestellt hat, so äussert er doch gleich beim Eintritte in die einzelnen Klassen, die cr nach dem Beispiele der Franzosen in Thiere mit ma olne Rückenwirbel abtheilt, dafs Ordnungen, Familien, Gattungen u. s. w. bloses Machv.crk der Willkühr und Phantasic seyen, und dafs es wohl eine linienartige Stufenfolge in Hinsicht der Bildung einzelner Organe, nicht aber des ganzen Thieres gebe, sondern hier eine netzartige Verwandschaft statt habe ${ }^{a}$ ). Dei diesem Reichthume von Bücherlienntnifs liefs er es bewenden, und ohne einen Gebrauch von seinen Grundsätzen bei den einzelnen Kílassen der 'Thiere zu machen, folgte er gleich bei den Sängthieren dem Systeme der Franzoscn. Li bedachte nicht, dals auch die Menschen und Afon unter die Thiere mit Nägeln gehören, dals die Abtheilung der Süugthiere in solche mit Nägeln und hlauen, laut obiger Beurthcilung, unzureichend, die Fledermäuse nach den ž̈̈hmen und Geschechtshieilen viel volliommener

4) Gottfr. Reinhold Treviranus Biologie oder Philosophie der lubenden Natur B, 3. B, 3, S. 445- i7 . Göttiıgen :802. 8 . 
als die Ningre, dic Cetactén aber wegen Ylangel des Bechen, wegen den hossenatigen Listemiäten, verhïmmerten Simnorganen und Gehine, die unvolikommensten aller Süugthicre seyen, sondern reihte demolmgeachtet seine \& Ordnungen und Familien folgender Gestalt:

Ord. 1. Homo, Simiae.

- 2. Ingruiculata: canes, glires vespertil. bradypod.

- 3. Cetacea.

- 4. Ungulata: porci, pecora, equi.

Fin ainliches Bild der Säugthiere entwarf der grelelinte Verfitser der Ansichten der Nachtseite der Naturwissenschaft a). Er latte bemerlit, daís die meisten fossilen Süngthicre Pachydermen, wolche sich gerne in Sümpfen anfhalten, und ibberhaupt Grasfresser seyen, im Gegentheilc fossile Bruchsücke von Fleischifessern z. B. Hunden, Bären, Lüwen, Tigern, Myänen u. s. w. weit seltener nud nur in den jüngst anfgeschwemmten Flötzen, ja selbst in noch nicht lange verschütteten Höhlen untermischt gefunden werden, dafs endlich von Affen und Benschen gar licine Epur fossiler Reste rorliomme. Scharfsimnig glaubte er num schon in der orgmischen Geologie zwei Reihen von Säug-

a) G. II. Sahubert. Ansirhten der Nachiseite der Naturwissenschaft. S, 219. S. 270. Dresden 1808. 
thicren angedentet zu schen, woron die cine die Wiederkäuer, Schweine, Pachydermen und Cetacéen, die andere die Affen, Bären, Ichneumonen, Hasen, Carien, Eichhönnchen, Fledermäuse und Beutelihiere, als den Vögeln nach den lurzen vorderen Füfsen und der Lage der Geschlechtstheile zunächst rerwandt, bilden; jene Reihe wäre als die ätere auch die rolllommnere, diese der Fleischfresser aber die unedlere; der Mensch stehe als das edelste Thier zwischen beiden in der Mitte, und die Natur, welche ron den Grasfressern herauf endlich neu geliräftigt aus dem Wasser heraus sich in der Schaifung des Menschen erschöpfte, schleppte sich nun olmmächtig in der Bildung der anderen Reihc, nämlich der Afren u. s, w. fort. Der Verfasser glaubt auch am Skelete diescr Thiere, an der Mehrheit der Rüclienwirbel der Pflanzenfresser, ihre Volliommenheit, an der geringeren Anzahl derselben bei Fleischfressern ihre Unrollkommenheit und so beide Reihen selbst bestättigen zu lö̈men. So walir auch diese angeführten Thatsachen sind, so glauben wir doch gerade das Gegenthcil daraus herzuleiten. Je weiter wir ron dem Mienschen, den Affen, Fleischfressern, Nagern zu den Pacilydermen, Zwei - und Einhufigien, zu Amphibien und F'ischen hinabgehen, so nimmt die Anzahl der Rüclienwirbel im Durclto schnitte immer zа, die Brust-oder Bunchliölle 


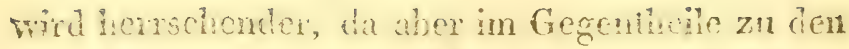
Fleichinzsem nut dom Venschen heranf, Masse wnd Anzahl abnimut, Darch- Bust - nnd Kopfbïble, der Schuld mol das libhrid in jenes harmonische Vorlatunifs der Vollhommenheit za cinander wetul dals der hohe Geist dieses Arehitek ten in cinfachen Gebänden sich answicht. Ein gleiches ofrenbaret sich auch in fem fussilen Vorlommen diver rhise: whitrend ceracen im Alamschier a) und Thon b) die (enveihe ron Mirenen in Hand and Dänemark nuch drthur Young und Pontoppidan's Aussange im Torfinoore, Antilopenhöncr, Lspern zu folge c) schon neJen den Leberbleibehn von Klephanten und Büffeln in Eichstältishen, der Flephant, dis Rhinozeros, Paläolherinm u. S. w. nichb tief unter der Oberfläche der Frde, and selbst bei finmündungen ron Flïssen liegen, so furten sich die Fleisch fresser meisters in versebilleten llëhlen, oder es ist wie ron Afen und hienschen rar heine Spur in fossilen Zustande ron ihnen rorhanden. Wer sieht nicht, dals auch hier die Erde sich gleich einen rerwandelnden Inselite rom Unvollionmenen und Massiren zu geisigeren Formen, gleichsam zu rerhlülen Lidern, ron Periode zu Periode
a) phil. transact. 1758. p. 688 .
b) mém. de l'acad. des Sc. de Paris 178». p. 211.
c) Schriften der Berlia. Gesellsch. BA. 5. \$S. 97 。 


\section{$-229$}

cmpor arbeite, und cincin Uerlunles glcich, simren des münollen Anfanges bis zu ihrer Yergölterung zurükliefs?

Uciberhapt dienen auch dicse wenigen Naturforscher ron einem höhercin Strehen, dic Gehemnisse der Natur zu erlicunen, besceli, źum Belege, dafs man auch da, wo man ein natiuliches System crichten will, schon mit Limst zur Natur lingehe. Nichit nach ciner Linic, nicht nach cinem lirese oler Ivetze, nicht nach magnetiech entgegengesczten Polen - nicht mach sulch einseilizen Richtungen hat die Natur iire Geschüpfe gebildet. So lange die Tunst die Natur hlos bemeistern oder machahmen, und nicht stalt der rieIcn schönen Vorte durch Thatcn in das Ideal derselben cingreifen wird, so lange wird sich jene Thlage unserer Žeit Wber den V́rfall der schönen Thinste auch auf naturgeschichilichem Boden wiederhohlen, dafs durch obertlächliches Nachahmen and Stionpen, die lunst sich nie zu Natur erhea நen wirà.

\section{48 .}

Pemnant war der erste, wehier anfing, sich die Ansichen srincr Vorgüner ehtilisch einzurerleiben, und nebshei dit neve Betrachung des Ver wachsen - oder Freiseyns der Zehcn cinfuhrte. Blumenbach und Store folgten scinem Bcispicle nach und waren so glühlich, scine Crdnungon zu 
rerbesscrn, ihre Aufeinanderfolge richiger durch dic Linnëischen zu bestimmen, und manche neue Charahtere, wie jenen der verschiedenen Fliche des Fufstrittes, zu Unterabtheilungen unfzufuden. Auf diesem Wege giengen nun auch die franzölsischen Zoologen fost, und errichteten unter den Sängthieren cin System, welches aus der Berichtigumg und Ausgleichung der beiden Lezteren be. steht. Cuvier war hierin der Vorliufer und Anführer seiner Landsleute. Zwar hatte schon ror ihm Vicq d'Azye die Ansicht Baubentons rou dieser hlasse hekannt gemacht, die Cetaccén ron den lebendiggebährenden und behaarten (jadrupeden, als eigene hlasse, nach diesen, wie Brisson hingestelli, und jene in 15 Kilassen folgender. Massen abgetheilta): quadrupeda vivipara pilosa - pedimani : Simiae (pithecii, cercopithecii, sagouins, sapajous), mali, Lori, tarsii, marsupiales S. didelphides - glires: sciurii, palatouche, glirini, murini, surmurini (agouti, cavia, paca), inauriti (cricetus), planicaudati (castor), saltatores (jerbo), duplicidentes (lepores), spinosi (crinareus, hystrix) - pteropodii s. vesperti7iones. - talpii - soricii (musaraignes) edentati. - carnivori (ursini, mustelini, ichnemmoni, felini, hyaenini, canini, lutrini) -

a) Enryelopriclie méthodique - Systeme anatomique Quadrupedes par M. Felix Vicr d'Azyr Tome second, Paris ron?. 
involuti(phocini, manalini, rosmarii) - hiplopotamii - elephantini-tapiri - rhinoceri - porcini - ruminantes - solipedes. - Allein diese Vertheilung halle zu wonig Theil an den Veränderungen genommen, welche das Limnéische System bisher in der Zoologie herrorgebracht und sclibst erlitten hat, und blicb daher sclbst bei den Landisleuten, einzelne Sachen ausgenommen, ohne weiteren Finflufs, obgleich in den anatomischen Eeschreibungen der einzelnen Afien und Nager, welche eben in diesem Bande Vicq d'Azyr aus fremden und eigencn Beobachtungen zusammentrug, der erste Schatz und die erste Anregung für rergleichende Anatomie unserer Zeiten niedergelegt war. Der Grumdrifs hingegen, welchen Cuvier in Verbindung mit Geoffroi, Professor der Süugthiere und Vögel im Pllanzengarten, zum ersten Male in der Schrift: „nozlecu dictionaire de 7histoire naturelle" licferte, und späterhin in einem eigenen Werke, tableau elinnentaire ảe Thisioire a aturelle des animaux, Paris. an. 6" in dem zwei1, 1 Buch „, les mamniferes" ausfunte, blieb bei Iramzosen der Grund und Boden aller weiteren Verarbeiung. Curier behäl die neun Ordnungen Blumenbachs und ihre Aufeinanderiolge ganz bei, und macht nur folgende Abïnderungen: Dor Mensch ist aus der Reihe der Mammalien weggelassen, und wird gleich im ereten, blos fir iln be- 
etimmten Buche abgehanảelt; lie wilden Them und dia Butcn werden, statt wie bei Blumenhats in der Ordnung der Thiere mit Fingern begrifen zu seyn, in zwei abgesondcrt, die crste trägt den Namen ,carnassiers" und cnthält die Fledernïhise als dic erste Fanilic, Storr's Plantigraten als die zweite, jene, welche auf der Spitze der Zchen auftreien unter der Benennung "carnivores" als dic dritte, und seine Didelphen thiter der Ueicrschrift s,pedimunes" als die vierte in sich; - the zweite, nämlich dic der Bruten filimenbachs, bckommt die neve Anfschrift, edentis". Von hicr an lieht er die Aufcinanderfolge der Ordnungen der Ifufthice mu: der Llcphant stcht zuerst, und ihm ist, wie bei Ray, cine rigcne Ordnung gewidmet, der folgenten, nämlich den viellilaugten Blumenbache, ist der Name, ,pach ydermes", den Bisulken jener dor "ruminans", den Palmaten Blumenbachs oder den Piniipeden Storrs dieser der ,amp)hities: gegeben, die Celacéen ondlich bleiben wic bei seinen Vorgängern, mveründert. Hicraus crgiebt sich, dafs Cuvier, das erste Buch über den Menschen abgerechnet, die Iilasse der Säugthicre unter folgende zehn Ordnungen brachte:

Ord.1. quadrumanes: simice, maki.

- 2, carnassiers: Fam.1. Cheiropteres (wespertil. galeopitheque).

- 2. planitigrad. erinareus, sorex, talp. uersits) 


\section{$-2.53 \rightarrow$}

Fam. 5. carnivores (mutste?. felis, canis, viverr.)

- 4. pédimanes (didelph.)

Urd.5. rongeurs: hystrix. lep. hyrax, cavia, castor, sciurus, mus.

- 4. édentés: myrmecophag. orycterop. dasyp. bradyp.

- 5. éléphas.

- 6. pachydermes: sus, tapir, rhinorcr. hippopotam.

- 7. ruminans: camel.moschifer. cerus, giraff. antilop, capra, ovis, bos.

- 8. solipèdes: equns, asinus, zebra, quagga.

- 9. amphibiess phoca, trichec.

- 10. cétacées: delph. physet.balaen. monodon.

Cuvier hat durch scine Bearbeiung an dem Systeme der Säugthiere das nümliche Verdienst, wic scine nächsten Vorgänger, nämlich: die Ordnungen des Einen durch dic des Andern berichtiget, und ausgeglichen zu haben. Allein hierdurch hat er sich ein eigenes erworben, dafs er die Auf* einanderfo!ge der Orkumgen nach Abuahme der Zahl der Zehen, nichi wie jene, plötzlich bei Hufihieren unterbricht, und zirerst auf die cinhufigen springt; sondem dafs ex umgehehrt ron den viellufigen zu den Bisulken fortgeht, und mit dem Pferde schliefset. Freilich scheinter dieses, wenn man anderer Scits bedenlit, dafs er anf die einhufigten noch die Orainnng der Amphibien, alsa Thiere mit vielen Zehen-filgen läst, mehr aus 
cincm glühlichen Einfalle, als hiezu durch die rergleichende Anatomic geleitct, gethan zu haben; ja er geht in eincm neucu Memoir so weit, dafs er den Lamanin, Dugong, und das ron Strller beschriebene Seethirer (novi comment. petropol. tom. 2. p. 294) als drei verschiedene Gattungen und als eine ron dem Wallools verschiedene $\mathrm{F} a$ milie aufstellt, und sie, wie dic Pholien den Fleischfressern, den Cetacéen entspachen lïlst $a$ ). Otme "Zweifel finhlte er den Widerspruch der Sleling: dieser Ordnung, mit dem Gange der rerglcichenden Anatomic, aber das ätssere Aussehen mod das Streben, die wcite Lüclie, zwischen den Säughthicren mit Zehen und Flossen auszufuillen, verfuhren auch ihn, wie schon einen hilein, Pennant, Blumenbach, Storr, ron denen Einer dem Andern der benemmug und dem Inhalte dieser Ordnung nach widerspraci. Jedoch bleibt, da die scheinbaren Flossen der Phoka, dǽs Trichtius u. s. w. nicht wie bei Delphinen, sondern wie bei Thieren mit Zehen gestaltet sind, immer noch die alte hluft unausgefulit, und würde auch im entgegengesezten Falle zwischen dem einlunfigen Pferde und der Phoha zurüchelichren. 'Wwar scheint er den scheinbaren Irrthum Pennant's und Storr', in der Benennung als Flofsartiger, dahin zu berichtigen, dafs er sie nicht nach den Ex-

a) annal. du museum de Paris Tom. Is p. $27^{3}$. 
rimititen, sondern nach dom abwedselnden 1 uf. enthalte zwischen Wasser und Land Amphibien nennet; wie rielon der Säugthicre aber müste er dann in dieser Ordnung ihren Platz anweisen? an den Hydromis, Biber, der Oidatra, Wasserratte, TVasserspitzmaus, Cavia, Paca und Copybara, erhiclte er auck Vager in dieser Ordnung, an dem Schnabel. thier jene der Zahnlosen, der Fischotter wiude die Anzahl der Fleischfresser, der Hippopotam, der Pachydermen rermehren; aber dann wäre es auch win desto auffullender, dafs diese ganze Ordmung ans allen ibrigen zusammengestoppelt, und cine wahe hricke dieser Naturforscher sey. Auch das Imnere der Ordnungen herveist, dafs Cnvier nicht ron dem lebendigen Gange ciner Abstuffung nach dex Volltommenheit unter den Säuglhicren, welcher sich jedem bei dem Stidium der rerglcichenden Anatonie aufdringet, sondern mehr ron dem äusseren Iabitus, bei Anreilum. gen der Familien und Gattungen geleitet wurde; deswegen blicb der MTensch von den Süuthieren weg, die Galcopithelien mrésen nicht, wie bisher am Enle der MIaki, sondern der Fledermäuse, dic Bären nicht an der Spitze der Plantigraden, sondern der Igel, Manlwurf, die Hunde und Katzen bex den Carniroren nicht zilerst, sondern in der. Mitte stehen, und die Mistelen diese Familie mit den Bären, die Viverren nit don darauf folgenden bon- 
telthicren rerbinden, nur damit Fileines an Fileines, wurmfinmige Gestalton an Gleiche, Thiere mii diesen Zühnen an Achinliche sich figen, und nirgends ein grofser Sprung sich einstclle, wodurch zwar das Einzehne gut verhicistert, dits Ganze aber doch volier Risse ist. - Eine zweite Tauptreränderung, volche Curier an dem Systrme seiner Vorginger macht, ist die der Umwandlung der alien Benemumgen in newe. Bei der bisjezt herrschenden Willitihr, in der Benemmng und dem Ausdruclie in der Naturgeschichte, wäre es zu unseren Zeiten das giöste Verdienst, der Willhïh durch Zurïliweisung, auf die Natur als das Original, zu steuren. Durch die Sprache, besonders durch jene der Worte, suchet die Natur das Imnerste auch äusserlich, das Concrete in flïsiger Rede darzustellen. Gicichwie es aber eincm Bildhaner oder Mithler nicht freistchet, diesen oder jenen Zug, diese oder jone Farbe anzubringen, sondern jeder Theil sein Ideal ans:prechen holfm soll, eben so sollen die Worte des Naturforschers genati ihren Gegenstand ausdriicken, die Ueberschriften, wie der Titel eines Buches, glcichsam der Auszug und die Wurzel der Abhandhng seyn, und alle cinzelnen cinen und den nämlichen Simn und Plan des Ganzen offunaren. So gewissentaft haben es lei. der, bisher dic Zoologen nicht genommen, an wenigsten aber die Tranzosen, unter woldme ai- 
unge mit Worten, wir mit Masken spielen. Was sull dic Ueberscherif ,rmminans" heissen, während him doch des fingmals, Pecoris, Fanlthicres, Stacholschweines, Domnns, Tapirs und der Celiwen, welche alle sich ebenfalls durch die vichen Magen anszeichen, nicht erwihnt wird? wozn jencr, édentés" wenn gleich darauf von dem Schuppenthier und dem smeisenfresser der Manoel ailer Zahne, den Fanl- und Gürtelthieren nur die Anwesenheit der Stoclizähne ausggesaggt wird? Varum wird jene Ordumg , camassiers" über" schrieben, da es doch auch unter Affen, AmphiWien, Nagern u.s. w. Fleischfresser gie!t, und da man sclbst IImde, Coati, Biren u. s. w. mit blosen Vegetabilien ernühren hann, und er selbst in der nämlichen Abtheilung die Phalanger und Kängaruh ols Pflanzenfresser schildert? IVelcher Unterschied ist wolil zwischen einem, ,carnassiers"6 mol dann ,carnivores" da das eine die Ordnung, das andere cine Familie bezeichnen soll? Eben so wird die eine Familie "chciroptéres" überschrieben, obgleich von demfliegenden Eichhörnchen und. dem Phalanger anderswo Lrwähnung geschicht; eine andere erhält den Namen "Plantigraden" was doch nur ausschliefsend von dem VVenschen, Affen und Bären gilt; ja die Spitzmars und der Mangoust haben nicht einmal diesen Charalter, der Maulwurf mur an den vorderen, nicht abes Hinterfirsen, di: 
Coati, der wákhtir u. s. w. treten schon mehr aut der Splze der Zelien anf, und wie viel. Sïugthiere z. B. Muthetten, Cavien, Murmelthier, Amcisenfresser, Danan, Virenen, nuifsten nach dieser Figenschaf, oder nach der maliten Fläche des Untertheiles des Fufes bentheilt, hier stehen? Der Nam" "pributines" paifst nicht aul alle Beutelthieve z. B. nirlit auf hingarnh, und dann findet sich dicse nuwerentliche Sonderheit auch unter den Nageru am Cheiromys. - Eine gleiche Nachsicht herrscht in der Angabe der Charaktere jeder Ordmmng: Su sollen sich die Fleischfresser durch die drei Arten ron Zähnen anszeichmen, und gleich daranf werden Fledermäuse ohne Schn-idezithe, dic Lingaruh ohne Echzalne anfgezänlt. So ist die arilte Ordnung ,sans dents canines ou ronyeur" überschricbenl, gleichsam als wären beides weichbedentende Sachen, da doch anch die Faulthiere, Wiclerküucr и. s. w. heine Hundszälne huben; ron den Pachydermen heirst es: "yui ont plus de deux subots a chuyue pied ", was dieselben weder von dem Elephanten, der ibrigens doch anch den Namen Pachyderin rerdiente, noch von Cavien, Küngaruh u. s. w. unterscheidet; endlich der Charaliter der Ordnung des Elephanten "les incisives forment des longues dejenses" sich auch üfters, wenn gleich als Monstrosität, 


\section{$-239$}

bei Aem Nurmelthine und Sicbenschlafer, wo sie zu einer grofsen Länge herauswachsen, einstclict. Gleichen aber gleichwohl diese Beschreibungen, gegen die rom Limné zusammengehalten, jenen eines flüchtigen VVanderers, so bezenget doch selbst diese früheste Arbeit jenes grolsen Anatomen, schon die Reichhaltigheit und den Scharfim in Snndermig des Inhaltes. Er ist der erste, welcher die Familien der $\Lambda$ ffen nicht mehr nach der Irange oder Kürze ilures Schwanzes, sondern nach ihrer Verwandschaft vermittelst des Camperischen Gesichtswinkels näher bestimmet, und die Orang Ontang, Sapajous, Guenons, Maliags, Paviane, Alouats, unter den Makis die Indri, Lori, Galagos, Tarsiers als ganz natüliche Gruppen aufeinander folgen läfst. Die Koati und Tïnkajous standen bis jezt noch unter den Viverren, durch ihn erst erhielten sie ihren gehörigen Plałz unter den Büren; in der Familie der Didelphen herrschte allgemeine Verwirrung, und nun sind unter jenem Namen die Sarigues, Dasyures, Phalanger als eigene Familien ron den Fängaruhen geschieden; bei demiläusegyeschlecht lag alles wic in einem Sandhaufen durcheinander, und mu stehen sie als MIurmelthiere, Campagnol, Ratte, Hamster, Springmaus, Siebenschläfer gesondert da; die Antilopen sind nach der verschiedenent líümmung ihrer Hörner unterschieden, dem Daman ist in einem späteren 
Mcmoire, slatt wie Anfangs bei Nagern, jezt de? freicren Meinung Dïmerils gemäls, bei den $\mathrm{Pa}$ cindermen, und zwar zwischen dem Phinozcros und Tapir ein Platz angewiesen ${ }^{a}$ ). - - Wahhaft! lätte Curver die Kilasse und die Ordnungen èben so gut charaliferisiret und gereihet, als er es an cinzeluen Gatungen that, häte er, wie in sement IYandbuche der vergleichenden Anatomie die Süug. thicre nach den cinzchen Organen, so einmal hier nach allen zusammen verghchen, stati die anato. mischen Nerlinale nur als Anhang hier hinzuzufüzon, liurz, häte or die Säughiere nicht nach einzelnen Absichien, sondern nach cinem und dem nümlichen amfassenden Plane bchachtet, dann wiude sich chenfitls das Einzche zu cinen widersipuchlosen Ganzen gefigt haben, wid Ordnungen, Charahtere und alligeneine Benenmungen, würden das Siegel eines und der nämlichen umfússcnden Ansicht seyn, was auch bei ciner neuen Ausgube scines Fandbuches, von der gegenwïrtigen Reife der Bildung des Verfassers, zu eswarten ist.

\section{ง. 49 :}

In dem nämỉichen Geiste, mehr das Einzelne als das Ganze, melr Absicht als einen Plan ror Angen haltend, haben seine Landslente ihr unsterbliches Verdicnst weniger in der Bearbeitung

a) Aunal, du mucíum Nation, dhist. nat, T. 3. p. 171 . 


\section{$-241$}

des Systemes, als in der Bildung und Charakterisiring von Arten und Gattungen gegründet. Dümeril ist der erste ${ }^{a}$ ), welcher dem Gange Cuviers folgle, und nur darin ron ihm abwich, dals er die Familien, welche jener, wie Linné, olme weiteren $Z$ wang $\downarrow$ aufstellie, unter drei Gesichtspmlte: onguiculés, ongulés, nectopodes (amplibies ceta cées) brachte, dic Menschen als Bimanen zu dieser hilasse rechnete, den Carnivores die Benennung ., digitigrades"gab, die Cheiropteren, Plantigraden, Pedimanen, jede als gesonderte Familie betrachtete, die Faulthiere zu einer eigenen ,turdisrades" genamu, erhob, den Elephanten dagegen mit den Pachydermen, die Kängaruh mit den Nagern vereinigte, und so die ganze Klasse in vierzclin Familien annöfite, welche sich gerade so folgen wie die Ordnungen 'Cuvier's, und in der Präcicion des Beschreilungen nirgends ihres Glcichen haben. - Noch getrouer, als dieser, blieb Lacepede in dem Systeme der Säugthiere, welches er im rierzehnten Bande der Detervillischen Aus. gabc Büffon's aufstellic, und sich nur diese Verändermeg erlaubet, die Pedimanen, wie Storr gleich mach den Malis, die Fledermäuse lurz vor den Anpubici und Cetacéen zu setzen, und leztere in eincr cigenen Monographie, nach der Auwesen:leit

\footnotetext{
a) Zoologie analytique ou methode naturelle de clasification des animax, Paris 1806.
} 
oder dem Mlangel der Zühne, nach der zahl nud Stcllung der Flossen, weitliufig in eine Nenge ron Gattungen, welche ebenfills Diimeril in scine Schrift mit aufnahm, abtheilte und beschrieb. Desmarest wiederhohlte gleichfalls das Systom Cuviers in dem Ausznge des ,nourcan dictionaire d'histoire natureller, und ergänzte es nur mit jenen neuen Familien und Gattungen, welche Geoffroi, Professor dieser Kilasse von Thieren, theils in scinen Vorlesungen, theils auch in einzelnen $\mathrm{Ab}$. handlungen gemacht hat. - Lamarcli hat endlich neuerdings in seinem Werlie "philosophic zoologique Tom. 1, 2. Paris 1809 " das System Cu. vier's, wie es sich in der genannten Schrift Dümeril's vorfindet, aufyenoumen, und blos die Familie "nectopodes" des Lezteren in zwei Ordnungen gespalten, wodurch er diese vier: „mammifères onguicules, ongulis, amphibics, cxongulés (cetacées) erhielt. Iieser tiefsimige Naturforscher Frankreichs, welcher dic Natur in einer fortlaufenden Linie gebildet ansieht, und daher jede Lücke in der Zoologie sogleich mit einer auch nur scheinbaren Aehnlichkeit auszufüllen strebet, ist der erste, welcher den Miderspruch der Benen. nung Mammalien, in Bezug auf das Schnabelthier und die Echidna zu heben dadurch sucht, dafs er diese beiden Thiere als ein Mittelding und als einen Uebergang zwischen Süngthiere und Vögel, 
mer dem Titel Geoffroi's "monotrémes" sezt, Freilich zeigt sich in der Lage der Geschlechtstheile dieser sonderbaren Thiere die liloakenartige Bildung, und die Schmäbel derselben entbehren, wie die der Vögel, der Lippen; allein das erste zeiget sich auf eine ähnliche Art bei vielen Nagern, besonders bei den Faulthieren und Beutelthieren, und viürde sie ja eben so gut an die Reptilien, denen sie auch wirklich Einige beizugesellen gedenlien, anschliefien, als an die Vögel; das Leztere aber ist gerade so unwesentlich als die Flügel der Fledermäuse, um diese zu einer abgesonderten Klasse herauszuheben, was noch mehr bei jenen der $F_{i l l}$ ist, indem dann die ganze hlasse blos aus zwei Gattungen bestïnde; übrigens sind der behaarte hörper, der vierfüsige Gang, die freihängonden Lungen, die Anwesenheit eines Zwergfelles, der Rest von Stoclizühnen bei dem Schnabelllice, und wie ich bei ciner andern Gelegenheit zeigen werde, das den Sütg thieren, besonders dem Tatu ähnlich gebaute Skelet, überwiegende Gründe, un sie zwar' nicht als 'Thiere, welche ihre Junge süngen, aber als zu der Klasse der Säugthiere ge. liörig, zu erlilären. -.. Z Zwar hat auf solche Art das Liméische System der Säugthiere, durch das Studium der vergleichenden Anatomie, bis jezt noch nicht jene Reform erlitten, welche ihr durch dasselbe noch berortuti allein dic cinzchen Fa 
milien, Gattungen und Arien, wclch bedintende Berichtigung und welchen $Z$ uwach an Indivinen sowohl als an Abbilungen haben sic nicht bisher, besonders aber dmch dic Franzosen whalten? fömen die Tentschen die Werle cmes Schebers, Bumenbachs, dio hussen cines Pallas, die Lngländer eines Bewiclis und Eenuan's aufweisen, so ha. ben die Franzosen die Merke eines Biffon und Daubenton, die Allonographie der Aften cines Audebert, dic Menoires eines Geoffroy und Cuvier. Wer hemut nicht die velen Abhandingen der lezteren, ats so schöner Bruchstüclie zur Geschichte der Sängthiere? Durch Goofroy wurte zuerst die Liméische Fandie der Didelphis näher entwicliclt, das Peramcle, nath seinen Zähnen und der Gestalt des hiöpers, mit jenen, nach scinen Zehen mit den hïngarulien verwant, wude zuerst von ihm beliannt gemacht, wid chlielt seinen Matz zwischen jenen beiden "). Die Dasjuren wuilen genauer charakterisiret, und mit den nenen ans $\mathbb{N}$ cuholland ron Tapitain Baudin mitgebrachten Aricn bereichert ${ }^{b}$ ), unter den Lemuren die Indri, Lori, Galago, Tarsier - unter den Nagern ier Hydromis c) und Phascolom - unter den Fledermüusen die noctilio, nycierus, rhinclophus, molossus cepha-
a) annales du musćum de paris, T. 4. p. 56.
b) ejusd. Tom. 5. p. 355. Toin。 25. p. 501,
c) ejusd, Tom. 6. p. 8 . 
lotes, phyllosiomes, megudemines a) als eigene Gatungen anfgestellt, das Schnabelilier und die Echidna zu einer eigenen Ordmung, ,noiotrènes", der Ameisenfresser von Acespten nebst dem Tatu unter dom Ivamon ,orycterope w menerdings

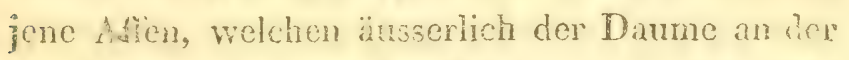
Hand mangelt, unter ler Penennung, ,atheless $b$ ) zu eisenen Familien erhoben, und die leztr schon mit mini Arten bestïtigg; durch itm endlich wurde eine Menge Abändermgen und Bereicherungen mit nenon Arten, beinalue in den mosten Familien hervorgebracht. Was Gooffroy im Reche der lebendigen Sunghicre, diefs und noch mehr that Curier in jenem der fossilen. Zwar haben bisher beinatse alle Schrifstelier in der gesammten Zoologie Abzeichntungen mid Beschreibungen von fossilen Säughtheren in ihren WVerhen gegeben. Valch, Scheuchzor, Lang, Mylins, Collini, Merk, Fisper, Rusenmüller, Kaxg, Faujas, Fhmenbach, T'ullas, Inuter, Camier u. s. w. haben rerschiecicte Nachrichten ïbr. einzcine Gcgonsiünde dicser Sache ertichet; aber Nimanci hat noch diese fruersuchungen über cine solche Menge von Fatmilien ma Gatimgen fossilcr Thicre ansgedehnt, als ehen Cuvier, welcher, so wie der verigleichen-

a) annales da museum de paris, Tom. 6. p. 150. Tom. 8. p. 205. Tom. 15. p. 86. p. $15 \%$

b) ejust. Tom. 7. p. $260-275$, '17om, 13, p. 83 . 
den Anatomie, auch đer organischen Ǵcologic durch die Nicnge vou Materialien Vcranlassung zu einem neuen Umschweng gab. IVur erst durch ihn wissen wir, dafs der Boden ron Paris ahmline Thiere wie Amerika in der Familie der Pachydermen, an den 2 fossilen Arten von Tapir (le grand et le petit) a) - an den 5 Arten von Palibotherium (nugnum, medium, minus) ${ }^{b}$ ) - an den 4 Arten von Anoplotherium (anoplotherium commune, medium, minimum) c) - unter den Didelphis an einem Sarigue d) enthält. Durch in ist es jezt ausgemacht, daf jene colossalen Faulthicre, - das Mrgatherium aus Paraguay ron der Gröse des Rhinozeros e), das Megalonix ars Virginien ron der Gröfse cines Ochsen $f$ ) - zwei rerschicdene Arten bilden - dafs es zwei fossile Arten ron Hippopotam s) (le grand el le petit) - : fossile Art von Phinozeros ${ }^{k}$ ) und Elephanten $\left.{ }^{i}\right)$ giebt - dafs das Mammouth nicht, wic Hunter den Irrthum rerbreitfle, eines init dem Ohio Thicr,

\footnotetext{
a) Cuvier annales du mus, d'hist, n. Tom, 5. p. 152. 158. Tom. 5. p. 52 .

g) cjust. Tom. 3. p. 275. 44z. Tom. 4. p. 66. Tom. 6. p. 253 .

c) ejusd. Tom. 13. p. 471. Tom. 6. p. 546.

d) ejusd. Tom. 5. p. 277 .

e) ejusd. Tom. 5. p. 376-383. r) ejusd. Tom 5, , , 358.

g) ejusd. Tom, 4. p. 299. Tom, 5. p. 56. p. 99.

h) ejusd. Tom. 3. p. 52. Tom. 7. p. 19-5x.

i) cjusd. Tom. 8. p. 1. 58, 93. 155. 249. 269,
} 
sondern lezteres eine eigene, ron dem Elephanten besonders durch die Zitzenfürmigen Zülne verschiedene Gattung, und daher ron Guvier neuerdings unter dem Namen ,mastodonte" nebst 5 fossilen Arten desselben aufgestellt ist a). Durch ihn sind wir jezt rersichert, dafs dic fossiIen Bruchstücke in diöhlen von Gaylenreuth oder vielmehr ron Teutschland und Ungarn überlıu!pl ${ }^{b}$ ) von Bären (ursus spelacus Rosenmül., arctoideus Blumenbach) Tigern, Lüwen, Völfen, Shakalen, Zorillen und der IIyäne, welche lezte nach allen Femzeichen mit der rom hiap übereinstimmt, und so, mit Bruchstïclien von Bären aus dem kalten Norden, in den Höhlen bei Gaylenreuth, und ron asiatischen Elephanten remischt, bei liannstadt angetroffen wird c) herhommen. Dals die in den Spaiten der hohen Felsen von Giherallar, Antiben, Nizza, Corsilia, Dalmatien u. s. w. wohl erhaltenen höpfe und sonstige Reste, von Pferden und Hasen herstammen \&), welche den noch lebenden nicht sehr mähnlich sind, mad vielleicht, wie die fossilen Fleischfresser in den Bärengrubn Tculschlands und Ungarns, erst in späteren, wicht selir von cinander cntfernten Zeiten verschüttet

a) Cuvicr annales du mus. dhist. n. Tom. S. p. 270.512. p. 401.420.

b) cjusd. Tom. 9. p. 428. Tom.7. p. 501- 372.

c) ejnsd, Tom. 6. p. 127, d) ejust, Tom, 13, p. 86. 
wurden. - Dals um Paris hermm, nicht bles $\mathrm{In}^{-}$ diviluen von Pachydermen, sondern auch von Tleischfresserm, von welchen die cinen zwischen Hunden, der Genetta und dem Mangonsi von he. gypten in der Milte stchen, die anderen dem lezteren am meisten fleichen a); dann von Schweinen und Fierden b) welche leztere aber hänfiger and z. E. anch mit Theilen mon Elephanten ver. mischt bei Canstadt rorkonmen, -- duch ihn wurde ausgemittelt, dafs sich unter don so häuligen fossiten Wiederhüum, blos jenes in Thand ausgegrabene Rlenthice, die Hirsche ron Schonen, der grofse Büffel ron Sibuien, nicht mehr unter den lelsendigen Arien rorfinden, und gegen die fossilen Bruchstiichic des gemeinon Iiro hes, Rehes, Aucrochsen und Büfel, wie die Nam. moutin und Hastortonten, in einer viel früheren Focke hegraben wurden c). - Dafs man in den aufgeschwemmicn Lagern des Thales der Somme, bei Geweithen ron Tirschen, Tïpfen ron Ochsen u. s. w. auch Käple und Zihne ron Bibern antrift, und das rom Gessuer beschricbene und vielfache misgedeutete Thier im Oeninger Thonschicfer, entweder ein Meerschweinchen ron Amerilia, cine Campagnol oder sonstige Cavia, jenes ans Böhmen

a) Cuvier annales du mus, d'hist, n. Tom. 9, p. 210.

b) ejusd. 'Tom, 14. p. 35. c) ejusd. Tom, 12, p. 335. $5 \mathrm{~g} 8$. 
ron Waich als cine Taserrate leschrinhene, wahrscheinlich eine Schermaus scy "). - Durch iln ist neucrdings dargothan, dafs in den hallschichten der Loire und Maine nebst Cetacécn anch fossile Brurbstiocle, anfallend verschiesen ron den bekannten I.amaztin und Pholicn, min?mischt gefunden werden ${ }^{b}$ ). - Dafs das Collinische Thier ron Richslitt, welches bei der Menge und dem gewöhlichen Forlomnen obiger fossio len Thicre als das cinzige hisher gefundene Fxemplar sciner Art in liürgithen habinette zu Miunchen anfhewahrt wird, ein dem Drachen ämnlicheo Reptil sey, was ich jedoch als cin Mittelgied zwischen Galeopitheken mal Filedermänsen zu rechtfertigen boffe c). - Curiey stellt entiich von allen scincu Linicrsuchungen als Resultat anf, difs tie meisten Gattungen oder Arton der fossilon Thiere ausgestorben, und an elon dem Orte hegraben worden seyen, wo sie grlobt und jezt grfmeln werden. ${ }^{d}$ ). - Bald werten wir durch solch fortgesezte Beabritung bei allen Nationen in Stando seyn, dic Süugthiere der alten und nomen Schinphumg zu ibserschanen, die Lïchen unter den noch Icbenden durch die fossilen anszufuilien, und alle diese Thice als eben so riele Glicder zu einem.

\footnotetext{
a) Cuvicr annales du mus, d'histo n. Tom, 14, p. 47.

b) ejusd. Tom, $14 . p \cdot 273 . \quad$ c) ejusd. Tom, 14, p. 24.

d) ejusd, Tom, 8, p. 422 .
} 
organiaclien Ganzen der Rele, wie sie es in dex concretes Notur selbst sind, zu gestalten.

Z VVEITES CAPITEL。

Vögel-Ornithologia.

๑. 50 .

Aristo- Aristoteles zeiget, wie in den Säugthieren, so auch in der Geschichte der Vögel, eine sleich unerschöpliche Quclle von Kenntnissen. Nachdem er sie durch alle z̈brige 'Thierklassen hindurch verglichen, ilıre Stellung auf zwei Füfsen mit dem IMenschen, die Flügel mit Fledermäusen und Inseliten als gemeinsam angegeben hat, so untcrscheidet or sie ron den Inschten ( $\pi \tau i \lambda \omega \dot{\omega} \alpha)$ und sczt

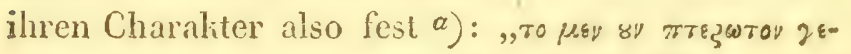

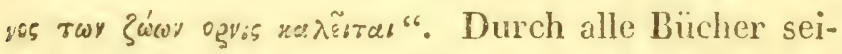
ner Thiergeschichte behaupten die Vögel nach den lebendiggebähenden und eicrlegenden ?uadrupeden immer den nächsion Rang, und dic Organe der Verdaung und des Geschlcchtos, die Sinneswerlzeuge, die Stimme, Degatiung, Ricrlegung, Sitten, das cinsame oder gesellschafiliche Zusammenleben, die Auswanderung, der Eimflus des Filina and der Jahreszeit, auf Farben, Gesang, die Verschiedenheit in der Farbe der Eier, in der Anlage der Nester u. s. w. hichen abwechselnd die Gelecren-

a) Aristot. Ihistor, animal, I, 1, p. 18 。 


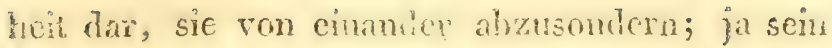
Forschungsgeist gehi so vieit, daís ex den Lmbryo rou der ersten Bebrüumng des Eics an, durch alle einzelue Tage, bis zur Zeit des Aushichens beobachtet und beschreibt s). Cicher lieinen der angegebcnen Unterachicde aber läst er sich so weitJinfig ans, als riber folgende drei, nämlich

-wach den Pibisen b, Foran alle ohne Unterschicd mit filanen und Zehen versehen silut

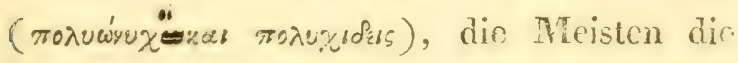
Zehen frei und unvervachsen, entweler dre: nach rornen and cine nach hinten, oder zwe: nach linten und rben so viele nach rornon - oder andere durch eine sorbwimmhan! verbunden (

- nach der Nahrung ") in solche,

- welche rom Ficisclic leben, wobogen? Flawen an den Zehen haben, und bei Tag oder Nacht anf den Faub cusgehen

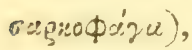

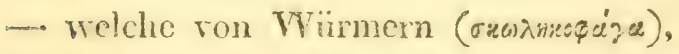

- wriche von Mitichen oder Inseliten über-

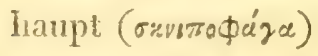

- wolche cudlich von Früchten ( sich nähren,

a) Aristot. histor animal. L. 6. p. 551 .

b) ejusd. L. 2. p. 79. c) 'ejusd. I. 8. p. 6.6. 
- nach dem Aufenthaltsorte a) in solche

- welche auf dem Lande,

- welche zunichst den Flüssen, Seen oder dem Meere,

- wclche im Wasser selbst leben.

Frr bemerlit, dafs diese drey Punlite einer Abthei lung zu Grinde golegt werden liönnen, und spricht nun gemäfs denscllen an rerschiedenen Stellen ron den Adlem, Fichteulen, Sperbern, Raben, Paradiestögeln, Staaren, Amseln, Kukinlien, Spechten, Lerchen, Rebhïhnern, Ta:ib:n, Vriescuschnarrer, Ibis, den liranichen, Storchen, Reihern, Pelikianen, Enten, Gänsen, Tauchern, Struste s. w., ohne sich jedoch bestimmi und ausschlic. send für einen Einzigen derseiben zı erlibiren.

Plinius liefert ein noch umstäntlicheres Reryister von Vögeln als Aristoteles. Nebst den bisherigen, erwibnt er aucl? zum crston Male des Strausses, der Diomedea, des Flamingo u. s. w., unterscheidet sie überlam?, wic sein Vorgänger, nach den Krallen, den freien Zehen urd der Schwimmhaut, nennt cinige die Singrögel (oscines), dic Papageien plaudernd (scrmocinantes), und zählet sie sümmîlich ohne Rülisicht auf inncre Ordnung mohr in Anelidoten und anderseitigen Rüksichten auf.

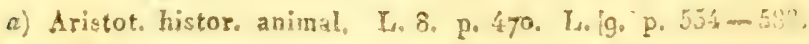




\section{$-253$}

Oppian bleibt in dem Werke über den Vögclfang, wie man aus der Paraphrase des Sophisten Fntelinus ersieht, seinem Vorgänger ganz getreu. Dic Schilderung der Jagd beginnt or mit den Landrügchn, und delinet sic dann auch auf dic der Gc. stade und des Wassers, welche er Amphibien nennt, aus.

$$
\text { 6. } 51 \text {. }
$$

Von num an schlicf mit der gesamnten Naturgeschichte auch die der Vögel den tiefen Schlaf der Vergessenheit. Erst mit Isidor ron Serilla erwachet sie wie im Traume. Die einzelnen Gattungen werden in Fïrze und ohe irgend eine Ordnung im Geiste Plinius ron ihm beschrieben, und ihnen die beflügelien Inseliten mber dem Titel: "de minutis volatililus" beigefigt. Albert. M. beschränkte hicrauf die Vügel blos auf Thiere mit Fedcrn, und brachte die bisher belianiten Gathmgen in alphabetische Ordmung und rolhdiurtige Beschreibung. - Langolin sezt in einem armseligen Gespräche die teutschen und lateinischen $\mathrm{Na}$ men von Haushühnern, Lerchen und Sperlingen fest. - Turner liefert gleichsam ein alphabetisches Verzeichnifs der in Aristoteles und Plinius vorkommenden Namen und Bemerliungen über Tögel. - Bellon, durch seine Reise nach Afrika und $A$ sien angeregt und bereichert, giebt nicht nur trenere und umständlichere Beschreibungen, nehst 
bortreflichu tholzstichen ron Vügeh heraus; sonz dern bringl diese sogar in schililiche Ordnungen und Abthiluagen, und vergleicht liuhnen Muthes das Slelet eines Vogels mit dem eines NIenschen in mebneinandergestellten Holzstichen. Der Aufenthalisort - - das Iand und das Wasser - dient Iîn zur Liassifhation, die Nahrung und Gröfse des liorpers zu Lnicrablhcilungen; das erste Buch lamult ron den Vögrh im Allgenenun; dis zweite ron den Ranbügehn des Tags oder der Nacht, wozu er anch die Wü̈rger, den kinluk, Zirgenmellier and die Flecicrmaus rechnet; das drille ron den Wasservëgch, und zwar ron solchen, welche in Wasser schwimmen; das vierte rondencn, welche sich zunächst dem Wasser auflalten, wohin er anch den Eisrogel zühlet; die lezten drei Bücher exthullen, wie es scheint, alle jene, die nimgends unter obige Abtheilungen pafsl’n, nämlich das fünfte whe massiven Vügel, wel. :he wie Stransse, Hüher, Waldschepen, ihre I.ier zar cbenen Erue leugrn, das sechste jene, de. ren Nihumg manchfallig ist (Raben, Wiedehopf, papageicn, Tauben), das siebente endich alle lifinen Vügel, welche in Gobüschen und Gestrüuchen leben.

Gessuer bemat gleich hierauf den Reichthum Bellons, venachlasiget aber seinen Forgängos in der Treue und Genaugheit bei Leschecibun- 
gen, in der Schönheit und Richtiglieit der Holzstiche und statt einer natürlichen Abtheilungr bringet sie dieser rerdienstrolle und unermüdete Sammler in alphabetische Ordnung.

Allmählig nimmt mit der Plinianischen Sucht zu sammeln; ebenfalls die Liebe für Ordnung und System zu. Wotton ist auch hier wieder der ersie, welcher einen systematischen Grundrifs der Vögel nach Aristoteles entwarf. Er theilet sic in solche mit gespaltenen Zehen - Landrögel (fissipedes) - und in Palmipeden - Wasservögel ab. Zu den ersteren rechnet er die Gattung der Hilhw, Tauben, Drosseln, der Flcischfresser (Adler, Raubrögel, Kukuk, Eulen, Schwalben, Itaben) dex Inselitenfressenden (Spechte, Sperlinge), hicrauf lolgen jene Vügel, die zunächst dem Wasscr lcben, dan die eigentlichen Schwimmer - die Gänse - endlich die monstrosen, als Stymphaliden, Sirenen u. s. w., und zulezt der Straufs, den er als cin Mittelding zwischen Quadruped und Vogel angiebt.

Was Bellon und Wotton begonnen, fuhrte Al. drovand weiter fort. Obwohl dieser alles, was er in Bezug auf Vögel in irgend einem Schriftsteller gelesen hatte, hier wie auf einem Haufen zusam. mentrug, und beinahe in der Masse seiner Poly. historia erstilite, so liefs er doch nicht ab, sich gegen die alphabetische Ordnung zu erliziren, und 
nit jeucu buche und Abschnitte auf cine naturliche hangordmug der Vögel zu dringen. Er legte stinschweigenu das Element des Landes und des Wassers zur Ábtheilung dor Vögel seinem Werle zil Comnde, und handelie diese in zwanzig Büchem ab. In dritten 3 ande, welcher die Vögel, so in Wasser oder zunïibst demselben leben, enthält, blicb or dem dellon ganz getreu, so auch in den eroten acht büliern, welche die Rambrögel de: Wages oder der Nacht zum Gegenstande habei. me schon in Aristoicles so meisterhaft auscinum diergesezt sind; allein die Anordnung der ïbriwn Landrögel, crlitt durch ihn eine auffallende Verbesserung. Aldrovand sonderte, als der erste, die Iletermäuse und Strausse von den übrigen Vügelı (i), wind stelle sie als Mattelling zwischen dicsen and den lobendiggebähenden_und eierlegenden Gualrupeden in neunten Buche hin, er filiste allo fubchaltun Vägel im zchnten zusammen, und schied, was Bellon in den lezten drei Büchern zusmmnenwarf, nach ihrer rerschiedenen Nahrungsart ansinander; die Fruchtfressencien Papageien werien wegen getirummien Flanen und Schnabel als Verwandte der Raubrögel im eilften, das Rabugeschechi (corzi, procte, buceros) mehr in der Nahrmg a's in dem Bane den Raubrigyehn älmlich, im zwölften abgchandelt; die drei nächsten Bücher cothalton dis Kivnerfressenden mul zivar das 
eine, die nichtzahmen Huhner, so in sitanbe scharen, das andere die zalmen, das lezte dic Tauben und Sperlinge, die sich mit stambe bestrenen und waschen, das sechzchute beschreibs: Beerefressente Drosseln und Amsehn, das siebzehnte die Viurmerfressenden Schwalben, Pario diestügel, Wiedhophe, Motacillen u. s. w.; das acinzehnte beschliefst endich don zweiton Band mit den Singrögeln.

Die Ansicht, welche bisher der Ornithologic stillschweigend zu Grunte gelegen hatte, hoben. Jonston und nach ihm Churleton heruns, und überschricben damit die Abschnitte und Lapitel. Die Landvügel werden in fleisch- und inselitcnfressende oder in Sungrögel mind gesanglose - die des Wassers in Schwimmfifsler ma Fissipeden, beide dann nach der Nalnung in fisch - inseliten - oder grasiressende abgetheilt.

Villughby und Ray rollendeten endlich die Richlung, welche beit Aristoteles cingeleitet war, Wie Bellon, Wollon, lldrovand und Jonston, nahWillushby und Ray. men auch sie das litenent des Landes und Wasscr's zum Prinzipe, die Nuhrung und den Gesang zur Nebenabsichi, mal erweiterten das bisherige System dadurch, dails sie die Gestalt des Schna bels und der Lilauen, glcich nach dem Elemente, 
צn Literabithilungen wer Vögel einfitiren a). Die Lamüügl (terrestres) sondern sich in sulche nil krummen (adunci) oder geraden Schnabcl and Hanen (rectunsues); jene leben vom Fleische and suchen als Raubrögel ifre Nahrung bei Tage, sind - gröfser, auch edler, wic z. B. die Ádler, oder unedler wic z. B. die Vulturen, - lieiner und zwar dic cdleren (generosiores) haben wic dic Falken lange, oder wie die Spcrber und Taubenhabichte hürzere Flügel (bruchypterac), die unedleren (iฐnuriores) zum Vogelfange nicht benüzten, wic dis Weihen, Whirger, Paradiesrögel - sie sucien ine Taurung bei der Pracht, wie die beohren oder chrlosen Vulen und Ziegenmellier - oder sie Ichen ron Früchten, wie die Papageien, nach der Gröfse des hörper's rerschicden. Dic zweite Familic, nümlich wit seruderem Schnabel und lilanen, sind - nach der Gröfse des hörpers (majores), als stransse, Raben, Aelster, Spechle, Eisrogel, zahme und wilk Unhner, Tauben, Drusseln, Anseln, Staaren - nach der Kilcinheit (minors) als dünnschabliche: Lerchen, Schwalben, Naisen, Wotacillen - als dilschnabliche: Spenhinge, Ammer, von einander gesondert. Die Masserwögel (aquaticae) werten nach den

8) Willughly. Ornithologiae libri tres - totum opus recognovit, digessit, supplcrit Juanmes Rajus, Londini $16 j 6$. in Fol. 
freien Zehen (fissipedes: grus, ciconia, ardea, mumenius, scolopax totanus, phuvialis, gallinula), je nachdem sie grölser oder lileiner sind, einen mehr geraden oder gebogenen Schnabel haben, oder wie die lezteren selbst schon ins Wasser gehen - nach den durch eine Schwimmhaut rerwachsenen Zehen (palmipedes: avocetta, alcae, onocrotal. colymb. lari, dionedea, mergi, anseres, anas), je nachdem sie lange oder linze Füfoe, einen dicken oder dïnnen, vorne geraden oder getirimmten Schnabel, alle Zehen ganz oder zum Theil rerwachson haben - ron einander mnterschieden, und beiden Abheilumgen die neuentdehten Vögel Brassilieus ron Marcgraf, jene ans Mexilio von Hermandez, die von Jamaika von Sloarle beigefügt.

Das Medium, worin die Vögel leben, ist die Inft. Zwar findet sich schon ein gröfserer Theil als bei Säugthieren, welche ihr Leben neistentheils oder immer im Vasser zubringen; allein, obgleich diesen dic Luft in ihrem ganzen Umfange als freier Spielraum nicht rergönnt ist, so ist es doch richt wie bei Fischen, das Wasser, sondern die anf demsclben ruhende niedere Luftschichte, Neiche ihnen zum Elemente eingeräumt ist, und zu welchem sie nach einem liurzen Verhalten un. ler dem Wasser sogleich zurüchelichren. Ist fü 3ie PAanze dic Erde, oder überhaunt das Feste, ist 
für den Fisch das Wasser das Element, ohne relches sie nicht linge subsistiren liunnen, so ist es for den Vogel die Luft; ja Planzen, Insekten und mplibies gefalien sich in der mephitischere fexchi in Luft, und lagern sich deswegen gerne und zahlieich um die lindsgrotte und den See Aremo bci Ncanel, während sich ringsum hein Vogel erbliclien lifet, und diese also für die reincre and eigentliche Inft, welche sie nach allen Rich. tumgen frewlig durchschneiden, geschaffen sind. Welchon Rusg tie Luft unter den Elementen, eben iecen behaupten anch ihre personificirten Bewohner - die Vey - anf ouganischen Eebiehe. Die Vigel sim "s auch, bei welchen die Lungenbildung cinen michigen Schriti vorats that. Hier ist es der Natur von den nicieren 'Thisen heraut zum ersten Blale whingen, die Brust ron dem

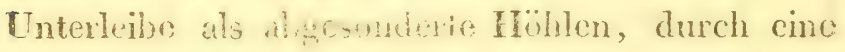
Scheidewant, die bei firatsscu schon ziemlich mit. Miskelíbern uberzogrn, also ein wahres Diaphragma bided, die Irmgon selbsi fü beständig in jener zn fxiren, und diesen als simmetrischen Hätfen ihre mabände liche Iagge oberhalb dem nun zweitianumigten Wexzen zu beslimmen; obgleich anderer Seiis dadurch, dafs die Lungen der Vögcl nach ihrer hinteren Fläche an den Rippen angewachecu sint, und durch Lücher nach vornen, wie auch duxch einte offue Spalte des unte. 
ren Kehlkopfes, dic Luft in die hohlen Tno. chen, Federn, durch die durchlöcherten Hautsäclie der Brust in den Unterlcib, gerade so unmittelbar, wie die Tracheen der Inseliten an Muskel, Nerren und alle Organe führen, und vielleicht durch einen solchen Vorrat! sich das Verbleiben mer dem Wasser, und die Leichtigheit im Fluge möglich machen, dicse Thiere weit hinter den Süugthieren, wo alles dieses ricl rolliommener ist, zurüchblciben. Ist abcr glcichwol! nur dio Luft das eigentliche Element der befederten Thiere, so bowolmen demolngeachet the eincn mohn die höheren, dic anden moler die niederen Enfachicho tcn, wo nümlich dieses Dement cin andores benihiet. Allerdings liefsen sich also die Thigl in solthe des I andes oder des Wasscrs, med in Snnpeund Strandrügel, welche glcich Amphibien zwischen jenen in der Mitte liegen, abtheilen. Selbst die Spicrlinge, Tasben und Hühner, welche sich schon im Wasser zu baden lichen, wïrden allmähligr die Landrögel mit den storchartigen, welche zim 'Theil selbst schon elwas in das Wasser gelen, wnd mit den eigntlichn Günsen venbinden; So wäre denn ron dem Conkur an, der sich in rem obersten Iuftschichen gefullt, dureh dic Raben, Sperlinge, Ilibner, Storche und Güns his 211 den Allon und Apicnodyten, die sirh beimahe fur nicht ans dem Whomente des Wasons entero 
nen liönnen, cine schöne fortlaufende Stufenreihe hergestellt. Doch so schön und wahn im Allgegememen dieser limstreiche Plan der Natur ist, wie viele Ausnahmen werfen sich der Betrachtuns entgegen? Der Kiönigsfischer (alceto ispida) und der sogenannte Wasserschwätzer (cinclus aquatic.) halten sich nur am Wasser auf, und hohlen, wie Limé roll Verwunderung sich ïber den ersten ausdrïlit, emergit non painipes" aus demselben ihre Vahrumg - Rigenschalten, weswegen die Omithologen bis anf Ray und nenerdings bewik, sich hintergelien lielsen, dieselien unter die Wasservingl zu setzen. Der Secretä spazieret mit seincu hohen Füfsen an Gestade und an Sümpfen, wie ein Storch herum, weswegen ilun cinirge Ornitholngen, wie z. L. Cnvier, früher nuter die Grallen gesezt haben. Der Flufs- und sceadler, dic surimf-Rolr - und Wasserweyhen weichen nicht ron Secn, Flïssen oder dem Mecre, um hicraus ihre Beute z.n erhaschen; Die Raben halten sich, so wie auf hohen Bümmen, ebenfalls in sumpfigien Gexenden, in halbausgetrolineten Weihern und am liebsten am Meeresgestade auf, die Náchtigallen leben an Büchen, der Rohr- nud Sumpfsinger, die Rohrdrossel und der Vasserpieper in Schilfe und Sümpfen, die Bachstelzen lanfen gerne längit dem Ufer des Wassers, die Schwalben verkindeu durch ihr Baden den beror- 
stehenden Regen, Sperlinge, Tauben und Hihner lieben sich ebenfalls zu baden, lauler Eigenschaften, welche nicht an die Trigel des Landes sondern des Vassers erinnern. Auch dip Storche nisten auf den höchsten Gcbinden, und ficgen ron da an sirunfigle Gegenden, die Reiher leben abwechsclud anf Päumen und an Uffern, dic Waldschnepfe nielel, wie viele Landrögel, zur ebenen Erde in Talden, die Gälnse bringen einen grofsen Theil des Tages auf dem Lande, cinige Entenarten z. B. ,anas arborea Latham." auf Bäumen zu; welcher Unterschied ist num wohl nach dem Aufenthalte zwischen den Land- und Wassenvögehn, und mit welchem Rechte liamn man, wie Ray, die Strandliufer zu den lezteren rechnen? Nach dem blosen Aufenthalte kann man also nicht leicht dic Ordnung eines Vogels erliennen, nimmt man nicht. noch auf andere Merlmale Rülisicht, wie es seine Nachfolger thaten. 'Zwar hat Ray noch einige wichtige Gesichtspunlte, wie z. B. die Beschaffenheit des Schnabels angefülurt, nirgends aber durch das ganze Gebicth dicse Detrachiung fortgesezt, sontern blos zur Dezeichnung cinzelner Familicn gebrathe Um sowciter Ausfihrung hat er hinregen der Rülisicht der Gröfse oder Klemheit des Törpers gestaltet. Freilich hätte er diese so oft wiederhohlte Abtheilngg, ron dem pferdeartigen Stratsse an, bis zu dem Trallnufegrofsen holibri, 


\section{$-264-$}

Whitich dor alphabetischen Ordnung anstchnen lönnex, was er mit lilugheitthat, inden die Gröfse naci den Alter, Geschlechte, Flima mid der Nahrung varürt, und beinahe in jeder Familie abwechselt. Uebrigens glcichet die bisherige Geschichte der Vözel woren den ausserordentich vie. Ion $A$ btheilmsen und Rälsichten, cinem Walde voll Gestrïichen, aus welchem man keinen Ausweg finden kann.

\section{52.}

Limně. Von num an ward das Imn - und Anslino gुefiannter, und dic Anzahl der Vögel und slliciansgen von ihnen wuchs mit jedem Tage. Alarviglives licfert jene der Donan, Caksby bereichent uns mit denen von harolina, Florida, Virginien und der Insel Bahama, Albin und rorzüglich Edwards mchen sich durch Zeichnungen ron einheinisch en and ausländischen Vögehn belianut, Friscli lärt tio Tügel Teutschlands, Secp jene ron Nicderlaten in rortreflichen Abbildungen erscheincis. In dieser Umgebung und bei diesen Vorarbeiten, legto Iinné in seinem Systeme der Naiur auch das dor Vögel nieder. Zwar waren dicse nach dem $\Lambda$ uf: enthalte auf dem Lande oder in Wasser, schon in Haupigruppen durch seine Vorgünger georduet; allein im Innern herrschte noch Verwirrung, nut der Ansichten und Unterabthcilungen waren so viele, dafs sich der Blick des Naturforschers wio 
in einem Labyrinthe vertor. Limne filhte thetls den Zwang and die Lüchen, diese Thiere nacl! aem Aufenthalte zu reihen, theils die Unstitigkeit and die Unordnung in Benennung und Vertheilung des Tunern; or machte daher auch hicr von scinem Echema der hlassen, Ordnungen, Gattmgen und Arten Gebranch, fixirte die Ueberschrifien diescr and die Namen der Arten, fügte ihnen die Synonimien anderer Schriftstellor bei, entschlug sich jenes Kwanges, welchen die Ansicht der I Lank and Wasserriggel mit sich fuhrte, und stellte als der crste dice filasse in wenigen Gruppen gegliedert, dem forschenden Augo zur leichten Jeberschmang dar. So crecheinen dem, nachdem or aiv जrtummg dor crsten Ausgabe , mactorilynchere (sonhe, leiher) in der Folge mit jener "sculopace" in eine Linzige rerband, und späterhin vutce dem Namen ,orallae" anfstcllic, folgon(i) schs Ordnungen dirch alie Ausgabon an Zahl, Anichunderfolge mal Berenung mweründerl: "accipitires, picae, anseres, grallae, gallinat;

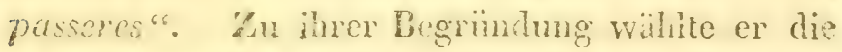
rerschicdene Ineschaffenheit des Schnabeis, welche schon Aritoletes angegeben, Ray aber bei revschiedenn Gulogenheien als Nebenunterschied gobraucht has, und nur, wic er nach und noch scine Literatur durch die gleichzcitigen Arbeiten cinc: liein. Brisson n, s. we erweiturte, werden anch 
noch ron der zehnten Ausgabe an, andere Charalitere nümlich der Füse, des Ganges, der Gestalt der Maxillen, Zunge, Nasen, des Scliwanzes, der Flïgel, Nester, Lebensart hinzugefügt. So unreränderlich aber auch die Ordnungen blieben, um so melır veränderte sich in den verschiedenen Ausgaben seines Systemes das Innere derselben, und Gattungen und Arten werden theils von ciner Ordnung in die andere rersezt, theils in der Folge in ausserordentlich vicle aufgelöfst, wie aus der Vergleichung der einzelnen Ausgaben erhellet:

I. ord. ,accipitres." Dicse Ordnung den reissenden Säugthicren entsprechend, bestand bis zur zchnten Ausgabe aus den Gallungen: Papagei, Eule, Falke, in der Folge wurde dieses ungeliehrt, die Papageien werden zur zweiten Ordnumg geworfen, dic Vulturen ron den Fallien getremet, and die Würger gleich nach den Eulen als vierte Gattung hinzugefügt.

II. ord. "picae" den Primaten unter Sängthieren entsprechend. - Die lezte Ordnung ausgenommen, erlitt diese die meisten Umwandlungen. In der fünften Ausgabe ist der Wrendehals noch eine Art von Kukuk, dic Spechtmaise und der Baumläufer bilden ron cinander gesonderte Gattungen; in der sicbenten vereinigt der liönigsfischer auch den Baumläufer in sich, der Wende. hals erscheint als eigone Gattung, und dis? Enech! 
maise wird zu den Sperlingen hinaherworen, dit Gatturgen Touhan und halat treten zum ersten Male anf. Mit der zolnten wird die Anzahl und Aufeinanderfolge bicihender, dic Colibri, Spechtmaise werden ron den Sporlingen hicher rersezt, der Bienenfresser rom Bammläfer als cigene Gattung getrennt, mil der Ani, in der zwölften mit "buphaga" endlich "Zucco, trogon" u. s. w. wächst dic Anzalıl der Cattungen zu einer solchen Menge heran, dafs ihrer statt 9 jezt 21 sind, welche nach dem Gang- Litetter - oder Schreitfü'sen in den drei lezten Ausgaben abgetheilt sind.

III, ord. "anseres" den Belluen unter den Säuğthieren analoģ. Dic Gänse slanden früher zwischen den macrorkynchen und Schnepfen in der Mitte, behaupteten aber nach der siebenten. Ausgabe, wo diese unter dem Nanen ,ardeas" den Schnepfen einverleibt wurden, immer diesen Rang. So wenig Versutzungen die eigentlichen Schwinmfuifsler crlitten, so wechselten doch die Löffelgans, der Flamingo und das Wasserhuhn häufig ihre Ordnung, bis sie endlich bei den Gratlen rerblichen. Der Sturmvogel stand in der siebenten Ausgabo bei den Sperlingen, eben hier wurde erst die Allie rom Schwane, dic INecrschwalbe von àer Mlöre als Gattungen gesondert; von der zchnten Ausgalue an erscheinen auch dio Albatros, Phaeton, Rhinchops und alle zusammen, 


\section{$=263-$}

werden nach der Anwesenheit oder Abwesenheit des Nagels an der Spitze des Schnabels in zwei Familien abgetheilt.

IV. ord. "grallae" den Bruten der Sängthicre yleichnesezt. Sic waren, wie schon crinnert, frihor in zwoi Ordnungen gespalten. Von der zehnten Anscgabe an wuden alle diese Arlen ,ardea, numenius, charadrius, tringa" zu Gattungen crhoben, so dafo stall sichen nun fünfzchn anfgezallt, und fruher nach den langen oder hurzon Schnabel, jezt aber nach der Zahl der Zehon mutersclieden werden. Blos in der zchnten und zwölften Ausgabe haben sich cinmal die Stransse and Trappen, mit Ausschlues der Dronle hieher verloren, sonst waren sie immer den Wühnern beigezählt.

V.ord. "gallinae" die "pecora" von Süngthieren rorstellend. - Sie waren, jene Veründerung mit den Straussen and den Tasserhulun, welches leztere cinmal hior stand, ausgenommen, unter allen an wonigsten dem Wechsch interworfen; anch blichen die Gattungen so zienlich immor in gleicher Anzahl, ausser, dafs fribher ler Phasan rom Valdhuhn, und neuerdings las Perlhuhn von dem IIahn als cigene Gattungen gesondert sind.

V1. ord. "passres" den Nagern der Sängthiere parallel. - Kicine Ordnung war so hïuf. 


\section{$-269-1-x$}

gem Versetzungeis und terriplfaltigungen untero worfen, als diese. Lutrar wurden, ausser der Spechinaise und dem holibri sonst heine Gattungen ron yir enixisson, aber einzelne Arten wechselten un desto melir zwischen dieser und der zweiten Ordnung, cinzche Galtungen selbst lülsten sich später in ausserordentlich ricie auf: So wrurde der lanius carnifex zu ampelis, der com. patrulis, zu muscicapa übergetragen, der Am. ner wird in der funften Ausgabe von Fringillen als eigene Gattung getronnt, eben so in der zelnten caprimulgus ron hirundo, in der zwölten die pipra von parus, die tanagra ron fring̈illa unil cimberi=a, die muscicapa von motacilla, der colius von loxia als cigene Galtungen hingestellt, die ganze Ordung seli; aber noch dem mehr dichen oder dümen Schnibel früher in zwei, jezt in vier Abtheilungen gebracht. Durch solche Vervielfültigung geschah es dem, dafs die Fringillen in der ersten Ausgabe 10, in der lezten 103, die Motacillen dort 9, jezt 175 Arten ausmachen. Auch in der Aufeinanderfolge der Individuen die. ser Ordnung, giengen manche Veründerungen vor: So standen bis zur zehnten Ausrabe dic Tauben und Drosseln an der Spitze, ron der zwölften an hommen die Fringillen zuerst, und die Staaren and Tauben machen den Beschlufs der sürnmli. chen Vögel. 
Limé hat das grofse Verdienst, den viden Unterscheidungen und dens dadurch entstandenen Chaos, durch wenige und leicht überschantichs Gruppen ein Fnde gemacht zu haben. ' $/$ waw hat er sich aller Grundablheilung und Rechlfertigung der Anzalil and Aufeinanderfolge seiner Ordnungen überhoben, und scheint zuvorderst blos nach dem ätsem Iabilus und nach dem physiognomischen Whiche dieselben gebildet zu haben, inden Aie Charahtere weitschweifig, und nicht auf alle micrgeordnetc Glieder passen. Allein die Beschaffenheil des Schubels war es doch rorzüglich, welche seinen plyysiognomischen Blick in Bildung der Ordnumgen leitete, womit er auch jede zur Anszcichnung durch alle seine Ausquben überschrieb. Freilich ist aer zahnlose Schmabel, welcher nebsi den Rlanen und Flügeh diese Thiere so anserordentlich unithlich der vorigen hlasse nache, von wichtiger bedeutung. Je wejter wir ron den Vuluren, Spenlingen, Hühnern, zu don strandläfern md Gänsen himagehen, desto melix nimmt der Raum der fiopllible, dann die Fürzs nnd limümmug des Schnalscls ab, die Länge nnd Massivitä des lezicren alere auf hosten der crsteren zu; Ranon and Schmabel werden bei Strandund Wasservögeln melir gerad und lang, während sie bei haubrögehn hurz md gelirümm sind. Die Aller, Eulen und Pupageien, haben den gröfsten 


\section{$-271$}

Umfang der Kopfhöhle, aber den liürzesten und gclirimmtesten Schnabel, und gleich beschaffene Jilauen; mit den Vürgern, Tanagren und den meisten der Ordnung der Sperlingen ist von jener halenförmigen Frïmmung nichts als der sogenannte Zalnn, an den Raben, Wiedehopfen, Drosseln, Spechten und den den Fringillen nach dem Schnabel so ähnlichen Hühnern, nur noch die Frimmung olne Haclien zurüligeblieben, mit den Storchen wächst er zu einer pfriemenartigen unbehïillichen Länge heran, mit den Pelelianen und Gänsen behält er leztere, wird aber auch nach der Breite massiv, und nicht der eigéntliche Schnabcl, sondern der hornartige Nagel an der Spitze desselJen ist etwas gekrümmt. Aber wie vicle Ausnalımen stellen sich bei dieser Suffenreilie ein? Dex fulco aquilinus hat den Schnabel gelirummt und zwar ohne Hacken, gerade wie die Hühner. Bei Toukanen, Nashorniögeln, Flamingo, Albatros welche sonderbare destalten von Schuäbeln? und welche Manchfaltigheit offenbart sich selbst in jeder cinzelnen Familie oder Gatung? die alaud. calandec hat den Schnabel kurz und dick wie die Fringillen, die afrikanische sichelfürmig ähnlich dem der Kolibri, die anderen haben ihn mäsigg lang, mehr gerad und spitzig auslaufend; lei den Tauben ist er mehr gerad, die columba recurvirostra aber hat ihn gelirümmt, der Straus, Ka- 
siar und die Dronte, obwohl von cincr Familic, wciclir abreichende Schnabel hat jere diezer Gaitumon? die huluk, wekh manchallige Women von Schnübch bictleis sie dar? Wer gromel sich also wohl, die Vögel noch der Verandschafteder Schnibel zu warahterisiren? Lben dowegen sind die Limúischen Chambere der Ordnmgen nichts wenieg als entschedend, denn wer vollte doran

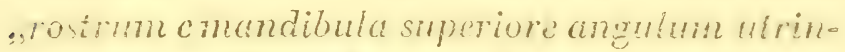
gie cxsercns" die liavbrögel, wer daran "ros"wum subcompressum conexum" irgend cincn der picae crliennen? wer will unter diesen Charaher ,rostrum conirim "teminatum" dic ver" schiedenarligsten Schliblu dor Sperlinge bringen? Limé selbst hat sich nicht an seine Aufschifion Gehaiten, und z. B. die Parageicin nit dem llabichtschnabel, die Spechte mit dem pfriomenarigen in eine Orduung, den Rhynchops mit den geraden mu schmalon Niaxillen, wo:on selbst die obcre ziemlich vicl lïrzen isi, mid tie Gänse mit breiton und platien Schnel zu don leztren, dic Patalea nit dem lificlariges, des Flamingo mit dein winklicht in der Rilte gelwimmen und die Peher mit priemerablign sdmabel nner die Grallen, knrz Fögel mit dan hoterogensten Schnäbehn in cin wnd die nünliche Ordnung znsimmengeworfen; ja die Qrdnung der Sprolinge, welche dem Schnabe! und selbst dem übrigen liörper nach 


\section{$-273$}

jener der Aelstern am meisten verwandt ist, stehet gerade am entgegengeseztesteri Ende, und zwischen ilmen beiden sind die umbehiulfichen Wasservögel. Limné scheins späterhin diese Lüclien eingeschen zu haben, und suchte daher in den leztoren Ausgaben die Charaltere jeder Ordnung durch Beisilze der Beschafienheit anderer Theile zat erginzen, welche aber, leider, nur ron einzelnen hudividuen genommen, niemals auf das Ganze passcn: So werden an den Raubvögeln liurze Fülse angegeben, während der Sekretür sehr hohe, wie ein Strandläufer hat; so heifst es bei den picae: peules ambinlatorii, nidus in arboriúus, und gleich darauf werden sie mach den Fletter- und Gangfufsen interschieden, und von dem hönigsfischer wird angemerit, dafs er am Strande seine Eier zur ebenen Erde lege; von der Ordnung der Sperlinge wird ausgesagt, dafs ihr Gang ein hüplender sey, während doch Tauben, ohne zu hüpfen, einhergehen. Auf gleiche Art liönnte man die Vidersprüche der allgemeinen Charalitere der Ordnungen mit denen einzelner Individuen durch alle hindurchfuihren. Vortrefflich im Gegentheile ist sein Bestreben, eine Parallele zwischen den Ordmungen der Süugthiere und der Vögel darzustellen. Wenn man die Bildungen der Natur durchiforschet, so dringt sich Jedem die Beobachtwe mit Gewalt auf, dal's die Natur ron den unte- 
ren und einfachen Gebilden an, sich in ten lwhet ren, obgleich in imner schöncren Formen, wiederhohle, ja man liünnte beinalie als Probe fir jedes Systcm aufstellen, dists dic Klassen, Ordnungen, Fanilien, Gatmingen und ihre Anfeinanderfolge, einander wechselseitig entsprechen. Lei den Sängthieren war es nicht schwen, dis Cetucéen als den Fischen, die Pachydermen als den Amphibien, die Fledermäusc als den Vöguth cintsprechiend zu bestimmen; Bei den Vögnin wird dicse Analogie schon unliemulicher: die Raubriggel entsprechen den Raubthieren unter Mammalisn, die Sperlinge den Nagern, die Struthion nden Pachydernen, die Mühner den Vicderhänern, die Grallen denPforden, die Günse, besonders die Allien, Aptenodyten, den Cetacéer. Jedoch Limné salı diese Parallele zwischen eincr hilasse und der andern, nicht fïr so wichtiog an; deswegen er auch die Aneinander* folge der Ordnungen der Vügel, jener gar nicht anpafste, und sclbst die Paralle!c bci einigen Ordnungen, wie z. B. bei der der Aelstern als den Primaten, „bei der der Günse als den Belluen entsprechend, nachlärsig und grundlos gestellt, und überltanpt nicht bis auf Farnilion und Gattungen herab reriolgt ist. Wie die Rangfolge der Ordnungen gieich verwirt ist, so ist es die der einzelnen Familien und Gattungen, und chen dieses ist es, worin das I timucische System Ferbesserung vor semen Nachtolgern erwartet. 


\section{\$). 53 .}

Linie hatte haun das System der Vögel in ei- Elein. sigen Ausgaben dem Publikum vorgelegt, so erwachte auch hicr ein gleicher Eifer in lilein. Gar nicht zum Nachbehen geboren, stellte er sich auf dicsen Grbiethe jenem Mrister entgegen, ind be: arbeitete fir die Vögel cineil ganz en!gegengesezton Weg. Die Fuifse, wclche Ray und Limé als blolse Nebencharahtere besclureben, wïhlte cr zu seinem leitenden Prinzipo in Bestimmung der Familien, den Schnabel áber zur Bildung der Gattugon und Zünfte. Getreu sciner Ansicht der Säug thiere nach den Zehen, behät e: dieselbe auch hier in den Vögch bei, und fullict so zu allererst in scinem Prodrome ") danf später in den Stemmaters der Fögel b) in wulchem er sein System durck recht instruhtire liupfer der Füfse und des Schnabels durch alle cinzeline Familien erläutert, jene Beobachting an Vögeln consequent durch, welches Aristoteles schon empfohlen und die Nachfolger benilizet haben. Nach ihm zerfällt die Ordnung der Vögel in acht Familien: Die erste bilden jene nit zwei Zehen (Struthio), die zweite mit dre: (struthio nothus, Casuar.tarda, gavia, himan.

\footnotetext{
a) Jacab. Theod. Klein, İlistoriae avium prodromus, Lü = becas 1750.
b) ejusd. Stemmata avium so tabulis aencis ormsta, is. Lipo siae 1759.


topus, ostrulegus) die dritte mit vier, worori zwei nach vornen und zwei nach hinten stchen (psittacus, picus, cucullus, ispid. touraco rasutus), die vicrte mit rie: Zehen, wovon hlos sine mach hinten gerichtel ist (accipiter, corvus, pica sturnus, turdas, alaud. fiecdula (luscinia, trochlodytes, sylvia), hirind. (2ulgar. caprimus.s), parus, passer, scolopax, glarcola rallus, mellisuga falcator (falcincilus, numenius, merops, uрup)a), sallinaceus (alector, pavo, melcagsr. phasian. perdix, coturnix, lagopuss), columba, grus, hamiola (ardea, ciconia, tantalus), die fünte die Pahipeden, bei welchen die hintere Zehe frei ist (plotus: anser, anas, larus, mergus), wie sechste, ]; ei welchen alle vier Zehen durch die Sahwimmhat rerwachsen sind (onocrolatus), die siebenie, welche nur drei Zehen und zwar alle durch die Schwimmlaut rercingt haben (alcae, albatros, procellaria) die achte mit vier Zehen, wo die Schwimmliaut in Lappen gespalten ist (colymb. fulica).

Hätte Limé sểne Ansicht so consequent, wie Filein ducligefilht, so wirden die Fehler auch eben so dentlich wie hier in die Augen springen. Obwohl likin im Allgemeinen sich sehr durch Consecuenz auszeichne, so hat or doch bei den Vögehn nicht immer dic nümlicho Ansicht ror Augen gehatht, sondern bxi dien ersten vier Ordnum- 


\section{$-277-$}

gen die Anzahl der Zehen, bei don folgenden nie Schwimmhant zur Abtheilung genommen. Hätle er blos das Frei - oder Verwachsense'yn zu seinem Prinzipe gemacht, so wären statt acht nur zwei Familien, nämlich der Fissipeden und Palmipeden, ähnlich denen der Iand- und Wasserrögel, bei Berïhichigung der Zahl der Zehen aber nur die drei ersten Familicn, die ibbrigen hingegen als $\mathrm{Tn}_{n}$ terabtheilungen von jenen geblieben. Allein bein Jiefs sich bald durch dieses bald durch jenes leiten. and warf daher ohne wcitere Rüksicht anf Nah-rumg, Antinthult u. S. w. Landrögel und Strandlïufer bunt durcheinander. Zwar finden wir, dafs schon bei den Hithnern die Zehen nicht mehr ganz frei sind, sondern die Schwimmiant vorzulanfen anfingt, und jone unter sich rerbindet, ein grossor Theil der Strandlinfer z. B. die Platalea, ReiLır, Tantalus, Numcnine, Mämatopus, Clareola, sisd Semipalmipeden zu nennen. Boi dem Wasserhuhn und Sicifsurs rerlängert sich die schwimmhaul schon in vicle I appen, der Arocet1, Corrira, Flaningo, endich dic Möven und Gïnse haben noch dis hintere Žehe daron frei, die Taucher, Peliliane, Amhingen, Aptenodyten alle vicr Z: hen vermittelst derelben verbmaen - eine Stuffenfolge, welche allerdings zu der Abtheilung der Vügel nit frcien, halb oder ganz durch eine

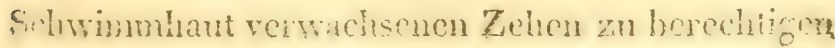


scheint. Allein man hat bisher rernachläfsiget, dafț die sogenanute Schwimmbaut anch an der Mur: zel der Zehen dor Vuluren, Adler, Fâl'en, Lnlen und noch in ctwas bei papageien siati hat, dafo sic sich bei den meisten äbrigen Landrig in nur anf schlise Ant rer!iert, dafs einzelne Finger ganz cher wis zur Hälfe verwachon sind; daber

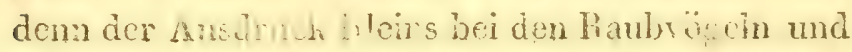
Sperlingen, digiti striptirs, voliti" nithe gegründet ist. Van der nändichen Deochnfusiheil ist es mit der grölseren otur geringen Freiheit in Dewegung der Zchen: Vulturesi, $\Lambda$ dler und Fallen gehen mit drei Zehen nach romen, whd eincr nach linten ciuher, beugen aber zuweilen dock eine Zche seitrürts und solbigt grgen linten, wo sie sich auf einem Aste anhlammern, bei Fulen jet diefs Lezte nocă mehr der Fall - Pupageien zind Galbula haben, obwchl zwei Zchen schon nach linien stchea, die cine noch gegen romen

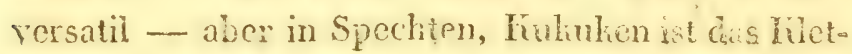
tern nur noch als die cinzige Dewegnng ürig, und Aic Stellung der zwei nach hinten gelchrten $Z$ e. nen uarerrihbar. - Bei den übrigen Landrägeh, die himuncio apus and melba ansgenommen, wo alle vier Zehen nach vornen gerichtet sind, strhen drci Zutien nath romen nủ cine nach binton, je doch so, dafs jene zun Theil inter sich verwach sen, und bei den mejoten zui hiipfendon bewc- 
gung bestimmt sind, bis endlich Hiihner, Storeke und Gänse, ohne die drei vorderen Žehen gegen die hintcre belicbiø drehen zu lïnnen, nur einherschreiten oder wie die Lezteren schwimmen. Die Zalll der Zelen belreffend, woran sich hỉein in scinem Systeme rorzüglich hielt, so findet freilich der Mancel der linteren niemals bei einer ganzen Familie der Lancirögel, wie diefs bei den Wasserrägeln der Fall ist, allgemein?, sondern nur als Ausiame an cinzelnen Individuen statt; aber eben diese Ansuahmen hindern auch, diese Thiere nach der 2 ablu der Zehen reihen zu wollen, denn sonst müfsion scibst die verwandtesten Gattungen ron ihren Familien gerissen und in fremde, wie es anch Klcin that, veipflanzt werden. So hat unter den Stranssen dic Thea nicht zwei, sondern drei, die Dudu vier Zehen, so giebt es unter den Waldliühnern einige mit vicr andere mit drei, es gicht cinen picus, alcedo, loxia, phytotoma, welche nebst dem Cucullus abyssinicus als die einzigen in :hrer wcillüngen Familie nur drei Zchen hao ben, unter den Strandläufern findet sich allein bei dem Regnnpfeifer, Lüufor und Strandreuter die 1.ztere Anzahl, welch bizarre Vertlıilnng brächte so eine consequente Anordinung der Vögel nach der Anzahl der Zehen hervor! Häte Klein dic Blöfsen und Lüchen, welche in seiner consequent durch-

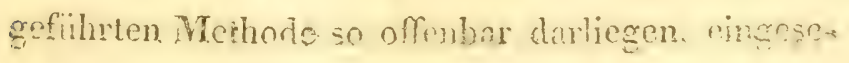


hen, so wiurden ihn diese noch mehr in Vericgen. heit gesezt haben, als der picus tridactylus, durch welchen reraniafst er am Fnde der Vorrede zu den Stemmaten voll Verzweiflung mit Haller ausruft:

„, Ins Innere der Natur dringt kein erschaffuer Geist. “

\section{5.: 54 :}

Möh-

Gleich nach Klein trot. Möhing auf, und ring. theilte a) die fögel nach cinem nouen Gesichtspunlit ab. Ray hatte die Befiederung der Füise, bis unter das nutere Linirgelenk als Unterschied der Vögel des Landes von fenen des Vassers, wo diefs niclit statt findet, angegeben, Imint, hob diesen Mangel bei seinen Grallen, Klein die Anwesenheit bei den Raubrïgeln heraus, Miiluing machte es zu seinem Hauptgesichtspunlte, rerband mit ihm noch eine Beschaffenheit, nämlich der mehr schuppichten, raulien oder nahten Haut, welche dic Fülse bedecliet, auch schon von Limné hie und da angemerkt war, und brachie darnach alle Vögcl in vier Kilassen, die nach der Verschicdenheit des Schnabels, dann der freien oder durch cine Schwimmhant verbundenen Zehen sich in immer kleinere Gruppen absondern. Diese Kilas* sen sind folgerde:

a) Mtoehring. Avium genera. Bremae 1752. 8. 
7. classis. Thymenopodes (gemutusantice plumosis, pedibus tenui mombraia syuamosa tectis et digitomn arcte inter se connexorum (picre, passeres).

IT. Dermatopodes (genutus antice plumosis, pedibus cute coriacea rugosa tectis (accipitres, gallinae).

III. Brachypterae (genuhus antice nudis, alis ad volatun incptis, fissipedes, cursores (Struthio, Otis, Didus;:

IV. Hydrophila e gemb, anlice nudis, pedib. mute mollicoriacea tertis (odontorthinchae, platyrhignchae, stenorlynchae, urinatores, scolopaces).

Es ist nicht zu liugnen, dals die Beobachtung ron Möhring sehr neu und genau, besonders die der Refiederung oder Nahtheit bis ober-oder unterhall, des unteren hinegeicnlies ist. Bei allen Landrïgeln olne Ausnahme, erstrelit sich die Befocicrung bis zum linirelenlie, selbst bei Stranssen, ron denen er das Gegentheil angiebt, und beh

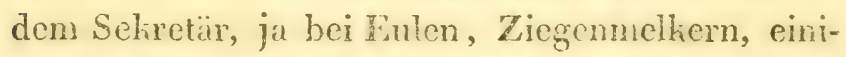
gen Tauben und Waldhithnern beinahe bis auf den Fufs; im Gegenthile haben alle Strandlanfer und Wasserrögel das untere Finiegelcnk unbefie. dert, obgleich nach der Zeichnung in der Latha mischen Uebersetzung a) der virginische Regen:

a) Johann Lathams allgemeine Uebersicht ler Vögel aus dem englischen ibbersat von Bechstein. Ften Bd. xser Th!? S. $17 \overrightarrow{0}$. 
pfeifer, nach jencr in dem Taschenbuche ron Wolf und Weyer a) die colymb. atrogularie, abca larda, fodiceps cornutus, welche diese Oini. thologen bis unter dem Kniegelenke befiedert darstellen, lievon cine Ausnalime machen wïrden. Allein hätte er sich genau an dieso seine Ansicht gehalten, so wiirde er nicht vier, sondern ņur zwei hlassen, ähnlich denen der Land- und Wasservögel, nämlich solcher mit befiederten, oder unbefiederten liniegelenke gebilact habcn, .ja um noch consequenter zu verfahren, hätte or jene nach der allmähligen Zunahme ron Federn an dieser Stelle, ciese nach der Abnalme aneinandor reihen müssen, ein Verfahren, wobei das Schnechuhn, der Averhahn, einige Eulen, welche bis axf die Klanen in Federn eingewichelt sind, an der Spitze der Vögel, die Strandläufer aber am Ende stïnden, was er scibst als Unordnung anerhemnen würde. - Unbestimmter und unrichtiger ist aber jene Beohachung der Beschaffenheit der Mautbodeckung der Füfse, nämlich als leçerartiger, rauhes, schuppigter oder naliter; dem nicht bî́s seine ersie und zwcic Klasse, sondern alle Vögel haben die Furshan ledorartig, und nur bei Gänsen ist sie mehr weich, bei andern mehr rauh und spride. Auch ist sie bei allen rom Finiegelenk an mit

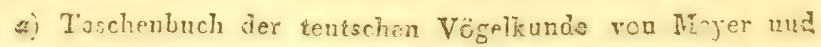
Wolf. Frankf. a. MI. 1810. 
Schuppen bedcht, nur sind dicse an Rarbrögeln libues und platter, woduch die Ilant am oberen Theil des Fufses melr sanh and löcharicht er: scheint, gegen die Zehen selbst aluer deulicher schuppicht wird, bei Sperlingen und Iuhnem sind die Scimppen breiter und concarer, bei den Straussen bilden sie wahre Schilder, und winden sich wie bei dem Selzetär, der Ani and den Strand. läufern, in schraubenförnigen Bärdern lëngst den Fufse herab. Jedoch Nibing scheint weniger durch jene Bcobachtungen, welche obgleich so un. bedeutend, doch schon jenc Thiere anhiundigt, wo Schuppen, Flaisfifsc herrshender worden, als durch die Eetrachtung des äusseren Habitus, bei Bildung seiner Gruppen geleitet worden zu seyn. Diês ist sorvohl aus sciner unbesimmten Charakteristili, als auch aus der Bcnemmug der Jilassen selbst zu crschen. So häıten doch dic śllien und Aptenolyten, sicher chor den Namen, Jrachyptesae" als der Straufs, noch mehr als dic Trappe verdient, stilt der bedentumgsiosen Ueberschrift

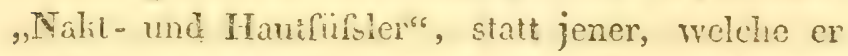
nacis ihrem Aufenthalte an od 2 rin Wasser Hydro. philen benennt, häkte er diese Aufschritien nach seinem Gesichispumbie willien soilen. Aber alles. dieses wurde nicht berilssichtiget, or was schon zus frieden, diese Thicre nutershieden zu haben, os.

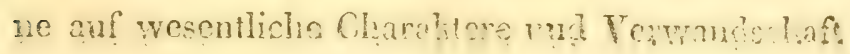




\section{- $234-$}

aer Grupven sowohl, als der Gattungen zu schen. Es ist daher liein Wunder, dafs er jene Familie mit hiltterfiirsen, durch seine Klassen verschiedentlich vertheilt, dic Spechte und Trogon zu den IIymenopoden, die Papageien zu den Dermatopoden rersezt, und gleichgillig mit den Spechten und Sperlingen die Reihe der Vögel eröfnet, aut sie die Raubrögel, Hühner und Strausse, dann die (iänse und endlich die Storche folgen lïlst, welche Aufeinanderfolge wohl in der Williühr, nicht aber in der Natur gerechtfertiget ist.

So hleinlich auch der Gesichtspunlit von MJ̈hring ist, so fand er doch an Scopuli cinen Nachfolger, welcher mit einiger Veränderung hierauf cin ähnliches System crbaute. Gemäls der Beschaffenheit der Haut der Füse, macht er in den Vögeln zwci Hauptabtheilungen, nämlich solcher, wo jene ein netzformiges Ausschen hat (libiis reticulalis: urinatores, palmipedes, longipedes, gallinae, rapaces, psittaci) und solcher, wo sie scinlderformig gebildet ist (tibiis scutatis s. annulatis: scandentes, ambulantes, canorae (tenuirostres, crassirostres, brevipedes). Aus den oben angegebenen Fakten erhellet, dafs Scopuli eben so wenig streng als Möhing bei der Betrachtung und Vertheilung dor Vögel nach dem schuppichten schilder-oder ringartigen Aussehen der Füfse rerfahgen ist, und dafs beide zwar einige Eigenschafien 


\section{$-285$}

an diesen Thieren näher auseinandergesezt, ol:w gleich nicht $\mathrm{zu}$ einem vollstündigen Systeme erhoben haben.

\section{ง. 55.}

Brisson benuzte, was bisher in der Ornithologie geleistet wurde. Von Ray und hlein entlefinte er scine zwei Grundahtheilungen les doigts dézués, ou garnis de nembranes), von Möhring jene der Befiederung oder Nalitheit der Beine (jambes cauvertes ou dénuées de plumes) und der mehr oder weniger rerwachsenen Zehen bei Landvögehn, ron Limné die weitere Sonderung derjenigen mit befiedertem Kuniogelenke nach der Gestalt des Schnabels, von Klein die Unterscheidung der Palmipeden nach der Reschaffenlieit der Scliwimmhaut, nach der: Zahi der Zehen und endlich nach den mehr verborgenen oder sichtbaren liurzen oder langen Beinen. Alles dieses trug er zusammen, und sezte es weitläufg in 26 Ordnungen in sechs dafür bestimmten Bänden, worin mehr als 115 Gattungen und 1500 Arten beschrieben, und mehr als 500 in Fupfern anschaulich gemacht sind, auseinander. Der erste Band enthält die drei crstelı Ordnungen: Tauben, Hühner, Raubrögel - der zweite fün: Raben, Drosseln, Staaren, Viedehopf, Schwalben - der dritte vier: Sperlinge, Beccafige, Spechtmais, Baumläufer, Folibri - der vierte zwei: die Kletterer, und jene, wo die Zc- 
hen, to w. B. bein Tiunguscher, Dicnontresser, zum Bleile rexwehsen sind - dr funfe drei: Stansse, dann die Trapre, Regenpfeifur mit drei, die Schnepen, Ruher u. s. w. mit vicr Zehen der sechele enthält die nenu lezten Ordnungen. welche die Sctrinmfifuer atsmachen.--

Bei Drisson hunt äber die cinzelnen Abtheglungun dis Lribeil zuruk, welches bei seinen Vorgängern, von dexen or jene enilchnte, gefilit wurde; mar lat er das kigene, beinahe immer so viele Ordungen anfzustellen, als es selbst Thiere giebt. So vortreflich sonst seine Beschreibungon sind, so ist es ihm doch entgangen, dafs die Schwimmhut nicht etwas Aucgezeichnetes der Strand- und Vasserrögel ist, sondern sich auch an den Raubrögeln, Straussen und Hühnern rorm finde, und also gar nicht den Namen Schwimmhant ver! fork?. Hown so irrig ist seine Behauptung mit Mnuring, dals die Stranse das Lunegelenk nalit labren; gieich wie anch dieses, dals in der Ordmug dex fögel mii slei Zehen nach vornen, unter sich meir oler weniger verwachsen, der Würger, Drosetn, Staaren u. s. w., wo dieses ebenfalls stati hat, nicht erwähnt wird. Dock Brisson suchte sich romzüglich in der Unterscheidung der Tögul nach dem Schnabel als Mioi ior zud zeigen, olne aber zu bedenlicn, dafs dieser 'Theil des Vogels cuner so grofsen Marchifaligheat unter- 
liegt, dafs heine Bcschreibung diesen Wechsel ełen so genau auszudrüchen im Stande ist; deswegen Gile Charakiere ,le bce en alêne, efjilé, en cône allorgé, court, crochu, petil" nicht viel entscheiden, Niemand bei der Rubrili "le bec en aléne" sicl der Lerchen and zugheich der Maisen erinnern mögte. Uebrigens lüfst sich über die dufeinanderlolge seiner Ordnungen und Gattungen von Tonben, Hihnern zu Sperlingen, Papageien, Straussen и. sow. eben jencs strenge Urheil, welches der durch seine Genanigheit in Beschreiburgen, und durch scine scharfsinnige Unterscheidungen der Vügel so sehr verdiente Verfasser in der Vorrede über Kileins System fallet, wiederhohlen ${ }^{a}$ )。 "tout s'y trouve pêle-inêle".

\section{563}

Die Verschiedenheit der Flügel an Vögeln ist bisher den Naturforschern nicht entgangen. Ray schlago hatte schon dic Raubrögel nach der Lünge oder Kürze der Flügel unterschicden, und von Straussen ward leztere allgemein angemerkt. Niemand hatte aber ndch diese Theile als das Wescntlichste der Vögel herausgehoben, bis es endlich Silber.

a) Ornithologie ou méthode contenant la division des oiseaux par RI. Brisson, T. I. p. XII. Paris $27 \mathrm{Cog}_{0}$ 
schlag in einen Aufsalze that a). Er ninmt die Flügel als das Hanptinsirument zum Hluge an, und theilct alle Vögel in zwei Ordnungen, minlich in solche mit liurzen Flïgehu ron spitzigen oder stum1fen Schwingen, die lang oder liarz seyn hömen - und in jene mit langen Fligelu von breiten oder schmalen Fächen mit silzigen oder stumpfon Schwingen, die ebenfalls liurz oder lang seyn kïnncn. Dic haub - und Zng ïgel würden die lezte, alle ibrigen die erste Ordunng biken, und jene, welche vie Schwallon mi hüren die Luft pfoilsclucll in allen hichungen chuchschnciten, häten spitzige und lange Schwirgen, die andern das Ge* gentieil. - Auch in der Art der Bewegung der 'There, hat die Natur den Ausdruch ihner immer' molir zur Volliommenhei! sich erhebenden Bildung an cedcutct. Moch nicht liann sich die Madrepore ron ihren Mlabum Iosreissen, hriechend und hümmenu strebel der Wurm sich über die Erde $2 n$ erheben, den Fischen ist es endich gelungen, int thedim zum Spiclname in vielseitigen Wendimgen zu gebrauchen, die Anphibien sind schon abers den Poden exhölt, der Vogel endlich lauft suit cmpor tragendom Liope anf der Lrde, oder onrchechwingt ficudig alle Schichten der Luft, bis

b) Silberschlag. Fon dem Fuge derVögel, in den Schriften

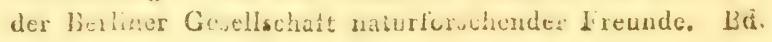
$3,5.22 \%$ 
endlich dor Mensch anfrecht auf der Erde stehend, dicse, die Gestrne und die Veltgegenden mit seinem geistign Auge durchmifst. - Allerdings ist der Fhig und scin Instrument einer der rorzïglichsica Charalitere der Vögel. IMan hat bishet einen Vogel im Fluge mit cinem segeluden Schiffe, den Hals und Schwanz mit und dem Stenetruder, die Flïgel mit den Seitenudem ode\& den Segehn nicht unpassend rerglichen. Nach dem mchr horizontalen oder schiefen, stürlieren oder schwächeren Vibrationen der Flïgel, bleibt dex Yogel in der Luft hängen, oder hebt sich nuchr oder weniger geschwind in die Hohe oder nach Seitwärts, und fält cndlich nach eingezogenen Flïgeh duch dic Last seines hin" pers ans der Luft herab. Je grörex und breiter nun die Flugel, and jo weniger massiv zugleich der liörper, un so weniger beschwert ist der Flug. und so umgehehri, ein Umstand, welcher bei jeder Fomilic bcinahe in einem eigenen Vorhältnisse sich zcigt: Stransse, Allien und Aptenodyten haben die lieinsten Flügel, aber die relativ schwersten hörper, und sind daher die zum Fluge untauglichsten; die Günse nnd Strandlänfer, besonders aber die Fregatte und Albatros, haben zwar schr lange und breite Flügel, aber zugleich sehr massive hïper, welche daher, cinmal zu den höheren, leichtes en Luftschichten gelangt, durch die Ausbreitung itreg 
andassenden Flingel sehr leich getragen werdent mit den Thihnern, besonders aber nit destruben vud Sperlingen bis zu den lhaubvögeln, nimme die Masse des haxpers relativ ab, und so die Schivung lirat und relabe Grofe der Filigel zu, daher die Landrörel es sind, weiche die Luft nach allen Richtungen drarchscheiden, und die fiecste Thillïhs im Flige zacisen, wo in Gegentheile die Wasscroder Sirandügel sich mu mit lö̈hster Ausirengung schiof za den oberen Luftschichten hinaufarbotiton, und dann inner die horizontale lichtumg fortabehalen suthen. So stiuden denn

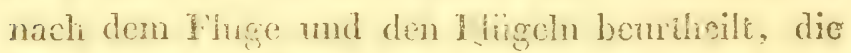

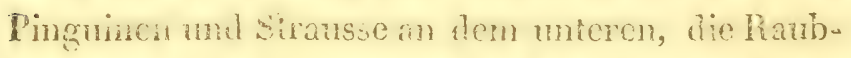
rögel, hesonders der Combur, an den ubern Ihnte

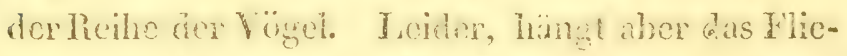

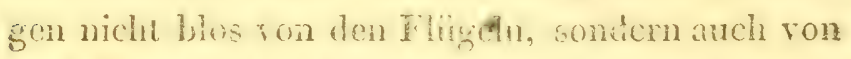
der Schwere oder Leichigh rit und der ganzen Geslalt des fürpers, von der gröfsenen oder geringeren Fähiglicit, dic Luft durch die oflene Spalte des unteren lichlliopfs, durch die offenen Lï̈her der Innge, in die Lnftsäcle der Bust - mul Lnterleibhöhle, in die hohlen Federn und linochen zu vertheilcn, ab, was nach Verschiedenheit des Alters und $\mathrm{der}$ Constitntion uberhaupt rerschieden ist. Dic abwechsehde Anzahl und Gestalt ron Schwumpercin sowohl, als der ganze Ilingel, ist fisher fur die cinzehen Fumilien und Gallungen 
ein sehr guter Unterschied, aber nie kann er sich zum volliommnen Systeme erweitern, will man nicht, wie Silberschlag die Raub - und Zugrögel, damn dic Schwalben und Müven, auf eben solche Veise sonst so heterogene Familien mit einander verbinden. Silberschlog selbst würde die Schwierighcit gefullit haben, hätte or scine rortrefliche Beobachtung zur vollständigen Ausfuhrung zu bringen gesucht.

\section{57 .}

Bisher enthielten die ornithologischen Verlie entwoder blofse Beschreibungen und Abbildungen, thaoder trochicne und einseitige Systeme. John Latham, durch dic berihnite Sammlung des Ashton Lever, durch jene und die reichhaltige Bibliothek des liberalen Joseph Banks in den Stand gesezt, vereinigte die Arbeiten aller seiner Vorgünger, und Jegte in seiner general symopsis of birds $1731 \mathrm{den}$ Grund zu cinem Werle, welches alle bisherigen Systemevan Vügeln sich einverleibte, ausführliche and richtige Beschreibungen ron allen bis jezt behiamnten Arton, und gute Albbildungen aller Gattungen enthült, durch ein bald darauf erfolgtes Supplement sich crgänzte und endlich neun Jahre später in der Ausfiuhrichlicit und Vollständigkeit unter dem Tital: ,index omithologicus s. Systema Orrithologiae 1790. 1. volum. 1.2. nebst cinem 
neveron suplonente herrorima. Ray diente ihm durch seine Abthcilung in Lanh - und Wasseroücl zur Grundlage, rom Limé behielt ox die O: dunngen unier den Landrögehn und überhaupt scine Gattungen bei, ron Tilein nalm or die Veranlassung zur Errichung der nenen Ordnumgen ,pinnatipcrles und prilmipedes", Erlwards benuzte or in den Lupfern, Brisson und Büffon hierin und in den Beschreibumgen, allein die Aufcinanderfolge der Ordnus:on, eine Menge neucr Gattungen, und ein ausserordentlich Reichthm in Arten, dicfs bleibt ins zum ansschliefsenden Verdiensic. Den Pang, welchen Pennant unter den hilassiliern der Sängthicre, diesen belanptet folgendes System Lathams, welches von jerson auch in der arhischen Zooiogie befolgt ist, unter dcanen der Vügel:

I. Sectio. Aves terresires.

1. ord, accipitres: rultur, falco, strix.

2. - picae - ambulatores: lanius buphaga, callaeas, 'musophag. corv. coraci. oriol. gracul. paradisea, sitta, upue. certhi. trochili.

- scansores: psittce, ramphastos, scythrops, crotophag. trogon, bucco, cucull. yunx, picus, galbula.

- gressores: momot. buceros. alcedo, todus, merops. 
5. ord. passcies - crassirostr: lowice, fringil. phylotom.

- curvirostr: colius, pipra, hirund. caprimulg.

- emarginatirostr: tírdis, ampelis, tanagra, muscicapa.

- simplicirostr: sturnus, alaud. modacill. syilvia, parus.

4. - Cotrmbae.

5. - Gallinae: paro, meleagris, penclope, numid. craw, menura, phasian. tinames, tetrao! perdix, psophia, otis.

t. - Struthiones: struttio, didus, casuerius, rhea.

II. Sect. Aves aquaticae.

7. ord. Grallac: platalca, palamedea, mycteria, caneroma, scopra, ardea, tantal.' numenius, scolopax, tringa, charadrius, Cereopsis, sursorius. haematop. glareota, rallus, parra, gallinut. vaginalis.

8. -. P'innatipedes: malaropus, fulica, pow diceps.

9. - Palminedes - nedib. longiorib.: recuruirostra, corrira, phroenicopterus. 
- pedib. brevior: dio. medea, alca, uria, colymbus, rhynchops, sierna, larus, procellarica, mergus, anas, aptenodytes, pelicanus, phateton, plotus.

Aus dieser Darstollung des T athamischen Sysiemes ersicht man, dafs er in Dilung der Ordnrugen ganz dem Linné getreu geblichen ist, nur mit der Ansnahme, dafs er die Oxdnumg der Gänse in zwei, nämlich der ,pinnatipedes und puinipedes" die Tauben und dann cie Struthionen als eigone Ordnumgen aufgestelit, rand so die suzahl mit drei neuen rermehrt hat, Auch in mern dieser neun Ordnungen hat er ilm zum inuster ror Augen gehabt. Er behielt alle die Gattungen des. selbeu bei, reihte ihnen dic nenen: "munura, musophaga, Seytrops, Cercopsis" cin, dic Tinomu, Feld - und Waldiühncr sind als eigane Gate tungen und damn nach der Zahl der Zehea gesondert, dic Ordnung der Aelster, wie bei Limné, nach dem Ganghe, die Sperlinge nach dem Schnabel untersdieden. Die Chamaliere der Ordnumgen sind ebenfalls jene des Limne, und selion haben jene der Gittungen und Arten einen neuen 2,1 satz chlalten, ihre Beschreilungen aber sind viel ausfuhlicher und selbst histowicher geworien. Die Anzan der Arten hat in Gogentheile auscer- 


\section{$-205$}

ordentlich an Ruwachs gewonnen, so dars jene den Vulturn sintt 15 anf 25 , der Fallicn slatt 120 auf 168 , die Certhicn statt 5y anf 93 , die Papageien stalt 14 an 375 , dic PIotacillen statt 175, nebst den Sylvion auf 20.5 n. S. W. herangewachsen sint. Allow in Stellumg der Ordnungen und Gatmugen, hierin wr Lathan niche so sorgonlos wie Limé unu scine orginger, sondern er dachte immer nur damuf, Porwande neben cinatider zu Ixingen; desweren hat er dic Günse des Limné s.icht in dic Mitie der Landrögol, sondern am Ende der gaizen lilase geseri, die Sperlinge gleicl nach der Ordnung der Aelsten, dic Tarbon als den Ueljergang zwischen jenen und den Hilhnern, die Strausse eben doswegen zwischen lezteren und den Grallen gestell; den Wïrger hat er ron den Raubrogeh getrennt, und an die Spitze der zwei. tcin Ordnung, um diese mit der crsten zu verbinAen, gehhan, die Agami aus den Grallen zu den Hühnern crhohen, den Arocotta und Flamingo aber wegen ihrer beinahe vollständigen Schwimnhart ars den Grallen zu den Palmipeden gewor. fen, mu so diese, romittelsí der Pimatipeien, bei dencn die Schwimmlant noch in Lappen ges theit ist, an dic Grallen anzuschliefsen. - - Vox treffich ist dinse Verbcsscrung Lahams, an den Aufeinanderfolge der Orimmgen, boi scinen For

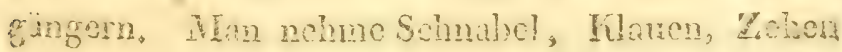




\section{…. $20,6-$}

zar Betrubung, wat mon sicht mit it wer Succes-

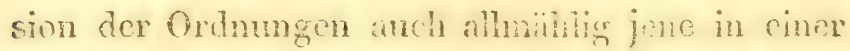
gleichformigon, von der ersion his zine lezten abnehmesden Bildung hegrifen. Jedoch in cisn Lnnern, in der Folgenreihe der Gattungen und Arten, Iner sucht man unsonsi jene Vortreflidhlicit. Welche Achlicheit ist whl zwischen Gen hithernden, lungschnäblichten Galbula, wnd einen lurzand diclischnabichten Kombeiser? welche zw:schen einer Maise urd einer Tarbe, der lhea und dor Löffelgans, dem Wasserhuhme und dem Trunmschnäller? und doch sollen dicse ?ie Binrefticảer zwischen don Ordnungen seyn! Die Papageien, welche nach Schnabel und Klanen den Fulen so ähnlich sind, stchen von diescu ausserordentlich weit entfernet, dafür aber soll der unanschnlicho Viüger, weicher die millere Zehe schon verwachsen, die Gestali und den gezalmten Schma: bel der Tanagren und Drosseln hat, welchem als Fleischfresser die Raben, Aelstem uid selbst die Maisen nichts nachgeben, die Raubrögel mit der Ordnung "picae" verbinden. - Latham hat bet der Bildung und Aufeinanderfoige der Ovthungen mehr dos ganze Acussere des Vogels im Auge ge.. habt, allein im Innern hat er sich gemifs dem Iimné an einzelne Beschaffonheiten gelnalten, und gleichsam die Indiviuluen darmicer gezyungen. So werden in sciner zweiton ordntng dic WVürger miț 
äer verwachsenen mithleren Zehe, die ketiernde? Certhion als Ambulatoren anfigestolt, wihrend die Maise, der Flicgenfinger, der Colins alle drei Zehen getrennt haben, und doch nicht hier siehen; die Sylvien, Seidenschwänze und Pipren haben die mitllere Zche verwachsen, und doch werden sis nicht bei dieser Familic (gressorcs) aufgezähli; cine andere Familic heist die der Fletterer, während doch auch Raubrögheln jene Stellung möglicn ist, ja Papageien noch cine andere als diesc annehmen lümen, während die ani ambullatoria, des picus tididactyl. u. s. w. licine Fletterfufse habon, und doch hier stchen müssen; ja alle diese zusammen werden noch mit dem allgemeinen Naznen der Aclsiern belegi, denen sie, wie sich untereinander selbsi, so mähnlich sind. Anf die nämliche Art werten auch die Sperlinge nach dem mehr odcr weniger diicken oder langen Schmabel, bunt durchcinandergeworfen, und bei den Wasservëgehn werden der lirummschnäbier und Flaningo, welche mit den Storchen nach dem gamzen liöperbau ïherninstimmen, wegen der längeren Schwimmhaut unter die Gänse versezt, und die Palamedea welche so grut, wie die Agami, den Münnern glcichi, wird ron den Strandlüufern nicht getremut. - Lahams System hat also wohl der Auf. cinanderfoige der Ordnungen in nutuliches Ans.

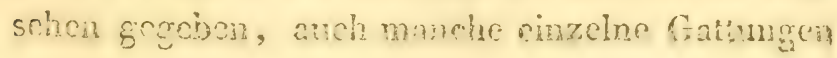


gehorig rersezt, allein gegen seine Manptabthei. lung lichien alle jene Einxendungen bei way, gegen die Benennung und Charaliterisimg seiner Ordnungen jene bei Linné, gegen die Abtheilung nach der Schwimmhant jene bei Kilein, und gegen die Charahtere der Gatumgen nach dem Schmabel md dem Gange endlich alle jene Lüchen, welche bei Iimné aufgezeigt wurden, zurük. VVird Latham einen gleich gliblilichen Verbesserer seines Systemes, wie er sich an dem Limnéischen bewiesen hat, finden, und wird der innere, bisher noch wenig brhannte Bau der Vögel mehr gekamut, die Verwandschaft der Individuen melir ausgemittelt, die cinzelnen Gattungen noch mehr ron einaxder anterschieden werden, dann wird lezteres elinn so Ferherrlicht auferstehen, wie das Liméuscie in dem seinigen auferstanden ist.

\section{ค. 58 .}

Anf́ dem Viege, wcichen Linné cingelcitct, Lathim aber verfolget hat, fuhren anch Leslie, Blumenbach uni Batscly fort, Verbesserungen anzubringen. Ersterer wiederhohlet die sichen Ordumgen Einnés, und weicht nur darin in der Aufinanderfolge ab, dufs or mit den Struthionen becimi, ziz den Khhom, Rawbögeh, Aelstern, Sperlin-

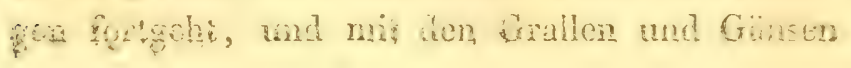


whliefsta). Bhmenbach beholt dis Anzahi und Aufeinanderfolge der Ordumigen des Engländers bei, um vereinigte er die Tauben mit den Hihnorn, licfs die Pinnatipeden nit den Günsen vere:nigt, stcllte aber dargegen dic Papageien, Toukane, Nashornvögel, wcgen ilmen gyofsen, hohlen and leichten Schnäbeln unter dem Namen ,levirostres"s dann dic Raben gesondert von den Spechten auf, und erhiolt nach solchicn Veränderungen folgende ṇeun Ordunngen der Lanci- nud Wasscrö̈gel: ac. cipitres, levirostres, pici, coraces, passeres, galIinac, siruthiones, grallac, anseres ${ }^{b}$ ). Datsch nulun cbenfalls diese nem Ordnungen an, nur ver. band er die Raben mit den Sperlingen, und schied dafü jone der Spechte in zwei, nänlich in die der Iieilschnibler (cuneirostres: pici, alcedo) und in die der Dünschübler (tenuirostres: certhia, trochil.). Seine Ordnumgen luigen gerade so aufcinanter, wie dic Bhnmenbachs, obgleich er übrigens offenilich gesteht, dafs Kcine Orlnung der Vogel in dem geringsten Zhasammenhange nit dew anderen zu bringen sey c). Nerman behieit das System Linncis bei, änderte die Renennuis, "picas

\footnotetext{
c) Anfangsgründe der Naturgeschicite von N.G Lajke, Leipo 2 ig 1779.

b) I3lumeubachs Handibuch der Naturgeschit:ın, Göting. 180.3.

c) Versuch ciner Anteitung anr Kenunice wnd Guschichte der Thiere und Mrimeralien vor Dr. J. G. C. Ratsch, Jema a.jSS,
} 
in jone der ,oscines" und rersezte die Ordnumgen also durcheinander: accipit. oscines, gillinac, fusser. grall. anseres. Treviranus wiederhohlie die Ordungen Plumenbachs, und folgle in de: Aufcinanderfolge dersciben melr dem Lestie: (struthion, gallin. passer. pici, coraces, accipitr. ardeae, anseres. So mbedentend auch die Veranderungen sind, welche durch diese Mümner am Linnéisclien und Lathamischen Systeme herrorgebracht wurden, so scheinen sie doch rorzinglich đic IFauptlücke des Leztern, nämlich die Ordnungen ,picaic und passeres" in Auge gehabt zu liaben. Zwar haben sie diesem Umstand durch Errichtung der neucn Ordnungen von Leicht - IeilDümschnäblern und Raben abzuhelfen gecuchit, ohne jedoch den neuen Riulifall zu bedenlien, dafs man dadurch die so natirliche Familie der Liletterfüsler zerstrente, dafs ferner dieses unwescntliche Merkmal von leichten ofler vielmehr voluminösen Schnäbchn nicht auf alle Arten z. B. nicht auf bucceros nusutus, auf die klcincren Papageien passe, jenes von dümnen oder licilartigen Schnabot nicht die Motacillen, Lerchen, Drossehn, Paradiestögel und beinahe wenige von den Speringen ausschlicfse. Bechetein hat neucrdings das System Lathams durch die Abänderungen der crst genannten Schrifteller verbessert, in sciner Naturgeschichte dor Vogel Tenischlands folgondermassen aupli- 
ret ,accipitres, levirostres, pici, corcices, pusseres, oscincs, chetidones, columbue, sellinae, struthiones, grallae, anseres a). Meyer und Vyolf haben das Bechsteinische in ihrem nenesten. Werke ${ }^{b}$ ) anfonommen, lezterer hat bei den Landvögoln nur die Berichtigmg angebracht, dafs er die Ordumg der Spelinge mit jener der Sangvögel unter dem Nanen der iezicren vereinigte, die Raben ror den Spechten sezte und z. B. aus den Schwalben mit den vier faehen nach vornen, mit Rechi eine cigncne Gatung "micropus" genannt, bildcle, zu gleicher Zeit hawen beide die neuen Gattungen der Franzosen, besonders bei den Raubrigch averkannt, und ih. Werk ganz nach dem Bcispicle Wleins in scinen Stemmaten mit blofsen Abbildungen von Köpfen und Füscn jeder Gattung erläntert, obgleich auf die Befiederung der Füfse, auf das rauhe, schuppigte oder schildartige Aussehen der Haut derselben nicht so genaue Rïksicht, in ihren sonst instruktiven Fupfern genommen ist. Durch die Bemühungen der Leztern, wurden zwar jene zwei Ordn!ngen noch mehr geschieden, als es in Latham und Blumenbach geschah, allein die Vidersprüche bleiben doch im-

\footnotetext{
c) Joh. Natthä。 Bechstein. Gemeinnützige Naturgeschichto der Vögel Teutschlands, 3 Bde. 8. mit K. Leipz. 1805-7.

b) Dr. Mreyer und Wolf Taschenbuch der teutschen Vögelkunde, 2 Bde mit illumin, Kupf. Frankf, a, RT. 1810.
} 


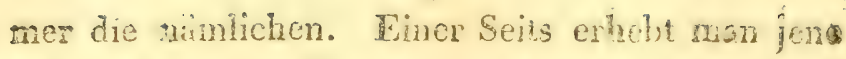
Schwalben, welche alle rier Zchou nach rornen gerichict habon, zu eince cignen Gattung, anderer Seils aber sind jene ebea so merhwirdige Vögel mit hleucruteen, wo nümlich zwei Zehen nach vornen und zwei nach linten stehen, unter die Roben, Snchte, Leichischnäbel verheili, und nicht eton so einer eigenen Familie gewüright. Durch die Verüdermg der Namen Sperimge in Singrögel, simh die Schwierigliciton nux noch mehr rermeht: so singen z. $\mathbb{B}$. die Wirger und Schwaibcn, die Spechte, Certhicn u. sow. zwitschern eben so gut wie die Maisen und manche der Fringilen, und doch wird ihrer in der liubrils der Singwgen nicht gedacht. Ueberhanpt sucht man jezt, durch den äussem Habitus verfuhrt, sich dadureh ron der Schwicrigheit zu classificiren zu befreict, dors man das, was sonst schwer unterzubringen ist, sogleich au cincr cigenen Ordnung crhebt, wodurch es zulezt cben so riel Ordungen als Gatturgen gebon wird, und statt nach einem und dem nämlichen Plone alles zu ordnen und zu benemen, so hit man hicr den Raub- dort den leichten Schmabel, an diesen desang, an anderen das ähnliche Aussehen im Auge - ein Verfuhren unseres Zeilgeistes, welches Kindern gieicht, die immer nni nach den Grellsten und Schimmernden haschen. 


\section{5.' 59 .}

Iinne hatte, als der erste, die Vögel nach seinen plysignomischen Bliclie in wenige Ordnungen abgeilicitt, und zur begründung den Schnabel als Iauptcharaliter eingefuht, die Engländer und Tentschen machten mehr von jenem physignomi。 schen Mhiche, als ron der Reschaffenheit des Schmabels Gebrauch. Sie rerbesscrten zwar in rieler Riilisicht cie Charaliteristili des Lezteren, dachtan aber doch vorzïglich mur auf die consequente Aufeinanderfolge der Ordnumgen. Dic Franzosen nalmen die also terbesserie Rangordnumg auf, und strebten, wie schon Brisson, nun mit allen liräften dahin, jene Linnéische Clarahteristik des Schmabels gonan und allseitig durchzufuhren, und das Innere der Vögel weiläufig darnach zu unterschảe den. Curicr vereinigte die Ordnung "picae" mit jener der "passeres" die der Tauben mit den IIihnern, stellte die Kletterer als eine cigene auf, schied die Gypaetos als eine eigene Gallung von den Vulturen, die übrigen Raubrügel aber in aisles, autours, buses, miluns, faucon ab, sonderte die Galungen der ersten sechs Ordnungea genau nach dex Verschiedenheit des Schnabels, die lezte aber nach der Anzahl der Zehen und nach der Beschaffenheit der Schwimmhaut ab. Dümeril fulgte genau seinem Beispiele in der Zahl und Auleinanderfolge der Ordnungcn nach, nir mit des 


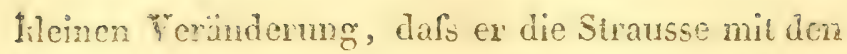
Iühnern vereinigte, die mehr nahthalsigen Vulturen ron den befiederten unterschicd, den Sohretir aus den Grallen, wic anch schon Blumcnbach that, zu den Fallicu rersezte, und den bisherigen Unterschieden der Familien nach dem Schmabel allecmeine Benemungen (termini) gab. So erschien denn das System Curiers, blos durch die nowen Anfschriften der Fanilien veründert, in jenem des Dümeril folgender Massen:

8. Rapaces - Fam. 1. nudicolies s.ptiluderes: sarcoramphus, vultur.

- 2. plumicolies s. "cruphoderes: gyptos, buteo, asiur, falco, serpentatrius, aquila.

- 5. nocturnis. nycterins: surnic, bubo, strix.

II. Passeres - Fam. 1. crenirostres o. gilyphoramphes: lanius, turdus, muscicapa, ampelis, tanagra.

- 2. dentirostr. s. odontoramphes: phytotoma, momotus, buceros.

- 5. plenirostr. s. plereos ramphes: gracul. paradise, coracias, corvus, picale. 


\section{$\therefore 505$}

Fan. 4. conirostr. so conoramphes: oriolus, glau. copis, buphaga, sturnus, fringilla, emberiza, colius, loxia, cruvirostra.

- 5. subulirostr. soraphioramphes: pipra, parus, motacilla, alauda.

- 6. planirostres s. 'omalor a mp hes: hirundo, apus, caprimulgus.

- 7. tenuirostr. s. leptom ramphes: sitta, certhia, trochilus, orthorincus, upupa, merops, alcedo, todus.

III. Scansores - Fam. 3. cuneirostres s. sphew noramphes: cucull: galbula, crotophaga; yunx, picus.

- 2. levirostr. s. cenos ramphes: bucco, trogon, ramphastos, psitfartus.

IV, Gallinae - Fam. 1. columbinis. peristew res: columbae.

- 2. domestici solectrides: pavo, meleagris, crax, penelope, numida, tetrao, phasian. otis.

- 3. brevipenines s. brachypteres:'didus, rher, casuarius, struthio. 
I. Grallai - Famor.pressirostr. so ramo phostenes: porphyrio, fulica, parra, rallus, haematopus.

- 2. cultirostr. so ramphocopes: ardea, ciconia, grus, mycteria, hyans, tantalus.

- 3. latirostr. s. ramphoplates: cancroma, platalea, phoenicopter.

- 4. tenuirostr. s. rampholites: avocetta, tringa, charadrius, numenius, scolopax.

DI. Palnipedes - Fim.1. scrrirostr. s. prionoramphes: phoenicopter. anas, mergus.

- 2. pinnipedes s. podo p teres: pelican. phalaerncorax, fregata, sula, phaton, plotus.

- 5. longipennes s. macropteres: avocetla, rhincops, sterna, larus, diomedea, proceilaria.

- 4. irevipenness. uropodes: colymbus, uria, torda, aptenody'tes.

Zwar hat durch diese Bcirbeitung das System der Oruithologie wenig Forthil gewomen. Die Ord. 
inungen, die neue der Kletterfüsler ausgenommen, sind jene des Linné, ihre Aufeinanderfolge die des Latham geblicben, und die bisherige Verwirung in der Aneinanderreihung der Indiriduen, hat sich durch die Vereinigung, oder vielmehr Vermischung jener beiden Ordnungen, nämlich der ,picae und passeres $^{6}$ noch melir rermehrt. Allein hierin scheint es, wollte man scine liräfte erproben, nümlich die Unterabtheilungen Limé's nach dem Schnabel zu rervielfiltigen, und, was schon Batsch und Scopoli rersuchten, durch eine eigene Terminologie zu befestigen. Leider! sind aber hier wie in einer Boutique, der Abtheilungen und Ueberschriften so viele, dafs das Aug sich kaum aus der. Menge herauszufinden, und an solchen Benennusgen, wic der Dümn - Plat - voll- oder KegelschnäbIer, das Mehr oder Weniger zu untorscheiden im Stande ist. Kein W'under, dars sich die Verfasser, um doch der Verwandschaft nicht auffallend entgegen zu handeln, bei Trerthoilung der Gattungen nicht so genau an thre Ceberschriften hielten. So stehen die Pipren, Motacillen, Ziegenmelker, SylFicn, wolche den zahnfömigen Einschnitt haben, doch nicht in dieser crsten Fanilie der Sperlinge; die Mirsophaga und Touraco, bei welchen die Scitenründer der Maxillen gezühnelt sind, werden nicht bei den Dentirostren aufgezählt, wohl aber dio Nashornyögel, denen dieser Charahter feillet; 
die Trotoplnga, deren Schnabel etwas gebngen nind nach oben in cinen breiton Kamm anslanit, stchet zunäclsst dem Spechle, dessen Schuabel garz platt gedrülit und gorau ist; ja - was noch mehr dio Sache verwim - tie nïmlichen Ueberschriften wie bei Landrügeln, wicderhohlen sich anch bei Wasservïgeln, und des Arocetti und des Flamingo wird bald unter den Breitschüblem, bald mier den Sägeschnäblern, balt unter den Dimmschnäblem, bald nuter den Langbeinigten ron dem Verfasser mehrmalen crwälnt, endich, wo sich licin Name mehr zur Bezeichung der Schübol der Hühner finder liefs, werden die Finen Tauben, die Andern zum Manfs gehörige genanint, greichsam, als wenn diefs bei den Tauben nicht anch dex Full wäre. Die nünlichen Ordnmgen und Emilien Dümcrils wiederholilt aucli Lamarck in seinem obengenamnten Werke "zoologische Philosophic" nux sondert er die Tauben als eine eigene Ordnung ron den Hühnern ab, und lichrel, um scine belicbte fictlenreihe der Thicrc herzustelien, die Aufeinanderfolge der übrigon gianz um. Gleichwie Ronnet die Stuffenreihe nach der Vollkommenheit immer im Munde hatte, nber bei der Ausfuhrung nach cinzelnen Aehnlichlicion haschte, und z. B. von dem fliegenden Eichhorn und den Flederminsen den Uebergang zu den Vïgeln, ron den amphibienarkigen Vëgeln zu den flegenden Tischen, von den Aalen zu den Schlan- 
ger, und ron diesen zu den Schnecken machte, eben so suchet auch Limurch das natin?iche System bei den Yögeln zu berverkstellicen. UTm die Vögel mit den Siugthieren und dann mit den Peptilien zu verbinden, vergifst er sein Prinzip der Vollliommenheit, schliefset die dümmsten und unvollliommensten der Schwimmfífsier, an das gleichfalls schwimmende Schmabolthier an, und sezt, rermrithlich weil die Schildhröten den Sclinabel der Papageien haben, diese, so wie alle Filetterer, am Ende der Feihe der Vïgel, die von den Süugthiesen und zwar den Monotremen her also aufeinan. deifolgen: palnipedes, ccỉassicrs, gallinacés, coZombins, passereaux, rapaces, grimpcurs.

Ilat glcichwohl das omithologische System wenig an Krwciterung and lilarheit auf franzö|sischem Boden gewonnen, so ist doch das Verdienst dieser Nation in Bearbeitung einzelner Familien und Gattíngen nicht zu rerkennen. Können sich die Fnglünder eines Ldwards, Lathami und Dewik, dic Teutschen eines Frisch, Wirsing, Kílcin, Naumann und Borhausen, die Niederländer eines Seep, die Italiener sich des Werhes der Geschichte acr Vïgel a), welches Prachtwerli sich das onithologiche Systom Rays zur Grundlage machte,

a) Storia degl'uccelli s. ornithologia methodice digesta ae iconibus aeneis ornata T:5 autor. MIanetti, Lorenzi, Vanni, Flosentiae 1767. in Fol. 
und leider, mit sonsi sehr miltehürsigen Fuphern begleitet ist, rühmen, so tretfen unier den Franzoscn Büffon, als Monographen Vieillot, Audeberts Sauvages ${ }^{a}$ ), Levailant ${ }^{b}$ ), ma Desmarest ${ }^{c}$ ) ihnen wetteifend zur Seite, Auch zur Tenninils des inneren fïrperbaues der Vögè haben die Franzosen das Thrige beigetragen. VVas Vice d'Acyr in Vergleichung der Mushelnder Vügch mit denen des Menschen, was er über den Bau ihres hichlliopfe; mangelhaft liefs, dicfs hat Curier in scincm Vor he über vergleichende Anatonic auszufülen, disse Vergleichung über alle Organe auszubreilen, und durch die Entdechung des unteren Kehlliopfs ${ }^{d}$ ) zu berichtigen gesucht. Ja dieser grofse Naturforscher bestrebet sich nicht blos Materialien zur Ge= schichte der Vögel aus den noch lebenden, sondern auch aus dem Reiche der fossilen zn liefern. Er ist der Erste, welcher die Existenz der Ornitholithen, die Walch, Hermann, Gessner, Delisle,

a) Histoire naturelle dos grimpereatus sucriers, promczops et des oiscaux de paradis par L. P. Vieillot, J. R. de Aude. bert et C. Sauvages, Paris 1801. Fol.

b) Histoire naturelle des oiseaux de paradis, des Roliiers of des Promerops, suivic de cellé des Toucans et des Barbus par F. le Vaillant 13or. Fol.

c) Desmarest, histoire natur. des tangaras, des manakins $\in \mathbb{t}$ des todiers, Paris $1805 . \mathrm{gr}$. in Fol. avec 72 planches imprimées en couleurs.

d) Cuvier. Magaz, encyclop. Tom. 2. p. 50̃o: 
Schenchzer, Zanichelli, Blumenbach bisher aus mehr oder weniger fabelhaften Exemplaren gegen fan Linglauben Fortis zu beweisen suchten, durch evidente stiliche aus der Natur constatirte, ja sogar die Nuhmasung, dafs dicse fossilen Ornitholithen, welche auch in Gypse ron Montmartre bei Paris gêfunden werden, meistens ron Sumpfrögeln z. B. ron eich grofsen houriis, ron Sclunepfen, Strandläufern horrühen, auch einige den Staaren und Wachteln glichen, bestättigte a). Er ist ebenfalls der erste, welcher den Irrthnu der bisherigen Or a nithologen, wolche dic ägyptische Mumie des Ibis ganz für einen andern Vogel, als dieser ist, hielten, berichtigte, die Meinung des dahir gercisten Brüce durch das Skelet und noch andere U'mstände begründete, und als cinen bisher nirgends beschrie= benen Vogel unter der Benennung , numenius ibis" aufstellte. Aber wie viele Punlste sind noch an den Vögeln zur Errichtung liünstlicher Systeme übrigg? Auch in dem Baue der Nester, in dem gesellschaftlichen oder isolirten Umgange, in dex Auswanderung oder dem Zurïlbleiben, in dew verschiedenen Aeusserung der Stimue, in der Nahrung, der Brühezeit, in dem Baue des Innern, liegt eine sich gleichbleibende Gesetzmäsigkeit, ja nimmt man auch nur die Forn der Eier zu sci.

a) Cuvier. Annal. du musćum d'hisioire natu:, Ton: 3 . p. 536. Tom, 14. p. 45. 
nem Gesichtspunle, wie regẹmäsig verlicrt sich nach und nach die mehr runde Figur bei jenen der Strausse, Raubvögel, und wird allmihlig bei denen der Sperlinge, Hühner, Strandläufer, Gänse, immermehr spitzig! Ist die Ornithologic so givililich auch hierin mit der Zukunft durch cinen gleichen Vorrath ron Materiolien bercichert zu werden, werden die Familien und Gatimgen durch fernere IrIonographien noch gekannter, und werden wir endlich durch urasichtliche and gcnaue Anatomen über den Bau der einzelnen Gruppen ron Vögehn, in deren Bildung man bis jezt aus Mrangel an unständlicher henntnifs nichts als Monotonie sicht, durch gute Beschreibumgen, Abibil. dungen und passende Zusammenstellungen mehr mterrichtet, dann kann es sich bei so zalhireichen und reichhaltigen fiabinction nicht fehlen, auch in das Innere der hilasse der Vögel mchr Ordnung and Licht, als bis jezt geschehen ist, zu bringen.

DRITTES CAPITEL。

$$
\begin{gathered}
\text { Amphibien }-H e r p e t o l o g i a . \\
\text { ø. } 60 .
\end{gathered}
$$

Aristo: Aristoteles unterscheidet unter den Thieren mit teles.

Blut melirere, welche er unter der Benemming:

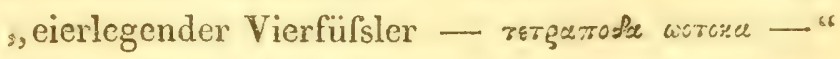
als cine blose Abtheilung der Quadrupeden immer zwischen den lebendiggebährenden und den Vö- 
roln durch alle Bücher seiner Thiergeschichte abhandelt $\left.{ }^{a}\right)$. Hierin sind dio Schildliröten, Eidechson, Furchodile, Stellionen, Kameleonen, Frösche und der Fordylus benrifen $b$ ). Ob man auch die Schlangen (०\$:5) dahin rechnen lönne, dieses läfst cr freigestellt; nur müsse man sie alsdann den Eidechsen, welchen sie am meistor verwandt seycn, an die Seite geben ${ }^{c}$ ), auf allo Fäle aber zwischen den Landthieren und Fischen in die Nitts setzen ${ }^{d}$ ). An rerschicdenen Stellen spricht er von ihren abwechselnden Aufenthalte, ron der Zeit und den Tmständen des Licrlegens, von ihrem Winierschlafe, ja sogar öfters ron ihren inneren Theilen, und sagt ron dem frordylus aus, dafs er nebst den Füfsen auch Branchien habe ${ }^{c}$ ), und dafs die Mcisten von diesen Thieren überhaupt vorzïglich den Namen "Amphibien (suporegs"s) " rerdicnen $f$ ). Zwar ist er hier lange nicht so wcillüufig wie in den eigentlichen Klassen, und gestcliet seil)st, dafs man sie wegen ihrer zu grofsen Vorschiedenheit sicht wohl unter gemeinschaftiche Renennungen bringen liönte s); jedoch thut er cines Ilauptunterschiedes - der üusseren Hautbedecliung -
c) Aristot. hist. animal. L. 1. C. 6. - L. 2. C. $10-$ C. 45.
b) ejusd. 'L. 2. C. 17 - L. 5. C. T. - L. 5. C. 35.
c) ejusd. L. 2. C. 17. d) ejusd, L. 2, C. 14a
e) ejusd. L. 1. C. 1,5, L. 8. C. 2.
f) ejusd. Li. 8, C, 2 . of ejusd, L. 2. C. 15. 


\section{$-314 \longrightarrow$}

Erwaihnung, gemäfs welchem man sie abtheiles loonnte ${ }^{a}$ ), nämlich:

- in solche, wo jene schuppenartig ist (\$odka c(vrc'),

- wo diese Schrippen den Muscheln, wie bei

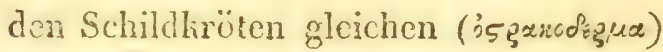

- wo die schuppigte Haut mehr weich, wie bei Stellionen, Eidechsen und Schlangen ist

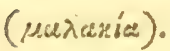

Unständlicher lärst er sich aber auf die Sonderung einzelner Familien ein: Dic Schildkröten ( $\chi \in \lambda$ wimn) theilt er in solche des Mecres (รarartik) - des Landes $\left.\left(\chi^{\varepsilon p \sigma a i x}\right)^{b}\right)$, und des süfsen V Vassers, welches sie, um die Eier zu legen, verlassen

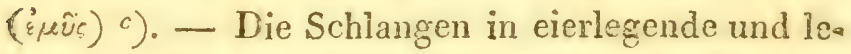
bendiggebährende $\left.\left(\varepsilon^{\prime} \times 5\right)^{d}\right)$, in solche des Landes, des sïfsen und salzigten Wassers ${ }^{e}$ ) und endlich in giftige und giftlose $\operatorname{ein} f$ ).

Plinius zeigt sich auch bei Amphibien mehr als Polyhistor, denn als Zoolog. Statt richtiger Charaktere, hat er diese Thiere mit wunderbaren Sagen ausgestattet, die Salamander z. B.als feucrbeständig und geschlechtslos, dic Blindschleichen als aus dem Rüclicnmarke des Menschen geboren, ange-
a) Aristot, hist, animal. L. 8, C. 1\% - L., 2, C, 17
b) ejusd. L.2. C. 17. - 1.5. C. 3 .
c) èjusd. L. 5. C. 33. d) ejusd. L. 5. C. 54.
๕) ejusd, I. 2, C. 14, f) ejusd. L. 8. C. 22. 
geben. Durch ihn hat weder das Syrstem, nock die Deschreibung, wohl aber dic Anzahl der Indiriduen gewonnen. Gemäls scincr Einthcilung nach dem Elemenie wird des Drachen, der Schlanfen (basilisc. cerastes, amphisbaen. aspis, vipera) des crocodil. scinc. rana rubetc, chamacle. cn, siellio, lacert. salamandr. bei den Landthiezen, aller Schildivöten aber bei jenen des Was. sers erwähnt.

Umsiändlichor und richtiger hat Nicander in reinem Theriahon nebst dem Stellio die Schlangen beschricben, und mil neuen Arten rermehrt (vipera, cerast. haenzorhoon, sepedon, dipsas, chersydr, amphisbaen. scytale, dryina, cena chris).

\section{5. $6 x_{\text {a }}$}

Mit Isidor ron Sevilla fing der systematische Geist wieder an zu erwachen. Der Anordnung des Plinius getreu, handelt er gleich mach den Landthieren, und vor den Würmern, folgende: Reptilien unter der Aufschrift de serpentibus ab. draco, vipera, seps, hydra, natrix, boa, lacerius. salamardra, stellio $a b$, gredenket des Kameleor zunächst dem Rhinozeros unter den Bestien, nennt: das Kroliodil, die Schildlröte und den Frosch Ain. phibien, und spriclst von ilmen, als Wasserthicron, bei den Fischen, 


\section{$-316-$}

Albert d. G. folgte ganz der Spar scines Vorgingers. Im finften Buche sciner Thiergeschichte betitelt, won den lirichenden Thieren, Schlangen und derghlichen Ungeziefer" beschreibt er die nänlichen Thicre in alplabetischer Ordnung, nud crwähnt der Schildliröten and liroliodile bei den Fischen, der fröte bei den insehten.

Cessner erwehte wieder das alie Andenlien des Aristoteles, und nun crscheinen diese Thicre, obgleich nach dem Alphabete gereiht, doch in einer cigenen Abtheilung, als eicrlegende Vicríiifsier nach den lebendiggebährenden (chalcid. chamaeleon, Crocadil. scincus seu crocodil. terrestris, lacerta, rana, salamandra, stellio, teitudo); Die Schildirüten werden in solche des Landes, des siifsen Wassers und des Meeres abgetheilt, und alle jene, welche sich zu gleicher Zeit anch im Vasser aufhalten, werden ebenfalls bei den Wasserthieren wiederum aufgezählt. Diese Abtheilnng becraf aber nur dic eierlegenden Thicre mit Fïfsen; die fufslosen Schlangen hingegen, welche schon bei Aristoteles ohne bestimmten Platz herumirrten, haben ein gleiches Loos auch bei Gessner, der sie ganz abgesondert abhandelt, und in die des Landes und des Wassers abtheilet ${ }^{a}$ ).

c) Gessner de serpentibus liber Vtus, ex shedis et collectancis ejusclem per Jacob Carroni francofurtensem compositus Tigur. $158 \mathrm{y}$ 
Mit Wotton gewamn alles cin strrngeres mol. reichhaligeres Aussehen. Die Froliodiln, Schilrkrüien, Frösche, Eidechsen und Schlangen, worder als cine gemeinsame Abtheilung nacil dou leterdimebahrenden Quadrupedon, freibh mier dert felschen Titel als eierlegender Vierfufier, aufgen. stellt, und nicht nach dem Alphabete, sondern noch ilirer Verwandschaft gercinct. Die Rrolindite und Scinlien, stehen in den ersten Kapitel .- die Land.Süfswasser - und Meerschildliöten im zwcilcn -. die Frösche (rana fluviatil. paỉusto. mônefa, arborea) im dritten - die Eidechson, Salamander. vierfüfsigen Seps, Stellionen, Chancleonon, im vie?n ten bis achten - die Schlangen und rwax cunguts dann die des Wassers: hydrus, natrix, cheisydr. enhydr. coluber, dryinus, chelydrus, serpens marinus (ophisurus) biceps im achten - jene des Landes: aspis, dipsas, presier, cerastes, han modytes, hatmorrhus, sepclon, seps, cenchiris im neunteu, zehnten und eilften - die weniger giftigen: basilisc. draco, amphisbacn. anguis aesculapizs, scytale, typhiops, caecilia im zwölften.

In Geiste Aristoteles arbeiteie Aldrovand fort: Auch bei ilim irren die Schlangen, von den Eidechsen getrennt, olne fixen Platz herum, und werden nebst den Drachen in zwei Büchern ganz alleinig abgehandelt. $\operatorname{Er}$ ist aber der erste, welcher Aristoteles Lnterschicde zu benutzen, und so 
in dic ciorlegenden Quadrupeden, die er inter den Ausdruk, , nulla nobilitate commendatass nach den lebendiggebainrenden sezte, Ordnung zu bringen wufste. Im erston Buche spricht er von jenen, welche mit einer rauken Haut bedelit sind, cute seu momuranseco conto tecta: Frosch, Lideche, Chalcide, Kordylus is, s. w。 - im zweiten ron jencn, welche mil Schildern bedelit sind (testriane tecte: testud. terrestr. aquae dulcis, matina); in beiden herrscht eben dieselbe W Teitläu= fighitit rud der Reichthum an Litteratur, wie is den übrigen Kilassen.

Ganz seinem forgünger getreu, hat Jonston diese Thiere bchandoit und cbenfalls die Landund trasserschlangen, dann die Drachen, ohne iho ren Platz zu bestimmen, bechrieben.

May trat endlich zur Vollendung dieser Rich. iung der Iiprpetologic und zur präcisen Abgränzung dersélben auf. Er suh ein, dafs man mit Unrecint dic so verwanate. Schiangen und Eidech. sen getrount und zerstrenct lat, er rerband also diese rochmals, wie schon Wotton that, als eine Abihcinng der Quntrupeden zusammen. Yedoch eingedcnt, dafs sie jert nicht mehr als Quadrup. den zu Überschreiben sind, bonuzle er zu ihrer Chanherisimg die anatonischen Boobachnugen seiner Kcil. Severinus, Redi und Charas hallen veiltufig cich uber das Gift dez Vipern erkïrt, 
Lezterer es im Momente des Zornes erzeugen las sen, Redi aber für materiel und nur gewissen Thieren angeboren, betrachtet, bei allem Streite hatten jedoch beide die äusseren und inneren Theile näher zur Kenntnifs gebracht; Wurfbain hatte in seiner Salamandrologie die Beobachtung aufgestellt, dafs die Salamander lebendige Junge ohne wech. selseitige Vermischung gebähren; Swammerdam lieferte die gesammte Anatomie des Frosches, und bemerkte am Hälse der Larren derselben fimbrienartige Anhänge (appendices fimbriatae), Perrauit zergliederte das Fiamelcon, Tyson die Klapperschlange, Jacobäns thut in scinem VVerke über Frösche und Eidechsen von den Bcobachtungen seiner Vorgänger Erwähnung, und stellt die Anatomie des Frosches und Salamanders in Fupfern zusammen. Von allem diesen machte nun Ray Gebrauch. Er bemerkte, dafs alle hicher gehörigen Thiere nur einen einzigen Ventriliel des Herzens, dafs die Schildhröten, Eidechsen und Salamander die Lungen doppelt, die Schlangen aber einfach haben, und bei lezteren sich zwei Herzohren vorfinden, er entschlug sich nun des Charaliters ranch den Füfsen, und überschrieb sie als eierlegende Thiere nit Blut, Lungen, einem cinzigen Herzventrilicl a).

\footnotetext{
a) Ray. Synopsis quadrup. S. 247 : „animalia sanguines, pulmone respirantia, cor unico tantum ventriculo instrus ctum habontia, ovipara".
} 
Obwehi er so den Aristoleles verbesserte, so blicb er decb demselben darin getreu, dafs er diese Thiere an die haarigten lebendiggebährenden Vierfüfiler anlinüpte, ja sie sogar eierlegend namnte, während er doch die Yipern als lebendiggebährende schilderte. Ohne wcitere Aufstellung ron. Ueberschrifien, handelt er zuerst von den naliten Fröschen (run. aquatic. terrestr.) ron den liröten, von den bepanzerten Schildiröten des Landes, des sürsen und salzigten Wassers, dann ron Ien schuppigten Eidechsen (lacerti) endlich ron den Schlangen (serpentes). Er ist der erste, welcher dic Drachen und die ürigen Fabelhaften so wie auch den Fisch "ophisurus" welcher bishcr immer als Meerschlange aufgezählt wurde, wegliefs, diese Abtheilung von Thieren hingegen mit vielen neuen Arten bereicherte, wozu ihm der Catalog des englischen Naturalienliabinets ron Grew, das Museum von Wormius, die Entulechungen BeIon's, Hernandez, Markgraf's, Rocheforts vorzüg liche Dicnste leisteten. Seine Beschreibungen sind liurz, mit obigen anatomischen Beobachtungen bereicher ben hergenommen.

\section{56.}

Linne. IVit Limn: nalım diesen Zwweig der Zoologie sine ganz neve Richung. Bisher hatte man das 
Acnssere und Inncre dicser Thicre so weit henners golennt, dal's man sic mit denen anderer lilas. son rergleichon lonnte, ma dic Schlarigen haben nun allmählig ilhen besimmten Platz zunächst den Eidechsen erhalten. Ray hatte schon aie $\Lambda$ bstufing der Natur in Bildung des Nerzens angezeigt, und num machte Limé, durch seinen physiognomischen Blick grëfstentheils glülilich geleilet, zuerst den Lïhmen Schritt, diese ganze Abthcilmg ron den Quadrupeden zu trenmen, nach den Tügeln als eine eigene hlasse, mit der leberschrift ans Aristoteles "amphibia" zur selzen, und sie mach dex Beschaffenheit der Bewestng in zwei Ordnungen, nänilich jene der licptilien (replitia) and der Schlangen (serpentes) zu theilen. Diese zwci Ordnungen behieit er durch alle Ausgaben seines Systemes der Natux bei, nur nit der Verän. derung, dafs er anfangs die Schlangen zuerst, in der Folge aber nach den Reptilien aufzillite, in der zehnten und zwölfien Ausgabe die horpelfische unter dem Titel: "ampribia nantia" als aritte Ordnung beifingte und in einer eigenen $\Lambda \mathrm{b}$ Irandung für den Siren ron Garden die vierte unter der Aufschrift ,amphilia meaniia a)" bestinnte, wolche beide lezten Gmclin, dem Beispiele Campers zufolge, in der dreizchnten Aus.

4) Limnaei dissertntio Lpsaline anno 1760 edita (amoenitates acadeuicae, I. \%. p. 3.s.) 
gabe zil den Fischen rersezte. Um so öfter aber änderten die Gattungen jeder dicser Oretnuncen ihren Platz, bis sie endlich ron der zehnten Ausgabe an also verblieben:

- reptiles: testudo, draco, lacerta, rana.

- serpentes: crotal. boa, coluber, anguis, amphisbaen, coecilia.

Die Schildkröten hat er frïher nach dem Aufenthalte in siifsen und salizigten Wasser, oder auf dem Lande, später nach den mit einer Schwimmliaut verwachsenen flossenartigen, oder mchr freien Zehen, die Eidechsen nach der Gestalt, Länge und Fï̈ze des Schwanzes, nach der Zahl und Beschaffenheit der Zehen unterschieden, ja die Abtheilumgen der lezteren späterhin bis auf sechs rermehrt, bis endlich Gmelin diesclben in eiff auflürste, und nach den herrschenden Individuen:

",rocodili, cordyti, stelliones, iguanae, salamandrae, Gertiones, Chamatcontes, sepes, lacerti, scinci, chalcidae"

übcrschrieb, die Frösche in bufones, ranae, hylae, und die obigen Gattungren von Schlangen, wie es schon Linné von der ersten Ausgabe an that, nach der Gestait und Zahl der Bauch- und SchwanzSchuppen (scuia, scutclla seu squama) absonderte.

So grofs auch das Verdienst Limnés um die Bearbeitung der Amphibien ist, so bleibt doch an seinem Systeme noch viel zu verbessern übrig. 
Leberhaupt hatte man, wie aus dem ersten Theile zu ersehen ist, $z u$ seiner Zeit das Innere immer noch zu wenig gekannt, daher seine Beschreibungen und Charalitere zum Theile vag oder falsch sind. Der Name Amphibien ist nicht wohl gewählet; denn, obgleich auch diese Thiere meist am Gestade, an sumpfigten Gegenden oder abwechselnd zwischen Land und Wasser leben, so machen doch unter den Süugthieren die Phoka, der Biber, Hippopotam u. s. w. auf cine gleiche Benennung Anspruch, ja selbst dic meisten Landschildliröten verbleiben immer auf dem Lande, und riele der Eidechsen halten sich auf Bergen und Büumen auf. Eben so unbestimmt sind jene Ueberschriften "reptiles - serpentes"; denn das Iriechen kommt auch vielen der Säugthiere, den Raupen u. s.w., die schlangenförmige Bewegung auch Viurmern zu, und nebstdem machte ja hieron das Hïpfen der Frösche, das Schwimmen der Meerschildliöten eine Ausnahme, und fon den Chalciden und Seps mit so hurzen Füfsen, kam mail weder sagen, dafs sie blos kriechen, noch auch dafs sie sich blos wie Schlangen winden, in. dem beides zugleich statt findet. Zwar scheint diese zweifache Unterscheidung, wenn auch die Benennung falsch ist, durch den Beisatz von der Anwesenheit oder dem Mangel der Füfse gestüzt zu seyu; allein, wenn ma bedenkt, dafs der proo 
pusblus zxa vondere Furse, der Scheltopusitk ron Thallas blos cinen stimipten, zehenlosen Rest ren hinteren, whe alle rordere, der ophisautas, welther dem rorigen franz stcichet, änsscrlich gar hine Exiremiäton, an Sheicte aber Reste desclben, und auch, wie die Whindschleiche, cines belicn hat, sc ersicht man wohl, dafs die Tidechsen durch hwe so weite hluft ron den Schiangen getront sind. Linné selbst hat diese Verwandschaft grofint, und deswegen in der lezten Ansgatse die lezie der Eidechsen "anguinu" grenamia, die Schlangen aber mit einer "angrtis bipes" begonnen, in der zwilften Ausgabe auch einer g cinghis ynadrupes" Emelin sogar eirer "cotaber lipos" crwähnt. Filli aber anch diese Wintheinng, so sind die Gruppen der Gatumgen dieser Thicre demohngeaclstet vortefilich; nur häte ex den Drachen, der sich blos durch seine rlieghant ron Siellionen und Iguanen unterscheidet, nicht roin diesen trennen sollen; denn zu einem gleichen Verfuluen wïrde anch die flotirende Inat auf dem liople, den Tonden, dem oberen nind unteren Schwanzande bei dem Dasilish, die scinlderartigen Schippen auf dem Püiclien bei den hrolodile und der Dracina berechliget haben; ja hälte er sich in allen durch die herrorstechendsten Eigenschaften Iciten lassen, so hizile ihn doch der Wechisel der Zehcn, der Mangel an Nägeln, die 
nalie, schïpfrigte Hant, die nänlichen Ir Tetamorphosen, der gleiche Zustand der Jarren mit Branchien, und das Verharren der Sirenen als Larven, mit hevaushängenden Branchien ma unveränderlichen Exiremitäten, diẹs alies liäle Limé aufnerksam machen müssen, dafs Früscho und Salamander unter sich verwandt seyen, und nur am? Finde aller Amplibien, liuzz vor den Fischen stehen lï̈nnen. Jedoch diefs berülsichtigte Limé nicht. Er war schon zufricden, dic Schildkröten wegen den Schildern, obgleich anch bei hrolodilen und Dracänen die Rüelienschuppen schilderartig sind, die Frösche wegen ihres Naktheit, obglcich er selbst eine rana squamigera aufzählt, die Schlungen nach der 'Zahl und Gestalt der Bouchand Schwanzschupncn, wolche doch selbst bci den nïmlichen Indiriduen, nach $A$ ussage Vosmacr's und Lacepedes ${ }^{a}$ ) variircn, zu unterscheiden, und als Hauptgattungen aufzistellen; So wercien bei der coluber natrix unten längst der Mitte des Schwanzes, zwei ungetheilte Schilder (scuta) gefunden,

a) Lacépede les serpens p. 7 . nous pensons d'après des observations et des comparaisons très multiplićes, que nous avons faiț sur plusieurs individus d'un grand nombre d'es pèces, que le nombre de ces plaques peut varier suivant s'age, augmenter a mesire, que les scrpens grandissent, et dryendre de beaucoup de circonstances particulieres et acsiderielles。" 
bei der boa constrictor sind die Schilder mit klei. nen Schuppen untermischt, und crscheinen ab. wechselnd an mehreren Individuen der coluber melanocephal. in dem Pariser Kabinett, bald als Schilder, bald als Schuppen. Ja er nemnt sogar auch die Eidechsen nakt, und legt den Reptilien einen allgemeinen Charakter ,os respircuns pulmonibus, pede's quatuor, peris simplex" bei, welches wohl auf einzelne, aber nicht auf alle zusammen pafst; denn blos die Schildliröten haben einen einzigen äusseren Geschlechtstheil, die Eidechsen und Schlangen haben zwci, Frösche und Salamander gar keinen - die Frösche und Salamander athmen im Larvenzustande mit Branchicn, die Sircnen, Proteen, athmen ihr ganzes Leben hindurch mit Branchien und Lungen zugleich - und er selbst sagt von dem bipes und apus den Mangel zweier Füfse aus. So vag und unwesentlich sind die meisten Charalitere, und eben deswegen auch eben so willkührlich und nachlärsig die Aufeinanderfolge der Gattungen. Allein hat hierin auch Linné nicht etwas Ausserordentliches geleistet, so bleibt ihm allein doch das Verdienst, diese Thiere zu allererst als Klasse herausgehoben, und ihnen, gegen die bisherige Aristotelische Behauptung, zuerst zwischen den Vögeln und Fischen den gehörigen Platz angewiesen $\mathrm{zu}$ haben. 


\section{-527
9. 63.}

Seit der ersten Ausgabe des Limméischen Syste. mes der Natur, wurden dic Amphibien immer mehr gehannt. Ob sic gleich durch ihr gespensterartiges, monströses Ausschen, durch ihre liriechende und mühsame Bewegung und selbst durch den giftigen Bifs so mancher, die Naturforscher eine Zeitlang zurückeschrekten, so fing man doch jezt an, die Natur auch in ihren abenthenerlichen Formen lieb zu gewimen. Seba liann, obschon sonst leichtgläubig und blos sammelnd, doch wegen der Menge der Beschreibungen und Kupfer von Schlangen und Eidechsen, als Repertorium fïr dieses Fach angesehen werden ${ }^{a}$ ). Catesby machte uns mit den Amphibien von Karolina, Florida und der Insel Bahama durch Beschreibungen und Kupfer bekannt ${ }^{b}$ ); und Flein, auf diese beiden Kupferwerlie gestiizt, hebt die Unterschiede, welche dem Ray und Linné stillschwcigend zu Grunde liegen, heraus, behält die Gattungen des Lezteren bei, und vereiniget sie nach der Hautbedccliung wie Aldrorand unter allgemeine Gesichtspunhte. Seinem

a) Albertus Seba. Locupletissimi rerum naturalium thesauri accurata descriptio et iconibus artificiosissimis expressio per universam physices historiam. Amstelod. 1754. T. 4. Fol.

b) Mark Catesby. The natural history of Carolina, Florida and the Bahama islands, cuntaining the figures of Birds, Eeasts, Fishes, Serpents, insects and Plants, Lond. 17.51. yol. 1, 2. 
Prinzipe gemäis, ändert or dic Aufscirift împhibien in dic , digitata depilata uud crpcta" um, handelt jene bei seinen Pedaten, gleich nach den Nagern ab, und wirf diese beinahe gegen das Ende der Thierreihe, zu den Wümern. Die crstexen sind nach der Ilautbedechung, die anderen mach dem Verhälinifs des liopfes zu den Schwanze und nach den Zühnen also abgotheilt:

I. Quadrupeda pedata, non aurita, depilata ").

- testudinata: iestud. - pedib. ciscretis anomalis.

- cataphractes: crocodil. Caimar.

- nusla quae habent rulem glabram, vel pliss minusve squamatam: lacerta, sa! amandr. gecko, cordyl. scinc. seps, chamaeleon, batrachus.

II. Apoda: erpeta

- angues: 1. capite discreto, cauda decres. cente:

- dentibus caninis (ruvodov): viperce

- dentib. pectinatis ( viper. aquatica.

- dentibus acicularibus: coluber. absque dentib. (anodon).

2. capite indiscrelo, cauda quasi truncata: scytale, amphisbaena.

- vermes (inmbricus, hirudo).

a) Klein, Historia quadrupedum. Lips. 2751 。 


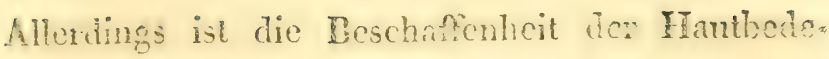
chung, welcle schon Aldroraud, Hay und Linné im Ange latten, Ilein wher als Boborshriftheraushob, ein wichiges Moment bei den Amphibicn. Schon an den Füsen der Wigel hai sich die Schuppenbilang cingestellt, bei den Schidtrüten exschenen dio Schuppen als Schidur, bei den hroliodilen, der bracine, sind diese Schihts nur vorzïg.

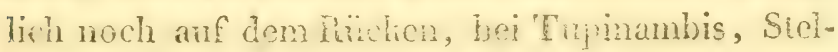
lienen, Uronkit, den eigcntichen Eidechen, bilden sic lö́chrihte Pun!ite, mù crst in Scinhen, Chalciden, Ophisam mol Schaigrn, so wia auf dem Barche auch auf dem Rivicen wahre Schnpon, ahmlich denen der Fische, und nur an dem hopfe dieser Thice haben jene noch die Cestalt ron schilderarligen Platten; aber längst hat der. Banch schon dic Schuppenform angenonmen, und ist bei Schlangen halbmondformig danit gepanzert, während die Schuppen auf dem Rüchen noch rhomboidal und dachzicgelförmig liegen; bei Conchylion sind die Schuppen als Schaalen, bei den Madreporen, Alcyonen u. s. w. endlich als eine scheinbar morganische, zum Thiere nicht gुchörige Masse zurükgeblicben. Froilich licfsen sich so dic Amphibien in solche mil Schiliom wio Schildiröten, in solche nit wenigeren Schildern, aber wohemrschen. den Schuppen, wie Krokoilile, Kaimanen, Dracia non, in elche mit blofsen Schupen, wie tilch. 


\section{$-330-$}

sen und Schlangen abtheilen. Allein die Natur, wolche, im Ganzen betrachtet, nach einer stäten Linie fortschreitet, weichet im Einzelnen von diesem stäten Gange ab; so sind die meisten Frösche nakt, die Fröten und Salamander haben die Haut durch Drüsen höckericht, die Coecilia unter den Schlangen nakt, und wie von kleinen Poren durchlöchert. - Wollte man die Kleinische Methode in etwas berichtigen, so würden sich die Amphibien als

- testudinata: testudines,

- squamata: lacertae, serpentes

- nuda: ranae, salamandrae,

so ziemlich natülich gruppiren, und die Coecilien, welche auf der Haut statt Schuppen kleine Poren, vud die Rüchenwirbel platt, und eben so ziegelförnio auleinanderliegen haben, wie Frösche und Salamander, wïrden die Schlangen mit den lezteren eben so verbinden, wie es durch Seps, Chalciden, Bipeden n. S. W. zwischen Eidechsen und Schlangen geschicht; Leider! haben aber die Uroplaten, Stellionen u. s. W. bei den" Eidechsen, - die Amphisbänen, Hydrus u. s. w. bei den Schlangen, die Haut mit Körnern statt mit Schuppen besezt, und bei den Fröschen machet die rana squamigera und clypeata eine Ausnahme. Jedoch Klein wollte diese consequente Verbesserung nicht im geringsten, indem er die Schlangen als fufslos zu 


\section{$-331-$}

den Apoden, und zwar zu den Wiirmern hinabsezte, ein Verfahren, welches nur durch den Schlein des äusseren Habitus, nicht aber durch die innere Struktur gerechtfertigt werden kann. Stehen aber auch die Schlangen nicht an ihrem Platze, so ist doch jene Beobachtung, dals der hopf, Irals und Schwanz, entweder gleiche fortlanfende Diclie haben, oder der Hals dünner ist, der Schwanz spitzig zulauft, und so der hopf herziormig von dem übrigen Körper hervorspringt, nichts weniger als ungegründet. Bei der coecilia amphisbaena und typhlops hat der Kopf, Sckwanz und Mittelleib beinahe gleiche Dicke, und ist der Gestalt der Blindschleiche ähnlich; in hydrophis. platurus, crotalus findet dieses zum Theil noch statt, aber doch ist der Schwanz schon zur Seite flach zusammengedrülit - bei dem ophisaur. ist hopf und Mittellcib gleich dick, und nur gegen den Schwanz conisch zugespizt. - Von nun an aber wird mit erix, acrochord. bis zul erpeton, coluber, bungarus, vipera, trigonocephalus, boc der Hals und Schwanz dïnner, der Kopf und Mittelleib relativ dicker und herrorspringender. So auffallend auch diese Unterschiede in einer reichen Sammlung ron Schlangen, wie z. B. in dem Kabinette zu Paris und Paria, sind, so lifst sich doch eine solche nuiancirte Gradation nicht in Worten ausdrücken, und erleidet auch, wie z. B 
Joi colubr, wo bei einigen der Topf herzformig horvorsteht, bei andern nicht, manche Ausnatimen. Allein Klein hat dergieichen Charaktere mehr aus hiupen, als aus der Natur genommen, or selbs: scheint scine Täusclung, in der Abtheilung der Schlangen in solche ohne alle Zähne oder mil blosen Hunds - oder Fischzähnen später cingeselıen, und seine Armuth in Beschammg, der Natur gefliht zu haben, daher er seine Unsicherheit in diesem Fache mit eigenen Worten gesteht ${ }^{a}$ ).

\section{64 .}

Almählig machet die Herpetologic cincn merklichen Schritt rorwärts. Limné hatte schon die Amphibien nach der Art ihrer Bewegung in liviechende und schlangenartig sich windende abgetheilt. Laurenti wählet sich die ersten zum Thema ciner medizinischen Preisschrift, hing der zooIogischen Betrachtung auch die Untersuchumg über die giftigen Amphibien von Oestreich und über die Heilmittel an, und theilet sic, nach dem nämlichen Prinzipe des Linné, also von einander ab:

\section{Reptilia}

- salientia: pipa, bufo, rana, hyla, proteles:

Ђ) Klein. Erpetologiae tentamen, Leidae et Goetting. 1755. p. 44: "generum ratio hactenus fuit vaga, unde est, ' qnod non interponeren fidem meam, omnes viperas colubrosqune acu tetegisse." 
- gradientia: triton, salamandra, carediverbera; chamaeleo, igtuana, basilisc. draco, cordyl. crocodil. scincus, stellio, seps.

- serpentes.

Freilich ist die Verschiedenheit der Bewegung bei ficptilien ein aufallendes Phänomen: die Frösche hïpfen, dic hroliodile gehen trägen Schritles einIer, die Schlangen suclien sich windend über don Poden zu cracben. Jedoch diese Eigenschalten machen nichts desio weniger ihre wesentlichen Charalitere nicht aus; auch der Frosch schleppt sich manchmal hiechend auf dem Boden oder auf Lüunen fort, die Eidechsen hüpen im Lanfe, die Clalciden, Sops u. s. w. kriechen theils mit den Füfscn, theils winden sie sich mit dem Förper, wie die Schlangen, fort, die Wirmer ahneln in ihrer Bewegung eben diesen lezteren, ja die Drachen scheinen in etwas fliegen zu können, die Mceresschildkröten haben lieine von allen diesen Bewegungsarten, sondern schivimmen im Wasser einher. Wie viele Abtheilungen müfste man also noch jenen des Laureni beifügen, wenn man die Arten der Bewegung dicser Thisre erschöpfen wollte? wic viele rerwandte Gattungen, z. B. Landund Meerschildkröten, müfsten dann von einandergerissen und zerstreuet werden? Zwar hat er noch andere Kennzeichen zur Unterscheidung der Klasse sowoli, als ảer Ordnungen angebracht; Leider! 
ist aber eben so wenig als hier das Wresentiche von dem Unwesentlichen geschieden, ja rage und unbedeutendere Merkmale machen dic Mchrzahl aus. Dafs die Benennung "Reptilien" auch Würmern, Inseliten, Raupen, Schneclien u. s. W. zn० lomme, wurde schon erinnert; das verdächtige Aussehen, wovon bei vielen Anolis und Schlangen das fregentheil stait findet, das langsane Verdauen, das lange Ausharren chne Nahrung, das langwierige Ueberwintern u. s. w. was alles noch vielen anderen Thieren gemein ist, solche Merlimale sind in die Definition dieser Thiere mit aufgenonmen a)! Auch heist es hier, dafs diese Thiere beinahe ohne Rippen seyen, was doch allein von den Fröschen gilt - dafs die hörper bei der Begattung lange 'Zeit vereinigt bleiben, was wohl aut' die Eidechsen, Schlangen und besonders Schildlirö. ten anwendbar ist; allein schon Frösche hängen blos noch zusammen, ohne Geschlechtstheile in cinander aufzunchmen, und dieMännchen bespritzen die Eier, so wie sie aus dem Bauche heraus. treten; bei Salamandern endlich findet selbst nicht melir jene. Verbindung statt, und da Wrurfbain bcobachtete, dafs sie lebentige Junge gebähren, da Blumenbach ron einem Weibchen, welches er vier Monate isolirt in Wassis aufbewahrte, unerwar.

x) Laurenti. Specimen medicm exhbens synopsin reptilium cıendatam. Viennae 1768. 
tet Junge erhielt, so ist die Vermuthung wahrscheinlich, dafs die Weibchen den Saamen der Männchen aus dem Wasser aufsaugen, und damit auf eine noch längere Zeit, als Vögel, befruchtet werden; Eben so unrichtig ist es, dafs von den Fröschen im allgemeinen Naktheit ausgesagt wird, da Wrallbaum die rana squamigera gesehen hat; der proteus oder die eigentliche rana paradoxa fällt nur als Gattung weg, da sie als Larve el* kannt ist. Auf solche Weise werden vicle falsclic oder unwesentliche Kennzeichen angegeben, wälrend des so bedeutenden Unterschiedes des $\mathrm{Her}^{-}$ zens, der Anwesenheit der Branchien in Fröschen und Salamandern in dem früheren Larvenzustande, gar nicht gedacht wird. - Bei der zweiten Ord. nung "gradientia", die blos dem Namen nach von dem "lacertae" des Linné verschieden ist. hat er die Gattung des Lezteren gröfstentheils beibehalten, und nur den bisher unbekannten proteus, welcher in dem See des Alpen Etscher, den triton anguinus, welcher im Tschirniker See in. Kärnthen lebet, und welche beide nebst den Füfsen, Branchien und Lungen zugleich behalten, an die Spitze derselben gestellt, ohne sich rerade zu entscheiden, ob sie für Larren zu halten seyen. oder nicht; den Schlufs bilden seine Seps, oder die eigentlichen Eidechsen, bei denen er die einiger Poren um den Anus, gegen die Schenliel zu, al. 


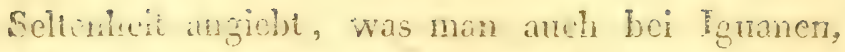
Gechos vo s. w. und mier den Schlangen bei Amplisbinen antrift. Gutrener noch ist er dem Linsé bei den Schlengra gebletson, wo cr sich blos die Ven̈udermer enlaubte, cinzelue Arten der co7uber z. B. lutrix, ccrustes, coronallu, dipsas, naju, vipera, cupra, cisplis, laticundu zu eigonen Gattugen zu eifteben. Obwonl iibrigens Latırenti anf die Anfuinanderfolge der Ordmugen mel Gatlungen seine Aufmerwatheit nich gerichel zu

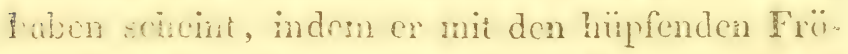
schen dern Anfuige machet, dic Lidechson und Schangen abu bei ihner volliommeren Bilding mutisczi, so lat er docis die freilich anfuilende Vermandschaft der Lidechsen mit den Schlangen

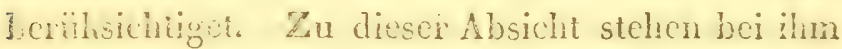
dic chukin. hiduity t. epps monoductyl. an der Givitze der furslosen schlangen, und die coecilia, asi?phisbucna, angulis, welche bei Linné an Kinde sichen, folgen densciben; Vielleichi daís anch dex Salamander mit Absicht den Anfang bei den "grcilientia'smacht, um diese mit den vorausge. 1:enden Füschen zu rerbinden. - Zwar ist an den Gatlingen chalcid. sepse, propris, scheltopusil, ophiscur. nicht zu verlemen, dals die Natur hier rincrecils nath der Anwesenheit, der freilich liur. zen und fimstehomen Extremitizen, andererseits

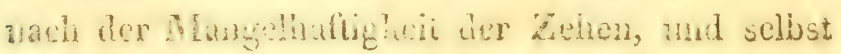


der einzehnen Extremitäten, danin nâch dem Tinechenden, schlangenarligen Gange zwischen der Bildung der Eidechsen und Schlangen schwanlie. Jedoch aic Fatastrophe des gä̈izzlichien Mangels der Extremitäten an allen Schiangen, ist zu auffallend, als dafs man jene Gattungen ron marigehthafien Videchsen an die Spitze dieser stellen, oder dic coecilia, weil sie dem Slieiete nach den Fröschen md Salamandern, sonst aber den Schlangen gleicht, zü der Ordnung der hüpfonden rechnen lïnnte. Das $\Lambda$ cussere mufs der Plyysiolog so gut als das Innere, ja der Znolog jenes mehr als diescs schititzen. Alle jene mil Füfsen, oder bei welchen sich ̈̈nsserlich noch einc Spur von Extrcmitäten zeight, müfsten daher den Eidechsen beigezählt, oder als eine mittlere Ordnung aufgezühlt werdon, der Ophisaurus aber, obgleich er wie die Eidechsen einen äusseren Gehörgang, eine Nilihaut, nebst dem rechten Lungenflügel anch einen Ansatz zı einem linkien, die nämliche Gestait des Schä० dels, die nümliche Lage des Herzens, den Rest von Extremitäten und Beclisn am Slielete hat, und so nach innen eine Eidechse, nach aussen eine Schlange vorstellet, dieser würde nun die Abtheilung der Schlangen eröffnen, Ist es aber auck Laurenti nicht gelungen, dis gehörige Rangordnung in das Linnéischo System der Ainphibien zu brinzen, so hat er doch gerade durch jene Versetzun- 
gen anf dic schwicrigsten Punkte, und mit der Entdeching des proteus anguimus bei seinen Nachfolgern nachmals das Nachdenken über den von Garden aus Amerilia mitgebrachton Siren, über ihre Achnlichlicit cincrseits mit Salamandern, andererseit mit Fischen rege gemacht.

\section{65.}

Statt zu rerlieren, erhob sich im Gegentheile das Ansehn Limnés immer mehr bei den Naturforschern. Scopoli wiederhohlet in sciner Iinleitung zur Naturgeschichte, genau das System der Amphibien desselben; or theilet sic in Reptilien unit Schlangen ab, macht mit der coecitia ron diesen den Uebergang zu den Grätenfischen, sondert jene in zwei Ordmungen: caudata: testud. draco, lacerta, siren - ecaudala: rana ab: und sezie die Knorpelfsche unter der Benennung , spuria" an die Spitze, um so rermiltelst des IMeerpferdchen den Uebergang zu den Vügeln zu machen. Eber so getreu gegen Limé, benahm sich Lestic in seinen Anfangsgründen zur IN. G. ja er nahm sogar die neue Familie auf, welche Limnć auf das Ansehen von Garden aus dem siren lacertin. unter dem Titel ,meantes" machte, und erhielt so vicr Abtheilungen:

- replites: testud. rana, draco, lacerla.

- meantes: siren lacertin. 
- serpentes.

- nantes.

Gronov und Blumenbach liefsen die Knorpelfische und den Siren aus dieser Klasse weg, und blieben bei der alten Abtheilung in reptiles und serpentes, so wic auch bei den darin aufgestellten Gattungen. Ein gleiches thaten Batsch und Sukiow in ihrem Versuche zur Anleitung zur hennsnifs der Thiere. Hermann ging auf der Bahn seiner beiden lezten Vorgänger fort, er machte seine gewöhnlichen Bezielungen, nämlich, dafs der Drach, die Amphibien mit den Vögeln, die Chameleonen durch ihre lange Zunge mit den Spechten, die Frösche mit den In. sekten, die Chalciden mit den Würmern, die Wasserschlangen mit den Aalen u. s. w. verbänden, er hob noch mit mehr Nachdrucke als Laurenti die Uebergänge zwischen den Eidechsen und Schlan. gen, vermittelst der Chalciden und jener Eidechsen. mit mangelhaften Füfsen heraus, und bemerkte endlich, dafs die Salamander mit den Fröschen zunächst verwandt seyen ${ }^{a}$ ).

\section{S. 66 .}

Lacepede ist der erste, welcher den grörsten Theil der Amphibien nach der Natur beschrieb, and abzeichnen liefs. Aufgefordert von Büffon, seine Naturgeschichte fortzusetzen, lieferte er je-

\footnotetext{
8) Hormann. Tabul. affinitatum p. 257 .
} 
nes reichlalige Werk über eierlegende Oradrupeden und Schlangen, worin er den weitlünfigen nud mahlerischen Beschreibungen nach, jencun, in der allgemeinen Aufschrif dem Daubenton, in den $\Lambda$ b. theilungen und Crattungen aber dem Limmé gefolget ist ${ }^{a}$ ). Dem Lezteren und den Scopoli gemäls, unterschied er die eierlegenden Quadrupeden in solche mit und ohne Schwanz, jene ferner nach der Anwesenheit oder dem Mangel der Schilder, und ling dieser Abtheilung noch jene Reptilien mit blos zwei Füisen, entweder vorderen, wie den propus, den er zu allererst beliamnt machte, oder hinteren, wie den Sche:topusith des Pallas med der Bonemnung ,bipedes" an; zu gleicher Zuil bemerlite er von den Lezteren, dafs sie nelst dex Chalciden den Uebergang ron den Eidechen zu den Schlangen machten. Die Schildirötcn, wclche zu der Abtheilung der Geschwänzten gerechnet werden, obgleich bei vielen der Scliwanz wegen seiner Kleinleit haum sichbar ist, sind, wie bei Filein, nicht nach dem Aufenthalte, sondern blos nach der Beschaffenheit der Füfse, vermuthlich, weil die testudo clausa des Bosli und die carolina des Linné, obwoll die Fürse wie die Flufsschildkröten habend, doch öfters auf das trokme Land

๔) Lacépide. Histoire natur. des qnadrupedes ovipares of hes arpeas T. $x, 3$. Paris 3788 . 4. 


\section{$-54 x$}

gehen, nach der Beschaffenheit dor Fürse und des Aufenthaltes in zwei Reihen gebrachi. - Dic Familie der Eidechsen ebenfalls mach zwei Gesichtspunkten, nänlich nach dem an don Seiten zusammengedrüliten Schwanze (Torohodil, Gavial, Dracäna, Tupinambis $u . s$. w.), - - die ubrignn nach dem rundon Schwanze, dann nach der Fluoshaut, der Zahl der Zehen, Beschafenheit der Schwanzscimpen ferner mterschieden. - Wie in den eienlegenden onadrupeden, so folgte ex auch in den Schlangen ganz dem rimé, num rerInchrte er die Gattungen de as lyen mit zwei nenen oder , langahe" nach Briggeres und der ,acro"hord" nach Hornstedt, und, oboleich er selbat anssagt, dafs die Zathl und Crestalt der Bauch- und Schwanzschnpen varie, heriksichtigte or doch die lezteren, nud mache sowohl ron Boddacrt ${ }^{a}$ ) -- wclcher das linzige an limé ünderte, dafs ez die boa mach den Schilderu oder Schuppen des hopfes, die coluber nach dem stmpen oder spilaigen fime in zwei lianilien theile - als auch ron Gray ") Gebrath, welcher die Vipern durch cinen licrzförnigen fiopl mil hicinen Schildchen,

\footnotetext{
a) Boddaer. Specimen norae methorli distinguendi serpen tia. Nova acta physico medica acadeniace naturae curiosn)rum T. 7. p. 12.

b) plilosophical transactions, rol. Lxxix. p. 1
} 
lielförmige Schuppen und kurzen Schwanz aus: zuzeichnen glaubte.

Lacepedes Verdienst um die Amphibien ist gröfser, als das aller sciner Vorgänger, und man darf frei gestchen, dafs er die Grundlage für alle seine Nachfolger ward. Jedoch ist dieses Verdienst nicht in deir System, als viclmehr in der geschichtlichen Schilderung der Individuen zu suchen; ja durch jene falsche Ueberschrift ,cierlegender (bradrupeden" durch die Keigmag, Gathungen nach ihren Farben zu benennen, hat er dem Systeme vichehr Schaten gethan. Zwar hat er angemerlit, dafs die Bipeden und Chalciden den Uebergang zu den Schlangen und besonders zu der Amphisbäna machen, dal's die Salamander mit den Fröschen verwandt seyen ${ }^{a}$ ); allein in der Ausfuhrung ist nichts ron dieser Bemerkung in Anwendung gebracht, die Frösche stehen weit von den Salamandern, die Chalciden weit von den Bipeden und Schlangen, diese werden mit den Colubern cröffnet und als Bindeglied am Ende der Amphibien liurz vor den Fischen gesezt. Seinem Beispiele folgte ganz und gar Bonnaterre in dem $\mathbf{A r}$ tikel der Encyclopedie über Erpetologie und Ophiologie nach.

a) ,les salamandres se rapprochent des quadrupedes ovipares sans queue, par leur formation interieure, et par leur yeas dénuée d'ecaịlles." 


\section{$-543-$}

\section{6\%.}

Wie das Aeussere, so wurde auch immer mehr Brog das Innere der Amplibien getiamnt und beschrie- niarto ben. Swammerdam, Perrault, Charras, Tyson, Laben uns schon mit der Anatomie des Frosches, des hameleon, der Viper und der Filapperschlango bekannt gemacht, und die auffallendsten Charaktere herausgehoben. - Dïverney licferte cine rollständige Anatomie des Herzens der Schildkrötc, er funt, dals dieses ans zwei Ohren und einem einzigen Ventriliel mit drei hanmern bestche, er verglich es lierauf mit juncm der Viper, das ebenfalls zwci Ohren und cinen einzigen, aber nur einlammerigten Ventrikel cuthält, dann mil dem des Frosches, wo er nur cin cinziges Herzohr nebst dem cinzigen einkammerigten Ventriliel, und seine imere Strulitur, als selr rewsandt mit dem Herzen der $\mathbf{F}$ ische angicht, und suchet damit die Behuptung ron Mlury, als ob die Circulation in der Schildkröte jener in dem menschlichen Embryo ähulich sey, zu widerlegen $\left.{ }^{a}\right)$. - Rössel führte norhmals die Anatomic des Frosches nach Swammordan ins Andenlıen, und begründete sowohl durch die umständlichere Auscinandersetzung aller Organe und durch die Beschreibung der Larren, als vorzüglich durch die entscheidende Beobarh-

(1) Durerney. Iistoile de l'academie royale de l'année $169 \mathrm{y}$ p. $3 i-227$. 
tung der freihängenden Rranchien an Lezterc», sein Verdienst in diesem Fache a). - Zim that die Aehnlichkeit der Geschlechtstheile des Frosches and des Salamanders dar b). - Geofroi untersuchte das Gehörorzan der Amphibien iberhà tot. - Blumenbach zog die Gräne zwisclien dra Thieren mit warmen und Estem Blut, und bestattigte, dafo auch selbst die I andsalamander in $\mathrm{L}, \mathrm{nT}$ renzustande Branchien baben. Caldesi cnthilloz die inneren Theile der Meen - Flufs- and Landschildtröien in neun lisppertafeln, und macht zelsst andern vortreflichen Beobachtungen auf den Unterschied des Blutes jener und der Ridechsen aufmerhsam c). - Goltwald zeigte ebonfuls an der Anatomie der Schildlröte corettu die bisherigen Beobachtungen nach d). - Van Lier beschrieb rinige Schlangen, Walbaum sechs Arten von Schildkröten. - Nach den zoologischen Ligenschaften hatte schon Linné die Ordnungen und Gattungen entworfen, Laurenti, nach ihm Lacepede und Hermann, deuteten auf eine Rangordnung in der Aufeinanderfolge und aufUebergänge.

a) Roesol. Histor. natur. ranarum nostratium. Norimb. z8on, Fol.

b) ephemerid. Goetting. ann, 1757 .

c) Caldesi observat. anatom, intorno alle tartarughe. Fiom renza, $1687,4$.

d) Christ. Goltwaldts physikalisch-anatomisrhe Bemerkmgen über die Sohildkröten, Nürnb, 3781 。 
Schncider geht jezt die bisherigen anatomischen and zonlogischen Charalitere an ismphibien überhanpt, damn eigends an Schildhröten, endlich auch an cinzehen Gattungen von Reptilicn und Schlangen, mit cinem Reichihume ron hilischen, philologischen und naturgeschichtichen ficminissen durh a). Mehr als Hh. bisher, macht er in lez. won Werle anf die Yervandschaft der Ordnungen mud Gattungen anfuncrlsan, or handelt dio Sala-

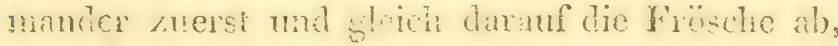

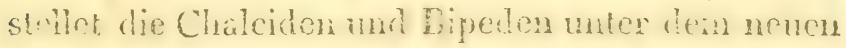

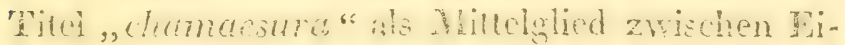
dechen, besonders den Schicn net Schlangen, mi

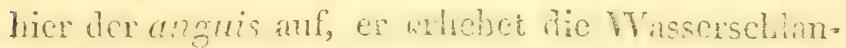
gen zu ciner Gatting , ,hyelrus and schlied'st die Schlangen durch die coccilia an die Aab nuler den Fischen an. Untrubssen bestrebun sich, abci ganz dem Limétischen Systeme scixcu, Schöpif die Schildhöten b), Russel die Schianm

r) Gestll. Schnniter. Amphihiorum physiologiae specimen primum. Züllichoviae 1797.

- Allgemeine Natur jeschichte der Schildkröten, Leipzi $\dot{z}_{z ;}$ 2783. 8, nebst Beitrág.

- Historiae amphibiorum naturalis et literariae Fasci. 1, 2. Jenac $1799-1801.8$.

b) Joa, 3a. Schripf. Historia testudinum iconibus illustrate. Fascio. I-VI, Erlangae 1793. 4; 


\section{$-346$}

gen a), Shaw die Amphibien überhaupt, durch Zeichnungen zt: bereichern, ja Shaw, welcher dem Limméischen Systeme aufs pünlitlichste nachfolgte, blos die zwei neuen Gattungen ron Lacepede, die Hydrus ron Schneider aufnahm, und sein Werki mit rortrenlichen hupfern rerdentlichte, dieser ist auch der erste, welcher wicher auf die fischarligen Salamander mit bestelienden Branchien aufuertisam macht; Camper, Hermam, Pallas, Lacepede, erkilüten sie gegen Linné und Laurenti für Larren, spälerhin Camper, Blumenbach und hierauf Gmelin, versezten sie unter dic Fische, Schneider hält sie cbenfalls für blofse Larven von Salamandern; allcin Shaw stellet sie (siren lacertin. Linné: proteus anguin. Laurenti: gyrin. mexican. s. (axalotl.) als eine zweifelhafte Familie (dubious comphibia) ans Ende aller Amphibien liurz vor den Fischen ${ }^{b}$ ).

Jezt trat Brogniart auf, und suchte mit Hülfe der vergleichenden Anatomie Ordnung in den zerstreuten Reichthum über Amphitien zu bringen. Sie waren bereits schon in Familien und Gattungen

a) Patrik Russell. An account of indian serpents, collected on the coast of Coromandel, descriptions and Drawings of each species, London 1796.

- a continuation, London $180 x$.

b) George Shaw. Gencral Zoology or systematic natural hise tory with plates. Amplibia. Vol. III. lart, I, II. Lond. $802,8$. 
abgeschieden, und Limné hatte ihnen schon ithren Platz in der grofsen Reihe der Thiere angewiesen. Allein im Innern lag alles noch durcheinander, und es bedurfte nur die Andeutungen der Vorgänger zu benutzen, die anatomischen Entdeckingen zu vergleichen, und so mit einem natïlichen Bliclie auch cine natürliche Aufeinanderfolge herzustellen. Dicfs that mun Brogniart. Vor allen aber hatie er die Beschaffenheit des Herzens und der Geschlechtsorgane bei seinen Abthcilungen vor Augen. Er sah aus den bisherigen Beobachtungen ein, dafs zwar bei allen Amphibien das Ilerz nu: aus einem einzigen Ventrikel bestehe, dals aber Schildkröten und Eidechsen zwei Herzohren, Schlangen (seiner Behauptung gemäfs) Frösche und Salamander, nur ein einziges haben; Er sah ein, dafs die Schildliröten, Eidechsen und Schlangen äussere Geschlechts!heile haben, und sich domit vermischen, die Schildliröten nämlich das männliche Glied cinfach, die beiden andern doppelt besitzen, die Frösche und Salamander aber solche entbehren, sich daher nicht vermischen, und als Larven, nebst Lungen, gleich den Fischen mit Branchien erschcincn. Fühm entschlug er sich also des bisherigen Wahnes, die Früten den Schildkröten, die Salamander den Kidechsen alo verwandt anzusehen, er vercinigte somit die Frï sche und Salamander, sezic sie ans End aller Rep. 
tilicn, and nun schied sich alles ribrige ron sclbst in dieser Anzalil und Aufeinanderfolge anseinander a).

Reptiles.

ord. 1. chéloniens: chelone, emyrla, festudo.

- 2. sauriens: crocodil.iguan.draco, stellio, gecho, camcieleon, lacerta. cinc. chalcides.

- 5. ophidiens: anguis, amphisbaen.crotal. viper. coluber, boa, coecilia.

- 4. batraciens: rana, bufo, hyla, salamandra.

So rortreffich Brogniart dic Ordnumgen dieser Filasse abgesondert, und ihre Aufeinanderfolge bestimmt hat, so ist doch noch immer nicht der Charaliter so begründet, dafs aller $\mathbb{Z} w$ weifel ausgeschlossen wäre, was auch so lange noch danern wird, bis wir ein Werk besitzen, welches die Achnlichkeit und Verschicacnheit, wenigstens der Hauptgattungen, nach ihren zoologischen und zootomischen Beschaffenheiten darthun wird. Weit entfernet an der volliommneren Bildung der Schlangen vor Fröschen und Salamandern zu zweifeln, so liefse sich doch, durch das Ansehen eines Jinné, Hermann's, Lacepedes, Lanentis, Scluei-

a) Alexandre Brogniart. Fssai d'une classification naturelle des reptiles. Paris 1805 .

(bulletin de la sociét, philom, an. VIII, n, 35. 36). . 


\section{$-349$}

der's 1i. s. w. verfuhrt, welche alle mit aen Schlangen den Uebergang zu den Fischen machen, vieles dargegen vorbringen. Das Respirationsorgan ist anscrebildeter bei Fröschen als bei Schlangen, denn dort finden sich zwei simmetrische Lungenflïgel, hice aber nur einer - die willizïhrlichen Be. wegungsorgane sind bei Fröschen vollhommener, die Schlangen aber, denen diese, so wie anch dis Brust und das Becken ganz und gar fehlen, ricl unvollhommner; - Früsche haben ein äusserlich sichtbares Gehörloch und cine Nilihant, Schlangen fiht, den Ophisaur und für das Leztere dic Blindschleiche ausgenommen, beides; - die Nicren und Hoden der Fröscle sind runde, auf cinen geringen Raum concentrite Organe, bei Schlangen wie boi Fischen längst dem Rülgrate ausgedchnt; - die Frösche haben einen menbranösen hichlliopf, und eire laute zusammenhängende Stimme, worin ihnen die Geclio gleichen sollen, bei Schlangen findet beides nicht statt, und liaum können sie einen zischenden Laut von sich geben; - Leztere haben wie die Fische die Knochen der oberen Maxille, des $\mathbf{Z}$ wischenkieferbeins, und die Schenkel der unteren Maxille beweglich und freistehend, und das vierechigte Bein (os carré) artikulirt den Unterliiefer nicht, wie bei Vügeln und Eidechsen an das schwammigte Bein, sondern wie bei Fischen hin. ten an das Hinterhaupt, was alles bei Früschen 
der Fall nicht ist, - bei diesen sind auch die Win. dungen der Gedärme häufigcr, bei Schlangen aber schon melir grad gestreht wie bei Fischen. - So lange naan nicht das ganze Innere dieser Thiere, und selbst die physiologische Rangordnung der Organe übcrhaupt kennen wird, so lange wird man sich nur mit cinzelnen Jï̈lisichten behelfen muissen, und die Zoologie wird immer einseitigg bleiben. Wirlilich liat Brogniart sich beinahe allein durch dic Abstuffung in der Bildung des Herzens und der Geschlechtstheile leiten lassen, und daher alles andere entweder ohne durcligefuihrte Vergleichung, abgerissen, oder selbst falsch angegeben. So ist es z. B. irrig, dafs alle Frösche sich durch Naktheit auszeichnen - irrig, dafs alle Eidectisen und Schlangea Schuppen, alle Schlangen kein Brustbein und nur ein Herzohr haben, denn die Geckonen haben den Kiörper mit Kiörnern besczit, die Coecilien sind nalit, die Blindschleiche hat noch Becken und Brustbein und alle Schlangen zwwei Herzohren. Hätte er jedes Organ einzcln durch alle Gattungen oder Ordnungen verglichen, so würde sich der Unterschied der Abstuffungen selbst fir Gattungen immer deutlicher ergeben has ben. Zwar hat er z. B. stillschweigend die Entdeckungen des Duverney in Hinsicht des Herzens benuzt, aber doch führt er nicht einmal an, dafs die Schildkröten den Ventrikel aus drei Kammern 
bestehend haben. Hätte er selbst das Merz einer Schildkröte und eines hroliodiles intersucht, so würde entheils die Mcinung gegen dic Annahme der Aehnlicheit der Cirkulation in den Schildliröten und menschlichen Embryonen berichtigt, und dann den Zwveck jener drei Ventrikeh angegeben. haben. Bei Schildirüten und Frokodilen theilen sich die Blutgefässe, zunächst, wo sie aus deme Herzen hommen, ganz wie bei Vögeln. Gleich bei ihrem Austritte ist die eigentliche Aorte in eine rechte und linke, dann in eine aufsteigende (caroiis) gespalten; bei den übrigen Eidechsen ist diels der Fall nicht, sondern jene lauft beim Austritte noch ungetremnt fort, und dieser Stamm theilt sich erst später in cine einzige aufsteigende, und eine einzige absteigende, bei Eidechsen, Schlangen und Fröschen, giebt leztere auch die Lungenarterie ab; bei Schildkröten und Krokodilen aber ist eine ur. sprüngliche Lungenarterie da, welche sich gleich bei dem Austritte aus dem Ventrikel in eine rechte nnd linke theilt. Eben so ist die Bildung des Her. zens nicht blos durch das einfache oder zweifache Herzohr, sondern auch durch die Zahl der Ven. trikeln verschieden. Im Krokodile bildet der einfache Ventrikel des Herzens gleichsam zwei Höhlen, in die rechte ergiefst sich das Blut der Hohiadern, und nachdem ein Theil dieses schwarzen Blutes vermittelst einem dahin führenden Tianal 


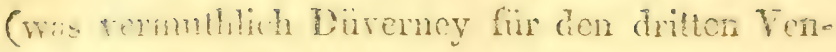
trikit anitht) zn der driten himabstugenden Aole abgegeben ist, so llieist das ubrige in die linlie, welche zugicich ctwas iefer liegi, vermische sich hier mit dem rolhen, durch die Lungentenen heringefiblnten blute, mi strünt hierall so ver. mischt durch dio drei Acrten und beiden Lungen-

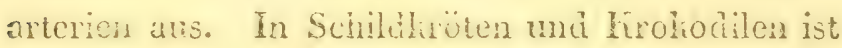
also die ureprüngliche Vertheilung der Arterien, so wic die Strultur diceses cinen Henzrentrikels selbst,

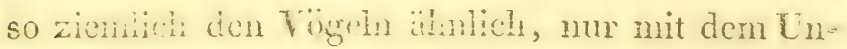
terschicie, cats bei den lögeln jene beiden ham. mern duch die feischigte Scheidewand gesonden, bei diesen aber durchbrochen ind in cinander geoffnet sind, cine Einrichtung, welche trotz derge. genseiligen Memung Düreney's jenc: bci dem menschlichen Embryo gleicht, wo der gröfste Theil des schwarzen Bintes, nämlich jenes der Irohladern, duich die durchbrochene Eushochische Vaivul als solches in den linken, arteriellen Vonn triliel geht, and so mit Ungehumg des Lunges Fireislunfes, wie dort bei firoliodilen und Schildkröten, iì ganzen liörper ausgetragen wird. Felck cursequente und successive Abstuffung offenbas: nicht so die künstlerische Natur in Bildung des Herzens, bis dahin, wo es iln gelingt, ihr Ideal in Tügeln, Säuglhioren, Menschen darzustellen! In niederen Thieren ist der grofse und hileine hreiso 
lauf ununterschieden eins und olne allem IIcrzen rorhanden, und die Trachecn fiihren die Luft nimmittelbax zu allen Theilen des Rïrpers, wo den emährende Saft anlanget; in Mollusken und Fischen treten die Tracheen schon concentrirter, nämlich als Branchien auf; abcr noch immer nicht liehrt das Blut aus den Branchicn in das Herz zn riik, sondern rertheilet sich sougleich ron dont ans in den ganzen Törner, bei den Amphibien sin: schon einige Lungenvenen da, ja bei den Schililirüten, Lirokodilen, Eideclisun und Schlangen i=b nebst dem Herzohre fur dic Hohrenen, auch jenes fïr die Lungenvenen de, und in der Schildivöus und dem hroliodile fäng selbst der Herzventriki! an, mehrere, obwohl noch durchbrochene hanmern zu bilden, bis endlich in Vögehn dio venïn und ariorielle Herzhimmer geondent sind, un! sie endlich in Sänghtieren und Menschen als volilommenes, gleichsam sinmetrisch ans zwei Yent1:liehn und eben so viclca Herzohren bosteinendis IIerz, und als lileiner imi grofser fireislauf gin sondert, auftreten. - Eben so liälte ihn auch dic Lage des Herzens zu bedentenderen Unterselicden dienen liönnen: In Schildliröten, hrolindicen und Fidechen liegt jenes in der dazu bestimmen. Brusthöhle, und zwar dircht der Rïidiensüule entsprechend, oder selbst schon ctwas fecenen limlis geneigl; das Gleiche fintel sich anch bei dem Olili- 
saur; n Schlangen, wo Brust - und Bauchhiohle ohne alle $\mathrm{Ab}$, ränzmg in cinunder überfieísen, liegt es mehr nach iechts und nach unten, gegen dea Nagen und Bauch zu, ja öfters mehr als ein Drittheil rom hopfe enternet, in liöschen endlich, sie in Fischen, zunächst dem liopfe. Auch an den Lungen hätte er den Uebergang der Tidechsen zu den Schlangen zeigen liömnen, inden bei diesen mur cin einziger, sehr langer Lungenflügel statt findet, bei den oplitsaztr. und der coecilia alli... ventris aber sich auch ein bemahe einen Zoll langer Ansatz zun linken cinstellet; cine glciche Achnlichkeit zeigt auch das Sliclet, indem bei dem ophisaur. noch Spuren ron Extremititen und Bechen, bei der Blindschleiche blos von dem Bechen und der Brust, und bei beiden dic Finöchelchen des Schüdels, wie bei den Eilechsen gestaltet, sich rorfinden. Selbst die Erschemung der Erer giebt Tienuzcichen dar, die Abstuffung dicser Thicre zu charahterisiren: Bei Schildhröten sind sie hart und werden einzeln wie auch bei Lidechsen gelegt, bei Schlangen sind sie weich und trelgen schon aneinander gelicttet herror, bei Früschen endlich sind sie ganz weich, und bilden einen regellosen Hautun, die Froschlaiche genamnt. Auf solche TVeise hätte Brogniart durch Vergleichung aller Theile. des hörpers und Festsetzung ihrer Charalitere, dic Ordungen, Gattumen mu ihre Auleinander olge 


\section{$-355$}

rechtfertigen sollen. Sicher hätte er bei ciner solchen physiologischen Untersuchung nicht die einseitige und zum Theil falsche Ueberschrift ,reptiles" gewählet, bei einer so genauen Auseinander* sotzung die Dracäna nicht unter Iguan begriffen, sich in Schlangen und Schildliöten nicht so genau an die Gattungen von Limné und Laurenti ģehalten, mo sichor hätte er sich nicht, würe die ana tomische Zergliederung des Proteus und Axalotl nicht später erfolgt, für die Klassificirung derselben für unentschieden erliläret. Ist aber gleicho wohl an den Ordnungen und Gattungen des Linné wenig abgeändert, ihre Charalitere selbst nur nit wenigen ausgebessert, so bleibt doch Brogniart das hlassische Verdienst, eine naturliche Aufeinanderfolge in die Amplibien gebracht, und durch ein so kurzes MTemoir ein Beispiel gegebon zu haben, svie auch im Uebrigen der Naturgeschichte, mit wea uigen Worten viel ausgerichtet werden kam.

\section{S. 68 .}

Die neve Reformation in der Rangordnung dex. Familien und Gattungen der Reptilien, durch Brogniart, war so einleuchtend, dafs dieselbe bald hierauf ihren Werken über diese Thiere ron scinen Landsleuten zu Grunde gelegt wurde. Latreille hiclt sich zwar in der detervillischen AusGabe won Büffon, wo Sonnini die Bearbeitung deg 


\section{$-556$}

Salamander, or abor jene der ubrigen Reptibien ̈̈bernahm, und beide in vier Bänden ausfibhten, noch an dic Methode Lacepede's, ron dem er sich in der Ausfithrung überhaupt nur dadurch unter. schied, dafs or den weitliatigen Beschreibungen die Charaktere gicichsam als eincn liurzen Auszug voransezte, die neucren Renerlungen von Schöpf und Schneider benuzic, und mehrere Arten von Schlangen z. B. scytal, viper. platur, heterod. hydroph. cukydra zu Gattungen erhob. Auch hat er die cierlesenden Vierfuifster nicht nach der Anwesenheit, oder Abwesenheit der Schilder, sondern jener der Nügel, wie schon frühen in cinen gesonderten Abhandlung iber Salamander abgetheilt, olme aber zu bedenlien, dal's die Neerschildhüten nicht mehr als zwei vigel an jeder Extremitat, und unter den Fidechen die Uroplá ton gar heine haben. Elsenfills ist er der crste, welcher durch die in der I innöischen Gesellschaft zu London rorgclesene Abhandhug des Scheiber iiber den ,proteus anguin." ron Laurenti, reranlafst, aus diesen Thicren, mit bestehenden Branchien und Lingen zugleich, cine ciggene Ordnungs "pnetimobranchiens" machte, und sie ans End aller Reptilien rersezte. Jedoch bald nach der Frscheinung des Werlies ron Daudin über die nämliche hlasse von Thieren schlofs auch or sich on das System Brogniart's an, und indem er die 
Beobachtungen des ersteren benuzte, entwarf ex folgendes Schema der Feptilien a):

Reptiles

chéloniens (marins, fluviat. terrestr.)

- sauricns. 1. écussonés: crocodilo dracaena.

2. à langue fourchue: tupinamb. lacert. tachidrom.

3. goitrcux: camaeleon, iguan. draco, basilisc. agam. stellio, anolis.

4. serpentiformes: scinc. seps, chalcid. sheltopusik, bipes.

- ophidions. 1. imbriqués: ophisaur. anguis, pelamis, erpeton, cryx, elothon.

2. 'itplaques: boa, python, corallus, crotal. scytal. bungar. langaha, huria, acanLophis, cenchris, coluber, viper. entydris, platur.

5. clépidotes: acrochord. amphisbaen. coecil.

- batraciens. 1. coureurs: salamandr. bufo, rana, hyla.

2. pisciformes: proteus, sireli.

T:alreille lat sich hicr blos an dic grellsten Eigenschaften gehalten, wodurch sich diese Thicre

a) Tableaux móthodiques d'histoire not. i Paris. - Extrait sn. 1805. p. $61-70$, , les reptiles par MI. Latreille." 
freilich ron einander unterscheiden; aber eben ein so einzohes Morkmal trennt öfters gerade die rerwandtesten, was anch hier der Fall ist; So steht der Igum, Deache, Ibasish, Stellio weit von der so rerwantien Dracina, dic Anolis ron den Eidechsen wes. All in selbst lie angegebcnen Kemzeichen sind seinen Familien nicht ausschliefsend eigen. Der Zunge gemäls würden die Schildkröten, Lrohodile, Dracuena|ünd alle joue mit einem Sacke an Hals eine einzige Familie, nämlich mit dicher, hurzer und ungespaltener Zunge bilden, wozn freilich auch die Batracher gerechnet werden müfsten, alle übrigen Reptilien aber geliörten zu der Familie mit gespaitener Zunge, worunter die Tupinambis die am meislen getheilte, die Scincus aber dieselbe beinahe ungetrennt haben; die Bezeichnung seiner ersten Familie der Eidechsen liommt mit mehr Rechte den Schildkröten zu, und beide zusammen hätten also als "écussonés" übcrschrieben werden müssen. Seiner Abtheilung der Schlangen nach der Gleichförmigkeit oder Ungleichförnigheit der Rückenand Bauchschuppen, wird tiefer unten gedacht werden; ron den Früschen und Salamandern endlich, könnte man gerade das Gegenthcil ron dem Charahter "coureurs" aussagen, indem sic sich nur lanģam und träg auf dem Boden hinschleppen, fund crstero sogar grölstentheils hïpfen. J Libril. 


\section{$-359$}

le's Verdienst um die Herpetologic besteht also. wic aus Allen erhellet, mehr in einzeinen Beob. achlungen und Combinationen seiner Vorgänger, als in der Verbesserung des Ganzen.

Auf gleichem Wege suchte hierauf Dandin die Ilerpetologie zu vervolliommmen, und lieferte die Geschichte derselben in acht Bänden, in der Fortsctzmng der Werlic Büfons nach der Ausgabe bei Düfart a). Sein System ist jenes des Brogniart; was aber dieser hierin, diefs leistete Daudin in Innern, nämlich in Festsetzung der Gattungen und. Arten, obgleich seine Charalitere Jang nicht so präcis sind, sondern sich öfters in eine Menge unwesentlicher Verhmale verlieren.. Wie scin Vorgänger, so benuzte auch or die Beschreibungen Lacepeds, ergänzte den liurzen Auszug ron Charakiteren Latreille's mit manchen neuen Zusätzen, und fügte denselben soriel möglich die Synonimie der Reptilien seit Limé bei. Daudins Werk, welches auf solche Art alle Schriftsteller dieses Faclics, so wie viele Reisebeschreiber zur Bereichesung benuzte, liönte mit allem Rechte, wäre das system nicht cntlehnt, als ein classischer Lcitfaden der Herpetologic, so weit sie nämlich bis anf unscre Z Zciten in Allgemeinen und Einzehen bearbeitel ist, angesehen werden. Zwar blicb auch cr

a) Daudin. Histoire naturelle, senerale ot particulice des reptilcs. T. I-VIII. Paris ain. XI. 8. 


\section{$-560$}

in der Abtheilung der Schildliröten und der Frösche dem VVerlie Brogniart's getreu, und sezte mit Latreille den Protens und Siren als eigene Gattungen nach den Salamandern; allein in der Vertiseiinug, der Jidechsen wich er noch mehr als Laareille ron jenem ab. VTas bisher blofse Arten waren, dicse werden jezt nach mehr oder wenigger auffallenden Unterschieden ron diesem uncrmüdcicn Naturforscher als Familien und als Gathnegen anfesostellt; So erscheinen bei den Eidechsen die atracaena, tupinambis, tachydromus, basilisc. aggam. anolis; - bei den Schlangen, wo cr sonst gröfstentheils dem Latreille gefolgt ist, und sie chenfalis nach dem Unterschiede mo der Anzald der Bauch - und Schwanzschuppen alssondert, erscheinen pytho, corallus, bungar. acantophis, Zachesis, cenchris, erix, pelanis als cigene Gattungen. So belobenswerth der unerniüdete Kifer dieses Naturforschers ist, so tadelnswerth ist doch sein Streben, alle Arten sogleich in Gattungen zu rerwandeln. So sieht man nicht ein, warum der Tupinambis, Tachydrom nicht wie zuyor, bei den Xidechsen stehen liönnen; ferner ist die Unterscheidung der eigentlichen Eidechsen nach der Farbe ein so ungewisses Verfahren, dafs man darpach die lacerta agilis nicht unter eine Rubrik bringen wird; eben so hinfillig ist die des scincus, vortreffich aber die der Etellionen und Anolis; 
auch dio Unterscheidung der Seps rmd Chalciden nach den ziegelfürmig übereinander gelegten Schuppen bei jenen, und den slernförmigen bei diesen, wärc schr gut, aber dann gehörte sein seps sheltopusiti nicht zu jenen sondern zu den Chalciden. Bei der Errichtung der neuen Gattungen ist Dandin zwar eben so gïlilich als bei Eidechsen, allcin, da thm die nähcre Uniersuchung im Kabi。 netio des Planzengarten, aus lilcinlichen Absichten rersagt war, so mufste er sich hicr mehr auf dic Abbildungen ron Scba, Calesby, Russell, RTerrem u. s. w. rerlassen, daher dem anch ilre Charakbere riel schwächer, sie selbst weniger belestigt sind, und thre Aufenanderfolge von Doa bis zu Ophisaur, Amphisbacn, noch weit verwirler als bei Eidechsen ist. Demohngeachtet aber, obgleich sein Werk kein eigenes System enthäl, und selbst dic historischen Beschrcibungen mit vielon unwesenthichen Sachen angefuillt sind, so wird doch noch langुe Daudin die Quclle für die Herpetologie bleiben.

Dïmeril, welchem neuerdings Lamarck in seiner philosophischen ruonlogie olıne alle Veränderung folgte, ist der lezte und neueste, welcher das System Brogniart's aufnahm, und auch im Innern eine gleich strenge Ordnung herzustellen suchie. Hinsehend, wie schr man sich bishor blos in das Geschichtiohe verlor, strebte pr nur immes 
dahin, die micrschnidenden Charahtere herausznlieben, und alle Gattungen unter cinfache Gesichtspunkte zu bringen. Dieses leislete or in scincr analytischen Zoologie folgender VIassen:

Reptiles:

ord. 1. chcloniens: chelonée, chely's. emyde, tortue.

- 2. sauriens:

- planicaudes: crocodil. dragone, uroplate, lopliyr. basilisc.

- tereticaudes: iguán, dragon, agam. caméléon, gecko, stellion, anolis, lezard, scinque, chalcide.

- 3. ophidiens:

- monodermes: cecilie, amphisbaen. acrochord. ophisaur. orvet. hydrophide.

- heterodermes: erix, erpeton, boa, couleuvre, vipère, scytale, crotale, platûre.

- 4. batraciens:

- anoures: pipa, crepaud, grenouille, rainette.

-urodèles: triton, salamandre, protée, sirène.

So vich auch zur leichten Ueberschaunng die Ansicht der Gestalt des Schwanzes bei den Reptilien 


\section{$-563$}

mit Füfsen, und die Vergleichung der Pürcken. and Bauchschuppen bei Schlangen beiträgt, so ist diefs doch nicht der wesentliche Charakter dieser Thicre, und kann dahcr unmöglich zum einzigen Anhaitspunkte bei Abtheilungen gemacht werden. Limes hat schon beides in die Charakteristik der cinzelnen Thicre mit anfrenommen, Lacepede bei den Eiderhsen selbst als Ablheilungen herausgehoben, Dimeril hat endich dafü technische Benennungen cingefülyet. Freilich sagt or selbst aus, dafs der Uroplat seiner Natur mach ein Gecho sey, nand der Topinampis zu den Eilechsen gehöre, hitlen beide den Schwanz nicht breitgedrülit; alues habon'denn stellio platurus, agitnu, superciliosa, anolis bimaculatus den Schwanz nicht anch breitgediüht, obgleich sie nach ihm unter don rendich geschwänzten bei inen rorwandten Gattungen stehen? Bei den Schlingen ist zwar die Aelnnlichlieit und Verschictenloit der liucken - und Bauchschuppen aufullenu; allein diese Differenz verliert sich so allmällig, dafs sich jene niclst unter zwei so schneidende $A$ btheilungen bringen lassen; ja die Coecilien und Ampluisbänen entbeliren se'bst nach seincr Aussage allo Schuppen, und doch müssen sie unter den Homodernen erscheinen! Bei der Blindschleiche und dem Ophisaur sind auch die Schuplen des Bauches nicht mohr jenen des Rüichens gicich. Teberhaupt wollts 
man die Schingen nach der successiren Ausbreibung der Janchschuppen zu jenen des Rïchen an cinander reihen, so würden sic in folgender Orlnung sich folgen: die Coecilia, bei welcher statt Schupen nur Poren sichthar sind, macht den Anfang, bei der Acrochord treten diese in Geshalt ron fürnchen auf, und beginnen schon sich ancinander zu reihen - in der Amphisbäna netmen sie eine rechtwinllichte Gecialt an, und liegen in Vrticillen mit der Haut verwachsen - im Ophisanr sind es num wirliliche Schuppen, ron denen die des Bauches schon etwas grö́ser als lie des Rïclien sind allmählig nehmen jene in typhiops anguis zu, in der scytale nehmen sie schon die Mitte des Unterleibes cin - in Erpeton erstrelit sich ihre Breite schon gegen die Banchseien - in Erix ist die dem Rücken entgegengesezte Bauchgegend ganz wie mit Schildern bedelit, dicses ist soch mehr am Platurus und der Boa der Fall, ja an den Colubern, besonders an trigonocepliculus, vipera, und rorzüglich an crolalus, laufen die halbmondförmigen Schuppen des Bauches ganz gegen die Lenden herauf, so dafs in eben dem Grade, als die Bauchschrupen an Ausbreitung gewinnen, zwar, jene des Rüclien sich einzeln rergröfsern, aber im Ganzen an Raume beschrünlt werden. - In Hinsicht der Frösche und Salamander läst sich freilich, nachdem die rana pa- 


\section{$-565-$}

radoxa als blose Larve erwiesen ist, nichts gem zen die Abtheilung nach der Anwesenheit oder dem Mangel des Scliwanzes einwenten; allein würde wohl der Verfusscr selbst eine Froschlarve für cinen Salamander, oder iezteren, wen ihm der Schwanz abgehanen wäre; für einen Frosch halten? Zwar haben ihn solche liunstliche Unterschiede auf Errichtung mancher nener Gattums (chetys. uroplut. lophyr.) gefwhrt, aber dafs dieses Verfathen doch nue ein Zwang und cine Mlar. ter fir die Natur sey, erhellet sclion darans, dafs er sich gezwungen fuihte, des Aufeinanderfolgo der Gatimgen jenen litinsilichen Ansichten enfge. gen, immer die natülichen durch Zahlen anzudeuten, obsyleich auch hicrin sich men die Manien als Natur antündiget. Jedoch dicsen licmntuifsreichen Anatomen und 'Zuologen, bleibt das Verw dienst, die abstechendsten Unterschiede der Ordnumgen und Gattungen mit genauester Präcision herausgehoben, und dieses Fach durch manche neue Charaktere bercichert zu haben.

\section{5. $6 \mathrm{~g}$.}

Durch solche eirige Bearbcitung rerbreitele sich immer mehr Licht über die Herpetologie, und Männer aus allen Nationen bestrebten sich, das Gebieth derselben inmer mehr zu erweitern. Schat gab gleichsam die Materialien her, und bleibt dos- 


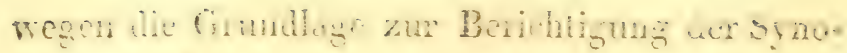
uimien. The Englinder buleby, Rused. Shaw, Own tragen buch ine hupferwerle zur Berei-

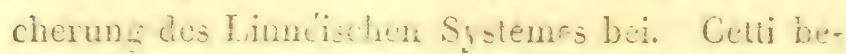
schreibt nebet allen ubrigen Thieren anch die Anphibien von Surdinien. Fontuna nacit rielfitige Verenclie iber dus Viprengitt, ma lables es in jenen hervarastuden Zahue durch cine darin liegende litilse absondern. Nerrem liedent in Beyträgen zur Geschichte der Amplibien sehr un: standliche Desincibungen und vortreffliche lin= ptir ron schungen, whichen jene auf den ülsseren Eindrule berechnete ron Russell weit nachstehon. Laurenti und Schneider unter den Teut. schen, Laceneule, Dundin und Brogniart unter den Franzosen, reilessen n das System Linnés, nud besonders mulh die Lezteren entwiclicln das Ge. schichliche dicess Thicre. Geoffroi beneme frïher die cinzelnen hopflinoclien des Krolivilis a) und reuodings durch dic eigene Abhandlung Eod= dewil = wher die testudo carillaginea - durch die Enhebung der testudo membranacea ron Blumen. back zu einer Gathng - endlich dmeh die neve techinische benemung dafür ,amyda" in enen dem Nationalinstitute zu Paris rorgelegten Mammscripte über Schildiröten uberhaupt ron Srhweig. ger, Profseor der Botanil in liüngsberg, nuf-

a) ans, d. m. T. io, p. 2们. 
merksam gemacht, änderte er den Nimen des Lezteren in "trionyx" um, und bestilltigte die Entdecking desselben mit acht Arten, wodurch denn also Brogniarl's Gattung "emycie" sich in zwei auföfste "). Curier nahm, wie schon früher im Wiedemannischen Journal, nochmals̀ die hirohodile zum Gegensiande cincr Untersuchung, und sezte fiir sie in einer rortreflichen Abhandhung drei Gatiungen nebst folgenden Arten fesi $\left.{ }^{b}\right)$ :

- alligatores (dente infero utrinque quarto, mavillae superioris recipiendo, plantis semipalmatis:

crocodil. lucius, sclerops, palpebrosus, trigonatus)

- crocodili (dente utrinque quarto per scissuram maxillue superioris transenute, plantis palmatis, rostro oblongo:

crocorlit. vulgaris, biporcatus, rhombifer, galeatus, biscutatus, acutus)

- longirostres (rostro cylindrico, elongato, plantis palmatis:

crocodil. gangeticus, tenuirostris).

In eincm gleich rortrefflichen MTemoir entschied er endlich über die bisher zweifelhaften Amphibien mit Branchien, Lungen und Füfsen, bei Gelegenheit, wo Humboldt - dieser kühne Reisender, bei so grofser Fülle von Kenntnissen, auch für die vergleichende Anatomie nebst andern den uxolott.
a) aมn. d. m. T. 14. p. 1.
b) ejusd. T, 12, p. \&. 
ans Inirits anuibibrachte. Er hatte schon friher in Jahir 1300 an cincm jungen Siren, welchen licaurois ans Karolina milnahm, bewicsen, dafs die Cxtremititen nicht Flossen, sondern nach ihren bestandheilen wahrhaftige Füse seyen a), und num zeigle or aus der Anatomie des siren, proteus, sxololl, dafs Lezterer mehr eine Larre, die beiden ersten aber, wcil sic das Shelet nicht linorplicht. sondern hü̈chern, und demohngeachtet die Branchien-Aeste linorplicht haben, ausgebilikete, lieiner nciteren Mietanorphose unterworfene Thiere seyen b). Zwatr sind wir weit enternt, diesen für jeSen Anatomen hinreichenden Gründen entgegen, then alten Zweifel zu hegen, als hïmten jenc whiere eben so wie die rana paradoxa larige Zeit als eigenc Gattung anerkannt, ind zuiczt chcufalls als blofise Larven dargethan werden; allcin, dafs sic den Tinorpelfischen zunächst verwandi seyen, mnd zu ihnen den Uebergang machen, davon wird liefer unlen, wo über dic Fische dic Picte ist, das Gegentheil bewiesen werden. In der nämlichen Ablandlung spricht er zu gleicher Zeit von den Sarven der Salanander und Frösche und zeigt,

i) Bulletin des sciences par la Soc.dphil. no, 58. Flor. an. 8. p. 206.

6) Reclierches anatomiques sur les reptiles rectardćs encoro comme douteux par les naturalistes, faites it l'occasion do L'Axolotl rapporte par NI. de Humbullt du Hexique; pas F. G. Cuvier. Paxis 1807 . 
welche Umwandlung vorzïglich die Circulation. die Anfangs wie bei Fischen, nachher aber durch Verwachsung der Branchienöfnung und der Branchienarterien, durch eine ganz andere Verzweigung der Gefilse, vermittelst den Lungen geschiehi, daur die Extremitüten, Gedärme und endlich der Mumd. bei Fröschen erleiden. Jedoch folgende merkwürdige Erscheinung, die ich im verflossenen Frïhjahre an einer Larve der "sulamandra palustris" cntdekte, und welche offenbar beweist, dafs dic Schwimmblase sich in die Linge, durch Lostrenmung ron der Spciseröhre unwandle, ist dicm sem grofsen Anatomen entgangen. Ich fand nänlich in dieser zwei Zoll grofsen Larve, nebst den. Branchien, zu jeder Seite statt der Lunge eine länglichte Schwinmblase, welche sonst frei häno gend, oben in den Pharynx des ocsophagus einmüncieie, bei cinem gelinden Drucke durch diese Oeffmung die Luftiügelchen herausliefs, und bei nachgclassenem Drucke sich auch wieder von hier. aus damit fültte. Sollte es sich bei fortgesezien Untersuchungen ergeben, dafs sich diese Schwimmblase, mit der Verwachsung der Branchienöfnung ebenfalls gegen die Speiscröhre rerschliefse, und sich im Innern zu noch mehreren, aber kleineren Säcken (Zellen) vervielfültige, und so nach der lezten MItamorphose als viclzelligter durchsichtiger Lungensack auftrette, sollte sich dieses aus 
meinen fermeren Beobachungen, wie es höchst wahscheinlich ist, ergebon, so ist fir die Lumernbilhung, wie sie ihren frihesion Lrpromg als Tratchea ron der äusseren, als Schwimmblase von der inncren Haubedechung der Speiscröhre nelme, eben das daxgethan, was der schartsimige und kenntnifseiche Oken, durch seine physioiogische Dentung über die Bildung der Gedirme ants des vesicula umoilicalis nachwiefs. - Wie die Geschiche der lehendigen, entwichele sich auch nach und nach jone der fossilen Amplibien, wnd num wissen win, dals es, die Sellangen bis jezt ansgenoumen, von allen übrigenz. H. von Schildircente Sulamandern, Fröshen, firohulen, Monitorn in den älteren Fallischichten der Fide Enuchstïche gielst, und dafs ihre Originalion in der newen Wett. gröutentheils nich mehr rorgefunden werden. Cuvier ist auch hier derjenige, welcher dic bisherigen Endechungen näher montrobluc, und zu Gewifsheit atusmittelte. Ex hat bewiesen, dafs das Thicr ron Mästricht, ron welchem dic fossilen Reste des Jiopfes jezt in Pariser Kabinett sind, nicht, wie Camper glaubte, zn den Celacécn gehörte, sondern nach den meisten Rubisichten, besonders auch den palatal Zühnen mit dem Monitor, nach cinigen anderen mit dem Iguan verwandt sey, aber loch als eine cigene, obwohl colossale und ausgestorbene Guttung zwischen beiden iu der Mitte 


\section{$-371$}

stehc a). Er hat ausgeforschet, dafs die in der Gegend ron Harre und Honflcur vorkommenden fossilen Reste zweier unbehannten Arten ron Gavial, dafs jene von Alerenn, I'hitby, Jincentin zu den nämlichen Arten gehören, dafs slie ron Alt. dorf, ron denen Exemplare im Liabinche zu Darmstadi und Wrmulim aufbewahrt werden, rom Gavial verschieden, aber doch verwand seyen, nud dafs cudlich jene in den Schichten von Thüingen von der Gattung , monitor" abstammen b). Er hat dargethan, dafs jenes fussile 'Thier ron Oeningen, welches Scheuchzer für cinen Anthropolithen (homo (liluzii testis), Gessner und nach ihm Blumenbach, Razonmowsliy und Tiarg für den. Wels hiclten, ein Salamander oder Proteus, drei Fufs grofs, und unbeliamier Art sey, dafs der ebenfalls in Oeninger Stinlischiefer vorkommende Frosch, sehr viel mit der bufo calamita übercinstimme, and das berüchtigte fliegende Thier, in Eichstält ausgegraben, und von Collini beschriehen, eine eigene Gatung unter den Reptilien, zunächst dem fliegenden Drachen bilde c), jedoch wir habcn schon früher bemerkt, dafs das leztere Thier, mit der Beschreibung und den ziemlich guten Abbil dungen der inneren Theile des fliegenden Drachen

\footnotetext{
a) ann. d. m. T. 12. 'p. $145-176$;

b) ejusd. T.12. p. $7^{3}-110$,

e) sjusd. T. x4. p. 401 .
} 
in einer eigenen Abhandlung von Tiedemann rerglichen, gar nicht mit diesem, wohl aber mit den Fledermäusen sehr viele Achnlichlseit hat a). End. lich hat or durch seine Untersuchungen herausge. bracht, dals jene Bruchstüclie von Brïssel und Mästricht ganz unbeliannton Arten von Meerschildliröten, jene ron Glaris einer schwer zu bestimmenden Neerschildhröte, jene von Aix ciner Landschildliröle angehören ${ }^{b}$ ), und dafs nenerdings in Monmarire Reste ron trionyx enyda und von einem hrokiodile sich rorgefunden haben ${ }^{c}$ ). Bei solchen Vorarbeiten der noch lebenden oder selbst ausgestorbenen Anphibien, fehlt zur weiteren Beförderung dieses Faches num nichts, als dafs die vergleichende Anatomie die imncre Struhtur der Mauplgattungern, und nach und nach der Arten, so weit sie schon bekamnt ist, zusammenstelle, oder noch ferner enthïlle, und die pliysiologische Vergleichung auch in Abbildungen darlege, um damn die Gruppen dieser Thicre nach eben jenen $\mathrm{Al}_{3}$ sätzen zu machen und zu befestigen, welche die Natur in Bildung des Imneren und Aeusseren ihres Körpers einhält.

a) Dr. Fr. Tiedemann. Anatomie und Naturgeschichte des Drachen. Nürnb. 1811, 4.

b) annal. du mus. T. 14. p. 227

c) ejusd. T. 26. p. 115. 
VIETTES CA PITEL:

Fische $-I c h t^{h}$ olog $i a$.

5. 70.

Unter diejenigen Thicre mit Blut, welche Ari- Aristostoteles mit der eigentlichen Benennung einer teles. Klasse "2\&yos" aufstellt, geliören auch dic Fische (¿xớss). In allen seinen Büchem über Thiere behaupten sie immer nach den lebendiggebährenden und eierlegenden Quadrupeden und Vögeln, als die lezte Gruppe der Thiere nit Blut, den nächsten Rang a). 'Zwar zühlt or bei den Fischen auch die

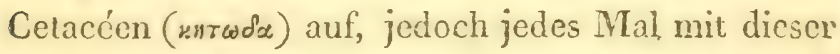
besonderen Benennung und der Bemerkung: dafs sie sich durch die Anwesenheit der Brüste und der äusseren Geschlechistheile ${ }^{b}$ ), des Fehlliopfes, der Lungen c), und der wirklichen Krnochen statt Finorpeln und Gräton ${ }^{d}$ ) von den eigentlichen Fischen unterscheiden, welchen diefs alles fehlet; ja er gestelit sogar, dafs die Cetacéen - der Delphin und Balän - die sonderbarstc Constitution haben, und daher nicht recht unter Land - auch nicht blos unter Wasscrthiere gerechnet werden können $\left.{ }^{e}\right)$. Diese nun ron den eigentlichen $\mathrm{Fi}_{\text {- }}$ schen absondernd, sezt er den Charaliter der Lez.
a) Arist, hist, anim. L. T, C. G, - L: 2, C, 13.
b) cjusd, L.2. C. 15. c) ejusd. L.-4. c. 9.
d) ejusd. L, 3, C. 7, •) cjusd, L, \&, C. 2. 
veren im dreizehnten hapitel des zweiten Buches arscinander, und gicht die Prombin und Wlosen

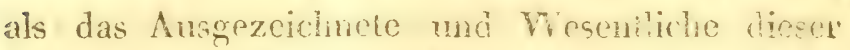
There an a). So viclen findemisen anch alie bieobachtung der Fische, weren dem mangünglichg. ren Medium, worin sir sich anfinilen, minerwer. fen ist, so waren sie doch dem Aristuteles eir (begenstand der beionderen Aufnewlisanlieit und

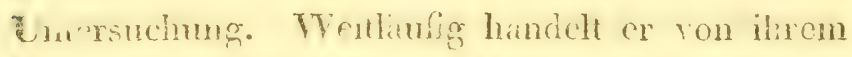
Zustande des Sohlifens mul Wachens (L. 4. C. 30), ron ihrcm remstielenen Aufenthalte in Miece, in Seen, Flüssn, in scichten oder tiefen Stehlen, ron der zwnifachen Art dẹ Befunchunge, entweder durch Anniherung und Verbindung def liöper, wie bei horpelfischen, oder durch bespritzmug der abgelegten Eier mit dem minnlichen Stamen, wie bei Grätenfischen b), von der Zeit und den Nehen. umständen bei der Eicriegung, welche nach ihm besonders un das Frihlings - and Ilerbst-Aequinolitum geschicht (L.6. C. 17); er bemerket disjenigen Fische, welche er filschlich ohne Rier, blos aus dem ausgetrokneten und bei Gelegenheit wieder bentzien Schlanme, so wie auch die Aale aus dem Leibe gewisser Vürmer entstehen lifst; er behauptet, dafs bei den Meernadeln die Eier aus

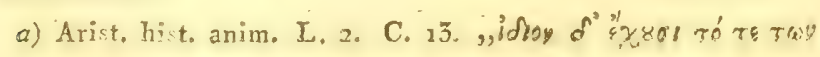

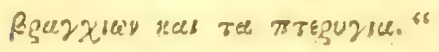

3) ejusid. Li: 6. C, 15. 
den aufyeschlizten Unterleibe hervorliommen "), dafs melnere Hische Ilemaphroditen zu seyn scheinen ${ }^{b}$ ), welches beides neucre Beobachumgen c) z. B. des Carollini bestältigen. Obgleich er ihnen Geruch und Gehör zusclireibt, so bestimint er doch, dafs sic weder üusseren Grehörfang, noch (was freilich falsch ist) cin Geruchsorgan haben (L. 2. c. 13.). Auch ron den inneren Theilen - dem Magen, den viclen Blinddärmen bei cinigen - den Nicren, der Gebümutter u.s. w. wird im zweitcu Buche ansfithrlich gesprochen, leider abei zu glcicher Zeit ansgesight, dafs allo Fische licine Iloden haben. Nebstbei werden dicjenigen Fische aufgezählt, weiche rom Fleische oder Pflanzen leben, welche von der Tiefo des Wassers gegen die Füsten oder Flïse auswandern, nnd sonst grofse Ziige unternelmon, um das Gcschält der Forlunanzung zu feicrn - es wird der Wanderung bei Tagt oder Nachtł, am Morgen oder Abend, um die Fahrung aufzusuchen, — der Wankerung vor dem Winierschlafe, welchen die Nähe dieser Jahreszeit in allen Thieren hervorlringe, und zu gleicher Zeit anch cine grofse $\mathbf{M l e c}$ -

e) Arist. hist, animal. 1, c.

b) 1. c. - L. 4. c. 11. L. 5. c. 1.

c) Philipp Cauollini. Abhandlung über die Erzeusung des Fische und Krebse, übers, von $\mathrm{E}$. A. W. Zimmermann. Berlin 1792. 8. 


\section{$-576-$}

reshewegung zur reichen Ausbcute der Fischer verursache, - des Einfusses, welchen Weligegend, Kälte, Wärme auf diese Thiere hat - alles dieses wird rom dreizchnten bis zwanzigsten Fiapitel des achien Buches weitläufig erwähnt, und er figet noch die scliarfsinnigen Bemerkungen bei, dafs die länglichen Fische mehr gegen Norden, dio breiten mehr gegen Süden gefunden werden ${ }^{a}$ ), dafs alle mehr den Regen als die trochene Jahreszeit lieben, dafs der Eliz dem Wels schade - ja im nenuten Buche erimert or sogar an die Ge. müthseigcuschafien dieser Thiere, wie nämlich der Froschfisch ganz schlau seine langen Fühlfaden als Lokspeise ansstrecke, wie dor Zitterroche durch cine elelitrische Frschïterung sich sciner Bente zu versichern sucht, wie zärtlich die Welse die Eicr ihrer Weibchen licben, und endlich die Delphinen gutmüthig dem Menschen nachziehen. So weitläufig Aristoteles alles dieses durchfuihret, und, wie erhellet, nichts unterläfst, was zur Charaliterisirung der Fische dienen liann, so sind es doch einige Unterschiede rorzüglich, welche mehr oder weniger immerfort zurückekehren. Die Fanilien der

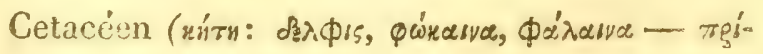
รия, В४г -)

a) Arist. histor. anim. L. 8. C. 190 
(Dclphin, Phocäna, Balän - Sägcfisch, IMeerochs -) ${ }^{a}$ ).

als cine zu klassificircn zweifelhafte Familic vor ausgesezt, wiederhohlen sich folgende Abtheilungen der eigentlichen Fische am häufigsten:

I. nach dem Skelete, nach der Geburt und dem Respirationsorgane

a) in solche, welche ein hrorplichtes Skelet (L. J. c. T.), verborgene Branchien (L.2. C. 13.) haben, und lebendige

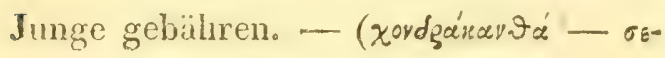
$\left.\lambda \alpha^{\prime \prime}\right),-$

b) in solche, welche Gräten, offene Branchicn haben und Eier legen (čraviádzss).

II. nach der Hautbedechung (I. 2. c. 15)

a) in solche, bei denen die Haut nakt ( $\lambda \tilde{s} c 6$ )

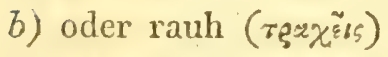

c) oder schuppigt ist ( $\lambda \varepsilon \pi i \delta \omega^{\prime} \tau 0$ ) .

III. nach dem Aufenthalte (L.6. C. 13, 1/4 L. 8. c. 3, 13, 15, 19, 29).

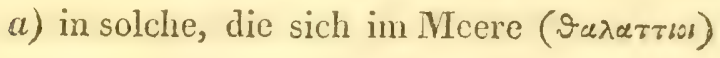

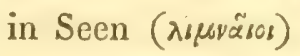

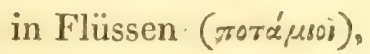

b) in solche, die sich in der hohen see $(\pi t \lambda a z b s)$,

a) Arist. histor. anim. L. 6. C. 12, 

c) oder zunächst dem Gestade ( oder zunächst den lielsen (retzäus aut- Lalten.

IV. nach der Zahl der Ilossen (L. 1. C. 5. L. 2. c. 13.)

- in solche, welche vomen oder hinten, oben oder unten, vier, zwei, oder gar keine Flossen haben.

F. nach dor Gestalt deg hürpers (I. I. c. 5. L.2. c. 13. L. 8. (. 19.)

- in lange und breite.

I. nach dem Umgange (L.8. C.13. L.6. C.1\%)

a) in solche, welche in Gesollschaft brisammen leben, und selbst einen Aifílimer

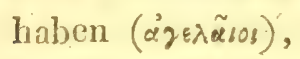

b) oder cinzeln und cinsam leben (pudés).

Plinins wirft alles, was Aristoteles von cinander gesondert hat, sey es vicrfirfsiges Thier, Conchylie oder Polyp, wenn es mur irgend eine Bezichung zu dem Elemente des Wassers hat, in seinem neunten Buche in die Rubrik , aquatilia" zusanmen. Nach der Haubedeckung werden dieselben in solche mit nakter Haut (Delphin), nit Schil. dern (Schildiröte), mit Muscheln (Conchylien) mit lirusten (Lohusten), mii hurusten und Stacheh (Igel), mit Schuppen (Fische) mit raher Haut (squatina), mit woiclier (Aate) endlich olme aus- 
gezeichnete Hautbedecliung (Polypen) untersclic. den. Dieser Ansicht genäls füngt er ron den massiven Baläncn, Delphinen, Physetern an, rermehret Aristorcles Cuacécn mit den. fabchaften 'Tritonen, Nereiden mud IIcerelephanten, schreitct hierwuf zu den gloich grofsen Schildiröten, md lionime endich zu den eigentichen Fischen (pisces), ron denen er 7 is Anten, so vic suäter ron don hrustacén 30 angicut. Hier hamelt $\mathrm{cr} z \mathrm{z}$ wst ron den Thumfichen, ron dem Silurc, we?cher in Mil, Main, oder der Donau, ron dem. Hechte, welcher in Rheine vorkonm!, von de! Scombren, Ileringen, von den Angurion tiber Fische, von dem Einfuase des Sommers und Winters, ron den Mugilen, Siören, Scaren, Zeus, Gaden, Rhonben, Solcen, Aalcn, ron den breiten hinorpeifischen, rour Trchenis, niegenden Fischen u. s. w. gelut hierauf zu den Conchylien, firustaceen und Polspen über, und schliclst dic an Anelidoten so reichlaltigen Aquatilien mit einigen Beobachlumgen aus Aristoteles, und mit der Bemerkung äber Frriclitung der Piscinen u. s. w. - Dem Plinius, wie er,alle Wasserthere in cinen bunten Laufen zusammenwarf, und mit fabelhaften Individuen und Sagen rermehte, folgte das ganze Heer der liommenden Schiftsteller bis auf Ray, der das TTahre ron dem Fabelhaften schied, und den bunten Houfen in gelierige Ahboimg brachte. 
Oppian ist der erste, wclcher dem Geiste seines Vorgängers genäfs dic Bürger des Neptuns in seinem vortrefilichen Gedichte „halieuticon": genannt, in schönen Wendungen und in einem Reichthume von Beschreibungen besang, wic es nur allein der Luxus der fömer, möglich gemaclit hatte. Nachdem er Neptun und Venus angerufen hat, durchwandelt er das Meer, und besingt die cinzelnen Fische, wie sie mehr das sandigte Ufer, oder den schlammigten Grund, oder die Tiefe des Gewässers licben, und gleitet hieranf in lurzer Rede über Krebse, Conchylien und Polypen hin; die manchfaltigen Eigenschaften des Gemiuthes läfst er im zweiten Buche im Spiele ihrer Handlungen erblicken, das dritte schildert die verschiedenen Netze und Kämpfe der Fischer, um die Bewoiner des Wassers zu überlisten; das vicrie mahlet in angenehmen Anckdoten, wie gerade die Liebe es ist, welche die Mämnchen und Weibchen in diese Fallstricke führe; das fünfte endlich zeigt, wic selbst die grörsten Thiere z. B. Cetacéen, Phoken, Schildkröten der schlauen Kunst des Menschen nicht entgehen.

$$
\text { 5. } 71 \text {. }
$$

Von nun an gewann die Ichtyologie lange Zeit fort weder an Ordnung noch an Zuwachs neuer Entdeckungen, Fische und Wasserthiere waren 
gleichbedeutende Namen, und Plinius blieb so das INuster, welches man immerwährend copirte, und nur im Einzelnen zu ordnen suchte. Decius Magrus Ausonius thut in seinem Gedichte, worin er die Mosell besinget, von ungefähr fünfizehn Fi schen Erwähnung. Isidor zählet den gröfsten Theil der Amphibien, wie anch die Pholia, den Hippopotam in seinem sechsten liapitel, so ron den Fischen handelt, auf, und die Cetacéen und Schwerdifische, die Squalen, Torpeden, die eigentlichen Fische, die Polypen, Sepien, Krebse, Frösche, Neerfedern u. s. W. folgen sich in solcher Gestalt bunt durcheinander.

Nhert d. G., und mit ihm Cuba als Verfasser des Garten der Gesundheit, und Megenberg, jener des Buches der Natur, ändern in ilırem Buche über Fische gar nichts an ihrem Vorgänger, ausser dafs sic das nämliche Gemengsel in alphabetische Ordnung brachten, mit den rerschiedenen Meerwundern, als Mecrfräulein, Meermönch, Meerfasan, Meerhaas, Meerochs u. s. w. vermehrten und mit den scheuslichsten Holzstichen begleiteten. Ihre Beschreibungen gehen grürstentheils mehr die $\mathbf{K}^{\circ}$. che, als die Naturforscher an.

Paulus Jovius, Arzt ron Norocoma, fing zuerst an, die Fische von Ron, zwar ohne Ordnung, aber doch nach der Natur zu beschreiben. 


\section{$-383-$}

Von jezt an gewamn alles ein anderes Ausse= hen. Wution erhebet sich untor den Engländern, IBelon und Fondelet wuter den Franzosen, Salviani anter ten Italienern, und Gessner meer den Teutschen. Wotlon rerläfot den bisherigen Weg, welcher mit Pliniss eingeleitct war, häit sich genou an die Aristotelische Abthelmag der There mit und ofme Blut, handell die Fisclie in seinem achten Buche gleich nach den Wögeh ab, und liefert ihre Geschichte gieichsam in cinem huzen Auszuge aus Arisloteles. Ther beginti er zuerst mit den langen nud breiten Fuerpellischen, damn mit den langen Gratentischen (Aalen), den breiten (Plewrouctiten), denjenigen, welche sich am Suande oder an Felsen anlhaten (de scaris, anthis, exococto, mugilib. $e$. c), fäht mii ren Fluls- and Teichfischen fort, und schliefst mit den Cetacten, endlich mit dex Beschroibung, dor Seeungeheuer.

Belon. Hat Votton mehr aus den Schriften des AriRon- stotelos geschüpft, so nehmen sich seine Nachfol-
delet. Sal- fer nelu dic Natur zum Ninster, Plinius aber zu viani، ihren Fiarer. Die beiden Fıanzosen Belon und Rondelet, welche zu glcicher Zeit ein Werk über die Wasserthicre herausgaben, trugen sowohl zur Vermehrung der Anzahl, als auch durch die ge. renen nach der Natur gemachten Holzstiche zur nähiercn ficuntnifs der Fische bei; jedoch das $S_{y-}$ stem gewann durch sie wonich an Vervollkommo 
numg. Dem Gange des Plinius gemäls beschreibt Delon in scinem Werke ,aquatilia" betitelt, in crsten Buche die Fische, in zweiten die Thiere olne Bhit als: Polypen, Frustaccéen und Conchylion. Fon jenen handelt er znerst die grofsten und sonterbarsten Gestalien ab, und zwar im ersten Fopich die Celacíen - im zweiten die Thiere, so im Vasser und anf dom Lande zugleich leben, als: Phoka, Hippopotam, Meerpferd, Biber, Fischotter, Thasscratte - in dritten die Meerwunder: Tritonen, Sirenen, Najaden, Nereiden und den Mecrbischof - in vicrten die Amphibien, velche Füse haben mal Wier legen: Nilcrocodil, Ichneu. non, chas lirocodil von Arabion (stellio spinipes?) Scink, Fordyl, Mocrschildhröte, Frosch, Tameleon - im füfen die lebendige Jung gुebähren. den linorpelfische und zwar die länglichten : carcharias, zygaena, pristis, vulpes, catulus, petromyzon - in sechsten die breiten: squatina, raja, lophius, torpedo, lamia - in den folgenden die Grätenísche, welche auch Eicr legen, und zwar in siebenten und achten: sturio, silur. thymmus, merluccius, morrhua, aselli - im neunten die platten: pleuronectes, solea, antria, - im zchnten die schlangenartigen, die ron run. der und langer Figur sind: draco marinus (ophisurus?) myrenis (murenophis?), belone, sphyraena - im eilften jene, welche mit Schuppen 
bedelt sind, und sich in der hohen See aufhalten: clupea, trigla, pelamis, hirundo exocoetus. iyra - welche am Gestade leben: uranoscopus, callionym. blennius - im zwölften jene, welche die Nähey der Felsen lieben: sparus - in dreizohnten dic Fische in Flïssen und Teichen: cyprin. salm. alburn. tinca, esox, orbis. - Das zweite Guch enthält die blutlosen Thiere des Aristoteles.

Pondelet unterscheidet sich blos durch dic $\mathrm{Ab}$. änderung, welche er in der Aufeinanderfolge dew mänlichen Ảbheilungen scines Vorgängers macht. 'Vas bei Belon zulezt, steht hier am Anfange; er bicginnt mit den Schuppenfischen, welche sich am Gicstade und an Felsen aufhalten, und schliefst seine creten sechzehn Bücher mit den hinorpelSischen und Cetacéen, die blutlosen Mollusken, Irustacéen, werden hicranf in den nachfolgुenden beschrieben. Weitläufiger aber als jener, sezte er gleich im Anfange die manchfaltigen Thterschicde aller Fische auscinander, beschrieb diese sehr genati nach der Natur und fügte seinen umstindlichen Beschreibungen eben so zahlreiche nnd richtige Holzstiche bei. Die nämliche Geschichte der Fische von Rondelet, suchte bald hierauf Boussuet in dem Werke "carmen de natura aquatilium" sowohl durch Holzstiche als wenige Verse, worin er die Nahrung, Lebensart und Nutzen jedes Fisches besinget, wiederzugeben. 
Zu glcicher Zeit lieferte Salviani ein Werli, ins titelt: "historiae aquatilium " von welchem nits der erste Band erschien, und die lische in 5/4 11 istorien beschreibt. Seine Beschreilumgen l:cm schänken sich aber mehr auf die granmotikatische Erliärung und Synonimie der Nanen. Die einzelnen Historien tragen selien eine andere $\mathrm{A}$ ufschrift als die des abzuhandelnden Fisches, und nur zuweilen liest man die Ueberschift: "platte Fische, Steinfische;" ja die woichen Wassertiere, als $l o l$. 7igo, polypus sind in der Mille derselben aufoem zählt. Jedoch crsiehi man aus dem Gange der einzelnen Ilistorien, dafs er sich in der Aufemon derfolge durch lie rerschiedenen Figmen, welntuc die einzeluen Fische anzeichnen, leiten liefs: So beginnt er nil lünglichten Fischen - den Aalen schrcite hieranf zu breiten - Salnen, harpfen - endlich zu den breitesten - den Rajen. Sind. anch die Beschreibungen nicht so rollstündig als die des Rondelet, so stehen doch scine Holzsticle jenen nicht viel nach.

Haben diese drei Natuxforsches die Ichtyologie durch ihre Beschreibungen nach der Natur, und durch itre instrulitiven Folzstiche bereichert, und gleichsam den Grund hiezu geleget, so thum dieas Gessner und Aldrovand in Minsicht der Litteratur dieses Faches, Sic nahmen die Holzstiche diesz Vorgänger in ilne Tierlic auf, und statteten itue 
Beschroihungen mit litterarischen mi grammatikas lischen Benerhungen aus allen Schrifistellern ans. Was die innere Ordnung angeht, so wich Gessner in der ersten Auswabe nicht im geringsten ron der alphabetischen ab, und astac. baluena, buccin. cancer, castor, phosi, salmo scolopendra, scinil7a, testudo, tethys u. s. w. folgen in solcher Reihe aufeinander. Nur in der dritten rom Jahre 3666 liefs or bei den Fischen das $\lambda$ phabet ausser Acht, und theilte sie nach ihrer Figur und ibrem Aufenthalie (pisciculi malla certa formu comprehensi - saxutiles, lyriformes, lati, rolundi, longi, plani, cartilaginei u. s. w.) ab.

Aldrovand zeigt sich zwar anch als Anhänger des Plinius, indem er nach den Vägeln ohe $\mathbf{U}_{n-}$ terschied alles abhandelt, was im VVasser lebt; jedoch blieb er der Aristotelischen Ansicht, wie in seimen übrigen Schriften anch hier darin getreu, dafs er den Hippopotam, Fischotter, Biber, KroLodil ron den Wasserthieren ausschlofs, die Mol. lusken, Krustacéen, Conchylien und Inscliten zu den blutlosen Thieren rechnete, und gleich in der Vorrede zu den Fischen die Abtheilung machte: „unum aquatilium est, cui natura pulinones, alterum, ai branchias tribuit." Diesem Grund. salze gemäl's handelt er ron den Cetacéen, wobei $\mathrm{ev}^{2}$ auch die Pholia und den Sägefisch aufzählet, in einem eigenen Lande; die übrigen Fische aber son- 
dert er in fïnf Büchern nach ihrem Aufenthalte ab, und zwar in Steinfische: saxatiles (scar. glauc. unthias, gobius) - in jene des Ufers: lit. torales (mullus, hirundo) - in jene des hohen Mepres: pelagii (squamosi: aselli, hareng. non squamosi: carcharias, amia, xiphias, remora, muraena, zygaena, mola und dis sonstigen limorpelfische) - in jene, so im Meere und Fluissen zugleich (salm. petromyzon, orbis, ostra. cion) - oder blos in Flüsen (fluviatiles) leben. Dem Aldrovand folgte, wie immer, auch hier Jonston getreulich nacil.

\section{72.}

Nicht ohne Bedeutung ist das Gewässer und scine Tiefe, wclche rerschiedene Fische bewohnen, eben so die Gestalt, wodurch sich verschiedene derselben auszeichnen. Die Knorpelfische leben gröfstentheils im Meere und zwar an den tiefesten Plü:zen der hohen Sce, und nur die Tetrodon, Lam• preten und Störe halten sich auch an den Mïn. dungen der Flüsse ins Meer auf; die Grätenfische leben theils im NIecre, theils in Seen und Flüssen - sparus centrodontus, coryphaena dactylifera werden zu 500 bis 800 Fufs tief aus dem Meere gefischet. - Die Triglen, Scorpaenen, Trachinen werden blos aus der Tiefe auf hoher See zur Beute. - Die Aalrutte wird im Winter nur von 
dem Nietze, wolches bei tausend Fuls tief im Ses von Genev hinabgelassen wird, erreichet - nach Delaroche's Angabe gewährt noch eine Tiefe von 1665 Ful's Ausbeute an Fischen a). - Der Kurl und die Schleihe lieben schlammigte Teiche, die Forellen seichtes ()uellwasser. Ja die meisten Fische wechsehn mit der Jahreszeit, mit dem Tage odur der Nacht ihre gewöhnlichen Standorle: Die Hüringe beginnen ihre Vancierung mit dem Frühling, und hommen von Norden her mit den Junius an schwedische, englischc und hollindische fiusten Die Stohfisclie und Störex rerlassen wit dem Mai das Meer, und wählen die Mündungen ron Flïssen - Die Lachsed werden in Fliissen ausgebruitet, erwachsen dann im Meere, und ströncn cndlich wieder ins reiferen Aiter, zur Herbstzeit, den ersteren zu. - Die Aeschen steigen in Czirlinitzer See in hrain jählich durch viele grofse Löcher unter der Erde auf und ab, gehen weg und lommes wieder. Eben die Laichezcit ist es, welche wic in den Fischen des Meeres, auch in denen dex Flïsse und Seen die Wanderung an scichtere Plä. tze veranlasset, un hier das Werk der Fortpfland zung zu vollenden. Freilich ist so der Aufenthalt an tieferen oder seichteren Stellen des salzighen oder süfsen Wassers ein wichtiger Moment zur

al) Observations sur des poissons aux iles Balcares et Pythiue ses par Delaroche. Annal, du mus. T. 13. p. 15. 


\section{$-539$}

Charahtrisirung dex Fische, ja beinahe könnte man es als cin Gesetz anfstillen, dafs die Fische, in je seichlerem Gewässer sie leben, um decto ausgcbildeter dic Form ihrer lilasse an sich tragen, cinen um so härteren Grätenban haben, und schon den Anphibien und Iandthieren zustreben, je mohr sic sish in Gegentheile in Meere aufhalten, desto unförmlicher ihre Gestalt sey, desto mehr sie sich im liane den Kinorpelfischen nähern; AlIcin wer getraute sich alle diese Grade der Ticfen zu bestimmen? wer so gerade auszumitteln, ob dieses cin Meer-Flufs - oder Seefisch sey, da schr wicle ron cinem Gewässer in das andere wechseln? When so wenig ist es die Gestalt des hörpers, wornach sich die rerwandtesten Fische gruppiren liefen. Zwar herrsch: bei den horpelfischen eine Ihüufgere Manchfaltigheit ron geometrischen Figu* ren: Die Raien sind plattgedrükt, und liegen horizontal auf dem IVasser auf, - dir Squalen, Lamıpreten sind schon zugcrundet, und länglich - die Secteufel, Sccpferdchei, Ostracion, Cyclopteren ઔ. s. W. wolch sonderbare Formen ron Gestalten stclien diese dar? Unter den Grätenfischen sind es blos dic Pleuroncliten, welche horizontal auf dem Wrasser schwimmen, alle übrigen, seycn sio alich, wie die Trichimen, Amodyten, Stromateus, Gihactodon, Rrachsen, Karnfon mehr nash den

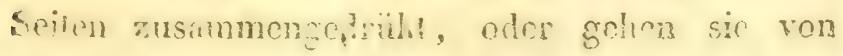


hier aus in die mchr zugerundete und länglichte Fignr wie die Salmen, Siluren, Aale ülsen, durchschneiden in rerihider Richnng das VVasser. Allein wollte man sich ausschliefsend an die Figir der Fische lattran, so müficn linorpel - und Grä. tenfische durcheinander geworten, und die rerwandtesten ron einander getronnt worden, und wer getraute sich selbst das Mehr oder Veniger in der Verwantschaft zu bestimmen? Immer werden also der verathiedene Auffuthalt, und die revschiedene Figur, hedeutende Mcrlmale zur Cha. rahterisirung der Fische bleiben, aber nienals als die einzigen und wesentlichsten heransgchoben werden können.

$$
\text { 5. } 73 .
$$

Wotton Bisher hat die Ichtyologie blos am Inhalte und Ray. einzelnen Peschreibungen gewonnen. Willughby und Ray sind die ersten, welche es wagen, diesen Inhalt auch unter eine allgemeine Form zu bringen. Wohl einsehend, in welches Chaos sich dieses Fach durch die Plinimische Ansicht rerwicliclt hatte, nach welclier Fische, Conchylien und Polypen in eine einzige hasse ,Aquatilien“ genannt, zusammengeworfen wurden, leitete Ray nach dem Reispiele Wotton's den Aristotelischen Weg ein, und sonderte alle weisbliitign Thiere ron den Fischen dadurch $a b$, dafs cr diese ais solche nit rothom 
Blute, mit Flossen statt Füfsen, mit naliter, rau* her oder schuppichter Haut, und inmer in Wasser lebend definirte. Zur Bildung der Ordnumgen wählte or die Respiration und Zengung, zu jener der Familien und Gattungen die Gestalt des Körpers, und die Anzahl der Rüclienflossen, und erhielt so folgendes Schema:

Pisces.

- pulmonib. respirantes (cetacci: erientati. (baluena) dentati (delph. phocacna, orca).

- branchiis respirantes:

1. ova magna concipiunt - cartilaginci -

- longi: squali

- plani: raia, torped. squatin.

- anomali carlilagincis affines: lophius

2. ova parva concipiunt - plerique ossei -

- plani: pleuronect. solea.

- dorso erecto natantes

A) zonico pinnarum pari, pinnis ventralibus carentes:

a) anguilliformes: muraena, lamprella.

b) corpore contractiore: orbes.

B) radiis pinnaruin dorsalium flevilibus:
a) dorso tripinni: aselli
b) - bipinni: merlucius, thynnus, scomber.
c) - unipinni
* radiis mollibus: uranoscop, per- cal, zeus, clupea, acus, luciug, ac- cipenser, hugo, cyprin: 


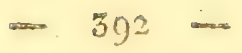

* anterioribus aculeatis, posterioribus mollibus: scarus, scorpaena *** radiis omnibus spinosis: americani.

- prisces incrrtae sedis: indici, annericani jarnaicenses.

Ray ist der erste, welcher durch scin Beispiel zeigte, dals die Fisclie nichr nach der Gestalt ihres Dinpers oden wach dem rerschindenen Aufeut. halte natiulich abgetheilt werdeis honnen. Fr be= nuzte dafiu die bisher angeregten Unterschicde zach den I angen und Branchien, nach den knorpe dichten oder grätichten Sliclete, ja er that schon der Cetacren bei den behaarten Qn drupeden Er. withmung, mò̀ erimnerte, dafs er sie hicher lersetzen würte, wenn er nicht alle Neuerung verneiden wollte. Gerno hätte or anch jene Abtheinug nach dem skclete unverïndert beibchalten, hättc er nicht den Einwurf refuhlt, dals cinige Tinorpelfische, wic z: B. die Stören, keine lebendige Jungen, sondern, wic die meisten Grätenfische, Eier zur Velt bringen. Er sonderte daher in der Herausgibe der Fische des WVillughby die lebendige Junge gwhihenden von den cicrlegenden ab, und erst später, nachdem or fand, dafs blennius vivipara, anuraen, anguilla Junge statx Eier gebähren, verbesserte or in sciner Synopsis der Fische diese Dïcke, und theilte sie zusammen in solche, wclche grofse oder klcine Eier herroibringnn, ab. 
Allordings sind die grofsen, platten, an den ries Ecken in lange Höncr auslaufenden Eicr, da diese sonst bei allen Thieren eine mehr rundliche Form haben, ciil auffallendes Phänomen an den Squalen und Rajen, und die Natur selbst, scheint es, wolle diese Thiere so wie durch den monströsen Iïrpexbau, auch durch diese monströsen Eier auszeichnen. Jerloch, so auffallend auch dieser Unterschicd it, so bringt er, zum Hanptgesichtspunlite gemucht, doch dis grörste Tnorduung in diese Cilasse, indem die übrigen Finorpelfische zu den Grätcnfischen geworfen werden müssen, mol hei Ray wirlilich dic Lampreten, Stören, Meernadel, unter den lezteren herumiren, während dic Lophien, obwohl sic lileine Eicr legen, zu den ersteren gerechnet werden. Vichtiger als alle dice LuterEchiede ist jener nach der Z Zahl der Rüichenflossen, wolchen or als der crste bei den Grätenfischen einfiblrte. Twar giebt auch disser licincn bestehen" den Charaliter ab, indem sich unter gaclus, blennius viele finden, welche 1, 2, 5 Rüiclienflossen buben, und somit ron cinander getremnt werden müften; allein Ray blcibt bei solcher noch obwal. tender Verwivung doch das Verdienst, seino Nachfolger auf dicsen iczteren Gesichtspunlit auf merksam gemacht zu haben.

Mas nïmliche System Ray"s, wie es in der Ausgate des Millighby stcht, wiclerholdt Daleius in 
semer Pharmaliologic, und merket nur bei den Aalen an, dafs sie zwar nicht am Banche, aber zunächst den Branchien Flossen haben.

Artedi hringt endlich Ordnung in das bisherige Chaos der eigentlichen Fische. Er hielt sich genau an die alte Abtheilung der Cetacéen und der ibrigen Fische, unterschied jene von diesen durch den breitgedrüliten Schwanz, sonderte diese in hnorpel- und Grätenfische, dic ersteren ferner nach dem Mangel oder der Anwesenheit des Kiemende. hels, die lezteren mit Ray nach den weicheren oder stachlichteren Rückenflossen folgender Gestalt $\mathrm{ab}$ :

I. pisces cauda perpendiculari s. Catheturi

A) pinnarum radiis osseis

a) branchiis ossiculatis

1. malacopterygii (pinnis inermibus)

- pinna unica in medio feredorsi (synginath. cobitis, cyprin. clupea, argentin. exocoet.)

- pinna zinica in medio et unica postica dorsi (coregon. osmer. salmo)

- pinna unica in extremo dorsi (echeneis, esox)

- pinna unica, pluribusue per totum dorsum extensis (coryphaen. amodyt. pleuronect, stromateus, gad. anarhich)

- pinna unica longa, vix a cauda distincta (muraen. ophidion.) 
- pinna exigua unica in extremo dorsi vel nulla anableps, gymnot.)

2. Acanthoptery gii (pinnis osseis)

- capite glabro (blennius, gobius, xiphias, scomber e. c.)

- capite aspero (perca, trachinus, trigla, scorpaena, zeus e. c.)

b. branchiostegi (branchitis ossibus destitutis)

balist. ostracion, cyclopt. lophius.

B) chondropterygii (pinnis cartilagineis).

II. pinces cauda horizontali (plagiuri: delph. bataen. siren e.c.)

III. appendix pisces indispositos continens: silur. phycis, taenia $c$. $c$.

Zwar ist die Unterscheidung der Cetacéen von den übrigen Fischen durch den plattgedriliten Schwanz unwesentlich, und liomm zum Theile? auch den Pleuronehten zu, die stachlichten Rï. clienflossen zeichnen nur rorzüglich die Scorpe. nen, Barschen und noch einige andere ans, und machen bei verschiedenen Arten der gasterosteus, blemius, scomber u. s. w. Ausnahmen; Allein durch die Alhtheilung nach den Finorpeln und Grüten, nach der Anwesenheit oder dem Mangel des Fiemendechels, ist Licht und Ordnung in die Hauptgruppen der Fische gekommen. Nur ist es Schade, dafs er diese Andeutungen nicht strenge durchgefithrt. und z. B. die Neernadel und die Branchiostegen untor dic Gritenfische gezithi hat. 


\section{$-396-$}

Jedoch Artcdi war nur bestimmt, die sichtharsten Ï̈rchen Ray's zu rerbessern, und die Grundlinien zu cinem Systeme zu werfen, welches sein Nachfolger blos weiter zu läutern und auszuführen brauchte ${ }^{a}$ ).

\section{74 .}

Linné. Was Ray begonnen, Artedi aber unrollständig gelasien hatle, führte cndlich Limné weiter aus. Er blich bis zur zehnien Ausgabe seines : ystenips sowohl in der Benennung, als Anzahl der Ordnumgen und Gattungen dem Lezteren ganz getreu, vind änderte mu in etwas dic Aufeinanderfolge derselben (plagiuri, chondropterygii, branchiost.egi, acanthopterygii, malacopterygii). Er ist aber der erste, welcher die Branchienhant ron dem Kiemendechel unterschied, und die Stellung der Flossen nach dem Bauche, Halse, der Brust, dem Schwanze oder Rüchen, die Anzahl der Radien in den Flossen und der Kiemenhant nebsi der Manclıfaltigkeit der Zähne, schon ron der ersten Ausgabe an, bei jeder Grattung anmerkte. Allein die zehnte Ausgabe bezcichnet auch hier seine Tiatastrophe. Von dieser Zeit an sezte er die Plagiuren unter dem Namen „Cetacéen“ zu den Säugthieren, die Linorpelfische, von denen er fülschlich

a) Artedi Bibliotheca et philosophia ichtyologica. editio Walbaumii Grypeswaldiae 1789 . 8 .

- Synonymia piscium-edirio Schncideri, Lips. 1789. 4. 
nebst den Branchien auch Lungen muthmassic, als Amphibien (amphibia nantia) zn den lieptitien, ja in der zwölften ging er gar so weil, duls er auch die Branchiostegen, mit Veglassung dieses franeris mit jenen vereingte. Eben in dieser Ausgabe, der zehnten nämlich, zcigte Linné sein eigenes Verdienst in Hinsicht der linorpelfische, ind'm e' die unter den Grätigten bisher zerstreuten (den syngnath. pegas, ientrisc.) zusammenlas, nit den Brancliostegen rerband, und in der zwölften auch den cyclopter. hinzugesellte, den mornyr. hingegen zu den Grätenfischen zurüliversezte; in Hinsicht der Leztern aber, welche bei ihm alleinig die Fiasse der Fische ausmachen, hier trat er in sciner Originalitit, und als Schöpfer cines neuen Systemes auf. Ray hatte schon nach der Zahl der Riuckentiossen abgetheilt, und ron den Aalen anzemerlit, dals sie heine Bauchflosscn, Daleius aber, dafs sie Flossen zunächst den Branchien ha. ben, Linné selbst hatte schon in früheren Ausgaben die Unterschiede einzelner Gattungen nach der Stellung der Flossen bemerket, und nun die Artedische Eintheilung in Malacopterygen und Acanthopterygen reilassend, hob er diese selbst als Grundlage eines Systemes heraus. Er benennte die Flossen nach der Lage des Förpers, nahm die Bauchflossen zum einzigen Gesichtspunkte, und bildte nach der Abwesenheit derselben (upodes) 
und nach ther Gegenwart und zwar, so fern sie vor den Lrusillossen (jugulares) oder hinter den lezteren (thoracici) oder noch weiter zurüli am Banche (abdominales) stehen, diese vier Ordnumgंen. Die Benennungen und die Aufeinanderfolgge der Lezteren sowohl als der Gattungen, blieben sich durch alle Ausgaben gleich, und nux in dex zwölften sonderte er die cepola von dem ophidion ab, versezic sie ron den Brustflossern zu den Apow den, und bereicherte das Ganze mit viclen nenen Arten und Charakteren. Gmelin liefs dic Grätenfische Lime's in de' dreizehnten Ausgabe unverandert, remehrte sie blos mit einigen neuen Gattungen z. B. slemoptyx, leptocephai. liurtus, centroguster u. s. w., und mehreren Arien, vereinigie wieder die Kinorpelfische und Branchioste. gen mit jencn, nachdem schon die meisten Schriltsteller dem ersten entscheidenden Urtheile Cannper's gefolgt waren ${ }^{a}$ ), und wiederhohlte unter solchen Abänderungen das Linnëische System der Fische folgender Géstalt.

Pisces.

1. apodes (pinnis ventralib. nullis: muraen. gymnot. trichiur. anarhichas, ammodyt. ophidium, stromateus, $x i$ phias, sternoptyx, leptocephal.)

a) Camper in den Schriften der Berliner Gesellschaft, Bd。 $\%$ S. 197. 
s. jugulares (pinnae ventrales ante pinnas pectorales: callionym. uranoscop. trachin. gad. blennius, kurtus.)

5. thoracici (piun. rentr. sub) pinn. pector: cepola, echeneis, coryphaen.gobi. cott. scorphaen. zeus, pleuronect.chaetodon, sparus, scarus, labris, sciaena, perca. sasterost. scomber, centrogast. mullus, trigla.

3. abdominales (pinn.ventr. pone pinn.pect. cobitis, amia; silur. teuthis, loricaria, salm. fistular. esox, elops, argentin. atherin.mugil, exocoet.polynem. clupea, cyprin.)

5. Granchioslegi (branchiis ossib. destitutis: mormyr. ostracion, tetrodon, diodon. syngnath. pegas. centrisc. balist. cyclopter. lophius.)

6. chondropterygii (branchiis cartilagineis: accipens. chimaer. squal. raia, petromyzon.)

Es ist nicht zu läugnen, dafs die Flossen unter allen bisherigen Gesichtspunkten die am meisten natülichen Abtheilungen gewähren, obgleich sic nicht, wie man bisher glaubte, der wesentliche Charaliter der Fische sind, indem der apterychtus coecus gar keine, und lüngst den Rücken liaum 
die Spur einer Nath hat. Allein dam hälle Linne sein Augcumerti nicht blos auf die Bauchlossen. wodurch er consequenier nur zwei Orbungen, nümlici solcher, dis jene haben (peduti) oder nicht (apodes), erhieito, sondern auf alle zugleich richten sullen. Fein Wundex ist es daher, wenn or für diese einzigen eingenommen, scinem Prino zipe ginz widerspricit, und selbst bei den Hals. flossicrin die ror den Brustlossen stehenden, Banchílossen nenuet, während weder er noch andere die Gegend zwischen brust und hont an Fi. schen die des Bauches nemnen wird. Gesezt aber auch, dais dieser Irsthum in der Bencmming doz' Flossen gehoben wird, die eroteren Mlossen rom Kopfe her immer die des Halses and der Binst, june hinter diesen die des Bauches betitelt werden, so bleibt es loch öfters ein zwcifelhaftes Unternel:men, nach dem Mehr oder Weniger der benachbare ten Stcilung der Hals - oder Brust - und der Bauchflossen, die Ordnung des Fisches zu besimnen. Von welch lileinen Nïunçen solche Unicrscheilung abhüngt, ersieht man anch daraus, dafs späterhin Gronuir die Hals - und Brustflossler in eine Ord. nung zusammen vercinigte und Scopoli lant be= liennet: nec limites certos inter pisces thoracicos et jugulares natura ubique constituit a). So

a) Scopolo introducto in laistor, patur. po $44 S_{0}$ 
vortrcflich aber demohngeachtet diese ricue An: sicht bleibet, so hat es Limné doch unterlassen, die Rangordnung der Flossen und somit seiner Ordnungen darnach zu bestimmen, eine Lïclie, welche er seinen Nachfolgern auszufuillen übrig liefs:

\section{75 .}

Von nun an wurde das Linnéische System allen Werlien über Fische zu Grunde gelegt, und alles bestrebte sich, dasselbe zu verbessern. Jedoch Tllein, welcher seine zwölf Fascikuln über Fische gerade zu einer Zeit herausgab, wo Linné noch ein getreuer Anhänger Artedi's war, machte am wenigsten von seinem Systeme Gebrauch, und hielt sich ebenfalls mehr an Artedi. Dem Lezteren gemäfs theilte er sie nach dem Respirationsorgane in solche mit Lungen (Cetacéen), mit verborgenen Branchien (Uranchiis occultis: pisces cartilaginei), mit gewöhnlichen Kiemen (branchiis apertis: pisc, ossei) ab. Die Knorpelfische sonderte en nach der Anwesenheit oder dem Mangel der Flossen, dam nach der Anzahl der Luftiöcher (xad latera - pirnata: - spiracul. quinque: galeus, cynocephal. rhina, - spiracul. unico: batrachus, conger. - apennia: muraen. petromyzon. ** in thorace pinnata: rhinobat. e.c.). Von den Grätenfischen enthält der erste Fascilie! diejenigen von schlangenartigem körper (anguis 


\section{$-402$}

form.), der zweite jene mit langem Schnabel (notabiliter rostruta), der dritte die platten, durch die Stellung der Augen merlwürdige folani et uclilati), der vierte die an der Brust bewaffneten (thorace notabiliter armali) der füfte und sechste jene durch liopt und brust sonderbaren, der siebente den tripterus, der achte den pscudotripter., der nenute bis zum zwölften die Gathungeu dipter. pseudodipter., monopter: pseumionopter:- Obgleich lilein nanche nicht nuwichtige Charalitere in seinen Fascilieln anfuht, und das Gehör der Fische lä̈̈tig gुegen die Einwürfe der Franzosen rortheiliget, so scheint er doch hierin mohr als irgendwo in die Sucht, originell zu crscheinen, ansyeartet zu seyn, indem er beinatie so viele Ordnumgen als es lische giebt, und zwar unter ganz nenen Benennumgen zu bilden strebte. Fin gleiches gilt anch ron A. J. C. Schüffer, welcher in scinem Briefe über die Methode in der Ichtyologie grörstentheils die Kleinischen Ordnungen und Benennurigen wiederhohlet.

Gctrener als Klein hielt sich Gronow, welcher so wie reich an naturgeschichtlichen Produliten, dienfalls an naturgeschichtlichen Kemntuissen war, an das System des Limé. Zwar beschrieb er in seinem friheren Verke a) die Fische seines Kabi-

a) L.iar. Theod. Cironovins. Museum ichtyologicum sistene piscium. Lugduni Batavorum 1754 . 
nettes unter der nämlichen Anzahl ron Ordnungen wie Artedi; allein in seinem Zoophylacinm schlofs er sich ganz an Linné an ${ }^{a}$ ), und wich nur darin ron demselben ab, dafs er die Cetacéen und hnorpellische zu den eigentlichen Fischen zählte, die gräticfen ,branchiales" nannte, die Hals - und Brustflossler in cine Familic zusammenzog, und diese und die Bauchflossler ferner nach der Zahi der Rückenflossen unterschied.

Brünich, welcher durch die Monographis der Fische ron Marseille dieses Fach bereicherie, durch seine falschen Bencummgen aber leicht Irrthümer veranlafste, wählic den Linné ganz zu seinem Muster. Er liefs die Cetacren weg, ïberschieb die Cliondropterygien (spiraculis thoracis lateralib.) und die Eranchiostegen (apertura li. nearis) nit dem Titel, von unvolliomnenen Branchien (branch. incon?p)letis), die Grälenfische aber mit jenem von volliommenen (b. completis) und handelt die lezteren, eben so vie Limné, als Flossenlose, Hals - Brust - und Bauchflossler, dic cinzelnen Züufte selbst aber als Malacopterygen und Acantoptrygen unter gleicher Anzahl und Benennumg der Gattungen, jedoch mit verändertek Aufeinanderfolge der Lezicren ab.

a) Lanr. Theod. Gronovius. Zoophylacium exhibens animalia guadrupeda, amphibia, pisces e. c. Lugd. Batayor. 1782 ,. 
Gotuan $\left.{ }^{\circ}\right)$ rechnete die Cetacéen und Finorpelfische zu den Amplibien, und behielt für die Grätenfischic die Veründerungen seines Vugängers bei. Auch bei ihm sind leztere nit "bran hiis completis" überschrieben, die Acanthopterygen und Malacopterygen aber als Hauptgesichtspunkt, und die Unterschiede nach den Hals - Brust - und Bauchflossen oder nach dem Mangel der lezterer als Unterabtheilungen benutzet.

$$
\text { s. } 76 \text {. }
$$

Scopoli.

Limne hate durch dic Bestimmung der Flossen nach ihrer Lage, dic Aufmerksamkeit auf das Verbältuifs der einzelnen Thcile des Körpers an Fischen rege gemacht. Scopoli dadurch aufgewelit, wählte den Anus zum Verglcichungspunlite, und bildete darnach folgende drei Ordnungen:

Gens. 1.

ano inferiore so caudae plus minusue ap. proximato

a) pinna dorsali unica:

- corpore oblongo (clupe. cyprin. erythrini mormyr. elops. callyodon. holocenthr.)

- corpore teretiusculo (fistular. xiphias. esox, cobitis, anableps, argentin.)

b) pinnis dorsalib. binis: salmo, mugil e. $\hat{\text {. }}$

a) Antun. Goüan. Fistoria piscium, Argentorati $17 \% 0$ 
Gens. 2.

ano superiore so copiti plus minusve approximato.

a) edentati: Toricaria.

b) dentib. in lingua. palato. maxillis: echeneis.

- in maxilla et faucib: gymnotus, pleuronectes, silurus.

- in maxilla: gad. blenn, trachin. scomber.

Gens. 3. ano medio

a) abciominales: exocoei. amia, atherin.

b) Ihoracici: scraen. pholis, scorpaen. trigla, perca, zeus, gobius, cepoli, coryphaen. gasterost. labr. chaetod. spar. e.c.

c) apodes: stromatens, anarrichas. trichiur. ammodyt. murcien.

Nicht zu gedenlien, dafs Scopoli die Lnorpelfische ans der hlasse der Fische wegliefs, und zu den Amphibien rechncte, so ist auch dieser neue Gesichtspunlit nichts weniger als gegründet, und zer* reisset nicht nur alle natirliche Bande, sondern dicnt nicht einmal selbst zur Bezeichnung von Familien, noch viel weniger der Ordnungen. Beinahe hann man bchauptcn, dafs die tange des Anus unter allen Theilen des Fisches am meisten dem Wechsel unterworfen ist. So hat ihn der silur. rho:nbus in der Mitte, der sil. bifasciat, mehr gegen den Schwanz, der sil. bimaculat. und hairechus mehr gegen den hopf zu; noch wein wecha 
soll er bei scomber, ja der sr. sardus hat ihn nicht mehr gegen den hopf, sondern den Schwanz zu; bei scorpaen. und labrus liegt or nicht in der Mitte, sondern bei den meisten mehr nach hinten, bei dem labr. Latifusciat, aber ganz nahe am liopfe; noch auffallender ist diese Lnbestündigheit bei blemius, zeus, chaetod.; ja bi chaet. teira liegt er vorwärts, bei echeneis nancerate (Lacepede) in der Mitte, bei echen. remora mehr nach hinten, bei cotius monopterygius nicht in dex Mitte, sondern ganz nach Vomen u. s. w. Welche Unordnung und Widernatirlichlicit entstïnde so nicht, wollte man endlich gar noch strenger, als Scopoli, alle Nüançen, wie der Anus ron dem gymnot. trachis. ophidium, pleuronect. bis zu zhurenophis und synbranchus von Vornen nach Hinten allmählig zurïliweicht, durchfïlren.

\section{ऽ. 77.}

La- Nummehr waren die Fische nach ihrem Aeusscren so ziemlich gekannt. Was Aristoteles für Unterschiede angeregt hatte, wurden beinahe alle geprüft, und durchgefihret. Die früheren Ichtyologen haben ihre Gestalt und ihren Aufenthalt zur Untersuchung herausgehoben, Wotton und Ray llaben sie von den übrigen Wasserthieren als eine eigene Klasse abgesondert, Lezterer hat auf den Unterschied der knorplichten und grätigten, anf 
die Figenschaft Fier zu legen, und lebendige Junge zu gebähren, anf die Rivichflossen, - Artedi auf die Anwesenheit oder den Mangel des Kiemendecliels, - Limné endlich auf die Unterscheidung des liiemendeckels von der hiemenhaut, und auf die Zahl und Stellung der Flossen - anfmerlisam gemacht. - Danbenton hat in der Encyclopedie die Inorpelfische mit den Grätigten in eine Flasșe verbunden, und ist sonst dem Systeme Linnés gefolget, Bonnaterre ganz dem Beispiele dieses scines Vorgängers getreu, erweiterte hierauf dicses Fach in dem "tubleau encyclopedique et methorlique" mit vielen neuen Arten und Charahteren aus allen möglichen Schriftstellern. - Rondelet, Salviani, Willughby, Seba, Katesby linferten Abzeichnungen und Beschreibungen ron den Fischen, unter mehreren Vonographen stellet sich endlich Bloch durch die Menge vortreflicher Kupfer und Bcschreibungen der äusseren und zum Theile anatomischen Theile gleichsam als Commentator des Iiméischen Systemes, welches er nebstbei mii rielen nenen Gattungen und Arten vermelirte, als Vereinigungspunlt und als Grundlage für a!ls? kiunftige Beabcitung der Fische hin ${ }^{a}$ ). Auch das Innere fing allnählig an uniersucht zu werden.

a) Bloch ökonnmische N. G. der Fische Teutschlands, Borlin 1,-82. III B. 4 .

- dessen ausländische Fischo. ibio, 1785. IX. D. A. 
Duremey that die Circulation des Blutrs am Karpfen dar, wie nämlich das Blut der Hohkadem ron den einzigen Herzohre und V'chuikel (Ilerz) auf genommen, durch die einstämmigte Lumgenarterie in die Branchien gefwhrt, und endlich sach Gemeinschaft mit der Luft durch mehrere Lungenvenen, die sich bald zu einem Stamme gleichsam zu einer gemeinsamen Aorte vereinigen, wegen des Mangels cines artericllen Herzens sogfoich in den übrigen hïrper ausgetragen wird. Fölrenter nud nach ihm Camper entdehten das Gehörorgan der Fische. Ilunter und Vica d'Azyr bestätigten diese Entdeckungs, and Lezterer machte in zwei $A b$ handlungen uber fie Fische, vortreffiche Bemerlimgen über ihren Lnochen - und Muskelbat. Willis und Collin machien Untersuchungen viber die Beschaffenheit der Gehirne der Fische, Lorenzini über die Geschlechtstheile derselben. Goüan, wenn gleich nicht so gliklich in seinen Deutungen, verglich die einzelnen Theile des Fischskeletes mit dem des Menschen. Haller, Camper und Sömmering legten ihre Beobachtungen über die manchfaltige Kreuzmog der Augennerven nieder. Monro brachte endhich mehr oder weniger alle diese Beobachtungen so wie auch dic der Geschlechtstheile in seinem Werke über die Physiologio der Fische zu. sammen, und liefs sich hier vorzüglich, wie auch Hewson, über die lymphatischen Gefäfse, die sie 


\section{$\rightarrow \quad 409$}

boide in diesen Thieren cntdekien, aus ${ }^{a}$ ). Carn. per hatte schon in seinen hileineren Schiften über die Nerven gesprochen, Scarpa nahm endlich in seinem rortreflichen Werke über die Organe des Geruchs und Gehöres aller Thiere, bei Gelegenheic der Fische dieso und dann das Gehini mit semen Nerven, zum Gegenstando gründlicher Untersuchungen und Abbildungen. Ueber die Funlition dor Schwimmblase endlich, welche bei einigen ganz mangelt, bei anderen in Magen oder in cilis Speiseröhre einmündet, oder auch ohne allem tus. gange ist, wurde, wie ebenfalls üher das Vipernoift mohr rersucht und geschricben, ais über alle $\mathrm{F}$ sche selbsi. Needham liefs die Luft ron des Schwimmblase in den Magen zup Verdaumg, Vicq d'Azyr ron diesem in jene zur Aufsarigung und Ernährung strömen. - Borelli and mit ihm Ray, Cuvier u, sow. erklärtẹn sie mechanisch als Erleichterung zum Schwimmen - Fischer zum Schwimmen und Respiriren zugleich - Fourcroy fand Azot - Lacepede Hydrogen - Configliat: Sauerstoff - Vauquelin, Geoffroi, Biot bei Fischer in der Tiefe mehr Sauerstoff, in seichteren Ge. wässern mpehr Azot - Humboldt ìn Flufsfischer

a) Monro. Vergleichung des Banes und der Plysiologic de: Fische mit dem Baue des Menschen und der übrigen Thip re, übers. von Schneider, mit Anmerkungen you Camper. Leipz. 1787,4 ? 
vorziglich Azot und etwas kohlensaures Gas Delaroche bestätligte neuerdings die Beobachtung Biot's ${ }^{a}$ ).

Bei solchen Vorarbeiten trat Lacepede auf, und Jieferte die Geschichte der Fische als Fortselzung der Verke Jüuffons. Nicht an einzelne Punlite sich haltend, sondern alle seine Vorgänger in sich vereinigend, crbaute er das System derselben. Mit Brisson und Linné versezte er die Cetacéen zu den Silugthieren, mit Camper räumte er den Linorpelfischen wieder ihren Platz auf diesem Gebicthe ein, mit Linné führte er die Unterscheidung nach den Flossen nicht blos bei den grätiggen ein, son'dern dehnte sie auch noch ïber die knorplichyon aus, und brachte so alle Fische unter folgendes Schema:

$\boldsymbol{P}$ isces (sanguis ruber, vertebrae, branchiae loco pulmonum)

\section{Cartilaginei}

a. absque operculo et membrana hranchiali :

- apodes: petromyzon (9) gastrobranch. (2)

- abdominales: raia (36 species) squal. (52), aodon.

6. membrana branchial. absque operculo - apod.

a) annal. de mus, sur la vessie aërienne par $\mathrm{m}$. Delaroche. T. 14. p. 184.

- sur des poissons aux îles Baléares et Pythiuses. T. 13. 
- jugul: lophi (8).

- thorac: balist (2g).

- abdomin: chimaer (2).

c. opercul. absque membr. branch.

- apod. - jugul. - thorac-

- abdomin: polyodon, accipens. (4).

d. opercul. et membr. branch.

- apod: ostracion (15), tetrod. (19), ovoid. diodon. (6), spheroid. synginath. (8).

- thorac: cyclopt. (12), lepadogaster.

- abdom: macrorhinch. pegas. (5), centrisc. (2).

II. ossei.

e. opercul. et membran. branchial.

- apod: coecilia, monopter. leptocephal. gymnot. (6), trichiur (2), nolopter. (2, ophisur. 5 , triur. apteronot. regalec (2), odontognath. muren (4), ammodyt. ophidium (13), macrognath. xiphias (2), makaira, anarrich. (5) comephor. stromateus (5) rhombe.

- jugul. murenoid. callionym. (5) calliomor. uranoscop. (2), trachin. (2), gadus (22), batrachoid. (2) blennius (2), oligopod. kurt. chrysostrom.

- thorac: lepidop. hiatul. cepol. (5) tuenioid. gobius (22), gobioid. (4) gobiomor. (4) gobio moroid. gobio esox scomber (14), scomberoid. (3) caranx (20), trachinot. caranxomor. (4), caesio (2), caesiomor. (2), coris (2), gomphos (2), 
nason (2) kyphlios. osphronem. (2) tris chopod. (2), monodactyl. plectoríninch. pogonias, bostrych. (2) echeneis (5), macrour. coryphen. (16) hemipleronot. (2) coryphenoid. aspidophor. (2) cottus (9) scorpen. (16) scomberomor. gasterost. (3) centronot. (11) lepisacanth. cephalacanth. dactylopter. (2) prionot. trigla (12) peristedion (2), istiophor. gymnetr. mulli (14) apogon, lonchur. macropod. labrus (1.50) cheilin. (2) elieilodipter (12) ophicephal. (2) hologymnos. scarus (19), astorhinch. sparus (98), dipterodon 6), lutjan. (74) centropom. (21) bodicon (24) taenianot. (3) sciaen. (11) micropter. holocentr. (65) persec (14) harp. pimelepter. cheilion, pomatom. leiostom. centroloph. eques, leicgnath. chetodon (42) acanthinion (5) chetodipter. pomacentr. 7) nomadasys, pomacanth. (7) holacanth. (13), enoplos. glyphisodon (2) acanthur. (6) aspisur. acanthopod. (2) -selen ( $(2)$ argyreios. zeus (3), gal. grysostos. capros, pleuronect. (29) achir (6).

- abd o minal. cirrhit. cheilodactyl.cobit (5) misgurn. anableps, fundul. (2) colubrin. ainia. butyrin. tripteronot. ompok, silur. (11) macropteronot. (4) malapterur. pimelod. (24) doras (2) pogonath. (2) cataphract. (5) plotos. (2) ageneios (2) macroramphos. centrano- 
don. loricaria (2) Thypostom. corydo ras, tachysur: salmo (29), osmer (6) coregon. (20) characin (16) serrasalm. elops, megalops, notacanth. esox (9) synod. (5) sphyren. (5) lepisost. (5) polypter. scomber esox, fistular. aulostom. solenostom. argentin. (4) atherin (4) hydrargyr. stolephor. (2) mugil (7) mugiloid. chanos, mugilomor. exocet. (4) polynem. (5) polydactyl. buro, clupea (17) myste, clupanodon (6) serpe, mene, dorsuar. xyster, cyprinodon, cyprin (70).

f. operculum absque membran. branchial.

- apod. sternoptyx

g. membran, branchial. absque operculo.

- apod. stylephorus.

- abdominal. mormyrus (9)

h. absque membran. branchial. et operculo

- apod. murenophis (12) gy'mnomuren; (2) murenoblennius, sphagebranch. unibranchapertura (5).

Vas bisher sich nach und nach entwickelte, diefs hat Lacepede durchgeführet, und das künstliche Gerüst, wozu Aristoteles schon den Grund legte, vollendet $a$ ). Ganz dem Gange der successiven Bildung gemäls, beginnt er bei den Knorpelfischen mit denen, welche weder Kiemendeckel noch Kie。 menhaut haben, schreitet hierauf zu solchen, die

a) Lacépdde. Hist. ñ. des poissons T.1 - VI. Paxis 17980 \&o 
Hincs von Beiden, und endlich zu deuen, die beiAns zugleich haben. Freilich hätte er dic nämliche Gesctznilsigheit auch bei den Grätenfischen beibehalten, und nit denjenigen, welche in Hinsicht des hicmendecliels and der Branchienhant noch unrollstindig rersehen sind, wie z. B. nach sciner Angabe die murenophis, stylephor. sternoptyx, den Anfang machen sollen; er that es aber nicht, woniern sezte sie ganz anslind derselben, wodwch hem der Alstand der rolliommneren Fische in der Mitte dcr unvollionmmer en um so mehr aufallend in. Jedoch scheint die Lntersuchung des Lieneniechels, und der Kienenhaut bei vielen noch nicht o ganz ausser Zuweifel gesezt zu seyn; So fincic ich an dem Skelete der Mürenophis Helena, allexdings eine Kienenhaut mit biegsamen liadien, welche freilich zugleich die Stelle rom hiemendechel vertritt; an dem des IIppocampus trefle irh woll cinen Kicmendeckel, aber nichi, wie er rorgieht, anch eine Kiemenlaut an. Uebrigens ist zwar die Eintheihung der Fische nach linorpeh und Gräten - das Fundament, worauf sein ganzes System beruhet - in der Natur gegründet, und diese Ansicht, alle Thiere nach dem Grade der Verhnoche. rung zu ordnen, selbst von Aristoteles in Anregung gebracht ${ }^{a}$ ). Je weiter wir von dem Menschen, den

a) Arist. hist. anins, L. 3. c. \%. 
Säugthieren, Vögeln und Amphibien bis zu den? Fischen und Sepien hinabsteigen, desto mchr rerlieren die huochen an Festigkeit, sie werden in den Vögeln schwammigi, in eingen Fischen grätigt, in andern linorplicht, in den Lampretfen selbst lederartig, und endlich ist ausser einem horplichten Virbel im Kopfe an der Sepia, von ciner Rüchensüule nichts mehr ïbrig als ein loclierer, membranartiger, spröder, längst dem Rüclien unter der Haut verborgener hörper (os sepiac), in der Dolabella, Aplysia u. s. w. blos eine unter der I Iaut liegende Schuppe, und endlich bei den Conchylien die Schaalen als blorses Hantgebild da. So richlig auch dieser Abstand bei den Fischen ist, so wird er dieses doch nur so allmähilig, dafs man unuëglich eine su weite Lücke zwischen jenen setzen ham. Bei der Lamprete ist der hinorpel so weich, dafs er sich im Wasser, besonders aber zu gewissen Jahreszeiten, beinahe in Schleim auförst, die Rückenwirbel sind rerwachsen, oder vichmehr gar noch nicht getremnt, obgleich ihr Schädel nicht mehr knorplicht ist, sondern wahrhaft einer beinartigen Membrane gleichet. Bei den Squalen hat das Sliclet schon an Consistenz gewonnen, und obwohl die Kmorpel noch zart und auch noch lederartig sind, so ist doch von ihmen ein Skelet möglich, und die Wirhel selbst sind schon getremnt. In Rajen ist dieses noch mehr der Fall. 
In teitoton mola, tophi. piscatorius, cycloptes s.t die Festigkeit schon auffallend, und dem bali. stes unl centriscus lïnnte nan vermöge des Skeletes schon unter die Grütcnfische rechnen; vielIeicht, dafs auch jenes des ophisur. branchaper. anr. mornzy. nicht viel solider ist, und daher so allmählig die hrorpelfische an die grätigten anschliefst, so wic leztere dirch den polypterus biclics, Geof. an dem die Maxillen und Extrewitä-. ton an meiston Aehnlichheit mit denen der Am. phibicn haben, an diese sich anreihen: Besärse man eine reichhaltige und ziemlich vollständige Sammlung ron Fischslieleten, sicher würde man dic allnählige Ausbildung des Slieletes ron gasirotranchus, Iampretia, den Linorpelfischen, den Balisten, Monmyx, Pleuronénten, Acanthion, Si Inren, Nü̈̈nen und ron dem Polypterus bis zu den Amphibicn nachweisen können. Gleichwie mit dem Eutstehen des menschlichen Embryo die hino. chen crst schleimartig, knorplicht, schwammigh; und später nit dem reiferen Alter die gehörige Soliditat erhalten, oder auch bei gewissen Trrankliciten ron der Stuffe des Finochens zu einem Zustande fleischartiger Weichheit herabsinlien, eben so scheint die Natur glciche Stadien des Wachsthumes im Grofsen zu beobachten. Dieses aber vorausgesezt, wie kann nan num wohl den Knorpel. fischen den Vorzug vo: den grätigten einräumen, 
oder sic gar wie Linné zu den Amphibien erhebon? Wie am Shelete so sind diese auch den übrigen Theilen nach unvollkommener. So hat man den Lampretten bisher die Narinen abgesprochen, obgleich mich nähere Untersuchungen berechtigen, dieselben in den sogenamnten Spitzlöchern anzu* nehmen, welche mit einer vielfach gefalteten Schnciderischen Haut ausgelileidet sind, aber noch immer stehen sie nicht, wie auch bei Raien und Squalen, wo sie mit dem Munde nach unten geh.ehrt sind, an dem gehörigen Platze; den gastro-. branchus beschrciben alle Schriftsteller als Augenlos, allein ich entdekte sic bei näherer Prüfung unter der äusseren Hautbedeckung; an dem apterychtus coecus sollen sic, wie mich derjenige versicherte, der ihm abzeichncte, schon in etwas äusserlich sichtbar seyn. Die Unstätiglieit dieses Organes erstrelit sich, ron Inscliten und Mollusken herauf, selbst noch bis auf einige Grätenfische z. D. die Pleuronelites, wo sie auf einer Seite rechts oder links beisammen liegen, oder wie bei Uranoscop, Scorpenen, Anaplebs zu nahe nebeneinander and nach oben gerichtet sind, und diesen Fischen gleichsam ein schielendes Ausschen geben. Auch die Branchicn, welche man bei den Knorpelfischen sonst den Lungen gleich schäzte, sind hier viel unrollkommener als bei den Grätenfischen. Hier sinđ sie auf eine einzige Oeffnung concentriret, und 
flottiren gauz frei, dort aber sind sie durch cine Fortselzung der innrsten Haut der speiseroblue in mehrere einzehe Süche rewwachen, welche, gleich fen Tracheen der histhen, lingst dem llilse durch Lücher nach Aussen and in die Speiseröhre selhst münden; ja bei den Gastrobranchus ölnen sic sich sogar weit ron dem hople weg an Banche, und wer wcis, ob die vielen cinzelnen Lücher lingst den Flanken des Lcibes, nichi sowohl zu mucosen hanälen fuhren, sondern vichnehr wahrhiftige Lacheenatige Branchien sind? Die Ostracion und Tedrodon, lïnnen vermitielst der durch das Peritonäum gesildeien und an die innere Wand der äusseren huste angelegten Irautsielie jene belicbig aufblihen und zusammenzir hen; sollte diese Vorrichtung nichl wohl schon ein Ansatz zur Schwinn blase, welche die Grätenfische vor den hinorplichlten auszeichnet, und leztere überhaupt mehr als rin Rest der Tracheenbildung der niederen Thiere, als für den blofsen Nutzen zum Schwinimen oder Verdauen bestimmt seyn? Die Eigenschaft, lebendige Junge zu gebünen, kann ebenfalls nicht be. rechtigen, diese Thiere vor den gräligłen Fisctien zu setzen, indem es auch noch bei einigen ron die. sen vorlionint. Der Hauptgrund aber, welcher mich in der Amname der unvollkommmeren Bil. ding jener bestirket, ist nicht blos das wurnartig" and schlingrighte Aussehen bei den meisten, ferner 
dafs sie mehr die Tiefen des Mccres bewolnen, während die Grätenfische mehr die seichtcren Ufer oder Secn und Flüsse aufsuchen, und so gleichsam sich schon den Landthieren, oder vielmehr den Amphibien nähern, sondern es ist die ausserordentliche Aehnlichlieit des Schärlels der Lampretle mit dem der Sepia, welche beide ich mit vieler Mühe präpariret habe, und in Weingeiste aufbewahre. - Wollte man also auch das System Lacepede's gelten lassen, so miifste doch dic Aufeinanderfolge der Ordnungen dcselben gerade zu umgeliehrt werden, die Tnorpelfische, welche im Anfange stchen, mürsten die lezte Gränze dor Fische ansmachen, und vermittelst jener grätigfen, wo Fiemenhaut und Deckel noch unvollständig sind, den Uebergang zu jenen herstellen. Jcdoch aller aiescr Lückien ungeachtet, und trotz der mangelInften Definition der Fische, indem die Branchien and der gefärbtere Saft den MTollusken, die Reste des Slicletes auch den Sepien zuliommen, und der apteryclitus coecus ohne alle Flossen ist, so beHauptet doch Lacepede elon den Rang unter den Hassischen Schriftstellem über Fische, welchen Pennant unter denen der Sängthiere, Latbam unter denen der Vögel eimclmen. Ifat Gmelin in dex Limnéischen Ausgabe nur 35 Arten und 66 Gattungen - Bloch 523 Ablildungen von Arten und 31 ron Gattungen gegehen, so enthält im Gegen- 


\section{$-420$}

theile Lacepode's Mcrli, aus sechs Bunten beste hend, 1.403 Arten, woron 559 ganz neu, und meistens aus den in Paris niedergelegten Handschriften des Commerson und Plümier genomnien sind, forner 223 Gatumgen, woron auch 127 net errichtet sind, und eben so vicle, wemn slcich richt ausserortentlich vortreffliche, doch instrulitive liupfer. Freilich hätte man sich cinigerms. sen wber die vielen neuen Gattungen nicht zu rer * wundern, wenn man bedenlit, dal's Linné unter silur. percu. epurus, chatodon, zus alles auch noch so heterogene zusammengoworfon, Lacopede aber jezt anseinander gesucht hat. Allein demohngeaclitet ist die Sucht des Lezteren, alle Arten in Gattungen aufzulüsen, zu anffallend. Hat Limé die labrus, scarus, perca, cyprin. nach der Form des Schwanzes, den Dlemius nach der Anzahl der Ruichenflossen und nach der Aluwesenheit oder Gcsenwart der Bartfuden, die Pleuroneliten nach der Lage dor Augen, und damn nach der Form des Scliwanzes blos unterabgetheilt, so ist dieser Un. washicd für Lacepede schon Grund genug, diesc untorabgetheilten Arten zu Gattungen zu erheben; dulier denn häufig der Fall cintritt, dafs bei ilım schr viele Gattungen ohne alle Arten ganz isolirt dastchen, wahrend bei Limé jede Gattung rollireich ist, und alle Arten auf allgemeine Gesichtsfunliti zurülgebracht sind. Elon dalier geschah 
es auch, dafs manche Gattungen doppolt beschrieben seyn sollon, anch manche Charaktere nühtsere Untersuchungen verdienen, wie ich dieses unter andern auch an leptocephal. morrisien bestätfigt finde, an welchem ich allerdings Halsflossen bemerlit zu haben glaube. Jedoch Lacepeden gebührt der Ruhm, das liünstliche Gebäude der Fische, woran man seit $\Lambda$ ristoteles arbeitet, mit vielen neuen Entdechungen bereichert, und durch gehö. rige Benutzung der bisher vorhanden gewesenen Materialien zu seiner Vollendung das Meiste beigetragen zu haben.

\section{78 .}

Lacepede's System der Fische ward für scine Landslente in Bearbeitung des nämlichen Gegen. standes das Vorbild. Latreille legte es zu allers: seiner Abhandlung über Fische zu Grunde "), schaltete die Artedischen Benemungen, chondropterygii und branchiostegi, bei den Fuorpelfischen ein, und deutetc an, dafs dic squatina als eine eigene Gattung, zwischen Squalen und Rajen gesczt zu werden rerdionen. Seinem falscher Prinzipe gemäfs, dafs dic Natur immer die Ord nungen und Klassen mit lünglichten Thieren beschliefse, erscheinen die Lampretfen am Ende des Chondropterygen, die Apoden nebst der $25 \mathrm{ten}$,

a) Tableaur method. d'hist. $n$, sur les poissons. 
28 ten und 29ten Ordnung des Lacepede's, welclie ron ihm wie als Anhang betrachtet wurden, am Ende der Grätenfische.

Ein Gleiches that Dimeril, welcher auch die Inspiration bei Fischen als eine wahre Deghtition wie bei Fröschen erwiefs, aber fälschlich jenen allen Geruch, als dem Elemente der Luft entsprechend, ablïngnete, und dafiir die Narnen als das eigentliche Geschmalisurgan erhlürte ${ }^{a}$ ), in seiner analytischen Zoologie. Er behielt noch getreucr als sein Vorgänger das Lacepedische System bei, erhob einige Arten, z. B. torped. rhinobat. syuatin. piscatorius zu Gattungen, rersezte das Niceipferdchen zunïhst dem Stör, sammelte immer in jeder Ordnung mehrere Gattungen zu ciner Fumilie zusammen, welche er nach dem ausgezeichnestem Merkmale benennt, und erlaubte sich nur dis einzige Veränderung, dạs er Lacepede`s System in technische Ausdrücke umsezte.

Lamarck entlehnte in seiner zoologischen Pliilosophic das Nümliche aus Dümeril, und handelte nur seincm Plane gemäfs, die Natur gleichsam als eine fortlanfende Linie darzustellen, die Kinorpelfische, wie schon ror ihm Treviranus in seiner Biologie, ganz am Ende aller Fische ab. Freilich

a) mémoire sur l'odorat des poissons

- sur le mécanisme de la respiration des poissone par IM. Dumeril 1807 . 
White er, da er von den wnvollkommomen Thicren zu den volliommneren rorschncitet, Dimeril aber den umgelichrten Gang in genamintem Werke beobachet, dic Aufemanderfolge der Grätenfische bril.czterem plenfuls unlohren mïssen; allein cr that es nicht, und liefs auf dic Finorpelfische die volliommensten Grätenfische, und zulczt die unvollhommneren der lezteren (murcnophis c. c.) folgen. Da die franzôf sische Sucht, cine nene Nomenclatur aus der Vebersetzung der Benennung ins Gricchische, mil franzöfsischen Endsylben zu schafron, und Dümeril's Scharfsinn und Nreigung darin gerade lier am siclitbarsten ist, so mag das Lacencdische System in die neuen techischen Bcnemungen Dümerils ungelileidet, und in dic naliirliche Anfinanderfolge von itamarch gebracht, aus der zoologischen Philosophie des Lezteren hicr stehen:

I. Pisces ossei.

Ord.1. ophichthyes: gymmomuraen. mure nophis. splagebranch. unibranchapertur.

- 2. cryptobranches: stylephor. mormyr.

- 5. sternoptigès: sternoptyx.

- 4. holobranches:

* abciominales -

Fann. 1. siagnotes: scomber esox. polypter. lepisoste. sphyren. synodon, esow megalops, elops. 
Fam.2. dermopteres: scrasalm. chat racin. corregon. osmer. salmo.

- 5. gymnopomes: cyprin. xyster. dorsuar. mena, serpa, clupanodon: mysta, clupea, buro, stolephor. hydrargyr. atherin. argentin.

- 4. lepidomes: mugilomores, chanos. mugiloid. muge.

- 5. dimmeredes: polydactyl. polynem. cheilodactyl. cirrhite.

- 6. ophlophores: plotos. cataphract. pogonat. doras, pimelod. malapterur. macropteronot. silur.

- 7. cylindrosomes: ompolk. butyrin. colubrin. fondul. anableps. cobit.

- 8. siphonostomes: solenostomes; aulostomes, fistularia. ** thoracici -

- 9. 7eptosomes: capros - chetorlon.

- 10. acanthopomes: persec. - lutjan.

- 11. heterosomes: pleuronect. achir.

- 12. dactyles: peristedion.trigla, prionot. dactylopter.

- 13. ceptlalotes: scorpaen. cottus, aspidophoroid. gobio, esox.

- 14. lophionotes: eques, centroloph. taenianot. coryphenoid. hemiptero- not. coryphlaen.

- 15. osteostomes: leiognath. ostorhine: sccurus.

- 36. leiopomes: mulet. cheilion. dipterodon, sparus, hologymnos. - la= 
brus, pogonias, - osphronem. gomphos, coris. hiatul.

Fam.17. atractosomes: pomatom. istiophor. lepiscicanth. - scomberomor. caesiomor. - scomber.

- 10. eleutheropodes: echeneis, gobiomoroid. gobiomor.

- 19. plecopodes: gobioid. gobius.

- 20. petalosomes: gymnetr. bostrzchus, taenioid, cepola, lepidop. $\star \star \star$ jugulares -

- 21. auchenopteres: chrysostrom.e.c. $\star \star \star \star$ apodes -

- 22. pantopteres: rhombus - muraena.

- 25. pteropteres: regalec - coecilia,

II. cartilaginei

Ord. 5. teleobranches:

Fam.24. osteodermes: syngnath. - ostracion.

- 25. plecopteres: lepadogaster, cyclopter.

- 26. aphiostomes: centrisc. solenostom. macrorhinc.

Ord. 6. eleutheropomes :

Fam. 27. accipens: pegas. polyodon.

Ord. 7. chismopnes: chimaer. balist. lophius. piscatorius.

Ord. 8. trematopnes:

Fam.28. plagiostomes: aodon, squal. squatin. rhinobat. iaja, torpedo.

- 29. cyclostomes: lampretta, gasterobranclius. 


\section{$-426$}

Vie schr hat die Ichtiologic scit Aristoleles bis auf unscre. Zeiten an Bercicherung sowolil, als an Ordnung gewonnen \$! Waren die einzelnen Fische in Anfange obne Familie, und wie in einem Chas, so sind sie jezt mit Artedi, Linné und Lacepede in Gruppen gesammelt, und nun fehit nichts, um gleichsan das Gemälde der Fischwelt zu rollenden, als jone Gruppen selbst wieder zu cincm historischen Ganzen gleichsam als Glieder zu eincr und der nämlichen IIandhug zusammen zu stelien. Zwar hat man anch schon dieses rersucht, aber wie schwanliend hierin irren noch die heutigen Fiinstler von einem Extreme zum andern? welche schüchterne und blos muthmafsende sprache führen noch die Schriftsteller in Betreff dieser 1 nordnung! Freilich mögte zu dieser Vollendung die Tiefe des Meeres noch vicles rerschliefsen, die Schichten der Gebiirge manche Gattmg und Familic nur noch als fossile Reste und Denlmäler aufbewahren. - Freilich lïmnte uns so auf diesen Wege noch manches Räthselhafte offenbar werden. Allein auch zur fiemtnifs der fossilen sind schon durch dic classische Monographic fossiler Fischr, welche in den Kalhbrüchen des monte Bolca von vestena nova mit Farrenträutern, Mimosen, Scekrebsen und Phylozoen rermischl, rorlommen, die Gränzlinion gezogen. Durch dirse rerdienstvolle Untersuchung wissen wir, dafs cs 49 
Gattungen und 125 Arien um Terona herum giebt, dafs darunter Fische aus Flüssen, Seen, Meeren ron einheimischen und indischen, aegyptischen, amerikanischen Gewässcrn, ja selı viele junge Brut ron chactodon, tetrodon, sparus und nach cinem Exemplare im Pariser Muscum aus jenon Stcinbrithen ein e:ox mit einem kleineren Fische in Nunde, aber alle mit eingezogenen hienen, and offenem Nunde, also bei noch natülicher Ausathmung begraben worden sind a). Dieses schätzbare TVerli enthält ron allen fossilen drten genane lisschreibungen und lèpfer, nud zählt unter denellbigen folgende Gullungen auf:

- Cartilaginei:

squcil. raja. lophius. tetrodon, diodon ostracion, centriscus, syngnathus, cyclopterus, pegcusus.

Ossei:

1) apodes: muraena, ophidium. ammodytes, synbranchus, monopterus.

a) "senus denique piscium in hac ardesia consepulti, sunt fere omnes maritimi: iis viventibus non eadem nunc rejio, non clima. Nonnullis multiplex patria et in Europa et alibi. Insis tamen et pisces fluviatiles inmixti sunt ex. aquis dulcibus fluminum nostratum, ac americanorum aut indicorum " p. 32 - Ittiolitologia veronese del museo Bo ziano ura amesso a quello del conte Giovam Battista Gav zola e di altri Gabinetti di fossili veronesi, con la versione latina. Verona della Stamperia Cinliari STIDCCVCVI, rudc 
2) jugulares: callionum. uranosrop. sadus, blennius, kurtus.

5) thoracici: iorphacna.blochus, gethius. cottus, scorpaena, zeus, pleuronectes, chaetodon, sparze, labrus, holocentrus, lutjan. - ophicephalus, sciaena, perca, scomber, trigla.

4) abdominales: amia, silur. loricaria, salmo, fistularia, esox, exocoetus, porynemis, clupea.

Tie ricie andere hierin eben so reichhaltige Gegenden sind hingegen noch nicht beschrieben! In Teutschland, Frankireich und Italien findet man jone rerstcinerten Zühne (glossopetrae) durch ihre Grölse meist ron dem jezt behannten IIayfischen verschieden, ebenfalls die sogenannten Bufoniten, welcle rermuthlich ron anarrhichas lupus, oder den Arten des sparus herstammen. Auch trift man vollstündige $\mathrm{Abdrüclie} \mathrm{von} \mathrm{Fischen} \mathrm{in} \mathrm{der}$ thüringischen Kinfergrube bei Suhla, in der Gegend ron Coburg, Eisleben, Eichstädt, zu $\$ ix, Montmartre, Nanterre in Frankireich, zu Stabia, Gifon in Neapel, anf der Insel Lesina in Dalmatien, auf Cerigo im Archipelagns und auf dem Berge Li. banon an. Der Stinkschiefer bei Oeningen enthült, wie auch bei Glarus und Schlenhofen im Pappenbeimischen, Petrefaliten ron Fischen, wclche nach der Beschreibung grüfstentheils den noch lebenion 
in dortigen Gewässern z. B. den Aalen angehörcn. Mögte es doch einzelnen Gelchrten und Reisenden gefallen, diesen Zweig der organischen Geologie sowohl durch cinzelne Beschreibungen als auch durch IIonographien zu bereichern. Mügte der grofse geologische Zoolog Curier bald scin öfentliches Versprechen in Eifulling setzen, und uns eben so genaue Ausmittlungen und Uebersichten ron fossilen Fischen geben, wie or es bei den Säugthieren geleistet hat, und uns auch hier in den Stand setzen, über die Bildungsepochen und Zeit• alter der Erde, über die Fische einer alten und neuen Zeitperiode muthmafsliche Urtheile fällen zu Jünnen. Aber unendlich weit mehr ist uns das Gebieth der noch lebenden Fische aufgeschlossen, durch Broussonet ist uns ein Beispiel in der Beschreibung ihres Aeussern überhaupt an wenigen Individuen ${ }^{a}$ ) gegeben, und neuerdings ist uns der Horizont durch viele neue Arten ron Russell ${ }^{b}$ ) crweitert worden. Schon kennen wir den grösten und beinahe wesentlichsten Theil aus den Meeren, Seen und Flüssen. Schon sind hierin der MIaterialien so viel rorhanden, dafs es einem philosophischen Naturforscher möglich ist, gleich dem MIa-

a) Broussonet. Ichtyologia tisteng piscium descriptiones et icones, London 3782. Fascic. mmus. '4.

b) Russell. Descriptions and figures of iwo hundred fisho: of Coromandel, London 2803. Tol. I. 2. 
themathin von bekamen Grifsen aul unbehante zu schliel'sen, und so das Finzelne zu cinen Ganzen zu verbinden. Nur fehlet uns noch trolz der cinzeluen Bemühungen der älteren Anatomen, jener eines Geoffroi, welcher anfing, die Knochon. der Brust und der vorderen Lxiremität mit denen des Menschen genaner zu rergleichen a) und eines Cuvier, welcher alle bisherigen Beobachtungen darüber in seinem Ilindbuche der vergleichenden Anatonie zusammentrug, noch fehlet uns, um die Vergleichung auch auf diesem Boden herrschend zu machen, ein VVerk, welches wie Bloch die Abbildungen rom Aeusseren, so diese ron den inneren Theilen zusaminenstellt. WVird sich in Zulkunft den VTerken eines Linné, Lacepede und Bloch ein gleiches der rergleichenden Anatomie entgegenscizen, damn wird es jenem Zeitalter leicht seyn, auch anf dem Gebiethe der Fische die gesetzmälsig fortschreitende bildung der Natur cinzusehen, und als ein schünes orgunisches Gliederwerk darzustellen.

F ÜNTES CAPITEL。

Mollusken. Conchyliologia.

ก. 7 今.

Aristoteles. den Quadrupeden, den Vögeln und Fischen hat

a) Annal. de mus. T. 9. P. $357,-$ p. 4.13. - T. 30, p. 87. 
Aristoteles die erste Reihe, nämlich der Thiere mit Blut geschlossen, und nun hebt er im vierten Buche der Thiergeschiche mit der zweiton - den blutlosen (avabra) - an. Je nachiem diese die harten Theile nach Imnen, die weichen mach Aussen, oder umgeliehrt, und zwar, so ferie sie jent mehr spü̈l oder durch Finschnitte gctheilt haben, sondert or sie in vinr llauptgruppen (nas) .... Mollatien, Crustucien, Protucéen, Inselatu-... ab. Dic Molluslicn ( $\mu x \lambda a r i a)$ nehmen hier greich nach den Fischen miter den blutlosen den ersicn Rang cin, ?und begreiffen in sich den grofsen und lileinen halmar (tevsis) den Dintenfisch (entic) und die Polypen nit langen Armen und limzon Tiöper (moxutiós), hei welchen lezteren er gro-

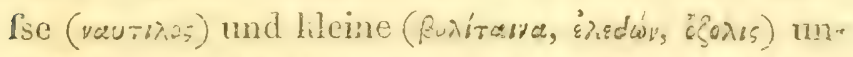
icrsclicidet. Die Testacéen hat er am drilten Platz, nämìch nach den frustacéen gesezt, vermuthlich, weil diese die äussere Hautbedechung nicht so hart wie jene, und dann lange Füfse, Schecren unt Antemen, ähnlich den Armen der Polypen haben. Hieher rechnet er alle Thiere mit Schaalen, nnd thut auch nebenhei der Seeigel und Seesterne

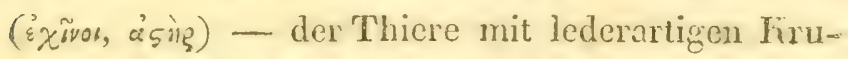
sten, welche den Priapen gleichen sollen, und daher wahrscheinlich den Holothurien entsprechen

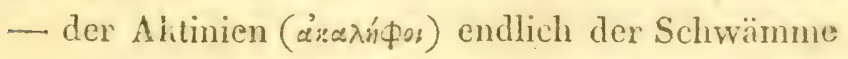
(otro2,201) Erwähnung. Aristoleles ist zwar bei 
dé blutlosen Thieren nicht so weillünfig wie bei jenen mit Blut, führet aber doch schr viele Eigenschaften an, welche sowohl den Charaliter dieser Thiere als auch seinen genauen Forschungsgeist bezengen. So beschreibt er die üusseren Theile der Mollusken und Testacéen, meldet ron den inaeren der ersteren, und zwar ron dem Finorpel im thopfe, welcher das Gehirn in sich einschliefst, on den Eingeweiden, Eiern und der Lage des intensackes bei Sepien "), ron ihrer Begaltung sat Verbindung der hörper und mit wechselseitier Aufnahme der Geschlechtsthcile ${ }^{b}$ ) - er schildert bei Testacéen die Lage der Geschlechtsorgane als eines Kanales, ron dem er lieinen Ausgang fund, und dessen Funlition er nicht cinsal, ferner wie sich hier die Gedärme durch die Eingeweide tvinden, und meistens ihren Ausgang zunächst dem Kopfe nehmen c) - er merket an, dafs die Schaalenthiere die Geschlechter nicht getrennt haben ${ }^{d}$ ), sich ohne Vermischung blos ans einem Schlamme, welchen sie aber selbst von sich geben, erzengen, und dafs sic ilıre Schaalen ron dem umgebenden Sande, dem Felsen u. s. w. bilden c), dafs sowohi die nakten als beschaalten Schneclien ohne Stimme scyen, da!s sie zwar nicht alle Sin-
a) Arist. Ho an, L. 4, c. Io
b) ejusd. I. 5. c. $6-18$.
c) ejusd. L. 4. c. 4 .
d) ejusd. L. 4. c. 11 .
e) ejusd. L. 5. c. 5 . 
nesurgane, aber doch offenbar die Wintunger derselben z. B. des Grchörs, Geruchs, Gesichts u, s. w. haben "), dafs sie sich in Winter zintihziehen und verbergen ${ }^{b}$ ). Von allem diesen spricht er weitläufig, allein die Hauptunterschiede, wel. che or bei Testacéen am öftesten wieder!nohlet. sind folgende:

- nach der Anzahl der Schaalen T. A. c. is.

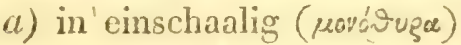

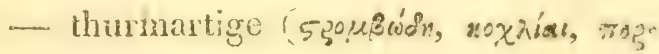

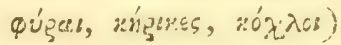

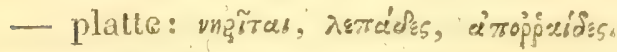

b) in zweischaalige ( 8 iqupe)

- wo das Thier nur an einer Seite an. gewachsen und sonst ganz frei ist:

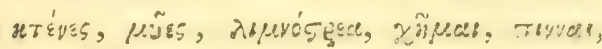
xór $x x 6$.

- wo es an mehreren Punkten ange. wachsen ist, und die Schaalen sich nur nach einer Seite öfnen: $\sigma \omega \lambda$ uี⿲:丨

- nach dem Aufenthalte. L. 4. c. 4.

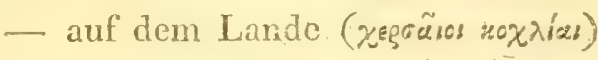

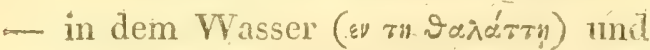
zwar dic cinschaaligen (kíx rest) und zweischaaligen (ösçáa)

an der hiliste oder in der Ticfe. $\boldsymbol{L} .5$. c. 15 .

a) Arist. H, an, L. 4, c, 8, b) ejusd, I, 8, c. 35, 28 


\section{- $434-$}

- mach der Bewegung. L. 5. c. 1 J. L. 8. C. $1-2$.

- in solche, die wilitilinrlich ihren Platz verändern künnen (แทйти)

- . . oder die an ihrem Platze ange-

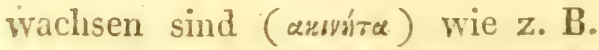
Pimen, Austern, die Balanen ( $k \alpha^{\prime}-$ davor. L. 4. C. 8.).

Plinin: mulerscheidet ebenfalls die blutlosen Thiere in jene vier Galtungen, jedoch mit der $A b$ änderung, dufs or die lnseliten ganz zulezt und abgesondert, die ïbrigen aber in gleicher Aufemanderfolge bei den Fischen, miter dem Titel: ,pisces sanguine carente's im neunten Buche abhandelt. Er nemnet die ersteren derseiben die ITeichen. "mollia" die lezteren die Schaaligen "testacea" und zühlet benahe eben so viele Arten, als Aristoteles, auf. Zwar merhl er ron einzelnen manchmal eine neue Eigenschaft wie z. B. ,saliunt pectines" an; allein bei allen Testaceen (buccin. purpur. murex, pinna, pectines, mituli, wstreac, dactyli, margaritifera) läfst er sich mehr auf die Erzählung ein, wic z. B. dic Penlen sinc Geburt der durch Thau befruchteten Muschellhiere sind, oder wie sie überhaupt für Schmauscreicn, fur Belustigung in Piscinen, für Schmock, in Tileidern ron Purpur und Perlen, ron den Römern rerwendet wurden. 
Seinem Vorgänger getreu, singt anch Oppian in dem Buche über Fischerei, von Polypen, Austern, Purpurn, und mahlet in einem angenehmen Bilde aus, wie das Weibchen der Sepia an das Hintertheil des Schiffes gebunden, das Männchen, oder wie blos ein grüner Zweig ins Wasser gelängt, diese Thicre ins Netz fuhret.

\section{79 .}

Fon nun an strebte man das, was Aristoteles zerstreut angegeben hat, zusammenzulesen und in Ordnumg zn bringen. Lange Zeit folgte man hierin dem Beispielẹ Plinius, und zählte die Mollusken und Testacéen immer unter den Fischen auf. So machte es Isidor ron Sevilla, jedoch mit der Ausnalume, dafs er den "limax" zu den Wümern rechncte; Albert d. G. äuderte an seinem Vorgän. ger nichts, ausser dafs er dic Wasserthiere unter alphabetische Ordnung brachte.

Wotton ist auch auf diesem Gebiethe der erste, welcher das Ansehen des Aristoteles wieder einführte. Wie dicser, tremte auch er die blutlosen Thiere ron jenen mit Blut und somit die Schneclien ron den Fischen ab, selzet hier die Insekten zucrst, handelt hieranf die Teichthiere, wolin er auch den 1 Iecrliasen tethys? aply. sia? rechnet, dam die himstacéen, mo endlich vor den Zooplyten, wonmter er dir flotuthrien, 
Nuchingen, Mecheseeln und Schwömme bogreifi, die Testucien ab (- lurbindti: cochicu, murices, purpure, buccinum, ne'the chini, balani - un ivalues: lepas, auris ma rina - bicalres: ostrea, chama, mytuli, mascult, tellinue, pitinu, pectuncul. dactyl.).

Bellon und Rondeiet liefsen sich zwar in Gane zen ron ihrer Plinianischen Denkungsart nicht irre machen, sonderten aber demohngeachet diese Thiere, in ilrem Wuilie über Aquatilien oder Fiscle, unter der Lenenmung der Blutlosen ab. Beide sprechen hier zxierst ron den sogenamten

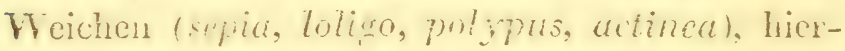

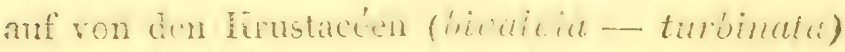
wo llondelet sich blus derch die I cherschrit "ostracodermule" (spondyli, muscah, solen,

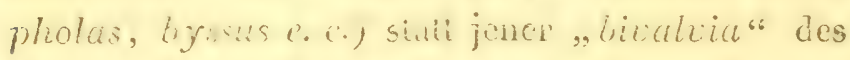

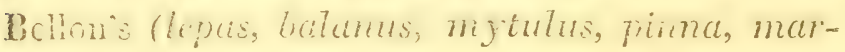
Getritifore, telima, chuma, pecten, pectuncul. dacty. ostrea) untershoilet. Judoch hicrin folsen sic dem Wollon nach, duls sie fü jenc Thiere, wolche bei Aristoteles cigentich ohne Platz hermirren (Tehys, Meentaas, Iolothurien, Meerwïmer die nene hilasse, , $=00 p h y$ ta" mit in ihe Wirhatuahmen, aber zu gleicher Zeit auch dahin die Merigel und Meerstene recheten.

Saivini handelt ron den blutlosen Thieren nur (iit) Trechen diese aber mitten unter den lischess ab. 
Eine gleiche Anzahl wn Llassen bei den MTas-

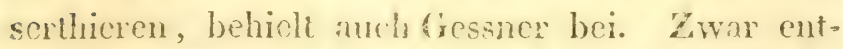

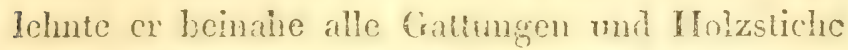
ans dem Vientien seiner Vorsünger, dock wich er in der Anordnung ganz ron denselben ab. In seiner Geschichte der Fische und Tasserthiere wählte er hiezu das Alphaber, doch so, dafs er die Schaalhiere beisanmen unter dem Buchstaben ,Coctrest und Conche "beschrieh; in eincm anderen Wolic, betitol: "Momonclator aguatiliwize" thoilte or hinerewen alle blutlosen (mollia,

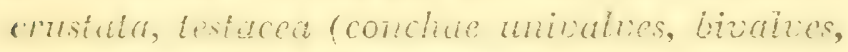
zugues, turbinati, neritae, cochlede) insecta, zoophyl(l) in die des Hecres und des süfsen Wassers ab.

Von jozt an wird das Anschen des Aristoteles nud scines ersten Commintaiors, nïmlich des Wotton herrschender, die blullosen Thiere bleiben fïr inmer von den Fischen resontert, und erscheinen nicht mehr unter der Denemuner von VVassertheren. Aldrorand a) und mit ihm Jonston sind die crsten, wchle in der Abheihmg und liangordmug der Hullosen 'Thiere dem Beispiele Wvallon's fulgten. IVic Gessner, hielten sic sich ebenfalls sm die Gratungen und Holzstiche von Bellon und Hiondelet, sie handelten nach den Inschten, Weich-

a) UI:ssis Aldrowandi de reliquis animalibus exaguibus lihri IV. post mortem editi, Franeol. 1623. 
thieren und Krustacéen, die Testacéen (turbinata - bivalvia - univatvia) ab, zählten die Balanen bei den Bivalven auf, und schmiiliten, wie überhaupt, das Ganze mit ciner gleichen Masse von Gelehrsamlicit aus. - Charleton machte an sein:m Vorgänger nur diese Veränderung, dals er die Einschaaligen mit den Dentalien und Entalien rermehrte, und wie Jonston die Thurmatigen ir. kugelartig - oder länglichgewnudene, die zweischaaligen in rauhe und glatte absonderte.

Fabius Columna hatte in seinem Werkic iiber Wasser - und Landthiere ") vorzüglich aber in dem über die Purpurschnecke, rerschiedene der nakien und beschaalien Schnechen nach der Natur und meistens sammt dem Thiere beschrieben und abgebildet. Major gab das leztere nachmals heraus, und legte in demselben scin eigenes System (univalvia - plurivalvia) dar ${ }^{b}$ ). Hier läfst er die Echiniten ron den Teslacéen ganz weģ, vereinigt die Thurmartigen wit den cinschadigen unter der Benenmung der Lezteren, welche er nach der längligen (penicilli marini) breiten (patellae) oder engen Mündung der Schaale, und zwar ohne Schraubenwindungen (concha venerea) oder mit

\footnotetext{
a) Fabii Columnae aquatilinm et terrestrium aliquot arimam lium observationes, Romae 1616. 4.

b) Fabii Columnae de purpuza, npera ac sturio J. D. $3 \mathrm{I}$ i 3675 . 4 .
} 
bauchichten oder bauchlosen (nautilus, murices, turvo, buccina) abthcilt, und stcllt endich die zwei- und vielschaaligen unter dem Titel ,plurivalvia" auf.

Sibbald fïhrt hierauf dic Ansicht Gessners ins Andenken zurük, und unterscheidet diese Thiere in solche des Landes und des Vrassers (cochleac terrestres, aquaticae); die ersteren zählt or zu den fufslosen Inselten, dic lezteręn aber werden in solche der Flüsse und des Necres (furiatil. marin.) und dann die beiden Ifautfanilien wieder in thurmartige, ein- und zweischalige abgetheilt ${ }^{a}$ ).

Bonnami bleibt der Abtheilung in ein- und zweischaalige getreu, scheidet die ersen in ringsum bedekite (echini) und thumartig, wohin er auch die Mecroliren zälılet, uml sezt die Balancı zu den zweischaaligen ${ }^{a}$ ).

Tournefort hinterlifst unter scinen Manuscripten ebenfalls seine Ansicht, die Testacéen in Ordnung zu bringen. Hier benuzt er dic Unterabu theilungen der bisher gängigen Rübsichten, und wiederhohlet die drei Ordnungen des Mlaior unter

\footnotetext{
a) Rol. Sibbaluli Ecotia illustratz. Edimburg 168i. Fol. part.

$\therefore$ II. B. III. p. 26 .

b) Ph. Bomannns. Fecreatio mentis et oculi in lobservatione -animalium testaceorum curiosis naturae inspectoribus, Romac 168\%.
} 
folgenten neuen Benennungen: , MTono-, Di-, Poly-toma". Die ceston merden nach der Gic. stul! der Schaato in cinechaslige (lepos), in spimalfömige (spiwatia) and zwa: mit Vindungen narh Aussen (marires, buccin. tarbo, purpura, cochlea, neritu) oier nach Imen (notili, conchae venereac) - in yöhrige (fistulosa, dentalium, enta7ium, tubuli marini) - die zweiten nach der Lage des Schlosses und der dadurch rerschick . men Mrindangen - die Polytomen weralen cnd. lich, je nachdom dic Schaalen durch Nähic artihuliyen (colini) order duch linoupel rerbuaden scyn sollen (balani), minterschieden ${ }^{a}$ ).

Thump isi meln durch scine Reisen, durch sein Conchylieniabinett, und durch die Bescheibungen und Abbildungen der NTuscheh ron der Insel Amboina, ais durch scine Methode, welche eigentiich scinen Fremde Sipmann zugeschriebast wird, beriilme. Fr hat die alte Abtheilnng in cinand zwcischanlige beibehalten, beide mit vioken newen Arten vermehrt, una selbst manche Arten zu Gatumgen (cassides, strombi, volutae, alatae, porcellanae u. s. w.) erhoben ${ }^{3}$ ),

a) Introductio Tournefortif ex collice m.s. a Nic. Gurlicri i: indice testarua conchyliorum exhibita 1742. Fol.

b) Georg Eberhard Ruminfi d'Antrainsche Rarilyt - Kemey Amsterdąm 3705 . 
Fangins licfert cine Tilasifiration der Acemmschch, worin er sich an dic weilläufgen (unternbtheimgen Tomnelouts hit, und alle Testacen in cinschatige - nirht thumartige (no:2 contorta: balan. patell. Lubuli - in se contorta: porretlanan, cornut Ámmonis) damn in Cochlecin und Conchen minterseheidet a) - - Lumbmam wiederhohlet ebenfalls diese dres $A$ theinugen nämlich in universaliu non lurbitutu - invinute bivaluia "). - Valen!in nimmt das System ron Bonnamin auf, und stellet sich in dex. Tortefllichlicit der Žcichnungen dem Rumpe gegenüber o).

Ireboustreit hat das, was bei Journefort und Phmof al: Uncrabheimes steht, zti acht Honptabtheihusm hermesehoben, woron die einschatligen sechs ausmachen (mizatria, a) irregulue. ria: baian. vermicul. ß) regularia - spiran non habentia: dentatiun, penícill. patell. bullae, porcellanae - spira per totum decurrente gaudentia: trochi, helices. comuásmizonis, trombi, buccini, neritac, nuubili - vertice tantum turbinata, ora

a) Car. Nic. Tangii methudus nova testacea marina in suas classes, genera et species distribuendi, Lucern. 1722, 4.

5) Joh. Clır, Kundmam. Prompluarium rerum matura!ium e! artificialium, Wratislav 1726.4.

c) Oud en nuw Ostindien, pe 11 . Tom, 2, Amsterd, 1726, Fol. 
frer totum hiante. turbinibus oblique flexis: cussidue - spiris circa ventrem flexis: cymbium, rhombi - minus turbinatu. spira nnica: aures marinae). Die Bivalsen werden ebenfalls in zwei Thassen valuis per singlymume onnextis: chumer. my.

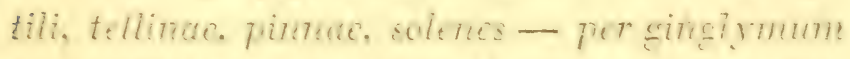
cohurentibus: pectuneut. conchae, pectints. ostrue - algesondert, der Echiniten aber wird nirgends gedacht ${ }^{a}$ ).

An Wwheit and Finze vibertrifft alle seine Vorgunger Breynus, welcher zugleich als der erste anch der rersteinerter Belemniton und Orthoceraten gedentit, und anf die vielen hommern einiger Muscheln anfmelisam macht. Nach ilim zerfallen die Conchylien in $b$ ):

I. tubulosa:

- monothalania, z. tubulus: dentalia. entalia, belemnitae.

ß. cochlidium: nautili, aures marin. nerit. cochlea, buccin. murex. e. $c$.

- polpthalumiar anm siphunculo iel ad axem id al peripheriani transcunte: orthocerus. cornie Ammonis, nautilus.

?. Jo. Ernst. Htetenstreit dissertatio de ordinihus conlat livrum methodica ratione instituendis, Lips. 1728. 4.

b) to. Breyrii diasert. physira de rclythelamis, nora testaceorum classe. Gedani 1732.4 . 
II. vasculosa:

- simplicia: patellae, lepades,

- composita: a. ex duabus valvis: chamae, tellinae, mytit. pinnae, ostrea, pectines, anomiae.

B. conchoides (ex plurib. portionib. composit.): pholades, anatiferae.

2. balanus,

s. echinus.

Yon nun an wurden conchyliologische Kabinetle und Kupferwerke immer häufiger, und Fürsten und Privatpersonen diente beides zum Gegenstande des Vergnügens. Lister tritt endlich, wie die meisten bisher mehi durch die VIenge von Abbildungen beruhmt, als das Haupt der alten und als Wondepunlit einer nenen Periode der Conchyliologie auf. Seine beiden Töchter Anna und Susanna haben die sehr genanen Zeichnungen zu seinen vier $\mathbf{B} \ddot{u}$ chern gelicfert. Z Zwar enthielt sich Lister aller Beschreibung, demohngeachtet aber ersieht man doch aus den Ueberschriften und Benennumgen, dafs er der Methode eines Gessner, Sibbald, und Langius machfolgte, und daher alle Schnechen -.. cins - und zwcischaalige, gleich - oder unglcichschaalige, linumartige, platlgedrülite, rechts oder links gewundene - unter folgende drei Ueberschrifton: terrestres, fluciafiles, marini brachte. 


\section{$\therefore \quad 44-$}

That Breynins zuerst der viclen Tiammern mancher Lnivalien Erwähung gethan, so mache Lister zuersi weilläliger anf cincn anderen $\mathrm{C}_{\text {nuter- }}$ schied derselben, nïmlich der rechts oder linlis gewundenen aufinerksam ${ }^{a}$ ).

Ihm folgle getren Argenville nach $b$ ). Fr sonderte dic Sand-Flufs - nnd Meerconchylien, je- nachdem sic cine oder zwoi Schaalen haben, ab, und begicitcte scine liupfer mit selw tumständlichen Brschreibungen, so, dafs er dadurch lange das Muster blicb, womach man die Conch lienJiabinette cimichtete, und was ebenfalls Darila rom Verzcichisse seiner Conchylionsammiung zu Grunde legte.

Gualtieri nahm ebenfulls den Anfenthalt dieser Thiere zur Ansicht bei scinen Abtheilnneen in Iand - Flufs - und Mecrconchylien, ferner in thurmartige orler nicht thmmartige, in Cochlern, Conchen und riclschaalige. Ist aber gleithrohl diese Metiode nichts weniger als neu, so bleibt doch das Werk dieses Conchyliologen wegen der Präcision und Pichtiggkeit in Beschreibungen und

a) Martin Lister synopsis methodica conchyliorum, London 1685. sq. Fol.

- ed. 2 da (recensuit et indicibus auxit Gu. Ituddesfort) Oxon. 1770. Fol.

b) Desall. D'Argenville conchyliologic, Paris 1757.4 .

- ed. Jème par de Faranne de MIontcerville, ilid, seit $\$ 780.4$. 
Fupfern, dic Quelle zur Auslegung in rorlommenden Ziweifeln.

Lesser wiederhohlte endlich nochmals das Sy. stem des Breynius, und stellte also zwei hilassen "tubulosa und vasculosa" auf; jedoch liefs or dis Orhoceraten und iveerigel weg, rereinigte die Ammonshörner mit den Cochleen und unterschicd diese nach ihrer Figur (disciformes, splicierici, ellyptici, trochif. ventricos. fusiform. pyrif.)

\section{80.}

Soit Aristoteles hat man sich liei der Betrachtung dieser Thicte, entweder in die ihres Aufenthaltes, oder ihes schönen Gchäuses veiloren, ja der nalien Schuection wurde bei den meisten Conchyliologen gar nicht geedacht. Limé laat jezt auf und zeigle, dafs es nichl sowohl genug sey, diese Einzeluheiten für sich zu liennen, sondern dals e's auch darauf' ankomme, welche Verwandschaft zwischen den Thieren der naliten und beschaalıen. Schnecken obwalte. TVie der griechische Naturforscher, sonderte auch cr sie von den Thieren mit Blut ab, und rätunte den sogenamiten Blutlosen des Aristoteles den nilidisten Platz nach den Fio schen, und somit an hinde der ganzen Thierreile ein. Jedoch in der Anzahl und der Rangordnumg der Klassen derselben, schlug er cinen ganz andern Wreg cin. Mit Wrollon rermelnte or die Lahl dez 
Aristotelischen Filassen durch jene der'Zoophylen, und stcllte ebenfalls die Insekten gleich nach den Fischen, fafste aber die sogenannten. Würmer, Molluskien, Testacéen und Zoophyten unter die gemeinschaftliche Bonennung ,vermes" zusammen. In der ersten Ausgabe seines Systemes behaupten die eigentlichen Würmer unter dem Namen "reptilia" die erste, die Molluslien und PoJypen des Aristoteles unter dem Namen , $\approx 00-$ phyta" die zweile, die Conchylien unter dem Titel ,testacea" die dritte, und erhalten in der folgenden Ausgabe an den Lithophyten, welche rorher an Ende der Planzen standen, die vierte Ordnung. In der zelnten Ausgabe änderte er nur cinige Benennungen um; er giebt der ersteren dic Aufschrift "vermes intestina" der zweiten "vermes mollusca" der dritten "vermes testacea" der vierten wegen der Härte ihrer Liruste ,7ithophyta" und benannte die weicheren, „zoophyia", welche beide lezteren er aber in der Folge unter der gemeinsamen Benemung von 'Zoophyten aufstellt, und Gme?in auf sie noch die Infusorien folgen läfst. Bei solcher Anzahl, Benemnung unl Aufeinanderfolge, verblieb num diese lilasse der Würmer durch alle Ausgaben seines Systemes. Allein wie in allen. Fächern, so bestand auch hier scine Hauptmetamorphose in der häufigen Verselzung der Gathungen entweder muter cinander, 
oder selbst ron einer Ordnung zur anderen, und damn späterhin in der Verrielfaltigung der ersteren. So stand der Echinit früher am Ende der Testacéen; in der Folge am Ende der zweiten Ordnung und zwar nach der sepic und asteric in der zehnten Ausgabe wurde die teredo zu den. Intestinen rersezt, erhiclt aber bald hierauf wieder ihren alten Platz. - Die Intestinen nach ihrer Naktheit und dem Mangel aller Glieder, von den gleichfalls nakten, aber doch mit Gliedern versehenen Mollusken, dann diese von den Testacéen (mollusca domo calcarea tecta) absondernd sezt Jinné in der zwölften und Gmelin in der dreiz.chinten Ausgabe die Gattungen und Abtheilungen der Mollusken mach der Lage des Mundes also fest:

Mollusca: animatia simplicia artibus instructa

a) ore supero: actinia (clava, mammaria pedicillaria; ascidia (słalpa, dagysa)

b) ore antico - pinnamobili ad abdomenvel caudam: pterotrachea.

- foramine laterali: limax, aplysia, doris. tethys.

- corpore tentaculis anterius cincto: holothuria, terebella

- corpore brachiato: triton, sepia, clio (lobaria), lernaea, scyllaea (glaucus??) 
- corpore pedato: aphrodita (annplitrite, spio), nereis (nais).

c) ore infero ut plurimum centrali: physoplora, medisa, luccmaria, asterias, echinus.

Auf giciche Weise suchte Lime die zweite $\Lambda \mathrm{b}$ theilung dr. Wümer, nümlich die Testacín, in fine fublotiende Ordnung zu bringen。 welches or mach ủer Zahl der Schaalen bewerlisteliggte. Gatrungen und Áticn irrten bisher unter Benennimgen and Abheilungen nach den verschiedensten Gu. sichtspuhten herum. Limné hithe zwar ans doe Vergleichung der Thire der ein - zwei- und vielschanligen mit jenen der Mollushicn, verschiedene Achiichleiten, und somit anch Unterablheilingen heransbringen hëmnen. So fand er z. B., dafs das Thier ron lepas der dorits, jenes ron pholus zinga, soten der assidia, von tellina der tethys gliche. Jedoch er fand bei don cinschaaligen die Heschaffenlicit ron hammern wid der abwechselnnen Miimung zu ihrer wciteren Sondrimg fiur hinlänglich - bci den zweischaaligen bemerlite ar zuerst die Verschiedenficit in der fuzohl und Stellumg der Zähne an Schlusse, und bildete daher hiemach die Galtungen. Obgleich die Gato ringen mit den verschiedenen Ausgaben Zuwachs und manchmal anch einge Abrinderung crlitten, so bestand doch die hauptä̈chlichste in cicr rölli-

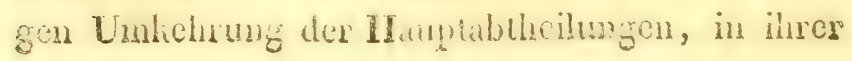




\section{$-449-$}

Aufeinanderfolge, bis sie in den lezten Ausgaber also fixirt wurden:

Testacea

a) maltivalvia: chiton, lepas, pholas

b) bivalvias conchae: mya, solen, telo lina cardium, mactra, donax, venus, spondylis, chami, arci, ostrea, anomia, mytilus, pinna.

c) univalvia:

- spira regulari - Cochleae: argonauta, nautil. conus, cypraea, bulla, voluta, buccin. stromb. murex, trochus, turbo, helix, nerita, haliotis.

- sine spira regulari: patella, dentalium, serpula, teredo, sabella.

\section{81 .}

Von num an wurde das Schaalensystem, wie es von Linné festgesezt wurde, zur Grundlage ihrew. Werke ron den Schriftstellern gemacht. Kloin gab sich anch auf diesem Gsbicthe den Schein, als ginge er cinen von dem Linnéischen gesonderten Weg, obgleich seine Methode nichts als cine nüliere Zusammenziehung jener des ersteren, vermittelst der Breynischen ist. Er bestrebte sich zwar, das Innere der Conchyliologie durch Compilation seiner Vorgïnger und ihrer Unterabtheilungen recht weitlüufig zu detuillixen; allcis durch eben diese Vervielfiltigng, so wie durcis 
die Sucht nach nenen Nomen, hat or die Sache mehr rerwirt als anfgehellet. Er theilte sie also $\left.\mathrm{ab}{ }^{a}\right)$ :

I. Cochlides

- simplices seu ex una testae circumvolutione constantes: planae, convexae, fornicalae, cllypticae, conicae.

- compositae seu ex duab. circumvolutionib. constantes: rostratae, volutae, longae, ovatae, ulatar, murices.

\section{IT. Conchae}

- monoconchae: patellae, ansata.

- dironchae (aciuales: conniventes interruptce - inaequales)

- polyconchae: anatifer. balani

- echini marini,

- tubuli marini.

INchr zur Bercichorung als zur Vorbesserung dow Schaalentheoric in der Conchyliologie, trugen durch ilire Limperwerlic Seba, hnorr ${ }^{b}$ ), und dic naturgeschichtichen Reisebeschreiber Sloane c),

a) Klein I'cntamen ostracologiae, sive dispositio natural. cochlid. et conchar. Lugduni Batavor, 1553. 4.

b) Wolfig. Knorr. Deliciae naturae oder auserlesenes Naturaliemabinet aus den 3 Reichen, fortges. von dessen Er= ben, bese hieben von Statius Müller, Nürnb. 1751-1; 66 : Fol. T. 1, 2.

1) Hans Shane a voyage to the islands Madera, Barbados, Nieves s. Chistophers and Jamaica with the natural histor. Tom. 1, 2, Lond. 1707. Fol. 


\section{$-451$}

Brown a) und Forskal ${ }^{b}$ ) bei, besonders die beiden lezten, welche vortrefliche Beschreibungen und Abbildmgen ron naliten Mollusken und selbst von einigen noucn Gallungen lieferten. Allein molh immer hiclten sie Mollusken und Testacien enternet, und erlaubten sich höchstens nur wie Linné die Thiere beider mit einander zu rergleichen. Jedoch Adanson blieb bey diesem blofsen Vergleiche nicht stchen. Zwar betrachtet auch er die Testacéen ron den Molluskicn abgesondert, wnd reihet die ersteren, wie Linné, nach der Zahl ihrer Schaalen; allein er gebrauchet doch nebstdem die äussere Beschaffenheit des Thicres zu Uisterabliteilungen. Nachdem er in seiner Schrift cine weitläufige Beschreibung seiner Reise nach Sencigal ruransgeschilt hat, so widmet er die iibrige Hälfte des Buches, der Abhandlung der Conchylien dieses Landes, und zwar sezt er zucrst dic Terminologie dieses Faches, dann die Unterschiede nach den Schaalen, endlich noch den Thieren auscinander, und becinnt hierauf mit der hlassification wa Reschreibung scibst, wclcher or soviel möglich die Schalen sammt den Thieren, in sehr

a) Tatricl: Rrowne. The civil and natural history of Jamaica, Lond, 1789 . Fol.

b) Pctr. Furskat. Descriptiones animalium avium, amplibiorum, piscinm, insectorum, yerrinm, quae in itinere orientali olservarit, cdita a Diebuhr. $T$, Stius Hauras 2775.4 . 


\section{$-402-$}

genanm Iimpern beifiget. Zur formeren Vertheilung der rinschaaligen fülnt Adanson zwei ganz. nene Gesichtspunkte in die Conchyliologie ein; diese sind der Mangel oder die Anwesenheit des Deckels (opercutum) und die rerschiedene Lage der Augen; die zwcischanligen unterscheidet or nach der Form des Muntels, wie derglcichen Veränderungen am Limnéischen Systeme aus diesem seinem Schema zis erschen sind ").

I. Limaçons univalves

- sans opercule:

- ceux, qui niont ni yeux mi cornos: cymbium.

- ceux qui ont 2 cornes et les yeux placés a leur racine et sur leur côté interne: bulimus, coretus, pedipes.

-. . qui ont 1 cornes, doni les 2 exterieures portent les yeux sur leur sommet: cochlea, haliotis.

- . 2 cornes et les yeẹux placés à leur racine et sur leur côté externe, ou par. derrière: lepas, yetus, terebra.

- . 2 cornes et les g'eux posés un per au dessus de leur racine et sur leur cóté externe: poicellana, cypraea, peribolus.

- operculés:

b) Adanson. Histoire, aat, du Scnégal - Coquillages - Pá ris $275 \%$. 4 . 
- ceux qui ont 2 cornes renflés et por tants les yeux au dessus de lener racine et à leur côté externe: strombuis, purpura, buccinum, cerithium.

- ceux qui ont 2 comes sans renflement et les yeux placés, à leur racine et sự leur cốté externe: vermetus, trochus, natica.

- ceux qui ont 4 cornes, dont les 2 extéricures portent tes yeux sur leur sommet: turbo, nerita.

II. Conques bivalves.

- dont les a lobes du-mantear sont séparés dans tout leur contour: ostrea.

- dont les 2 lobes du manteau forment 5 ouvertures sans aucun tuyau: jataronus, perna.

- dont les 2 lobes du manteau forment 3 ouvertures, dont 2 prennent la figure d'un tuyau assez long: chama tellina, pectunculus, solen.

III. multivalves: pholas, teredo.

Jezt erschicnen entlich die Männer, welche das System und die Menge ron Conchylien, so weit beide bisher beliannt waren, in einem $\mathrm{Mer}$ Iie zusammenfafsten und leztere in illuminirten Kupfern darlegten $\boldsymbol{x}$ ).

a) Neues systematisches Conchylienkabinet, georlnet und beschriehen von Fr. Wilh, Martini - fortges, von Chemuits. 12 Bände, Nürnb. $1769-1788$. 4. 
Seba, Gualtieri, Bomami, Rumpe hatten schon hiczu den Grmat gelegt, Regenfufs schicn ein gyleiches hupferworli, und hiezu den Anfung durch dic illuminirten Abbihungen ats dem $\mathrm{Wience}$ Conchylicnlabincte reranstalton, fieven das system der Conchyliologir vollenden zal wollen; atJein die Terle beidre blieben unvollendet. MTartiui fufste endich, wie schon chmals Lister, den nünlichen hähnen Lntschlufs, dic bisher gängigen Systeme durch wechsolscitige Verenigrmg zu ergünzen, wnd alle Conchylien, soriel mürlich, in illuminimen fupfern und in cinem Werle zusarnmenzustellen. Lister und Martini verdienten daler wirlitich, wären sic die Lifnder und nicht die blotien Compilatoren in dem Systeme, gheichsam als cin gemeinsamer classischer Autor herausgeschrieben zu verden. Ihnen bleibtaber doch der Ruhm, wenn gleich nicht so rortrefliche Monographen, doch die voliständigoten Iconographen, jener der alten, dieser, gleich einem l'enuant, Latham, Laceperde, Bloch bei den rorhergehenden Jilassen der Thiere, der zweiten Periode der Conchyliologic zu scyn. Leider, starb zwar Martini schon mit der Vollendunses des dritten Bandes, aber zun Gliiche fühte Chemnitz, Prediger in Coppenhagen - cin noch niberer licnner des Limnéischen Systemes - das angelangene ITerk bis zun zwölften Bante fort. Was System, woraf urspring- 


\section{$-455$}

fich dieses TVerk erbaut ist, ist jenes ron Gessner mud Lister, nänlich der Aufenthalt dicser Thiere. In den ersten acht Bïnden wird ron den MIeersclmecken, in den übrigen von den rechts oder linlis gewundenen, ron den Land- nind Flufsschuecken und einigen nachgetragenen Conchylicn frchandclt. Dic weitcre Unterabtheilung ist ron linne, wolcher in rielen einzelnen Charahteren and Gattungen berichtigt und revolstindiget wird, hergenommen, und latutet al:o:

A. Testae univalves

- non turbinatae:

a) fistulosae seu tubulosac: tubuli

b) rasculosa: lepas, patellae.

- turbinatae - cochlides - ellypticae, planae, volutae, claviculatae, trochiformes.

B. Bivalves.

- cardine non dentato

a) cardine foveato, cartilagineo: conchae longae, extremitalib. inaequalibus (mytuli, pernae, pimnac, pholades, pectines).

b) semicardines seu cardine ligamentoso: ostreae

c) cardine crenato: arca $e, c$.

- cardine dentato.

-valvis conniventibus: spondyli e. c.

- valvis hiantib.; fistulue, solenes e.c.

C. plurivalies: pholcis, anuiffor. halunus. 
Währond dieses liuhme Unternelimen ausgegefuihrt wurde, machte sich Janus Plancus durch die Beschreibung von verschiedenen Conchylien und andern Sceproduliten, an dem Ufer ron Rimini berühmt. Geofroy wiedeshohlte in scincr Abhandlung über die Conchylien um Paris, da; System Limé"s, nach der Zahl der Schaalen, und beschieb das Acussere dieser Thicre nach dem Beispicl? des Adanson. - Schrüter trug durch Merausgabe des Gottwalitischen Conchylienhabinettes - durch semen Versuch iiber den inneren Ban der See - und ciniger ausländischer Frd - und Flnfschuechen, welche er eben so gonars, wie Chemnitz vor ihm dis Schaale des nautilus, zer. gliederte - durch seine Geschichte der Flufscon. chylien, besondors jener cier thüringischen Gewäs ser - durch das Nanenregistor zu dem NTarrini. chomnitzischen Trerlio - endich durch seine Eina leitung zur Conchylicuhenntries nach Isimné. Durch alle diese Verhe trug diescr ämsige Vorfus ser, sowohl zur Verbreitung der Conchyliologie viberhatpt, als besonders der Linnéischen bej. Gronov, Dom a), Spralowsky b), Penmant c),

a) Janat. Born. Teslacea musei cesarei vindobonensis, Vino dobonace 1780 . Fol.

b) Jo. Spaluwsky. Prodromus in systema historicum testaceorum. Viennae 1 - 5. Fol.

-) Penuant, British Zoulogy. Tom. 4tus, - crustacea, mollusca, testacea, London $5777^{\circ}$. 
Scopoli. Eeshe behiclen in ilren Schinten gans. rlie Althelinngen der Vüuner und elsen so anch der Tentacéen ron Limé bei, und Blumenbach wich num darin ab, dals or dic Secigel mind Mecrstabe zn eince cigenen Ablicilung "cruslaced" mul dam eine andere, infusoria" genannt, lesanshob. Allein molu Teründerungen an dem Limnerischen systeme als allo dirse erlaubte sich Drufriere, dessen Arbeit in der Encyclopedic, leider! curch den Tod unterbrochen, von Lamarch aber soch fontgesezt wurde. Tr bestätligte zwar die beidon Ilaupthlassen nò blutlosen Thiere, nümlich der Inscliton und Viurmer, romehrte aber doch mit Blumenbach die Ordnungen der lezteren bis auf scchs: vers infusoires, intestins, mollusques, echinodermes, testacées, zoophytes. Obgleich or wie Linné die Mollusken und Schaluluicre trennte, ma leztere nach der nämlichen Zah! der SchaaIen abtheilte, so ist er ihm doch darin entgegen, dafs er die Nereiden, Aplroditen, Amphinomen noch zu den Intestinen rechnct, und die cigentliclicn Molluslien nach dem Mangel oder der Anwescnleit ron Tentalieln sonderte (suns tentacules: mammaria, ascidia, pedicellaria, planaria, fas. ciola, teihys. Ternaea, biphora - woec des terziacules: actinia, hydra, holotlumin, seguia, clios Doris, aplysia, limax, myxine, physopleora,

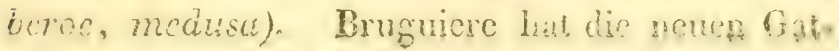




\section{$-458$}

tungen theils ans den Reisebeschreibern nud anderen Schriftutellem zusammengetragen, theils hiezu mehere Arten erhoben, seine ganze Arbeit aber auf vortrefliche Beschreibungen und gleich genauc himper eingeschränht, wodurch or das Muster der Nachahmung für seine nacholgenden Landsleute wurde.

Micnit endieet sich fü die Geschichte dex Conchyliolngie cine Periode, wo leztere eniwoles auf die Zahl der Schaten, oder anf den Aufenthalt diver mhiere oder anf die Veremigng heider Tiethoden, so, dafs man den Aufenthalt als das Entscheidende, dic Schatic als das muterecordnete rie in der des Listers und Chemnitz ansah, erbaut wurde.

\section{82.}

Alic Schnecticn, sowohl beschaalte als schaaionlose, licben zwar mehr das feuchte als das trockno Element, weswegen sie remmuthlich ron den alteren Zoologon seil Plinius ohne Unterschied unter den Wasserthieren abgehandelt, manchmal sogar in die Eencmung der Fische mit cingeschlosscn wurden, und z. B. die Sepien u. s. W. noch bis jezt ron den Secbewohnern als Fische benent werden. Jedoch alle haiten sich auf festerem Grumd und Boden anf, nur mit dem Unterschiche, dues dieser entweder bios ron sciner tiefen I age in Thïlers, vom Thaue befeuchet, oder sellyst in 


\section{$-459$}

Flïssen gुelagert, oder von den tieferen Mecreswellen bedelit ist. Welche wunderbare, aber gesetzmäfsige Absturfung hicrin triff man nicht bei den Seconchylien an! Durchmusterl man bei einer starken Whbe die jezt von Mecereswellen auf cinige Zeit rerlassenen Felsen, oder den Veeresgrund, so erscheinen die Fielsen und ler sandige Boden belebt. Alles zischet und ranschet, die Schneclien öfnen ihre Schaalen, die Aphrodicn, Nereiden und Meerwürmer bohren sich mil dem Liopte aus dem Sande heraus, und alles entledixet sich der verdorbence Luft, rersieht sich, ehe es sith wicher gegen die gesetzmälsig zuriklehronde Fluth verbirgt, durch Einathmen mit frischer, and alle Thiere scheinen nun so eine gleiche Ebbe des Meeres in inren Verrichtumgen auszudrüiclen. Jie Schnecken mit schraubenartiger Schaale z. B. buccinum lupillus, persicum, cassiala bezourdica, trochus nnesres, minutus, luúio u. s. wo nehmen dipjenigen Felsen des Viceres ein, wclche zunachst dem Gestade liegen - die Patellen, Chitomen lilcben an Felsen, welche schon weiter ron Arm Ufer enternt sind - cber lier graben sich auch die Pholaden z. B. pholas dactylifer, crispes, in das Innere der Fallibrochen hincin, dic Terebellen strochen aus den aus Sand verfertigten und im steingen Boden befindlichen IZ̈hren ihre viel. fodrgen branchion lienus: mun erscheinen an des 
inmeren Grinzlinie von Whbe und Fluh ans dem Boden licrans grofse Strelicn von Sandruhren, wele ron dén Holothmien bewohnt werden, auf sie fulgen in der Lluene Conglomcrate vou MIytilcn, glcichsam in Eänken, die Solcn, Cardien u. s. w. Lalten sich in dem Sande vergraben auf, die Austern bilden ganze Lager zusammen, und sind öters, wie auch die Terebratulen, Anomien, mit cinem Walde von fucus bedelit. Die Balanen endlich überzichen Felsen, Muscheh, Schiffe u. s. w. sowohl an der liüse als anch in der hohen See. Vier getranct sich aber so, da doch alle diese Thiere inmer auf festem Boden sich aufhalien, und ron blos bethanten Plalzen, durch seichic Flüsse bis in die Tiefe des Aleeres sich erstrechen, die Absuffungen ihres Aufenthalies angeben zu wollen? ja, da cin Theil der cinschaaligen in Ineere, cin anderer in Flüssen, oder in Thälern oder Waldern oder selbst an Mündungen dè Wlisse ins Meer lebet, wähend freilich alle vielschaaligen, und dic Allermeisten der zwoischanligen blos in Meere gefuncion werden, wer getrauet sich hicr, 'sie nach ihrem Aufenthalte in Land- Fufs - und Meerschneclien zu unterscheiden, wind so die rerwandtesten auseinander za reissen?

Eben so einseitig ist jene Ansicht, dicse Thiere nach den Schaalen zu classificiren. Zwar ist das 
Fnochengerïst ein twichtiges Organ, um hiornacts die animalischen Geschöpfe zu charalterisiren. Dasselbe ron dem Menschen und Süngthieren an, durch Vögel, Amphibien, Fische bis anf Schncchen, Inseliten und Zoophyton verfolgend, sieht man cin, dafs es allmählig von Innen nach Aus. sen rükt, statt der lnochichten, die schwammichte und dann die knorplichte Beschaffenheit annimmt, endlich auf jener Stuffe, wo sein Saame gleichsam mit der jezt vorherrschenden Tautbildung zusammenfillt, mit der Hautbedeckung sich ilentificiret, und als ünssere Schaale oder Frusto, und zwar nicht mehr sowohl als Stütze, sondern als wahre Last fiir das angewachsene nakte Thier, und als blosser Rest eines Sheletes. crscheinet. Selbst bei den Mollusken und Testacéen wiederhohlet sich nochmals und eben so allmählig jene architeltonische Succession. Die Sepien und Loligo haben von dem Fnochengerüste nur noch einen linorplichten Wirbel als imeren Träger des Kopfes, ron der knöchernen Rückensä̈ule ist nur noch ein schwammichtes Bein, gleichsam als Andeutung untor der äusseren Hautbedechiug des Rückens verborgen. Von nun an ist auch in Kopfe kcine Spur mehr von einem Finorpel zul finden, whit roux dem Rückenbeine der Sepia, ist an Aplysicn, Do. labellen, Bullaeen, dem Limax, nur noch cime breitliche, biegssame, linorplichte Schaale, itrnlich ciner 
Schinpe, jedoch einenfulls nock unter der Haut des Rïickens zurükgeblieben - bei testacella und parmacella ist diese Schuppe, obwohl noch lilein, auf die äussere Obcrfliche gegen das hintere Ende des Rücliens gotretten - bei Chitonen wiederhohlet sie sich Dachziegelfümig längst den ganzen Rüchen - bei Patelien nimmt sic nun zum ersten Male die Form einer Schaale, welche das ganze Thicr bedelit, an - bci Bullion, Cypreen beginut. sich dieso Schaile za winden, nad stellet gleichsam nur chac cinzige Windung dar - bei Meeroh= ren, Natica, Nerita lesonders bei Planorbis, nimmt sie mehreic, aber loch sich noch nicht von dem Horizonte erbebende Windungen an; So wie sich jezt ron der natica und nerita an durch alle Cochliden lindurch allmällig die Windungen vermohren und thurmartig in aic Höhe steigen, so wächst auch mit ilnen die Vieite der Mündung, und bei denen, wo sich ein Deckel (operculum) einstellt, auch ebenfalls lezterer, so dafs er gleichsam als eine zweite Schale dadurch die Nähe der Eivalien andeutet. Unter diescn sind noch bei Anomien, anch bei Austern und zum Theile bei Tellinen die beiden Schaalen sehr ungleich, und wie bei Patellen, denen sie eigentich hier entsprechen, platt - mit Cardia, Venus, Chama, Donax, mit den Mytilen, Pimen und Solenen werden sie ganz glcich, ctras crhüht ja zulezt rührenarlig, 


\section{$-463-$}

und num tretten - wie bei cinem Theile der Ein. schaligen nebst der Schaale noch ein Dechel -hier nebst den beiden Hauplschaalen woch kleinere Stücke, in Pholaden, der anatifa und dem balanus auf. Wohl herrscht so auch in den Scliaalon cine gewisse gesezzmäfsige Succession. Allein dic bisherigen Conchyliologen waren schon zufrieden, den Unterschied in Hinsicht ihrer Anzahl angedeutet zu haben, und eröfneion daher gleichgültig bald mit den einschaaligen, bald mit den rielschaaligen diese Klasse; noch sorgenloser aber haben sic in der Aufeinanderfolge der Gattungen rerfahren, und es war ihnen gleich viel, die Porcellanen oder Buccinen, die Herzmuscheln oder Austern, die Solenen oder Pholaden zuerst zu sctzen. Iläto man sich consequent verbleibon wolion, so müfsten auch dic Serpulen, Tubiporen 1. S. W. unfer die Schaalthiere gerechnet worden, was man freilich und zwar mit Recht, weil sie nach den Thieren verglichen, himmelweit ve1schieden sind, nicht that. So natülich aber auch die Testacéen nach den blol'sen Schaalon geordnet werden hünnten, so wïren doch, wic Chemnitz bemerkt, dis Zähne allzuschr variend, die Gleichheit oder Ungleichheit der Schaalen, wie Lamarck behauptet, ein al zu gezswungenes Merkmal, um darnach natïliche Gruppen zu bilden. Jedoch der Hauptwiderspruch gegen die 
Schantulinoretilier bieibu immer dieser, duls vicle Prstaceen in der Natur sich blos durch die Shimale, nicht aber nach den Thieren ron den naliton Molhstien unterscheiden, bei den Schriftste'lein abre doch beide ron einatider granz abgesondent sind. So ist das Chiton nach der inneren Simblur mit den nalien Golluslien verwandit, und doch mofs es wegen den Schaalen unter den muliiviturn sichen - die Testacelle lommt mit den fincix und dieser grörstentheils mit holix, die mhen Salpen und Ascidien mit den Bivalven Therein, mel doch sind sie wegen den Sclualen and der Natitheit ron cinander getrennt. - Miris(c) aber ron rechtswegen nicht anch die Sepia, Any, Plourobranchus n. s. w., weil sic cine un i. ver Mant verborgene Schaale tragen, von den malien Mollislien zu den beschalten rersezt wero An? Tohin will man endlich die hycelaea rechman, ron der Curier aussagt, dafs ihre Schaale als -infach oder auch als zweifach a) angenommen rerden liönte?

Zu wenig hat man bisher das Thier selbst beribichtiget, und statt def schaalen gar nicht die

a) , La coquilie ditiyale n'est en effet ni bivalre, ni univalve; bivalve par la forme, elle a cependant ses deux parties

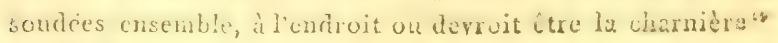
annal, d, mus, T. 4.. p. 225. 
innere Strulitur dieser Geschöpfe untcreinandes rerglichen; kein Wunder daher, dafs linné die Inseliten ror den Mollusken und Testacéen stellen, und die Würmer mit diesen verbinden konnte, dals er nach so einzelnen Merkmalen der Schaale die heterogensten Arten in die nämliche Gattung, wie z. B. helix, ostrea, besonders aber anomia ist, geworfen hat, ja dafs Linné und Gmelin z. B. die Tingula anatina unter den einschaaligen als patella unguis - und Chemnitz, welcher ihre beiden Schaalen bemerlite, unter den Pimen anfzählte. Nur dieser Unkenntnifs mit den Thieren der Testacéen ist es zuzuschreiben, dafs seit Aristoteles bis jezt, die Mollusken von den Schaalthieren abgesondert standen, und dal's es Linné kaum wagte, nur die parallele der Thicre beider, nach dem äusscren, öfters falschen Scheine anzugcben, und dafs Adanson blos die Oberfläche der Thiere beschrieb. - Nicht blos die Bedeclinng, sondern auch das Innere dieser Thiere muis crforscht werden, um ihre Vesenlieit, und ihre Verwandschaft zu einander bestimmien zu können.

Wie Kinder haben bisher die Zoologen blos nach den glänzenden Schaalen gehaschet, und gleichsam das Gold mit dem Flitter verwechselt. Freilich hat auch diese Spielerei und Liebhaberei ihren Nutzen gehabt, und nur durch sie rerleitet, haben uns Fürsten und Privalpersonen, die reichc- 
sien Sammlangen ron Muscheln hinlerlassen. Nun follt uns, da wir die Hülse der Fruchit liennen, nichts mehr, als auch den Fern derselber zu untersuchen, und ehen so liabinelte ron den bewohnern, wie wir sie von ihren Schaalen haben, zu errichten.

\section{85.}

Pol. Poli, liniglicher Leibarzt in Neapel, ist der erste, welcher diesen Weg einleitete. An der Füste eines so fruchtbaren Aeeres wohnend, war er nicht zufiedon, wie Limé und Adanson diese Thiere blos ausserlich zu verglcichen, oder die Vergleichungen juner zis berichtigen, sondern er antersuchte das minere dicser Geschiopfe selbst, and fand hicrin bei aller Ueboreinstimmmg so tiele Verschitricnheit, dals or auf diesen Grund. and Boden die Conchyliologie zu crbauen anfing. Lister und Swanmerdam hatien schon die Anatomie der Hausschnecke gegeben, Dehaye hat die innere Eimichtung des mylil. esculent. obwohl in mateutichen fupfern dargelegî, Löwenhöck und Baster haben jene der analifer. liennen geletort; yor allen aber ist es Swammerdam, welcher durch seine Zergliederung und durch seine höchst in. struktiren Kupfer ron der Anatomie der Gartenschneclic die Bahn gebrochen hat, und dessen Beispiele num Poli in der Untersuchung der zwei- 


\section{$-467$}

and rielschaaligen folgte. Er hat diesen seinen Schatz ron Entdechungen in dem berühmten Werle über die Testacéen beider Sicilien dargelegt a? woron die erste Hälfte des ersten Bandes der Mhy. siologic und Zoologic dieser Thiere, dic lcate, wo wie der ganze zweite Band, den meisterhaften fin. pfern und der ihnen parallel laufenden Eithlärung in italienischer und französischer Sprache nach dux Limnéischen Terminologie gewidmet ist, Gleich in der Einleitung hebt er ron der Erzcugung dex Schualen und zwar von der falschen Meinung Rt, : numur's an, wolcher sie fü ein liristalisirtes, an organieches Aggregat von einer ausgeschwiztcs Materic des Thieres herrührend, ansah, und bohauptet dargegen, dafs die Materie zu Perlen und Schaten in einem zunächst dem Herzen liegenden Sache bei rerschiedenen Schnechen auch in manchfaltiger Farbe zubereitet, ron da durch dio Blutgefuifse in den Mantcl gefiihrt, und mit der äussersten an der imnern Wand der Schaale ankle.. benden Schichte jenes Mantels abgesezt werde, and in abwechselnden Blattern diese cben so bilde, gleichwie nach Dühamel das Periost in Funochen, oder der Bast in das Ifolz des Baumes ungewandeh. werde. Er untersucht hierauf ihre chemischen

a) Joh. Xav, Poli testacea utriusque Siciliac eorumq̨ue histow ria et anatome. Parmáe 3791 . II. Vol. Fol. 
Desianducile a), beginial jezt den physiviogischers Theil, nämich ron den Organcn der licspiration, von den Orarion sciner sogenumben happenten (subsilientes), wedchen die mïnnlichen Geschiechtstheile fohlen sollon, ron den Mrusheh, Verdanungswerhzengen; er sagt ats, dals der Vänegrad dieser Thiere immer geringer als jener der magebenden hlhmosphine sey, bafs ihr. Blut ans crtivr, welcher nit sïnen brane, und aus $s c$ rum bectehe, welehes wie Salzwasser schmeclic,

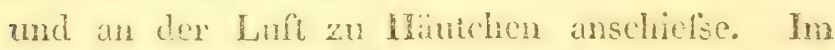
driten Theile liefert er cinen Auszug der Systene von Listu, Ilein, Agenvile mo Linné, lälst sich iiber die Tcrminologie dieses Faches aute, mul beschreibt scine finstruinente, welche or zu diesen Zergliedenungen gidurathehe - Nin hommt es denn an die Beschreibung der victschaaligen und zwcischaaligen, von welchen lezteren, nümlich den aweischaaligen, der zweite Band dic Iorlsetzung endiaill, und der dritte, leider wegen dem Exïs des Verfasser's nach Sicilien noch immer nicht erschicnene, die Anatonic seiner reptantia und brachiata liefern soll. Diejenigen Arten, von denen er Zergliederungen und matomische Abbil-

a) duae uncise testae pinnae continent vitriol. 马ji $^{\mathrm{ji}}$ selenit. $\zeta^{\text {vjii. }}$

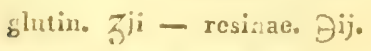

RC kibersimam acris acido mephitici copiam. 
Jungen in illuminiven Fipforn, wolche wahrhast Genaiden glewhen, harlegte, siad: chimm cine reus, lepas, balanus, anatifere, pholas acetylifer, nuga piciorum, solme siligua, sirigilatus; tellina planata, laciea, chana cor, ardium ru. sticume, mactia meapolifana, donax trunculus, renus chione, spondylus gaicerpus, cama griphoid. calyeulut., arca noe, pilos. ostrea jacobuea, sdutis, anomia caepa, conica, mytilus communis, Tithopleag., pinna notitis. Jedoch stimmen cinige der anatomischen behauphugen Polis gar nicht mit denen eñes swamertam und Curice übrein. So gesteit er selbst, dalo es beinahe mglublich sey, dafs diese Thiere licin Nervensystem haben "), dafs ihre Lympligelifse so ziemlich das Aussehen ron Nerren tragrn, aber doch solche nicht siyn hömten, weil er sie mit Qnelisiber anszisprizen im Stande war b). Frein lich ist an der Eclumgenen Auspprizung dieser Organe, indem es der felehrto und aufrichtige

a) T.1. p.44. "quisnan sibi persuadebit, in cunctis menmoratis vermibus nullum unquam nervorum vestigimn ineqse? hoc sanc arduum ac incredibile esse nos quoque fas temur".

b) p. 49. "nulla molluscorum pars adeo nervorum habitum mentitur, ac vasa lactifera. Tempore autem procedente ed pervenimus, ut non moda corum truncos, sed etiam mulliplices ipsorum surculos, in quos dirinuntur, hydrargyro complere potuerimus, unde errorem nostrum perspicue doteximus." 
Verfasser selbst aussagt, nicht zu zweifeln; da er aber doch ihre Verbindung nit Blutgefäfsen nicht dargethan hat, im Gegentheile ihre Verzweigung, ihr gangliöses Vorliominen, dic bcim Galkate nisiren durch sie erregten lempfindungen and Zuchingen, und inre Lage wie bei lnseliten sie firr Neren anzunehmen berechtigen, so ist jene Einspritzung für nichts anders als eine Zerreissung, oder als ein gewaltsames Vordringen des guelisilbers durch das weichere Nervengewebe anzuse. hen. Allein ausser allem Zuweifel sind jene Eighenschaften dieser Thiere gesezt, woranf er das System der Conchyliologic zu crbauen gedenket. Dals sie im Vasser Sprünge machen, oder anf dem nakten Unter leibe liriechen, oder sich zur be. wegung und zum Fange der viclen Tentalieln am Kopfe bedienen, - Bewegungsorgane sind also der Gesichtspunkt, ron welchem er das erste Sy" stem, nicht auf Schalen sondern auf Thiere sclist erbaut, in drei Ordnungen, und zwar die erstere im ersten Rande aus 15 Gattungen, im zweiten aus 18 bestehend, folgender Masson aufstellt:

I. Mollusca subsilientia - longo pede insiructa, rupibus affixa aut non, omnia acephata et oculis carentia - (mullivalvia ac bivalvia).

1. Fam.tracheis binis atque pede inst.ructa: hypogaea (solen, pholas, tellind inacquivalvis), peronuere (isllinia), 
- calista (venus), arthemis (venus exolata), cerastes (cardium).

2. Fam. trachea unica atque pede instructa: loripes (tellina lactea), limnaea (mya pictorum, mytilus cigneus, anatinus).

3. - trachea unica, pede nullo: chimaera (pinnae) callitriche, mytili.

4. - trachea abdominali pede nullo: pectines, spondyl. Bstrea lima, bullata.

5. - trachea nulla, pede autem instructa: axinea (arca pilosa) glycimeride.

6. - trachea nulla, pes nullus: daptine, area noe, barbata, peloris (ostrea edulis, cristata), echion (anomia laeva, squamula), Criopus (anomia imperforata).

II. reptanlia - Tati pedis auxilio limacum more rependo progrediuntur, ommia capite oculisque instructa (univalvia).

III. Brachiata - Tydrarum modo, piuribus brachiis pracilue sepia, nautilus, tritones, terebellae, serpulac.

Poli hat durch Berilisichtigung der Thicre statt der Schaalen, diesen Zuweig der Zoologie mit seln umständlichen Zergliederungen, Beschreibungen und Abjildungen ron jenen bereichert; leider! ging aller dicse viurdignug doch nicht so worit, 


\section{$-472-$}

dafs er die Mollusken und Testacéen unter sich rereinigte. Beide stehen daher noch immer getremt ron einander, und die Testacéen mit Ausschlufs der. II (nluslien, ron denen er blos die Sepia, ohne den Grund anzugeben, dahin rersezte, sind der einzige Gegenstand scines Verles. Allein auch ron dicsem abgesehen, ist seine nene ththeilung nichits weniger als gegründet, und schon daw durch lüchenhaft, dafs bei den beiden ersten Ordnungen die Art der Bewegung, bei der lezteren die velen Arme an hopfe - also zwei verschiedene Gesichtspunlite - gewählt sind. lemer wie lönnen wohl chance und arca, welche am Felsen angुeschmiedet sind, wie hönnen Mytulen, Spond) len, Kämmo und Austern, welche auf dem Sande oder an Felsen angeheftet, ganze Bänle bilden, muter die hinfenden gerechnet werdon, da ilmen doch durch diese Fixirung eine solche Bewegung Jenommen ist? lir gesteht es ja im Verlaufe von den Pimen, Mytilen, Austern u. s. w. selbst, diafs sie jenes Fufses zum hüpfen entbehren! An allerseichtesten sicht aber seine dritte Ordnung da, und in diese ist beinahe alles zusammengeworfen, was nirgenis anders wohin pafste; daher denn die heterogensten Geschöpfe, als z. B. Sepien, Scrpulen n. s. w. sich beisammen finden. Würden nicht so nit gheichem fiechte als die Sepia, auch die Ne* dusen. Acinien u. s. w. wegen Jen vielen Tenti- 
Inzh un hen linge in dicse rritte, dic schanjen?sen Landichneclien, weil sie cbenfalls hiochen, in dic zweite Ordnung rersezt werden liminen? mud unter welche Ordumng würde er das Chiton, welches lrichn, und doch zuglcich rielschalig ist, hringen? - Aus allem erhellet, dafs Poli, diesen Tidersprüchen gemäs, sich noch immer nicht rechl von der Schaalcutheoric losmachen Bomnte, and dafs scine Ordnungen cigentich jenen nuibi-und multi-zatzin des Limé cntspredien. Thitte er ganz einfach einige der ron inm ange-

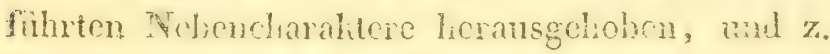
B. mit Aristoteles diese Thicre in solche, die sich bewegen oder bewegungilos angeheftet sind -.. oder in solche, dic cinculiopf haben oder hopflos sind, abgetheilt, so würde er lange nicht so vicle Widerspüuche begangen haben, als wekderer sict wintilich schuldig gemacht hat. Doch eben dieses an scincm Systeme zu bessern, war scinm Nacho folgem vorbehalten, und inm bleibt das Foxdionst, den Blick von der Schaale auf das Imnere des Thicres selbst gerichtet, dis innere Strulhur der zwciund vielschaaligen Mollusken enthüllet, auf Merk* male zu neuen Abtheihmgen aufmerksam gemacht, und endlich durch dieses sein Urtheil über Linne in Hinsicht der Parallele der Thiere, der Mollus Jen und Tesiacécn , Rinzaci schtentian, motiuscorum genera ad testuce tratucendi, cssio om- 


\section{- $474-$}

nino erroneam ")" eben diese Lücke noch mehr in Anregung gebracht zu haben.

\section{84 .}

Cuvie:. Cuvier ist der erste, welcher diese weite Lïclie finhlite, und in ihrer Verbesserning ein Muster allgemeiner Nachahmimg auf franzö|sischem Boden yvurde. Wohl einschend, dafs die Thiere zwischen beschaalten und schaalenlosen Schneclien nicht blofse Anspielungen, sondern selbst wirkliche Aelnnlichliciten und Verwandschaften unteremander erlitten, wrat er nicht zufrieden, wic Linné und Adanson, jene hlos anzmereben, oder wie Poli blos die Thiere der Testacéen zu zergliedern, und hiernach zu reihen, sondern er hob den Unterschied nach der Schaale orler Nakilicit als geringfügig anf, und vereinigte die Trstaccen und Mollusticn unter den femcinschaftlichen Namen der Lez!cren, ja er ging in seinen Veränderungen noch weiice. Limné hatte ohne Ribicicht auf imnere Strukbur alles noch so heterogene unter dem Titel: "W'urmer" zusammengeworfen, und diese den Ynscliten nachigesezt. Cusior machte die Testacéen und Schnechen von den Würmern los, errichtete für sie eine eigene hlasse: „Mollusques" und sezte sie, weil sie Venen und Arterien nebst einem Herzen, und dann Branchien vor den Inscliten

a) $\mathrm{T} x, \mathrm{p}, 2 \%$ 


\section{$-475-$}

Foraushaben, uminitelbar ror diesen, und zwar gleich nach den Fischen, wic es schon §. 55. S. I.1 näher crörtert wurde. Was aber Poli lange vorher nur als Nebencharaliter anführte, dieses gebranchte jezl Curier, um Ordnung in dicse nenc Tilasse zu bringen, und sonderte sie hicmach in scincm Werke "tablene élémentaire" in drei $\mathrm{Ab}$ theilungen, welche sich blos dem Namen nach ron jenen seines Vorgangers unterscheiden. Freilich sah or in der Folge ein, dal's diese Anzahl ron $A$ b. theilungen vicht alle müghiche Mollushen umfursic, nut z. ID. nicht anf clio, hyalaea, pnemnoderma, ptcrotrachea pafste, dafs diese lezteren durch den Mangel ron Tentalich, und durch die Anwesenheit cines cinzigen Herzens ron den cephalonocies, durch die Gegenwart des liopfes ron den acephali, durch den Mangel der lianchschibe zum liriechen von den gusteropodes sich unterscheiden, er fand sich daher gezwungen, nebst obigen drei Ordnungen filr diese leztrem noch eine vierte zu bilden "), welche daher diesem seinem Sysicme ron uns jezt beigesezt wird:

IMollusques

1. criphulopodes - à corps en forme de sae, ì teite libre, couronnce par les pieds: - sepia, octopus, argonauta, nautilus

- cmmoniles, orlhoceraites, camerines -

a) Annaì, d, nus, T, \&, p., 223 . 


\section{$-4: 6-$}

11. petéropodes sfu pinnata - corps libre, nageant, the distincte; point d'autre membre que des nageoires:

cho, pheumoderma, hyalaea, pterotrachea.

III. gastéropodes - rampant sur le ventre, ayant une tête libre et mobile. -

a) nuds: limax, tethys, aplysia, doris ( - tritonia, aeolis - ) phyllidia, scyllaea, thalis, lernaea.

b) testacés:

- à plusieurs pièces: chiton

- à une seule pièce,

- non spirale: patella,

- spirale: halyotis, nerita, planorbis, helix, bulim. bulla, turbo, trochus, murex, strombus, cassidea, buccinum, voluta, olisa, cypraea, conus.

IV. acéphales - sans tête distincte -

a) nuds: ascidia, salpa

b) testacés:

- suns pieds et à coquille inéquivalve: ostrea, spondylus, placuna, anomia, pecten.

- munis d'un pied, à valves égales, manteau ouvert par-devant: lima, perna, avicula, mytulus, pinna, anodontites, unio, tellina, cardium, mactra, venus, chama, arca.

- ...... à coquille ouverte per deux bouts, à manteau fermé par desant: solen, mya, pholas, teredo. 
- sans pieds, munis de deux tentacules, charnus, ciliés, roulés en spirale: terebratula, lingrala, orbicula.

- munis d'une multitude de ientacules arículés, et ciliés, rangés par. paires: anatifa, balanus.

Tat Poli sein Verdicnst durch dis Zergliede. mug der viel- nud zwcischanligen, so hat dieses Curier durch dis Anwomie der nakien Mollustere mal der cinschaligen br gündet. Früher schon hitle or in scinci Naturgeschichle cinzelne Arten als Gattungen angedeulet, und cinige z: D. avicu-

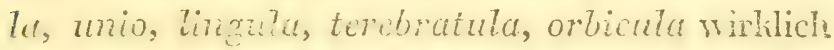
dazu erloben, Jez! sih ce anch die bisherge ATangelhaftighit in Bhbme ma Charakerisirung der Gattungon, wegen Unwissenheit in der Struka tur dieser Thicre $\epsilon$ in, wnd nun beliam ev, unter. stiizt yon llecinchmenden Mämnern an der Tiiste des europäischen Meeres, besonders von Lomberg in Hare, und ron Peron, welcher eigends zur Bercichewng des habinetles der vergleichenden Anatomie der Expedition des Fapitains Baudin nach Feuholland mitgegeben war, dic Gelcgenheit, die meisten Gattungen und selbst Mrten anatomisch zu untersuchen, die neuen Gattungen reisender Gelehrte z. B. der thatia ron Brown, der salpa und pterotrachea von Forstiahl, des on chidium a) ron Buchannon näher zu prüfen, und

a) Sur l'anatomie de l'onchidium Peronii anualo du mus, T, jo p. 37. 
Gischlaupt dic Synonimien der Schriftsteller hierin zu berichigen. Auf solche Weise gingen aus sciner Hand die neue Ordnung "pteropodes" und lier hyale und pncumoderme ${ }^{a}$ ) - unter den gasteropoden die tritonia, aeolis, slaucus b) -acces c) che alle Schate - der plcuirobranchus wit rerborgener Schatale - die testacella und marynacella mil dor likinen schuppichten Schaale am Ende des Riickens, als ganz nene Gallumgen hervor; von alien diesen, wie auch ron den Gattungen aplysia, doris $\left.{ }^{d}\right)$, scyllaed, thatia und sulpa e) Tinux und helix (stagnatis, cornea)f), intinina and phasianellat (Eunareh), helix viipara,buccinum undatuni, murex, strombus.5), tothys h) ist die Anatomic in eigenen Abham gen nit limpfern und Beschreibungen nindergelogt. Vor ailen aber hat er den Typus der imewen StruTitur der einschaaligen in der Zorgliedelung des limax und helix gegeben, wiml hiedurch alle bisher falschen NIciuungen beseitiget. Lister

a) sur l'anatomie de l'Iyale et Pneumoderme annal. d. mus. T. 4. p. 223 .

Di) - . sur la Scyllece, l Lolide et le Glaucus annal, d. mus. T. 6. p. 416 .

c) sur les aceres. annal. d. mus. T, 16, p. x.

d) sur le Doris, annal. d. mus. T. 4. p. 447 .

e) annal. d. mus. T. 4. p. 360 . f) ejusd. T. 7. p. 140.

s) ejusd. T. 11. p. 121. - p. 170. - p. 447 .

h) cjusd. T, 12 . p. 257 . 


\section{$-479$}

lieit die Speicheldrüfse für ein Epiploon, die Blase, welche in die sogenannte Gebämulter cinmündet, nach Swammerdam den Pupur ábsondern soll, und deren Fimlition bis jezt noch im Zweifel isi, hielt er fïr den Hoden, die 'Zunge für den Trachea - Redi nahm die Gebümutter fur den absleigenden Samentianal, und er und Swan:merdam beschrieben den eigentlichen Testiticl fü den Eierstock und die blasenartigen Anhängsel an. dern Gebärmutterschlauche für Hoden - Poli rer rvechselte die Lymphgefälsc mit den Nerven. Alle. diese Irthümer hat Cuvier aus der Natur seibst: berichiget. Durch seine Zerglicderungen ïherhampt sind wir nun gewifs, dafs dic susteropoden und pleropoden Ifermaphroditen sind, und sich wechselseitig hegallen; jedoch mil der Ausnahme, dafs bei helix stagnalis, wegen enfernt stehenden Ausgängen beider Ceschlechtsorgane, die Begattung eines Indiriduums mit melireren zugleich statt finden hann, bei buccinum undatum, strombus, voluta, murex aber die Geschlechter, änlich den Dioecisten unter den Pflanzen, an verschiedere Indiriduen rerheilt sind, während nach Poli's und Anderer Beobachtungen, bei den zweiund vielschaaligen, jedes Individuum sich sellost ohne alle Begattung befruchten soll. Aus seinen Beobachtungen über die Cirkulation des mehr bläulichten Blutes hei diesen Thieren geht hervor, dals, 
vie cs Summerdam in seiner Bibel ict Natur blos an der Sepia nachweifst, alle Cephalopoden das Hicrz dreifuch, die Gasteropoden, Pteropoden and Acephalen einfadh, jedoch unter den lezteren die ared und lingula in zwei geheilt, und üherlaupt die meisten Acephalen anser den Austem ron dem Darmhanal dur hbohnt haben. Bei den ersteren, nämich mii drei Iferzen, wird das Blut, ron den Liobladern zun onderst in jenes Merz gefiuht, welches auf jeutr Seite zumächst den tie. men liegt, und gleichsan ein rechtes und linkrs vonoses Herz rorstellt; ron da wird es durch die Lungenarteric in dic fiemen, dann durch zurüllanfule Lumgencenen (Tilesius hielt diese filschlich firr Luftzufübrende Tracheen, die eigentliche Arerie aber für ein Ligament) in das cinzige Fiferz, nümlich das arterielle gebracht, und hieranf durch die Arterien in den ganzen liörper ansgetrager. Bei den zweiten, wo mu ein einzigos Herz statt findet, rerwandelt sich die Hohlailer, olme dapzwischen gelegter Branchienhorr, scylnich in die Lungenarterie, gerade wic sich ploizlich die vena portae mesaraic. in die vents port. hepatic. unwandelt. So wahr auch dieses alles sich in der Natur bestätiget, so mögte doch wohl jene Vermuthung zu voreilig seyn, dafs diesen Thieren die I,ymphgefirse fehlen, dafür aber die Hohladern die Lymphe sogleich aufsaugen sol- 
In ; cine Hypothese, welche blos darauf gestüz, dafs dic Hohlader der Aplysia beim Aufblasen den ganzen Unterleib und die Gedärme mit Luft erfiillic, mit jenem Irrthume Poli's in Bezug auf die Nerren zusammengestellt werden lönnte, sonst aber schon der täglichen Umwandlung der speisen in Chylus, dann in Venen - und zulezt in arterielles Blut, endlich den Erscheinungen des Aufsangens bei Inselten, Wurmern, Zoophyten and Pflanzen, bei welchen allen heine Spur eincr Wirlung von ciner Vene oder Arterie mehr angewoffen wird, widerspricht. Zwar ist es nicht zu liugnen, dars die Natur bei diesen Thieren eben so den grofsen Freislauf des Blutes heraushebt, wie sie es im Gegentheile bei den Fischen mit dem lilcinen thut, ja dafs auch hier sich die Tracheen schon zu Branchienmenbranen concentriren, und sich selist bei den rolliommeren das Jungen und averielle Herz der Wirbelthiere, freilich nock gesonder: und zerstrent, oder selbst wie bei vielen Acephalen von dem Darmkanal sich entwindend, andeutet; allein alles dieses berechtiget noch nicht, mit Cuvier sprechen zu liömen "la classe entièc des mollusques jout ditine circulation auss? complette qu'un aninal verlebré a)". - Ii Minsicht der Respirationsorgane hat er ausgenit-

a) Cuvier. Leçons danatomie comparce. 'T. 4. 1).40\%. = Paris 1808 . 
ielt, dals sie bei diesen Theren watue hiumen, und zwar bei Cephalopoden und Acephalen in Form ron länglichen Blättern, im Innem des Läpers verborgen seyen, bei dun Gasteropoicn bald, wie bei tethys, phemnodemut,plenrohunchus, tritonia, doris, scylaca, fancus, acolis, clio in Gestalt rom Rännchen, Flossen u. s. w. cinfach oder vielfach anf der Oberfiatche des Rüchens, bald wie bei chiton, patela, phylliala un cen Rund des Türpers herum nach anssen flüliren, und durch! Anspichung des Wassets sich die getiörige Lufi. zum Almmen aneignen, bald bedelit mad wie bei Landschnectien, z. B. helix, limax, testacella, parnacella oder boi jenen in Wasser z. B. onshidium, unimus, plenorbis nicht durch Bespülung des Wassers, sondern durch wilhührliche Ocfinung und Schliefsung cincs zur Seite angebrachten Lamales oller Loches, die Luft aufnehincn. - Das Nerrensystem endich hat er bei einem grofsen Theile der Molluslien und Testacéen nachgewiesen; man ersicht aus seinen Zergliederungen, dafs es nicht wie bei Inseliten ans einer forllanfenden Reihe ron einander ctwas weniges fernliegender, aber durch zwei Fäden in der Län ge verbundener Ganglien, sondern blos aus jenen beiden bestehe, welche bei jenen dic speiscröhre unfassen, und als ein oberhalb, und unterhalb der. selben liegendes unterschieden werden - dafs das 


\section{$-433$}

obcre - auch das Gchim der Schneclien genann - bei Tritonien aus vier lileineren Ganglien, bei helix vivipara, clio u. s. w. aus zwei, bei doris, tethys aus viclen lileinen hörnern zusammengesezt sey, bei Manchen diese Ganglien durch einen. dazwischen laufenden Nerrenfaden symmetrisch abgesondert seyen, oder wie bei helix und limax das Aussehen eines Bandes - im allgemeinen cine weisgraue, bei helix stagnatis und cornea aber xöthliche Farbe haben. Anch bei dem zwei- und riclschaaligen hat or jenes obere und untere. Ganglion als durch Seiten und Queerfüden unter sich resbunden, aber im Vergleiche gegen die vorliergchenden Ordnungen als viel cinförmigex angegeben, jedoch Mangili, Professor der Naturge. schichte in Paria, hat ihn späterhin berichtiget, indem or in mytil. anatinus, cygneus und in dex mya pictorum noch ein drittes Ganglion nach dom Durchschnite des Fufses entdelite, und dieses, weil es ron der Milte aus mit jenen beiden anastomosiret, und die Eingeweide mit Nerren rersorgt, mit dem Namen, il cervello" belegte a).

Dümeril benuzte zu allernächst einige Beol. achtungen Curiers, erhob die brachiopodes zis einer eigenen Ordnung, steigerte somit die Anzahl auf fün (cephalopod. ptéropod. gasteropod. ace-

a) Mangili nuove ricerche zootomiche sopra alcune spacis de Conchiglie bivalyi. Milano 180 . 8. 
phat. brachiopod.), und unterschied sieh nur dadurch von jenem, dafs er die Gasteropoden nach dem Respirationsorgane unter drei Lnterabtheilun. gen brachte, nämlich ,dermobranches, welche dic Branchicn in Gestalt von Blïttern u. s. w. mach aussen haben, und den Gattungen von den Familien "phyllidiens, tritoniens des Lamarcle - adelobranches, welche durch ein cinfaches Loch athmen, und jener Familie ,point de syo phon des Lamarch - endlich siphonobranches, welche durch cinen eircnen hanal athmen, und jener Familic „acee un syphon" des Lamarck entsprechen.

5. 85.

So grols auch das Verdiensi Cuvicr's darin ist, dafs er die innere Eimrichtung vieler dieser Thiere und ihre Verwandschaft unter sich und der Mollusken mit Testacéen näher liennen lernte, sehr viele neue Gattungen ausmittelte, und dieser ganzen Klasse ihren alten Vorrang vor den Insekten, dem Systeme Linnés entgegen einräumte, so ist doch seine neue Abtheilung nicht ron der Art, dufs sie nicht, so wic schon cine vierte, auch noch eine Vienge neuer Ordnungen zu ihrer Vervollständigung zuliefse. Lamarck sah diese Vielseitigkeit der Ansichten, und der daraus sich ergebenden VVeitschichtigheit seines Systemes cin, und brachte an demselben gerade die nümliche Verbes. 
serung an, wie es Lezterer zuvor an jenem des Poli that. Er wählte nur die Gegenwart oder den Mangel des hopfes zum einzigen Gesichtspunkte, und zog hienach jene vicr Ordumugen in zwei (céphalés, acéphalés) zusammen. Unter jenen mit Kopf begreift er die drei Ordnungen seines Vorgängers „céphalopodes, gastéropodes, pteropodes" und unterscheidet sich blos durch eine beinahe umgekehrte Aufeinanderfolge der Untorabtheilungen und durch eine HInge ron Arten, welche ex zu Gattungen erhoben hat. Wie Cuvier, rereinigt auch er die beschaalten und schaalenlosen Schneclien, ind gebrancht sic nur zu allernächst als Nebcunnierschied in jeder Ordnung (nuds, conchyilferes). Die dritte Abtheilung hat er ron der Schaale hergenommen, und zwar früher in seinem Terke ,svrtine des animanx sans verte. bres" bei den Einscliaaligen ron der Beschaffenheit derselben (coquille univalve non spirale spirivalve --. multiloculaire) - bei den zweischaaligen ron der Gleichheit oder Ungleichheit (coq. iquivalves, iniquivalves). Jedoch sah or bald ein, dafs durch solche einzcine Riulisichten thie verwundtesten Gallungen von einander getremnt werden, or gesteht dieses von den lezteren nit folgenden Vorten ${ }^{a}$ ), und dachte daher

a) Ira consideration de l'it: galitó des ralves, écarte les genres, que les rapports maturels foreent d'izitroduire dans 
auf oine natirlichere Anordnung. In den meisten seiner Abhandlungen in den Annalen hatte er inmer die verschiedenen Musheleindrüclie als Nebencharaliter angegeben, nun lob er diesen als Hauptunterschied heraus, und brachte sie darnach unter folgendes Schema a):

Acéphalés

I. nuds: ascidies, biphores, mammaires. II. conchyliféres:

- à impressions musculaires séparées et laterales : solenacées, myaires, pholadiaires, mactracées, conques, cardiacées, arcacées, camacées.

- à impression musculaire subcentrale, soit simple, soit composcé : bissiféres, ostracées, brachiopodes.

Olen, Professor der Naturgeschichte in Jena, hat ror Kurzem den nämlichen Gesichtspunlit in eincm Aufsatze: ,über die Erlienntnifs des Muschelthicres aus der Schaale, und die darauf grïndbare natiuliche Klassification" der Socielät zu Göllingen vorgelegt, wie aber aus cinem Auszuge zu ersehen isl, sich mit der blorsen Andentung, ohne vollständige Ausführung begnügt $b$ ). Dieser

la civision, que ces mollusques doirent former" anmal. du muscie. T. 10, p. 591.

a) "la dispostions des impressions musculaires dans les coquilles biralves, est donc de premiere importance annal. de mus, T. 10. p. 30. l'an 1807.

b) Okrn - Göttingische gclehrte Anzcigen y figtes St. den 22ten Octob. 1810. 
gelehrte Verfasser, von der Idee, das Macrocosmische in Microcosmisclıcn inmer wieder nachzuzeigen geleitet, hatte schon in seiner Biologie die Schnechen mit der Schwere (Oxidationsprozefs), dem Wasser, der Lunge, dem Tastsine parallelisiret, und fibric num in genamter Abhandlung einige Andeutungen weitcr aus. Zurorderst erliärte er die doppelen Schaalen diescr seiner Lungenthiere, fir rinen nach rom gespaltewen Thorax, woron dic Schlolszihne das Püligrath sind, und zwar läfst er jene bald den hiemendeckeln der Fische, bald unter sich rerwachsenen Rippen, bald der Sehulter und der Ihüfe, ihre Schliefsmuslieln sclbst den Schulter - und Hüfimusheln entsprechen. Eben nach der Zahl der Eindrücke, welche dic Sehnen dipser Muskel in den Bivalven zurutilassen, theilt er hierauf diese ab, und nemnt sio zuecimusticlichte, sofern zwei Eindrüclic in der Schaale, einnuslieliclite, sofern nur ein einzige: statt fundet, und alle Muslieln somit in eine cinzige Sehne, wie z. B. bei Austern, rerwachen sind. Zwar sagt er aus, dafs es auch vielmuslelichte zelue, aber diese wolle or hier nicht in Betrachtung ziehen. Zur femeren Unterscheidung dient denn anch nach seincr Angabe, dic eingedrülite Figur, welche der Mantel in der Schaale zurililäfst. und worin sich die ganze Form des Thiercs und scine Organe verrathon; So ist diese Mantelfurche 
in der Mahlermuschel, Herzmuschel, in chama cor, in Austern u. s. w. Śchcibenförmig, bei den röhrenförmigen Conchylien aber gewöhnlich huckenförmig, und zwar gleich lang, oder auch länger als die Röhrenfurche selbst. Diesen Gesichtspunkten gemäls, schliefst denn der Verfasser weitor, dafs die tellina lactea and pensylvanica wegen ihrer Soheibenfurche nicht unter dë Tullinen, die venus tigerina nicht unter Venus, die myt:Jus rugosus durchaus nicht unter Mytilus, cben so wenig mytil, pholadis und chama gigas unrer diese Familien getören. - Freilich ist eine einzige physiologische Dentung, sey sie als Idee aus dem Gcbiethe der Philosophie, oder als Resultat aus vielen Beobachungen hergenommen, wenn sie nur mit der concreten Natur zusammenstimmt, für die Naturgeschichte öfters ron gröfscrom Werthe als eine Menge einzelner Entdechungen van Thierarten, oder anatomischen Bestandtheilen. Auch scheint es für den ersten Augenblick, wenn man das successive Oeffnen und Schliefsen der Bivalven, ähnlich dem Ein- und Ausathmen und der Ebbe und Fluth betrachtet, ganz wahrscheinlich, dafs die Schnecken Repräscntanten der Lungenthiere sind, ihre Schaalen selbst eimen Thorax vorstellen; ja in limax, aplysica, dolabella, parmacella, bullaea, testacella dient die Schaale licinem anderen Organe zur Bedeckung, 


\section{$-489$}

als den Branchien, und nur bei dem Plcurobrant clus, wo jene auf der Mitte des Rücliens, die Micme aber zur Seite liegł, fünde eine Ausnahme statt; bei den Bivalven werden selbst die gelegten Eier in den Branchien ansgebrütet. Allein demohngcachtet crscheint mir die Erhebung der Schnechen zu Personificaten von Lungenthieren, da doch die Allonciston gleich den Fischen die Luft mihsan von Wasser absondern, eben so falsch, als wem man das Wasser nit der Luft, den Fisch mit den Vogch rerwechselte. Noch vielweniger kann his bei diesen Thieren von ement Slielete, von einem Thorax, von lippen, Schulierblatt, oder Bechen die Rede seyn. Sind Scluiterblatt und Bechen nebst ihren Extremitaten nich das crste, was sich an Shelele verliert? und erscheinen dic Rippen in ihrem Verschwinden nicht als blofse Queerfortsütze der Wirbel? Hier ist somit, wie auch \$. 82. gezeigt wurde, weder mehr ron cinem Wirbel, ron Dorn - oder anderen Fortsätzen, sondern ron der Schaale als einem Hantgebilde die Spracḩ̣. Gleichwie die Grundidec, so sind auch mit ihr alle wcitcre Folgerungen z. B. die Benennung als Hüf- und Scluntermuslich falsch. Zwar hat sich Poli diese kühne Doutung der Muskeln der Schneclien nicht erlaubt, aber auch sonst sich hierin nicht als vergleichender Anatom gezeigt, sondern sic nach ibrer Funliton. oder nach che fiwhtome 
ihrer Fiborn (musc. adductores, obliqui transversi u. s. w.) benannt; jedoch kann auch hier sicht melir ron Muslieln, deren Funlition und Insertion nur durch die Gegenwart des Slieletes bedingt ist, sondern, wie bei allen wirbellosen Thieren, blos von Hautmuskeln, muscul. cutanei, constrictores pharyngis, ani, musculi abiominal. u. s. w. - gesprochen werden. Vill man nun die Muskeln und die Lindrücke ihrer Inserionen an Schaalen zur Abtheilung wählen, so ist diescr Gesichtspunlit allerdings von Tichtighieit, und Lamarcli und Olien hätion denselben nur nicht auf eine einzelne Familie, und blos anf die eine Schaale bei Bivalven einschränlien, und daher wie lezterex dem Ganzen widersprechende Benennungen einfuhren sollen. Gleichwie die Zahl und Beschaffenheit der Schaale, so liönnte auch jene der Muskeln zum Prinzipe der gesanmten Conchyliologic herausgehoben werden, und gleichfalls Dokumente der Verwandschaft dieser Thiere abgeben. Bei den nakten Molluslien dient grö́stentheils dic äussere Houtbedeckung zum Träger der einzelnen Muskeln. Auch bei Chitonen, Patellen und Fissurellen, ist das Thier, obwohl an die Schaale gelitebt, doch nicht daran angeheftel, weswegen diese im Weingeiste sehr leicht abfallen, bei a'len übrigen Einschaaligen ist es sclion rersnittelst Mtuslichn angowachsen, jedoch blos an ci- 
ner cinzigen Stelle der Axe (columella) der Schaale; bei anomia, ostrea, pecten haben es die Sehncn schon an zwei Stellen, nämlich am irittelpunlit, der oberen, und an jenem der unteren Schaale befestiget; bei tellina, cardium, venus, channa, donax, arca, solen, pholas geschicht dieses an vier verschiedenen Punkten, nämilich an den beiden Seiten des Schlosses, und zwar eben sowohl an dem obcren, als an dem unteren Dechel, so dafs diese Insertionen, und ihre zıriil:gelassenen Eindrüclie, in eben dem Grade sich auscinander entfernen (laterales), als die Schaalen selbst allmählig ron der rundlichen Gestali zur länglichen und röhrichten überychen. Dieses leztere gilt auch von dem Manteleinduche, der bei allen Bivalven mehr sphäroidisch, almählig eutilicl in solen strigilat. noch mehr in soicn siligua. und in der pholas, mehr in die Lünge gezogen is!. So gesetzmäfsig auch ailes dieses in der Nat!n wirklich rorwärts schreitet, so sind doch tie Mn: licl- besonders aber die Mantelendrüclic kein $\varepsilon$ : zuverläsiges oder vielmehr deutliches remnei. chen für die Conchylien, als die Zähme oder dic Gleichneit und Ungleichlicit der Schaalen. So sind diese Furchen an durchsichtigen Schaalen z.. B. in anomia caput scrpentis, ostrea fasciata $u$. s. w. gar nicht sichtbar, obwol!? dic Mushclein. drüclic bei den Bivalven im Durcuschnilte wahre 
Gruben bilden, so ist doch, z. B. in solen sitiqua, jener an dem entgegengesezten Ende des Schlosses haum benerlibar, nimmt man nicht die Stelle des Muskels am Thicre zu Hülfe; ja in pholas crispa hat sich der Muskcl zunächst des Schlosses an verschiedenen Punkten festgesezt, und die Insertion im allgemeinen ist also mehr als vierfach. Ueberhaupt gleichen gar oft die Eindrüche der Muslieln, noch weit mehr aber des Mantels einem Flecken, welchen das VVasser in die Schaalen eingefressen hat, oder atich einer glatten Fläche, wolche sich blos durch ihr elwas glinzendes Aussehen unterscheidet, öfters aber durch Vitterung oder Polirung an anomalen Stellen herrorgebracht ist, und daher ohne die Analegie, oder das Thier selbst zu Pathe zu ziehen, öfters im Zweifel den Forscher läst. Woraus demn erhellet, dafs MTushel - und Manteleindrüclie zwar zur Charalerisirung im allgemeinen, selbst auch zur Festsetzang mancher neuen Art oder Gattung gebraucht werden liönnen, und daher nicht wis bisher von allen Schriftstellern ausser Poli vernachlärsiget werden dürfen, abcr dafs sie niemals so selbständig und deutlich, wie die übrigen Beschaffenheiten der Schaalen sclbst sind.

Lamarck scheint diese Schwierigkeiten gefühlt zu haben, daher er in seinem neuesten Werke , zoologie philosophiune von scimen alten Unter- 
abihcilungen ganz abging, und für aile Vollusken folgendes Schema entwarf:

I. Molusques Céphalés

A. Céphalopodes

- sans test: sépialées (poulpe, calmax, seche.

- à test uniloculaire: argonaulacées (argonaute, carinaire),

- it test multiloculaire: nantilacées (nautile, orbulite, ammonitc, ammonocératite, turrilite, baculite), lituolacées: (bélémnite, hippurite, orthoceres, spirule, spirolinite, lituolite), lenticulacées: (nummulites, lenticuline, discorbite, rénulité, rolalite, gyrogonite, miliolite).

B. Gastéropodes

- colps en spirale: un siphon:

1. enroulêes: cone, porcélaire, ovule, tarrière, olive, ancille.

2. columellaires: volute, mitre, columbelle, marginelle, cancellaire.

5. purpuracées: nasse, pourpre, monócéros, concholépas, buccin, eburnevis, tonne, harpe, casque.

4. ailées: strombe, ptćrocère, rostellaire.

5. canalifíres: murex, fuseau, pyrule, fasciolaire, turbinelle, pleurotome, cérite.

- corps en spirale: point de siphon.

1. calyptracées: trochus, cadran, calyptrée, crépidule. 
2. It iéroclîes: janthine, bulle, woivaire,

5. turbinacées : vermiculaire? turritelle, scalaire, dauphinule, monodonte, turbo, phasianelle.

4. stomatacées: stomatelle, stomate, haliotide.

5. néritacées: natice, nérite, nacolle, néritine.

6. orbacées: amprillaire, planorbe, vivipare, cyclostome.

7. auriculacées: lymnée, mélanie, melanopside, arivicule.

8. colymacées: maillot, agathine, amphibutime, butime, helicine, helix.

- corps droit, rémil au pied dans toute ou presque lout sa longueur.

1. limaciens: testacelle, vitrine, parmacelle, limace, onchide.

2. laplysicns: sigurct, bullée, dolitbelle, laplysie.

5. phyllidiens: emarginule, fissurelle, patelle, oscabrion, phyllidie, pleurobranche.

4. tritoniens: doris, teth's, tritonie, scyllée, éolide, glaucie.

\section{Ptéropodes}

- deux ailes opposées et nataloires: hyale, clio, pneumoderme.

II. Acéphalés

- ascidicis: mammare, biphore, ascidic.

- pholadaires: arrosoir, flitulume, taret. pholade. 


\section{$-495$}

- solenacées: saxicare, rupellaire, pétricole, sanguinolaire, solen, glycimére.

-myaires: anatine, panorpe, myes.

- mactracées: mactre, lutraire, crassatelle, onguline, érycine.

- conques: capse, galatli, cyclade, lucine, telline, donace, cithérée, venus, venericarde.

- cardiacées: isocarde, cardite, hippope, tridacne.

- arcacées: trigonie, cucullée, arche, petoncle, nucule.

- naïades: anodonte, mulette.

- c a mu a cées: pandore, corbule, dicérate, came, éthérie.

- hyssiferes: avicule, martean, perne, crenatule, modiole, monle, pinne, linie, houlette.

- ostracées: peigne, spondyle, plicatule, grypliée, huitre, rulselle, placune, anomie, cranie, calcéole, radiolite.

- brachiopodes: orbicule, térébratule, lingute.

Ans Ende der Mollistien hat Lamarce? in neuexer Zeit (voy. philosophie zoologique) noch zwei eigcne Iilassen, welche den Uebergang von jener zu den Frustacéen machen sollen, angehängt. Die Gattungen der ersteren (balan. anatif.) haben anfangs unter den Tielschaaligen, die der zweiter unter den Würmern gleich nach den Inschten gestanden, weil aber Curier in ihmen Branchien, rothes biut führende Gefürse anmerlile, und selbst in 


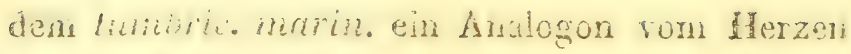
gesehen laben will, so wurdea lestere for Inseliten, Araneiden und Limistacécn, gleich nach den Molluslien, von Laniurch unter dieser Aufschift aufgestellt:

Yr Classe. Cirrhipedes: anatif. halan. coromule, tubicinelle.

VII. Classe. Annelides: planaire, sangsue, lombric. aphrodite, serpule $e_{0} c$.

Bose folgte hieranf dem Lamarch in der Deter. villichen Ausgabe Buffon's wohl in der Amnahre der Gattungen, nicht aber des Systemes nach, sondern wählte hierin Linné und Bugnicre zu seinem Voubilde. Wie Leztere, handelt auch ex die Inseliten zuerst, und nur damn die linstacéen, Testacen, endlich unter dem Namen , Wüment (vers.), die makien Mollusken (cephatis - acimhalés), dic rou ihm also betitelten , vers proprement dits" (aphrodite, serpule. e. c.), die Inestinalsüner, die Echinodermen, die sternfömigen (vers radiaires), zalezt die Polypen (vers coralligénes, rotifères, amorphes) ab, die Tcslacéen selbst muterscheidet er wie gewöhnlich in ein-zwei- nud vielschaalige a). Bosc's Verdienst um die Conchyliologie ist also nicht im Systeme,

a) Bosc. Hist. nat. des coquilles, Ton. 5. Paris chez Deterville. An, $\mathrm{X}, \mathrm{I} \%$. 
um so mehr aber in der vollstindigeir Beschein bung aller bis jezt beliannten Arten zu stichen.

Montfort nahm sich in ciner anderen Ausgabs Büfon's, nämlich in der Düfartisclien, den närnls. chen Zweig der Zoologie zur Bearbching, nind wich nur darin ron seincm Vorgünger ab, defs ex? das System Cuvier's adoptinte. Sclow hrite ce sechs Gatiungen ron Mollusken (sepia, calmar, pulpa u. 5. w.) in den ersten vier Bünden solis weitläufgु beschrieben, als er plützlich in der vï ligen Ausfuhrung gehindert wurde, und Roissy als Fortscizer an seine Stelle trat. Leziever gobrauchte wieder statt der unpassenden Aifschrift „coriacea" jene des Cuvier „céphalopodes" und lieferte Cuvier's und Lamarcli's Arbeiten in diescm Fache gleichsam in einem Auszuge, unter der Abtheilung ,cephalopodes, pteropodes, gasternpoutes, aciphates" in einem fünften und seclisten Bande a).

Latreile hatte haum das System Lamarch, wie es in dem Werke, systêné des animaux suns vertibres" dargelegt ist, in den schon oft genamien ,tableau méthodiquer wiederhohlet, und nur zun Unterschiede die Gattmgen balanus und.

a) Hist natur. génerale et pirticuliere des mollusques; ou vrage taisant suite aux ocurres de Leclerc de Bufron par Ienys Montert, continue gur Ruissy. Tom. 6. Paris chez Dufart. An. X-XIIS. 8. 
ancalifa von den Testacien zu den Anneliden versezt, so erschien drenfalls unter dom Namen Ilontfort cin neues Werli, welches blos die Testacéen zum Gerrenstand hat, und selbe in coquilIes univalees (chissonies - spirées), dissizalwes (dont les ialoes ne sont pas réunies), muttivalies (doni hes valiés sont riunies) - und bivalves absondert. Der Verfasser hat alle nur mögliche Andeutungen von vielhammerigon Schaalen ans allen Schiltitellern zusammengctragen, beschrieben und alsgebildet, aber leider! so vicle Arten der Testacéen zu Galtungen erhoben, dafs er beinalie auch die mifsverstïndlichsten Mörter z. B. fersonu, ultimus, bufo, radix u. s. W. zu ihrer bezeichung gebranchen muls a).

Ein vorzighlihes Verdienst un die Condryliologsic hat Draparnand durch seine Monographie der Land - und Fifubsinechen Franlecichs b). Den Systeme Cuvier's zu Folge theilt er sie in gateropodes und actiphles ein, crrichet viele ucue Gattungen, wie z. B. valtie, aneyle, physe,

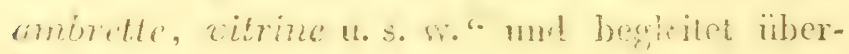

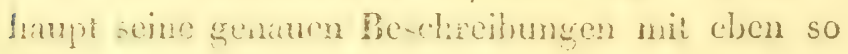
richtigen Kupfern.

a) Denys Hontlur. Conchyliologic systematique. Tom. 1, 2, 1808. Paris. 8.

(i) Draparnatul. Tlindile natmelle des mollusques correstred.

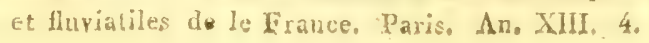




\section{$-499$}

5. 85.

Hat man seit Aristotcles bis ani 1 centson ma Poli die Anzahl und Beschaftonheit der Schalen, oder selbst den Mangel derselben aur Crundlage der conchyliologischen Systeme gemacht, so ist es seit Cuvier bis anf den gegenwätigen Aurenblic blos die Beschaffenheit des Bewonners derselben; welche diesen Thieren $\downarrow$ don Platz in dor Anord. nung bestimmet. Es ist nicht zu längnen, nui crhellet auch aus dem Obigen, dal's die Schaalentheorie enseitig sey, und sich niemeis ron den vielen Wielerspü̈chen losmachen löme, dafs aber in Gegentheile das Schmechenthier - der Bau. meister seiner Schaalen - der vorzüglichere Theil dieser Behausung sey. Jedoch wo liemen hier die Charalitere so sichtbar und unbewerglich da, wie es dort in den Schnalen - dem wahren äusseren Abdruck des Thieres - der Fall ist? Leider! hat man aber auch an den Thieren nicht das Ganze, sondern blos etwas einzelnes wie z. B. die Gegenwart oder den Mangel des hopfes und der Tentaliuln aufgefafst, und sie darnach rubriziret. Lamarck hat wohl eingeschen, dafs die Anzahl der Ordnungen, wom dicse blos nach dem Vorhonmen selm greller Mcrkmale an Thieren gebildet werden, niemals fixiret und rollsändis: ist, sondern wie nenerdings durch jene der ,p plpropodes" in Zulumft auch noch dirch ribic au. 
dere rermchrt werden liönnte. Mit Recht zog cr daher, da anch bei Medusen, Actinien, Zoophyten der Nund mit vielen Tentaculn umgeloen ist, und leztere bei vielen nebstbei zum Schwimmen gebraucht werden, die Ordnungen der Mollushen Cuvier's auf jene zwei - cephalis und acéploalis - zusammen. Allein wozn überhanpt alle diose, theils anf wenig ron ausen bemerhbare, theils selbst zweifelhafte Organe exbanten Abtheilungen? Es giebt eigentlich licinen hopf obne liopflühle, ohme hopflinochen und Gehirn, heine Rïcliensäule ohne Wirbel und Rïckenmark, and ansser den S̈̈uwhicren, V̈̈gehn, Amphibien und Fischen. ist nur nuch an Sepien stult der gewöhnichen hopflnochen ein eingiger hopfwirbel anzutreffen. Nicht nehr sollte also bei wirbellosen Thieren, bei denen ohnediefs ron heinem Gesichte (fucics) mehr die Fede ist, dic Benenmung lionf mod Gehim gebrauch, sondern wie bei Wümonn us. w. bios ron einem vorderen und hinteren Theile des lieipers (pars anter. poster.) gesprochen werden. Zwwar ist bei den naliten und cinschaaligen Molluslien der uncigentich sogemannte Kop! ron der Natur noch immer dadurch ror den übrigen liörpertheilen ansgezcichnet, dafs er, obgleich nicht Träger eines Gelinnes, doch einiges Ganglien mod mehrerer von ilmen mit Nerven versehener Simnergane ist. Aber cben diese Sin- 
nesorgne, welche sich ans dem, allon Theilen, mul besonders der Hantobertliche des thierischen Jïrpers zuhommenten Bupfindmingsime (senstis communis) zu ganz verschiedenen 'Tastorganen, nümlich als Tast - Cieschnitis - und Angenpapille qualificiret labcu, werden auch anf diesem Gebiethe so allmählig undentlich, dafs z. B. jene Tastaugen, welche bei vielen der naliten und einschaaligen Molluslien auf der Epilze der ätsseren Fïhllörner, bei anderen ron dicsen schon an der Thusel der lezteren sitzen, endlich bei den zweiand viclschatigen gane rerschwinden, und die Fühliörner selbst nur noch als Ilantlappen rorlikzien sind. Ja erkennt man nicht die Gegend des liopftheiles darans, dafs das Thier bei der bewegnug denselben inmer rorwärts trägt, oder sucht nita sich nicht der Lage des, mit dem hopfe immer verbumbenen hisudes zil rersichern, so fiam man - ausser den Sepien beinalie in keiner der Schneclien, wem sie ine Tentaluh cingezogen habon, ein Vorder-oder Hintertheil merschei 7en. Schwanhend und selbst faisch ist also die Abihcinng der Nollushen in solche nit und olne Tiopí, indem alle ohne Unterschied mit dem mieigentlich genamnten Jionfe ausgestattet sind, und Lezterer an der scyllaca, tritonia arborescens, glaucus, phyllidia, oscabrion, citio n. s. w. eben sn weing, wic in den zwei- und victerhaligen 
atusevlich sill erliennen ist, hat man sich zuvor nicht der Lage des Aums und des Mlundes versichert. Wollte man doch blos die grellesten Beschaffenheiten des Thieres zur Grundlage ron Sy. stemen machen, so liönnte man mit mehr Rechte alle Moluslien nach den Geschlechtsorganen in Hermaphroditen, Dioecisten und Tiryptogamen nach der rerschieden Lage der Oeffnumg derselben nach Aussen — nach den so sehr varirenden Branchicn - liurz nach allen einzehnen Theilei, und sey es anch nur die so sehr abwechscinde Lage des Anus, ahtheilen. Jedoch alle cinzelnen Ansichten und Mchloden werden rielleicht noch in der Zulimft ausgefihnt, da diese Richtung überhaupt erst seit Swammerdam nieglich, rou Poli und Cuvier eingefiht, und ron den beiden Lezteren sowohl, als durch die zerstreuten beschreibungen verschiedener Mollustien in der dänischen Zoologie von Muller a) und gegenwärig auch durch die nenenGallungen romet von Peron $b$ ) erweitert ist. Feunt man aber einmal dic Schnecken eben so gut als ihre Schaalen, dam wird man auch die Spuren und

a) Otho. Fr. Nuller. Zoologiae Danicae seu animalium Daniae et Norvegiae rariorum ac minus notorum icones, fascic. 1. 2. in Fol. Havniae 1777-80.

- cum descriptionibus et historia edit, a fratrc auctoris. Vol. 1. Havniae 1788.

b) Peron. annal, d. mus, T. p. 57 
Abdrülie des Thieres in der Schaale sclbst, was bisher in allen concingliologischen hupferwerlien, jenes des Poli ausgenommen, vernachlarsiget ist, aufuchen, und dic Thiere und ihre behausung zugleich beriksichtigen, um jedem der Mulluslien seinen whrerinderlichen Platz anzuweisen. Allein wie weit stehen wir noch ron dicsem Zicle ab? Freilich waren bisher alle Nationen becifert, dicses Fach ror allen übrigen zu bearbeiten: Dic Vunglünder a) haben hich einen Du Costr, Martyn, Monturgy nu an der Spitze dersclben einen Lister - die Sicliwecien cinen Limne - die 'Teüschen cinen Rumijh, Regenfus, Boru, SchïoLer und als das Oberhaupt derselben einen Rartini

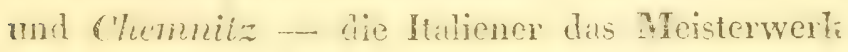
eines Puii - die Franznsen einen Argenvilie, Geoffroy, Bruguire, Diapamand, Montfort rund als Anfibler derselben cinen Curier, und Lamarck anfuwcisen. Zerstrent und rereinzelt jedoch sind die Kntdechungen und Beobachtungen dieser Schriftsteller, wh noch bedarf es eines Mannes, welcher alle cinzelne Arbeiten in diesem Fache lritisch durchgeht, und nach ciner allgemeinen Prevision lic bisher sich rorfindenden Gat.

r) Da Costa Elements of conchology. Lond, 1784.8.

- Martyn. The universal conchologist. London 179 f́. Tom. 4. Fol.

- Montargy Testacea britannica, Pars. 2. 2. 180.. 4'. 
tungen und Arten anfähllt und beschiroist. Diesen liilmen Schritt hat nun Lamarck unternom* men, und schon in den Annalen des Muscum an den Gattungen und Arten von conus und porce?Iana eine Probe dargelegt, gleich wie er auch in andern Abhandlungen sowohl durch rie newen Gattrngen, phasianella (annal. d. mus. 'T. A. p. 205), gatathea, diceras, amphibutima (annal. T.6), etheria (annal. T. 10), ats anch durch neue Arten z. B. voluta undulata, ziivosa i. s. w. dio Conchyliologie vermehret hat, Allerdings hat dieser verdienstvolle Conchyliolog noch ein weites Feld zur Ausführung vor sich. Allein sind wir cinmal im Besitze der vollstïndigen Gea schichte aller heliannten Arten ron Molluslion, dann ist uns auch der Weg gebahnt, die fossilen Reste derselben zu deuten, und die Vorabeiten eines Knorr, Walch a), Hïnsch, Burton, Lapeironse, Fortis, Faujas, Blumenbach und sehr vicler Reiscbeschreiber hierin zu crgänzen, Beinalı alle Weltheile und Provinzen lieferi) Abdrüclic, Versteinerungen, oder selbst Fossile dieser Thicre, und zwar öfters von der nämlichen, häufig unbekannten oder in anderen Welttheilen lebendig

a) Die Naturgeschichte der Versteinerungen, zur Erläuterung der Knorrischen Sammlung von Mierkwürdigkeiten de* Natur heransgeg. von Joh.Imman. Walch. Nürnb. I Tl'e, 758.75 . Folio. 
norh rorkommenden Gattung eine solche Menee, dal's filschlich einige Naturforscher die Kalkgebürge selbst als rerwandelte Reste derselben, andre aber als den Sitz ron Naturspielen oder ahndungsrollen Vorbedeutungen des Thierreichs, oder selbst als ihre Geburtsstäte betrachten, aus der die Thiere ihre Schaalen sich aneigneten, und gleichsam zum Leben auferstunden. So findet man in dem Thale ron Trento ron der Fläche bis 500 Fuls hoch gegen den $A$ bhang des Berges vicle Tausende von Ammoniten, welche nach ihren Windmigen parallel übereinander geschichtế, und ron x 3 f 2 Fufs im Durclimesser sind. So sinc? cinige der Hïgel von Siena so sehr mit versteinerten Muscheln angefuilit, dafs das Erdreiçh dadurch weils erscheinet. Lngeheure Mengen ron fossilen Muscheln liegen in den Möhen um Parts und Bourgogne; die Hügel bei Chaumont bestehon beinahe ans lanter Sclneclicnschaalen; in den anfgeschwemmten I ande ron Champagne finden sich furslange calcinirte Strombitcn, bei Rheins cin ganzes Bett ron Conchylien, welchẹs auf viele Meilen sich ausdchnt, bei Touraine eine Schichte ron Miuscheln, die cinen Raum von mehr als 150 Millionen Cubilifaden eimnimmt; in Ingland gielt es Steinkohlengruben, worin nach Aussage des Richard Richardson mehrere Meilen lang nichts als die nimliche Art ron Conchylien sorlomunt Ra* 


\section{$-506$}

mond behauptet, dafs man anf den Pyrenion mit jedem Schrite anf Lentinulien tritt, Lapeirouse, dafs sich hier die Orthowatiten in Menge rorfinden o), und wer hemut nicht die mähtigen Lagen ron Lenticuliten in Nieảerigypten, aws welken grüstenthoils die Pyramilen erbut sind? Feron lat Conkhiten in rerschiedenen Hohen z. I) anf dem Diemenland, anf der Ined Vlaria, ant jener der lüngenh, anf der spitze der Gebinge ron Timor in einer Hohe ron 1500 Fufs, endlich die Insel Dorre und Dircli-Trortog ganz ans denselben gchiltet, angetroffen $b$, Ramond c) hat in der Mitte sowohl als auf der Spitze des bïchsten Gebürges der Pyentien, nünlich anf dem NontPerdu, in einer Hohe roin 60oo Fufs, Ulloa ma nacb ihm Humbelat in Amerita in einer thile von 12000 Fufs cine Menge fossiler Musciteln gefunden; wie viele der microscopischen Conchylien endlich sind wo noch anwer juen in den Schrifton eines Soldani und Plancus unter den Italicnern, eines Boys und Wallier unter den Wneländern, eines Batsch nnd besonders eines Fichtel und Moll unter den Tcutschen bis jezt unbeliannt! - So riel auch immer in diesen Zweige

a) Dicot. Lapisouse. Description de plusieurs nourelles espices d'orthnceratites et d'ustracites ì Erlang. 1, -Sr. Fol.

b) annal, de mus. T. 6. p. 26, c) cjusd. T. 3. p. 7 4. 
Aor grologischen Conchyliologie vorgearbeitet ist, so unsicher und ungewits sind wir doch noch in den einzelnen Thatsachen, noch mehr aber in den allgemeincren Resultaten. Zwar schliefsen wir aus den regelmärsigen Schichten, in denen z. B. die Ammonitcn rorkommen, da!s diese nicht durch eine gewaltsame Fluth herbeigefuhrt wor. den sind, sondern an Ort und Stelle selbst geclebt haben müssen, dafs die meisten rielhammerigen Muscheln z. B. Ammoniten, Qrthoceratiten, Gryphyten, Belemniten u. s. w., weil sie als die frïhesten Verstinerungen des Thierreichs beinahe blos in der ältesten uud ursprünglichsten Tlützformation in megeheurer Masse und Verbrcitung, und in einer Menge von Arten, wie z. B. die Ammonshürner zu \& Fufs im Durchmesser und nach Jussieu zu 150 verschicdenen Arten, in Frankreich aber immer nur fossil und ausgestorben, sich vorfinden, unter den übrigen Sclinecticn gleichsam die Unbilder und die erste Generation vorstellen, und daher glciches Alter und gleiche Simultancität mit jener Flötzformation selbst behaupten; wir schliefsen aber im Gegentheile, dafs die Turbiniten, Strombiten, Biccarditen, Chamiten, Mytuliten, Ostraciten u. s. w., da sie meistens in jüngeren Flötzgebürgen und in aufgechwemmten Lagern, theils ebenfalls blos fossil und unsegioten, theils nach der Versichemig ron 
13:atuan a), Mipsch b), Taujas o) in ancicien Iminclsctichen noch lebend, rorliommen, riel spiateicn me jüngeren Lirsprungs, und vielleicht gar aris dicsen fremden Himmelsstrichen sowohl rom Vecre hergeschwommt, als auch rom siblen Vasser abgesczat sind." Jedoch zu aller diesen Schlisen fehlet uns noch die ausgemachto ficherheit: Dolten will ein Ammonshorn nach abgi löster Thonianote aus leweglichen stichen wie ungefahr das Schwanzend der hiapperschlange ist, and somit ahmlich den Incriniten gefmeten habon "); Plancus zeichnet sogar molirere Arlen nicht fossiler Anmonshorner ab, weiche er in Sande ron limini durch Hiile des Microscops culdehe e); Sanssuc chlubl, dafs das Thicr der viellammerigen Muscheln anfings in der obersten Zelle gewohnt, und das aus ihn heranswachsende Jumge die nïchste Zelle, und so nach riclen Generationen endich die Menge ringsumgeschlosse. ner hammern angebuut habe $f$ ); Beudant wicher-

a) Kalm's Reise. Band 2. S. 281.

b) Neue in der Naturgeschichte des Niederdentschlands ger machte Entdeckungen einiger Schaalthiere, S, I 1 .

c) Hist. nat. de la montagne de St. Pierre de Mastricht. p. 3̄o. - Essai de Geologie. T. 1. p. 58.

d) Beschäftig, d. Berlin. Gesellsch.Bd.4. S, 510.

e) Jani Planci Arimensis de conchis minus notis, Romae 1761. 4.

f) Saussure's Reisen. Th. 2. S. 84: 


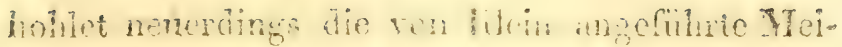

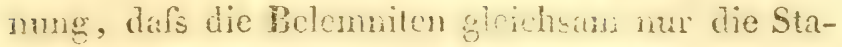
cheln von Secigeln seven "; Peson hat von der Fipedition nach Neuholland das Thier nebst der Schate ron spoirula migebracht, worans man er. sicht, dafs jenes wie die Fiantilen nicht un leztere angewachsen ist, blos dic unterste Zelle bewohnet, and wie die Sepien viele 'Tentalinh um den hopt mend cinen atmlichen scimubel lat o); Von gleicher Ingewifsheit und Unbestimmtheit sind anch die Abbihlungen und Bescheibungen der übrigen fossilen Conchylien, velche man in den Schriften bisher funtet; wie die Arbeiten über die noch lebericten schnectien, eben so bedarfen auch jene cincr mastundicheren lierision und ciner genaueren Iburtibing. Aber eben dicses scheint Lav natch in Plane zu haben, und zu dieser Absicht sich zurorderst bios auf jene Conchiten, welcho anf 50 Stuxten um Paris hetum rorliommen, zu bcschränlien. Freilich triflt man nicht alle nöglirhe Gattungen, wie z. B. nicht sanguinolaria, cilymera, mya, pholas, lieine Turriliten, Baculiten, Hippuriten und Belemniten in diesem Bezirke an, demolngeachtet ist doch die Anzahl der hien vorfindlichen Gațtungen und Arten, wie aus folgen-

a) нunal. d. mus, T. $16, \mathrm{p}, 76$.

h) annul. d. inus. T. 5. p. 1t:0 - Montforto Couchyliologie 3808. 'T. 1. p. 100. 


\section{$-510$}

dem Auszuge aus den einzehen Abhandhngen dieses grofsen Conchyliologen erhellet, ausserordentlich grofs:

\section{Univalves:}

Aunal. d. mus. T.5. pleurolom. - 25 espèces, cerithium - 6o esp. toutes inconnues.

-4. Trochus 8. solarium 9.turbo 4. delphinul. 8. cyclostoma 6. scalar. 5. turritella 10. bulla 4. bulimus 10. phasianella 2. lymnacea 1. melania 12. auricula 7 .

-5. Volvaria 1. ampullaria 12. helicina 1. nerita 5. natica 5. - nautilus 1. discorbis 1. rotaliat. lenticulina 5. nummulites 4. lituola 2. spirolina 2. miliola $\%$. renulina 1. gyrogona 1. patella 4. emarginula 2. voluta 1. porcellana 2. terebellum 1 . oliva 1. ancilla 2. mitra2. marginella 2. cancellaria 1. buccinum 1. terebra, harpa, cassis, strombus, rostellaria 1. murex 4. fusus 6 . pyrula 4.

Bivalves:

- 6. Pinna 1. mýtilus 2. modiola 5. nuculula 5. pectunculus 5. arca 7. cucullaec 1. cardita 2. cardizim 8. crassatella 7. mactra 1. erycince $1 \mathrm{l}$. 
T.7. Venericardia 10. venus $6 . c y-$ therea 9. donax 6. tellina 9. lucinca 12. cyclas 1. solen. 5. fistulanati.

- 3. ostrea 8. chama 2. spondylus 1. pecten 5. lima 5. corbula 8.

Was Lamarck durch diese Beschreibungen für die Monographie scines Vaterlandes und zugleich fim die gesammte WVissenschaft leistet, dieses thun Cro vier und Brongniart ebenfảls dadurch, dafs sie ein Bild der successiven Formationen der Gegend von Paris zu entwerfon, die Verschiedenheit der vorkommenden Conchiten nach den verschiedenen Schichten selbst, und ihre Lagerung ats Mecr. und zum Theile Flufswasser darzuthun, sich bestreben a). Mögte es doch auch anderes Gelehro ten gefallen, gleich genatie Grundrisse von der Aufeinanderfolge der in ihren Gegenden vortiom. menden Frdschichten and der in ihnen befindlichen fossilen Thicre zu liefern! Dann liömnten wir, wenn die Strulitur der Schnechicnthicre ebert so gut als ihre Schaalen, dic noch lubenden eben so gut, als dic fossilen Feste gehiamnt und abge.. bildel sind, durch Vergleichung ein System du Conchyliologie herstellen, welches nicht anf ein.

a) Sur la géographic minéralogique d: s envirous de Paria pas Cuvier et Brongniart, annal. d. mus. 'T. r1. p. 293.

- sur des terrains qui paroissent aroir eté formés solzs l'eau douce par Brongniart, i T. 15. p. 357 . 
zelne, sondern auf alle Theile zusinnen erbant, den einzelnen Mollushen ihren Plıtz untercinander, in der übrigen Thiorreihe und in der ganzen Erdbildung anweisen würåe.

SECHSTES CAPITEI.

\section{Insecten - Entomologia.}

5. 36.

Aristo- Unter den blutlosen Thieren hat Aristoteles teles. jene, bei welchen die harten, jedoch nech zrreiso baren Theile nach Aussen liegen, unter der Denrn.

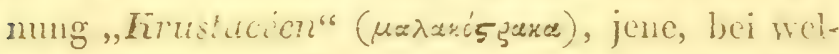
chen die äussere Deche des hürpers weder hat noch weich, and durch Einschnilte abyetheilt ist.

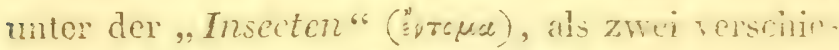
dene Lilasscin abgesondert, und erstere zivischen Mollushen and Testacén in die Mite, leztere nach allen dreicn und so ans Thit her ganzen Thierrihe gesezt. In dicser liangerimung he. gimnt cr immer ron den limstacén roi ten Itrselien, und menterschridet die cinzelnen Gatumgen ron jenen nach der Zahl der Füfse, nach der Beschaffenhit der Schecrun, nach der nahen oder entfernten Lage der Augen, und nach sonstigen äusseren Merlunalen. In Hinsicht inrer anderen Beschaffenlieiten merlit er an, dafs der Magen zue närhst den M!mude liege, mul ron da ans der Damianal gonz gedad am enigegenyesezten Linde 
des Körpers, oder wie bei hrabben unterhalb dex Brust hinausmünde, dafs alle mit zwei Zähnen am Munde und einer Leber rersehen seyen ${ }^{\alpha}$ ), dafs dic Beugung der Fülse seitwärts wie bei Insehten geschehe, dafs sie heine Stimme und sonst keinen. Ton ron sich geben, dafs sie abwechselnd schlafen und wachen ${ }^{b}$ ), einige im Trühlinge, andere in Herbste nach gelegten Eiern sich häuten, alls im Winter sich verbergen ${ }^{c}$ ); von Unrath, Pflan. zen, Holz u. s. w. sich crnähren (), mit deliz Viunde Vasser rerschlingen und answeren ? und nobst den Erscheinngen des Sehrns auch jene des Hörens, Sclimecliens, Riechens musem ffy, Von allem diesen thut en Erwäbnung, aber nir. gends findet sich bei ihn eine Sper von cineng Nerwen-oder Gefüfsysteme. Lm so mehr jedoc? berichtet or über ihre Fortplanzung: er gicht dic Geschlechtor als getrennt an है), cr schillert genau die Saamen absondernden hanäle zu jeder Seito der Brust, nur lästc: jeden fulschlich an untersten Fufse anfangen, und mit dem Anus cuden ${ }^{h}$ ), ex beschicibt, wie sie Banch gegen Bauch vereint, aber olne cigentliche Vermischung der Geschlechtstheile sich begalten, die Weibchen dio
a) Aristot. histor animal. L, 4. c, 3. b) ejusd, L, 4, c, g.
c) ejusd. L. 8, c. 17.
d) ejusd, L. 8, c. 2.
e) ejusd. L. 4. c. 2.
f) ejust. L. 4. c.8.
8) ejusd. I. 4. co 11.
h) ejust. I. t. c, zo. 
Eier zunïchst dem Anis und zwar jone der länglichten Frebse am Ende des Schwanzes, jene der rundichien aus einer Oeflnung des Brustdechels von sich geben ${ }^{\alpha}$ ), die Regattung selbst aber im Frïhlinge, oder einige noch zur Z⿱Zeit, wo die Feigen reifen, vornehmen, und die Eier theils unter dem Schwanze, theils in dem zottigten branchienartigen Flochen zur Seite der Lrust ausbrüten ${ }^{b}$ ). Ja Aristoteles dachte sogar darauf, die Krustacéen und Testacéen durch ein Nittelglied zu verbinden, and sah dafuir jene firebse an, welche in Schaalen von Muscheln zu wohnen, lieben ${ }^{c}$ ). Jedoch un tor allen Unterschicden sind es nur folgende, welche immer wieder zurücke liehren,

nach der Gestalt:

- in lange (

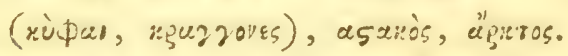

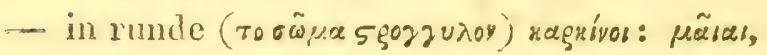

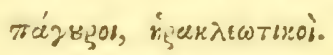

In noch ausfühlicherem Detaile durchmustert Aristoteles die Iilasse der Insehten. Doch hat or hier nur das Aeusscre ihres hörpers, und ihr Verhalten im Leben vor Augen gehabt, und von dem inneren hörperbau ist gar nichts erwähnt, ausser dieses, dafs bei einigen der Darmlianal Vindungen ma-

a) Aristot. histor, animal, L. 4. c. 2. - L. 5, c. 7 .

b) cjnsd, L. 5. c. 37. c) cjusd. L. 4. c. 4. 
che, bei anderen gerade auslaufe a). Er sagt im Allgemeinen von ihnen aus: ,dafs sie nur durch Geruch geleitet, ihren Frafs aufsuchen ${ }^{b}$ ), und sonst auch die Wirkungen der übrigen Sinnesora gune äussern, dafs sie dem abwechselnden Schlufen und Wachen unterworfen seyen ${ }^{c}$ ), dem Winterschlafe sich überlassen ${ }^{d}$ ), dafs sie, wenn dic äussere Oberfläche ihres hörpers mit Oel bestri chen wird, sterben ${ }^{e}$ ), dafs sie in einzelne Theile zerschintten, noch einige Zeit fortleben, einige ans Munde oder After verborgene, oder, wie z. B. die. Scorpionen, äusserliche Stachel tragen $f$ ), dafs sie die Töne blos durch Reibung der Luft mit den Flügeln und Ringen des fiörpers herrorbringen $s$ ). Am weitläufigsten läfst er sich über ihre Entstehung aus. Zwar behauptet er, dafs sich alle wechselseitig mit dem hinteren Schwanzende be. gatten k), das Männchen kleiner, dàs Weibchen größser sey, und ersteres den Rüiclien des lezteren besteige, dafs alle in der frühesten Epoche einen Wurm ( $\left.\sigma n \omega^{\prime} \lambda \xi_{\xi}\right)$ rorstellen, und zwar dic Schmetterlinge rom Wurme sich zur Raupe (rapsrn),

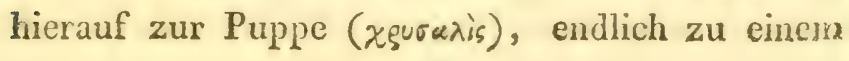
a) Aristot, histor, animal. L, 4. c, $7^{\circ}$
b) ejusd. L. 4. c. 8.
c) ejusd. L. 4. c. 10 :
d) ejusd. L. 8. c. I't.
e) ejusd. L 8. c. 27.
f) ejusd. L. 4. c. 7 .
g) ojusd, L. 4. c. g.
b) cjusd. L. 5, c, 8. 


\section{$-316-$}

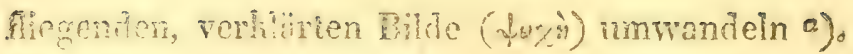
Demohngeachtei unterecheidet er sie doch nach dem rermeintichen Ersprunge ans rerschiedenen Materien: bei einigen, wie z. B. bei Spinnen, Phalangien, Nlenschreclien und Cicaden soll dieser Vurm ron ilmen geboren werden, bei Schmetterlingen aus grïnen Blättern, bei fiäfern aus trockenem Holze und Unrathe, bei Wanzen aus thicrischer Ansdünstung, bei Läusen aus dem Fleischo der Thiere, bei Empis ans Ascariden und bei lez. teren aus Schlamme oder TVasser, bei Kanthariden aus dem Feigenbanme, bei Miichen ans dem Lion. the, bei anderen endlich aus Thane, Schnee, Fener u. s. w. cutstehen. Noch mehn als ins $\Lambda$ llgemeine, geht er in die Lebensart einzelner Familien z. B. der Bicnen, Spinnen und Cicaden ein. Von der Spinnen zeigt er, wie sie sich auf dem Netzo wechselseitig zur Begatlung anluclen, mehrere ofters im Streite dariber begriffen, einander anffressen, einige Veiber ihe Fier unter I.m Bauche anhängen und ausbrüten, rerschiedene Gattmugen rerschiedene Netze spimen, und (wie er mit Democritus irrig glaubi) hiczu die Fäden nicht ans dem Inneren des Förpers, sondern aus der äusse. ren Haut gleich Haaren herausziehen ${ }^{b}$ ). Alles aber iibertrift die Geschichte der Bienen, welche

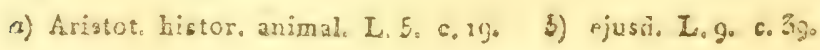


er in füften und nermten Buche seiner Thiergeschichte ${ }^{a}$ ) so umstindich liefert, daf's man frei gestehen mufs, sie habe bis anf uns beinahe liei= nen Zuwachs erhalkn. Vie eine Nation oder einen Staat, betrachtet er das Zusammenleben der Bienen; er unterscheidet in dem nenen Schwarme ('́rrios), wodurch sie den Beginn ihres Vereines feicrn, drei Arten von Stïnden, den ersten ränmt er dem hönige (Ka)

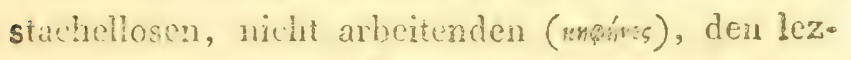

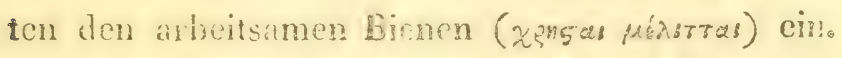
Thre Entitehum belangend, funt er die verschiedenen Meimngen dariber an, nümlich dals einige glauben, dic Bichen holıten den saamen zu den Bienonwinuchen aus den Bithen des Kalmus, der Ohven und fialyntren, andere, dafs sie diesen Suamen blos zn den Dronenwüuchen von den Wlïthen mithingen, der höng selbsi aber die ar* beitsumen Bienen erzcuge, weswegen or auch Bieo menmutter heifse, andere, dafs sic sich begatten, and zwar àie Dronen die mänulichen, die gemejnen Bienen die weibliclion seyen. Aristoteles läfst diese Meinungen uncuischieden, und beschreibt nur, wie der Game in die Wachszelle gelcyt, allmählig als Wuimchen, dam befliggelt, endlich a!s rollkommene Biene, jtdoch der König ohze alle

a) Aristot, histor, anima!, E, 5, c.22 - L. 2. c. 40. b2o 
Netamorphose, sogleich als solche erscheine. Hicrauf schildert er, wie die Arbeiten an rerschiedene Individuen der arbeitsamen Bienen vestheilt sind, die kmen den Honig, welcher bein Thaue, oder mit Erscheinung des Regenbogen herabfullt, sammeln, - die Anderen aus dem Staube der Blumen durch eigene Umwandlung das Wachs bereiten, Andere TVasser herbeitragen, Andere den Bienenstock reinigen, die Todten hinaustragen, Andere ausserhalb des Stoches Wache stehen, die feindseligen Inseliten und andere schädliche Thicre ablualten u. s. w., liurz, wie einzelne Geschäfte Einzelnen anvertrant sind, und die Ordnumg des Ganzen nur durch einen oder zwei hönige, denen bcim Schwärmen oder Friegen der ganze Zug folgt, aufrecht erhalten wird. Er merlit an, dars die Bienen Musik lieben, die berorstehende Veränderung des Wetters rerkinden, Norgens zum Austluge auf die Arbeit, besonders, aber zum Schwärmen, gleichsam durch einen Trompeter aufgewelit werden, und ihr Wohlseyn nur durch Sumsen an den Tag legen. Auf solche Weise fäht er fort, die Oelionomie dieser lileinen Fïnstler in Anlegung der Zellen, in Bereitung des mehr oder weniger guten Honigs, ihre hrankheiten, Feinde u. s. w. mahlerisch auseinander zu setzen, nicht selten nennt er sie die Wachsbereiter, , :m mosz" und zäblt ihnen zunächst noch sechs Gat- 
tungen, welche entweder in Gesellschaft wie z. B.

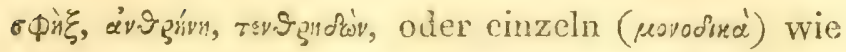
z. B. бะзда', Bopfúres leben, als rerwandt auf. So ausführlich aber auch Aristoteles die individuellen Unterschicde angiebt, so unterläfst er doch nicht, dieselben cbenfalls unter allgemeine Gesichtspunkte zu bringen, nach welchen sich folgende Abtheilungen am öftersten in seiner Thiergeschichte wiederhohlen:

nach den Flügeln

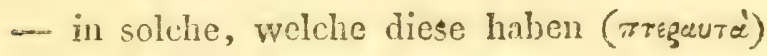
und zwar

a) mit hornartiger Bedeching ("rox:ó$\pi \pi \varepsilon g(\dot{\alpha})$

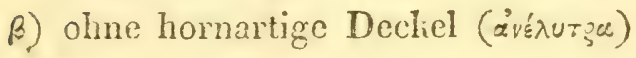

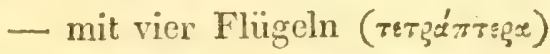

- mit zwei Flügeln (dir rรg

- in solche ohne Flügel (ärregx) als Vielfuls, Assel u.s.w.

nach den Frefswerkzengen und der Nahrung L.4. C. 7. L. 8. c. 11 .

- in solche, welche Zähne haben, und jegliche Nahrung ohne Unterschied genic-

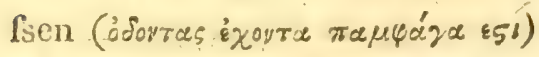

- in solche, wclche. keine Zähne, sondern die Zunge weich und rüsselartig haben

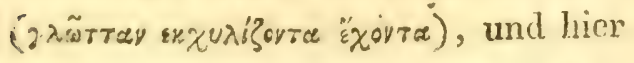


- entweder alle Säfte ohne Unterschied wie z. B. die Fliegen

- oder blos Blut wie z. B. dic Schná lien

- orler blos die suffsen, reinen Säfte der Planzen wie z. B. die Bienen aufsargुen, und sich daron ermähren, sic mögen übrigens mit oder ohne Stachel versehen seyn.

Dieson rorwaltenden Unierschieảen gemäls spricht mun Aristoteles von einer Menge vou Gattungen, die er theils zu Familien zusammen gruppiret, theils einzein an rerschiedenen Stellen zur Sprache bringt; und deren Aufählung hier cinen Beweis ron dem umfasscuden Beobachumgsgeiste des Vaters der Naturgeschichte liefern Jann:

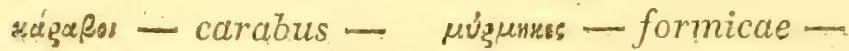

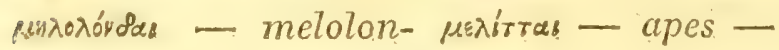

thae -

$\sec v \vartheta \operatorname{ag} 01$

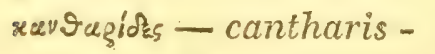

vañgos - clerus -

grúdaros - necydalis - túv

білфи - silpha -

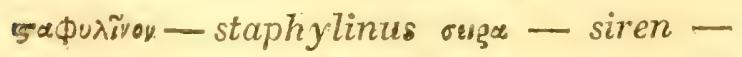

xogers - cimex -.

Poggures - cicindela - xथा

àsรgiva = vespa -

бөnгеs - sphex -

ixveupovs - ichneumon revigndwy - tenthredo -

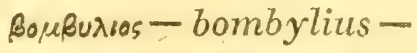
¿фи́p६por - ephemera - 
tuxas - papilio.

Trivíe

iै $\pi \varepsilon \rho ?$

नи̃Tรุ - tineae.

Bo, $\beta_{4} \xi-60 m b y x$.

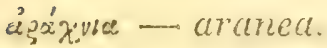

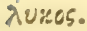

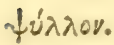

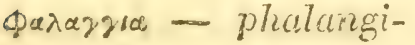
เın.

orogrios - scorpio.

tuara - pulex.

ascects: -

sgótrwnes - Tíicintis.

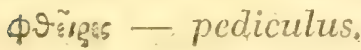

isros - julus.

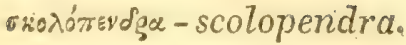

тยтสย - cicada.

-Eтtiónsa - teitigonia.

\&xєre acheta.

cimpirges - acrydium.

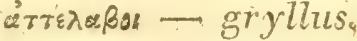

eusas - musca.

o. 15 p.os - oestrus,

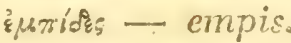

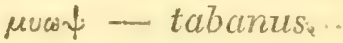

nungre - conops.

Plinins folgte dem Aristoteles nach, und lieferte von den Lirustacéen und Inseliten blos einen Auszug aus demselben. $\mathfrak{J}$ ene handelt er unter der $\Lambda \mathrm{b}$ theilung "iocustac und cancri" zwischen den Weichthieren und Testacéen bei den Aquatilien, die Insekten abcr gleich nach den Vögeln im eilften Buche ab. Nachdem er einige Unterschiede der Iczteren aus Aristoteles wiederhohlt hat, ruft er voll Verwunderung aus: „rerum natura nusyuam magis quam in minimis tota." Zwar ählet cr mehrere Gattungen, welche er cbenfalls ârs Thau, Schlamm, Wols u. s. w, entsehen Iälst, 
auf, jedoch geschieht dieses ohne alle absichtliche Ordnung, und die Bienen, Spinnen und Cicaden sind es rorzïglich, zu deren Geschichte er gleich nach der Eröffnung dieses Buches eilet, und wo cr sich am meisten verweilet. - Auch er betrachtet die Bienen wic in einem Staate lebend, und spricht von ihrer Eimrichtung beinahe wie ron dem römischen Staate selbst; , circa regem apium, sagt er, satcllites quidam lictoresque, assidui custodes auctoritatis"a), hicrauf führt or kiurz das Merkwïrdige derselben aus Aristoteles an, und erzählet, dafs Aristimachus ron Solium so von Liebe für diese Thierchen eingenømmen war, dafs er sie 62 Jahre fortwährend beobachtete, und Philischus von Thasus eben deswegen auch den Zunahmen "agrius" crhielt, eine Vorliebe, welche schon bei den Griechen dadurch sich ausdrükte, dafs sie die Biene gleichsam als den $\Lambda$ bgesandten vom Parnassus - den Homerus, Pindarus, Plato mit dem Honig der Pocsie emährend, ansahen, und diese noch ferner bei den Römern anch an Virgilius ihren Sänger, an Columella und Varro ihre Schriftsiellor gefunden haben.

Nicander thut in seinem Vorke "Therialion" blos einiger gifuiger Inseliten z. B. sieben Gattungen von Phalangien, und acht von Scorpionen Erwähnung.

a) Plinius, natur, histor. Líb. XImus p. 258. Biponti 1783. 8. 
5. 87.

Dic Absonderung und Versetzing der lirustäcéen und Inseliten, welche Aristoteles und nach ihm Plinius gemacht hatten, blieben noch lange fort der Gegenstand der Nachahmung. Isidor zählte die ersten bei den Fischen unter dem Na* men „cancri“ auf, sezte die Inseliten unter dem Titel "de minutis volatilibus" wie Plinius gleich nach den Vögeln, und wiederhohlte ausser einigen neuen Benennumgen z. B. ricina, cicindela, curculio blos die Zeugung der meisten aus leblosen Dingen z. B. der Bibionen aus Wein, der Crabro. nen aus verfaultem Fleische der Pferde. Ein Gleiches that Albert d. G., welcher ebenfalls der Krustacéen bei den Aquatilion gedenlit, und die Inscliten im 26ten Buche überschrieben „animalia sanguinem non habentia" in alphabetischer Ordnung also cinrubrizirte: apis, aranca, blatta, bruchus, bufo, cantharis, limax, papiliones, scor'pio, tinea, teredo, vermis, vespa u.s. w.

Bisher lagen dic Inseliten bei allen Schriftstellern wic in einem bunten Haufen beisammen; mit Wotton erst beginnen sio in etwas Ordnung zu? gewimnen. Zwar stehen auch noch bei ihm die Inschten und Frustacéen von eịnander entfernt, jez doch er ist der erste, welcher auf Rangordnung denkt, und selbst dem Aristoteles entgegen, den Inseliten den Vorrang vor den hrustacéen, MInluss- 
licn und Testarćen cinräumet - ein Schrit, welcicn spater anch Linné nachahmet. So an der Epize der blutosen Thiere stchend, werden sie dom Aristoleles genäls nach voransgुeschiliten allgemeinen Eigenschuften in Familien zusammen. gelesen:

- Iusecta quae favos sibi castrunt: apes, vesizce, crabrones, tenthredines, siren, bomlyylius.

- formica, scorpio, aranea, phalans ium.

- multipeda: scolopendra, julus, onisus.

- quae promuscidem s. aculeum in ore gerunt: muscae, culices, cicadae, locustae, truxales.

- vaginipennia so coleopteras metolontha, galentica, carali, iaurus, fullo, caniharis,

- erucaé et quae de iis generaintur: papiliones, ephenera, henzerobion, bonilix, cicindela.

Die lirustacéen werden im zehnten Buche zwischen den Mollushen wind Testacéen in solche mit langem liöper, und zwar mit beiden gleich diclien Scheeren (gammarus, astacus), oder mit der rechts dickeren (locustie), mit selsr ielen Fǘsen (squilla, arctus), dann in solche mit rundlichem hörper (cancri) unterschieden.

Von nun fingen Mahler und Kupferstecher an, aus blofsem Vergnügen Abbildungen von Thieren getreu nach der Natur zu entwerfen. Collard, 
Pruyn thaten dieses fïr die Fische, Collacrt fur die Vögel, Höfnagel für die Vügel und Inselsten, Visscher und zum Theile Wilte besorgicn hiezu den Slich und Druck a). IMouffet, englischor Arzt, benuzte die Jupfer dicser hiinst!er, und stellte sich ilmen als Schriffsteller gegenüber. lix wähte sich mit Ausschlues der KunsAeréen blos die Inschlen zun Gegensiande sciser Betrohnus, nud lieferte ron denselien cin Werk, ir dessen Ausfubrung schon der Tod dea Gessner gesolone: hatte ${ }^{b}$ ). $\mathbb{Z}$ war hat auch er gerade, wis Wolton, den er sich zum Mruster geo nommon zn liabn schein?, alles mehr obgerissen, in churchen Lapiteln rorgetragen, und wie Gess nor selir viel arf die Renennung elnes Insektes in verschieduen Spracben, so wie anch anf die Beschreibung des Nutzen desselben reiwendet; jedoch is er bei aller Verwirrung der erste, welo cher die Insekten überhaupt unter zwei Rubrilien "befügelte und unbeflüglte" bringt, seine $\mathrm{Be}$ schreibungen mit natürlichen Alsbilduingen begleitet und anch schon behauptet, dafs die Eier der Schmetterlinge vor diesen selbst gelegt werden。

\footnotetext{
a) Diversae insectornm volatilium icones, ad vivum accurao tissime depictae, per celelserrimum pictorem Hoefnağel tye. pisque mandatae a Nic. Visscher r630. 4.

b) Th. Mouffet. Insectorum sire minimorum animalium theam trum. Londini 1634 . Fol.
} 
Fon rien Beflugelten ist im orsten Buche die Rede, nls: apis, fuci, vespue, crabro, tcnthredo, musca (ephennera, hemerobiu, Tibellula), culices, pawiliones (nocturni - aimmi-) cicindela, locusta, cicada, gry?lits, blatta, buprestis, cantharis, scurabaci (majorcs - minores) proscarabaeus, sryllotalpa, iiprila, forficula, cimexim zweiten von impenta: - terrestria) pedata: erucae (glabrcte, hirsutac), staphilin. julus, asellus, scorpio, aranea, formica, vermes, lignarii (tripes, termites, cosi, teredines), fructuarii, humorarii, vestiarii e. c. - apoda: lumbrici) aquatica: squilla, locusta, noctonecta, hirudo, lumbrici, aquatici, scolopendra, hippocampus.

Nehr Abtheilungen als alle seine Vorgänger, brachte Aldrovand in das Gebieth der Inseliten, dessen Verk darüber erst spät nach seinem Tode in rerschiedenen Ausgaben crschien. Obgleich er alles sammelte, was über irgend ein Insekt ron Aristotcles an, in allen Schriftstellern zersireut lag, so vergafs er doch nicht, auf eine strengere Anordnumy dieser seiner Masse zu denlien, wozu er die bisherigen Ansichten, besonders die des Mouffet nach den Flügeln weiter ausführte. Belon hatte die Irrustacéen den Aquatilien beigezällt, Gessner sie sogar in die des salzigon oder süfsen Wassers unterschieden und Iczterer den hippocampus, eruca marina (aphrodite?) vermes, 


\section{$-527-$}

marin. hirado marin. scolopendra marina ais Meeriuseliten - den lumbric. und hirudo als

Süfswasserinsekten überschrieben. Aldrovand wich nun von allen diesen ab, und folgte hier dern Beispiele Votton's. Wie dieser sezte auch er die Inseliten an die Spitze der blutlosen Thicre, handelte die Frustacéen (locusta, squilla, cancer. cancellus, scyllartus) zwischen den Mollusken und Testacéen ab, und theilte die ersten folgender Massen ein ${ }^{a}$ ).

I. Insecta terrestria

- pedata

a) anelytra
a) - quatuor alas membrara- ceas habentia: favifica (apes).
farinosas: papilio.
- binas: musca, tabanus, culex.

b) obtecta: coleoptera, gryll, scarabae. canthar. buprest. ips, blatta.
B) - apteras
a) - habent pedes 6 : ricinus. ci- mex, formica.
- ped. 8: scorpio, aranea.
- multipeda: eruca, geometra.
- millipeda: onisc. scolopendr. julus.
b) - apoda: vermes, teredo, lum- bric. limax.

a) Aldrovand. De animalib, insectis, Libro 7. Francof, 1623 , Fol. 
II. Iquatica

- pedata: musca, iipula, tinea, prulex, scow lopendra.

- apoda: vermis, hippocamp. uva marina, stella marina, nereis, asteria.

Jonston blieb scinem Vorgänger sowohl in der Anordnung des Ganzen, als in der Zahl der Gattungen getreu, nur mit dem Unterschiede, dafs eı die weitschweifige Litteratur weglicfs, die Lamprette ebenfalls zu den Wasserinseliten rechnete, einige Abtheilungen und Abbildungen ron Mouffet benuzte, und sein Wenk mit einer Mengo ziemlich guter hupfer begleitete.

\section{88 ;}

Swam-

- Die Metamorphose, welche das Inscít rom mer- Eie und Vurme an bis zu dem Zustande seiner dam. Befligehng, oder überhaupt von der Zeil semes Entstehens bis zu jener seiner rolkommenen Gestalt zu durchlaufen hat, war schon seit Aristotc. les der Gegenstand der allgcmeinen Beobachtung and Verwunderung. Allein man lieis es theils aus Thieren derselben Art durch Begattumg, theils, oder vichnehr gröfstentheils aus der Fäulnifs fremder hiörper, ja selbst aus Schnee und Feuer entstehen, welche leztere Meinung sich bis auf gegeno wärtige Zeit erhielt. Erst mit dem 1,ten Jahrhunderte erwachte der Trieb, diesem Geheimnisse nather nachzulorsciden, and von dicm animalischen 
Gebietle eben so den Schleier der Finsternifs wio von unserem Erdplancten durch die Entdechuns der neuen Welthcile abzuheben. Fabricius ron Aquapendente hatle schion die successive Entwickelung des Vogels aus dem Eie beobachtet; Harm vei durch solche Beobachtungen aufgeregt, stellio endlich den Satz auf, dafs nicht blos Vögel, sondern alle Thiere ursprünglich aus der Form dos Eies hervortreten:

"nos autem asserimus, omnià omnino animalins, etiam vivipara atque hominem adeo ipsum ex ovo progigni" a).

Goedart machte hierauf seine Beobachtungen der Metamorpiose einzelner Insehten aus dem Eie bekamnt. Jedoch alles blieb noch im Đunkel, bis endlich Redi 1668 seine Experimente über diesen. Gegenstand herausgab, und dem Harreiischen Satze cinen anderen, gleich ailgemeinen und gleich wichtigen enlgegensezte, nämlich „omne animal per animales parentes" b). Nun war der Schleier von diesem Räthsel hinweggenommen, und nach vielen Kämpfen bestättigte sich endlich diese Wahrheit in der weiten Natur. Lister machte sich jezt an eine nochmalige Horausgabe der gewissenhaften Beobachtungen Goe-

a) Harvei exercitationes de generatione animalium, exercit. 2 da p. 58. Amstelod. 265r. 18.

b) Franc. Redi patritii aretini circa generationem inseotorum ad nobilisamum Carol, Dati. Amstelod, $26 ; 1.18$. 
aart's, suchte dieses Werk durch beigesczte Anmerhungen von der falschen Amahme der Entstehung ciniger Insekten ans Than, Blätern u. s. w. zu reinigen, fihte einige vortrefliche neue $\mathrm{Ab}$ theilungen der Schmetterlinge nach ihren aufrechten, horizontulen, zusanmengelegten, oder niedexhïngenden Flïrch cin, unterschied die Libellen wegen ihren durchsichtigen Flügeln ron den Bienen, Kifern, Cicaden, Müchen, rerglich die Metamorphosen der Inschien mit den Stuffen des successiven Wachsthunes der Pflanzen, erfand statt "chrysalis" die Bencunung "aurelic" und bemerlite endlich bei Gelectrnheil, wo er über die Häutumfor der Raupen spricht, dufs die inneren Hinte der Intestine eine biofse Unstïlpung nnd Fortsetzunor der äusseren Haubedechungs seyen, und dither beite in der Periode der Hantung sich zu gleicher 'zeit umändern a), (ine Becbachtungr welche erst in der neueston Zeit Bichat am menschlichen hörper bestäligle, und sich dadurch für Mnatomie, Plhysiologio und Pathologie cin unsterbliches Verdienst bogiundete. Allmählig wurde der angercgue Sircil wiver die Lintstehung der Insekten

a) p. 11. "frinimo in hac oplinione sum, crurac metamorphoain now ese superfucialem sed altius pronctrare, iutestinis etiam ac oris organis transformatiour subeuntilus cum interior intestinorum superficies sit altera pars etiam exterius in cunctis animalibus." Joann. Gucdartius de inseclis operâ M. Lister. Lond. 2685, 8. 


\section{$-531$}

lebendiger, selbst über das ganze Thierreich aus² gedehnt, und allmählig wurden alle mögliche Zeugungstheorien zur Sprache gebracht. Graaf wählte die Parthei von Harvei, Löwenhök deutete óbige Behauptung Redi's dahin, dafs er infusionsartige Thiere im männlichen Saamen von Hühnern, Fröschen, Hunden und Menschen entdeckend, diese als den ersten Stoff zur Bildung des Embryo annahm. Durch solche heftige firiege wurde endlich der forschende Blick auf die Geschlechtstheile der Thiere selbst gekelurt, und Malpighi ist hicr der erste, welcher uns jene der Inseliten an dem mämlichen und weiblichen Seidenwurme nachwcist, und sowohl dic Respifationsorgane (Tracheen) als auch das abwechselnd sich zusammenziehende und ausdehnende Pücliengefüfs als eine Reihe zusammenhängender Iterzen darstellet. Nun tritt Swammerdan auf, enthüllet statt einem einzigen Organe, den ganzen imneren Körperbau der Inseliten, nämlich das Nerron- Geschlechts - Respirations - Alimentar - und MusliclSystem an der Laus, NTcinbergsschneclie, dem Bernhardlirebse, der Ephemere, Eienc, dem Nas. hornkäfer, der Larve eines Tages - und Nacht-Schmetterlings, der Wasserflicge und rerewiget sich durch seine feine $\mathbb{Z}$ ergliederungen und gleich meisterhafte Abbildungen als Anatom der Insek ten. Jedoch Swammerdam that noch mehr: die 
bisherisen Eeobachtungen über dic cinzelnen Me。 tamorphosen rerschiedener Inseliter wicderhohlend, cutdechet er die Haptinterschiete in denselben, und erbanct lieranf cin System, wodurch er sich jezt anch als Zoolog cin Denlinal in der Thiergeschichte errichtet hagt. Er sczt 4 Grade von Verwandlungen fest, und theilet nach dicsen die Inseliten in eben so viele Ordnungen also $\left.2 b^{a}\right)$ :

Ord.I. Nympho - animal, seu insecta, qune praeter cuticulae mutationem omnino perfecta ex ovo prodeunt:

aranea, peliculus, ricinus, cimex, lectuarius, pulex, asellus, vermes, s. intestina terrae, scurpio, hirado, scolopendra, limax.

- II. Nympho - vermiculi, s. insecta, quorum. vermiculus priore nymphae habitu, quems in suo ovo alimenti expers gesserat, deposito, ope alimenti a foris ingesti in plura et evidentiora membra excrescit, donec is altorum veluti nymphae habitum, suo tamen motu retento, indutus, tanquam alatum animal inde prodeat:

libelia, ephemera, locusta, gryllotalpa, kakkerlak, blattac, cimices volantes et terrestres et aquaticae, noctonecta, forficula.

a) Joannis Swammerdamii hiblia naturac sive historia insectorum. Leydae $37 \overline{3} 7$. Fol. Tom. 2. 
Ord. III. Nymphae - rpes, vespae, sphex, ichneumon, crelex, formica, scarabaeus, mcloe, staphylinus:

chrysalides s. amreliue (in quibus membra insecti perfecti minus manifesta): papiliones diurni, nocturni.

- IV. Nympha - vermiformis s. insecta, quorum vermiculi membra nunquam extrinseens videncic afferint, verum intus in cute sue, quam non deponunt, in nymphas mutantur, ibidemque inmobiles fiunt:

musca latrinarum, asili, tabani equina, stercoraria, acarus.

\section{89.}

Die Mclamorphose ist eines der wunderharsten Plinomene, welche anf dem Gebiethe des Thicrreichs zum Vorschein lommen. Beinake sollte man glauben, die Natur habe die Stuffen der Me. tamorplosen ihrer ciuzelnen Glieder, nämlich der Gestime, Thiere, Pflanzen, Mincralien, sowohl einzeln fir sich, als wechselseitig untercinander, an jenen der Inschten darzustellen, und zu versimlichon gesucht. Dei denjenigen dieser Thiere, welche alle Grade der in ihrer Klasse vorkommenden Verwandilungen gesetzmälsig durchmachen müssen, erscheint jedes bei seiner Geburt zu allercrst in Form eines Lies (ovum) in nassem oder etwas Cuchtern Boden - in der zweiten Wetamor. 
phose als ein sich krümmender, fufsloser, oder mit Fifsen hegabter Vurm (larva vermicularis) Jicranf in der dritten als weich - oder harthäutige Puppe (chrysalis, aurelia, nympha) - endlich in der vierion wirft es scine zwangrolle llülle $a b$, ist mit deullichen Füfsen und einem Ansatze von MIiggeln versehen, und stellt nach einigen Häutunfen cinen un volliommenen, zur Zeugung reifin Vogsil (inugo, insectum declaratum) dar. Auf solche Weise müssen alle Inseliten aus dem Eie aufrystehen, wid dann verschicdene Familien durch rin: verschicdene Anzahl von Verwandlungen siohsam aus dem heime sich zu ihrem Ideale rerAliren, wo zugleich jeder Verwandlung ihre Zeit and Daucr festgesezt ist. Welch eine hohe und ertrabene Erscheinung auf dem Gebiethe der Inschten! Doch vielleicht ist die Metamorphose nicht das Gesetz cines Individuums, sondern das der ganzen Natur; vielleicht dafs jedes höhere Thier alle siufien der unter ihm stehenden durchlaufen mufs, um zu dieser Dignität z. B. des NTenschen, des Säugthieres, Vogels, Amphibium, Fisches, Schnecken, Inselts, Wurmes und Zoophyten zu gelangen, blos mit der Beschränliung, dafs je höher die Stuffe, worauf das Thier steht, um so liürzer die Distanz und die Zeit, und um so ummerklicher jede der Verwandlungen desselben ist. Vergleicht man das Zellengehäuls eines Zoophyten, 
die Zclle der Bicne, die Puppe des Schmeterlings, die Schaale der Schneclieł, die Höhlen der Am. phibien, die Nester der Vögel, die Palläste der Menschen wechsclseitig miteinander, so erscheint die Natur als eine und die nümliche Eauliünstlerin, und alle dicse Funstwerke des Instinktes oder der Vernumft, von welchen immer das Höhere das Nie. dere sich einverleibt hat, erscheinen zusammen als Glieder eines einzigen schönen Gebäudes. Auch hat wirklich schon der grofse Swammerdam die einzelnen Stuffen der Verwandlung der Insekter mit jenen der Nelkenpllanze - als entsprechend dem Saanonkeime, der Knospe und endich der Blïthe - ja sogar mit den Verlarningen der Frö. sche am Anfange und am Ende scines Buches ver. glichen, und diese Vergleichungen durch Abvildungen anschaulich gemacht. Eben so liefse sich dieser Vergleich anch auf den Menschen und die übrigen Thiere übertragen. Nicht blofse Versinnlichung ist es, dafs man in den Schriften über Fntbindungshunst an dem menschlichen Embryo einen Zustand unterscheidet, wo er noch gestaltlos, gleichsam als Infusorium wic ein Punlit mit flockichten Hänten umgeben ist - einen anderen, wo er wie ein Bieneuwürmchen in der Zelle gelirümmt, daliegt - einen anderen, wo jezt mit zunehmenden Elemente des Wassers, die Extremitäten sichtbarer heranwachsen, und der Embryo 
selost wie der Fisch im Wasser Bewegungen macht - cndlich wo das Element des Wassers allmählig sich veiringert, und der mil allen Gliedern versehene und wohl proportionirte Foctus aus der Gebärmutter an die Lift heraustritt, und hierauf nach viclen Häutungen (Hauthrankheiten) als zeugungsfühiger Jiungling und Mann, als fruchtbares Mädchen und Weib in aufrechter Stellung einhergeht. Wahrhaft! mit Rechte liömnte man den Aussprüchen eines Harvei und Redi auch noch diesen hinzufügen:

"omne animal seu creatura per metamorphosin; quo perfectius illud seu illa, co plures, citipres ac invisibiliores hae. "

So gewils-auch alles dieses in der Natur gegrindet ist, so ist uns doch die Zahl, Dauer und Art rer Verwandlung der einzelnen Reiche und Flassen sowohl, als auch der Gattungen und Individuen, ja selbst nur der Inseliten, beinahe ganz unbekanat, and es herrschot in allen Schriften hicrüber noch völlige Dunkelheit, so, dals es erst liüftigen Jahrhunderten überlassen werden mufs, dieses Feld mit weiteren Thatsachen zu bereichern, und dann erst aus der Menge derselben dic Gesetze zu abstrahiren. Freilich sind, Leider! die Naturforscher selbst noch nicht einmal über die Wesenheit der Verwandlung als solcher einig: Swammerłam glaubt, dafs das Inselit schon ganz volliommon in 
der Trumlarve liege, und nur durch Ansatz der Glieder von Aussen heranwachse und reife, ja er sagt ausdrüklich, dafs or dem damaligen Herzog ron Toshana, welcher sein habinett in Augen. schein nahm, den vollkommenen Schmetterling schon in der Chrisalide vachgezeigt, den Zwiefalter selbst schon in der Raupe erkannt habe; Harvei unterscheidet das $\mathbf{E i}$ nicht ron der Puppe, aondern belegt beide mit dem gemeinschaftlichen Namen des ersteren; Swammerdam nennt beide Ofters Puppe. Nicht zu verwundern ist es daher, dafs man bei so übertriebenen Beobachtungen, die Idee der Nletamorphose nit jener der Erolution verwechsclte. Allein das Ei und die Puppe sind zwei ganz rerschiedene Stuffen der Verwandlung, und die Metamorphose selbst ist empyrisch ange. sehen, nicht eine blorse Entwiclelung des schon Vorhandenen (evclutio), sondern eine wahrhaftige Umwandlung (transeubstantiatio). Lister hat daher ganz reclit, wo er in dem Artil.el über Häu tung sagt, dafs nicht blos die äussere Haubedecliung, sondern alie äusseren und inneren Theile sich zu gleicher Zcit umündern: so sieht man in den abgestreiften Häuten der Inseliten die Stigmaten, Tracheen, und welcho Veränderungen erleiIen nicht die Frefswerlizenge, welche z. B. bei den Raupen mit Maxillen versehen, bei Schmetterlingrn aber ohne diese rüssolartig gelildet sind? 
Mit jeder nenen Verwandlung ist auch das Thier ein neues, und nagt $z$. B. als Raupe an bestimmten Blättern, während es als Schmetterling den Honig der Blumen aufsauget. Nur die rergleichende Anatomie Kann den Einfluls der Metamorphose auf himper und Seele des Thieres aus der Ver. schiedenheit der Organe, der Sitten und Lebensart desselben nach dem verschiedenen Grade ihres $\mathbf{\Lambda}$. ters erweisen, und uns hieron in Zukuyft eben so in henntnifs setzen, gleich wic ir bis jezt auch durch sie wissen, dals die nicderen Thiere ähnlich den Pfanzen mit der Begattung, die höheren mit dem Genufse des Geschlechtes und des Geistes, den Freislauf ihrer Bestimmung erreicht haben. Allerdings stehen wir noch weit rou diesem schönen Zicle, und haum löunen wir uns r limen, die innere Beschaffenticil und die Metam . phosen der Inseliten nur im Allo emeinen zu lienilen. Jedoch Swanmerdam bleiwt das Verdienst, hiezu den ersten kustols und Giundrifs gegeben zu haben. Durch ihn wissen wir die rierfache Abstuffung, welche die Natur bei der Verwandlung dieser Thiere cinhält. Von der Spinne an durch ie Libelle hindurch, nimmt die Kembarkeit des rerLlärten Bildes in seiner Larve immer mehr ab, bei Bienen hat die Larve schon eine Metamorphose mehr zu durchlaufen, nämlich die der Puppe; Ġoch bildet diese hicr eine durchsichtige weiche 
Ilaut, wïhrend bei Schmetterlingen die Puppe sanz hart, aber doch noch das vollhommnere Thicr andeutet - bei Mücken endlich liegt die harte Puppe mbeweglich wic todt und ohne alle äussere Spur des liüftigen Thieres da. Freilich sind uns so die Hauptepochen gegeben; aber wer getrauet sich wohl die Periode jeder Epoche durch alle cinzelne Individuen, gleichsam als Glieder rerselben, durchzufuhren, da wir noch so wenig ron der Dauer, Jahreszcit, dem Aufenthaltsorte and selbst bei einzelnen Individuen ron der Zahl and Form ihrer Verwandlungen wissen? Wäre rs Swammerdam möglich gewesen, alle Inseliten eljen so umständlich zu beobachton, wic or es bei der Ephemere that, von welcher er angicbt, dafs das Ei in den Schlamm des VVassers ron ihr gelegt, bis zur Reife des geflügelien Insehites drei Jahre braucht, endlich als lezteres, Abends zwischen 6 und in Uhr an das trockene Ufer herausfliegt, zcugt und sogleich stirbt, dann hülte er nicht blos die Zahl der Lílassen, sondern selbst den Platz der einzelnen Individuen nach dem Grade der Vollkommenheit ihrer MIctamorphose bestim. men liönnen, und Alles wäre so im schönen, pasa scnden Gefiige erschicnen, was or aber, Leider! unterliefs. Schon zufrieden, die Anzahl der filassen ansgenittelt zu haben, behïmmert or sich nicht weiter um dic innere Anordnung derselben, 
thaher sich die üusserlich und innerlich heterogensten Thiere, wie z. B. Schneclie und Scolopenter, Scorpion und Regenwurm u. s. w. in der ersten Thasse, und eben so auch, wie aus dem obixin Schema einleuchtet, in den übrigen beisammen befmden. Selbst die Zahl seiner Lilassen ist nichts reniger als begründet und rollständig: bei der crsten und zweiten findet heine lopuppung statt, ansgenommen, dafs die Larven der Libellen, Ephemeien u. s. w. sich eine Huille aus Sand, Schlum ouder Rinde rerfertigen; dieze Thiere sehon ferner, so wie sie ans dem Eie kommen, sich mehrmals geizuitet, und jene der zweiten hlasse nelstdem noch rollhommene Flingel erhalten haben, schon als Laren dem roliliommenen Thiere gleich und haben nicht jene Formen ron Wumlarven und Pupper zu durchlaufen. Bei der dritten und rierten hlasse ist aoch eine dritte Vcrwandlung, nämlich der Wurmlare zur Puppe vorhanden. Eigentlich giebt es also nicht vier, sondern nur zwei Klassen, und dieses, dafs die Larven der Mücken ihre Hautbedeckung ror der Verpuppung nicht ablegen, die Bienen und Schmetterlinge aber sie abwerfen, ist eben cin so rinzulänglicher Grund zur Bildung eigener Kilassen, als es die weiche, durchsichtige Puppe bei Ameisen, die harte und undurchsichtige aber bei Schmetterlingen wäre. Allein auch von allem dic- 


\section{$-541-3$}

sen al gesehen, welch buntes Chaos bringt die Ar: sicht herror, die Insehton nach der Aelinlichlicit ihier Verwandlungen zu classificiren? Vallisnier, Reaumür, Frisch behaupten, dafs die Flïhe urs dem Eie gekrochen, noch eine Zeitlang als Wurmlarve leben, wohin lionnte nun dieses Thier andens versezt werden, als zu den Libellen, Wanzen u. s. w.? (!). Degeer hat bemerkt, dals die Keller. es I gleich nach ihrer Geburt einen Ring und eir Paar Füfse weniger haben, als im weiter rorgerïkten Alter (tom. $7 . p .531$ ) - dafs scolopen. dra lagura anfangs mit drei Ringen, und mic eben so vicl Paar Füfsen erscheine, später aber fünf Ringe und neun Paar Füfse mehr erhalte (ibid. p.576, 577) - dals julus terrestris anfangs acht Ringe und sieben Paar Füise, später aber gegen 50 Ringe und beinahe 200 Schilder zeige. Degeer will eine gleiche Veränderung in der Zahl der Fülse der Spinnen nach ihrem verschiedenen Alter beobachtet haben, und betrachtet alle diese allmählige Veränderungen als wahre Metamorphosen dieser Thiere. Auch der Ge* brauch der Geschlechtsfunlition, die erst mit dem reiferen Alter eintritt, und selbst der Irrthum Müller's, welcher von einer und der nämlichen cyclops zwei Arten von Larven annahm, liönnte als ein Belege für die Meinung Degeer's angeführt werden. Uebrigens stehen in Swammerdam's Sya 
teme Halb - and Ganzlügler wie z. B. Yuthemewis und Wanzen - Inseliten mit Maxilicn und mit blofsen Säugrüsschn, wie z. B. Libellen und Wanzen, Schnaken und häfer durcheinander, ja die flügellose Bettwanze mufste ron den übrigen Wanzen getrennt und beide in terschicdene Filas. sen gefügt worden! - Wahrhaft eine Gruppirung, welche noch so lange einem Sandhaufen oder einer bunten Triese gleichen wird, bis wir eine gröfsere Menge ron Inseliten nach der Jahreszcit, Dauer und Art der Verwandlung, nach ihrer Nalirung und ihrem Aufenthaltsorte während jeder Periode der Metamorphosen, beobachtell haben werden.

\section{90.}

Vallis- Mouffet ist der erste, welcher das Studium dicı

nieri. Inscliten in Anregung brachte; Redi reranlafste die Beobachtung ihrer NIetamorphosen, und seit Swammerdam treibt sich alles num danit herum, den wunderbaren Verwandlungen dicser Thiere cinzeln nachzuspühren. Sibilla Merian aus Frankfurt, welche ron Nümberg in die Niederlande, und endlich nach Surinam und Amerika reiste. ist ron num an die erste, welche sowohl durch inre Feerer, als durch ihren liüstlichen Pinsel diesen Nachforschungen cinen neuen Schwung gab. Sie bestrente sich nicht blos einzehe Insoliten ilires faterlandes $z u$ allernächol zu be. 
schreiben ${ }^{a}$ ), sondern auch diese nämlichen Beobachtungen auf einem fremden Velttieile zu be. liräftigen, mit ncuen zu vermehren, jedes Insckt nebst seiner Larve auf der Planze, auf welcher es lebt oder nistet, immer in die Beschreibung mit aufzunehinen, und in einer ausgemahlten Zeich. nung darzulegen $b$ ).

Blanliardt, ein Nicderländer, machte zu gleicher Zeit seine Beobachtungen über die Verwand. lungen einzelner Schmetierlinge, Müclien und anderer flegender Inseliten beliannt.

Lister trat mit der rortreffichen Schrift über die Spimen Englands herror, und Ray bearbeitete endlich die Inselitenliunde nach dem Systeme Swammerdams, von dem er sich blos dadurch untersclied, dafs er in jeder jener vier hlassen wieder Fufslose und Befufste - solche des Landes und des Wassers - Grölsere, Mitlere und Kileinere absonderte, und nebstdem die Schriften eines Monfet, Lister, Petiver benuzte ${ }^{c}$ ).

Durch solche fortgesezte Arbeiten über die Entstehung und Verwandlung der Inselten, wurde

a) Sibilla Merian. Der Raupen wunderbare Verwandlung und sonderbare Blumennahrung. Nürnb, 1679.' 4.

b) Maria Sibilla Merian. Dissertatio de gencratione et metamorphosibus insectorum Surinamensium. Anstelod. 1719. Fol.

c) Ray. Historia insectorum opus posthumum. I.oulini 1710. 4. 
atich der Linterschied des Aufenthaltes dersclbein immer mehr gekannt und auffallender. Seit Ariistoteles bis auf Redi, hatte man ihren Aufenthalts. ort mit ihrer Abstammung selbst rerwechselt, und sie so in solche des Wassers, der Luft, des Fen. ers, der Erde, der Thiere, Planzen u. s. w. abgetheilt, Aldrovand hatte alle jene Unterschiede in diesen der Land - und Wasscrinseliten zusammengefafst, Vallisnieri entwarf endlich den Flan, allo Inseliten nach ihrem Aufenthaltsorte und ihrer Nahrung zu gruppiren, and errichtete wie Swammerảam ebenfalls 4 Klassen ${ }^{a}$ ):

I. Inselti, che annidano nelle piante e te dirorano

- Insekicn, welche auf Pflanzen nisien, und von diesen leben -

II. . . che nuotano, crescano, pivanno e sempse dimorano ne'soli fluidi

-... welche blos im Flüssigen schwimmen, aufwachsen, leben und rerbleiben - -

III. . . . che si trovano denêro i marni, sussi, crete, ed altri corpi solidi

- ... welche sich im Marmor, Şicinen, in. Kreide und anderen festen Sachen aufhal$\operatorname{ten}-$

a) Anton. Valiisnieri. Esperienze et 'osservazioni intomo all'origine, sviluppi o costumi di varj insetti, - Pađ̉oa 2.713. 4 . 
If. . . . che fanno dicntio o sopre i riscentî it lor mondo (qu' dell romo, cie quadrupedi, de' volatili, de' pesci e. $c$.

- . . weiche obchalb oder imerhaib der Thiere îhe Eier legen: -

Allerdings ist der Aufenthaltsort und dic Nahrung bei Inselien ron ausserordenticher Wichtigheits Die Noifsnilchrane stirbe, wie man in die Wolfsmilchlanze entzicht; der holhläfer findet sich nur im Tothe; jede Art der Schildäuse bewclint beinahe ihre eigene Pflanzenart, jede Art der Lünse eigene Arten ron Thieren; die Kürer des Sjargels, der Lilie, Néssel u. s. W. erhalen nux ron ihrem Lieblingsintenthalte ihre Namen, Freilich wäre es erwünscht, einen vollstünảigen Insektenkalender zu besitzen, worin diese nach den Monaten und nach den Thieren und Pflanzen; wolche sie zu dieser Zcit am häufigsten bewohnen, aufgezählt und bescirrielen sind, wozu auch schon einigermassen Brahm den Anfang gemacht hat a), and wo es auch nicht an weiteren Unterabtỉeilungen fehlen lam, besonders, wenn man wie Vale lisnicri blos die erste Klasse nach den einzelnen Theilen der Pflanze in 41 Ordmungen unterscheiden will. Jedoch nie himen solche Unterscheiaungen auf den Namen eines Systemes Anspruch

\footnotetext{
a) Nir. Jos. Brahm. Inseltentalender für Sammler und $O=k$. nomen, ir u; ar Th, Mlainz -1790-91. 8 .
} 


\section{$-846-$}

maches, da eic mehr Verwimung als Ordnung hervorbringen. Wie viole lnseliten werden öfters auf fremuen Pllanzen, anf Blätern slatt auf Blïthen, auf diesem statt anf jenem Thiere angetroffen? wie rorvilig wïde man nun hande'n, wenn man diesen Ori als den ihres Aufenthaltes anschen und sie darnach in dem Systeme aufsuchen wolite! Auch ist woll zwischen dem Aufenthalie der Larren und dem des volllommenen Insches zu unterschciden: Behamntich lieben atle Inschaen ihro Eier dem nassen oder doch feuchten Doden dem IVasser, der kühlen Eric, den saftigen Blïttern, oder wie Tenthedex, Drensen u. s. w. der weichen Haut der Thiere anzuvertranen, md fliefen nach durchlanfencn Muamorphosen im Freien und Trodenen; Tassolüfer und Notonchten, leben den Tag über im VVasser, nud flezen nachts ausserhalb demselben herum; welche Blume endlich lielse sich für Papilionen und bienen, wehler ron den riclen Säften für Flicgen ausschliefsend bestimmen? Die Maikäfer suchen sich die rerschecienartigaten Bünme zu ihrem Aufenthulle aus; cine Ant der snimen lubt in Wasser, andere zinüchst demselben, andere an Maucm, ant' Wiesen, Büumen, auf ebenen Boden u. s. w.; Ther wird num wagen, dicses eine Ordnung der Inscliten zu nemien, wo die Larre ron ihrem ansgebideten Tixierc, die Arten son imen Gattungen 
nach der Ansicht der Nahrung, des Aufenthaltes und des Elementes auseinander gerissen verden? Vallisnieri selbst erkennt scine Methode als rielen Einwürfen ausgesezt, aber noch immer nicht batte or das Bild ron der Unordmung, die ihre Durchfilhung herrorbringt, row Augen, daher er diese Torte roll Selbstrertrauen zuruft;

„Bei allen diesen mübersteiglichen Beschwerden, so hoffe ich doch, dafs meine Methode muter allen bisher am wenigsten rerwirt ist " $a)$.

\section{91 .}

Von num an erwachite das Studium der Entomologie mehr als je sonst. Rcaumür verbreitete durch seine genauen und angerehmen beobachtingen, Beschweibungen und fiupfer eine solche Lust, dafs die meisten Naturforscher in Teutschland, Moiland, England und besonders in Frankreich sich mit diesem Fache beschäftigten. Er hatte sich nicht rorgenommen, ein eigentliches System aufzustellen, oder cin schon beliamtes zu vervollionmnen, sondern sein Plan ging hier, wie uiberhaupt auf dem ganzen Crebiethe der Naturgeschichte dahin, einzelne Individuen nach ilirer Struktur, Lebensart, Verwandlung u. s. w. zu um-

a) 1. c. p. 46. " non ostante perì cosi arduc e quasi inestrigabili dificultà, spererei, che il mio methodo fosse il meno confuso di quanti sinora sono usciti alla luce". 
tersncion, whe anf solche Vive Licht zeluc Arten, Gattungen und Familien zu verbre aen. Olne veitere lnordnung, als höchsiens nach der Verwantechal des änsseren Ilabitus, gau er seine Peobahnngen aber Inselicn in cinzelnen Ablandlumen in 6 fanden heraus. Die zwei ersten sind blos den Raupen, welche er nach der Anzahi und Lage der Fuifse - und den Schnetterimgen, welche cr wie Rionfet in Tag- nut Nachtrögel, hierauf aber nach den mehr hibich ten, grfiederten oder hawartigen Artem,on in drei Abtheilungen, endlich nach der verschtede nex lolung und Form der Flighel, wie J ister, nach der fegenwart oder dem Mangel des Riussels weiter unterscheidet - der dritie Band ist den Ti. neen, wolche sich aus Butiem, Helle, Pelz, Kleidern, Planzentheilen, Sanci in Frodicncm oder Feuchlon puppenartige Gïhlen baten. ferner den Blattäusen - der vierte den Gallwespen und den

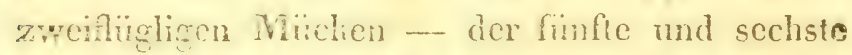
ist den verfitgligen Mhchen gewidmet, wolin or die Bienen, Vespen, T'entheden, Cicaden, Libellon reshnet, und sie nach der Anwesenheit der Zzitne orier des Rüssels unterecheilet. Reaumür hat vichto merlaseen, was die äussere Strulitur, den Anfenthaltsort, die Lebensart und Verwand. luns diesex Thiere angeht, ja er hat selbst, z. B. an thanch, die Tharicen und die scidenspinen- 
den Gofilse in Zeichnungen dargelegt, und das auf dem Rïchen almer hohten pulsirende Gefüfs zwar niche nie Malpigh als eine Reitie ron llerzen, ater doch als cine fortlaufende Arterie beschrieLear. Vermuthlich hïtte Reaumür anch noch die äh iren, welche er wie z. E. dic häfer, die flügellolo. Áschten, die Viurmer und Schnecten in der (1) cle zum vierten Eande als zu Insekten genöig anfinte, in forneren Bünden abgehandelt, wïrden itm, nicht Lmstüde hieran verhindert ha. ben. So wenig er sich ubrigens an eine Methode lielt, so schim er doch jene auf die Anwesenheit, Zahl und beschafrenheit der Iiligel gegründete wuhlen zu wollen, inden en den Lizwarf derselben als dis Cmulage seines Wertics, in der Vorrede wiederlegte, und iie Schmettedinge, Fliegen, Ameisen a's so'che mit minedeliten Fibrohn - die IIeuschechen, Grilien, den Exiluebs wind die Wanzen als solche mit cinen weichen Ueber. zugge üher die oberen Flügel - die liür, don Staphylin, und Ohrwum, als solche nit hormati= gen Viytren - die Flohe, Spimen, Relleresel Winmer nua Schncclien, als solche ohne alle Flí. fel, wad, mii Ansnahme des Flohes, chne alle Verwandlung aufzählte ${ }^{a}$ ).

Zu glwicher Zeit nit Reaumür, machtc auch Domet cinige, nicht uninteressante Bcobachtungen

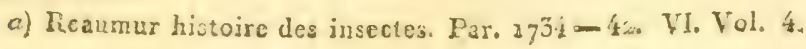


an Inseliten, besonders jene, dafs die eingesperrten Weibchen der Blanlüuse (pucerons) bis in die 15 te Generation fortgebähren. Jezt ging Lyomet aus der Schule Reaum"r's herror, lieferte eine Uebersetzung der Inselitentheologic ron Lesser mit eigenen Aumerhungen, und machte sich nun durch die rollstïndige Anatomic der Veidenraupe (bombyx cossus), und durch dic damit verbundenen meisterhaften hupfer allgemeinen Ruf a). Zwar lïst er sich nicht auf physiologische Willärumgen cin, desiohngeachtet äussert er doch, dats das ans rielen Ganglien bestehende Rühemmark bei Inschten als eine Menge zerstrentor Gehime, die Tracheen chen so gut als Organe zur Natrumg als zum Ahmen angeschen werden homen; über die sogenannten Nierchen und den Fettlörper, welche rielleicht mit den Geschlechtsorganen in Verhätnifs stehen, gesteht er aber seine Unwis. senheit. Oligleich Einige inn als imaginär rcrschicien wollen, so han doch die Entwiklung and Ablildung der Sciden - und Speichelgefäse (vaisseaux soyeux et dissolvans) die Genauigheit des Verfassers beweisen. Vielleicht ist es aber gerade die ungeheure Anzahl ron Muskehn, deren er an dieser Raupe 1647 abbildet, bei den Menschen aber sich nur 529 finden, welche, statt Be-

o) S, Yonnet. Traité anatomique de la chenille r!u sab? Tas. $: 760,4$. 
waise von der Gednht un der Geschilklichleit diew se Anatomen, vielmehr Veranlasstug zu dieser Nachrede giebt. Jedoch was man chender zur Vollstündighieit dieses Wrerlies, und zur volliommnen Kemninifs dieses Thieres noch wïuschen lönnte, wäre, dafs Lyonnet seine Zergliederungen rom Eie bis zum Schmeiterlinge ausgedehnt hätte, worin man auch noch mcir den würdigen Schüler Swammerdan's erkannt haben winde.

Zu gleicher Zeit stelle sich auf englischem Boden den verdienstveilen Entomologen - einem Lister und Ray - Abin ais Muhler durch seine illuminirte Abbildungen ron Schmetterlingen ${ }^{a}$ ) und dann von Spimnen und Läusen ${ }^{b}$ ) entgegen.

Nun erwachet auch auf toutschem Boden das Studium der Inseliten. Lesser sammclt alle bishe. rige Beobachtungen hicriber in gesonderten fia piteln über Zeugung, Eintheilung, Alhwen, Verwandlung, Geschlecht, Aufenthalt, Bewegung, Nahrung, Sinne, äusserliche Gestalt u. s. w. zusammen c). Frisch wählet die Inschion Teutscho

a) Elener Albiu. Insectorum angliae naturalis historia. Lono dini 1731.4.

3) . . . a natural histcry of spiders and other curions insects. Lond, 1756 .

c) Friedr. Christ, Lesser. Insektentheologie, oder vernunfiund schriftmäfsiger Versuch, wie ein Mensch durch aufmerksane Betrachtung der sonst wenig geachteten Inselio 
lands zu seiner Betrachlung, logt mbelimmert über eigentliche Anordnung, den Reichthion seiner Beabachtungen uber die Degaltung, Verwand. lung, Nahrung i. s. w. Finzelner derselbon in rortreffichen, gesulichtlichen Besclircibumgen, wind in nicht undentichen Holzstichon dar, und lsandelt alles in direizelin Abthoilungen $a b^{a}$ ). Alla Schriftstellor abcr, welche sich bisher mehr durch geschichtichen Reichtum als sirenges System in der Klasse der Luselaten anszeichueden, hat Roesce in seinem VVorlie , monatliche Inselitonbolustigung" ibbortrofon. Was Reamie durch ssinen șcharfsinigeu Beobachungsgrist - Merian und Albin durch ihrea krafigen Pinsel - wa Swanmerdam and Frisch darch die Fille an frfitheng auf dem Gebiethe der Inseliten geluisiet haher, beinahe alles dieses suchie Roesel sich einzurerleiben. Zwar hat en muterlassen, diese einzelne Abhandlungen nach eincan Plane und in systematischer Ordnug herauszugeben, aber eben dafï flutet er in der Vorrede zu dem ersten Bande folgendes Schema an:

ten zur Konninifs und Bewurderung Gottes gelangen könne. 2te Aufl, Frankf, 740 , 8.

. : trad. de l'allemand par Lyoṇnet 1742. T. 2. 8.

a) Joh. Leonh. Frisch. Beschreibung von allerhand Intekten in Teutschlaud. Berl. $1720-38$. XIII. Th. 4. 
A. Landinseliten

a) sich verwandelnde

- Wurmlarven mit

\section{Füfsen: Käfer}

- $10: 16=$ Schmetterlinge

- 18,20,22 - Blattwespen

b) sich nicht verwandelnde

- mit 6 Füfsen: Heuschrecken, Grillen, Wanzen, Lüuse

- $8^{\circ}-$ Spinnen, Milben $^{\circ}$

- 10 - Scorpronen

- über 10 - - Polypen, Asseln.

- ohne alle Fülse: Regenwürmcr, Schnecken.

B. Wasserinsekten

a) sich verwandelnde

- mit 6 Fülsen: Wasserliäfer, Libellen, Uferaas

- $16 \div$ Tineen

- ohne Fülșe: Vassermaden

b) sich nicht verwandelnde

- mit 6 Fülsen: Wasserwanzen

- $8=-$ Vasserspinnen

- $10 .-$ Krebse

- -14 - = Vasserasael

- ohne - Blutigel, Mrollusken. Conchylicn. 


\section{$-554-$}

Roesel fihrte zwar alles dieses an, und hemerlite noch, dafs man sie ferner nach Flügeln, Maxillen, Rüssel oder Fühlhörnern unterscheiden könnte, machte aber doch in seinen einzelncu $\Lambda$ bhandlungen nicht den geringsien Gebrauch ron diesem Plane a). Im ersten Bande handelt er ron den Tarschmetterlingen, deren Raupen sich weder einspinnen, noch unterhalb der Erde verpuppen, und zwar zuerst ron jenen Papilionen, deren Raupen dornicht sind, ihre Pupuen Goldflecken haben, und sich mit dem Hintertheile von Obein naci Unten an Manern u. s. w. anhängen, als Schmetterlinge am Tage herumfliegen, die rorderen Pioten sehr kurz haben, Kolben an der Spitze der Fühliörner und die Flïgel perpendiculär in die Höhe tragen, wemn sie ausruhen, (antiopa, io, polychloros, urticae, C. album, atalanta, paphia, cardui). Hieranf spricht er ron jenen Tagschmetterlingen, deren Raupen nicht mit Dornen besezt, sondern nalit oder feinhaarig sind, deren Puppen keine Goldflecken, als Schmetterlinge alle Pfoten gleich grofs haben (machaon, podalivius, crataegi, brassicac, napi, betulae, pruni, cardarnines u. s. w.). Jezt geht

a) Aug. Joh. Roesel v. Rosenhof. Monatlich herausgegehene Insekten - Belustigung. B. 4. Nïrnb. 1746. 4.

- Beiträge von Kleemann, B.1.11789.

- deren Fortsetzung von Schwarz $279^{5}$. 
er auf die Abend - und Nachtschmotterlinge über, deren Raupen nach hinten und oben ein fleischiges Horn tragen, ganz nakt, oder mit mehreren oder wenigeren Haarbüscheln besezt sind, sich unterhalb der Erde verpuppei, und welche als Schmettcrlinge dic Fühlhörner gefiedert, oder fein und spitzig auslaufend, dic Flïgel mehr schiefliegeml haben, theils blos am $A$ bend, theils blos in der Nacht ausfliegen. Der zweite Band handelt von 7 Gattungen, von Frulläfern, dann von Vasserkäfern, Libellen, Grillen, Reuschrecken, Cicaden, Hummeh, Wespen, Mïcken und Schnactien, der dritte enthäl blos Supp!enente zu don rorhergehenden, und beschreit weillinf die KFasserwanzen, Krebse, Scorpionen nid Polypen; der vierte, ebenfalls nur ein Supplement, ersclicint nach seinem Tode, der fïnfte endlich ist cin blofser Nachtray ron Kleemarn, worin er cinige selteno Schnetterlinge und besonders unchere Spinnenarten abbildet, und dessen Beirüge Schwarz noch fortsezte, und dic von Roesel unbenamnten. Inseliten unter Linnéische Terminologic zu bringen anfing. So lcbte Reaumir in Rocsel, glcichwie in der Folge nochmals in Degecr auf,

\section{S. $9^{2}$,}

Bis jezt war das Gebicth don Insekten so Linnè. ziemlich beobachtet, md bercicles? Auch cr- 


\section{$-556$}

mangelte man richt, die täglich wachsende Men* ge dieses Staates in Ordnung bringen zu wollen. Freilich glaubte man dieses durch Unterscheidung nach ihren Verwandlungsstuffen, wach ihrer Nahsungsart, und ihrem Aufenthaltsore bewirlit zu laben. Leider! blieben aser noch immer viele Vidersprïche, und nicht wenige V'erwirrung zil rïch. Ritlor Linné stand and, und suchte anf cinen ganz newen Vege die gew inschte Lebersicht und Ordmung herzmstellen, was er durch Beriilisichligung der Gegenwart oder des IVangels der Zahl un! Boschafenhcit der Fligel zu leisten gedachte. Aridoteles hatte schon diesen VVeg angeclentet, Aldrovand und Mouffet cingeleitch, Swanmerdan den ZZustand der Detï̈gelung gleichsam als das End, als dio hone und Blinthe der Verwandimgen heruuggeloben, Reaumür und Roesel zu Vebenabtheilungen gebraucht, bis endlich cer schwedische Naturforscher den Versuch in Wirlilichlicit aufihrte. Zurorderst schied ei das, was man bisher unter dem Namen ron Insekten als z. B. Würmer, Schnedien, Conchylien, Frustacéen und die eigentlichen Inschten begriff, auseinander, reseinigle die Luristacéen und die eigentlichon In scliten mier der Benemung der Lezteren zu ciner Filusse zosammen, führte eine ganz neue Teruinologie ein, and sezte sie wie Wotton ror allen ublugen gleich nach den Fischen. Ihre Metanor. 
phose belangend, unterschied er 5 Stuffen, woroz er diese rom Lie (ovun), der Larve (eruca), bis zur Puppe (ngrmpha) unvollstündige, habvoll. ständige und rollständige, die der Schnelteringe "metamorphosis pupa obtecta" jenc dor Fliegen „ $m$. coarctata" namnte. Schon in der frïhesten Ansgabe seines Systemes nahm er dic Flügellosigkeit, die Benlighlung und ihre Beschaffenheit in die Charahteristili mit auf, und sezte bis noch zur sechsten Ausgabe darauf vier Ordnungen - nämlich rliejenigen mit 2 weichen, und 2 oberen, hornartigen Flïgch (ely-irce) - Colcoptera - mit 4 oder 2 naliten - Egminontera -, mit 4 von doncm dis oberen zum Theile hornartig sind - hemijtera - endlich dicjenigon ohne alle Flügrel aptera - fest. In den folgenden fsusgaben stehen die Hemipteren gleich nach den $\mathrm{Co}$ leopteren, die Gymopteren selbst aber werden in 4 . nene Ordnungen - Nevroptcra (alce $4, \mathrm{mcm}$ branareae, ano inemi) - Iepidoptera (alas 4, imbricatae squamis) - hymenoptera (alae 4. membranaceue, ano aculeato) - aiptera (alate 2, laciteres 2) aufockibisi, wodurch denn die $\Lambda \mathrm{n}$ zahl der Ordnungen bis auf 7 heranwuchs, und diese in solcher Anzahl, Benennung und Aufeinanderfolge durch alle andere Ausgabon unverän* dert blicben, nur ruit dem Unterschiede, dafs er in lezterer Zeit dic Lepidopteren vor den Neuro. 
fleren whidhle. Meh" als die Ordnungen, crlit ton die Gaturgen Versetzung und Vermehrung. Doch wanderie ron allon mur blatta und gryllus ron den Coleoptercn später zu den IIemipteren, und ron der mutilla merhte $\mathrm{cr}$ an, dafs sie eiEentlich zu dew Apteren gehöre, aber wegen ihrer Achnlichlicit den Ameisen beigesellt sey. Um so läufger wreden aber die Gallungen in jeder Ordming untereinander versezt, mit neuen rermehrt, oder Arten selbst zu Gatlungen erhoben, so dals die noie Ausgabe schon 2322 Arten enthielt. ObHeich en übrigens die Flügel zum Lintheilungssrunde gebranchte, so vergafs er doch nicht, intner bei jeder Ordnung und selbst bei Gattungen, schon ron der frühiesten Ausgabe an die Verschion denheit der Mundtheile anzumerlien; er benuzle aie Beschafrenheit der Fühlhörner, jenachdom sie 1.olbicht, zelerbt, faden - oder seidenartig sind, zn Unterabtheilungen bei Läfern - die Gestalt und Haltung der Flïgel bei schnetterlingen, bei aikien er ron den Pháliticn späterhin die Sphyngen absonderte, und überliaupt in der Unterscheidung und Benennung der Gattungen dieser Ordnung sich als Meister zeigte - endlich die An. zahl der Fülse, den mit der Brust zusammenflicssenden oder getremnten Fopf bei Apteren, die Anzahl mad Ange cier Angen bei spimen und hrebsen. Gmehin fïgie diesen Linerschicden noch 


\section{$-559-$}

jene in Hinsicht des Rüsse!s bei Dipteren zu, und rermehte die Anzahl in solchem Maase, dafs der eine Dand, welcher vorher das ganze System Linné's cuthielt, nun in zwei Bänden blos die Insekten folgender Gestalt geordnet, in sich begreift:

1. Coleoptera

-natennio clavatis exrorsum incrassatis

- clava lanellata: scarab. lucanus.

- ... perfoliata: dermestes, meIyris, byrrhus, silpha, tritoma, hydrophitus.

... ... solida: hister, paussus, bostrichus, anthrenus, nitidula, coccinella, curculio.

- antennis moniliformibus: brentus, attelabus, erodins, staphylin. scaurus, zygia, meloe, ienebrio, cassida, opatrum mordella, chrysomela, horia.

- antennis filiformibus: apalus, manticora, pimelia, gyrinus, cucujus, cryptocephahus, bruchus, ptimus, hispa, buprestis, necydalis, lampyris, cantharis, notoxus, elater, calopus, alurnus, carabus, lytta.

- antennis setaceis: serropalpus, ceramliy $x$, leptura, rhinomacer, zonitis, cicindela, dytiscus, forficula.

II. Hemiptera:

Blatta, pneumora, mantis, gryllus, fulgora, cicada, noctonecta, nepa, cimex', macrocephalus, aphis, chcrmes, coccus, thrips. 
III. Lepidoptera:

Papilio, splinx, plalienci.

IV: Neuroptera:

Libcllula, cphemera, myrmeleon, phrygan nea, hemerobius, panorpa, raphidia.

Hymenoptera:

Cynips, tenthede, sircx, ichncumon, sphes, scolia, thynnus, leuropsis, tiphia, chalcis, chry'sis, vespa, apis, formica, metillia.

VI. Diptera:

- proboscide et haustello.

Diopsis, tipulu, musca, tabanus, empis conops.

- haustello sine proboscide:

Oestrus, asilus, stomoxy's, culex, lomlylius, hippobosca:

YII. Aptera:

- pedibus. 6. capite a thorace discreto: lepisma, podura, termes; pulex; pediculus.

- pedib. 18: 14: capité thor aceque unitis: acarus, hydrachna, aranea, phalangium, scorpio, cancer; monoculus, oniscus.

- pedib plurib. capite a thorace discreto: scolopendra, julus:

\section{5. $9^{\frac{1}{3}}$.}

Linné haite liam diesen neuen WVeg fü Lintomologic eingeleitet, so bestrebte sich schon alles, suf demselben weiter fortzugehen. Clerk, ein 
Schuler desselben ist der erste, welcher das $\$$ Sy: stem seines Meisters durch die Vortreffichlieit seiner liupfer noch mehr in $\mathrm{R}$ uf brachte. Yon dieser Art ist sein Verl, welches seltene Schmelterlinge enhät, und durch die Genanigkeit und Schünheit der Bilder als cines der ersten aller Bilderwerle in der Nuturgeschichte angesehen werden mul's a); ein anderes ist die Nonographie ảu Spimen ron Scleweden, worin er zwar auch als genauer Zeichner, aber noch mehr als Schrift steller erscheint. Hier theilt er sic in

1. alanei aerei

- retiaii, qui praedis capiendis reticulos diversimodo tendunt.

a) verticales, quorum retiolia orbiculati

B) irregulares, quorum retiola nec orbiculati, nec densa, sed ex filis transversim divaricatis, composita stent.

2) densa retrola spissis multitits tendentes.

sow soluatores, qui munquam irretiunt animalcula, sed assattim prehenduml (lupi, phaw langii, cancriformes).

2. aquatici.

and zählt, während fister in England tum ron 50 Arten Erwahnumg thut, gegen 60 auf. Sulzer:

a) Carol. Clerck. Icones insectorum rariorum cur nomir ibtos eorum trivialibus locisque e Linnaei syst. aatm. allesatis, Sectio sma Holmiae $575 y-$ Sectio 2 da Holm. $276 t$, to 
strebet das Linnéische System zu erläutern, und auf teutschen Boden zu verpflanzen ${ }^{a}$ ). Schäffer bereichert die Entomologie mit einzelnen Abhandlungen und dann mit dem schönen hupferwerke der Inseliten von Regensburg, welches späterhin Panzer in systematische Ordnung und Benennung brachte ${ }^{b}$ ). Sepp liefert eine Monographie der lusehten der Niederlande, in sehr vortreftlichen Fupfern "). Scopoli beschreibt die Inseliten vou Fiäuthen, und weicht nur lierin von dem Systeme Linnés ab, dafs er einen ron jenem angegebenen Nebencharakter manchmal zur Benennung der ganzen Ordnung grebrauchet, und sich z. B. statt Hemipteren der Benemung "proboscidea " statt Hymenopteren der "aculeata", statt Dipteren der "halterata", endlich statt Apteren jener "pedestria" bedienct ${ }^{d}$ ). Vor allen aber war es der scharfsinnige Gcoffroy, welcher das Limnéische System der Insekten nicht blos als Nachbether zu verbreiten, sondern es vielmehr zu verbessern gedachte. Fr zog die Nevopteren und Hymenopteren Linne's in cine einzige Ordnung „te-

a) Sulzer. Kennzcichen der Insekten, Zürich 1,761,4.

- desselben abgekürzte Geschichte der Insekten. Zürich 1776. 4 .

b) Schäffer. Elementa entomologica. Ratisb. 1766.

- icones insectorum Ratisbonensium. ibid. 1767. 4.

4) Chr. Sepp Nederlandsche Insecten. Amsterd. 1762. 4.

d) Scopuli. Entumulugia Carmidica. Yindob, $3765,8$. 


\section{-. 563}

lruptires à aîles nues" zusanmen, "otwauchir. fiir seine 6 Ordnungen statt der I.murinthon Be nennungen, jene ron der Bezeichnung der hah lder. Flïgel hergenommene. Uoch gebiat itm zuror derst das Verdienst, die 'Zahl dex Tarrers zu Un

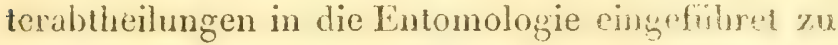
haben, wie aus seinem Schema ersichnlirh ist ").

I. Coleoptera. Alae elytris tectar. is maxillosum.

a) elytris duris, ventrem ommino obtegentib.

- tarsorum articulis b: scarabaeus, dermestes, byrrhus, cistela, elater, buprestis, bruchus, lampyris, cicindela, omalysus, hydrophituis, dytiscus, gyrinus.

- t. articul. 4: melolonth. prionus, cerambyx, leptura, stenocorzes, lupterus, cryplocephal. crioceris, clerus, altica, galeruca, chrysomela, mylabris, rhinomacer, curculio, bostrichus, anthribus, scolytus, cassida, anaspis.

- t. articul. 5: coccinella, tritoma.

- t. articul. 5 aux prémières pai. res, de pattes et 4 seulement à la dernières: diaperis, pyrochroa, cantharis, tenebrio, mordella, cero= coma.

b) elytris duris, dimidiatis.

- t. articul. 5: staphylin.

a) Geoffroy. Histoire ahreger des insectes. Tom. 2. Paris 1764.4 . 


\section{$=36 i \quad m$}

- t. articul. 4: necydal.

- t. . . 5: forficul.

- t. . . 5 aux deux prémiérespaires de pattes, et 4 à la dernière: proscarabaé.

c) elytris mollibus.

- toartic. 5 aux deux premières paires de puttes et a ladernière: blatta.

- t. artic. 2: trips.

- t. . . 5: gryllus, acrydium.

- t. . 4: locusta.

-t. 5: mantis.

1I. Hémiptères: $\left(\begin{array}{c}\text { cicada } \\ \text { tars.art. 5. }\end{array}\right)-\left(\begin{array}{c}\text { cimex } \\ t_{0} a_{0} 4 .\end{array}\right)$ $\left(\begin{array}{c}\text { naucoris } \\ t . \alpha, 2_{0}\end{array}\right)-\left(\begin{array}{c}\text { noclonecta } \\ t_{0} a_{0} .2 .\end{array}\right)-\left(\begin{array}{c}\text { corixa } \\ t_{0} \alpha_{.1 .}\end{array}\right)$ $\left(\begin{array}{c}\text { nepa } \\ \text { t. a. 1. }\end{array}\right)-\left(\begin{array}{c}\text { psyzla } \\ 2 .\end{array}\right)$

(aphis, chermes, coechis.

1

III. Térapières (í ́́ ailes farineuses - tarsorum artivil. j.) papiliu, sphina, plerophorus, phalaena, linea.

I). Tétraptères (à 4 ailes nues).

- t. artic. 5: libellula, perla.

- t. . 4: raphidia.

- t. . 5: ephemera, phryganea, hemerobius, formicaleo, panorpa, crabro, urocerus, tenthredo, cynips, diplo lepis, eulophus, ichneumon, vespor, apis, formitis. 


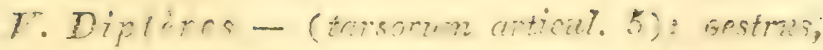
tabanus, asitus, stratiomys, musca, stomoxus,

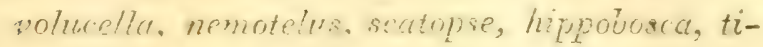
pula, bibio, culex.

5T. Aptères - (taror. artic. sicuti pedes numero permulli et wariahites': pecticulus, podura, forbicina. pulex, chelifer, ararus, phatangium, arenses, monoculus, binorulus, cancer, oniscus, asellus, scolopendra, julus.

\section{S. 94.}

Jezt wruchs die Neigung fur die Entomolngie mit jeden 'Tage und zivar unter allen Nationen Europa's, das Iinnéische System selbst gewann durch die rielen Fupferwerke, welche jezt erschienen, und auf die Eefügelung oder Flïgellosigleit Riclisicht nahmen, inmer mehr an Entwidielung: Drury gicbt vortrofliche Abbildungen rma Bcscheibungen ron cinzelnen Incchten her* ans. Deacer a) reriortigt ein ähnliches Terk Ziher Insolıten wie das ron Reaumür. Ernst, Esper, Borhhausen, Cramer, Hibner wetteifern die Geschichte der Schmetteringe zu erschöpen; WilJics, Marris machen jene ron England - die bciden I.chrer am Theresimum zu TTien, Schifermiller wnd Denis, jone ron Tien - Laug jene fon Augsburg - Ochsenheimer jene von Sachsen

a) De Cesr. IIstoire des insectes, Deris $1754-42$, Yolun. VI, 4 , 
Bergstresser jene um Hanau und auch ron Eu. ropa - Abbot jene von Georgien in vortreffichen Kupfern behannt a). Schrank stellet die Fauna Oestreiclis und späterhin Baiern's, Laicharting die ron Tyrol, Preisler die von Böhmen her. Fnoch und Scriba liefern nicht unwichtige Bciträge zur Entomologic. Schmiedlcin crläutert die Terminologie und das System Linné's. Jablonsky und. nach seinem Tode Herbst, arbeiten an cinem Natursystome der Insekten, Lezterer bercichert dasselbe auch mit einer ausfuhrlichen Monographie der hrebse ${ }^{b}$ ) und der Solpugen, Phalangien, Scorpionen c) in Kupfern - Wolff mit mehreren Heften ron Spimen - Stoll mit ciner Schrift über Spinnen und mit einer anderen iiber Cicalden und Wanzen. Martyns sezt aus Clerk und Albin nin Werk über Spinnen zusammen, und giebt auch die Küfer Englands, beide in angenehm illuminirten aber sonst nicht schr instruhiven Abbildungen heraus. Voct ${ }^{d}$ ) und Payliull nehmen sich

a) The natural history of the rarcr Lepidopterous inserts of Geurgia, collected from the observations of John 1 bbot by James Edward Smith. Vol, 2. Lond, 1797. 4.

b) Versuch einer Naturgeschichte der Krabben und Krebso von Joh. Fr. Wilh. Herbst. Bd. 3. Berl. 179a-1804. 4.

$\Rightarrow$ Natursystem der unbeflügelten Insekten von Wilh. Herbsto Berl. $2797-1800$. 4 .

d) Jo. Eus. Voet catnlogue systematiqgue des coleoptires ì la Haye 1766 \% 


\section{$-567$}

die Coleopteren zum Gegenstande. Meigen bear. beitet mit ausscrordentlichem Verdienste die Dip. teren von Europa. Otho Fr. Müller ersinzei die Apteren Linné's mit einer Menge lileiner, neuer Arten, wclche er in Dänemarli und Norwegen vorfand, einige daron schon in seiner zoologia danica, und jezt alle zusammen unter dem eigenen Namen "entomostraca" bekannt machte ${ }^{a}$ ). Blumenbach, Leske, Batsch, Brünnich wiederhohlten in ihren Handbüchern ïber Naturgeschichte das Liméische System der Inseliten ohne weitere $\mathrm{Ab}$. änderung.

Durch solche fortgnsezte Entwicliclung des Linnéischon Systemes, traten auch die Fehler desselben um so sichtbarer herror, und nun, nachdem wir an der Gränze dirser Hauptstrasse stehen, überschauen wir die Hindemisse und $\mathrm{Be}$ schwerden dessclben. Limné hatte ausser den Flügeln, alle übrigen Beschaffenheiten des hörpers ron Insehten ausser Augen gelassen, und eben deswegen die Mollusken - welche mit Branchien wie Fische athmen, einen Kreislanf, und zwar durch ein ilerz vermitteit haben, während bei den Whelien statt Lungen Tracheen, statt eines Krcis-

a) Otho. Fr. Mii]ler. Entomostraca, seu insecta testacez, una in aqquis Daniae et Norvegiae reperit, elescripsit, tet jeonibus illustravit, Lipsize et Havniae. 3785. 4. 
Imfres nom Trerens cin pulsirendes Rücliengefirs statt findet - jenen nachgesezt, ja dic hirustaceen, bei denen die nimlichen Vorzüge wis bei Mollusken obrvalien, ans Endo aller Inseliten verpllanzt. Jodoch hich or auf dem ganzen Coblicthe der Thire uirgends sciner gefwisten Ansicht so getrew, als elon hien, waf den der Inseliten. Gleichwic es bei den Planzen die Stanbfaden in der blune zn ihrer Anorhung white, eben so mabmer hice die fligel, und schritt in ahnlider Succession ron dey Virflüglem zu don ZiveilügInn, mol eudlich zn don Flïgcllosun lecrab. Alloin eben wie anf drm Planzengebicthe, so ist anch hier dic Zahl dex Orduungen höcint mule. simmt, und es bedarf nichts, als sie in befiligelte nul flügellose; jene ferner in soldhe mit vien harten oder weichen, mehr odeq weniger durchsich. figen Fliggeln, dann in Zweillïgler abzuhcilcn, and dieses hinstliche Syston sieht ganz in scinem Inustlichen Gefige da. Aber eben diese consefquente Durchithung, zeigt dis Vidersprüche nud Junlion dieser Ansicht um so auffallender. Wie Ramn wohl die cimex lectulurius, welche weder Flizgel noch Vilyten hat, zu den betlïgelten In. sehien, wie die Tyoaens apterus, welche wohl Flytren, aber wie auch Mausmann aussagt, meistens heine Pluge hat, zu den übrigen Wimzen gerchmet werden? Wio lömuen die Blattinise. 
Ton deren Tännchen und Woibchen ohne Unter* schied des Geschlcchtes bald beide, bald nur jene oder diese vicr Flügel, oder auch gar heine haben - wic dio Schildlaus, wo blos dás Männchen cin Zweiflügler, das Weibchen aber flügellos ist, bei den vionfligoligen Hemiptcren stehen? Wio die Ameisen, von denen llos dio Mäunchen und Weibchen beliegelt, die gescblechts!osen Arbeiter aber unbefingelt sind - ja sogar die Mänuchen ma Veibchen der mutilla, die sonst ganz den Ameisen gloichen, immer flïgellos bleiben, wie Lionnen dicse bei den Mymenopteren aufgezähit worden? So ist auch unter den Schmetterlingen das Weibchen ron bambyx antiqua immer flügel-

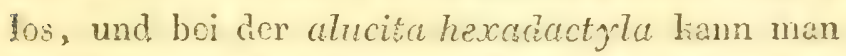
wohl die viclen gefiederten Fächer als shen so vicle Flïgel ansehen - bei den Nerropteren crscheincn mandimal Eplucmeren blos mit zwei Flïgeln, dis mantis lineuris, und das spectrum, haben liam noch Reste ron Flïgुeln, - Unter den Coleopteren sind melnere Galtungen blos mit Elywen ohre alle Flügel ausgeristet, und jene sind $\mathrm{z}$. P. beimeloe zwar noch gespalten, aber bei pime* iia, tenebrio und mehreren Curculi wachsen, dafs sie wie bei schildliröten gleichsam eine feste Declic haben; ja viele Gattungen $z_{\text {* }}$ B. melos, staphylinus, forficula, necydulis baben gleichsam 1.u Reste von Elytren wnd my-la- 
bris, cantharis, malachius u. s. w. leztere nicht hart sondern weich, wie es ungefähr auch noch unter den Hemipteren bei gryllus und blattce statt findet, einige Weibchen der Lampyrisarten endlich haben gar keine Elytren. - Unter den Lepidopteren sind die Flïgel der Gattung , sesic " $^{\text {* }}$ nicht bestäubt, jene des bombyx matronula wie die einer Phrygäna durchsichtig, und verdienen daher diesen Namen "Staubflïgler" nicht. Ferner sind bei allen beflügelten Inseliten die Flügel netzartig gebildet, was rorzüglich bei allen Weichflüglern sichtbar ist, daher denn die Benennung "nevroptera" nicht ausschliefsend einer einzigen Ordnung zukommt, gleichwie auch die Dipteren, weil die halteres doch die Stelle des zweiten Flïgels vertreten, auf den Namen „Viernligler" Anspruch machen. - Bei allen diesen Umständen, wie können diese Lücken und Vidersprüche in dem Linnéischen Systeme rerbessert werden, ohne selbst die Arten ron ihren Gattungen, ja sogar die Männchen ron ihren Weibchen zu trennen, und in ganz verschiedene Ordnungen zu werfen? So schön sich übrigens die Inseliten nach der Zahl, Gestalt und sonstigen Beschaffenheit der Flügel nicht blos in allgemeinen Gruppen, sondern auch diese und ihre Gattungen in eine gesctzmäfsige Succession fügen, so scheint doch Limne schon zufrieden gewesen zu seyn, 
blos die Iauptabschnitte angegeben zul haben, olme sich weiter um ihre Aufeinanderfolge zu behuimmern; daher die fernere Vertheilung der Gattungen bald ron den Antennen, bald ron anderen Gesichtspunliten hergenommen ist, Inseliten mit Süngrüssehn, wie z. B. Wanzen, und mit Maxillen wie z. B. Gryllen, Heuschrecken u. s. w. in eimer und der nämlichen Ordnung beisammen stehen, dis Aufeinanderfolge der Ordnungen und Gathungen aber ganz filanlos ist. Wie sollen wohl die Küfer die Lilasse der Insekten mit den Fischen, die Trebse, Spinnen und alle Apteren diese mit der folgenden hlasse der Wü̈mer verbinden? in wio fern soll ditiscus, forficula die Coleopteren mit der blatta und so mit den Ilemipteren, wie thrips die lezteren mit den Lepidopteren, die hippohosect die Dipteren mit lepisma und so mit den Apteren rerbinden? Alle diese Lüicken bei der Vortrefflichkeit der allgemeinen Gruppen, sah Fabrizius aus der bisherigen Entwickelung des Linnéischen, auf die Flïgel der Inseliten gebauten Systemes schon vor längerer Zeit ein, er änsserte seine Zweiffl darüber schon frühzeitig seinem Lehrer, und Iimné, welcher nur das wahre System aus dex Natur herausgehoben wissen wollte, foderte uneigennützig seinen Schüler zur Ausführung seiner neuen Arsicht auf: 
"oft und vinl habe ich, sagt Fabrizius a), "nit dem wïrdigen Alten, dem Lehrer und „Freunde meiner Jugend, über diese Materie s, geredet, und oft hat er mir angerathen, ein „, nenes Sysiem anzufangen, welches er selhst "wegen dier Nenge der Dinge, womit er in der „Naturhiclorie überhäuft gevegen, nicht hatte , erreichen können.“

Ris endlich Fabricins sein nemes system, wozn er durch scinen $\Lambda$ ufenthalt in Upsal im Jahr $176.3-$ 6.t den Fruml Iegte, im Jahre 1775 zum ersten NTale in einem öfentlichen Werke behannt machte.

\section{ง. 95 .}

Tabri- Johannes Fabrinins zu Tundern in Schleswigk
cins. goboren, studicrte die Medizin, und gewann auf der Universiät zu Upsal unter der Leitung seines T.ehrers Linné die Naturgeschichte, ror allen aher dic Entomologic lieb. Als Professor der Namrgeschichte wnd Landwirhschaft in Kiel angestellt, zauderte or nicht, sich durch vicle Reisen ins Ausland, durch Resichtigung offentlicher und privat Tuhinette in Dänemark, Teutschland, in der Schweiz, in Franlireich und England, welche

a) Retrachtung üher die Systeme der Entomologie ron J. Christ. Fabrizius.

- in den Schriften der Berlinisch"n Gesellschaft naturf. Freunde, ater Bd. S. g8. 
an naturgeschichtlichen Sammlungen so rcichthuttige Insel er sieben Mial besuchte, zin dem annu bilden, wozu er in sich den Beruf füllte. Soluh: Gestalt ausgerüstet, warf er sich zum Reformator der Entomologie anf, und zwar nicht nur dadurch, dafs er diese mit 5 bis $6 \mathrm{Mal}$ melır Insekten bereicherte, als es Limné that, dessen hatalog sich nicht viel über jooo erstrelite, sondern auch. dafs er einen ganz nenen Weg und ein ganz neues System cinlcitete. Limé hatte schon in den frühesten Ausgaben seines Systemes, wie auch Aristoteles bei jeder Ordnung und afters Gattuns Aer Insehten der Verschiedenheit ihrer Frefswerlizenge exwähnt, Gecffioy dieses noch nachdrucklicher wiederhohlet, scopoli die Linérischen Ordnungen zum Theil nach den Freswerhzengen benennet. Allein Fabricius ist der erste, welche: dicse Organe (instrumente cibaria) an Inseliten micrsichte, den cinzchen Theilen derselien benemung gab, mul ant dic An-oder Abwesenheil, unf die manchfaltige Gestalt der Naxillen, die: Anzahl der Ordungen, anf die Terschiedenhent der übrigen zu den Frefswertizengen gehürigen Theile, auf die Antcmen u. s. w. Gattungen mil Arten festsezte, und so auf die Frefowerlizenge, wie Swammerdam an die Mchmorphoso, Aldro. vand und Vallisnieri auf den Aufenthaltsnit, wne? Linné Tuf die Flügel, ein System gründete. So 
consequent sich auch inmer Fabricius in der Ausfiihrung dieser seiner Ansicht rerblich, so himderte dieses doch nicht, dafs er bei weiterer Untersuchung ebenfalls seine Ansicht erweiterte, und nur allmählig zur beabsichtigten Vollständiglicit ausbildetc. Das erste Werk, in welchem er sein System üfentlich niederlegre, war jenes: „systemu entomologiae", worin er alle Inschten nur unter 8 Klassen bringt ${ }^{a}$ ). Diesem getren, arbeitete er hierauf die Galtungen der Inseliten aus ${ }^{b}$ ), mind stellte nachlier in seiner philosophia entomologiae dieses Fach, was seine Iitteratur, was die Beschreibung der einztien Theile der Inselten, besonders der Frefswerlizenge, was die VIetamorphose, die Verschiedenheit des Geschlechtes, was das Schema des Systemes, was die Benenmung, die Unterschiede der rinzelnen Theile des Jiörpers, die Lchensart und den Nutzen dieser Thiere betriff, gleichsam in cincm allgemeinen Grundrisse dar $\left.{ }^{c}\right)$. Jezt erschienen die Arten der Insehten ${ }^{d}$ ) und seine Mantissa ${ }^{c}$ ), worin er die Anzahl obiger filassen beibehielt, und nur durch

a) Jo. Christ. Fabricii Systena antomologiae. Flensburgi et Lipsiae 1775.8 .

b) ... genera insectorum. Kilon. 1776.8.

c) .. philosophia entomologica sistens scientiae fundamenta. Hamburgi et Kilonii 1773. S.

d) . ... species insectorum, Hamb. i731. T. 2. 8.

•) Eabricii mantissa irsectorum, lom. 1, 2, Hafn。 1787.8 . 
Berichtigung und Vermehrung dex Gatungen gleichsam jene erste Schrift vervolikommnete. $\Lambda$ ber nun tritt mit dem Werke „entomologia systematica" die zweite Metamorphose ein a); ron der lilasse "synistata" werden die Bienen, Tenthredines u. s. w. als eine eigene unter dem Namen "piezata", von der Flasse , unogata “ werden die Libellen u. s. w. als eine cigene „odontata" genannt, die Scolopender, Julen und Onisken, von denen die lezten anfangs bei den Sinistaten gestanden hatten, als eine eigene unter der Ueberschrift "mitosata" getrennet, und so die Anzahl der vorigen 8 hilassen bis auf 11 vermehrt. Mit denı Supplementbande zu lezterem Werke, scheint der Verfasser seine MLtamorphose vollendet zu haben ${ }^{b}$ ). Hier bildet er aus oniscus, cimothea und monoculus, welche beide leztere vorhin bei "agonata" gestanden hatten, die neue Klasse "polygonata" die Benennung "agonata" selbst vertilgt er, und lüfst diese Flasse in die zwei nenen auf, nämlich "kleistognatha" welche die liurzschwänzigen Krebse des Linné (brachiuri) und "exognatha" welche die langschwänzigen (macrouri Limné) enthält, und sezt so in dieser

a) Jo. Christ. Fabricii entumologia systematica emendata et aucta, 'Tom. 1, 2, 5. 4. Hafniae. 1792-94. 8.

b) . Supplementim entomolugiae systematicae. Hafn 1728. 8 . 
Lezten Metamorphose die Anzahl der hlassen auf 13 fest. Gemäls dieser lezten Umänderung war Fabricius gesinnt, die einzelnen hlassen ebenfalls in einzelnen Büchern unter dem gemeinschaftlichen Namen ,systema insectorum" auszuarbeiten "). Wirklich hatte er schon die Eleu. theraten in 2 Bänden, dic Byngoten im Jten, dic Piezaten in 4ten, cndlich die Anthiaien herausgegeben, und war gerade nit der Bearbeitung der Glossaten beschäftiget, als ihn eine Wassersuclst. entrifs, und wir daher die lezien Bruchstiiclie seiner Arbeit nicht mehr ron ihm, sondern ron sci. nem Freunde Illiger zn crwarten haben. Zum Glïclie für die VVissenschaft, ist doch dieses neue System selbst durch seinen Tod zu lieinen Bruchstücke geworden, sondern licgt ganz ausgefülrt, folgender Massen vor uns:

\section{Eleuterata (maxilla nuda, libera)}

- antennis rostro elongato, corneo insidentibus: calandra, irlynchaenus, iiaus, cossonus, curculio, brenhus, attelabus, rhinomacer, antisibus. brachycerus, hylesinus.

a) Fabricii Systema insectorum

- eleuteratorum, Tom. 1, 2, Kíliae 180 1. 8 ,

- ryngotorum, Brunsvigae 1803.

- piezatorum, ... 3804.

- antliatorum, . . 1805. 
- antennis clava lamellatas. lucaritis. pusscilus, aesaluis, scorabatus, gcotrupes, onitis, copris, atezuchus, aphorlius, trow, -hexodon, melolontha, trichines, cetonia, sinodendron, dorcatoma; pausus; lethrus.

- antennis clava perfoliata: apate; melyris, ips, byrrhus, collyctizim, trichodes, corynetes, dermestes; scaphidium, spharidium, anisotoma, tetraiona, cossyphus, tritoma, aegithus, erotyliss, eumorphlus, pellis, necrophorus, silpha, hyclrophilus, diaperis, spercheus.

- anteinis clava solida: hister, bostrichus, lyctus, sienzis, eloptión. nitidul. coccinell.

- antenn. flabelliform.: hyjpophloeris, ptitinus, meíasis, rhipiphorus.

- anterizh eutrorsum crassiorib.: megalopus, trogosita, mycetophagus, upis, caiops, tentirio, bolihophastis, mykibris, clerus, notoxiss, anobium, helodess.

- antenn. cylindricis: hispa, cupes, sagra, parmus, sarrotrimm, imatidium, alurnuss.

- antenn. moniliformib.: erodius, cém rocoma, spondy lis, crioceris, slaphylin. cucujus, trachy's, scaurus, zygia, meloe, endomychus, horia, blaps, plati, nolus, hew lops, chelonarium, paederne, cassida, opotrum, mordella, axyports, itysomelo, scarites. 
- antenn. filiform.: apalus, manticora, pimelia, gyin. urontes, akis, heterocertus, cryptocephal. bruchus, ptinus, clythra, omalysus, adorium, lycus, cébrio, lema, malachius, buprestis, atopa, cistela, dasytes, sepidium, necydalis, cyphon, pyroshroa, lampyris, eurychora, cantharis, cnodulon, elater, colaspis, calopus, lyita, lymexylon, melandrya, lagria, tillus, aryops, dircaea, anthicus, eumolpus, anthia, galeruca, pytho, scolytus.

- antenn. setaceis: donacia, cerambyx, pronus, gnowian saperda, lamia, leptura, molorchus, clytus, callidium, rhagium, stenocorus, odacuntha, agra, drypta, collyris, cicindela, carab. cychrus, galerita, tachypus, calosoma, elaphrus, dytiscus.

71. Llon a ta (maxilla tecta galea obtusa)

- antenn. filiform: acrydium, gryllus.

- antenn. ensiform: truxalis.

- antenn. setaceis: forficula, blatta, mantis, phasma, acheta, locusta.

IIT. Synisiata (maxilla basi geničulata. comnata cum lavio): cphemera, phryganea, scmblis, lepisma, podura, hemerobius, procus, termes, rethidia, panorpa, myrmeleon, ascalaphus.

IT. Picsata (maxilla cornca, compressa, sacpe elongata):

- cynips, tenthredo, sirex, ichneumon, evaria, chaldis, larra, tiphia, chrysis, leucos- 
pis, vespa, mellinus, philanthus, crabro, formica, mutilla, dorytus, oryssus; ban-i chus, ophion, foenio.

- os ling u a inflexa: sphex, scolia, thynnus, masaris, hylaeus, andrena, nomada; apis; bembex; eucera.

r. Odontata (maxilla cornca, dentates palpi 2 breves): libcliula, acshna, agrion.

VI. Mitosata (maxilla comer, formicata, hand palpigera): scolopendra, julles,

YII. Unogata (maxilla cornea, mentivila. ta, palpi 2 porrecti): trombidinne, ara nea, phalangium, tarantula, solpugets scorpio:

FIII. Polygonata (maxillae plures intra labiam): oniscus, ligia, illoted, (ymothoa, monoculus.

$\boldsymbol{I X}$. Kl teistagnatha (maxillae plures extra labiuin os claudentes):

cancer, crilappa, ocypode, leiucosia, parthenope, inachus, dromia, dorippe, orithya, portunus, matuta, hippu, sjmethis; limulus.

X. Exochnata (maxillae plures extra labium tectae palpis):

allunea, scyllarus, palinurus, palaemon, atpheus, asiacus, penaeus, crangon, pats surus, galather, squilla, posydon, gansa muсти: 
1. Glossciu Ringua spiratis inter patpes reflexos, stuposos):

papilio, hesperia, sphinx, sesich, zy'gaena, bombyx, cossus, hepialus, noctua, hyplaed, phalaena, lithosia, galleria, phoycis, crambus, pyralis, tinea, aincita, pterophorus.

XIL. Ry ngota los rostro: nuginu articuldil) - rostro inflexo: fulgora, membracis, flatta, teltigonia, cicada, delphax, cercopis, acanthice, ligheus, cimex, coreus, miris, gerris, ranatra, pulex, aphis, naucoris, sigare, thrips.

- rostroarcuato; notonecta, nepa, reduvius.

- vagina pectorali: chermes, coccus.

XIII. Antliata

- os proboscide atque haustello: mydas, tipula, ceria, nemolelus, bibio, rhagio, stratiomys, syrphus, musca, tabanus, rhingia, conops, emipis.

- os haustello absque proboscide: oestrus, asilus, stomoxus, anthrax, myopa, culex, bombytius, volucella, cytherea.

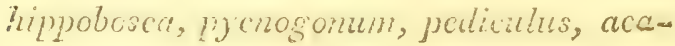
rus, nymplion.

\section{ก. 06.}

Lis ist nicht zu rerkennen, dals abrichus dis Liméische Schema ron Insekten ror Angen gehabs

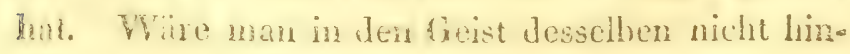
cingedrugen, so wirde nar beinate glauben, es 
habe in scinem fribhesien. TTerlic, wo er ebenfalts num 8 IH hsscn anfitrlie, ni: irts gethan, als blos an die Stclle der Limnéischen lenenmungen antere gesezt. So ent prechen den Coleopteren dés Limmé hier die Tlentraien - den Hemipteren dio Ulow naten und Myrgoien - den Lepidopteren dis Glossaten - den Nerropteren die Odonthen und Synistatm - den Hymonoptern die Piezaicn Aen Bipteren die Anthaten - den Apteren die Unogaton, Mriosatm, Nochaten, Kleitagnathen. Jolech Fanicins hat scin System anî einen ganz

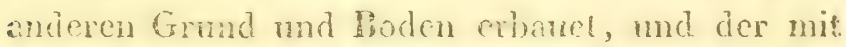
dem Systeme Inme's überinstinmende Erfo!n ist nichts als cin Beweis, dafs wir die ganae Natior. ants jeatem winzelnen Theile immer als dic nim-

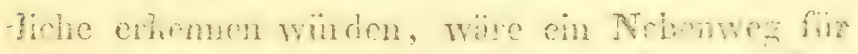
menechlicie Forscher nicht gुefilireolle" ais dia

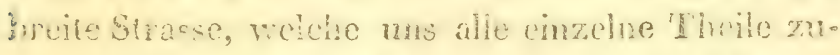

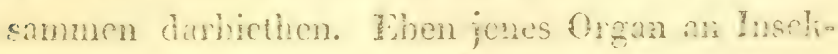
trin, das zwar schon ror ihm ancecente wurde. alier dessen Deail bis jezt immer noch im Dum. Jein blirb, dicses hat er znerst nather zergichent, Donommugen dafir engefuhret, und su cincm meum Systene gohranchet. Ailein weder er scibst bileb, unch weniger sind andere jezt noch mit scim ros Ang be and benenung dieser Theile cinstim mic. So hiefs or die Mandibulen in seiner exsicus Scurift tic wheren thoxillen, den sogenamenter 
c. yperes unterschied or nicht ron der Oberlippe, mal crst später beobachtete er das, was er ligula nennet. Eben so sind Latreille und Illiger in einigen nicht seiner Meinung: Beide halten scine Unterlippe fuir das limu (menton ou ganache), scine ligula aber für dic untore Lippe; Illiger betitelt die nitleren Palpen des Fabrizius die äusseron und rovderen, dic rorderen aber des Lezteren die inneren. Achr noch als dicse Bcide, weicht in der Angale der Dedeutung und in der Benemmung Firby in seiner Monographie der Biencu Lnglands ab, und erlaubet sich him Neuerungen. - Vor allem scheint der Grund der Abweichung der Meinungen dieser Gelehrten darin zu licgen, dafs Fabricius, und nach ihm dic Beliemer scines Systemes, sich bei diescu Restimmungen und Benenumgen durch die Williühr oder die oberfächliche Achnlichlicit haben leiten lassen. Allein der Mensch ist, wic Pythagoras und Aristoteles sich ansdrücken, das Metrum der Schöpfung, und nur nach iim müssen dic ähnlichen Theile aller Thiere benannt werden. Zum Theile hat man dicses auch wirlich an den Insekten beobachtet, and hicr, hopf, Brust, Bauch, Füfse, Tarsen u. s. w. unterschieden, nur hat man sich, leider! bei der Benenumg der Frefswerlizenge nicht so genau hieran gehalten, oder auch durch lialsche Deuiungen getäuschet. IVit Bewunderung verfol. 
get der Forscher die geseizmärig fortschrcitenden Metamorphosen, welchen alle einzolne Tinochen des Lioples rom Menschen an durch alle VVirbethiere Lindurch bis zu den Sepien, wo der lezte Rest noch als hopfwirbel erscheinet, unterworfon sind. Lr sicht ein, dafs hier, wo die Natur die Iinochen - und Finorpelbihing rollendet und eingestellt hat, die Ilautberlecling an ihre Stelle trete, jedoch so, dars in ihr wic in cincm Sigille das Sliclet gleichsam abgedrülit ist. Freilich sind dic edleren Linochen, welche das eigentliche Gehim bei Finochenthieren einschliclsen, hier entweder ganz rerschwunden, oder zu anderen $\not$ iveclicn $\% . \mathbb{H}$. für Mushelansïzc u. s. W. verwende? Jiben dieses gilt ron der foppschaale der Insthion. nud noch inmer lassen sich die cinzelnen Thrilo der. selben mit jenen des hopfes bei minbeltheren verglcichen. Ganz williührlich und bedeutungslos sind daher dic Bencumungen z. B. Clypeus, mandibula u. s: w. Vergleicht man die Kopftheile eines Jirebes und ciner Raupe mit jenen der Sepia, Fische und zulezt des Menschen, so wird man sich überzeugen, dals z. B. der clypeus dem os occipit. inferior. jener Theil, welcher beim Lirebse das Geliörloch cuthält, dem os petrosum, die mandibulae dem os intermaxillare, welches von den Afen an endlich in den Fischen ganz losgesondert zur Seite gewichen ist - die 
Sogrnamie maxilla der maxilla inferioy enta specten, die maxilleitae bei hrehsen das os b. yoideum vorstelien, welches sich hire wie bei don Fischen nnit den Branchicn - Resten rerbinbet - dab derjonire, spitzig zwischen den Antenyon vorlanfmic Theil, das os fronis $\rightarrow$ der an? dem os futromm nach romen mhende, die mexailla mprerior - der an ihe sizence Theil, we!-

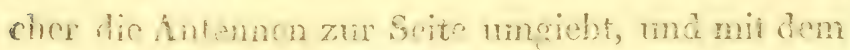

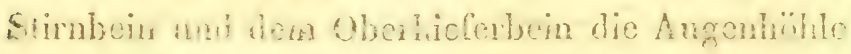
liddet - dic ossa nasulici - - dio oberen Antennen die waliren fiemrhstasior, die unteren dicken und Ingen die wahren Tastorgne sfyen, welche dem nervis infraorbila?. des nerv. trimmini zum IPehalter dienen, so wie die Palpen gleichsam fü àio Gesclimakspapillen bestimmt sind. - So pasadox auch diezes kithe Verfahren, die rrigleichende Osteologie selbst narh bis arf Hofe Mautthice anszudchon, rorkommen mas, nhd so wo mirg anch Fabricins mol seine Anhänger an solche Ferglefonmen und daruach zu machende Remennungen dwhten, so jet es doch in dex Juhh-

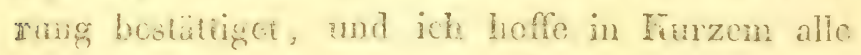
Arese Andentingon durch bivfer darthu und

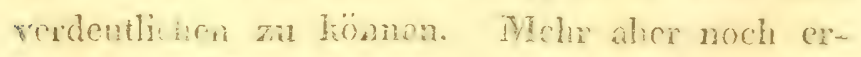

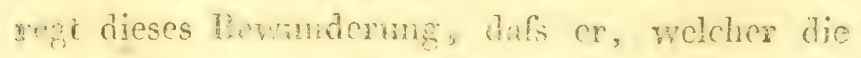
Trefswerkzeuge nitht blos durch alle fiassen son-

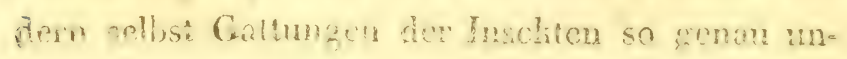


tersucht liat, nicht benchle, wio arch hierin cine gesetzmürsige, successive Lntwiclielung, von der gleichsam die cinzelnen llassen der Insekten die Absätze und Epochen dieser Melamorphose sind, herrsche. Fein Vumder daher, dafs bei ihm Nilassen und Gatungen, statt in cincr mabünderlichon Reihefolge, in bentem, willibirichen Goma sche arfeinarder folgen. Hatie cr cine solcho Metamopinose mur ron der Ferne rernathe, sicher hitte er sellust gefuhiet, dafs statt a libssin alle Inscliten mur in 2 zerfallen, nänlich in solche, wo die Mlandibula nud die Hibrigen Frefwerlizenge nicht zusammen rewwachsen sim, und dann in solclie, wo lczicres der Fall ist, mithe Verrentenseyn cincn Süugrässcl bilde. Ia solbst mit der hufeinanderfole wäre or nicht so fleichgillig mind sorga ins geween. Unstreilig sind hei don hrobsen, Spimen die Frofswertionge an wenigsten rerwachsen, sondern im Gegenthcile am donulichsten and individuellsten ausgebildet; dicsen gebuhro also ciznntlich der Name ,efeuterata" and der crte Rang mier den Inonition, da sie aber bei ihm in der Nite der Inshleweiho zwischen den scimcterlingen und Iilsellen steher. Nach den Trebsen fangen ron deis Eleuteraken, Clonaten, nlontaten cadlich in den synistaten die Frefs. werkzenge an zu verwachscn, die Piezaten naben

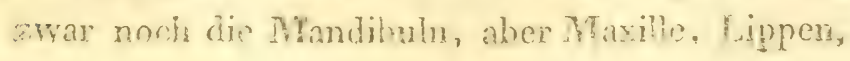


Tingelchen sind schon so verwachsen, da?s sie tie rüssclartige Form haben, bis endlich dieses verwachsenseyn zu cinem wirlichen Rüssel in hon Glossaten, noch mehr in Ryngoten und endlich in Antiaien auftritt. So hat also anch Fabricius, wie schon Limné, die Rangordnung der Inschien ausser Augen gelassen, und z. B. die sonst und auch nach den Frefswertizengen so vollhiommenen hrebse, weit hinter andere Ordnungen gesezt, ja er hat die Liméische Abtheilung derselben in lang - und lauzschwänzige selbst zu zwei eigenen Klassen (lileistugnatha - exochmata) licrausgchoben, obgleich er in jeder beinahe den xämlichen Typus ron Frefswerkzeugen angiebt. TVie bei Limné, so sind anch bei ihm riele Fer. setzungen anffallend, die pecticulus, acarus stehen z. B. unter den Mücken, der pulex unter den beflïgelten Ryngoten, der staphylinus unter den Fäfern, dic forficula aber unter den Gryilen und Heuschrecken u. s. w. So ist dic gezähnte Maxille, deren Zähne auch neuerdings de Serres zu Unterabtheilungen dieser filasse nimmt ${ }^{a}$ ), und so das Zahnsystem des Linné noch weiter als über die Säugthiere auszudehnen wünscht, kein hincichender Charaliter, um die Filasse ,odontate "zu

a) Comparaison dos organes de la mastication des orthoptires avec ceux des autres animaux par Marcel de Serres. annạal de muș. T. 14. p. 56. 
rechtfertigen, indem auch andcre, besonders aber die hrebse, selbe gezähnt haben. Eben so ist die galea bei Ulonaten, wie auch Illiger meint ${ }^{a}$ ), nichts als jener änssere bewegliche Fortsatz an den Fimuladen der häfer, der bei mehreren Gattungen den Namen der dritten Frefsspilze führt, mod ist daher ebenfalls licin ausgezeichneter und eigenthümlicher Charaliter dieser hlasse; ron dem Charalites der Anwesenheit der Maxille bei „mitosuta" weicht der julus ganz ab, inden ihm diese fehlt, was Fabricius übersehen hat. - Obwohl ron den geäusserten Linwendungen gegen das Fabricische System bisher von liemen Schriftstcller Liwähnung geschah, so fehte es doch nicht an anderen Einwüren, die man ihm machte. Seit seincr Entstehung vernimmt man einstimmig, dafs die MTundtheile der Inseliten zu lilcin und. deswegen zu schwer zu untersuchen seyen, dafs ihre Zerglinderung bei ganz lileinen Inschien unmöglich sey, und selbst bei grölseren öfters den Ruin des ganzen Individums, welches of hostspiclig und rar ist, nach sich ziche; man warf ilm ror, dafs er schr vicle Insehten olme Untersuchung ihrer Frefswerlizeuge blos nach ilirem änsseren Ilabitus rubriziret habe, ja trolz seiner vielen Zergliederungen, wer stehet ilm dafür, oh

a) Illiger's Magaizin für Iusektenkunde, iten Pis. Țtes Heft. S. 271. 


\section{8}

das Creschiecht, Rllma, Alter, der Standpmotit der Netamorphose u. s. W. an dem untersuchen Individuum nim cine Ausnahme machen a)? -.m Dic-

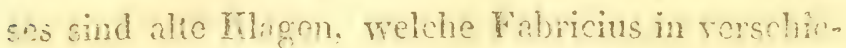
denen Abhandungen zugratcht, aber mit allem Rechte als momshiche Schwathe oder Fehler des Deobachers, nicht aber des Syctcries amslect i). Allertings sind die Frefswerlizouge ron silr wichtiger Belentung, indem sio scibst die Kab. rumg des Thieres charalieniviren, ob es mullich gleich den reiscnden Säugthicren Fleisch odse Elitter zerlinnt, oder blos saugend ron suften and anderen Tlissigkeiten lebt. Allein fur alte Jiunstliche Systome in der praturgeschichte muis es cine Regel seyn, dafs das Kennzichen, woment es erbanet ist, so riel möglich dentlich und har in die Augen springe, was freilich bei dem Fabricischen nicht so ausgezeichnet stalt findet, in wei. cher Ihinsicht das Iinncische auch inmer don Vorzug ror jenem bohaupten wird. Wras aler die Consequenz der Durchfühung seines Cesichts.

a) Jliger's Magazin für Insekten, über das Fabriciscin System " rten Bds 5tes Heft, $\mathrm{S}_{2} 61$.

\$) Schriften der Derliner Gescllschaft, S. 98 , über die Syo steme der Entomologie von Fabricius" zter Bard.

- Illiger Magazin . Inselt. zter Band S. x. "Verthüigung des Fabrizischen Systemes pon Fabricius." 
punlites angeht, so hat es bisher himes seines Gicichen. Klassen, Familien und Gatumgen sind. jilos nach den wnliegenden Fundheilen - nach Winer Zahl, Lage, Beschaffenheit z. B. der Mandibulen, Maxillen, Antemen, Palpen u, s. wo gebildet, und was Fabricius fir die Enionologie durch Degränzung der Gatungen und ảuch Ees reicherumg der Arten that, dicses hat for thm noch liciner geleistet. Hat Limé in cin und är nümliche Gattung rieles Fremuartige wie z. B. is corambyx, scaraliaeus, cimex, gryllus, libel. Tula, phalicna, cancor u. s. w. geworfen, so sten hen jezt durch jenen dic viclen Arten derselben in Cattmigen aufgelölst, and jede Gruppe nach Gattungen und Arten detailliret das Feilich ist his jezt das Fabricische Sysiem noch nicht so anisgen bildet, als es zu'werden verdient, aber ist dieses auch der Fall, und sind auch alle seine unverbesserlichen Lüchen aufgedelit, so wird Fabricius doch das unsterbliche Vexdienst bleiben, Stíter eines neuen Systemes and Erweiterer der ges sammten Entomologie zu seyn.

\section{গ̦. 97.}

Das System des Fabricius war lange erschienen, ohne dafs sich eben viele Theilnchmer gefunden hätten, bis endlich Römer und Coquebert durch roräbliche Funfer dasselbe erliuterton, 
Ronsius a) die fauna etrusca, Panzer ${ }^{b}$ ), Sturni dis Inschten Teutschlands, TValkenacr das schöne Merli uber Spinnen c), dann die Pariser Fama, Hentschius die Elentexaren Europens, Grusenhorst die coleoptera microptera, hiling die sirice's; Firby die Bienen kinglants ansabiteten, und" Mliser auf teutschem Boden, Olivier und besonders Latreille anf franzë|jsichen, zur nähtıen Entwicliclung dieses Systemes beitrugcn. Jedoch fer Einwurf, dufs die Frelswerlizenge so hilein und schwierig z!n intersuchen, and daher mur als Neboncharahicr anzusehen wären, hatte sich zu seìr, selbst der ersten Kniomologen bemächtiget, und daher das Systen Linné's immer noch mclir in Ansehen exhaten. Dicfs machte dem, dafs man cin System aus Limé mo Fabricius ehlshtisch zusammensezte, worim das Liméische die Grundlage, jenes des Fabricius das ergänzende des crsteren ist. Von dieser Art ist das System des um das Fabricische so verdienten Olivier, des Cuvier, Latreille, des Verfassers der helvelischen Entomo.

a) Rossius. Fauna etrusca, sistens insecta in provinciis flow rentina te pisana: Liburni. T. 2. 1790. 4.

- ejusd. Mtantissa. Pis. 1792. 4.

b) Panzer Insekten - Füune Teutschlands seit 1795. 12.

c) Walkenaer. Tableaù des aranéides. Paris 1805. 8.

$=-$ Histoire naturelle des araneïdes ouvrage iomjuse de 3ro planclies Paris i806, $18 ;$ 


\section{$-591-$}

Iogie, des Dümeril und Lamarck. Olivier hat ganz das Limnéische System beibehalten, nur hat er, wie schon ror ihm Degeer, von cien ITymenopteren die Mantis und die Gryllen als eine eigene Orduung unter dem neuen Namen "orthoptera" abgesondert, und also die Anzah! der Ordnmgen auf 8 vermehret, ihre Aufeinanderfolge aber also ungeändert: ,lepidoptera, nevroptera, hymenopiera, hemiptera, orthoptera, colcoptera, diptera, aptera" so dafs die hrebse, als die lezten, den Uebergang zu Würmern und Muscheln machen sollen. Jedoch hat er nicht gesüunt, diesen scinen Ordnungen, wie sie in der encyclopelle méthodiyue dargelegt sind a), ebenfalls den Charaliter nach den Frefswerkzeugen beizufiggen, welches leztere or in scinem vortreffichen Werlie über Coleopteren mit Kupfern, sogar auf Gattungen ausdehnte, obgleich er übrigens ilıre Gruppere nach der Zahll der Tarsen, wie es Geoffroy that, bildete $\left.^{b}\right)$. Seiner Ansicht folgte zunächst Tigny in der Ausgabe Büffor's bei Deterville (Tom. 46 .) nach:

Cuvier hat in seinen Elementen der Naturgeschichte, wie Olivier, ebenfalls das Liméische $\mathrm{Sy}_{\mathrm{y}}$ -

a) Encyclupédie méthodique hist. natur. "Les insectes par Olivier." Tom. 5ième, 1790.

b) Olivier. Entomologie on histoire naturelle des insectes -o "des Coleoptires." Tom. 5. Paris 1780. 4, - ebentally

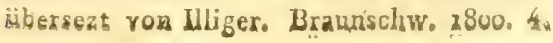




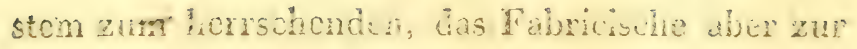
Completinung genominon, and so beile chehisch! vereiniget. Allein hiendir weicht ar ron allen seinen Vorgängern ab, dulse die Aufcinanderfolge der Klassen mein in tuge hatte, und allen seinen Vorgängen entgeren, the Succession der Ordnun gen umhehte. Er stellte 9 Ordnungen auf, wht fügte diesen dic VVumer, als den liseliten rex. mittelst der Raupen verwandt, bei

\section{Des Insectes et des Ners}

I. unsertes pourves des maihoires et sans auten a. crustaces (qui ond piusieurs de pares de mâtchoires

b. mille-pieds.

c.arachnéides (scorpions, araneà, phalangia)

d. phtyrécles (podura lepisma, ricinus)

11. Nínoplères (pouruns des mâchoires, it is ailes reticulées:

- libelles, peries timinirubes, panorpes, raphiche) - agiathes (phryganess, éplués mères).

III. Himenoplères s. pieztîa (pourvus des mdw chioires, à 4 ailes veinées et nori rêticulées.

IV. Coleoplires s. clouterati (pontrus des machoires, à 2 ailes recouvertes par a etuis de substance coinée).

V. Orthoptères s. Ulonata.

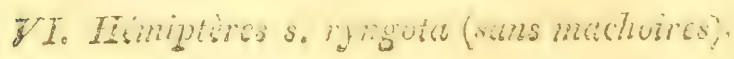


II. Leepidoptères s. glossati.

TIII. Diptères's. antliata.

IX. Aptères (pulex, pediculus, acarus).

Vicl consequenîcr als seine Vorg̈̈nger, vcrbes serte Clairville, der Verfasser der heivetischer Fntomologie ${ }^{a}$ ), das Linnéische und Fabricische System dadurch, dafs er beide auf ihe Hauptgesichtspunkte zusammenzog, und das Leztere als blofse Unterabtheilung von dem ersteren geIrancile; bis jezt hat er aher dieses Schema blos in der Rinleitung angedeutet, und erst an den Cow leoptercr damil den Anfang geniach:

I. Geflugelte Inschten (pterophora)

- mit Kiefern (manditulata): Scliaalflügler (elytroptera), Lederflügles (deratoptera), Netzlügles (dictyoplera), Ademflïglen (phlebopierci);

- mit Sungriusseln (hunsteilata): Baläncierthïgler (haiterictera), Staublïgler (iepidoptera), gemischte Fligiel (hemimeroptera)。

II. Ungeflugelte (aptera)

- mit Saugrüsseln (haustellata): Stichsauge: (rophoteira),

- mit Kiefern (mardibuilata), Läufer oder Vielfüfser (pododunera).

a) He?ceicche Entomologie oder Verzeichnifs der Schweize-

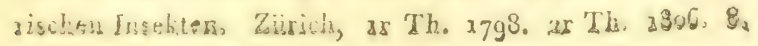


Die Ansichten des Swammerdam, I inné, Gee offroy, Fabricius, Olivier und Clairville, vereinigte endlich Lamarck in eine Einzige zusammen. statt wie Clairville das Linnéische System zum Mauptgesichtspunkt zu wählen, gebrauchte er es vielmehr zum zweiten, das Fabricische aber zum er* sten. Auch rerdanliet dic Entomologie diesem tiefsinnigr.n Forscher noch bedeutendere Nenerumgen: Cusier hatte nämlich den grö́sten Theil der Apteren an die Spitze der Inseliten gestellt, und in Frustacécn, Millepeden, Arachnciden, und Phtyreiton abgetheilt. Lamarck benante die drei lezten Abheilungen Arachneiden, und sezte so die crustacea und arachnides als zwei gesonderte hlassen unmittelbar vor lie linsehten hin:

\section{Class. VIII. Crustacées}

- pediocles (a yeux distincts álerés sur des pedicules mobiles,

*. queue courte et appliquée contre le dessous de l'abdomen: cancer, dromia, hepatus, calappa, ocypoda, grapsus, plagusia, dorripe, portumus, podophthalmus, orythia, matuta - maja, arctopsis, leucosia, pimnotheres.

8. queue allongée garnie des lames natatoires, ou de crochets ou de cils: porceliana, corystes, hippa, albunea, xamina - pagurus, astacus. galathea, scyliarus, palimurus, crangon, palacmon, squilla, branchiopoda. 
- sessiocles (les yeux sessiles et immobiles) polyphemus, caligus, limulus, ozolus, lynceus daphnia, amymona, cephaloculus, zoe, cyclops - caprella, gammarus, cyamus, asellus, ligia, oniscus.

Class. IX. Arachnides

- antennistes (2 antennes, la tête distincte du corselet;: julus, scutigera, scolopendra - podura, forbicina - ricinus, pediculus.

- palpistes (point d'antennes, mais seulement des palpes: la tête confondue avec le corselet; huit pattes): picnogonum, nymplium, acarus, bdella, hydraena - trombidium, elais, trogulus, phalanginm, galeodes, chelifer - scorpio, theliphon. phrynus, aranea, mygale.

Die Insekten, welche er früher in seinem Wer. lie: „systême des animaux sans vertebres" in solche mit Mandibulen und Maxillen - in jene mit bloísen IManbibulen und einer Art von Rüssel (hymenoptera) oder endlich mit blolsem Rüssel abgetheilt hatte, zog er neuerdings in seiner ,philosophic zoologique"s auf engere Punkte also zilo sammen:

Class. $\boldsymbol{X}$. Insectes.

A. Broyeurs (leur bouche offre des mandibules le plus souvent accompagnées de mâchoires).

- Coléoptères (des mandibules et des mâchoires, larve hexopode, à tête écailleuse et sarss yerix, nymphe inactive e. c.). 
- 2 ou 5 articles a tous les tarses.'

-

- 4.

5. aux tarses de prémières paires de pattes, et $\dot{4}$ à ceux de la troisième paire.

- 5. a tous les tarses.

- Orthoptères (des manaibules, des mâchoires et des galettes recouvrant les mâchoires): larve, comme l'insecte parfait, mais n'ayant ni ailes ni élytres, nymphe agissante e. c.),

- Névroptères (des mandibules et des machoires; hare havapode, diversité dans la metamorphose e.c.).

- nymphes agissantes: libell. aeshn. agrion. ephemex. raphid. - thermit. psor. panorp.

- nymphes inactives: myrmeleon, ascalaph. henierob. phrygan. nemur. per]a.

- Hymenoptéres (des mandibules et un. suçoir de trois pièces plus ou moins prow longées, dont la base est renfermée dans zune gaine courte, nymphe immobile e. c.).. - anus des femelles muni dune tarrière. - _ _ _ armé d'un aiguillon.

3). Suceurs (la butsche offre un sucoir muni ou dépoürvu de gaîne).

- Lépidoptères (suçoir de deux pièces, dínuarin de gaine, imitant une irompe tubuleuse et routé en spirale dans lination. Tarie munie de 8 in 16 pattes, chrysalide inactive e. c.). 


\section{$-597-$}

- Hemiptères (bec aigu, articulé, recourbé sous la poitrine, servant de gaîne ¿a un suçoir de trois soies; larve hexapode, la nymphe marche et mange e. c.).

- Diptères (une trompe non articulée, droite ou coucléc, quelquefois rétrartile; larve vermiforme, le plus souvent apode e.c.).

- Aptères (une trompe bivalve, triarticulée, renfermant un sucoir de deux soies, les ailes habituellement arortís dans le deux seives, larve apode, mymphe immobite dans une coque: pulex).

Haben sich Curier, Clairville und Lanarch, besonders an dem Systeme des l'abricius rerdient gemacht, so ist es nebst Olivier und Mlliger rorzïglich Latreile, wolchor tic Gattungen desselben noch näher untershied und beschrieb, und die Liztomologie auch mit einzchen Abhandlungen, z. B, über Amcisen, über Bienen 11. s. W. bereicherte. Zwar hat Lezierer das Systematische nicht remachlilsiget, ja er scheint sogar scinen erprobten Scharfsinn, und sein unverlembares Ferdienst in der Bihlung und pricisen Beschrenbung de Familien und Gattungen, fatschlich nicht snwohl hierin, sondera vielnchr in dem systeme suchen zu wolleri. Allein das System, welches allen scinon Schrifien ibser Insekten zu Grunde liegt, ist die Imnétecle Abtheilung in "ciptires "nd plérodiceres". Nue sind in sciurn msten, 
wenig bekannen TTerke ${ }^{a}$ ) die Frustacén nock nicht ron den Insehten gesondert, und stehen nach den Filassen der Beflïgeiten (coleopter. orthopter. e.c.) unter den $A$ pteren, welche in noch sveit mehrere Klassen (suctoria, thysanoura, purasita, acephala, entomostraca, crustacca, myriapoda) als bei Fabricius abgetheilt sind. In seinem zweiten ${ }^{b}$ ) schlols er sich an Curier's System an, sezte die Apteren vor alle ührs, en, tremnte hievon die Krustacéen als cine eigene, ron Inseliten verschicdene hlasse, und entwarf in boiden eine Menge ron Abthcilungen für seine nenen, mcistens nach dern herrschenden Individuum benanntea Familien (z. B. cicadaires, gallinsectes u. s. w.) was er auch in seinem dritten c) und vierten Werke ${ }^{d}$ ) beibehielt. In seiner nouesten Schrift endlich e') nahm er sich Lamarch zum Muster, und sonderte nebst den lirustacéen auch den gröfsten Theil der Apteren unter dem Namen "arachnides" als cine eigene hlasse von den In-

a) Latreille. Précis des caract, géner: des insectes $179^{5} 8$.

b) Latreille. Yiistoire nat. générale et particulière des crustacées et des insectes, ouvrage faisant suitc aux oeuvres de Buffon, Tom. I-XIV, Paris. An. X-XIII. 8.

c) Tableaux methodiques d'hist, nat. p. 124́. l'article des crustacées et des insectes par Latreille, Paris 1805. 8.

d) Latreille. Genera crustaceorum et insectorum. Tom. i, Parisiis 1806. 8.

e) Consilleration générale sur l'crdre naturel des crustacés, des arachnides et des insectes, Paris 1810. 8. 
sckten ab. - Bei allen diesen Verwandlungen Latreille's in der Methode, ist doch sein Streben unverändert dasselbe, die Inseliten nicht blos nach Tarsen, Fühlhörner, Flïgeln oder Frefswerlizeu. gen, sondem nach allen diesen zusammen, nach der Gestalt des Thorax und überhaupt nach der Achnlichlicit des äusseren Habitus, wie es Jussieu gleichsam auf dem Gebiethe der Pllanzen that, zu classificiren. Obgleich viele Gattungen dem äus= seren Habilus nach nicht immer in die nene $\mathrm{Fa}$ milie, wic dieses z. B. in jenen der carabici, clerici u. s. w. recht offenbar ist, passen, so verdient doch dieses Bestreben allgemein nachgeahmt zu werden. Nur hat, leider, der Verfasser bei allen dem nicht immer alle ïusseren Theile zusammen, sondern ifters cinzelne Theile, wie z. B. bei Coleopteren, gerade wic Geoffroy, blos allein die Tarsen, ror Augen gehabt, und selbst sogar zum auffallendsten Widerspruche, und grolieshen Abstande alle natirlich gebildeten Familien miter die einseitigsten und künstichsten Gesichtspunlie und Benemungen (z. B. coleoptera, entomophaga, saproplagi, malacostraca, pentameres u. s. w) gebrach. Diese Menge von Abtheilungen, welche die Entomologie gleichsam zu einen anfangand endciosen Labyrinth umwandelten, war so ausserordentlich, dafs sie selbst scinen Landsleuen, die doeh sonst inmer cin ähnliches zon thut 
lieben, auficl, und allgemein getalelt wurde. I.atrcille fuhlte in der Folge die Richtigkeit dieses Finwurfes, liefs daher in seiner neuesten Schrift einige Haupt - and die meisten Unterabtheilungen seiner vorigen Werlie weg, und stellte dic livus. tacéon, Arachniden und Inseliten in folgendem Schema, und in folgender Aufeinanderfolgc auf:

I Crustacea

- entomostraca: aspiciota (limul. apus, saligus, binoculus), ostracoda (lynceus, daph. nia, cypris, cythere), gymnota (cyclops, pow lyphem, zoe, branchiopoda).

- malacostraca:

- cancerides: podophthalm. porlumus; dromia, cancer, hepatus, calappo, ocypode, grapsus, plagusia, pinnothera.

- oxyrynchi: dorippe, mictyris, leucosia, corystes, lithodes, maja, macropus, - orithya, matuta, ranina.

- paguri: albunea, remipes, hippa, pagurus.

- palinuri: scyllarus, patinurus, porcellan. galathea.

- astacini: astacus, alpheus, penaeus, palaemon. crangon.

- squillares: squilla, mysis.

- gammarinaes phronima, gammarus; talitrus, corophium, caprella, cyamus.

II. Arachnides

- tetracera: asellota, oniscides.

- myriapoda. chilugnatha, syngnatha. 
- rligsanoura: Inpismenae, podurellars

- parasita: pediculius.

- i) rrogonides: nymplon, phoxichite, pychogonum.

- acera: scorpionides, pedipalpi, araneides (les araignées mineures, tapissières, crabes, loups, phalanges), phalangita, acaridiae, riciniae, hydrochnellac, microphthira,

11. Insect $a$

\section{A. Coleoptera}

*. pentamera:

- entomophaga: cicindeletre, carabici, hydrocanthari, gyrinites.

- sapropluaga: sternoxi, malacodermi, clerii, necrophagi. staplyylinii, ptiniores, dermestini, byrrhii, hydrophilii, sphaeridista, coprophagi, geotrupini, scarcibceoides.

2. heteromera: pimelariae, tencbriontes, pyrochroides, moxdellonae, cantharidiae, oclemeritac.

y. tetramera: bruchelae, curculipnites, bostrichini, paussili, xylophagi, cucuji, cerambicini, criocerides, chrysomelinae, erotylinae.

Primera: coccinellidae,

\& dimora: pselaphii.

3. Orthoptera: forficulariae, blattar, man-4 tides, gryllides, locustarige, rerydi. 
C. Temiptera

- heteroptera: corisiae, cimicides, hydrocorisae.

- homoptera: cicadariae, psyillidae, aphidii, gallinsecta.

D. Nevroptera

- subulicornes: libellulinae, epinemeridae.

- filicornes: panorpetae, myrmeleonides, hemerobini, megaloptera, raphidiae, termitinae, psoquillae, perlariae, phry yanites.

E. Hymonoptera

- terebrantia: tenthredines, urocerates, evaniales, ichneumonides, diplolepariae, cynipserae, proctotrupii, chrysidides.

- aculeata: formicariae, mutilariae, scolietae, sapygitae, pompilii, sphegimae, bembecides, larratae, crabronites, vespariae, masarides, andrenetae, apiariae.

F. Lepidoptera

- diurna: papilionides, hesperides.

- crepuscularia: sphingides, zrgenides, noctuo-bombycites, tincites, noctielites, phalaenites, crambites, plcrophorites,

G. Diptera

- proboscidea: tipulariae, stratiomydes, tabonit, riagionides, dolickopodes, 
mydasii, asilici, empides, anthracii, bombyliarii, inflata, syrphicae, conopsaricue, muscides.

- eproboscidea: coriaceae.

- phthiromyae: nycteribia.

\section{H. Suctoria: pulex.}

Auf innliche Art bearbeitete auch Dimeril in seiner analytischen Zoologie dieses Gebich. Tr sonderte die Krustacén als eine eigene hlasse in den ibrigen Inseliten, und theilte sie beinahe wic Itatreille ab. Die Insuten selbst miterschicd or wie sein Vorgänger nach Linne's sysimm in acht Ordnungen, doch so, dafs er aveh dis Spinnen, Aillipeden u. s. w. mer den Apieven und nur am Ende aller Inscliten aufzillile. Zwar strebte auch er, wic Isatroille, die Gattungen unter passende Familien zu sammen, jedoch wählte er jenem entgegen, immer gerade das hiustlichste Merimal, um diese zu bezeichnen, nnt zwang, indem or auch hiev in chras Scopoli nachahme, welcher die lezte, ron den Apteren absesonderte Thlasse, von Brünich, ,rtstaced" genamnt, in die , lucifuga"s umwanlelte, die Gattungen unter vage und zufällige Aufschriften und Charaktere z. B. Hartfügler, welche den Wald lieben, welche das Licht flichen, ron Pflanzen, ron Holze oder Fleische leben - Hymenopteren, welche sich gorne auf Blumen aufbalten u. s. w. (coléopteres 


\section{- $604-$}

omiphite, photophyges, phytophages, xylophages, hymenopteres, anthophyles e.c.).

Jurine suchte anf einem anderen Vicge als seine Vorgänger das Liméische System weiter anszubilden, Er wählte zur weiteren Unterab. theilung jeder Limméischen Ordnung von Insckten, dic Verschiedenheit der Zellen, welche ron $\mathrm{dcm}$ ersten und zweiten Aeusseren der vier oder fünf, aus dem Leibe in jeden Flïgel auslanienden Starilen, (ron ihm radius wad cubilus genanit) gubildet werden (collutae radiales, cubitales). Dicse Strahiu selbst, welche man sonst uneigent= lich Nerven hiefs, Swammerdan aber fü Adern lielt, erlilürte er nach seinen microscopischen $\mathbf{U n}_{n}$. icrsuchungen fur hohle Röhren, innerhalb welchen Trachecn laufen, und durch ihro Anastomo. sen jene Zellen herrorbringen. Bis jezt hat er diese Methode blos an den IIymenopteren versucht, und sie mit vortroßlichen Lupfern also orläutert ${ }^{a}$ ).

Hymenoptera.

Ord. I. Abdomine prorsus sessili, latitudinem thoracis adaequante.

Gen. 1. Tenthredo

a) L. Jurine. Nouvelle méthode de classer les Hyménoptéres et Diptères avec figures - Hyménoptères, Tom, 1. Geneve $1807.4 \%$ 


\section{$-605$}

Fam.1.- Cellulae iadial. 2, elongatie, fere - les.

Cellul. cubit. 5, prima angustata apicem alae attingit.

- Mandibulae iridentatae.

- Antennae capitatae, 5, 6, 7 articulis compositae, ultimus ovatus.

- 2. - Cellul. radial. idem

- - cubital.3, prima excipit, primum nerwum recurrentem secunda secundum.

-. Mandib. bidentatae

- Antennae 5. articulis compos.

Gen. 2. Cryptus

- Cellul. radial.1, maxima uppendiculata.

Cellul. cubit.4, fere - les, 2da et 3 tia duos nervos recurrentes excipiunt, 4ta apicem alcae attingit

- Mandib. e. co

- Antenn. e.c.

Gen. 3. Allantus

- Cellut. radi. 2, - les

- - cutit. 4, in - les, prima parua rotundata, sda et 5 tici $e x-$ cipiunt duos nervos recurrentes, 4ta apicem alae attingit

- Mandib. - Antenn. ...

Gen。4. Dolerus

Fam. 1. Cellul. radi. $2_{2}=l e s$ 


\section{$-606$}

Cellut. cubit. 5, wma parva, rotumdata; 2dre longissima excipit duos nervos recurrentes; $5 t i a$ apicem. alae attingit.

Fam. 2. Cellul. radi. idem

- cubit. 5, rma elongata excipit imum neroum recurrentem; zita 2 dum.

Gen.5. Nematus

Cellul. radi. 1, maxima

- cubit. 4: 1ma parva fere roturidaia; 2 da magna 2 nervos recurrentes excipit; 5tic minor, quadrata; 4ta apicem alae attin$\because i t$.

Gen.6. Pteronus

Cellul. radial. 1, magna

$$
\text { - cubit. 3, fere - les. }
$$

Gen.7-12. Cephaleia, oryssus, tracheIus, wrocerus, sirex, tremex.

Ord. 2. Sbdomine peíiolulo, petiolo supra thoracem infixo.

Gen.1-4. Evania, foenus, aulacus, stephanus.

Ord. 3. Abcionine plus minusve petiolato, pone thoracem infixo.

Gor. 48. ichneumon, anomalon, bracon, pompilus, spliex. e.c.

Preyisler debute hieranf die Idee Jirines noch woiter ans, mu inssosto den kühnen Vosschlag, 
auf den Rippenverlauf der Flügel ein System fiu alle Insekten zu erbauen a). Jedoch so gesetzmüfsig auch die Netze der Flügel der Insekten sind, so wenig kömnen sie doch zur Grundlage cines allgemeinen Systemes dienen, indem ein grofser Theil derselben ohne Flügel ist, unter den Befliv gelten viele Treibchen unbeflügelt, und überhaupt nichts mehr an Inschten der Verhiimmerung und. der Abänderung nach dem Geschlechte und Altor als die Netze der Flügel ausgesezt sind; ja Kluy behauplet sogar in sciner Monographie ${ }^{b}$ ), dafs sich diese Ansicht nicht eimmal blos auf die Piezaten anwenden läfst, indem er flïgellose Ichneumo: nen, und selbst beflügelte ohne alles Geäder (?) oder doch ihre Netze von der wumderbarsten Struktur in seinem fiabinelte zu besilzon vorgiebt.

\section{S. $98 . a$.}

Sinc die Systeme eines Swammordam, Lime, and Fabricius scit Aristoteles emzeh und nack und nach erschienen, so strebet man jezt, wie man aus dem Bisherigen ersieht, so viel als möglich, alle diese zu einem Einzigen anfzulölsen. Allein noch immer nicht sind diese einzelnen Richtungen, trotz dor häufigen Bcarbeitungen so

\footnotetext{
a) S. Illigers Magazin der Insektenkunde, rten Dids 5 tes u. 4tes Heft, S. 460 .

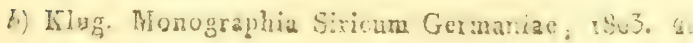




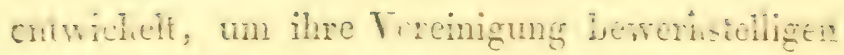
an hïnen. Durch Miger wurden die Elcuther. ton des Fabricius ansecrordontlich berichtiget, und noch immer arbeitct mon an cier Verbesecrung scines ganzen systemes, Jürine hat eimen nenen TVeg zur Erwciterung des Linnétichen cingeschlagen; und wie unvolstindich ist noch jencs der Motanowhose, und darm das des Geofroy auf die Zahi der Tarsen; oder jenes auf die Beschaffenlecil der Antemen erbaut, welche beide Lcz* foren sich selbst nicht eimal his jezt zur Whate cincs allyemonen Systemes anfechwingen lionten? Jedoch einen Curier, Clairrille, Lamarclis busonde: aber einem Iatrille, welcher sogan nobst den Tligeln, FrefowerIzengen, Antennen, Tarsen auf das Verhaltinifs des Fopfes, der Brues and des Abdonen zu chander Rïchsicht nimmi. and Familicn - Gruppen nud Anfschriften auf dic: cem Gebiethc einzufulmen trachế, diesen bleib: die Ehre, den ersten Ansiof zu cincm elilelischen Svstente aller Vorgänger geven zu haben. Frei. lich ist dieser Eklelitizismus blos anf das Aeusscro des Inselites gegrïndet, wnd nimmt ron der inucren Eineichtung desselben licine Notiz, ja er be: steht nicht einmal in der Durchdringung aller bislierigen Systcme, sondern in der Unterordnung nud liginzmo des cincin durh las andere; duher denn auch hier alle Einwinfe und Lithen de: 
ersteren zurückekehren, und da die Entwilinngsstuffen der äusseren Theile nicht ron einem In. sehte zum anderen, von eincr Ordnung zur andern beobarhtet werden, so folegen auch hier, wie bei den ursprünglichen Stiftern jener Systeme, die Individuen in jeder Familie und Ordmmg sowohl, als diese selbst in der regelloscsten Tinllitiler auf einander. Doch nur jenes System wird einst mit Thecht den Namen cines solchen führen, welches alle mertichen in sich verciniget, alle Theile, üussere sowohl als imere, nach den Stuffen ihrer successiren Ausbildung, durch Arten, Gattungen, Familien und Ordnungen im Auge hat, und eben diesen, wic in der Vatur, in einzelnen Gruppen ihnren unabänderlichen Plaiz und Pang bestimmet. Jedoch wie weit slehen wix noch, besonders aus Mlangelider imeren Stwhitur jeles Insel.tes ron diesem Zicle nib? Erst rillissen eben so unf einzelne innere Organe - Speisthand. Tracheen, Geschlechtstheile u. s.w. - einzelne Systeme ersivitel wetdon, wie es für die änsscren schon geschelen ist; dann hïnnen wir uns der rollotandigen limntuifs des ganzen Inschites, und ilırer Cedereinstimumur zu Gruppen rïhmen, und die. se hustellen. Maly hi, Swamnerdan, Lyomet, buben dieses zwar an mehreven einrehen hudi-

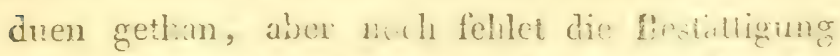
oder weitcre Ausdelnung, und dans die Verghi- 
hung. Was wissen wir z. B. wohl ron dem prit. sircuten Cefafse auf dem Piviclien der Insehten, welches Malpighi fü eine Reihe von Herzen, Swammerdam für eine Artorie angeschen hat? Noch immer blieb dieser so mertwüdige Gegen siand ununtersucht, und frst in nenerer Zeit äns sert Curier die Hypuliese, dalis auf diesem Gebiethe fiu ron kener Vene mul Arterie die Rede seyn liomne, indem die Absondemengergane bet hïheron Thieren durch din Bhtgchalse zn Drüsez rerbmulen, lier abor eben in lange, frei fottirende Linde andervicticlt sind, wie z. B. jone, welche speichel, die Materic zim Selle, oder weiche an den Gedirmen in ence Anzall von zwe lianalen in den Coleopieren, ron vier in den Tampen, und in Mrong:, abor ron Sivacen Lange in don Nemropleren, IJymenopteren wid Orhopheren, Galle absonicn; fener glaubl cr an jenem Ruchengefüse loine Vewweigung wahgenommen zu haben.

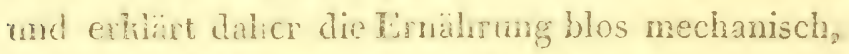
d. i. dinch Ansschwitzung des Chylus ans den Gedämen und durch Aufsargmeg desselben durch jecles einzche Organ, weswegen auch die Tracheen ans Mangel cines allgemeinen Gefrissysteznes zu jelem Theile des liöpers selbst gehen schlen a). - TVas wisien wir uber das Geschlecht

a) Bulletir des ociences de la sociens philomatinue. A.tu Thi, p. 3 . 
der Bienen und Ameisen weiter, ausser das, was schon Aristoteles remuthet, Swammerdan abes noch mehr in Umlauf gobsächt hat, ränlich, dafs die Dronen die münnichen, die anheilsanen die geschlechislosen seyen, und dafs eine und die nämliche Kiönigin joles Stnclie- die Eier für diese drei rerschiedenen Arten lege? Sollten aber nicht dic geschlechtslosen Arbeiter blofse Larren sejn, and nach und nach zur Geschlechtiglicit heraneifen? Wenigstens stellt nenerdings Huber die paradore Meinung auf, dafs die Bicnen, wenn sie ihner Fönigin bermbt sind, Zeilkn, worin das Wümchen der Arbeitsliencn litgt, in die der Königin umwandeh, und danu diese Thürmchen selbst stut Arbeitsbiencu williche hönigmen wer $\operatorname{den}{ }^{a}$ ). Eben so sireitct man sich noch, wemn man Scarpa's Entdeclung des Tympantm an Fireb$\operatorname{sen}^{b}$ ) ausnimnt, über die Cregrenwart beinahe al. ler Simesorgane: Reannior, Lyonnet, Clurk, Jä Blonsky, Latreillo halten die Spitzen der Antensen fiir Organe des Gernehs, Jüne fü Gernchsand Tastwerkzenge zugluch: Scarpa, Sulzer: schucider, Borhhansen frir solche des Gehrirs; Borhhausen liatt die l'ulpen filir jene des Gernchs; Lüneril giaubt, daro die trathen anch zugleich
a) Huber. Obscrvations siur les abeilles, pag: 346
b) Searpa. De auditu et olfactu, e, co 


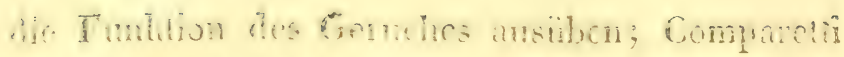

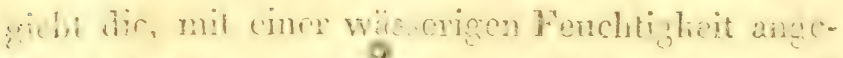
fullen suche, wolche er in den Fühen unter dere Ampupfoln ontrif, fir die Gehürwerhzenge ans; Mill halt dic won flin zuersi cutdcliten, auf dem

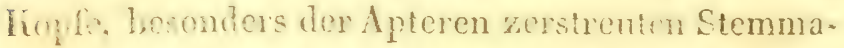
icn fir die cigentlichen Augen. YYos die Peepira tion angelt, so ist es anogemaclut, dais bei allen Tushlien das Amon durth cine geringere oder

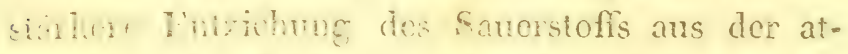

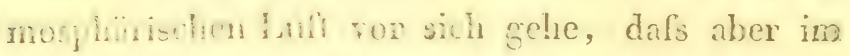
Stilgetse, mol noth gesthinder im Wasserstoffgace der Tod jener eintrete; es ist dargethan, dais the Hrobsarten nittelst Branchien athmen, bei Spimen die Trachecn blos einige Ampullen bil. Won, und dio Anzahl doy Shigmaten bei den übriyon Inefidon nacli dor Zahl der Segmente ihres höpers vare; bei ten Nilben, Nüchen, Raupen mả lätern sind die Trocheen gleich nachden sie das Luntoch rerlas on haben, und unter sich dr.s Läng nach anatono iren, zwei lange, hüngst

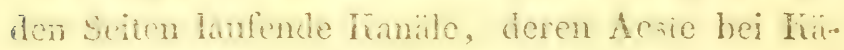
forn duch Andhwelumg zus ovalen blischen un

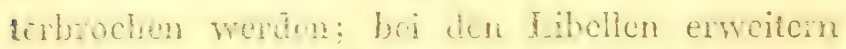

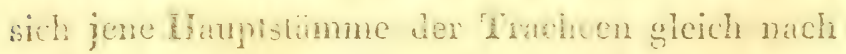
Aom Austrite ans den beblon luthohern zu noch

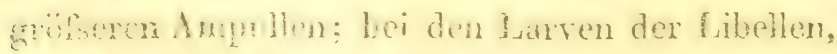

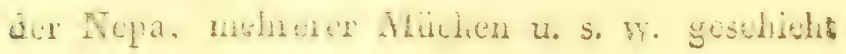


das Athmen blos am Schwanze; So ausgenach diefs alles ist, so glaubi doch Wuncril, durs die Tracheen bei Fisehien nicht blos zum Athmen, sondem auch zun Riechen, und fyonnct, dats sio and Frnähung dienten. - Auch die Geschicchtsdheile der Inseliton erhcicchen in Zuhnnfi noch gine cigene Bearbcitung; zwà homen wir im All gemeinen scit Malpighi ihre Ilauptumerschicie, wir wissen, dafs dia Geschiuchisongane sich auch erst alimählig nit den Verwandlungen ansbilden - dafs bei allen Inschten die beiden Gischlechtex getronnt sind, and bei Minnchen und Weibchens ähnlich hicnin den Sänghioren, ans simmetrischen Theilen bestetion - dafo abes dic Aismündung diver bgi ireissen und Spinnen doppelt, und zwar bei jenen unten am Thorax, bei den nümnlichen Spinen in den Palpen der Maxilien stati fudatdafs die Phalangicn mu alle ubjige Insthen diesc Ansmëndung mue cirfach, und zwar am Anus, die münnlichen Libellun vna dann die Julus ảer in der Bille des Tiöpers hiben. Allein welche Verschiedenheiten, welcho Nirancen in diesen Theilen, werden sich noch an einzelnen Ordnun. pen, Gattungon unt Arten finden! - Auf solche Jerise sind wir in Minsicht der inneren Eimich. tung des Körpers dor Insehten noch gröfstentheil: in: Dunhch. Noch feh'en uns melir solche Schritten, wie dio cines swammeriam, eines tyonnet. 


\section{$-614-$}

obgteich in unseren Zeiten ter zu frih fiu die Naurgeschicute verstorbene Posselt, welcher uns eine vollstündige Anatomie der forficula auricu. Taria in selir genauen Ablildungen hinterliefs und durch Vergleichung den Platz dieses Insehtes nicht mit Linné bei Coleonteren, sondern mit Fabricius bei den Glonaten rechtfertigte, diese Mei ster in der vergleichenden Anatomie vor Angen hatte *), und auch nenrilings ein Ramdois in diese Fufstapfen tritt, indem or nach Cuvier's Dentung der vicien Mhind?ärnchion an Incekien als Gallentianüro, und joner am Oesophagus als speichelabsondernder Gefiifse, blos den $A$ limentarkanal nebst diesen Anhängsh zmm Gegenstande der ge-

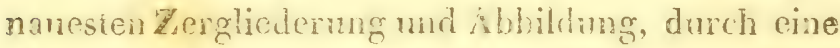
IVenge Arten ron rerschiedenen Ordunnen hindurch grnommen hat; nur ist noch von diesem feinen und planwollen Zergliecierer zu winschen, dufs er nolst den rorhandenen Beschreibungen and Abbihangen, auch die plyysiologischen Resultate, und cine, anf dis anatomische Vergleichung jedes einzelnon Organes grgrïndete Anordumg der Inseliten berikisichtigte $\left.{ }^{b}\right)$. - Noch riel we-

a) C. Fr. Posspit. Dissertatio inanguralis medica sistens tentamina circa anatomiam forficulae auricularize. Jenao 1800.4.

(4) Karl And. Ramdohr. Ablithungen zar Anatomie der In-

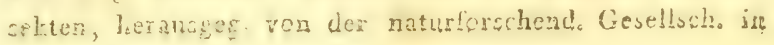


ninger als die innere Strultent, kennen wir das fos sile Vorkonmen dieser Thicre, un ihr Alice ans siner entsprechenden Schichte der Wrie, oder das Verhaltuils der ansgestorbencn Gattungen zu den noch cxistirenden zu documentiren; zwan wissen wir im Allgemcinen, dals, so wie Zoopliyten und Molluslien, auch Inustacéen in Uebergangegelirgen und in denen der altesten Flüzformation $z$. B. dex enthomolithus paraloxus im Thonschiefer, - dals mit den Fischrersteinerungen im Stinkschiefer ron monte bolea, Oeningen, in Mergclschiefor von Eichstäd auch hirebse, iTuscerwan.. zen, Libellen nebst den Larven der lezieres, be? Solalenhofon auch dor limulus gigets reratonert gefunten werden. Eben so trift min Inschiten, z. B. Miticlicn, Amcisen, Spinnen in Bamatcin, welcher meistens zwischen den 'Trümmen noch nicht schr zossezter Pflanzen $\%$. B. zwischen Torf und faulen Ilolzsticlicn unter ciner oft nur wenige Souhe tiefon Sardschinte Iiegt, eingeschlus. sen unc nuversehrt an. Treilich rühren die meisten Versinermgen dirser Thiore, wie jene in Bernsteir und besonders jono bei ecningen, ron noch in licser Gegent lequadon Indivituen her; allem fir manche Perefalite z. B. von fireben im

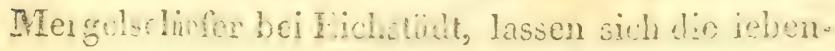

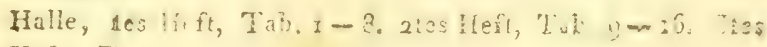
Heft, $\$ 17-24$. Ilalle riog. \&. 
digen Gegencticke meisiens nur in MTerren, und selbst oft nur in denen fremder Welthieile aufsu. chen, ja die Trilobithen (entomolith. paradoxus) scheinen offenbar eine ron den ausgestorbenen Gattungen zu seyn. - Mie riel aber ist uns so noch in Minsicht der inneren Strultiar und in Hinsicht des fossilen Vorliommens der Inseliten zu thun ubrig? Trur Schriften, welche uns entweder ein einziges Inselit nach alien semen Destandtheio len und Fiscnschaften hemmen lernen, oder eine und die nümiche Untersuchung wie ein Swammerdam durch eine Menge von individuen aus allen Ordmugen hindurchibren, mur solche wer den es in Zukunft dem physiotosischen Intomologen möglich machen, die Inseliton unter einander nach der ansspren wnd imeren Stulitur ihres Körpers, nacil ilrer Mietumophose, Lebensart u。 8. w. zu vergleicien, und in die Anfeinandorfolge der Familien und der in ilmen legriffenen Individuen die gesctzmäsige Ordmeng zu bringen.

SIEBENTES CA PITEL,

Würmer-Helminthologie.

\section{93.6.}

Aristo-

telw. für sich hestehende lilasse ab, sondern quicht mur gelegentlich ta ron ínen, wo er ror Inseliten bancelt. Iedrzuit unicrshoidet $\mathrm{cr}$ abo: jene, 


\section{$-617-$}

wclche als Larren sich zu Inschicn metamorphosiren, von denen, welche heme solche Verwand. lung erleiden, and in den Eingeweiden ron Thie-

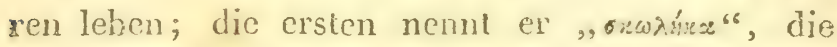

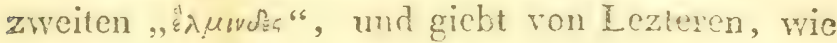
schon ehmals lippocrates, (vid. iib. $4^{t}$, de nor. bis - fener sect. $5^{t}$, aphorism 26t.), und späterhin Galen, folgende orei Arten an "):

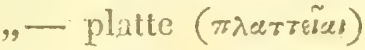

$$
\begin{aligned}
& \text { - runde (5g0zzúdral) } \\
& \text { - Ascariden (2isregidés)" }
\end{aligned}
$$

In keiner der bisherigen Abtheinngen ron Thieren, ister so hurz, und so wenig weiliänfig, als eben hier. Ohne nur des Sirdwurmes, Blutigcls oder anderer ansscrhall des Törpers dor Thiere befindlichen Wümer, ausser den Nereilen, welche cr Mecrscolopender (L. 2. C. I/1) nemt, zu erwahnon, begnüget er sich mit einigen wenigen Bemerlungen über die Eingeweidewümer, nämlich, dafs sic auch bei Fischen $\left.{ }^{b}\right)$ und Hun. den ${ }^{c}$ ) angetroffen werden - dafs die platten ganz solitär lcben, und hörnchen wie Tuliumen ron sich gehen $\left.{ }^{d}\right)$ - dafs die Wïmer in den Wïpfen mancher Hirsche e) gröfser als andere (sudat von ihm genannt, wolches Wort Scaliger
a) Arist. histor, animal, L.'1, c. 5. - L.5. c. 19.
b) ejusd. L.6. c. 17. - L, 8, c.20, c) ejusd. L. 9. c.6.
d) ejust. L. 5. c. 19, e) ejusd. L.2. c. 15. 


\section{- $618 \quad-$}

und Gaza anf die Wiurmer im fanlen Fleische erzeugt denten) und dafs endlich jene, wclche von rogeln gefressen werden, wahre Insehteniarver (orodinuce) sind $a)$.

\section{100.}

Linne. So seltr sich anch die Beolyachtung dieser There besonders den Acviten aufurang, so wurde dech ihe Geschinte und Anordnung beinahe bis anf Liné remachläwiget. Plinitus thut derselben gar nicht Erwänning - Isider besimmt zwar dajoir ein cizenes Kapiol, nämlich das fünte, wcl. clins die Aufschrift ,evmes" trägt; allein riele Inseliten, besunders aber alle Inselionlarven, finden hicr ihre Stelle, und die Namen s, Tumbricus, as caris, sengruisuga, vermes carniun "stchen unter jenen verutische -- Aibrrtus d. Gr. zählot in nem Bucho ibser bhilose Thiere ench sanguisuga mad rcomis in alphabetisclier Ordnung auf Follon exivilut von den Wumem ausscrhalt. des Whis:ischen Lörpers bios des Blitigels und nwar bei den fisclien, der Nereis - von ihm scoTopendra marina genannt - bei den Inselien, ron den ingewedewümern aber erwälnt er der drei behumben Arten - der platten, runden und dc" Askariten - und zwar am Ende der Insekton, huyz nacit ace Bescurcibung der Raunen und

a) Arist, histor. animal. L. 9, c. go 


\section{$-619$}

der Wümer, wclche aus Schnce, Holz u. s. W. entstehen sollen. - Belon und Tiondelet bringen blos den Namen vermes lumbricus bei den Zoo. phyten ror; Gessner führet sie bei Inseliten an, und zwar unterscheidet or die Würmer und Eluto igel nach ihrem Anfenthalte im süfsen oder saizigen Wasser. - Mouffet, Aldrorand unt Jonston flum ihrer ebenfalls bei den Inseliten Frwihnumgs und zwar theilen sie die beiden leztcren in die des Landes und des Wassers ab, und rechnen zu den ersten die teredo, ascaris, lumbricus terrestris, hominis et caeterorum aninalium, zu den Lezteren aber hirudo, lumilricus marinus, vermes in tubulis (serpulae), scolopendra marina (nereis).

Nun. fing man an, den Viürmern, besonders jenen in ren Eingeweiden der Thiere, nüher nachzuforschen: Redi zergliederte in dieser Absicht eine Menge ron Thieren aus allen Klassen, fand solche in bestimmien Individuen und Organen derselben "), und stellte, wie gleichfalls Löwenhök, der herrschenden Meinung: ,als entstünden diese Bewohner aus dem Chylus der Thiere, eine anJere cutgeg̊n, nämlich, da؟s sie aus Eiern von In* selten, von ausscn her in die Thiere gebracht, ihe ren Ursprung nühmen - eine Hypohtse, welche

a) Observazioni intorno agli animali virenti negli animali vio venti. Tom, 1. Opere di francesco Redi. Yenczia 2781, 4. 
Boerhave und Hoffmann daumch aufrecht zu erhalten glaubten, dafs sie, da doch z. B. von der tacnic nichts ähliches ausserhabb den Thieren gefunden wird, diese als eine blofse Irletamorphose ans anderen ansahen, ja Frisch alle Eingeweidivünier ful Matamorphosen des Tumbricus, and blos nach dem Alier rerschieden hiclt - An dry a) erhlinte die Niumer fü hleine Inselien, deren Fier sich in Lwift, WTasser und allen Speisen befinden, so in die Fingeweide der Thiere, und in die änssere Haubledecliung rerpflanzt würden, Mankanschläge und andere haulihciten verusachten - Vallisnicri ${ }^{b}$ ) widersezte sich hartnä cliy dieser Mcimng, ma behaupicte, da die Einoweidewümer nicht ausser den Thieren lebten, wnd sich schon in Embsyonen vorfünden, dafs sie deaschen angeboren wiren, und ihre Eicr von der Muttor anf das lind iibergetragen würden; zal gleicher Zeit erhärte er ảen Bandwurm für eine helte von selbstänäigen Würmern - Hart socker, Coulet, Plancus and Vallisnieri bekannten sich zu dem von Vallinicui, Clericus aufgestellen Ursprung dieser Thiere, und Lezterei licferte dis

a) Andry. Sur la génćration des vers dens le corpo de l'tomme. Paris 1700, 8 .

b) Vallisnieri. Considerazione ed esperienze intorno al!a geserazione de'yermi ordinarj de cuorpo humano, Padsa \$730. 4 . 
lisherigen Beobachtungen, so wie anch dic Abbildungen in den Scliriften eines Ruysch, Redi, Löwenhoek, Vallisnieri, Tyson, und vieler medizinischer Verfasser in seinem Buche über die breiten VVürner a).

Klein sezte die naliten Würmer und zngleich die Schlangen unter dem gemeinschaftlichen $\mathrm{Na}$ men „Ficptilien" an die Spitze sciner zweiten Abtheilung ron Thieren, nänilich der Apoden, diejenigen mit Schaalen aber glcich darauf unter die Testacéen.

Endlich rilliten diese Thiere ihrem gehiörigen Platze näher. Limé überschrieb die lezto Klasse der Thierreihe mit dem allgemeinen Namen . Nürmer" unter welcher Aufschift er, wie $\mathbf{A}$. bert d. G. unter jener seines fünften Buches, nümlich ,hriechendes Gewïrm", das heterogenste, obwohl in die einzehnen Familien, intestina, molZusca, lestacea, zoophyla" geschieden, begrif. Wirklich beticit er diese Aufochift, und alle diese Thicre in einer einzigen hlasse beimmen, nur gebrauchte or in den frihtern Ausgeben bis zur arlaten den Titel "reptilia" slat joues sintesfins" und zuhte hierin die Gatungen ,gordius, tuenia, lumbriats, hirudo, fimax" mul spüterhim ascuris, fusciolu auf; die übrizen Wumar-

a) Clericus. Filstorie vatualis et mecica latomin iumbresrum. Genevae 1715. 4. 
Aen, als aphrodite, ampritrite, nerels, mais, ser pula, tercio, dentatium, zu dencir ancle baha dio Guttum, limax rersezt whode, siandon nach jemen in der zweilcn Ordmug beatunt "Zrophyte" Mit der zehmen Areggale änlerte or die Aufo schrift ,zocphyta" in die ,moluscis" um, bediente sich de" Bencmung "Zooplyten" znr Rezeichnug cines 'I heiles dox h. thophyten z. B. der isis, gorgoniu, vorticellu, chase n. S. W. wozu er jezt auch die tunia reancte, und ver. nelnte lie Intestina mit den Giathugen mzrine: furic, sipunculns. Die nimliche Ventheilung und Anzahi ron Gatungen behielt Lindé auch in seiner lezten, eigenhändigen Ausgabe, nitnlich des zwölften bei. Gmelin that das Giciche in des dreizchnten, num pafste er sich der Mcimung der gegenwärigen Zeit an, und machte zwischen den innereñ und anseren Wümern einen Unter. schied, was inmostin Limé durob alle scine Ausgaben rerabsclicute, indem er sclbst wie Unzer. Gaddins, ron Docreren, I.ingcweiler umen ansserhalb den Thiren in fiewissen gefunden $\mathrm{zu}$ haben, hetmptete. So in etwas veundert, und

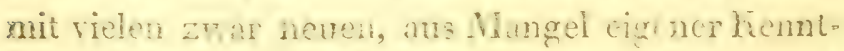
nifs aber ötcrs blos zu-ammengeraftion und unhaltheren neten Gattungen remehr, wicdor. Follte Gnelin das Limélische System des iVtumer jolgender Massen: 


\section{的 62 学}

Ciass VI. Vermes.

1. Intestina (animalix simplicia nuda. artibus destituta)

- intra animalia degentia:

- ascaris, trichocephalus, uncincria, filaria, scolex, ligula, linguatula, strongylus echinorynchus, haeruca, cucullanus, caryophyllacus, fasciola - taenia, furia, myxine.

$\rightarrow$ extra animalia habitantia:

- poro laiterali nullo: gordius, hirudo.

- poro laterali pertusa: lumbricus, sipunculus, planaria.

B. Mollusca: sect.1.2.3. 4 .

sect. 5, corpore pedato: aphirodita, amphitrite, spio, nereis, nais.

C. Testacea

- uniralria: paiella, dentalina, sexpula, teredo, sabelia.

\$. 101.

Nun war das Sohema und der Platz, welchen the Tiumer in der Therrihe einnehmen, festgesezt, und num bestrebten sich auch die Naturfors.lier auf diesem gebahnten Wege weiter fortzischeom. Torzinglich aber war es Mlibler, welc!on nubl inmeiche Experimente an Noiden, die Aulm fandan fer Gelehrten crregic. Reammix 
and Trembley nämich hatien schon den Versuch genach, wie sich die zerschnitenen Stïclie dieser Thiere zu rolliommenen Wümern îrer Ât ausbihten; Roesel beschieb selbst einen, sich in zwei Mndivinen anforsenden Vimm, ohne es sich geo rade entïiren zu liëmen, Minllor machte endlich diescs Gencimnis durch die Reobachnung orfenbui, dafs das Schwanzende einer cinzigen Naide, atrei his vier Ansitze ron Jumgen enlielte, ja dafs atuh diese Eprossen, walhend sie sich noch nicht von dem müticrlichen Stamme losgetrennt hatten, ein glciches wiederhohiten, und so eine einzige Naiden-Muticr nit rielen Tüchtern, und diese selbst wieder mit andern, aber immer wieder am Aftergolenlie schwanger gingen a). Zu gleicher Zeit gab or in der nänlichen Schrift sehr genane Charaliteristien mad Abildungen ron den Gat tungen ,nuis, nercis, aphrodile, amphitrite", nuchte sich hitumf an eine Cmarleitung der ganzen Limeischen hilase "vermes:", die er in infusoria, himinthicu, testacea abtheilte ${ }^{b}$ ), und fuhre cndich den nümlichen Plan noch weiter in acm Prodromo zun dänischen Zoolegie, worin er

\&) Otlo Frienr. Müller. Naturgeschirhte einiger Wurmarten des süfsen und salzigen Wassers. Kopenh. Ite Ausg. 1771 2 te Ausg. 1800. 4.

3) .. RTiller. Terminm terrestrium et fluviatilium histow ria. Harmiae et Lipsiae $\mathbf{3 7 7 3}$. 
sich dem Linnéischen System näher anschlofs, und späterhin seine Zoologia danica gleichsam nur zerstrente Abbildungen lieferte, folgender Gestalt aus $\left.{ }^{a}\right)$ :

Vermes.

1. Infusoria:?

2. Iielminthica: - mutica: gordius, ascaris, echinorhynchus, hirudo, taenia.

- setosa: lumbricus, nereis, amphitrite, nais, aphrodite.

5. Mollusca: planaria, fasciola, holothurio, clio, limax, medusa e.c.

4. Testacea.

5. Cellulana.

Noch getrener dem Linnéisclen Systeme als Müller, blieb Bränich, welcheı/sich anf dicsent Gebiethe blos dadurch untcrechicd, dals er statt zollusca den Aisdruck "fimbriata" gobrancl. te $\left.{ }^{b}\right)$. - Scopoli wich in seiner linicitums zur Naturgeschichie ron den Schwedischen S;stema thier blos in den Benennungen ab: die Lnfusorien liklen die crste Zunft, die Mollustien und Zooplyten sind unter der gremcinschaflichen Auf.

a) Otto Miuller. Prodromus Znologiae Danicse, Ilavnino $177^{6} .8$.

-.. Zoologia Danica vol. 2.

b) Irünich. Zoolugiat furdanerata. Hafu, et Lins, 17772, \$. 
shnit "helninthicu" als die zweite antgestellt, and nach cier Hutbedeckung also abgetheilt:

\section{Helminthica:}

3. corticata: tulu!dria, pennatula, spongia, gorgonice e. c.

2. nuta:

- brachiata: medusa, sepia, tethys, aplysict, clio, lernea.

- cirrhata: apherodite, actinia, holothuria, myxine, terebella, lumbricus, nereis, haeruca.

- mutila: taenia, ascaris, gordius, hirudo, fasciola, globaria, ascidia, siphenculus.

- tentaculata: iloris, limax.

Beinahe olne alle Veründerung, folglen abs Bhunenbach, Leslic, Bulsch und Lrxieben in den ersten Ausgaben ilues Mandbuches, den Aatursysteme Limés nach, und erweiterten nur in der Folge dic Anzahl der Gallungen z. B. der lingeweiderwirmer durch die cincs Göze und Bloch, besonders machte sich anch um leztere Thierarlen Baisch, abroh seme Abhandlungr wiber den Bandwurn und Leslie in jener rom Drehen der Sclaafe und dem Blasenbandwum in Cehirne derselben, um die Geschichte des polycephalus s. echinoco

Von jezt an wurde der Blick von den Viinmern im Allgencinen, auf die in den Eingewcides 
der Thiere geliehrt. Pallas hatte sich schon lange ror den Schniften eincs Müler, Scopoli, u. s.w. dic Eingeweidewürmer zum Gegensiande ciner Abhandlung, bei seiner Beförderung zur Dohtorswürde genommen, und so gleichsam das Studium lieron angereget. Olne gerade auf die systema. tische Anordnung dieser Thicre zugedenken, verfertigte er vielmehr zum Nutzen dor Armeiwissenschaft aus allen Schriftsiollern gleichsara cin Verzcichnifs der Thiere and ihre: Organe, in welchen bis jezi verschicdene Arten von Eingnwciùe. würmern angetroffen warden, führte die Gründr der Hypothesen über inren Ursprung, im Innerna der Thicre, oner ron Aussen an, ohne jedoch sich für cine ron Beiden ausschlicfsend zu enhlürep? und hantelte hicr nebst den bchamnten Gatungera Linnés (furia, gorcilits, ascaris, lumbricus, fasciola, icenia) auch eine nene , hatucte" ab "?. Num wurde sogar die Frage, ob dcr Suame zir. diesen Thicren angeboren sey, oder ron Aussen in die Eingeweicic lomme, ron der liöniglichen Societit z.11 Iinpenhargen zum Gegenstanie einer Preisfrage erhoben, und Göze und Dloch, welche beide ihren Ursprung ron Aussen anf das Krifftigste widerlegten, trugen nicht sowohl diesen Preis,

a) Pallas. Dissertatio merlica inanguralis de infestis viventibris intra viventia, pro grudu doctoratus. Lusdun. Batavor. 1760.4 . 
als anch jenen un die Geschichte der Eingeweide. whrmer überhaupt duron. Halte Limédie hetes rogensten Arten unter wenige Gaitungen gezwmgen, so wurden sie von Göze, welcher nich blos durch die Uebersetzun der Schrift Listers ïher Spimen, durch seine eurepüsche Fama, un die granc Nuturgcschichte sich Verdienste sammelte, sontern ich auch die Lingeweidewüner gleichsam $2 u$ semer ausschlichenden Beschäftignigg mache, min so medr ron cinander getrennt, mit Angibe der ansezedichesten, äuscren Reschaffenleten ihres fionpers gesondert, und dic Alich nach ilrer Gestalt wnd ihren Molnsitzon in ver. schiedenen Thieren und Organen benemnt - cin Unternehnen, wodurh Güze's Nüngeschiche

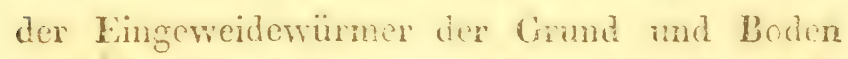

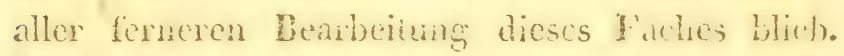

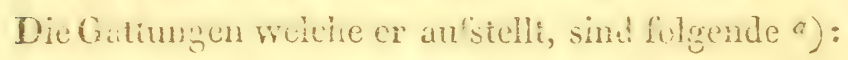

\section{Gattung 1. Rundwurm (ascaris)}

- Riese (gigas) in Plerden, Menschen, Schweinen, Kälbern, Seehunden und Nieren.

- Nittelrundw. (teres) in Sängthieren und Vögeln.

- Madenw. (ascaris minutior.) der Nadelw. (acus) in Hechten, Bar-

4) I. A. E. Goeze. Versuch einer Naturgeschichte der Lin-

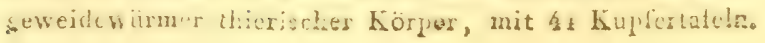
Blankenb. 1\%82, 4. 
schen, unter der Kchlhaut der Mandelkrahe.

- der Pfriemenschwanz (vermicularis) in Kindern, Fröschen n. $s$. W.

- der Fadenw. (filiformis) in Vögeln, Fischen und Fröschen.

- der Haarrundw. (criniformis) in den Lingeweiden eines Dachses.

- das Rundwürmchen (minutissima) in Erdregenwurm.

2. Ir a a rlopf (trichocephalus) in Menschen, Pferden, Mäusen, wilden Schweinen, Scheltopusit.

3. Zwirnw. (gordius) in Silsghieren, Vögeln, Fischen, Insekten.

4. Ii ppenw. (cucullanus) in Sängthieren, $F$ ischen.

5. Pallis adenw. (sirongylus) im Magen eines Pferdes.

6. Bastardiratzer (pseudoechinorhynchus s. haeruca).

7. Tratzer (echinorhynchus) in Simghieren, Wögeln, Iischen, Früschen.

3. Plattw. (p) Tanariu) in Säushlhicren, Vögeln, Fischen, Fröschen.

9. Bindw. (fasciola) in harpfen, Maulwurf, Taucherenten, Fi-chen. 
10. Bandw. (taenia visceralis): hy= datigena orbicularis, intestinulis (cucurbitina) in Säugthicren, Vögeln, Fischen, Amphibien.

11. Infusorisches Chaos in Schlcime des Mastdarmes, bei Früschen, WVasscr - und Landkröten.

Zwar waren durch soiche Bcarbeitung die Gattengen so zimulich in ihrer eigenen Charaticristik berr:undet, und ihre Geschichte selbst nit ciner Menge neuer berichert; allein beinalie verlor sich der Llick in lieser Masse, bis endlich, Bloch, dessen Abhandlung mit dem ersten Preise ron der Gesellschaft zu liopenhagen gehrönt wurde, anch diesem Uebel dadurch abhalf, dafs er fafst die nïmlichen Gattungen und Arten unicr folgende allgemeine Gesichtspunhte brachte ${ }^{a}$ ):

Vermes intestinales

1. Lati: ligula (pissium, avium). fasciola, taenia, (- inarmala: lanceolata, lineata, villosa, laevis, cucumerina, 7ata. e. c. - armata: tricuspidala, cana, cucurbitina e. $c$.

2, rotundi: vesicularis, echinorhynchus, ascaris, intestinalis, trichuris, gordius, cariophyllus, cucullanus, chaos intestinalis.

a) Marc. Elieser Bloch. Ahhandlung von der Lizeugung de: Eingeweidewürmer, eine Preisschrift. Berl. 178a. 4. 
Noch bedurfte es aber noch immer der nähe. ren Prifung, dor sich remohrenden Gattungen und Arten. Dieses hatte sich Frindr. Müller schon in scinen frïheren Schriften angelegen seyn lassen, or hatte schoa auf dem Gebiethe der Eingewcidewürmer die Gatmingen cucullamis, strongylus, den ihm von Zöga zugeschiliten echinorhynchus uuter dem Namen ,Hratzer" zu aller. erst aufgestellt, den scolex zuerst in Secfischen entdelit, don Irrthum Linne's und Schärer's, als wäre fasciola hepatica und planaria cines, und als hitime or von Aussen in die Eingeweide; durch ihre Trenmung in die zwei Gattmgen ,fasciola hepatica, und planaria" gehoben; und nun cntwarf cr, um die bisher geschehenen Fntdechungrn recht genau zu prïen, ein Verzcichnifs allex Eingereidewürmer, and der Thiere selbst, worin sie sich rorfunden a). Das nämliche Restreben änsserle auch Scluranl, doch hielt er sich in Allgemeinen so viel müglicls an MḦller, dessen Prodrome zur dänischen $z$ toologie gemäfs or die Linnéische hilasse der Wiirmer in sechs Ordnungen "infusoria, hohninthiea, iniestina, mollusca, testacen, ceilutana" abilicilte, und sich mit der" Auliablung der Gatlumgen olne fernere Unterab-

s) Otto Fricds. Miiller. Verzeichnifs der bisher entiekten Eingewcidewïmer, und der Thiere, in wolchen nie feitizden werden. Naturforscher 22tes St. S. 33. 
theilungen boniegte: zu den Helminthen - Gen meinwirner ron ihm genannt - rechnet er die Gultungen gordius, Tumóricus, nais, 7irudo, planaria, zu den Eingeweidewürmern, die filaria, Tigulu, trichocphalus, coryphy-7linus, ascaris, cucullanus, strongy \% scolex, festucaria, fasciola, cchinorhynchus, hydatis, tacnia, alcria; Schrank war der erete, welcher die Sangwiumer einer näheren Berüksichtigung würdigte, dic fasciol. Mäller. s. pranaria Gocze in die drei Gattmongen, festucaria, fasciola, alaria ariliefsic, auch machte cr sich sowuhl durch scin Verzeichnils der lingeweidewürmer, worin er 157 Arten und selbst manche neue beschrieb ${ }^{a}$ ), als anch durch scine fauna boica, worin or obige Orinungen durchfinte, und die Fiumer monstämbich charaliterisirio ${ }^{5}$ ), rum leztere verdient. Scin Schïler Frölich, folgro seinen Fufsstapfen in de! ferneren Untersuchung der Eingewidcwürmer und zwar nicht ohne Frofolg nach, indem cr nebst der Entdeckung odcr Bestätigung ron Aren anch einige z. B. planaria uncinulata (Braun) s, poZystoma (Zeder) unter dem Namen, ,linguutule" einige Strongylen, welche Gattung schon Mïllen

c) Schrank. Verneichnifs der Eingeweidewürmer. München 1788. 8.

ठ) - Fauna boica. 5ter u. lezter Bd. 2te Abthi. I ands= hut 1805.8. 
fongesezt latio, film aber mi Göz mbekann? war, unter dem Titel ,uncinuriu" zu Gattungen crhob c).

Was bisher Pallas, Lewenhock, Mïller, Abitganrd, Leslie, Batsch, Sciranl, Retzius, Trenter, Sulzer, Brera, Jördens u. s. w. in der Geschiche der Ningewridewürmer entwickeln halfen, Güze mad Blorls aber gleichsam in einer Schrift umfufsten, diefs haben Zeder und Rudnlphi der Vollendung entresengeführet. Zeder war der erste, welcher auf eine Umarbeitung der Naturgeschichte der Eingeweidewïmer ron Güze, und somit der Geschichte dieser Thicre üherhaupt dachle. $Z$ u diesem Zwerke lieferte er zuvorderst cinen Nachtrag zu jenem Werlie, brachte hicr die nothwoudigen Perichtignugen und Terbesscrungen be. sonders in der Charaliteristik an, hob die dort leise ongedeuteicn Punlite willikh zu allgemoinen Rubrilien heraus b), und legie sie nonerdings anch in seiner Alfeitung zur Naturgcschichte dieser Thiere also dar ${ }^{c}$ ):

7) Fröhlich. Naturforscher, 2ties St. S. 101. id. 25 St. S. 52 ,

3) Zeder. Erster Nachtrag zur Naturgesch. der Eingeweide.r würmer von Göze. Mit Zusätz. Anmerk. und 6 hinpferta? Leipz. 1800. 4.

c) Zejor. Arleitung anr Naturgeschichte der Eingeweirlewurmer, mit \& Kupfertaf, Bamb, 1803, 8. 


\section{$-65 \%-$}

Eingeweidew ürmer

1. Farn. Rundwïmer

- mit glcichem Uurchmesser (filario, tentaularia)

- mit nach vorne diunerem Durchmesser (cochlus. capsularia, capillaria, mastigodes)

- mit nach hinten fümnerem Durchmesser (cucullanus)

- mit nach vorne und hinten dimneren Durchmesser (strongylus, fusaria, ophiostoma?)

2. Hachenw. (echinorhynchus, hacrucu).

3. Sangur. (mono-amphi-di-poly-siuma)

4. Bandw.

- das Kopfend oline Saugmindungen (caryophylllaeus, ligula, scolex)

- des Koptend mit songundungen (rhytis, halysis,

5. Blasenw. (c)sticerus, polycephalus).

Noch molir trachete Puciolni dic Geschichte dieser There nach ihrer Litteratur, anach iner bis jezt beliannien Anatomic und Zoologie zu erscliöpfen. Seit seinem medizinischen Studium, hate or sich diesen $\mathbb{Z}$ weig der Naturgeschichte auserwählet, frühzeitig a) auf dic zweifelhaften Gathugen ,furia, myxine, haeruca" forner wic schon lange rorher Verner, auf die Unzwelimäsigheit des

a) Rukolphi. Observationes circa rermes intestinales, pars 1. 2. Gryphiae $172^{3}-9^{5}$. 
Prefschicbers, und der dadurch hewirlien Verunstaltung der Thiere und ihrer Theile, welelse vermittelst desselben die meisten Vorgünger als natïliche Beschaffenheit in die Beschreibungen aufnahmen, aufmerlisam gemacht, und alle beliannte Gailungen, nebst viclen neu errichicten $z$. B. ophiostoma, lyorhynchus, amphiostoma, tricuspidarit, echinococcus, und nebst vielen nenen Arten z. B. ron fesciola im VViedemamischen Archiv auseinandergesezt a). Jedoch hielt er sich an allernitilist an die Werlie Zeder's, nahn dessen System, blos mit der Umänderung in griechiscle Benemmur in scine Schrift nenerdings auf, bereicherie dasselbe mit ricken neuen Arten und Derichtiguncen und sonstigen Beobachtungen, nit den obign nenen Gattungen, zu denen jezt auch noch diese ,oxyuris, bothriocephalus, coenurus. ophiostnmu liamen, wiuhte zur allgemeinen $\mathrm{L}^{\top} \mathrm{e}$. bersehrift den nenen ritel "entozoa" wie diefs aus folgendem erhellet $b$ ):

Entozoa- brandias nervisque deslitula, corporis partibus internis difformibus -

a) Rudolphi. Archiv für Zoologie und Zootomie von Wiedemann, 2r Bd. 1s St. S, 1. 2 St. S, 1. Braunschw。 1801.

b) Rudolphi. Entozoorum so vermium intestinalium historia naturalis, vol. 1. eum tab. aene; 6. Amstelod. 2808.

- 2. pars 1. cum tab. 6. 180y.

- 2. 1810.8 . 
Ord.x. Nomatoidea (wnee, filtum; sodes, forma, s. vermes teretes) Gen. filaria, haemularia, trichoceplialus, oxyuris, cucullanus, ophiostoma, ascaris, strongylus, liorhynchus.

2. Acanthocephala (anavis, spina; кефеди caput. s. vermes uncinati).

Ger. echinorhynchus, tetrarhynchus.

b. Trematoda (rennua, forainen s. vermes : itclorii).

Gen. monostoma, amphistoma, distome, polystoma.

4. Cestoidea (nssos, cingulum. S. vernes taeniaeformes.

Gen. scolex, caryophyllacus, ligula, tricuspidaria, bothriocephalus, taenia.

5. Cystica (rusı, vesica. s. vermes vesiculosi).

Gen. cysticerus, coenurus, echinococcus.

Genera ad ordines enumeratos vix referenda: prionoderma, schisturus, diceras.

Sovicl auch durch die bisherigen Untersuchungen das Gebieth der Eingeweidewürmer an Trweiterung und Anordnung gewann, so liömmen wir uns doch noch immer nicht rühmen, den Ur- 
sprung, die Verwandschaft, die malünderliche Anzahl der Familien, Gattungen, Arten und ihre Aufcinanderfolge zu liemen; ja beinahe streitet man sich noch über die allgemeine Benenumg dieser Thiere, inden auch die neue, nïnlich ,entozoa" die Samenthicre und andere Infusorien im thierischen liorper nicht ausschlicfst. Hat Bloch thre Eintheilung blos ron ihrer Gestalt, so haben sie Zeder und Rudolnhi nebstdem auch von andesen äussercn und grellen Beschaffenlvciten des Körpers hergenommen. Jedoch alle haben, wie sie ebentalls nicht nach einem einzigen herschenden Gesichtopunte revfahmu haben, dieses ihr Gebuth auf lockeres um unbabaren Boden gebanst. Fen huntey dater, dafo die runden Wümer Blochs, bei seinen Nachfulgern in verschiedenen Ordmungen vertheilt sind, dafs selbst Zeder und Pudolphi, obgleich sie eine eigene Ordnmmg aus den Rnudwiumern machen, doch öfters anch in anderen Orónungen ron mehr oder weniger runden Individuen sprechen, nach eigener Anssage der Nellienwurm ron einigen rund, ron anderen flach geschen worden seyn soll, ja dals Güze die Blasenwärner zu den Tänien, Block aber diestiben zu den liundwürmern zidhlen lomuie. - So haben auch die Blasenwürmer, der sirongylus, eine Art von cucullanus, den fiopt oder die Lippen nit Hulichen besezt, und stehwa 
doch nicht in der Funilie der Hackenvümes "aconthoccphala". - So haben die Blaseriwüner mehrere Sängmündungen, welche Schelver fir Geschlechtsorgane, Sicinbuci für Respirationswerlizenge hält - ja Zeder macht sogar unter den Bandwümern aus dem Punzel - und aus dem hettenwum die Unterabthcilung, als jener, we'che Süngmündugen haben, und doch sint sie nicht

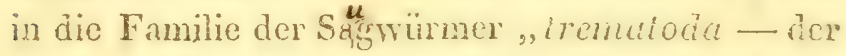
- viterus taeniaformis nicht in jene des Bandwurmer "cestoidea" eingereihet. -

Mias ron der bisherigen Anordnung der Einsmeiduminner zu halten sey, hat liudolpui früher schon mit den Worten a):

, dic erston 3 Familien Zeders sind natirlich, die anderen beiden, nïmlich die band- und Blasenwürmer aber keineswegs"“

nud newerdings wieder also angegeben ${ }^{b}$ ):

., Tisce antem, ordines naturals, genera oninio amplexos, nondum diuri, satis superque me probresse credo."

\section{ถ. 102.}

Scit Limé haben sich zwar die Zoologen, nieht sowohl mit den Wümern übchhaupt, als vielme!r

a) Wiedemann's str his für Zoologia unt Zootomie, ster Bd. 2 St. S. 45 .

b) Entozoa, vo:. 1. P. 201. 
ausschliefsend mit jenen der Eingeweide beschäftigt. Allein sie mufsten wegen der Linfachheit des Acufsem dieser Thicre, ihre Zullucht zur Untersuchung des Imern derselben nchmen, wad zux eigenen Verständignng die Struktur dieser mit. jenen, aussexhalb den Thieren lebenden, verglei.. clien. Auf solche Wreise ribkten denn Beide die äufseren und inneren Vurmes -- nach ilren zoologischen und anatomischen Reschaffenheites. zur niheren Erlicumifs heran. Redi, Vallisnieri Van-Plelsum, besonders aber Tyson ") lehrten mis nebst anderen benbachtungou, die getrennten Geschlechter und ihre Organe am lumbricus teres licnnen. - Willis macite auf die hermaphroditische Vereinigung der Lezteren im Erdwurme, auf die Anvesenheit von rothem Blute, auf das zumächst den Geschlechtstheilen, welche üusserlich durch cinen Viulst angedeutet sind, pulsirende Ilerz, auf das oberste Nervenganglion - von ihm Gehirn genannt - auf den fortlaufenden Nerrenstrang, filschlich unter dem Namen einer Arterie anfmerlisam, und erwähnte der Poren zu den beiden Sciten jedes Gliedes, als zur Respiration ge*

4) Edvard Tyson. The anatomy of a pygmy, compared with that of a monkey, an ape, and a man. To which is added the anatomy and description of a rattle-nake: also of the mu:k-ho:. With a discourse upon the jointed and roundworm. London 1751.4 . 
horig a). - Werner sezle die lingemeide mir die Geschlechtsorgane der MTämnchen und V(ib). chei an dem Zumbricus teres durch sehr gonatu A bildnngen ausser allen Zweifei und änsserte nclust mehrerei bemorliungen and Zorghliederungen vou verschiedenen Arien atch diese Vermulhung, dals der mittere, mit viclen Mebenzweigen verselene Fanal, welcher in tacnia zulgaris cinfach ist, in taenia solium aber mit cinem andern, in die seitenpapille jedes Gliedes nach Anssen sich öfimen.

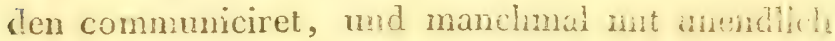
viclen Eiern angefullt isi, zur Geschlechishmlion, die vibrigen aus den vier, an fiople ausmündcuder

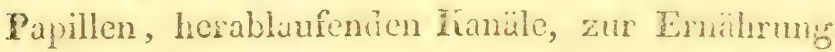
dienten ${ }^{\natural}$ ), eine Enriching, walche anch (jarlisle durch scine Untersuhmonen zu bestilligr

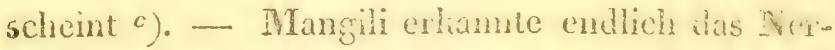
rensystem als solches in Mrdwume und in Bluiigel d). - Cuvier bestätligie mà delnote úise leztere Beobachtung selbsi auf Fereiden, Amplin-

a) Thoias Willis. De anima iruiorum pag. 13. - opara omnia studio Blasii edit. Amstelod. 1682. 'Tom. 2. 4.

b) Paul Christ. Frielr. Wernex. Permium intestinalium, praesertim taeniac lumanae brevis expositio c. Tab. VII. Lips. 1782. 8.

- coutinuata a Joan. Leon. Fischer 1736.

c) Carlisle. Transactions of the Linnean Society. rol. II.

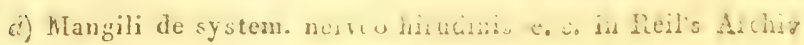
f. A. J'bysiol. 13,2. S. 219. 
nomen arenicola und gordits ans, wagte das Cinlulationssystem dieser Thiere näher zu crklären, und machte endlich, indem cr so die Verschiedenheit der Strulitur ron jener dor Zoophy. ten und Mollusken kannte, in seinem Fandbuche der Zoologie den liühnen Schrit, die Mollustien gleich nach den Fischen zu einer eigenen Kiass zu erheben, und hicrauf die Wiinther wegen ihror Aehnlichlicit mit Ranpen als Anlängsel ron Inselio ten also folgen zu lassen:

Livre $7^{t i e ̀ m e}$ des insectes et des vers.

A. Des vers pourzus d'ipines nu de soics pour s'aider dans leur mouvemens.

aphrodita, amplinome, amplitimite, serpula et penicillus, dentalium, nercis, nais, lunnbricus, furia.

B. Des vers depourvils d'ípines ot de soies:

hirudo, planaria, vermes intestinales ( fasciola (ligula, linguatula), taeiria (taenia, hydatis), ascaris (asc. lumbrical. trichocephal. echinorhynh. hacruc. strongyl. uncinar. proboscidea, cuciullan. scolex, caryophyll.), gordizs.

Lamarck wich in seinem Verlie ,systêne. des anim. sans verteb. "ron seinem Vorgüner $a b$, inden or die Wimmer ron den Inséten absonderte, diesen nacliscate, und in änssere welche aussch hall des therischen liöipens (cers externes) - nud is inuere - wolche nu inner- 
halb demseilben leben (vers internes) - unterschied.

Ilsm folgte in der Anzahl der Gattungen Bosk sach; jedoch begriff er dos Nämliche wie Linne wuter der Aufschrift "Wirmer", welche Klasse er jencr der Inscklen nachsezte, und auf dis IVlolo Jusken sogleich Lamarcks äussere VWürmer — ron ihm vers proprement dits - und dam die in. neren - von ihm vers inicstins genanut, abhandelie.

Unterdessen batte Curicr in seiner vergleichsu. den Anatomie dic imeren Bestandtheile dieser Thicre näher bekannt gemacht, er hatte gezeigt, dals jene Familie von Whinem, welche er wegexi inren violen Ringen vers aricules betiteite (Aphrouiten, Serpulen 3. s. w.) sich ror den Eixgeweidewumern anch Neriencyoiem und Brarchien auszeichnen, Branchion aber, so wie anck Tyachcen, an dem Bludigel und Lrdwurm nock unbehamnt sind - dafs erstere ror den lezteren das rëthliche Blut, und eine offenbare Circulation voreus haben, indem cine Hohlader, aus Zwiven lüngst der oberen und unteren Fläche des Darmhanals gebildet, das Blut den Branchien zufuhret, ron jeder Branchie aber cine limgenvene, welche z.12 einem Stanme vereinght, sich in eine, längl der oberen und unteren Wlache des Darnikanatc: Fon unten herauflaufende Arterie ergiefst, und bei 
Sher Eimmündung eine Art ron pulsirendem IFer. zen hervorbringt, wo im Gegentheile Nerven, Re. spirations - und Circulations - Orgune in Lingeweidewümern bis jezt noch nicht entdelit sind. Jedoch Cuvier liat demohngeachtet, troiz allen diesen Vorzügen, die artilulirten Wümer nicht von jenen der Eingeweile getrennt, sondern sie immer zusammen am Ende der Insekten, und nur einmal in seinen Vorlesungen über vergleichende Anatomie, bei Gelegenheit, wo er von Circulation and Respiration spricht, gleich nach den Krustacéen in Erwähnung gebracht ${ }^{a}$ ).

Dümeril benuzte in seiner analytischen Zoolo gie dicse Beobachtungen Curier's, und sezte Lamarcli's Gattungen der Eingeweidewïner als eine blofse Familie an die Spitze der Zoophyten, die artilulirten Würner aber unter dem Namen "vers" und zwar in der Abtheilung mit offenbas ren Branchien (branchidèles: nereis, aphrodite e. c.) und olme solche (endubranches: nuis, Zumbric. thulassema, gordius, hirudo, phunaria) als eigene Lilasse zwischen den Insekten und Zoos phyten.

Lanarck, nach dessen Forlesungen sich Tasrcille im tableutux methodig. d'hist. nut. in dicsem Abschnite schon vorher gerichlet hato, durch

a) Voy. les leçons d'anatomie comparés. 


\section{$-644-$}

alle diese Deobachtungen aufgefoderit, wagre ondich den kïhnen Schritt, Crrvier's articulirte Vürmer unter dem Nianon samiélides" und unfov der Abtheilung Dümeril's snlbst for den finatacen und gloich nach den Mallusten als cine

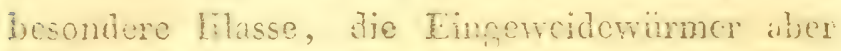

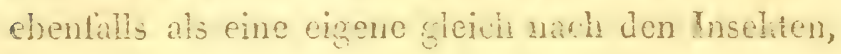
wie folgt, aufzustellen:

Class. PIT. Annelides

- gymnobranches: spirort. serpul. - sabellaria, amphitrite, terebella. - nereis, aphrodite, amphinome, arenicula.

- cryptobranches: thalassem. lumbric. nais, furia (?) - clavale. lernea, hirudo, planaria.

Elasss. VIII. Fers

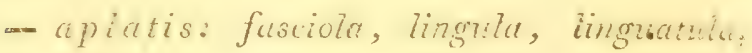
taenia.

-vésiculeux: hydat. bicorn.

- cylinariquess chimorhynch. tentaculur. caryophyzl. maselt. strongyl. cucullan. frichur. fissul. ascaris, crino, proboscid. Jiluria, gordius.

$$
\text { S. 10.s. }
$$

Alerdings hat die Gesclichte dex Wümer, besonders in unseren Zeiten, Wurch cinen Göze, Müller, Zeder, Pudolphi und Lamarck ausseror * dentich an Lrweiterung und Erlänterung gevonnen. Auch die innere Struktur aieser Thiere 
mus nicht roilig unbetiannt: So wissen wir durch Willis, dafs an dem Wulste des Regenwurms, wolcher, zwei Zolle vom liopfe enternt, sich nach Aussen erhebt, mehrere Eier - und auch mehrere Gaamenblïschen nach Aussen sich öfnen, und sirh daher immer zwci solche hermaphroditische Geschöpfe bei der Bogattung um dicsen Viulsi herumwinden - durch die Zcrgliedcrung eines Tyson und Werner ist es nun ausgemacht, dafs hei den mümlichen Lumbrikalwïmem die Geschlechtstheile einfach seyen, und durch den Anis nath Aussen müuden, bei den Vibehen aber zwei, längst den beiden Sciten des Darmlianals sich vielfach hinafwindende Trompeten zu rinem cinzigon hanale sich rereingen, welcher einigo Zoile rom lopfo cufont, seinen Ansgang nuch Anssen nimmt - durch Verner mid Carlilsen almden wir die Eiersiöclie im Bandwurne, wie iiberhaunt dic Trunung der Geschlechter in den Aslianden, ilse bermaphroditische Vercinigung aber in den Banlwümern - durch Mangili lien. nen wir dis Nervensystern im Blutigel und ini frowume - durch Cuxicr ist das NerrenBranchien - und Circulationsystem in den Annelidon nadugcwicseí - die Scrpulen, Dentalion, Tordullen und Naiden endich, sollen Hermaphoditen segn, die Aplroditen, Amphinomien und Anphinitcn aber die Geschlecher getremt ha. 
ben. - Jedoch, wie viele dieser Behauplungen fo. dern erst noch fernere Bestättigung, und wic räthselhaft und dunkel ist noch $\mathbf{z}$. B. das Reich de! Eingeweidewürmer von der Fanilie ascaris an, bis zu ligula, in welcher lezteren man bisher wew der äussere noch innere Organe, ja selbst nicht einmal eine Mundöftnung wahrgenommen hat! Kein Wunder daher, dafs Zeder und Sorg den Eingeweidewürmern, weil man weder 'Trachen noch Branchien und lezterer durch Experimente cine haum merhliche Verminderung des Sancr* stoffgases wahrgenommen hat, die Respiralion ab. Iäugnen, Rudolphi aber den Experimenten SpalIanzani's zufolge, welche cine Aufsaugung des Saucrstoffgases, selbst noch nach dem Tode der Thiere und sclist auch an den blofsen Schaa. len der Schneclien darthun, eben diese auch hier statt der eigenilichen Respiration annimmt: dafs fudolphi den Kingeweidewürmern das Nerrensystem, wofuir VVerner und andere fülschlich einen länglichen Muskclstreifen hiclten, abspricht, und das sensibic Princip als mit jedem förpertheile verschmolzen angiebt, dafs er endlich, um das Entstehen dieser Thiere, welche in den mangänglichsten Organen z. B. im Gehime, in der Leber $u_{0}$ so wo, nach Drendcl und Selle selbst im ahortus, nach Hartmann in cinem noch in Thaysacke gelegenem Lamme, nach Göze, Yeder wil 


\section{$-647-$}

Bimenbach in noch süugenden Thieren, glcichs wic anch die Fimen nicist an wilden sondern blos zahmen Schweinnn vorkommen, zu erliluren, sich zu der sogenannten generatio dequivoca s. spontanea belicnmet a). Noch haben wir bis jezt sichts al, Bruchstüclic ron Beobachtungen ïlor dicse Lilasse, und noch lässt sich nach allem diesen also nicht entscheiden, ob man mit latuarck die Anneliden und Intestinalwürmer als zwei gesonderte hlassen aufsiellon, und jene wogen An wesenheit ron Branchien und wegen der Circulation eines röhlichten Saftes vor den Inseliten, unủ zwar uach den Niollishen setzen - ocer beide ds cine lilasse, wie es Curier thut, und wegenz shrer Aehulichlicit mit Raupen als Anhang zu don Inschten betrachten - ouler mit Dumeril dis An neliden als cigeno filasso zwischen Iratiten und Zoophyen, die Eingeweidewürmer aber áls cine blofse Famile dic Zoophyten abhandeh far mit Linné und Rosc den Inseliten, selbst den Rang vor den Mollushen cinxüumen, und nit den lezteren die so verwanden Anneliden, die Eingeweidewürmer u. S. w. zu einer einzigen Flusse rercinigen durfe. So lange wir nock iber dic Gegenwart oder Abwescuheit einer Circulation bei Inscliten in Ungewifoheit sind, so lange wir die Deobachtumgen nber Nerrensystem, über Respira-

a) Rudolphi Entozoa. T, I. p. $237-243.20$ D. 403. 
tion, Cirlulation, über die Verdanungs - und $\mathbf{G e}$ schlechtswerkzenge von Anneliden, und so weit noch elwas hieron an den Eingeweidewürmern vorfindlich ist, in Fupfern nicht vor uns haben, - und vergleichen liönnen, so lange werden wir über die Stelle diescr Thicre im übrigen Thierreiche, über die Abtheilung und Rangordnung ihrer Gattungen und selbst auch über die Bildung mancher nener Arten in Widerspruche und $Z_{w}$ eifel verbleiben, um so mehr, da vielleicht sehr viele ron dieser sehr frühzeitigen animalischen Schöpfung ausgestorbcn, und theils wegen Mangel fester Theile gar lieine Abdrücle, ausser einigen im Mergelschiefer z. B. bei Eichstädt rorfindlichen, und auf Erdwürmor oder Areniliolen hindentenden zurïkgelassen habon, theils wegen dem Mangel an Nacliforchnngen bisher urs unbeliannt sind.

\section{ACHTES CAPITEL.}

Zoophyten-Zoophytologie

$$
\text { 5. } 104 .
$$

Seninale eben so wenig als über TVürmer, läfst sich Aristoteles ïber Zoophyten aus. $\mathbb{Z}$ war bedient or sich nirgends, wo or von den darunter begrifenen Thieren spricht, dieser Benernumg, or behamptet aber dnch, dals glew hwie der hörper, anch die Seelo des Merischen mit denen der ührigen Thiore eiae Vergloichung und selbst eine Ab- 


\section{$-649$}

sinflung znlasse, ja dafs es Thiere gobe, welche alimäiligg den Uohergang zu Pflanzen machen, and durch ih Angewachsenseyn und durch den Miangel eines Zeichen von Tmpfindung sowohl fiir Thicre als für Pflanzen gehalten wcrden können c). Freilich gicht er wicht an, welche von den ihm behannten Geschüpfen hieher gehören, ja er scheint sogar aich mehrere der Testacéen dalin zu rechnen, und begnüget sich überhaupt nur anzumerken, dals

- einige cinen fleischarigen Körper haben, wie z. B. die Tethys und Actinien (ra ти́-

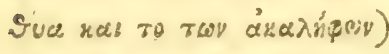

- die Schwämme aber (omoryos) ganz den Pflanzen gleichen.

a) Arist. hist. anim. L. 8, C, I.

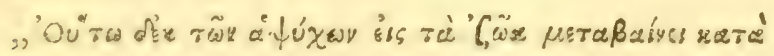

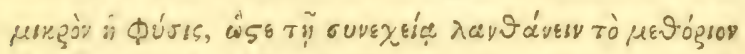

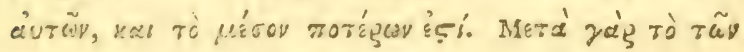

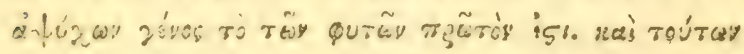

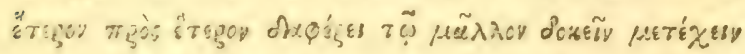

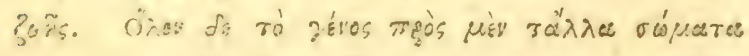

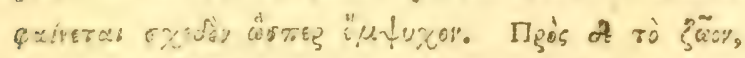

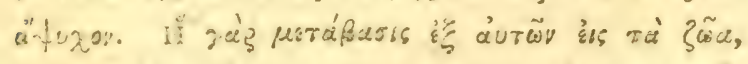

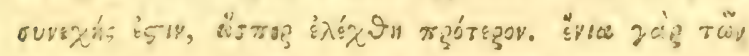

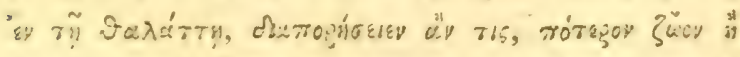

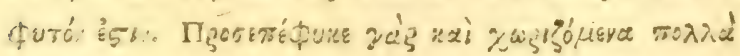

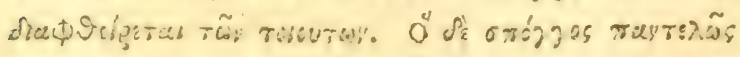

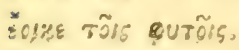




\section{$-650$}

Onne nun gerade ans diesen Thicren cine oigene Thlasse zu bilden, handelt er von ihnen verschiedentich bei Testacén ofler an Tnde der Insel:tea. So zählt or die Polypen, wommter cr auch den Natulus and mehrere sepienatige Thice, yäinlich mit hurzen lö̈per und langon Amen rechnet, bei den Nollusken anf, und theilt sic in

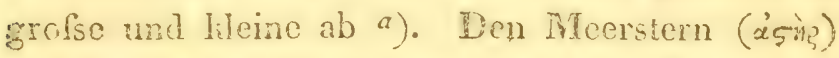
and dic Seciggel (éxint) sczt er zu don Testacien, andzwar sagt er von dom ersteren aus, dafs rermöge seiner warmen Tratur jede Dente soglcich vite ryliocht erscheine, dals or fü sich selber entsioke, ma chenfalls sich schon den Planzen nähere $b^{b}$; an den lezteren unterscheilet er viele Arten, fuhrt die cigenen Famen derselben - cta-

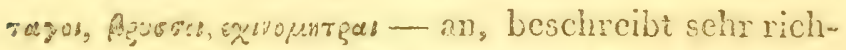
tim dic beweglichen Siacheln ihres hörpers sowohl als jestefun Zahne am ivanỏe, ferner die Windungen des Damlianales, und endich die 5 Lierrïule, welche um den Anus herumliegen, zin allen Jahreszeiten, besonders aber am Vollmonde und im Winter mit Eiern angefilli sind, und auch nur in dieser zur angenehmen Speise dienen c). Eben so answhils spricht er über Achtinion und Schwimme, unr thut er dieses bald bei Gelegenheit der Testacéen, bald an Lide der Insoliten;

a) Aristot. histor animal. L. 4. c. I.

b) ejusd, I. 5. c, 15. c) ejusd, L. 4. c. 5. c, 12. 


\section{$-65 x-$}

Fon den ersteren zählt er zwei Arten auf, nümlich solche, welche an Fulsen - gleichsam als den Stellveriretlem ron Schaalen - sitzen, me sich beinahe gar nicht ron der Stelle bewegen, und ancere, wolcho auf der flachen Fbene des Bodens, auf den Sande oder zwischen Stcimn sich antileben, und Nachts auf Frals ansegenen; beide Arten sollen vermittelst ihrer feinen Empine dung die herannahende Beute z. B. Trebse, Fische, Testacéen, Meerigel u. s. w. schon ron der Ferne wahrnehmen, keine Excremente, gerade wis auch dic Pflanzen ron sich geben, und nur im Vinter, wegen ihres festeren Fleisches, als Speise genossen werden a); ron den Schwimmen fihrt er an, dafs sie sich nach der Bchanpting Einger bcim Abreissen zusammenziehen, und daher cutwe. der eigene Empfindung haben, was man unicr den 4 bis 5 Arten - allgemein von den lungenuri-

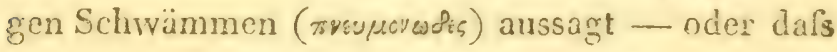
sie anderen Thicren zur Wohmmg dienen; auch führt or dic Vermuthung an, da!s die Löcher auf der Obcrfläche und die Thenäle im Innern der so porösen Schwämme zu nichts als zur Aufsangung der Nahrung für das ganze Individum bestinnt sind ${ }^{b}$ ); zu denjenigen Whicren endlich, wolche

\footnotetext{
a) Aristot. histor. animal, L. 1. c. 1. - L. 4. c. 6. $-I_{\Delta}, 5$, c. $16 .-$ L. 8, c. 2.

b) ejusd. L. 5, c, 16, - L, 3. c. 2. - 2., 8, c. 1.
} 
nerh Allon don Planzen elcichen, sich aber duw die cirene, freic Dewegrung von denselben auszeichnen, rechnet cr scwoll in seinem vierten Duche "de paribues animulium" als auch in seine: Thicrgeschichte, eine MIenge von IrIeeresproducten, welche ron sonderbarer Gestalt z. $\mathrm{r}$. mümlichen Geschlechtstheilen Zhnlich (holothuria?) sint, und welche alle bis jozt licine bestimute Namen tragen ${ }^{a}$ ).

Hot Aristotoles sich in finsicht des Platzes dicser Thiere in der Thierreihe nicht bestimmt orlibet, so thnt dieses Plinius. Er zählt die Actinien, fulwämme, Mecrsterno und Seeigel gerade 2.12 inter den Aquatilien, und zwar die Seeigel bei den Trebsen in dem neunten Buche sciner Natugecchichte auf, merlit an, dafs die Actinien (urticac) mả Mecrsterne (stellae marin.) mit ihren Magensafte beinate alles verbrennen, dals die Seeigel bei cinem heramahenden Stume sich nit Snude anfïlen, und dafs Aclinien und Schwämme ein Mittelding zwischen Planze und Thicr sind, aber Empfindung haben: ,equiden et his inesse sensuin arbitror, giuae neque aninalium, ireque

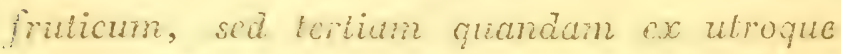
naturam habent: urticis dico et spongies" b).
a) Aristot. histor anima!. L.1. c. 7. - L. 1. c. 1,
b) Plin. oper. Bipont. Tom, 2, p. 172 . 


\section{§. 105.}

Diese Armuth ron Feminif auf diesem feo Bethe, wie anch das Ansehen les Pliniug, diese Liné. Whiere zu den Aquatilien zn rechnen, dunere noch lange Zeit fort. Tidor ron Serilla erwilnet in dem Ruche übor Ltymologie und zwar in dem. sechsten Taritel . Gi piscibas" nach den Fischen, Conchylien und hebsen, auch des ,echinus, stunga, penisilli"; Albrins Nagnus thut das Gleiche bei den blutlosen Thieren ron den $A$ sterien; Wotton stellt endich, wie in der Thiorge. schichte überhaupt, so besonders hierin, das alte Ansehen des Aristoteles her, und ist der ersic, weicher aus den, zwischen Thicren und Planzen schwankenden Gescliöpfen des Aristoteles und Plizuius eine ueue flasse mit der glcichfolls neuen Deberschritt "Zuophyta" errichter, und hicrunter, da er die sogenannten Polypen bei den Moilustien, bie Seeigel bei den cinschaaligen Testaceen anf zihlet, die tethijs, holohturia, pumo marizus, stella marin. urtica, spongia begreift.

Ven num an wurde diese neze hlasse ron allen zoologischen Schriftellern in ihre Terke afgenommen, aber mit den heterogensten Thio. ren angefillt. Belon becchredibl in seinem TVerhe Ziber Aquatilien die Polypen und Uilicen bei des Neichthieren, die Seeigel und Sesstenc bu den Testacéen, endilich tethys, polliceps, hotoinurit, 
spongite, crica marina (aphrodius?), Genitale nuthum, lepus matinzis (aplysia?), pulmo marinus (nedusa?), Tumbricus marin, remo"at, hippocanpus bei den Zoophyien; Rondclet folgt cbenfulls seinen Forginger nach, jedoch mit dew Enterschiedc, dafs cr schon anfüngt, eigene Benennumgen für Alten ron joder Galtung einzufiliren, dafs er die Erticen ais frei sich bewegende finculusce), wid an Fidsen licbende (actiniae) bei den Weichhieren - die Senige! (cchinus und spuitacres) bei den limstacéen, und endlich alles Teinige nebst eingon neuen Gatungen und einer Menge nener Arten wher der Aufschrift , de insectis ef zoophylis" also obhandelt: ,scolopendra matina, vermes marini ir. iubulis, penicilJus (tcrebclla?) Rirucio marin. Thippocampus, siella marina (laevis, arborescens (caput medusar) reticulaza, echinata (ophiurus), sol), hoTithutia, icthys (salpa?), mentula marina, reva Tiarina, cucumeris, pulmo marin., pennes marina, eschara, spongiae.

An Rondelet's Besclureibungen dieser Thiere, weine alle nach der Natur gemacht sind, hielten sirh seine Nachfolger, und unter diesen zu allermächst Gessucr. Jedoch unterschied Gieser die Insekten von den Zoophyten, theilte sie nach dem sülsen oder salzig'n Wasser, wie schon oben an cincm anderen Orte crinnert purde, ab, und 
Eähio penichlus, dentalium, echini, stellae marinue, holothuria, tcthys, putno marin., puGendun marin. zu don Testacéen, die hippocampus, eruca mutrin. Rirudo marin, scolopendra marin., tubuli marini, lambricus mapin. zis den Meerinschten (irsecta marina), die eschara, ruva matina, fenna matina zu den Meerzoophyten (zooplyyta marina), in einer späieren Luscabe ron 1604 crschicnen in Gegentheite alle diese Thiere in alphabetischer Ordnung unter den Aquatilicn überhanpt als delphinus, echinus eschara, holothuria, spondylus, spongiae e.c. , wobei er zugleich ron der gorgonia verrucosa ammerlite, dafs in ihren Poren ein vielfüsiges Thierchen (vemiculus multipes) wohne.

$\mathbb{Z}$ war hatie man bis jezt selir viele rou den Zoophyten bei den Thicren aufgezählt, aber noch immer geechah dieses wegen der alton Soge über

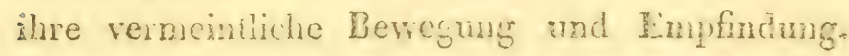
Timperait ist min der crste, velches jenes Terab. ren durch nene Deobuchtungen in der Natur xechifutigt. Freilich hat anch er in seiner Natux. geschichte, in welcher er als einen blofsen An* hans zu den Elementen, Nineralien und Iflanzer einige ihn neu scheinende Thiere und selbst rm-. stereinander vermischit z. L. scineus, comilh.. echini, rete merin. Torica menina (hohthurit)

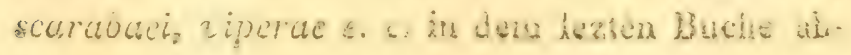


handelt, folgerde Z̈oophyten gicich meh ảen Wi: meralien unter den Planzen mit der Aufschrift

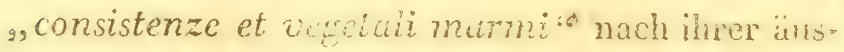
serea und inneren 'Texim roriteflich beschrieben: coralli, millepora, retepora, tibularit, jungi, spongiae, akyonimm, fuci nuarini e.c, masci c. c. Allein op morhi ron den Milleporen, leteporen und Matisepron an, dafs die Porch derselben mit ciner schlcimartigen That anggefullt sind, ja er stellet sogar die cntscheicende Bchaupting auf:

"la tubrilaria ¿ sumplice conceitacolo di concreazioni animali" a).

Vie Wolton, Belon, Rondelet und Gessner, behiolt auch Aldrovend wind nach inm Jonston dis Ordnungen der Theichihere, Krustacéen, Testam céen und Zoophyten bei. Zuvar hat er mit Wotton alle diese von dor Iilasse der Inschten geschie. den, aber noch immer haben beide bei thrn zu viele Gemeinschaft miteinander: die stella marinia, nereis, serpula stehen unter den fulslosen In. sekten, die Seeigel bei den Testacéen, die urticaes holoihuriac, tethrs, mentula marina, et epipetrum, uva marina, penna marina, fungrtó

a) p. 717. Dellhistoria saturate di Ferrante Imperato nepolitano Libri XXVIII, neila quale ordinamente si tratta deils diversa condition di miniere e puetre con alcune historie hi: piante ed animali sintiora non fata in luce. Niapol. MIDIC. 4. 


\section{$-657-$}

sharinus, manus marina (alcyon cxos?) unter den Zoophyten.

Jezl wurde das Siudinim dieser Klasse rege, and selbst das Streben und der setreit der Neio nungeì allgemein, um diese zwcifelhaften und auch nach dem äusseren Baue schon so sonderbaren Thiere näher zu erforschen. Hoodwerd hielt div eigentlictien Zoophyten für stcinartige Concretionen; Guisony, Arzt in Arignon, rerglich sie in einem Briefe an Paracelsus mit dem metallischen Silberbaum der Diana; Cäsalpin, Bauhin, Bonone, Ray, Tournefort, Geoffroy, More son stimmten der Meinung des Ovidius, Plinius, Solinus, Dioscorides bei, welche diese Produkte für Pflanzen des Meeres annałmen; nun rühte man immer melır dem Geheimnisse nüher: Marsigly beobachtete im Jahre 1726 in Marscille alcyon. palmet., isis coral., antipath., entảeste in ihren Poren Förper, welche sich bein Herausneh. men der ganzen Staude zusammenziehen, und era klärte diese Körperchen, oder vielmehr höpfchen, für achtblättrice Blumen (brieve ristrette del saga gio fisico intorno alla storia del mare. Venet. 4. Bald hierauf machten Geoffroy, Lemery und MTar* sigly selbst durch Experimente die Erfahrung, dafs diese Mecresprodukte grölstentheils amoniakali. sche Bestandtheile wie die Thiere hätten. Abes endlich wurde das Rüthsel gelörset, und die bishe. 


\section{$-658$}

rige lcise Andeutung gerechtfertiget: Peyssonet, Arzt in Marseille, und späterhin liöniglicher Leibarzt in Quadeloupe, machte in Jahre 1727 an Madreporen, Milleporen und ähnlichen Substanzen die Entrlechung, dafs jene Blumen des Marsigly wahre Thiere und zwar von ihm ,orties corallines" genannt, wären. 'Zwar blicb man, leider auch jezt noch für die Behauptung des Marsigly eingenommen, so zwar, dals Peyssonel's Entdecliung und Anzeige daron bei der Pariser Alademie gar nicht gehört wurde, und selbst ficaumür den Namen des Autors verschwieg, wo er die Abhandlung desselben in seinem Werke über Inseliten (Tom. VT. praefat. p. 74) einrükte. Allein Tremblcy, cntdekte in J. 1739 im süfsen VVasser Thierchen - von Reaumür Polypen, ron Linné Hydra benamit, - beobachtete an diesen, wie späterhin Miiller an Najaden, dafs sie sich, nach welcher Pichtung immer zerschnitlen, reproduciren, und durch sprossende Nebenzwcige fortpflanzen; auch benerhte er an der tubularia gelatinosa im süfsen Wasser aus der Röhre gleich. sam eine Thierplanze herauswachsen ${ }^{a}$ ); jezt beslïtligten auch Jussieu und Gucttard ${ }^{b}$ ) im J.

ai) Trembley. Mémoires pour servir à l'histoire d'un geme do polypes d'oau douce à Leide. 1744. 4.

b) Lernhard de Jussiev. Examen de quelques productiones marines, qui ont été mises au nonbre des plantes et qui 


\section{$-659-$}

371. auf einer Reise ans Mecr, jener an die Kü. sten der Normandie, dieser an dic von Poiton, zur Verwunderung der Welt die Entdechung Peyssonel's, und nun waren Reaumür, Limé und die meisten Naturforscher ron dieser Wahrheit überzeugt: Löfling fand sogleich dasselbe an der sertularia und eschara, und zeigte es der Schwedischen naturforschenden Gesellschaft an, Donaii ${ }^{a}$ ) ging in sciner Beobachtung sogar soweit, dafs, da er Eier an Forallen walmnahm, er dicse Thiere als Baumeister, ihre Fortpflunzung aber mittelst Eier angab, und seiner Idee über die, einem Netze ähnliche Verwandschaft der Dinge gemäfs, von den Pflanzen zu den Zoophyten als Thierpflanzen aufzusteigen trachtete. Ellis von einem teutschen Gelehrten Namens Büttner aufgefodert, und von ihm mit seinem Rathe unterstïzt, sezte es endlich durch vielfiltige Beobachtung ausser Zweifel, dafs die Sertularien, Alcyonien, Cellularien, Escharen zu den Thieren gehörten, dâfs die Lithophyten, Keratophyten und auch Schwämme nicht wohl aus dem Thierreiche ausgeschlossen werden dürften; Ellis beseitigte ${ }^{b}$ ) die Linwürfe eines Ba.

sont l'ouvrage d'une sorte d'inscetes de mer. mémoir. do l'Academ. 1742. p. 20\%.

a) Donati. Della storia naturale marina dell' adriatico, 17-50, 4.

ש) Ellis. philosoph. transactions for the yeaz $27,5,-$ p. 258. $\rightarrow$ p. $280 \rightarrow 287$. 
ster a), Hill, Targioni, welche ảiese Geschöpfe nicht für Thiere, sondern für Pflanzen, oder doch mur von fremdartigen Insekten eben so, wie cine Conchylie ron dem Bernhardkrebse bewolnt, annahmen, und fixirte zum ersten Male, ohne jedoch ausser der Reobachtung, der, aus dem nach Donati vermeintlichen Uterus, zur Seite jedes Po. lypen herausgetretienen Eier, oder der Lmwandlungen der Polypen ron Forallen in Conchylienthiere $^{b}$ ) etwas über ihre Fertpflanzung zu cnto scheiden, die Gattungen derselben durch gründli che Charaktere in 10 Kapiteln folgender Massen: corallines vesiculated, tubular, celliferous, articulated, keratophyta (Gorgonion) eschara, en glish corals, sponges, alcyonium, tubular corals".

Nach solchen Vorarbeiten waren dicse Thicre doch soweit geliannt, um sie in cine Tlasse zusam. menzufassen und dieser ihren Platz im übrigen Thierreiche anzuweisen. Dieses that nun Linne.

a) Baster. Opuscula subsecutiva, observationes miscellaneas de animalculis et plantis quibusdam marinis contincntia. T. 2. Harlem 1759 . 4.

b) p. 54. "These polypes turning into testaceous Bodies, opened a new Srene of wonder to me" - Ellis. An essay towards a natural history of the corallines. London 1755. 4. Uebersetzung ins. Teutsche von Krünitz.

... ej. natural history etc. - systematically arranged by D. Solander. London 2786.' 4 . 


\section{$-661$}

Doch war anch er den nämlichen Verwandlungen und Zweifeln in Hinsicht ihrer thierischen Natur and dann ilurer Gattungen unterworfen. In der allerersten Ausgabe seines Natursystemes 1755 theilte er die hlasse der Würmer in reptilia, testacea, und zoophyta (tethys (tethys, holothuria, penna marina), echinus, asterias, medusa (ur. tica marina, vermiformis, crinita, astrophyta), sepia, microcosmus) ab, und liel's spongia, isis, iubipora, cellepora, millepora, madrepora, retepora, corallium, acetabulum, eschara unter dem Namen "Lithophyta" als Fryptoganen an Ende der Pflanzen folgen; anch noch in den Aus. gaben rom Jahre 1740 blieb er dieser Abtheilung und Anordnung getreu, nur mit dem Unterscliede. dafs er die Zoophyta als die zweite Ordnung ror den Testacéen, den echinus und microcosmus aber ans End der Schaulthiere verpflanzte. - Mit der Ausgabe 1748 unternahm er ebenfalls, nachdem Iúsien die Entdecking Peyssouel's bestätligt Latte, den Schritt, die Lithophyta - unter die 4 Gattungen tubipora, madrepera, millepora sertuluriu gebracht - ron dem Pfanzenreiche in das Thicreich und zwar als die vierte Ordnung. der Würmer zu verselzen, wobei auch der Sceigel von den Testacéen zu den Zoophyten zurülliehrte. Von num an wich er in den folgenden Ausgaben ron der vorher festgesezten Anzahl und 
Aufeinanderfolge der Ordnungen ausser der ab. wechselnden Versetzung der Seeigel von Zoophyten und Testacéen bis zur zchnten nicht mehr ab, wel he wie in allem, auch in dieser hlasse seine lezte Verwandlung bezeichnete. Hier behiclt er die vorigen Ordnungen hei, gebrauchte stitt der Benennung , zoophyta" jene "mollusca", zer-

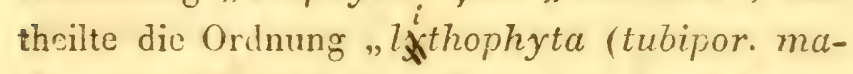
drepor. millepor)" in noch eine zweite, und zwar die lezte des Thierreichs, unter der Ueberschrift , zoophyta (- fixata: isis, gorgonia, alcyon. tubular. eschara, corallina, sertularia, vorticella-locomotiva: hydra, pennatula, taenia, volvox)“ auf; in der zwölften Ausgabe rermehrte er diese lezte Ordnung noch mit den Gattungen furia und chaos; in der dreizehnten ging endlich Gmelin soweit, dafs er, nachdem die Welt der Infusorien von Miiller aufgethan war, die Gattung , chaos" in jene ron Müller aufölste, und zwar unter dem Namen "Infusoria" als die füfte und lezte Orduming der Würmer und so das Linnéische System dieser Klasse also verändert auf stellte :

Vermes.

1. Intestina.

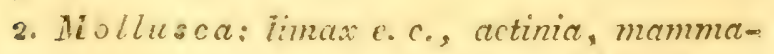
rice, pedicellaria, holothuria, phliysophora, niedusa, lucernaria, asterias, echinus. 


\section{$-663$}

5. Testacer.

4. Zoophyta (animalia composita, vegetaiv:lium more efflorescentia).

a) stirpe calcarea Lithopyta:

tubipora, madrepora, millepora, cellepora, isis.

b) stirpe molliori:

antipathes, gorgonia, alcyonium, spongia, flustra, tubularia, corallina, sertularia, pennatula, hydra.

5. Infusoria (animalia minima simpliciora)

- organis externis instructa: brachionus, vorticella etc.

- organis externis nullis: - complanata, gonium, colpoda, paramecium, cyclidium.

- teretia: bursaria, vibrio, bacillaria etc.

\section{106.}

Haben die Polypen des süfsen Wassers an Trembley, die Lythophyten an Ellis ihre Mono. graphen, die Würmer überhaupt an Linné ihren Systematiker gefunden, so werden jezt selbst einzelne Gattungen und Familien näher untersucht und gekannt. Link hatte schon lange rorher die ihm beliannten Meersterne abbilden lassen, ihr Aeusseres beschrichen, und die Gattungen nach der Zahl der Strahlen benannt a). Baher, Rösel

a) Joann. Henric. Link de stellis marinis lifer singularis. Lipsiac I753. Fol. 


\section{$-664-$}

und Schäffer *) bestättigen jeat die Reobachtum gen des Trembley an don Polypen des süfsen Wassers, Bohadsch lief rt vortrefliche Abbildungen und Bschreibungen zum Theile auch der inneren Organe von aplysia depilans, tethys fimbriaia, holothuria tremule, sipunculus, assidia, pematula phosphorea unter den Benen. nungen ternea, fmbria, hydra, syrinx, urtica, peirnab ${ }^{b}$. Diccuemare nuaclut die Beobachtung an Altinien, dafs sie ahgeschnitene Theile gea schwind reproduciren, die Veründerungen des Wetters anzeigen, lebendige Junge aus dem Munde von sich geben, und auch durch eigene Spaltung sich furtprlanzen sollen ${ }^{c}$ ). Klein entwirft cine vortreffiche Monographic ron eeigeln, welche er, wie schon ror ihm Morton und Wood. ward, nach dem Verhältnisse der Lage des Muma des zum Anus abtheilct, nobst meisiribaten $\mathbf{A b}$. bildungen boschreibt, und anch narh ilırem Innea ren, nämlich mit 5 Ovarien unả einem sich liüm. menden Nahrungshanale, in einer Zeichnung liengen lernt à). Baster von Ellis, über die thierische

a) Schäffer. Die Armpolypen im süfsen Wasser um Regensu burg. Regensb. 1754. 4.

3) Bohadsct. De quibusdam animalibus marinis. Dresdze 1761.4.

e) Dicquemare

d) Klein vaturalis dispositio echinodermatum, Lips. 2778. 4 . 


\section{5}

Natur der Lithophyten belehrt, Ledermiiller und Slaber tragen durch ihre Abhandlungen über verschiedene Gegenstände zur Vervolliommnung dieser Klasse bei ${ }^{a}$ ). Nun trat der teutsche Zoolog Pallas auf, und nahm sich ron der Limnéischen Klasse der Würmer blos die Zoophyten zur Bear. bcitung vor; hier trennte er die Brachionen von den Mydren, die Antipathen von den Gorgonien, die Cellularien von den Sertularien, erhob jedes von diesen in den Rang einer Gattung, versezte viele Arten, welche bisher fälschlich be Fschara, Millepora eder Madrepara gestandén hatten, zu ihrer gehörigen Gattung, stellte die Corallinen als noch zweifelhaft, unter die Thiere, und beschrieb, in a dem er genauer als bisher die Charaktere der Gata tungen und $\Lambda$ rten fixirte, die Zoophyten unter des Anzahl von 15 Gattungen, welche er nach ihrer natïrlichen Verwandschaft also aufeinander folgen liefs $b$ ):

a) Ledermüller. Microscopische Gemüth - und Augenergötzung. 176r. 4 .

- Slabber. Naturkundige Verlustigingen, behelzende min croscopise Waarneemingen. Haarlem 1778. 4.

3) Pellas. Elenchus zoophytorum. Hagae $\mathbf{1 7 6 5 .}$

- Lyst der Plant-Dieren beschreeven door den Heer Pallaa met Anmerkingen door Boddacrt. Utracht 3768. 8.

- Thierpflanzen übersezt und mit Anmerḱ, von Wilkens, s.ach dessen Tode hcrausgeg, vou W, Herbst, Nürab. 3787.4 . 


\section{$-666-$}

Zoophyta:

Gen. Mydra, eschara, cellularia, tubularia, brachionus, sertularia, gorgonia, antipathes, isis, millepora, madrepora, tubipora, alcyonium, perinatula, spongia.

Genera ambigua: taenia, volvox, corallina.

Endlich ward durch cin so fleifsiges, miliroscopisches Nachforschen auf zoologischem Gebiethe, eine ganz neuc Welt ron Thieren entdekt. Löwenhöck fand im frischen, männlichen Saanen der verschichenston Thiere hleine, kaum sichtbare thierische Geschöpfe, er untersuchte jezt faulende oder in Gährung begriffene Flüssigheiten, und sieh, da waren solche mit mikroscopischen Thieren angefullt ${ }^{\alpha}$ ), unter welchen die so bcrüchtigte vorticella rotatoria nach dem Vertrolinen des Wassers sterben, und bei Wiederbenässung selbst nach einigen Jahren wiederaufleben sollte. Fraum war diese Entdecliung von ncuen Thieren gemacht, so waren schon die Naturforscher aus alIen Nationen, und unter andern Vallisnieri, Bono, Ledermüller, Baker, Büffon, Needham, Spallanzani, Wrisberg u. s. w. mit Beobachten und Experimentiren über selbe beschäftiget, und nun entstanden die verschiedensten Meinungen über ihre Thierheit: Die Franzosen glaubten hierin ihre Atomen gefunden zu haben; Büffon, welchem

a) Leuwenhueck. Arcana naturae. - Batav, 1695. 4。 


\section{- $667-$}

Needham und Guettard beistimmten, hielt sie weder für Thiere, noch, weil sie aus sich selbst ihre Bewegung hervorbrächten, für Pflanzen, sonderı. unter dem Namen "molleculae organicae" für ein Mittelding und cinen Uebergang ron beiden, Lamarck neuerdings für die Quelle aller Wesen, Hill war der erste, welcher einige daron dem Thierreiche einverieibte ${ }^{a}$ ). Allein Spalanzani, Wrisberg und Müller, sezten die Animaliciat dieser Geschöpfe ausser allem Zweifel, ja Mlüler war es, welcher die Thierchen, so sich jedoch nur bcim Zutritte der Luft in Aufgüfsen ron verschiedenen Materien aus dem Pfanzen - und Thierreiche und bein:he in allen Flüssigkeiten, dic öligten und weingeistigen ausgenonmen, selbst sogar nachdem sie gesotten haben, meistens ebenfalls als verschicden rorfinden, Müller war es, welcher sie unter Arten und Gattungen brachte, und ihnen bestimmte Benennungen ertheilte. Hatten Needham und Wrisberg die gencratio aequivoca zu vertheidigen gesucht, und selbst schon beobachtet, dafs die Infusorien zuerst in Gestalt ron Bläschen (vesiculae globulares) erschienen, ehe sie irgend cine Bewegung äusserten, hatte Spalanzani ihre Fortpflaizung mehr durch eigene Spaltung ihres Körpers wahrgenommen, aber auch zugleich dic

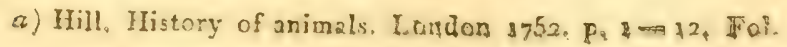




\section{$-668$}

Erzengung mittelst der, in der hiezu erforderlichen Luft enthaltenen Infusorieneier zu vertheidigen geschienen, so hat Miiller alle diese Meinungen rereint, und durch seine Beobachtungen in der Natur begrïndet: er hat bemerlit, dafs man in dem so durchsichtigen Förper von Bullarien, Intestinen- und auch Infusorien-Eier unterschcide, dafs einige dersclben sich durch Eier, lebendige Junge, Gemmen, besonders durch Spaltung (partitio spontanea) fortptlanzen, die Paramäcien sich der Länģe nach, von vornen nach hinten und umgehchri, dis Cycliden blos von hinten nach vornen, die Mona* den nach der Qneere, die Trichoden und Keronen nach den beiden Richtungen sich spalten, die Vorticellen theils durch Gemmen, Eier, lebendige Junge, theils durch horizontale oder perpendilu. läre Spaliung sich vervielfaltigen; er hat beohachtet, dafs die Infusorien in eine scharfe Flüssiglieit z. B. in Urin gebracht, unter Lrämpfen sterben, dafs aber die Behauptung vom Wiederaufleben der Bullarien, nachdem sie vertroknet sind, und wieder benäfst werden, nach seinen, des Spalanzani und des Wrisberg Experimenten, ungegründet sey, dals verschicdene Gattungen in besonderen Aufgüssen z. B. bullularia immer in jenen von den Meerlinsen, vorzukommen lieben, und dafs endJich bei allen Infusorien sich zuerst eine Schleimhaut und in dieser Ampullen, und leztere hierauf 


\section{$-669-$}

sich zu heweglichen Infusorien umbilden a), Durch diese Menge von Beobachtungen, und der dadurch entdeliten Arten und Gattungen, fand sich Müller bewogen, diese Thiere als eine eigene Ordnung in der Linnéischen hlasse der Würmer unter dem Titel „Infusoria“ aufzustellen, was er schon in seinem Prodrome zur dänischen Zoos logie, hicrauf in seinem Werle über Erd- und Flufswürmer that, und endlich in seiner lezteren。 erst nach seinem Tode herausgekommenen Schrift ${ }^{b}$ ) in einer Anzahl von 146 Arten weitlïufig ausfiihrte. Obgleich aber Müller vorzüglich durch Bearbeitung dieser Ordnung von Thieren sein lilassisches Verdienst in der Zoologie begründet hat, so rernachliässigte er doch auch die übrigen Zoophyten nicht, wie ans der Aufzählung dieser im Prodrome der dänischen Zoologie, aus den Abbildungen in der zoologia danica, und aus folgendem Schema der Infusorien im obigen Werke also zu ersehen ist:

Vermes.
1) Infusoria.

a) praefatio p. 23. "vidi vesiculas globulares seu punctula minima, vidi unum post alterum et quaedam simul a pellicula secedere, tremere et molilia fieri, motumque sensiun adeo augere, ut brevi in varias directiones discurrerent". Animalcula infusoria Othonis Fabricii. Havniae 1786.

8) Otho Müller. Animalcula infusoria Aluviatilia et narina, Opus posthumum, Harniac 1786. 
a) Organis externis nullis

- crassiuscula: monas, proteus, volvox, enchelis, vibrio.

- membranacea: cyclidium, paramaecium, kolpoda, gonium, bursaria.

b) Organis externis.

- muda: cercaria, trichoda, kerona, himantopus, leucophra, vorticella.

- testa tecta: brachionus.

2) Helminthica.

5) Mollusca: mammaria, ascidia, Fiyctra, actinia, sepia, pedicellaria, holothuria, medusa, asterias, beroe, Iucernaria.

4) Testacea: echinus, spatagus, buccinum e. c.

5) Cellulana

- calcarea: corallina, isis, tubipor, cellepora, madrepor. millepor.

- subcornea: fistularia, tubularia, sertularia, gorgonia.

- fungosa: pemnatula, alcyonizun, spongia, clavaria.

Den Fufsstapfen cines Linné in dem Systeme riberhaupt, denen eines Pallas in den Lithophyten, eines Müller in den Infusorien, folgten auch Brünich, Scopoli, Blumenbach, Leske, Batsch und Erxleben nach. Brünich blieb unter allen dem Linnéischen Systeme am getreuesten, nur dafs cr sich statt der Benennung "mollusca und testacer"s jener "fimbriata" bediente, und jene als Linter- 


\section{- $671-$}

abtheilungen gebrauchte (Vermes: intestina, fimbriata (nuda, testacea), lithophyta, ceratophyta gorgon. tubul. e.c. hydra, taenia, volvox, furia). - Scopoli rerband die Zosphyten, Mollusken und Intestinen in eine Zunft, unter der Benennung "Helminthica“ zusammen, und wies dieser ilren Platz zwischen jencr der Testaccéen und dann der Infusorien unter folgender Vertheilung an:

Trib. 1. Testacea.

2. Helminthica.

a) nuda:

- tentaculata: limax, doris.

-mutila: sipunculus, ascidia; hirudo, ascaris, taenia, fasciola e. c.

- cirrhata: nereis, lumbricus, terebella, holothuria, actinia, aphrodita.

- brachiat a: lernea, clio, aplysia, tethys, sepia, medusa.

b) corticata: asterias, echinus, madrepora, millepora, gorgonia, alcyonium, spongia, flustra, sertularia, pennatula, tubularia, brachionus, vorticella.

5. Infusoria.

Wenigere Veränderungen an Linné erlaubte sich Blumenbach, welcher in allen Ausgaben seines Handbuches die Ordnungen der Intestinen, Tholluslien und Testacéen unveründert beibehielt, 
und nur fir dic Secigel und Seesterne tie nene Ordnung - anfangs cartilaginea jezt aber crustacer son ilim genanit - schuf, und ron jener der Tonphlyten noch eine andere ,corallia“ absonderte:

Vermes.

1. intestina. 2. mollusca. 5. testacecis 4. crustarea: ectihus, asterias, encrinus. 5. corallia: tabipor. madrep. millep. cellep. isis, gorgonia alcyon, spongin, flustra, tubutar. seriular. ceilularia.

5. zoophyta: penatula, hydra, brachionits, vitrio, thatia, volvox, chaos (aquatile, infusorium, spermaticum).

Keiner lifste aber die einzige Linneische Klasse der TVurmer in eine so ansserordentliche Anzall! ron Ordnungen, mit glcich unbedeutenden Bencnnungen, als Eatsch in seincm Handbuche der Nas turgeschichte auf; er unterschied nämilich: Einge= weidewürmer - Borstenwürmer (nais, iumbricus, aphrodite) - Eicrinäger (sepiae, clio) Schneckien (limax, upplysia, fasciola, doris e. c.) - Muscheln (testacea) - Straufsköpfe (teredo, serpula, balanus, holothuria) - Varzenwïr. mer (echinus, aster.) - Zweigwürmer (ophiur. pennatula) - Biumenthiere (hydra, tubular. sertular. eschara, coral. e.c.) Somenthicre (voro ticella, brachionus, trichoda) - Infusionsthiere. 


\section{$-673$}

5. 107 .

So sehr auch die Klasse der Zoophyten durch die Bcarbeitung cines Illis, Pailas, Miiller, durch die nach der Natur gemachten Abbildungen and Beschreibungen eines Seba, Petiver, Brown, Fors kaol, Pennant, eines Barbüt ${ }^{a}$ ), Esper ${ }^{b}$ ) und besonders eines Sclander, welcher aus den hinterla: senen Papieren des Ellis gleichsam eimen zweiten Band zu der ersten Schrift desseiben herausgab, an Bercicherung gewonnen hat, so herrschte dock bis jezt die grölsio Unwissenheit in der inneren Strulitur dieser Thiere, und eben so auch die gröste Verwirrung in der Anordnung derselben, so, dafs Intestinen, Molluslien, Testacéen und In. fusorion bei jedem Schrifteller ihre eigene Versetzung erlitten, und das Heterogenste öfters in eine und die nümliche Ordnung z. S. Medusen, Scpion, Schnecken, Sceigcl, Achinien geworfen wurde. Zwar hälle man die hier und da zerstrenten Beobachlunges, welche ïber die Lebensart, dic änsserc und auch innere Strulitur dieser Thicre Anfschinls galsen, zucammenlesen und rexgleichorn kömen, um nux so die gröbsten Fehler in Bildung

a) Jasnes Barbut, The genera vermium, pars i.

- orders of the intestina et mollusca. Lond. 1;83. 4.

- pars 2da. testacea.

b) Eugen. Joh. Christ. Fiper. Die Pftensent spe in il!nnin. Ablild; neust Beschreib. 1r, 2r 'Ih. Nürnb. 1791-94. 4. 
Fon Oxumugen, Gattungen und ihror A $A$ einanderfolge zu vermeiden; allein man remachlafsigte dieses, und erst jezt ist unter den Naturforschem der Trieb rege, eine physiologische lienntnifs ron diesen sonderbaren Geschöpfen zu erhatten. Hat diesen Trieb Swammerdam besonders für Inseliten und Schnecken, so haben iln Tronbley für die Polypen, Donati, Ellis, für Zoophyten, Mïller für Infusorien rege gemacht, ja Cauolini geht neuerdings durch seine Beobachtungen an Gorgonien, Comallen, Mladreporen und Nilleporen sogar so weit, dafs er die Fermuthung ron Donaii und Ellis für gewifs bestätliget:

„scoprit sagt er a) uno sacchelo di uova, che per zina di quelle rime fralle basi de' tentacoli delel polipo, dal suo canale (butero) usciva"

and duls er wic schon ehmals Aristoteles die Strulitur dex Schwämme (j̄. 104), so den ganzen Körper cines Lithophyten als einen einzigen Polypen, ron dem die sogenannten Köpfchen und Blï• then fon Marsiglius, oder die jezt sogenamicn gelatinüsen Polypen nur einzelne MTndöfnumgen (bocche) zur Aufnahme der Nahrung sind, also zu erklären waget:

"quei polipi, che sorgono dalla gorgonia, non sono animali da loro, sono organi, che appar-

a) Filippo Cavolini. Minmoric per servire alla storia de, pose lipi marini. Napoli 2785. 40 pag. 20. tob. I. fig. 50 
tengono ad un animale maggiore, come tulto: che è quello, che albiam cituminato gorgonica a)。

Vor all $n$ aber ist es Cuvier, welcher die Vollfrommonheit des Innern so wie des Aeussern zu berilisichtigen, und dadurch der bisherigen Verwirrung zu steuern sucht. Blumenbach trachtete schon vorher diescr Unordnung durch einzelne Verbesserungen abzuhelfen, und erhobz.B. in dicser Absicht äie Seestente und Meerigel, welche immor ron einer Sblleilung in ảe andere bei den Schriftstellon wandern mufsten, zu eincr eigenen Ordnung; Roques von Miamont hatte die nämliche Absicht in Hinsicht der Lithophyten, ron de。 nen er cinige Linnéische Arten z. B. astroites, fongiporcs, méandrifes in Gatumgen verwandelte. and sie übcrhaupt nach den Grade der Hänte in melir weiche (corantines, escares, éponges, alcyons, herctophytes), mehr harte (ais) wa endlich in steinharte (coraux, madrépor. astroites, tuoip. méandrit. fongip. e. co) ablheilte ${ }^{b}$ ); Noch mehr als seine Vorgänger bemîhte sich Bruguiere, die Linnéische Klasse der Wümer zn verbessern: cr nahm die nene Ordnung Rlumenbachs nit Ausa schinfs des Encriniten, unter deu Namen ,échino-

a) it. ... p. 13 .

b) Roğues de PTaumont. Trímoire uñ les polypiess de zoer, \& zalle $178 \div 8$ 
derfies" terner die neue Ordnung "Infusoria"s eines. Müller, einige neue Gatiungen des Lezteren z. B. veroe, pedicellaria, eben so bei Zoophytera jene seuen ,méandrites, botryile" an, erlaubte sich die Anfeinanderfolge dor bisherigen Ordnungen in diese ,vers: irfusoires, intestins, mollus ques, échinodermes, lesiucies, zoophyles" umzuändern, las aus allen Schriftstellern alle mögliche Arten zu jeder Gattung, neist den selir ge* nauen Abbiliungen und Beschreibungen znsammen, und wurde eben hieduch, wie in den Tes. taceen, so auch in den ubrigen Ordnugen diesre Kilasse das Nuster, nach welchem die Franzosen ihre wcitere Verbesserungen anbrachten ${ }^{a}$ ). Allcia eben diese Verbesserumgen gingen zu allererst ron Cuvier aus, welcher sowohl durch die Erichtung newer Lilassen, Crdmungen und Gattungen, als auch duch die Einfihhung ciner Rangordnung die Linuéische Kilasse ,vermes“ ganz umgestaltete. Zuvorderst zersplillerte er jene einzige hlasse in viele, sezte dic Schnechen als eine cigene vor die der Insckien, rerband nit den Insckten die sogenamnten ausseren wal inneren Viümer, und stelite die vibrigen linochenlosen Thicre unter dern Titel „zoophytes" als die lezte hilasse auf. Aucln

a) Bruguidre. Encyclopédie méthodique -

- Tableau encyclopedique et méthodique Hist. nat. des Vers 1ygu: - 
hier befolgte er die Thangordnung nach dem Grade der Vollkommenheit der lörperlichen Bildung: Bumenbach's und Drugnier's Echinodermen machen, weil man an den Asterien und Seeigeln noch Eingeweicie, Orarien und Teitakeln, bei lezteren auch den Rund rom Anus gesondert beobachtete, die crsic Orhnng aus, welcher auch aus glcichem Grunce die Holothurie von inm bcigesel. let ist - die Medusen, Actinien, Bolypen und In. fusoricn, welche roch nicht angewachsen sind, soniern sich frei herumbewegen, und ron denen Linige, die Mcdusen ansgenommen, etwas dom Nahrungshanale ähnliches haben, sich durch Eier, lebendige Junge oder Spaltung fortpflanzen sollen, wnd daher auf licine Weise sich, wic es nach Linné geschah, mit den Mollusken rereinigen lasson, billen die zweite unter dem Titel „Veichthiere (mons) - dic übrigen Zooplyten, über deren Ban bisher gar nichts entschieden war, und zwar die Tubularien, Serularien i. S. w. die 3ritte - die Lischaren (cellular. flustra, corallin.) die vicrte - die ibrigen endlich unter der Beusmumgr ,Kerathophytu und Lithophyta" die Weiden lezien Ordnungen. G!cichwie Guvier neue Abtheilungen, und eine neue Aufeinanderfolge derselben cinfiihrte, chen so fand er sich genölliget, viele Arten zu Gattungen zu crheben (zo «n... the, corin, cristatella, floscularia, verefillum, 


\section{$-678-$}

umbelluta e.c.), oder die nencr eines MTilier und Bruguiere aufzunehmen, wie dieses aus den Schema in seinen Elementen der Naturgeschichte or. hellet:

\section{Zoophytes.}

1) Erhinodermes: holobhuria, asicrias, echimus.

2) Mous: medusa, beroe, aciinia, socintize, hydra (i, dra, bosryiles, corina, cristatdia) sortirella, infusoria rotifer, brachionus, tricharerques, capcoric, baccularia, voivox, monas).

3) Zoophytes proprement dits: flosctularia, iulublaria, capsularia, seriularia.

4) Eschares; callivilur. flustr, corallin.

5. Kciralophytes: antipath. gorgon corch lium, $i$ is, pennatula, veretillun, umbeliula.

6) Lithoplytes: madrep. fongites, msecindrit. astroit. porites, millevora.

7) Alcyon. Spongia.

Lan:arch blieb dom Gange Curier's getren, vereinigle uber die Echinodernen und Vieichtinere unter dem Namen "radiaires" zu einer eigenen Klasse, gab den übrigen Thieren als der eilícn und lezlen rlasse, die Aulschrift "polypes", und ertob noch viel mehrere Arten $2 u$ Gattungen als sein Vorgänger, welche Verändermgen er zuersż in seinem Systeme der wirbellosen Thiere, nud neuerdings mit noch gröfserer Bereicherung an 


\section{$-679-$}

Gattungen, in dem Werlie, ,philosophie znologin que" also darstellte:

XI. Class. ou 7rieme Degré d'organisa. tion (Fidiaires: point de mocile longiludinale nouguse, point de vaisseaux pour la circulation, quelques organes particuliers et interieur's (soit des tubes ou a'es pores aspirant l'eau, soit des espéces àoviares) all= tresque ceux de la digesition)

a) échinodermes (pean opaque, crustacée ou corjace, munie de lubercules rétractiles, ou dépines articulées sur des tubercules, et percée de trous por séries)

- les fistulides (corps allongé, le peau irritable et mobite; un (anus): sipsinculus, holothuria.

- Zes échiniales la pear non irritable; ni moüile; un anus.): echinus, nucleolites, galerites, aranchices, spritangus, cassidulus, clypeaster. .

- les sicllerides (ia pear non irricible, mais mobile; point d'anus): asterias, ophiura.

b) molasses (coms gélatincux, peau mobile, tran parente, dépourvue dépines articulées; foint d'anus)

medusc, rhizostoma, equorea, bcros, pyrosoma, porpita, velella, phlysalis, p.ij'ssophora, lucernaria, siephanomia. 
XII. Class ou biems àegré d'Organisa. tion (les Polypes et les Infu. soires-point de nerfs, ni de moelle longitudinale noueuse, point de vaisseaux pour la circulation, point dorganes restiratoires, aucun cutre organe intericur éc spécial. pas même pour la àgestion).

a) Polypes:

- nus: actinia, zoanthes, pedicellaria, corina, hydra.

- flottans: umbellularia, encrinus, pono natula, veretilla, funiculin.

- polypes à polypier (ils ont des tentacules en rayons autour de la bouche, es sunt fixes dans wn polypiei, qui ne flolle poiniv)

- polypier tout â fait pier$r \in u x$ et sans encroutement: virgularia, dactylopora, cyclolites, fungia, turbinolia, caryophyllia, madrepor, astrea, maeandr. pavonia, agaricia, millepor. retepor. eschara, ocellaria, alveolites, orbulites, siderolites, ovulites, lunulites, tubipor.

- polypier ayant un axe en partie ou tout à fait pierreux, et recouvert d'un encroutement corticiforme: corallium, isis,

- polypier ayantun axe corné, recouvert d'un encroûtement: 
gorgonia, antipathes, alcyon, spongia - corallina, acetahulum.

- polypier membraneux ou corné, sans écorce distincte: botrylus, cellepor. flustra, cellaria, seitularia, tubularia, plumatella, cristatella.

- polypes rotiféres (ils ont a la bou-che des organes ciliés et rotatoires): vorticella, brachionus, urceolaria.

b) Infusoires:

- qui ont des parties saillantes comme des poils, des espéces de cornes ou une queue: trichodes, trichoceque, cercaria.

- qui sont dépourvus d'appendices extérieurs: kolpodu, bursaria - vibrion, proteus, volvox, monas.

An dieses System der Zoophyten, wie es in dem Werle "systême des animaux sans vertébres" aufgestelit ist, hielt sich ebenfulls Bose in der Detervillischen Ausgabe Buffon's, jedoch mit der Einschränkung, dufs er mit Linné dic Insekten ror den Würnern und diese unter der alten $A u f$ schrift ,vers" in testacées, mollusques, vers profrement dits (vers extiricurs), intestins, échisoclermes, radiaires (holothuria, sipunculus, medus. beroe e.c.), polypes (nus, corraligines, rotifires, arnorphes) abtheilte, sonst aber beinahe alle Gattumen Lamarcli's wiederhohlte. - Ganz 
getren der Schrift Lamarcli's blicb Latreille in der Bearbeimng dieses Faches in den tableaux méthodiques dhist. nat., nud auch Düncril in seiner aralytischen Zoologic, in welcher er jedoch nuch dic Engewcidewürmer zu den Zoophyten rechnete, ma die Aufcinanderfolge der Orduungen Lamarck's also reränderte:

IX, Class. Zoophytes (animanx scins veriebres, sans nerfs, sans waisseaux, sans membres articutés)

1. Fam. Hélminthes.

2. - Échinodermes: echin. galerit. e.co asterias, ophiurus, holothuria.

¿- Malacodermes: medusa, rhizosiotoma, beroe, porpita, actinia.

1. -.. Infusoires ou Microscopiques.

5. - Litrophytes (fixés, agglomérés à enveloppe calcaire non flexibie, fragile. fungia, caryophyl. madrepor. astrea, maeundr. pavonia, millepor nullipor. reiepor. tubipor.

6. - Coralligènes ou cératophytes (fixés ou libres agglomérés à une masse. zzon entierement pierreuse): isis, coratiium, gorgonia, antipath. umbelizit. pennatul. corallin. sertuitar. flustra, veretillum, spongic, alcyon.

\section{S. 103 .}

Wie die Fenntnifs der Wirmer, so liegt auch die der Zonplyien noch gleichsam in der Wiege. 
Riaum wois man dieselben auch nur nach ihrer äussoren Beschafenheit zu wutorscheiden, so inbelannt sind wir nit der lörpenlichen Rinvichtung dieser Thicre. Statt irgend ctwas Positives über den Standpunlit der Biding des Verdanungs-, Cirkulations-, Nerven-, Dewregungs- und Sensibilitäts-Systemes in dicser lilasse zu erfahren, so liest man sollist in den nctacaten Schriften, wie z. B. eines Dümeril, eines Lamarch u. S. W. nichis als Negaionen ocier sclbst Privationen z. B. point de nerfs, point de circulalion, point d'organes respiratuires, pas mêne pour la digestion e.c. Ticin Vunder daher, dais hier in Natursysteme des Limé die heierogensten Thiore als Nedusin, Sepien, Schnedien, Molothurien, Seeigel n.s w. in einer fsbtheilung beisammen stchem. Freilich wurden scit Linné einzelne Beobachtungen gemachi, aber cben durch dicse wen gen Andeutungen gcleitet, wagte Curier, und genärs ihm seine Nachfoiger, neme Abtheỉngen, und cine neue Tangordnung fir diese Thicre festzuctzen; So. hat hade an ders Alexsterne mit funf Radion nebst dem Muncle auch anf die rielen Tentaheln, welche er fir Palpen, Link fir Züngelche.1 und Geschmalswerlizeuge, Nomro fir Respirutionsorgane, Reanmür endlich fü Füfse filleclitich hal. ten - auf vier tsaubenarige Organe in jedern Radius, woron er die zwei lïngeren irrig fü In 
testimien, dic zwei kïrzeren als ihm nach ihrer Inulion vibliannt angicbt, aufmerksam gemath a). - Klein hat die 5 Orarien der Meerigel in ihrer Lage, den Darmkanal in seiner Iirummung rom Munde bis zum Anus abgebildnt. - Donati hat eierartige Bugelchen auf liorallen vahrgenommen, und die Heinung veranIufst, uls treten sie aus der Seitengegend des gelatüisen Folypen heraus; Lllis will an Linigen ct was Achrliches beobachtet haben, Cavolini will endich diesc Vermuthung als cine Thatsache ganz anseser Zueifel setzen, indem er selbst einen jener kianale (uterus), welche sich unterhalb den Tenw fulch üfinen, und dic eierartigen hïgelchen nach Aussen befördem, in deser Lage an einem Polj pen der Corgonia abbiluen liefs. - Trembley md Müller haben angefangen, jener die Polypex des süfen Wassers, dicser die Infusorien, ron deInen cinige z. B. ron der Gattung volvox schon den Sertharien gievehen, nit der gröfsten Anstrencumg mad Genangheit zu beobachten, aber ausser der verschiedenen Gestalt, der Fortptin. zang durch Theilung, Eier oder lebendige Junge, aisser dem Anscheine cines Darnlianales in Eingen, und ausser den häufig angemerkten Molckulen oder cierartigen Kügelchen in den meisten

c) Kade. Stellae marinae quinque radiorum anatome vił. Linkii de stellis maris liber. p. 97. 
Gattungen und selbst Arten, gar wichts weiter ton der Strultur dieser Thicre Walurgenommen. Allein wie gering ist noch die Anzahl der buchaffenheilen, wie unsicher selbst alle dicse Angaben, wio zweifelhaft vielleicht selbst die meistin Gattungen von Infusorien, welche gröfstentheils nur wegen der Verschiedenheit ihrer doch sonst so abwech. selnden Gestalt ron Mibler unterschieden werden! - Wie unzurci hend, ja fulsch die Charaltere sind, welche bisher ron diescu Thieren, sclibt in den neuesten Schriftstellern, lant des roricrgehenden f. aufgestelit wurden, hann man aus der Enidechung des Nervensystemes an asterias rutra und actinia coriacea, ans jner der Geschlechtowerlizeuge an den beiden vorlicrgelicnden und an alcyon exos, so wie aus den anderen bcigefiigten Beobachtungen über die Verdaungs- Pcspirations - und Bewegungsorgane der sämlichen Thicre erselien, welche ron mir im Jahre 1809 in September an der Küsie ron Harre und Diepp getracht, und in einer Abhandhurg mit Abbildungen in den Annolen des Nationalistituts zu Paris einrerihit wurden ${ }^{a}$ ): ich fand nümlih in der ville di:s obengenannten Mecrsternes den Magen in Form cincr hohlen Fuggel, welche allein nach un-

a) Suit. Altemoise pour servir $d$ l'histoire de l'asterie rouge asterias rubens Jinn. - de l'actinie coriacée Cur. - et do balcjon exos, znnal. du mus. T. 13. p. $43 \%$. 
ten eich nuswäris öfnet, ron hieraus die Speisen anfimut, wul don Unath cxceniret, aber in jeden der inf Radien sich in Form ron zwei holslen nud blinden Sükchen hineinsenlict; in jecm einzolucu Radius traf ich zwei tranbenartige Ge. liröse, welche in den Mlogen eirmunden, und von mir is dic Lcber - zwci andere licinere, wolche wanz mit Liern aagefült seitwärls durch die

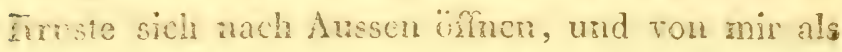
aic Ovarien beschrichen warden; zwischen jencu buhen blinden Sähcheii des Magens entdekte ich in jedem der funf Radien zwei durh einen Ner. rufuden verbundenc Vervenganglien, welche zaci Zweige ̈uber die Crundfüche des Magens, arvei an dic Lebor, zwei schr lange rnit rielen Ne。 beuztreigen ais die doppclic Reihe der dichten, den Füllörnom der Sulrachen anch arach der

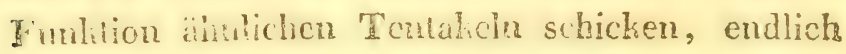
2.wei, wh he die incre Iinste durchbohen, um arz deu Wals des Dagens an gelangen ${ }^{a}$ ), in der mintichen Ahbandiung ist auch anf einen an der ansscaer Oberliche des Mitielstirlis - in allen Meerstemen, in den Echiniten : unächst den Alus - chiohten thist aufnerhsan gemacht, welcher nach imen hoi! ist, zweien cbenfalls hohlen, uno tcr. Sclianghugen sich rexeineuden und dort zum

a) vid. tab. 1. fig. 2, 3, 4, 5, 6 du mémoirs surdito 


\section{$-687-$}

Ninnde, hier zum Anus hinausmindenden TianäIen zur Declie dienet ${ }^{a}$ ). Da ich dieses ants moli. reren Gründen nicht für ein Spcichelgefifs ansehen lonnte, seine Achnlichlieit ober mit dem männlichen Gliede der einschaaligen Schneclicn mir auffallend war, so kam ich auf́ die Verm:thung, als möchte es, wie bei jenen Bitithen der polygamia superflua, ghleichsant nur als hest, und als lezte Andeutmg des männlichen Ceschlechtes bei diesen blos durch weibliche Befruch. tungstheile ausgezcichneten niederen Thieren gelten, und ols mögte die Befruchtung dieser, gleichsam nur weiblichen Geschöpfe, olme alle Beihülfe von mümnlichen, bis jezt bei Scesternen, Seeigentn, Actinion, Lithophyter noch nicht entelitcen, und wahrscheinlich gar nicht rorfindlichen Gesclilechistheile blos durch die Reife ihres Alters, Jurch dic Nähe der Jahreszeit, und durch die Auregung mittelst ihres gedrängुten Znisamncinleljens vor sich gehen. - Auch die Tracheen der Inseliten sind in dieser Fanilie noch nicht exloschen, inden die änssere Obarfliche der Seesterne an zerstrenten Stellen - bei Seeigein aber nur in fün Reihen mit bohlen, nach Aussen zwischen den Stacheln flottirenden, und nach Innen retralitilen, lileinen Schläuchen durchbohrt ist, welche, so man Luft

a) vid. Tab. 2, Eg, 2. lit. a, 
in sie bläfst, den Magcn und dì Tentahe'n anschwellen, also Fortsäize der nämlichen Membran sind, und wie die, frcilich zur Respiration und zum Tasten zugleich bestinmten Tentakeln cer Actinien, alle inneren Theile des hörpers nit Wasser bespülen. - Dei Actinien, wolche einem musliulösen, sich an der obern Flüche nach In. nen umstülpenden, und so hohle Tentalicln und sinen Magen mit einer einzigen Murd - und cbin derselben Anusöffumg bildenden Benicl gleichen, ist alles einfacher als bu Mecrstemen: die Secigul habun noch den Mund und Anns von einande gesondert, allein ron der Actinia an jis bej allen niederen 'hiscren Mind usd Anus cins, die Re. spirations - und die Tastorgane sind nicht mehr getrennt, sondern jene mit den Tentakeln, und vielleicht bei den Alcyonen, wo dicse dicht zu seju schoincil, mit dem Mrnde vereinist, wnd der Magen dient zugleich zur Linmündung run dere Ovarien; bei der Achinia rerlängent sich der Maw gen am meren Theilo schicr Seitonwäride in riele lundert, äussersi dünne, sich schlïngrinde Schlüne che, ron denen jeder sich in vier Orarien reszweigt, zwischen einer der vicleu, durch Fortse tzung der Tcutalieln in Form ron brciten, muskulösen Bundern nack Inrien gebildeten Faltra licgt, und dic Jumgen emweder in den Ovarima oder in dem Magen ausgelsritet duich die Mundo 
offunng und bei ciner Zerreissmg der Eierbehalt. nisse auch durch die Tentakeh von sich nach Aussen gicbt; unterhalb dem frei nach Imen hängenden Magen im Mittelpunlite der inneren Grundlläche, womit die Actinia an Felsen anklest, sind num auch abwechselnd zwei aneinander gec rükte Nervenganglien sichtbar, welche unterhalb der bandartigen Muslielconcentration zu einems wahron Netze unter sich communiciren, und ron denen nachher jeder Gang zwei lange, nach oben längst den Musliclis fortlaufende Fäden abo schilit ${ }^{a}$ ). - Am einfuchsten fand ich aber dio organische Biidung an cinem Stamme rom alcyon exos: wie ich die nit Poljpen gleichsam übersäete Oberaüche dieses Zoophyten nit der Luppe beschaute, bemerlite ich viele zunächst den Zellen liegende und auch aus dem Munde des gelatinö. sen Polypen gerade im Heraustrctten begriffene gelbe lörner, neugierig öfnete ich einige derselben, und exblikte zu meinem Frstaunen in jedens dieser hörner eine Menge Eierchen, welche jenen der Stubenfliege gleichen; hierauf machte ich mich an eine Einspritzung mehrerer gelatinöser Folypen theils mit Luft, theils mit Milch, und theils mit Dinte, endlich schritt ich an die Zergliederung

a) vid. $t a b, 2$, fig, $3,3,5,4,5,6,7$ " 


\section{$-6 g 0-$}

selbst; hier traf ith denn nach Durchschneidung der Muskelmembran, durch welche jeder Polyp in sciner $\mathbb{Z}$ clle an die Liruste angewachsen ist, cire hohle kugel an, die blos nach oben answäris mïndete, nach unten einen dünnen, nit $7-3$ gelben Lörnem angefülien Schlauch als Anhüngsel hatte, und bei ciner geringen Pressung des Lezteıen diesen gelben Körnern den Durchgang durch sich und durch ihre Inudöfnting und elien so auch den Rücligang vorstuttete, eine Erscheinuns, svelche mir die iehnlichl,cit dieses relatinöisen $\mathbb{P} \circ$ lypen nit der aciinia coriacea zcigte, nur sum Unterschiede, dafs dort nicht viele, sonden cin einziger Oridukt da ist, welcher in den Magen einnündet; in Hinsicht der Kruste dieses Polypen fand ich, dafs das Innere, ämlich dem Natie der Pflanzen, aus hohilen, gegen die Grumifäche des ginzen Stanmes convergirenden Wasserlianilen Lesteht, in denen sich der gelatinöse Polyp ron seiner Zelle aus durch einen Anhängsel (der nir wie eine Fortsełzung der äusseren, den Magen umgebenden Muskelhat vorkam) noch cine hurze Streche fortsezt ${ }^{a}$ ); dic äussere Oberfläche der Linuste ist höckerich, und wie mit lörnern (?) überzogen; aus dieser Beschafferheit, und duch

a) vid, tab, 2. fig. 8, 9, 10, 11, 12, 25, i4 


\section{$-\sigma 6 g_{1}-$}

die Beobachtung einer Firimmung ihrer Eschnitte, was immöglich als cinmittultare Folge d r kleinen gelatinösen Polypen, sondern als Wirhung der eigenen, wenn gleich durch jene erregtin Fraft angesehen wcrden kann, veranlafot, halte ich die Lruste gleichsam für die äussere Schaale des Eies, die sich unabhängig durch eigrene Kanäle und Drüfsen ernährt, und wie eine wahre Pflanze fortwächst. - Noch nachte ich mehrere hicher gehörige Beohachtungen an Sertularien, Tubularien, Pennaculen, Spongien, besonders während meiner lezten Reise lïngst der mittelländischen Küste, und deren Dekanntmachung in der Folge den Naturforscheru wegen Mangel an Arbeitern in diesem Fache, und öfiers sellust an der nothweindigen Gelegenheit, die Natur an Ort und Stelle zu beobachten, nicht unangenehm seyn wird; doch will ich hier nur etwas ïber die Strulitur der Medusen anfuhiren: die einfuchste, die ich untersuchte, ist eine beroe; sie stellt eine häutige Blase (einen Magen) vor, welche in der Mitte der unteren IIälfte in eine Mundörnung auslauft; leztere Oeffumng war nit zwei langen, gelblichrothen Franzen eben so umgeben, a!s auch die lüngligen Streife auf der Oberhläche der Beroe damit geziert sind, die vermuthlich die Stelle ron Tentakeln r... tretteu. - Bei einer andern, - ron Curier ne- 
gen Mangel des Mundes als Gattung , rhizostom ma" aufresielli, - welche den segmente einer Halblingel, oder cincm stark gewölbten Teller gleicht, befindet sich obige Blase in der Mitie der ganzen durchsichtigen Sulze; die Mundöfunng ixt zu einer Fläche verwachson, und an ihres stelle sind ringsum mgefihr 18 , an der Spitze blange. fürbte, mit Löchern durchbohrte Tentalieh, dise I iszapfen ähnlich sind, angebracht. - Am nanch. falligsten und sprechendsten ist aber die soge. nannte Nedusa, wo dic Obulippe des offenen Mundes nit 2 mittleren, wil 2 andern diesen zur Seite stehondon langon Tentakeln, die I'nterlinpe nit 3 mittleren, nit 4 zur Seite, und mit 4 sinz zu unterst umgeben ist; dic Mundöfinung leitet in den hohlen Magensack, dessen IJaut vielfach gefaliet, und gegen jeden der 4 Pilaster als Trager de: Teniakeln ron 3 mit cinigen Franzen (die Macri für Eierstöclie ansieht ${ }^{a}$ ) besezten Jüichern durckhohrt ist; jerles dieser Lücher führt zu eị. nem, am äussersten Saume nach Aussen sich öfnenden Kunale, welcher nach einer Einspritzung mit Milch sich in der Mitte blasenarlig erweitert, von hieraus durch einen Nebenast mit den rechts

a) D. Saverio Macri. Nuove osservazioni intomo la storis naturale del polmone mariuo degli antichi. p. 12. Napola ₹778. 


\section{$-693-$}

und links benaclibarten Fanilen anastomosiret, and bei ihrer Anastomose sich in cin wurzelartj. ges fichräusel von Kanälchen, die sich gegen den Mund und gegen dè Saum zu in die Substanz verlieren, aunlüst; das Nämliche findet bei allen 12 Kanälen statt, die vermuthlich, da sic Wasser and gröfstentheils Luft in sich enthaten, die Funktion von Nahrungs - Lymph- und Respirationsgefarsen zu gleicher Zeit ausïben. So besï̈nden demn die Medusen, die geromenen Mcenwasser, oder einer aus lanter Liörncrn (DrüCseu?) bestehenden, an der Luft gleich Schaum vertrolnenden Sulze, oder ciner gulatizösen Tre. zuelle glcichen, blos aus cinem Magen, der mit "rastern (Tentakeln) besezt, und innerlich mit Ucinungen durchbohrt ist, welcho theils Nahrung, theils Lift zur momentanen Fistyllisirung des Chylus herbeifuhrea; rou Nuslieln, Nerven, Geschlechtsóiganen wcis man wenirsteas bis jezt richts, ja ron ihrer floltirenden bewegung kanu man nicht mit Sicherheit sagen, cb sie eine Wir l:ung der Vluthen, ob sic, wie Poron behanplet, cin Aus - md Einathmen an ganzen Thiere, oder überiaup sine Folro cigoner liralt sey; So riel ist gewifs, dars sic ans dem Wasser genommen, anf dem Sando schr fest anlileben, der heisen Mlito Eugssoune ausgesezt, oder mist cinem Ziul - und 
Silberstäbchen galvanisiret, sich sichthar zusam. menzichen, was aber freilich mehr eine Contralitilint des Zeligewcbes als eine willhiihrliche Bewe. gum genannt werden liann. - Doch die Pearboitung rieser Familie haben wir ron den gelehrten Reisinden nach Neuholland - von einem Peron und Lesunir zu crwarten, welche schon eine ausfihrliche BIonngaphie ron einem ausserordentlichen Reichthume an Gattungen und Arten, nebst Abbilungen versprochen, eine linze Anzeige ih. Ier Abtieilungen gegrbon (meduses: gélatineuses (avee des côles cỉîs on suns côtes ciliés), mem bruneuses - gastriques, agiustriques - monostomes, polystomes - péäonculées, non pédoncuiees) ${ }^{a}$ ), nencrdings ilire isonhronische liewegung als eine wahre Respiration (?), ihren schnellen IVachsthum, die grofse Sensibilität ihrer Tentakeln behanptet ${ }^{b}$ ), und eine sonderbare nene Gattung von einer hricherichten Meduse - einem hohlen Fegel ähnlich - unler dem Namen "pyrosoma"c) errichtet haben.

Allerdings haben also die Mecrsterne und $\mathrm{Ac}$ tinien ein Nerven - Verdanungs- und Respirations. system, und bei beiden, wie auch bei den eigenili-

a) Peron et I.esupur. Hist. nat。 des méduses annal, du moso I. 14. p. 218 .

b) ibid, Tom, 15. p. 4\%, c) ibid, Tom, 4. p. 437 


\section{$-695$}

chen Zoophyten, werden weilliche Geschlechtsor. gane gefunden; anch bei Infusorien, welche, wio anch die Mledusen und Altinien gleichsam die nicht angewachsenen Polypen der Lithophyten sind, hat Fiviller an einzelnen z. B. an vibrio vermiculas, paramaccium marginatum cine Art ron Intestinum, ja in voirox pikula cine ceffo numg, welche er für jene des Munds hält, und fast bri allen Arten viele ihm unbekannte rïgelchen in ilsrem Körper zuwtilen benierlit. Vielleicht ist die innere Struktur des rothen Seesternes beilänfir jene aller Lchinodermen, die der Actinia jene der sogenannten Polypen, die der Medusa (bei der die Ovarien noch zu vermuthen oder jene ron Macri angegebene noch durch weitere Beobachunigg zu besiätligen sind) jene der Infusorien, die des alcyon exos, jene aller übrigen Zoophyten. Auf alle Falle ist der Magen bei allen diesen Thieren das vorherrschende Organ, und Actinien, Mle dusen, Infusorien und eigentliche Zoophyten, sind nichts als ein Magen mit anhängenden Or arien, wo denn das Eruahren und Zeugen in dem nämlichen Organc fleichsam als eine und die nämliche Funko tion ror sich geht; Asterien, Actinien und Polypen trifit nian gröfstentheils an einem Platzc beisammen ais, von den Infusorien fangen einige selbst schou an, zusammenzuwachsen, z. B. volvox so- 
cialis, monas vica e.c., die Pennatulen schwinto men zwar, nbeirich riele an sinem Platze zusum. mnn, herum, di Eermlarion, Tuhularien sind noch in unteracheid!aren Röhren rorwachsen, bis end lich in den Madreporen, Forathen, Gorgonien $u$ s. w. viele Tanende beinahe wie zu encr Masse and zu einem einzigen Thice verwachsen, mả wie eine Pfanze on Felsen angeheftet, regetiren. Jedoch wie gering sind demohngeachtot noch um sere liennuisse iiber die Strulfur und biber dio Arten dieser den Planzen so ähnlichen Thiere! ja obglich si die beobachtungon in unserem Jahr. Innderte rorzinglich anf die Fortplanzung der zonphyton und besonders der lafusorien beinaha concentripten, wie wenig wissen wir ron derselben! Jenweulsik läfst die Hunde, Menschen u. Sw w. aus ihren Sammonthieren eutstehen, Dalempatius will sogur an einem Infusorium im menschlis chen Satmen nath abgelcgler Hant dic Form des ITrenschen, Joblot in rinem Aufgufse ron Anemonon ein Infusoriun mit den Nasen, Augen md der gesammin Physiognomie des Menschen gesehen Laben; $S_{1}$ ulanzania a, und Therechowshy ')

a) Spalanzani dissertationi di fisica animale vegetabile. Tom. 2. Btodena 1730. 8.

b) Terechow oky. Dissert. inaugural. de chao infusorio Linaej 1775. Argentorati. 4. 


\section{$-697-$}

nehmen die Entstehung der Infusorion ans Eirm an, weiche gemäls dem ersteren in der Luft, gemäfs dem Lezicren in dem zur Frschcinmg derselben eisen so nothwendigen Viasser befundlich scyn sollon; Nectham ${ }^{a}$ ), Wrisberg ${ }^{b}$ ) und Nüller, zu deren Meimung nenerdings sich auch Pudolphi und Trevitanus bolennen, fïhlen sich zur Annahme der generatio acquiroca durch jene Beobachtung berechtiget, nach welcher sich in den Aufüifsen zuerst cine Haut bidet, diese sich in Noleknh in Form von Blïschen anflofst, und sole che anfangs unbeweglich, später aber die bewosichen Infusorien selbst werden; Müller läfst sie sich jedoch auch durch Fier, lebendige Junge oder cicenmächtige Spaltung foriplanzen. Büffon c) nimmt die Inf:sorien als in Luft, Wasser, Speisen and ïberall zerstreuke Molekn an, woraus sich alle organische Individuen ron Plavizen und Thic ren erwëhen, und anch durch die ron der Nase, den Augen, dem Gohime-n. s. w. zu dem Saü men des organischen ludvidimms herbeigeströnten Alomen sich lezteres wieder erzenget; Ohen giebt den Infusorion eine ähnliche Bedeutung,

b) Necdham. Nouvelles observations microscopiques.

b) Wrisberg observat. de animalculis infusorids

c) Euffon, Hist, nat. Tom. 20 
nänlich die einzige Quelle zu seyn, woraus sich alles Organische gestaltc: simnreich sielit er Zenging, Tod, Auföfsimg und Füulnifs auf dem Geliethe der Phanzen und Thiere als ein Zerfullen des Individuums in dic ursprünglichen Infusorien, Icben und Existenz aber als cin Potenziren der Iezteren zu neuen, vollkommeren Individuen an; nach dieser Ansicht ist jeder organische Kör. per, da er in jedem Momente ein anderer isl, d. i. stirtt und auflebt, gleichsim ein Convolut ron lunier sich immonwälıend rerwandelnden Infuso. rien, und die Pflanze und das Thier nehmen ihre Fntstehung niche blos aus den Cercarien ihres Saamen, sondern überhaupt aus Infusorien ron welchen Theilen immer; durch diese Ideen geleitet, verwirft er den Uebergang des Anorganischen ins Organische und umgeliehrt, erhlärt den Satz Murvei's "onne vivum ex ovo" fïr falsch, und stellt dafuir jenen des Redi als den allein gülligen also verändert auf:

$$
\text { "Nullum vivum ex ovo". }
$$

Wie entstehen also wohl bei diesem Streite von Niveinungen diese räthselhafien Thiere, welche Eleichsam als microscopische Meteore des feuch-

a) Oken, Die Zeugung. Bamb, «\$a5, 8, 
ten Elementes sich mit der Johreszeit und Witte rung verändern, in verschiedenen Infusionen vexschieden erscheinen, und selbst in dem nämlichen Aufgusse, den Versuchen des Treviranus gemäfs, nach der Stellung in erhöhten oder tjefen Plätze sich in andere umwandeln? Entstehen 'sie aus Arten ihres Gleichen? und zwar mittelst Eier? mittelst lebendiger Jungen? mittelst Theilung? oder entstchen sic auch aurs thicrischen und regetabilischen Stoffen? oder selbst auch aus unorganischen Körpern, z. B. aus einer Aufiösung ron mineralischen Substanzen, ron Flufsennd, Gantenerde u. s.w., wie einige neuere Versuche darzuthun strelen ${ }^{a}$ )?

Dafs es eine Verwandlung des Anorganischen ins Organische (generatio spontonea) gcbe, wer mögte daran zweifeln, da auch der Pflanzenorganism Kirsel, der thierische Kisen, Fall, Phosphor 11. s. w. bei welchen Nahrungsmitteln immer zu erzengen rermag, da Eisen, Thonerde, Wasser, Luft und sonstige Mediliamente und Nahrungonittel zur Eruährung und Erhaltung organischer Individuen beitragen. Dals aus Pflanzen Thiere, und aus Thieren Pflanzen entstehen lömmen (generatio aequivoca), dieses folgt aus den Beobach-

a) Fray. Nourclles expériences ou essai sur l'origine des aubstanes organisés et inorganicées. Bexlin 1807. 
fungen eines Needham, Mrisberg und Milller, nach welchen sich die regctabilischen oder animas lischen Theilchen in Anfüifsen sichtbar in Infusci rien umwandeln, aris denen sines Ingenhoufs a), xach welchen die ron Priesiley entdekte und fü cine Confervenart gehaltene, grïne Materie aus Infusorien gebildet wird; ja Lichtenstein will soo rar die Verwandlung der Federbuschpolypen in Alyonien, und dieser in Spongien beobnchtet haw ban "1, und wie liefse sich auch das Vorhommen de I Theweidewürmer in Gehime, in der Leben, : 1hl in Enbryonen, wie Scherer's Wairnehmunfur ber Bewegung an den Tremellen der harlsba1) r und Töplizer Quellen, wic endlich des GriroQhintran Erfahrung erliären, dafs die Byssus, Conferren und Tremellen, ein Convolut von Infusorion, und so ein wahres Polypengebäud sint cjo Woun man nicht a!nimm, dafs sich dieser plano zonurtige heim bald als cine Tholt ron Infusorien, Lertere bald als cine wahre Landschaft - als Planze - nach Abwechsiung der Jahreszeit und sonstiger Einflüsse darstelle? - Jecioch so wenig

a) Irgenhonss. Vermischte Schriften, pizysisch-medizin. Inw halts, Bत. 2. S. $13 \mathrm{I}$.

(3) Voig:'s Magazin für das Neueste aus der Physik. Bd. Ir. St, 2. S. $1 \%$

4) Bulletin de la soe. philomathique 3797. n.. 6. p. 43: 
ans tiem Samen sogleich die Dhume, aus derr Tie sogleich der rollkommene Schmetterling, aus der genossenen mineralischen, vegetabilischen oder thierischen Nahrung sogleich das Blut oder der Tinoche, Nerve, Muskel u. s. w. mit Uingehung de: darzwischen liegenden Verwandlungsstuffen hervorgehen kamn, eben so wenig liann eine mis neralische, regetabilische oder thierische Materie sogleich mit Ungehung der darzwischen liegenden Verwandlungsstufen in dieser oder jener Thicrform anftrcten; und hier wage ich als die Dasis jener Süize "ornne virum ex ovo" - „ornne animal per animales parentes" - "omne vijum e vivo" das $\mathbf{E i}$ als die ersie und früheste aller Metamorphosen aller Thiere aufzustellen: Donati, Ellis, Carolini haben an den eigentlichen Zoophyten Eier entdelt, - Donati will sogar aus den Eicrn den Polypenstamm wachsen gesehen haben - ich habe die befruchteten Ovarien von asterias rubra, actinia coriacia, und alcyon exos in obiger Abhandlung abgebildet, und besitze noch inmer diese Präparate in meiner Sammlung - Veruer, Göze, Bloch, Zeder, Rudolphi erwäh. nen der Rier, welche sie an sehr vielen Gattungen vo:i Eingeweidewürmern wahrgenommen haben; viclleicht dafs das Einmünden der Ovarien im Magen, wie ich es an Activia, und Alcyon be. 


\section{$-702-$}

scirielycu habe, bei den niederen Thieren allgemeiner isl, und vielleicht dafs der mittlere Schlauch mit den ron Diern angefülten Seitenkanälen im Bandwurme, was Verner und Carlilsen behaupsen, auf ein gleiches Verhältnifs hindeutete. Auch Trumbley erzählet, die Oberfläche von Süfs. wasscrpolypen mit Lömern, die gleich Eiern auch auf cien Boden des Gluses herabfielen, besezt ge. sehen zu haben, erlilärt aber diese Erscheinung (vielleicht weil er ihre Fortpllanzung durch Theilung nicht danit reimen lionnte) als Folge einer Ausschlagskrankheit a). - Müller führt von den meisten Arten der Infusorien die ihm unerhlürli. che Erscheinung an, dafs man in ihrem Körper ofters Molleliulen und runde gelbe hörperchen bemerke, uud spricht sogar öfters von sichbasen Orarien - Needham, Nirisberg, Mïller sa* gen einstimmig aus, in allen ilren Versuchen dis vegetabilischen oder animalischen Theilchen der Infusionen inmer zuerst als Membran, daun als losgetrennte, mbewegliche Bläschen (aesiculae globulares) und erst zulezt als bewe tiche infuso. rien gesehen zu haben - wer erinnert sich endlich nicht, dafs der befruchtete heim in den dazu geeigneten Orgarien bei Insekten, Molluslien, Fi-

a) Trembley, Miémoires sur les polypes, e. c. p. igt. 


\section{$-703$}

schen, Amphibica, Vögeln und Süugthieren zu aे leverst in die Form des Lies renlarvt ist? Vielo licht dafs der Fortpflanzung durch Theilung, die von Frembley und Müller bis jezt an Polypen des süfsen Wassers, an Naiden, Infusorien beobachtet, und wie jone durch Ableger auf dem Ge. bicthe der Pflanzen eine wahre Aftergeneration ist, chrn so ein Ei, wie jedcm Zweige an einer Pflanze das Saamenliorn in Form einer Gemme $z u$ Grude liegt. - Nicht also eine im Thiorreiche besondere Familie z. R. Infusorien oder Würmer n. s. w. ist die Geburtsstätte der übrigen Thiere, sondern das Ei ist die erste Larve aller Thiẹre, sie mirgen durch die sogenannte generatio spontasepa, aefuivoca oder epigenesis entstehen, und noch ist für den gegenwärtigen Standpunkt der vergleichenden Zoologie und Anatomie die De. hauptug nicht zu liuhn:

"Omnis animatium generatio ac incrementum, non est nisi metamorphosis, quarum 1ma ovum 2da zonpliytum - 5tia vermis - Ita insectum 5 ta molluscum - 6ta piscis - 7ma amplibium 8va avis - gna mammale - 10ma homo."

Doch wer yermag schon das Reich der Gegenwart und der Lebenden zu durchschauen, während noch ein dichter Schleier der Finsternifs über das Reich der Vorwelt, besonders in Hinsicht der fos- 
si! en Thiere liegt! - Noch termisscn wir mitct den noch lebenden Arten von Echiniten jenen, welcher mit den massiven, sogenannicu Judensteinen besezt, fossil angetroffen wird; noch stamen wir über die colossalen Pentacriniten, welche dor noch existirenden Seopalme wohl ähneln, aber von allen boliannten Arten verschicden sind, und ron denen einer mit einem 3 Fufs langen, gegliedero ten, cinfachen Stangel in bituminösen MTergelschie. fer im Wirtembergischen gefunden ward a), noch stannen wir über die colossalen Encriniten, de. yen hörper mit zusammengelegten Acsten, ähnlich ciner Maizhne oder einer noch nicht aufgeblihten Lilic, unter dem Namen Lilienstein aus dichtem Iiallistein ansgegraben wird, dessen Glieder aber z.crstrent unter der Benemnung Rädcrsteinchen, Warrochiten in Flötzlialkstein und zwar öfters in tungeheurer Menge in einer Versteinerungsschichto rorliommen, welche dein älteren Sanistein vols dem anf im ruhenden Lialkstein trennet ${ }^{b}$ ), nock stamen wir tiber ihre ungeheure Menge im fossilen Zustande, wä̈rrend dieses bis jezt noch sehr seltene Thier an der liüsie von Barbados blos eí. nigcmal im natïlichen Zustande gefunden wurde,

a) Hiemer. Capnt medusae utpnte novum dilurii universalis monumentum detcrum in a gro Würtcmbergico. Stuttgard,

Bj Buch. Geognustische Reohacirtungeu. B, 1, S, 14 g. 
und ein Excmplar daron ron Guetiard ron dort sach Paris gebracht, hier, cil anderes aber auf teutschem Boden aufbewahrt wird; Wer endlich hat alle die Gattungen und Arten der Madreporjo ten, die öfters in wahren horallenrefen in unermefslicher Menge und grofses Manchfaliglieit zo B. in dichten hallistein und MIarmor bei Genf, auf dem Ilarz bei Grund, bei Blankenburg u. s. w. - in Sandstein bei Maestricht - in Freide als sogenanute Fungiten in Ficnt - im Bratueiscustein an Harz und in Sibirien - wer jene dor Milleporien, und übenhant der fiorillonarten, welche in Sandsten bei Maestricht - im lenero stin be: Zille in Hamoverischen - in I'uddingstein in Ileutfortshire vorkommen a) - wer hat jene von Nucleoliten, Echiniten, Ananchien, Spabangtn, wer das fleer yon Asmoiten mul Ophiua ren, von denen sich anch Abrïülie so hüfig im Mergelschicier ron Wichstudt, also ganz rom Mecre enternt, vorfinden, wer lat alle diese fossiIen Thicre nach alien iliren Gatumgen und Arten bis jezt noch so durchmustert, um sagen zu liön nen, wolche als auscestorben blos der Vorwelt, und welche noch der gुegenwärigen Welt angehösen? Allein auch dicse Denlimäler der alten Ge-

*) Blumenbach. Ilexdbuo's ser INatargeschichto, S. 370. 


\section{- $706-$}

schichte werdon, jemehr die Schichten mseres

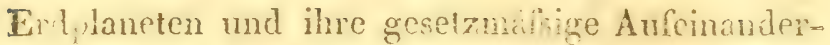
folge durch das geologiscle Stutim ausgoritult ist, noch ganz entziffert werdnn, und sie werlen darthun, dofs anch in dem fossileas Vorkommen der Thiere rom Zoophyten i:a ältesten Flïtzgebirge an bis zu Katzen, Mnurden, Bären in verschütteten Wällen, den Schichten der Erde parallel die nämliche Stuffenfolge horrscht, als diese götlliche architchitonische Kunst der Natur durch verule chende Anatomie und Zoologie an den noch lcjenden Thieren hergestellt werden laun. 
Verzeichnifs ron Drukfehlern, welche theils mit den Entlernung des V'erfasser's rom Drukorte, 1/,.its mit der V'erschiedenheit der Abschreiber zu er srohuldigen, der geneigte Leser ersucht wird.

Seite. Zeile,

5. 15. 3t, zwoderst, zuvorderst lies: immer zuvörderst.

7. 2. - verschieden winklichte 1, verschieden - wink-

10. 9. - erweissen 1. erweisen. lichte.

31. 17. - lezteres vorzieht 1. leatere vorziehen.

14. 9. - eigene 1. cigenen.

- 13. - Diese 1. Jene.

12. - S.8. 1. S. S. a.

17. - 5.8. 1. 9. 8. 6 .

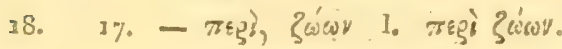

20. 20. - ipócídn 1. óรदín.

26. 25. - galatinösen 1. gelatinöser.

52. 6. - Collisäum 1. Colisäum.

53. 5,6. - Frejy, Pompej 1. Frejus, Pompeji。

53. 24. - Nerocoma 1. Norocoma.

55. 23. - Thiers, zusammen 1. Thiere zusanmer.

36. 14. - auf Erden 1. auf der Erde.

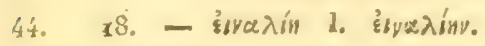

45. 22. - welches erstere und leztere 1. ron denen des erstere, das leztere.

45. 25. - für den 1. vor dem.

46. 2. - Anthistenes 1. Antisthenes.

58. 15. - während Drake als der 1. bis Drake, der.

59. 13. - Hermandez 1. Hernanilez.

6o. 5. - der Vicogna des 1. der Vicogna, des.

67. 7. - innern und äussern 1. innere und äussere.

- 8. - archacologiseher, ökonomischer 1. archaeo. logische, ökonomische.

- 9. - oder medizinischer 1. oder medizinische.

68. x, 2, 5. st. hutigt lies immer lufig.

7r. 23. st. Iöwenhök lies imner Leewenhök.

73. 1. - jedoch 1. und.

79.- 4. - seiresen, zu ziehen, als wenn 1. gewesen, als sich zu zichen, wean. 
Seite. Zeile:

81. 6. st. liessen, 1. liessen:

81. 16. - dieser 1. diesem.

82. 3. - Niederland 1. di Niederlanden:

82. 20. - ihn 1. sich.

S.. 2.i. - conseçuent seinem 1. consequent bei seinem.

89. 12. - Harderovik 1. Harderwyk.

- 17. - Boerhaar 1 Boerhaave.

102. 12. - den haltbaren 1. den unhaltbaren.

518. 25, 2C. - Sumini, Bosc, Tigny, Raissy 1. Sonnini, Bose, Tigny, Roissy.

Irg. 4, 6. - die Mane wird 1, die Mianen werden.

124. =0. - nicht blos zufrieden 1. nicht zufrieden.

126. 16. - Reaumure, Covollini 1. Reaumür, Cavollini.

333. 22. - nicht die 1, nicht nur die.

137. 12,20 . - Ka clismete, schwammigt lies Kallikuste.

x38. 6. - Knoche 1. Knochen. achwammig。

839. 24. - Brugnicre 1. Bruguiere.

140. 12. - Radiärs 1. Radiaires.

44. 27. - in eine 1, in einer.

845. $-5.36 .1 .6 .36, a_{0}$

252. - S. 36. 1. 5. 56. b.

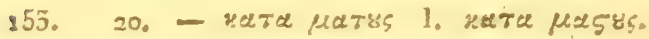

s6r. 15. - Käugaruh lies inmer Känguruh.

866. 21. - Kuochsplitter 1. Kuochensplitter.

E76. ó. - zu dem 1. zudem.

180. 3. - der Stachel 1. der Stacheln.

39r. 28. - Cavia, copybara 1. Cavia copybara.

Ig3. 5. - e siclr nicht 1. es nicht.

- $, 8,0$. - Iiund-Katzenartige, Fleischfressende I. Hiañkatzenartig, fleischfressend.

176. 5. - zum Ergänzen 1. zum Ganzen。

298. 14. - Gebürge 1. immer Gebirge.

213. 3. - Systemen 1. Systeme.

2ig. 22. - der 1. die.

- 23. - die 1. dor.

232. 25. - simiä 1. simiae.

254. 19. - das Trichekus 1. des Trichekus.

238. 1. - Wachbär 1. Waschbär.

23\%. 22. - bei den 1. bei dem.

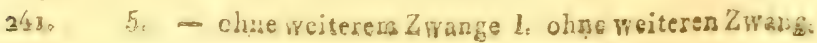


Seite, Zeile.

\section{$-109$}

243. 3. st. Thiere, die 1. Thicre die.

24\%. 10. - Audeberr 1. Audebert.

247. 19. - sonstige 1. snnstigen.

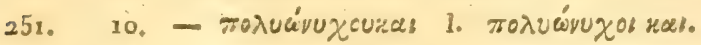

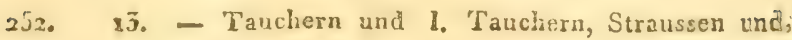

262. 27. - Uffer 1. Ufer.

264. 2. - Klugheit that 1. Klugheit nicht that.

289. 7. - mit vorderem 1. mit dem Vordertheile,

291. 19. - Systeme in 1. System von.

302. 24. - das Gesang 1. den Gesang.

5ı. 8. - der Muskel 1. der MIuskeln。

3.8. 27. - Charvas 1. Charras.

525. 24. - fuits 1. faites.

54 ro 1 $\vec{J}_{0}-$ Brïgeres 1. Brügniere.

543. r. - Brogniart 1, immer Brongniart。

557. 4. - chéloniens l. chéloniens.

358. 9. - Dracäne und 1. Dracäna (?) und:

363. I5. - bimaculata 1. bimaculatus.

573. 1. - Ichlyologia lies immer Ichthyologia.

575. 39. - bei Ta $=$ oder Nachts 1. bei Tag oder Wacht:

576. 4. - alles diesen 1. alles dieses.

581. 25. - Nuvocana 1. Novocoma.

384. 5. - Nähen 1. Nähc.

588. 12, 14. - Stören, Lachsen 1. Störe, Lachse.

- 28. - Pythiures 1. Pythiuses.

406. $7 .-$ bis 1. bei.

410.13, 1'́t. - grätigt, knorplicht 1. immer grätig, knorplig

417. 6. - Spitzlöchern 1. Spritzlöchern。

419. I1. - derselben 1. desselben.

426. 3. - gewonnen? 1. gewomnen!

450. 5. - jene 1. jener.

435. 11. - Beispicle Plinius 1. Beispicle des Pliniu.

441. 2. - die weitläufige 1. die weitläufigen。

447. 20. - scalpa 1. salpa.

463. 26. - ein als zu 1 , ein allzu.

46\%. 23. - statt den 1. statt der.

466. 2x. - gelernt 1. gelehirt.

480. 21. - ohne darzwischen gelegten 1. Ohne dazwi-

488. 8. - unter des 1, unter dic. schea gelegtes. 
Seite, Zeile.

502. 20. st. eine neue Gatung pyrosorna I, die neven Gattumsen callianina, phollirae, cymbulia, carinaria.

- 28. - Peron. T. 4. p. 45\%. 1. Peron. annal. d. m. Toin. 15. p.57.

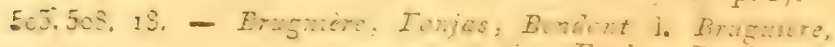
555. 2. - des Schnecken 1. der Schoecke.

5is. 18. - fiudi 1. finidi.

563. 24. - cutrentionen 1. curculionen.

572. I3. - Schleswik 1. Schleswig.

581. IT. - Epognaticrs 1. Exognathen.

cos. 7 - wonte bolea 1. monte bolca.

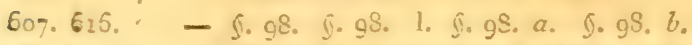

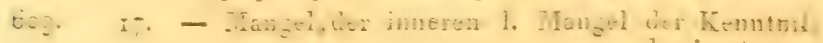

626. Ig.

655. 19. - Lammen, wählte 1. kamen, und wählte.

658. 9. - Sägwürmer lies immer Saugwürmer.

6í. I7. - résicuters I. résiculers.

645. 14. - hinabrindeade 1. linaufwindende.

6ะ6. 21. - länğlichen 1. längligen.

5i\%. 7. - diesen 1. diesen.

6rs. 15. - hindeutende 1. hindeutenden.

661. 8. - Litiophyta 1. Iithophgta.

606. If́. - c̈ligten 1. öligen.

668. 7. - u. a. 1. und aucle.

Die zwderen geringfügigerea Drukfehtor a!z z. B. Gutith,

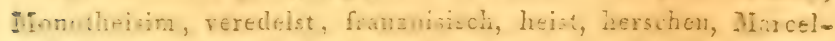
lus, Theuter, Horroilois, Ger ausgezcichnesté, Ecerenfressend 1. S. W. stat: Gelaint, Fouoristism, reredultst, franacisch,

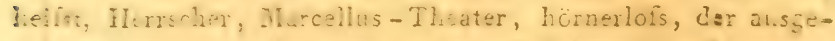

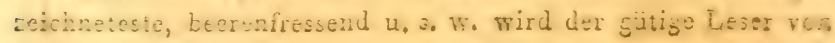
selbst leicht finden.

$$
\text { Ä̈rnberg, }
$$

Eedruckt bei Johann Georg MIilbradt. 
,

, 

$x-2=0$

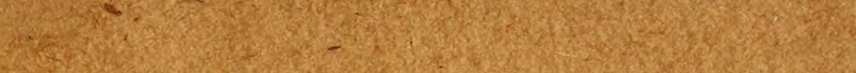
(2)

(1)

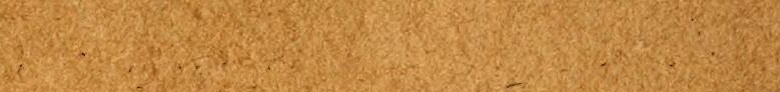

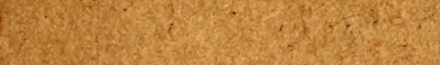

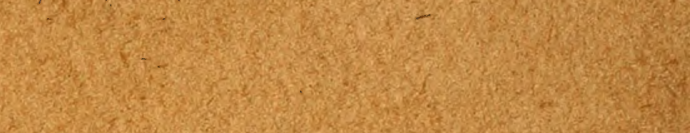

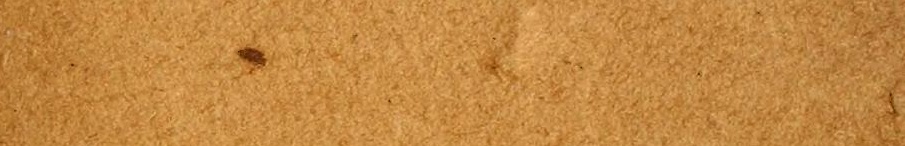
(1.

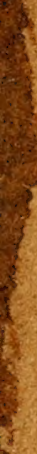

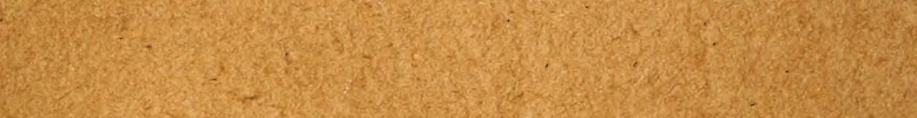

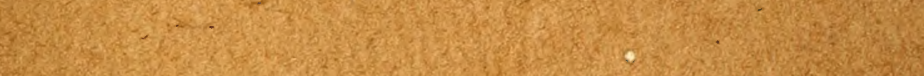

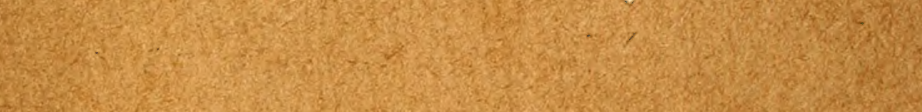
(i)

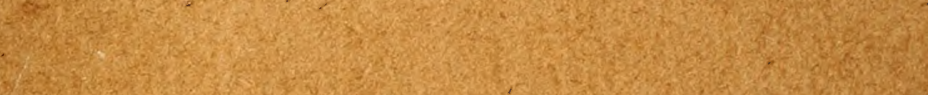
Q

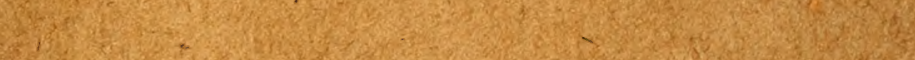
-

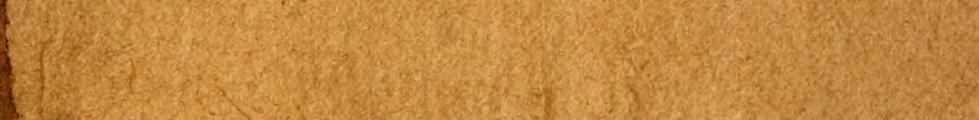
2. 


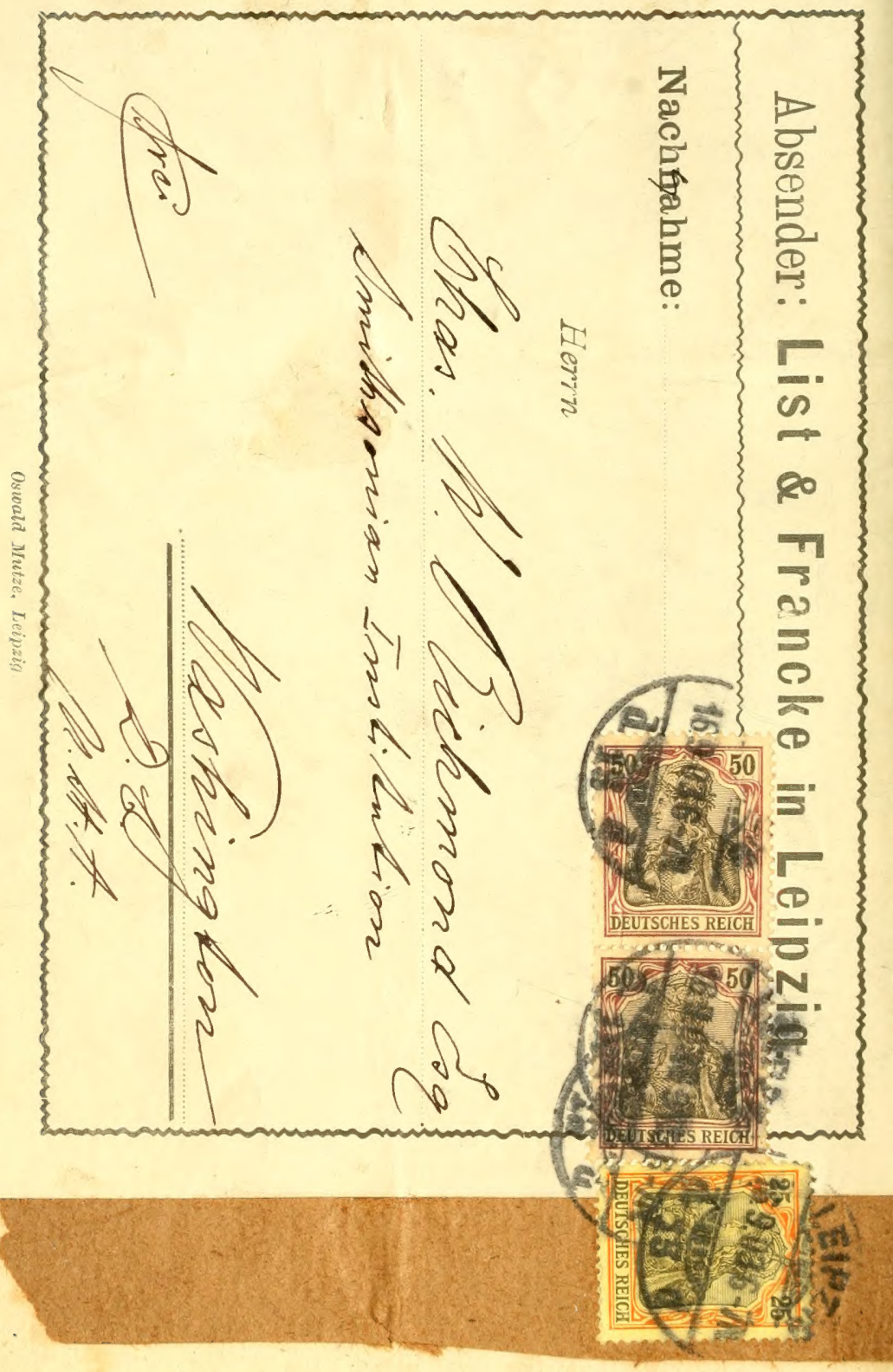



